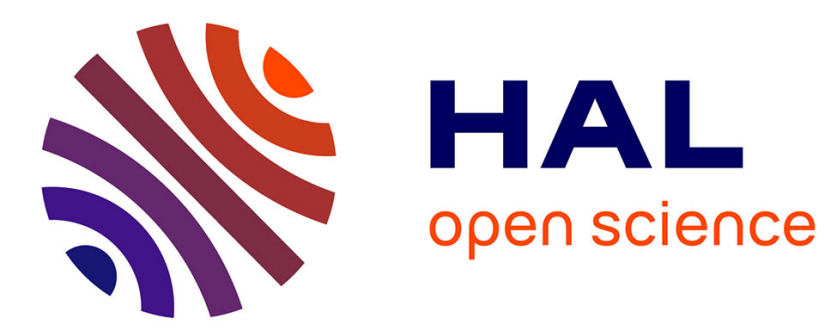

\title{
Zeolite Chemistry and Applications
}

\author{
Louis Benoit, Marcelo Maciel Pereira, Wang Qiang
}

\section{To cite this version:}

Louis Benoit, Marcelo Maciel Pereira, Wang Qiang (Dir.). Zeolite Chemistry and Applications. 2020, 10.3389/978-2-88963-656-3 . hal-03081124

\section{HAL Id: hal-03081124 https://hal.science/hal-03081124}

Submitted on 18 Dec 2020

HAL is a multi-disciplinary open access archive for the deposit and dissemination of scientific research documents, whether they are published or not. The documents may come from teaching and research institutions in France or abroad, or from public or private research centers.
L'archive ouverte pluridisciplinaire HAL, est destinée au dépôt et à la diffusion de documents scientifiques de niveau recherche, publiés ou non, émanant des établissements d'enseignement et de recherche français ou étrangers, des laboratoires publics ou privés. 


\section{ZEOLITE CHEMISTRY AND APPLICATIONS}

EDITED BY: Benoit Louis, Marcelo Maciel Pereira and Qiang Wang PUBLISHED IN: Frontiers in Chemistry

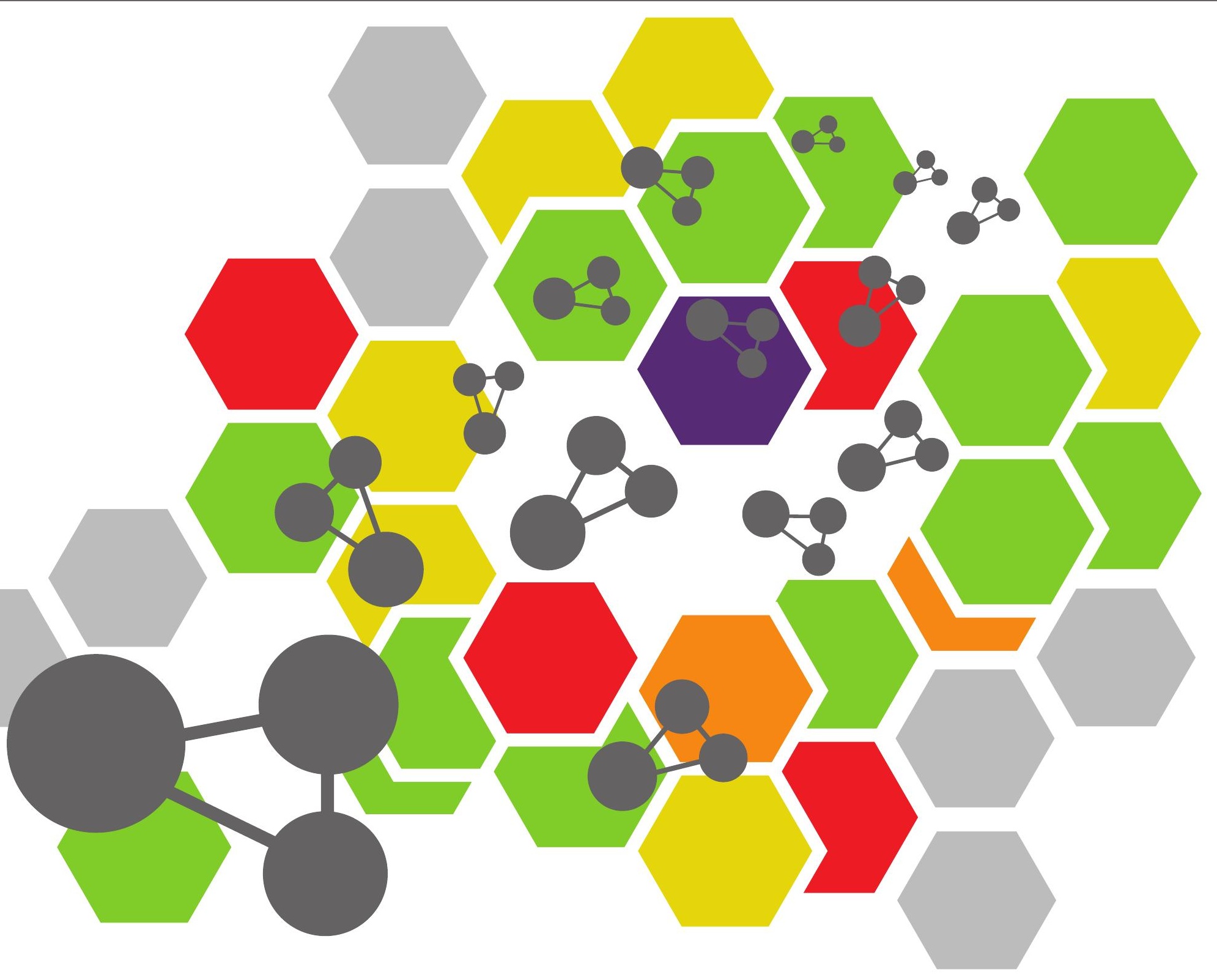

frontiers Research Topics 


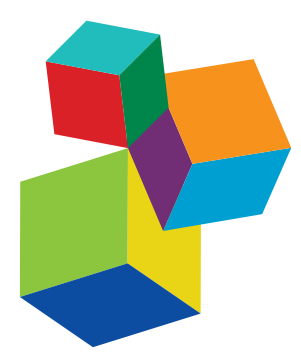

Frontiers eBook Copyright Statement

The copyright in the text of individual articles in this eBook is the property of their respective authors or their respective institutions or funders. The copyright in graphics and images within each article may be subject to copyright of other parties. In both cases this is subject to a license granted to Frontiers.

The compilation of articles constituting this eBook is the property of Frontiers.

Each article within this eBook, and the eBook itself, are published under the most recent version of the Creative Commons CC-BY licence. The version current at the date of publication of this eBook is CC-BY 4.0. If the CC-BY licence is updated, the licence granted by Frontiers is automatically updated to the new version.

When exercising any right under the CC-BY licence, Frontiers must be attributed as the original publisher of the article or eBook, as applicable.

Authors have the responsibility of ensuring that any graphics or other materials which are the property of others may be included in the

CC-BY licence, but this should be checked before relying on the

CC-BY licence to reproduce those materials. Any copyright notices relating to those materials must be complied with.

Copyright and source acknowledgement notices may not be removed and must be displayed in any copy, derivative work or partial copy which includes the elements in question.

All copyright, and all rights therein, are protected by national and international copyright laws. The above represents a summary only.

For further information please read Frontiers' Conditions for Website

Use and Copyright Statement, and the applicable CC-BY licence.

ISSN 1664-8714

ISBN 978-2-88963-656-3

DOI $10.3389 / 978-2-88963-656-3$

\section{About Frontiers}

Frontiers is more than just an open-access publisher of scholarly articles: it is a pioneering approach to the world of academia, radically improving the way scholarly research is managed. The grand vision of Frontiers is a world where all people have an equal opportunity to seek, share and generate knowledge. Frontiers provides immediate and permanent online open access to all its publications, but this alone is not enough to realize our grand goals.

\section{Frontiers Journal Series}

The Frontiers Journal Series is a multi-tier and interdisciplinary set of open-access, online journals, promising a paradigm shift from the current review, selection and dissemination processes in academic publishing. All Frontiers journals are driven by researchers for researchers; therefore, they constitute a service to the scholarly community. At the same time, the Frontiers Journal Series operates on a revolutionary invention, the tiered publishing system, initially addressing specific communities of scholars, and gradually climbing up to broader public understanding, thus serving the interests of the lay society, too.

\section{Dedication to Quality}

Each Frontiers article is a landmark of the highest quality, thanks to genuinely collaborative interactions between authors and review editors, who include some of the world's best academicians. Research must be certified by peers before entering a stream of knowledge that may eventually reach the public - and shape society; therefore, Frontiers only applies the most rigorous and unbiased reviews.

Frontiers revolutionizes research publishing by freely delivering the most outstanding research, evaluated with no bias from both the academic and social point of view. By applying the most advanced information technologies, Frontiers is catapulting scholarly publishing into a new generation.

\section{What are Frontiers Research Topics?}

Frontiers Research Topics are very popular trademarks of the Frontiers Journals Series: they are collections of at least ten articles, all centered on a particular subject. With their unique mix of varied contributions from Original Research to Review Articles, Frontiers Research Topics unify the most influential researchers, the latest key findings and historical advances in a hot research area! Find out more on how to host your own Frontiers Research Topic or contribute to one as an author by contacting the Frontiers Editorial Office: researchtopics@frontiersin.org 


\section{ZEOLITE CHEMISTRY AND APPLICATIONS}

Topic Editors:

Benoit Louis, UMR7515 Institut de Chimie et Procédés pour l'Energie, l'Environnement et la Santé (ICPEES), France

Marcelo Maciel Pereira, Federal University of Rio de Janeiro, Brazil

Qiang Wang, Beijing Forestry University, China

Citation: Louis, B., Pereira, M. M., Wang, Q., eds. (2020). Zeolite Chemistry and Applications. Lausanne: Frontiers Media SA. doi: 10.3389/978-2-88963-656-3 


\section{Table of Contents}

05 Editorial: Zeolite Chemistry and Applications

Marcelo M. Pereira, Benoit Louis and Qiang Wang

07 Preparation of Zeolite $X$ by the Aluminum Residue From Coal Fly Ash for the Adsorption of Volatile Organic Compounds

Tao Zhu, Xing Zhang, Yiwei Han, Tongshen Liu, Baodong Wang and Zhonghua Zhang

15 Catalytic Ozonation of Recalcitrant Organic Chemicals in Water Using Vanadium Oxides Loaded ZSM-5 Zeolites

Yingying Xu, Qinghong Wang, Brandon A. Yoza, Qing X. Li, Yue Kou, Yuqi Tang, Huangfan Ye, Yiming Li and Chunmao Chen

29 Synthesis of ZSM-5/Siliceous Zeolite Composites for Improvement of Hydrophobic Adsorption of Volatile Organic Compounds

Renna Li, Shijia Chong, Naveed Altaf, Yanshan Gao, Benoit Louis and Qiang Wang

39 Mass Transfer Behavior of Benzene in Hierarchically Structured ZSM-5 Xiuhong Meng, Chunhui Lin, Youhua Zhang, Huibo Qin, Shui Cao and Linhai Duan

46 Recent Progress in Direct Conversion of Methane to Methanol Over Copper-Exchanged Zeolites

Min Bum Park, Eun Duck Park and Wha-Seung Ahn

$53 \mathrm{CO}_{2}$ Adsorption Capacities in Zeolites and Layered Double Hydroxide Materials

Cristina Megías-Sayago, Rogéria Bingre, Liang Huang, Gaëtan Lutzweiler, Qiang Wang and Benoît Louis

63 Effect of Surface Structure and Adsorption Activity on Implanting of b-Oriented ZSM-5 Zeolite Film on Modified $\alpha$-Quartz Substrate Ruizhi Chu, Deguang Yang, Xianliang Meng, Shi Yu, Yongzhou Wan, Jiaxing Wu and Jian Wang

75 Novel Hierarchical Fe(III)-Doped Cu-MOFs With Enhanced Adsorption of Benzene Vapor

Xuejiao Sun, Xiulian Gu, Wentao Xu, Wen-Jie Chen, Qibin Xia, Xiaoyang Pan, Xiaojing Zhao, Yi Li and Qi-Hui Wu

84 Observation of Ag Nanoparticles in/on Ag@MIL-100(Fe) Prepared Through Different Procedures

Rubén Mahugo, Alvaro Mayoral, Manuel Sánchez-Sánchez and Isabel Diaz

96 Ketal Sugar Conversion Into Green Hydrocarbons by Faujasite Zeolite in a Typical Catalytic Cracking Process

Joana Pinto, Igor Pedrosa, Camila Linhares, Rosane A. S. San Gil, Yiu Lau Lam and Marcelo Maciel Pereira 
110 Molecular Dynamics Simulation of the Implantation of b-Oriented ZSM-5 Film Modified $\alpha$-Quartz Substrate Surface With Different Modifiers

Jiaxin Wu, Xianliang Meng, Ruizhi Chu, Shi Yu, Yongzhou Wan, Chengcheng Song, Guifeng Zhang and Tong Zhao

126 Polymer-Based Shaping Strategy for Zeolite Templated Carbons (ZTC) and Their Metal Organic Framework (MOF) Composites for Improved Hydrogen Storage Properties

Lerato Y. Molefe, Nicholas M. Musyoka, Jianwei Ren, Henrietta W. Langmi, Mkhulu Mathe and Patrick G. Ndungu 


\section{Editorial: Zeolite Chemistry and Applications}

\begin{abstract}
Marcelo M. Pereira ${ }^{1 *}$, Benoit Louis ${ }^{2}$ and Qiang Wang ${ }^{3}$
1 Departamento de Química Inorgânica, Instituto de Química, Universidade Federal do Rio de Janeiro, Rio de Janeiro, Brazil, ${ }^{2}$ ICPEES - Institut de Chimie et Procédés pour l'Energie, l'Environnement et la Santé, Energy and Fuels for a Sustainable Environment Team, UMR 7515 CNRS - Université de Strasbourg - ECPM, Strasbourg, France, ${ }^{3}$ Environmental Functional Nanomaterials (EFN) Laboratory, College of Environmental Science and Engineering, Beijing Forestry University, Beijing, China
\end{abstract}

Keywords: zeolites, porous-material, bi-functional catalysts, environmental, green fuel

\section{Editorial on the Research Topic}

\section{Zeolite Chemistry and Applications}

A better future for humanity demands improved chemical processes that are more efficient and able to use several types of feedstocks, with less environmental damage. In addition, the chemical industry must provide essential goods and desired products. Catalysts can bridge the gap to solving these issues. Thus, improvement in catalyst properties, new routes for catalyst preparation, and new catalysts will be key to impacting the development of green energy, efficient fuel production, and environmental remediation.

Zeolites, porous material, and bi-functional catalysts represent a significant market. They alone in the world respond almost entirely to fuel production, and besides being also relevant to petrochemical and pharmaceutical industries, contribute to decreasing greenhouse gas emission and environmental remediation. The present edition of "Zeolite Chemistry and Applications" explores not only regular but also new catalysts in current chemical and new processes. This edition contains 12 articles, mainly in three areas: (1) green fuel production, (2) environmental remediation, and (3) catalyst technology.

The first area includes the production of green hydrocarbons by introducing biomass in a typical refinery. In this article, it was shown that faujasite zeolite converts a ketal-sugar derivative efficiently into green-aromatics (Pinto et al.). A mini review article explores the direct methane conversion into methanol in the presence of a copper zeolite catalyst. The authors show that the type of zeolite is crucial to obtaining a high methanol yield, i.e., small pores have enabled higher methanol yields than medium and large pore $\mathrm{Cu}$-zeolites (Park et al.). Methane can be produced from both natural gas and bio-methane, and methanol is a platform molecule for sequential conversion. Thus, the route methane-methanol fits the requirement of green or friendly fuel production. Furthermore, methanol conversion into benzene, toluene, and xylene (BTX) was carried out in the presence of a b-oriented ZSM-5 zeolite film. This film was synthesized on the macropore $\alpha$ quartz substrate, modified with titanium dioxide $\left(\mathrm{TiO}_{2}\right)$, polyvinyl acetate (PVA), and chitosan (CTS) (Chu et al.). The modification improves the b-oriented ZSM-5 zeolite film; as $\mathrm{TiO}_{2}$ coating provides a smooth nucleus-substrate growth interface for the ZSM-5 zeolite film, it leads to a uniform distribution of the ZSM- 5 zeolite film growing along the b-oriented direction. Another way to modify catalyst properties is the preparation of zeolites on the carbons template (Molefe et al.). The metal-organic frameworks (MOFs) and zeolite template carbons (ZTC) showed a remarkably higher area $\left(1,054-2,433 \mathrm{~m}^{2} \mathrm{~g}^{-1}\right)$ with higher hydrogen uptake capacity $\left(1.22-1.87 \mathrm{H}_{2}\right.$ wt.\%, respectively at 1 bar and $77 \mathrm{~K}$ ). Finally, a series of ZSM-5 zeolites with hierarchical porous structures were synthesized using $\mathrm{NaOH}$ solutions treatment method. Herein, the hierarchical ZSM-5 was obtained with a uniform size of the mesoporous and microporous structure and high acid sites, and as a consequence produced more adsorption sites and thus increased the adsorption of benzene (Meng et al.). 
The second area explores environmental remediation by trapping organic compounds produced by regular processes, the carbon industry, and carbon dioxide. One article explores the hierarchical concept in MOFs of benzene adsorption. Novel hierarchical $\mathrm{Fe}(\mathrm{III})$-doped $\mathrm{Cu}-\mathrm{MOF}$ ( $\mathrm{Fe}-\mathrm{HK}$ ) were developed via the introduction of $\mathrm{Fe}^{3+}$ ions during HKUST-1 synthesis. It was found that the hierarchical-pore Fe-HK-2 exhibited optimal textural properties with a highly BET surface area $\left(1,707 \mathrm{~m}^{2} / \mathrm{g}\right)$ and a total pore volume of $0.93 \mathrm{~cm}^{3} / \mathrm{g}$, which were higher than those of the unmodified HKUST-1. Furthermore, the novel material showed enhanced diffusion rate and excellent reversibility of benzene adsorption. The outstanding adsorption capacity of benzene showed by this novel material might be an attractive candidate for volatile organic compounds (VOCs) adsorption (Sun et al.). In another paper, the trap of VOCs (by adsorption-desorption) was carried out in the presence of hierarchical composites of ZSM-5 with MCM-41 and Silicalite ( $\mathrm{Li}$ et al.). These catalysts were prepared for improving hydrophobicity by applying different optimized coating dosages $(25,50$, and $75 \%)$ on designed novel ZSM-5/MCM-41 and ZSM5/Silicalite-1 hierarchical composites. The relatively large specific surface area and pore volume of the ZSM-5/MCM-41 composite presented a longer toluene adsorption time no matter if in dry or $50 \%$ humid conditions. In another paper, Zeolite $\mathrm{X}$ was prepared by using aluminum Residue from Coal Fly Ash (Zhu et al.). The adsorption of isopropanol, benzene, and cyclohexane was carried out in zeolite as prepared, and values around $15 \%$ (in wt.\% of VOCs/wt.\% zeolite) were obtained. It is important to point out the advantage of this method in terms of both environmental friendliness and economic viability. Further, for a different application, zeolites, layered double hydroxides (LDH), and zeolites-coated LDH composites were prepared and used for $\mathrm{CO}_{2}$ trapping (by adsorption) (Megías-Sayago et al.). Those materials demonstrated good $\mathrm{CO}_{2}$ sorption capacity ( $>1 \mathrm{mmol}$ of $\mathrm{CO}_{2} / \mathrm{g}$ of material at $40^{\circ} \mathrm{C}$ ). $\mathrm{CO}_{2}$ capture strongly depends on the properties of the material.

One example of a bi-functional catalyst was found by adding vanadium (V) oxides onto the surface of NaZSM-5 zeolites (V/ZSM), then applying this to the removal of recalcitrant organic chemicals (ROCs) from the water by ozonation treatment (Xu et al.). The novel catalytic materials were found to be highly efficient in the removal of the nitrobenzene and benzoic acid archive, achieving 100\% degradation in $\sim 15 \mathrm{~min}$. The key for such a goal was the highly dispersed $\mathrm{V}$ oxides (V4+ and $\mathrm{V} 5+$ ) and $\mathrm{Si}-\mathrm{OH}-\mathrm{Al}$ framework structures that promote the surface reaction and generation of hydroxyl radicals. Another example of a new bi-functional material was also presented in this issue. Besides catalysis, loading of active metals and metal nanoparticles in Metal-Organic Frameworks (MOFs) is an emergent field, with applications in sensors, medicine, and even in the polymeric industry. It was shown that Ag nanoparticles of a size of around $2.5 \mathrm{~nm}$ appear inside the MOF pores periodically, as well as in the particle distribution with a much larger size (of ca. $\approx 13 \mathrm{~nm}$ of diameter) observed outside the framework. (Mahugo et al.). This work makes clear that simple experimental modifications can have a significant influence on both chemistry and the location of the Ag species. More importantly, the advanced TEM techniques developed in this study have shown enormous potential to characterize metal particles on several porous materials. Thus, it is expected that this approach will be used in several applications. Another important theme is the modification of a catalyst surface, enabling better stabilization of blended catalysts. A beautiful example of a new route for catalyst preparation is described in the article (Wu et al.), which worked on the structure-absorption relationship of common surface modifiers of chitosan (CTS), polyvinyl acetate (PVA), and titanium dioxide $\left(\mathrm{TiO}_{2}\right)$ with $\alpha$-quartz surface using molecular dynamics simulation. For example, the formation of several stable Ti-O-Si chemical bonds (between the $\mathrm{TiO}_{2}$ and the surface of $\alpha$-quartz) stabilizes the attached ZSM-5 film. Thus, several applications could emerge for this new type of catalyst.

To summarize, the present edition of "Zeolite Chemistry and Applications" showed examples that link the properties of zeolites and porous materials with application problems. It is impressive that one can find in these 12 articles very relevant questions on catalysis with broad applications. Let's wait to see the catalysts and related materials - the heart of chemical processes-contribute to a better future for humanity. This issue is a small sample of this potential.

\section{AUTHOR CONTRIBUTIONS}

MP, BL, and QW contributed equally to this article and have made a substantial, direct and intellectual contribution to the work, and approved it for publication.

Conflict of Interest: The authors declare that the research was conducted in the absence of any commercial or financial relationships that could be construed as a potential conflict of interest.

Copyright (C) 2020 Pereira, Louis and Wang. This is an open-access article distributed under the terms of the Creative Commons Attribution License (CC BY). The use, distribution or reproduction in other forums is permitted, provided the original author(s) and the copyright owner(s) are credited and that the original publication in this journal is cited, in accordance with accepted academic practice. No use, distribution or reproduction is permitted which does not comply with these terms. 


\section{OPEN ACCESS}

Edited by:

Qiang Wang,

Beijing Forestry University, China

Reviewed by:

Liang Wenjun,

Beijing University of Technology, China

Erhong Duan,

Hebei University of Science and

Technology, China

*Correspondence:

Tao Zhu

bamboozt@cumtb.edu.cn

Baodong Wang

wangbaodong@nicenergy.com

Specialty section:

This article was submitted to

Inorganic Chemistry,

a section of the journal

Frontiers in Chemistry

Received: 27 March 2019

Accepted: 25 April 2019

Published: 14 May 2019

Citation:

Zhu T, Zhang X, Han Y, Liu T, Wang B and Zhang $Z$ (2019) Preparation of Zeolite $X$ by the Aluminum Residue From Coal Fly Ash for the Adsorption of Volatile Organic Compounds.

Front. Chem. 7:341. doi: 10.3389/fchem.2019.00341

\section{Preparation of Zeolite $\mathrm{X}$ by the Aluminum Residue From Coal Fly Ash for the Adsorption of Volatile Organic Compounds}

\author{
Tao Zhu ${ }^{1,2 *}$, Xing Zhang ${ }^{1}$, Yiwei Han ${ }^{1}$, Tongshen Liu ${ }^{3}$, Baodong Wang ${ }^{4 *}$ and \\ Zhonghua Zhang ${ }^{4}$
}

${ }^{1}$ Institute of Atmospheric Environmental Management and Pollution Control, China University of Mining and Technology (Beijing), Beijing, China, ${ }^{2}$ State Environmental Protection Key Laboratory of Odor Pollution Control, Tianjin, China, ${ }^{3}$ Beijing Municipal Research Institute of Environmental Protection, Beijing, China, ${ }^{4}$ National Institute of Clean-and-Low-Carbon Energy, Beijing, China

In China, coal fly ash is a large-scale solid waste generated by power plants. The high value utilization of coal fly ash has always been a hot research issue in China for these years. In this paper, the synthesis of zeolite $X$ using aluminum residue from coal fly ash can not only realize the resource utilization of waste, but also achieve the effect of energy saving and emission reduction. Zeolite X prepared by hydrothermal synthesis method have been found to have higher purity and better crystallinity by chemical composition analysis. By comparing and analyzing the adsorption performance of zeolite $X$ and activated carbon on volatile organic compounds, it is found that the adsorption capacity of zeolite $X$ is higher than that of activated carbon, and it has stronger stability. This indicates that the zeolite $X$ synthesized by this environmentally friendly and economical method has a good application prospect in adsorbing volatile organic compounds.

Keywords: coal fly ash, aluminum residue, zeolite $\mathrm{X}$, activated carbon, adsorption performance, volatile organic compounds

\section{INTRODUCTION}

According to the definition of the World Health Organization, volatile organic compounds (VOCs) usually refer to organic compounds having boiling points within the range of $50 \sim 260^{\circ} \mathrm{C}$ (Kuo et al., 2014). VOCs are widely distributed in air, water, soil and other environmental media and have high risk biological toxicity properties, which pose significant threat to the human health (Ramos et al., 2010). VOCs are important atmospheric pollutants, which are precursors and participants of $\mathrm{PM}_{2.5}$ that can not only react with nitrogen oxides to form photochemical smog, but also react with hydroxyl and other strong oxidants in the atmosphere to form secondary organic aerosols (Wei et al., 2014a). In recent years, the multiple environmental effects on regional atmospheric are caused by VOCs, which has become one of the major problems for human survival and development (Wei et al., 2014b).

The adsorption method is widely used in gas purification and it has the advantages of mature process, simple operation, high purification efficiency and low energy consumption compared to other methods (Rioland et al., 2017). Therefore, the adsorption method is often used to deal with 
industrial organic gas with high air volume and low concentration. The selection of adsorbent is the key to the purification of VOCs by adsorption (Son et al., 2016). The ideal adsorbent should be characterized by large specific surface area, high adsorption capacity, reversible adsorption, strong hydrophobicity, high thermal stability and easy regeneration (Long et al., 2011). At present, activated carbon is widely used as adsorbent in gas purification. Although the adsorption capacity of activated carbon is strong, there are flammable and hydrophilic in the adsorption process which is difficult to absorb the complex and changeable industrial organic gas. Pen et al. studied the performance of activated carbon in the adsorption of VOCs and found that the activated carbon has problems such as poor stability and pore blockage, which strongly hinders the adsorption of VOCs (Chiang et al., 2001).

Zeolite $\mathrm{X}$ is a kind of nanocrystalline material with skeleton structure, which has large specific surface area and pore volume due to its special crystal structure and uniform pore channels. Therefore, zeolite $\mathrm{X}$ is characterized by strong adsorption and selection capabilities for VOCs. In addition, zeolite $\mathrm{X}$ shows excellent hydrophobic and hydrothermal stability, which effectively reduces the competitive adsorption of water molecules, so zeolite X is widely used to adsorb VOCs (Ling et al., 2016; Brihi et al., 2018). However, the reserve of zeolite $X$ is scarce in nature and the adsorption performance usually cannot meet the requirements of industrial applications. Zeolite $\mathrm{X}$ is generally synthesized by aluminum hydroxide, sodium silicate and sodium aluminate in the industrial production, which consumes a lot of energy and may cause severe secondary pollution. Coal fly ash contains various valuable elements such as silicon and aluminum that are required for the preparation of zeolite X. At present, using coal fly ash to synthesize zeolite $\mathrm{X}$ has attracted wide attention from numerous scholars and it has shown great application in the fields of gas purification and sewage treatment. Zhang et al. used different concentrations of hydrochloride and sodium hydroxide solution to modify coal fly ash for preparing zeolite. He found that the benzene adsorption capacity of zeolite can reach $151 \mathrm{mg} / \mathrm{g}$, which is very close to or even exceeds

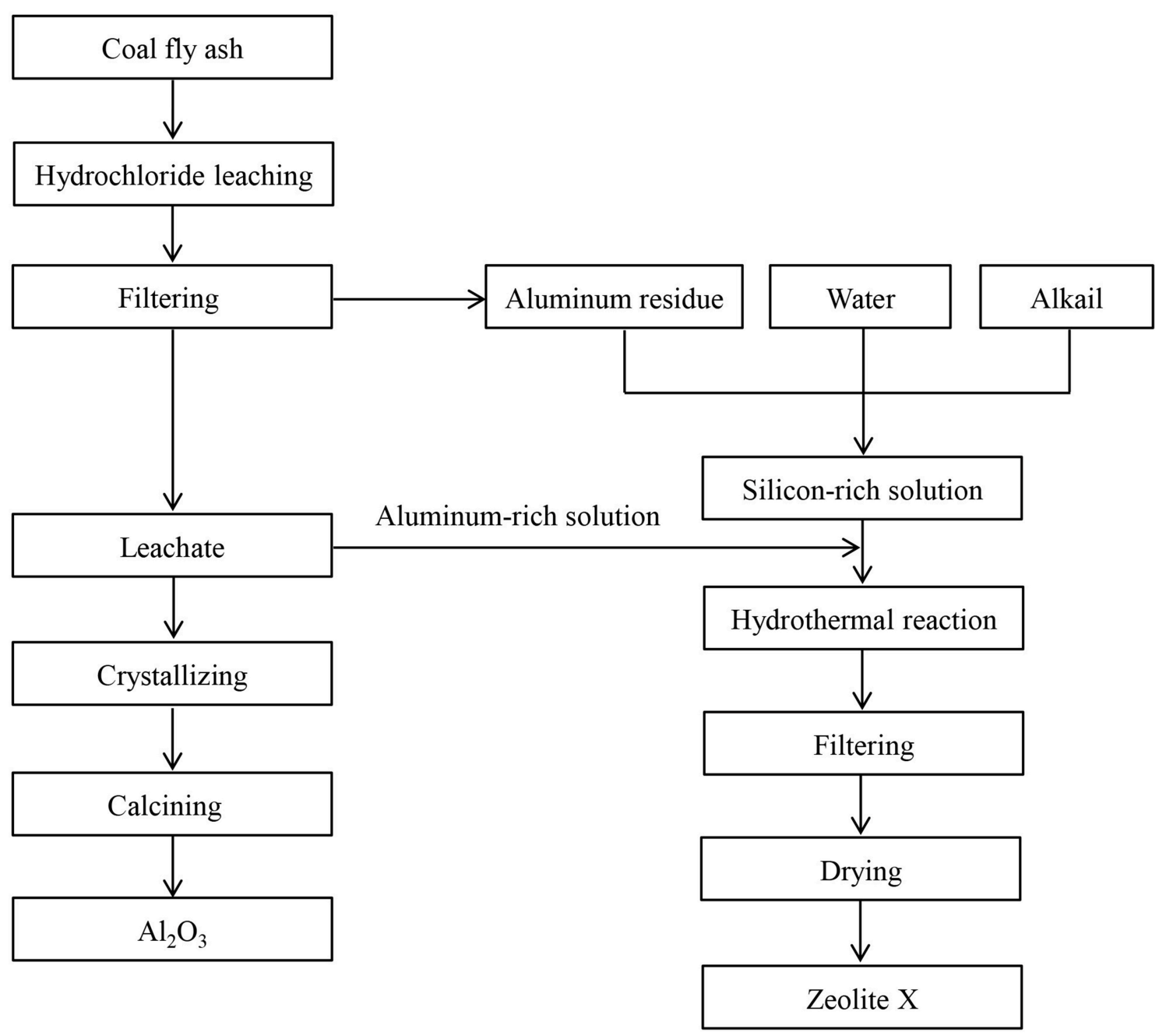

FIGURE 1 | Process diagram for synthesizing zeolite $X$ by aluminum residue. 
TABLE 1 | Chemical analysis of coal fly ash and aluminum residue.

\begin{tabular}{lccccccc}
\hline Chemical composition & $\mathbf{S i O}_{\mathbf{2}}$ & $\mathbf{A l}_{\mathbf{2}} \mathbf{O}_{\mathbf{3}}$ & $\mathbf{K}_{\mathbf{2}} \mathbf{O}$ & $\mathbf{C a O}$ & $\mathbf{T i O}_{\mathbf{2}}$ & $\mathbf{F e}_{\mathbf{2}} \mathbf{O}_{\mathbf{3}}$ & $\mathbf{S r O}$ \\
\hline Coal fly ash/\% & 35.0 & 54.4 & 0.404 & 3.77 & 2.43 & 1.99 & 0.12 \\
Aluminum residue/\% & 78.7 & 13.4 & 0.163 & 0.37 & 5.2 & 0.445 & 0.03
\end{tabular}

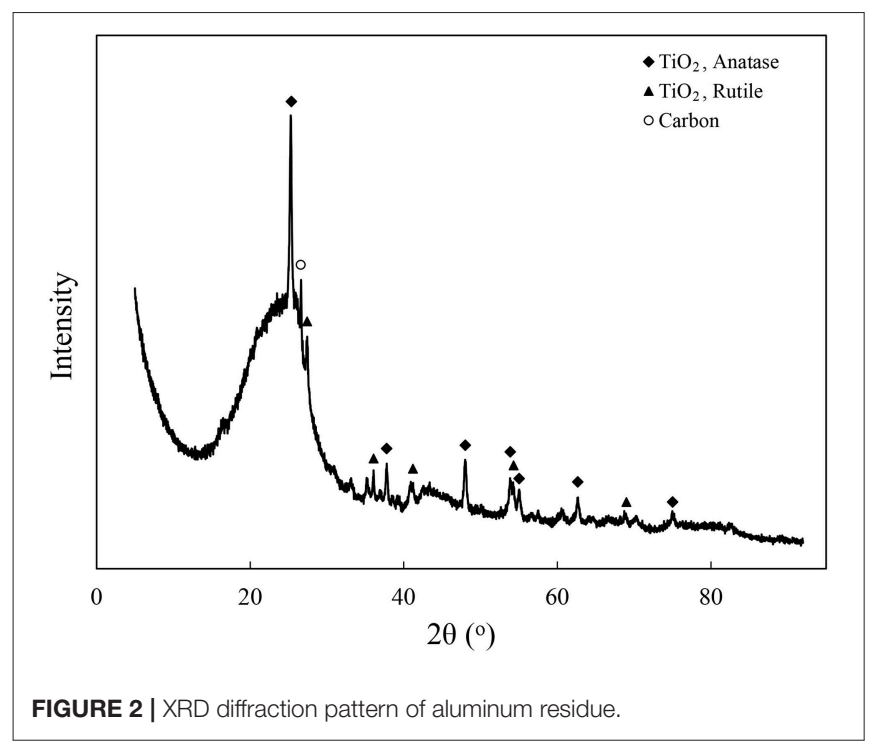

commercial activated carbon (Zhang et al., 2012). Although many scholars have conducted in-depth research on the synthesis of zeolite using coal fly ash, the prepared zeolite X exhibits excellent adsorption performance and meet the requirements of industrial applications. However, a large number of residues are difficult to be recycled and various mineral resources contained in the coal fly ash cannot be fully utilized in the preparation process. This study differs from others is that the zeolite $\mathrm{X}$ is obtained from the aluminum residue. So the aluminum residue is resourced and the comprehensive utilization efficiency of coal fly ash is improved. It saves not only a lot of chemical raw materials, but also preparation cost (Brunchi et al., 2012; Zhang et al., 2012; Huang et al., 2014; Yuan et al., 2015; Rioland et al., 2017).

\section{MATERIALS AND METHODS}

\section{Preparation of Zeolite $X$}

The coal fly ash used in the present study was obtained from an electric power plant in Inner Mongolia, China. Concentrated hydrochloride and sodium hydroxide were bought from the Sinopharm Chemical Reagent Co., Ltd. The coal fly ash was dried at $150^{\circ} \mathrm{C}$ for $12 \mathrm{~h}$ before the experiments and then it was leached with hydrochloride to form aluminum chloride. The remaining aluminum residues were mainly non-metallic inorganic mineral. The aluminum residue can be used as highquality aluminosilicate material due to its small particle size and high activity.

The hydrothermal synthesis method with mild reaction conditions was used to synthesize zeolite $\mathrm{X}$. The main chemical

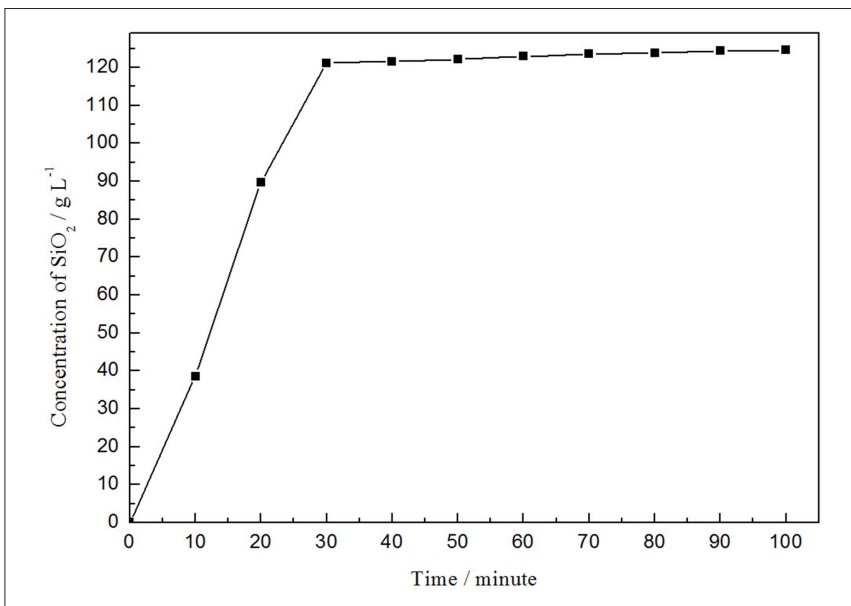

FIGURE 3 | Variation of silica concentration with reaction time.

components of zeolite $\mathrm{X}$ were derived from the aluminum-rich solution and the silicon-rich solution in the synthesis process. The aluminum-rich solution was taken from the filtrate during the aluminum extraction process. The silicon-rich solution was obtained by filtration and the alkalinity of the silicon-rich solution was adjusted by introducing different volumes of carbon dioxide. The aluminum residue, sodium hydroxide and water were stirred and mixed at the mass ratio of 100:60:400 to obtain gelatinous mother liquor. The mixture was placed in the vessel and hydrothermal reaction was carried out at the temperature of $95^{\circ} \mathrm{C}$ for $20 \mathrm{~h}$. The reaction product was filtered and washed until the $\mathrm{pH}$ of the washing liquid was 7 . The product of zeolite $\mathrm{X}$ was obtained after drying. The main instruments used in the study were the 2L hydrothermal vessel and the CS501 constant temperature circulating tank (Figure 1).

The coal fly ash and the aluminum residue are rich in silicon and aluminum. The total contents of silica and alumina are 89.4 and $92.1 \%$, respectively (Table 1). From the XRD diffraction pattern of the aluminum residue, it is known that most of the aluminum residue is amorphous phase material (Figure 2). The XRD pattern shows that the obvious peaks is between 20 and $30^{\circ}$. Its main phase is amorphous silica, mullite and quartz. In addition, a small amount of titanium dioxide minerals and some unburned carbon residue are present.

It can be seen that the reaction of aluminum residue and alkali is very rapid (Figure 3). The concentration of silicon dioxide is substantially stabilized at the maximum when the reaction takes place for $30 \mathrm{~min}$. Thereafter, the concentration of silica changes slightly as the reaction time increases. Therefore, the optimum reaction time for desiliconization of alkaliwashed aluminum residue is $30 \mathrm{~min}$ and the concentration of silicon dioxide in the silicon-rich solution is between 120 and $125 \mathrm{~g} \bullet \mathrm{L}^{-1}$.

\section{Characterization}

The phase analysis of zeolite $\mathrm{X}$ was carried out on the Rigaku RINT-2000 X-ray diffraction (XRD) with the operating voltage 


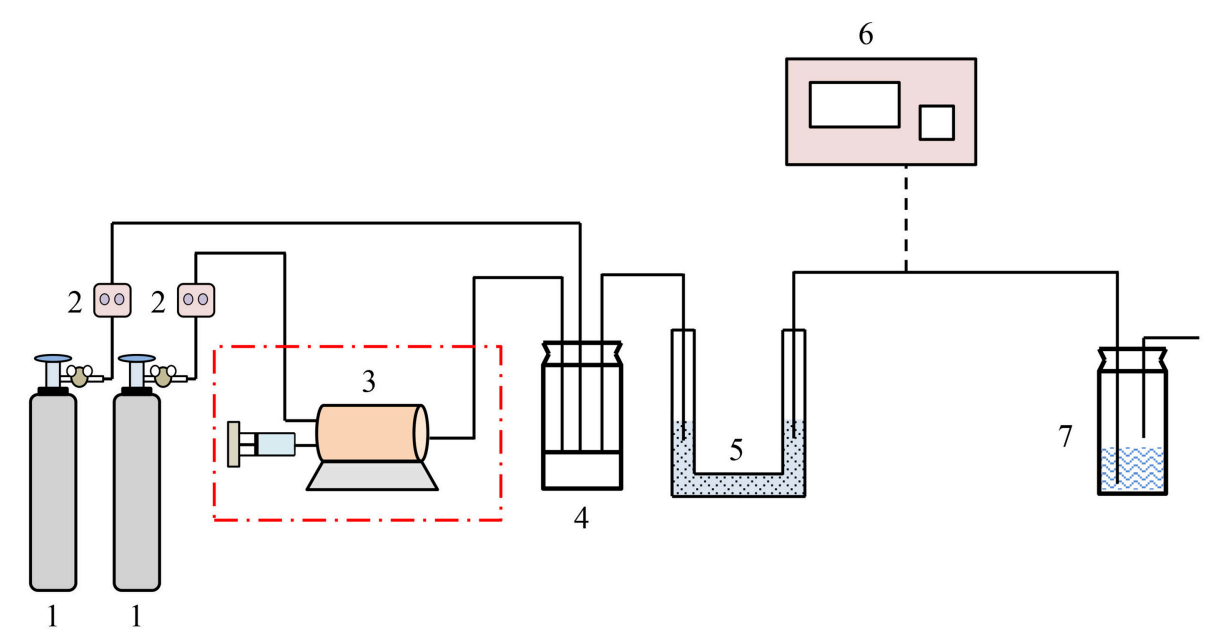

FIGURE 4 | VOCs adsorption experimental apparatus.

TABLE 2 | XRF analysis of zeolite X samples.

\begin{tabular}{lcccccc}
\hline Chemical composition & $\mathbf{N a}_{\mathbf{2}} \mathbf{O}$ & $\mathbf{A l}_{\mathbf{2}} \mathbf{O}_{\mathbf{3}}$ & $\mathbf{S i O}_{\mathbf{2}}$ & $\mathbf{S O}_{\mathbf{3}}$ & $\mathbf{K}_{\mathbf{2}} \mathbf{O}$ & $\mathbf{F e}_{\mathbf{2}} \mathbf{O}_{\mathbf{3}}$ \\
\hline Weight/\% & 18.2 & 32.3 & 48.9 & 0.114 & 0.413 & 0.0589
\end{tabular}

of $40 \mathrm{kV}$, electric current of $100 \mathrm{~mA}$, scanning speed of $0.02^{\circ} / \mathrm{s}$ and the scanning range of $5 \sim 80^{\circ}$. The microstructure was observed by the NOVA SEM 450 scanning electron microscope (SEM) with the operating voltage of $5.0 \mathrm{kV}$. The specific surface area and pore volume of the synthesized zeolite $\mathrm{X}$ were characterized by low temperature $\mathrm{N}_{2}$ adsorption-desorption method used the Micrometrics ASAP2020C type adsorber. The pretreatment was carried out before the adsorption measurement and the sample was desorbed at $250^{\circ} \mathrm{C}$ for more than $2 \mathrm{~h}$. The specific surface area of the sample were calculated by the BET method. The pore volume was calculated as the amount of adsorption when the adsorbate was at the relative pressure $\mathrm{P} / \mathrm{P}_{0}$ of 0.99 . The pore size distribution was measured by the $\mathrm{BJH}$ method and based on the desorption branch of the adsorptiondesorption isotherm.

\section{Adsorption Experiment of VOCs}

The experimental device was consisted of gas distribution system, adsorption system and detection system (Figure 4). The gas distribution system used nitrogen as carrier gas. One part of nitrogen entered the gas chamber through trace syringe to carry out VOCs vapor and the other part acted as dilution gas. The flow of gas was regulated by mass flow meter. The concentration of VOCs was controlled by regulating the flow of nitrogen in both parts. The U-shaped tube was used as adsorbent bed. The zeolite $\mathrm{X}$ was desorbed by nitrogen for $3 \mathrm{~h}$ to remove water vapor and small amount of organic compounds at $400^{\circ} \mathrm{C}$. The zeolite $\mathrm{X}$ was shaped into $20 \sim 30$ mesh granules after screening and then ten grams of samples were loaded into the adsorption bed.
Panna A91Gas Chromatography-Mass Spectrometer (GC-MS) was used to analyze the VOCs. The instrument column was HP$5 \mathrm{MS}$ and it was programmed to raise the temperature. The initial temperature of $50^{\circ} \mathrm{C}$ was maintained for $1 \mathrm{~min}$ and then raised to $170^{\circ} \mathrm{C}$ at the heating rate of $15^{\circ} \mathrm{C} \cdot \mathrm{min}^{-1}$. The temperature of front inlet and gasification chamber were 170 and $280^{\circ} \mathrm{C}$ respectively. The helium was used as carrier gas at the flow rate of $1 \mathrm{~mL} \cdot \mathrm{min}^{-1}$. The electron ionization EI source was $70 \mathrm{eV}$ and the temperature of ion source was $230^{\circ} \mathrm{C}$.

1. Gas cylinder 2. Mass flow meter 3. VOCs generator 4. Mixing bottle 5. Adsorbent bed 6. GC-MS 7. Tail gas absorption

The adsorption volume of VOCs is calculated by integrating the adsorption curve. The mathematical expression is as follows:

$$
q=\frac{\mathrm{F} C_{0} 10^{-6}}{\mathrm{~W}}\left[t_{s}-\int_{0}^{t_{s}} \frac{C_{i}}{C_{0}} d t\right]
$$

In this equation, $\mathrm{q}$ represents the saturated adsorption amount, in $\mathrm{mg} \cdot \mathrm{g}^{-1}$. F stands for the flow rate of gas, in $\mathrm{mL} \cdot \mathrm{min}^{-1} \cdot C_{0}$ stands for the concentration of VOCs at the entrance, in mg. $\mathrm{m}^{-3}$, $C_{i}$ stands for the concentration of VOCs at the exit of i minute, in mg. $\mathrm{m}^{-3}$. W is the quality of the adsorbent, in $\mathrm{g}$. $t_{s}$ is the adsorption saturation time, in minutes.

\section{RESULTS AND DISCUSSION}

\section{Analysis of Chemical Phase}

From the XRF analysis of sample, it can be seen that the mass of $\mathrm{Na}_{2} \mathrm{O}, \mathrm{Al}_{2} \mathrm{O}_{3}$, and $\mathrm{SiO}_{2}$ in the zeolite $\mathrm{X}$ reaches 99.4\% (Table 2). The impurities include $\mathrm{S}, \mathrm{K}$, and $\mathrm{Fe}$, which accounts for $0.586 \%$. It indicates that the prepared zeolite $\mathrm{X}$ sample is of high purity. Figure 5 and Table 3 show the EDS and elemental analysis of the zeolite $\mathrm{X}$ samples, respectively. Since EDS is primarily directed to the specific space of zeolite, it is commonly used to characterize individual particles or local samples. The analysis shows that the molar ratio of $\mathrm{Si} / \mathrm{Al}$ in the zeolite 


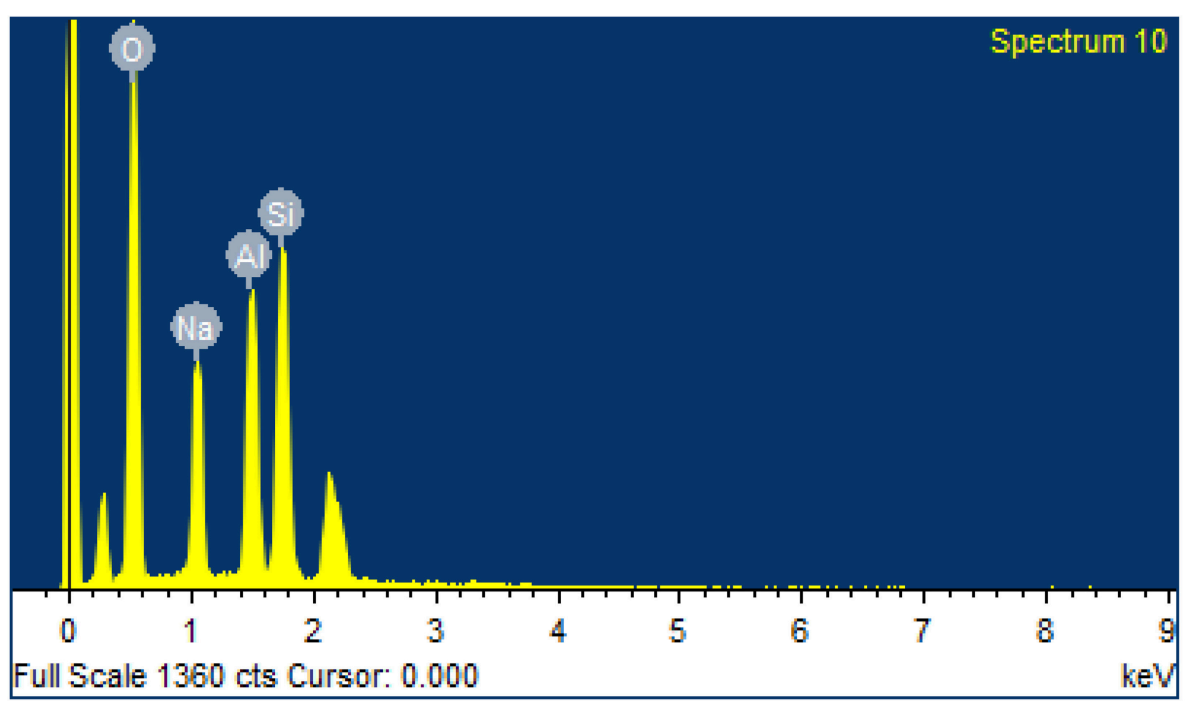

FIGURE 5 | EDS analysis of zeolite $X$ samples.

TABLE 3 | Elemental analysis of zeolite X samples.

\begin{tabular}{lcccc}
\hline Element & $\mathbf{O}$ & $\mathbf{N a}$ & $\mathbf{A l}$ & $\mathbf{S i}$ \\
\hline Weight/\% & 53.91 & 12.74 & 14 & 19.34 \\
Atomic/\% & 65.66 & 10.8 & 10.11 & 13.42 \\
\hline
\end{tabular}

$\mathrm{X}$ is about 1.33 and the molar ratio of $\mathrm{SiO}_{2} / \mathrm{Al}_{2} \mathrm{O}_{3}$ is about 2.66. The chemical composition of the synthesized zeolite is $\mathrm{Na}_{2} \mathrm{O} \bullet \mathrm{Al}_{2} \mathrm{O}_{3} \bullet(2.8 \pm 0.2) \mathrm{SiO}_{2} \bullet(6 \sim 7) \mathrm{H}_{2} \mathrm{O}$.

The XRD diffraction pattern of the zeolite $\mathrm{X}$ sample is shown in Figure 6. As can be seen from the figure, there is almost no amorphous peak in the XRD diffraction pattern of the zeolite $\mathrm{X}$, which indicates that the zeolite $\mathrm{X}$ is of good crystallinity and no other crystals are formed.

\section{Analysis of Structure and Microstructure}

The specific surface area and pore structure are important indicators to evaluate zeolite. The BET specific surface area of the synthesized zeolite $\mathrm{X}$ is $990.3 \mathrm{~m}^{2} / \mathrm{g}$ and the pore diameter is about $1.6 \mathrm{~nm}$. The microscopic morphology can reflect the crystallinity of the material. The SEM topography of the zeolite $\mathrm{X}$ sample is shown in Figure 7. It can be seen that the crystal form of the zeolite $\mathrm{X}$ is mainly octahedral structure. The particle size of zeolite $\mathrm{X}$ is between 1 and $3 \mu \mathrm{m}$ which indicates that the particle size distribution is uniform. The surface of the partial particle unit cell is rough and has some defects. It may be that the aluminosilicate ions are not completely dissolved in water and some of the ions are still adsorbed on the surface of the particles during the hydrothermal reaction. It also may be due to the presence of $\mathrm{Ca}, \mathrm{K}$ impurities in the mother liquor.

\section{Adsorption Results of VOCs}

The penetration point is set as the VOCs concentration of outlet gas reaches $5 \%$ of the inlet gas. The time from the start of adsorption to the penetration point is the penetration time. The capacity of adsorption during the penetration time is penetration adsorption capacity. The adsorption saturation is set as the VOCs concentration of outlet gas reaches $100 \%$ of the inlet gas. The time from the start of adsorption to the adsorption saturation is the saturation time. The capacity of adsorption during the saturation time is the saturated adsorption capacity. The physical parameters of VOCs are shown in Table 4. The adsorption of isopropyl alcohol, benzene and cyclohexane was tested by the zeolite $\mathrm{X}$ and activated carbon and then comparing the adsorption properties of two adsorbents. The activated carbon was bought from Jiangsu Zhu Hai Environmental Technology Co., Ltd, and the BET specific surface area was $1020.8 \mathrm{~m}^{2} / \mathrm{g}$ and the pore diameter was $2.7 \mathrm{~nm}$.

As is shown in the picture, the adsorption curve of zeolite $\mathrm{X}$ lags behind that of activated carbon and the adsorption capacity of zeolite $\mathrm{X}$ on VOCs is larger than activated carbon, which indicates that zeolite $\mathrm{X}$ has better adsorption performance than activated carbon. The adsorption capacity of isopropanol is higher than that of benzene and cyclohexane, whether zeolite $\mathrm{X}$ or activated carbon (Figures 8-10; Tables 5, 6). The adsorption performance of the adsorbent is closely related to the polarity of the molecules. The polarity of isopropanol is stronger than that of benzene and cyclohexane. In addition, the unsaturation of molecules is also an important factor to determine the adsorption performance of adsorbent. The greater unsaturation of the molecules and the stronger adsorption capacity of the adsorbent.

Activated carbon is composed of carbon, hydrogen, oxygen, nitrogen and other elements and the content of carbon usually accounts for more than $90 \%$. The skeleton structure of activated carbon is similar to amorphous carbon and it is mainly composed 
of graphite microcrystals in which $2 \sim 4$ layers of single layer graphite sheets are stacked (Min et al., 2017; Raj et al., 2018). A large number of micropores are formed in the process of disorderly superposition of adjacent graphite microcrystals and the pore diameter of activated carbon micropore is between 0.7 and $2 \mathrm{~nm}$. The activated carbon has large specific surface area due to its unique pore structure characteristics (Chmelik et al., 2010). The carbon atoms on the surface are easily oxidized with hydrogen and oxygen to form various functional groups due to covalent bond unsaturation in the preparation of activated carbon. Therefore, the polarity of activated carbon has significant effect on its adsorption properties (Bhatnagar et al., 2013; Prajapati et al., 2016).

Zeolite X has the function of screening molecules. Uniform pore size and honeycomb structure are the unique characteristics of zeolite X. The adsorbate can be captured when its molecular diameter is smaller than the zeolite $\mathrm{X}$ aperture (Zhou et al., 2014; Calero and Gómez-Álvarez, 2015; Brihi et al., 2018). The framework of the zeolite $\mathrm{X}$ carries negative charge because the silicon atoms are replaced by aluminum. The negative charge is compensated by strongly polar molecules outside the framework

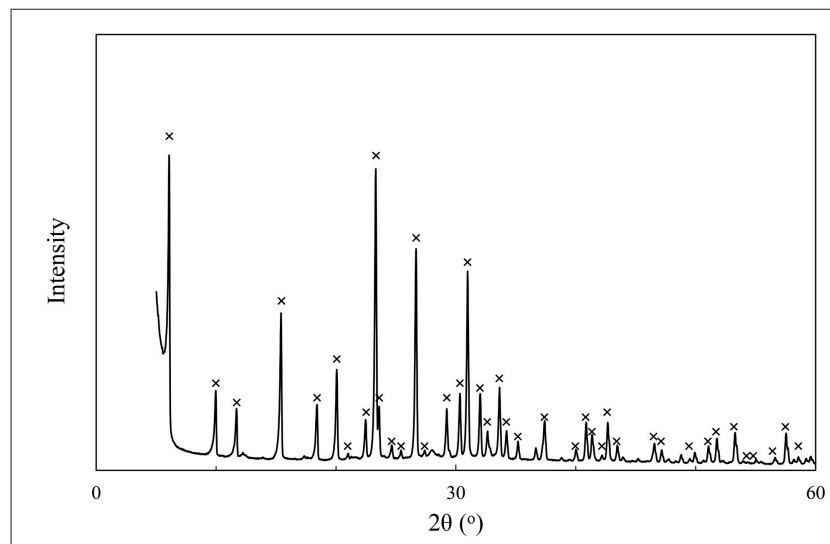

FIGURE 6 | XRD diffraction pattern of zeolite $X$ samples. of the zeolite X. The greater polarity of the adsorbate molecules and the higher adsorption capacity of the zeolite X (Akosman and Kalender, 2010; Gorshunova et al., 2015; Wang et al., 2017). Adsorbate molecules are activated due to special electric field effects in the pore channels of zeolite $\mathrm{X}$, which ensures that the zeolite $\mathrm{X}$ can identify the adsorbate molecules accurately and improve the adsorption performance of the zeolite X (Akosman and Kalender, 2010; Kim and Ahn, 2012). Brosillon et al. used zeolite to adsorb heptane and acetone respectively. The results showed that the adsorption capacity of zeolite to heptane was larger than that of acetone. The molecular polarity of heptane is stronger than acetone, which reflects the excellent selectivity of zeolite and it is closely related to the molecular polarity of VOCs (Brosillon et al., 2000).

\section{CONCLUSIONS}

The comprehensive utilization of coal fly ash can not only develop circular economy, but also produce huge environmental and social benefits. At present, China's economy is developing at high speed and the demand for resources is also increasing as well. The refinement and high value-added comprehensive utilization of coal fly ash resources should be the prospect in the future and it is an important way to achieve sustainable development strategies in China. This study may bring a new and alternative approach for recycling of coal fly ash. By analyzing the chemical phase, microstructure and VOCs

TABLE 4 | Physical parameters of VOCs.

\begin{tabular}{|c|c|c|c|c|c|}
\hline VOCs & $\begin{array}{c}\text { Relative } \\
\text { molecular } \\
\text { mass } / g \bullet \mathrm{mol}^{-1}\end{array}$ & $\begin{array}{l}\text { Density/ } \\
\text { g॰mL-1 }\end{array}$ & $\begin{array}{c}\text { Boiling } \\
\text { Point } /{ }^{\circ} \mathrm{C}\end{array}$ & $\begin{array}{c}\text { Tension/ } \\
\text { kPa }\end{array}$ & $\begin{array}{c}\text { Molecular } \\
\text { diameter/ } \\
\text { nm }\end{array}$ \\
\hline Cyclohexane & 84 & 0.78 & 80.7 & 10.34 & 0.61 \\
\hline Benzene & 78 & 0.88 & 80.1 & 10.03 & 0.53 \\
\hline Isopropanol & 60 & 0.79 & 82.4 & 4.400 & 0.47 \\
\hline
\end{tabular}

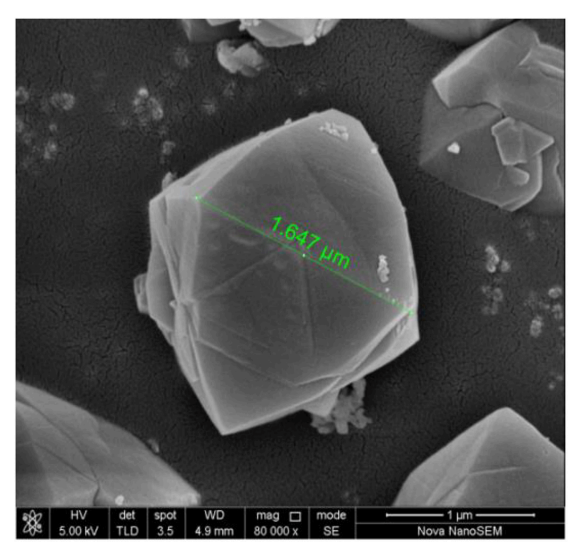

FIGURE 7 | SEM image of zeolite $X$ samples. 


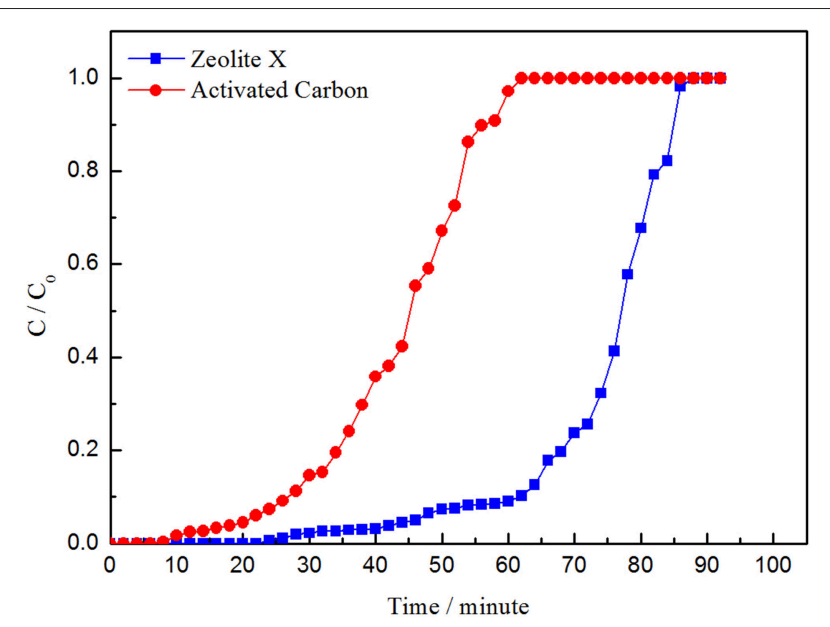

FIGURE 8 | Adsorption curves of cyclohexane by zeolite $X$ and activated carbon.

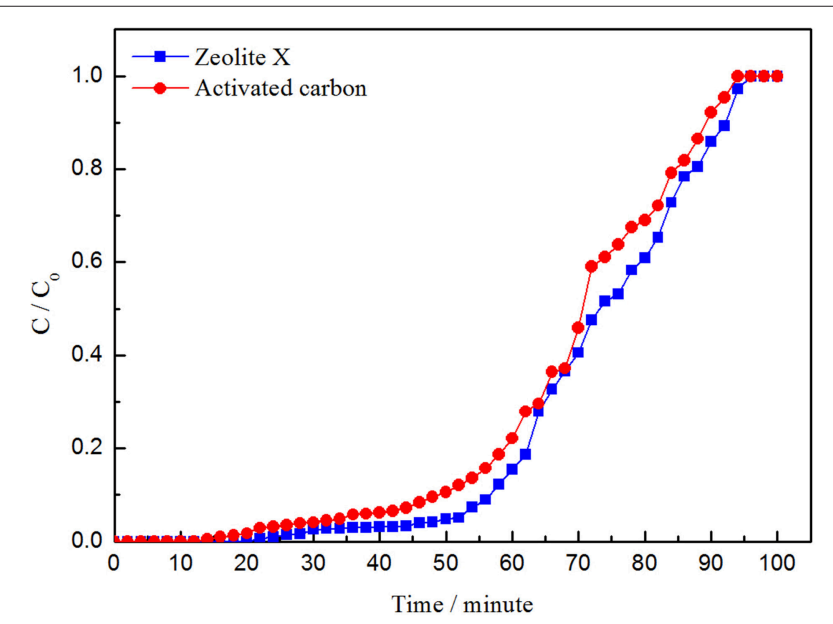

FIGURE 9 | Adsorption curves of benzene by zeolite $X$ and activated carbon.

adsorption performance of zeolite $\mathrm{X}$ and activated carbon, it was found that:

(a) The study has verified that the preparation of zeolite $\mathrm{X}$ by the aluminum residue from coal fly ash is feasible. There is no need to add silicon or aluminum source during the synthesis process. It effectively enhances the comprehensive utilization efficiency of the coal fly ash and enriches the product categories.

(b) The prepared zeolite $\mathrm{X}$ is of high purity and crystallinity through the analysis of chemical phase. The crystalline form is mainly octahedral structure and the particle size distribution is basically uniform. The structure and microstructure specific of zeolite $\mathrm{X}$ are analyzed. The results show that the BET specific surface area is $990.3 \mathrm{~m}^{2} / \mathrm{g}$ and the pore diameter is $1.6 \mathrm{~nm}$.

(c) Through the experiment of VOCs adsorption, it is found that the VOCs adsorption capacity exceeds the activated carbon. The adsorption capacity of cyclohexane on zeolite

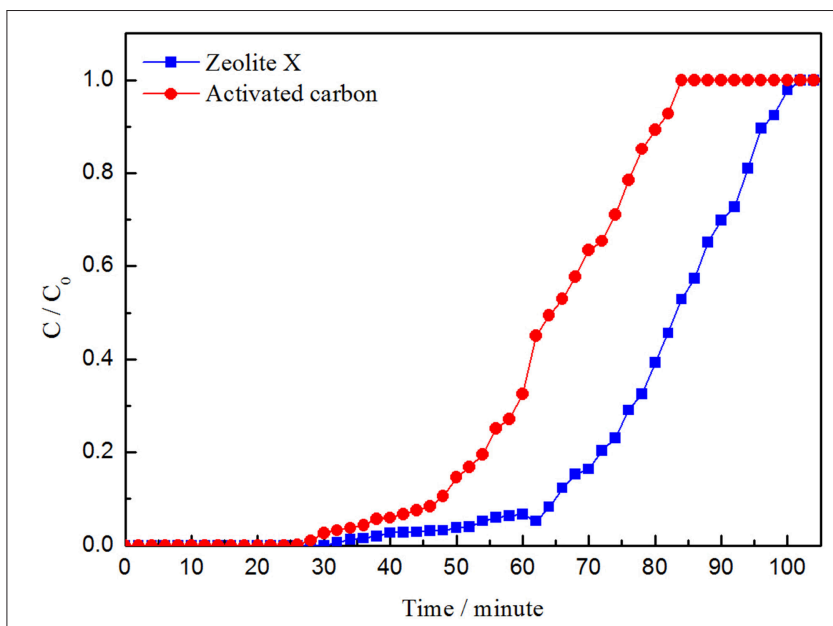

FIGURE 10 | Adsorption curves of isopropanol by zeolite $X$ and activated carbon.

TABLE 5 | Adsorption performance of VOCs by zeolite $X$

\begin{tabular}{|c|c|c|c|c|}
\hline VOCs & $\begin{array}{l}\text { Penetration } \\
\text { time/ } \\
\text { minute }\end{array}$ & $\begin{array}{c}\text { Penetration } \\
\text { adsorption } \\
\text { capacity/mg•g }^{-1}\end{array}$ & $\begin{array}{c}\text { Saturated } \\
\text { time/ } \\
\text { minute }\end{array}$ & $\begin{array}{c}\text { Saturated } \\
\text { adsorption } \\
\text { capacity } / \mathrm{mg}^{-1}\end{array}$ \\
\hline Cyclohexane & 46 & 16 & 88 & 117 \\
\hline Benzene & 52 & 23 & 96 & 136 \\
\hline Isopropanol & 54 & 27 & 102 & 141 \\
\hline
\end{tabular}

TABLE 6 | Adsorption performance of VOCs by activated carbon.

\begin{tabular}{|c|c|c|c|c|}
\hline VOCs & $\begin{array}{l}\text { Penetration } \\
\text { time/ } \\
\text { minute }\end{array}$ & $\begin{array}{c}\text { Penetration } \\
\text { adsorption } \\
\text { capacity/mg•g }{ }^{-1}\end{array}$ & $\begin{array}{c}\text { Saturated } \\
\text { time/ } \\
\text { minute }\end{array}$ & $\begin{array}{c}\text { Saturated } \\
\text { adsorption } \\
\text { capacity/mg•g }{ }^{-1}\end{array}$ \\
\hline Cyclohexane & 22 & 13 & 62 & 85 \\
\hline Benzene & 36 & 18 & 94 & 96 \\
\hline Isopropanol & 38 & 25 & 84 & 103 \\
\hline
\end{tabular}

$\mathrm{X}$ is higher than that on benzene and isopropanol. The preparation of zeolite $\mathrm{X}$ by the aluminum residue from coal fly ash for the adsorption of VOCs conforms to the environmental protection concept of "treating waste with waste." The energy-saving and environmental protection effect is obvious and it has strong application potential.

\section{DATA AVAILABILITY}

All datasets generated for this study are included in the manuscript and/or the supplementary files.

\section{AUTHOR CONTRIBUTIONS}

All authors have contributed in various degrees to the analytical methods used, to the research concept, to the experiment design, to the acquisition of data, or analysis and interpretation of data, 
to draft the manuscript or to revise it critically for important intellectual content.

\section{FUNDING}

This research was funded by State Environmental Protection Key Laboratory of Odor Pollution Control, Tianjin Academy of

\section{REFERENCES}

Akosman, C., and Kalender, M. (2010). Analysis of diffusion and adsorption of volatile organic compounds in zeolites by a single pellet moment technique. CLEAN Soil Air Water 37, 115-121. doi: 10.1002/clen.200800106

Bhatnagar, A., Hogland, W., Marques, M., and Sillanpää, M. (2013). An overview of the modification methods of activated carbon for its water treatment applications. Chem. Eng. J. 219, 499-511. doi: 10.1016/j.cej.2012.12.038

Brihi, T. E., Jeannoël Jaubert, A., and Barth, D. (2018). Determining volatile organic compounds' adsorption isotherms on dealuminated $\mathrm{Y}$ zeolite and correlation with different models. J. Chem. Eng. Data 47, 1553-1557. doi: $10.1021 /$ je025590q

Brosillon, S., Manero, M., and Foussard, J. N. (2000). Adsorption of acetone / heptane gaseous mixtures on zeolite co-adsorption equilibria and selectivities. Environ. Technol. Lett. 21, 457-465. doi: 10.1080/09593330. 2000.9618928

Brunchi, C. C., Sanchez, J., M. C., and Stankiewicz, A. I. (2012). Adsorption of volatile organic compounds. Experimental and theoretical study. Industr. Eng. Chem. Res. 51, 16697-16708. doi: 10.1021/ie302394d

Calero, S., and Gómez-Álvarez, P. (2015). On the performance of FAU and MFI zeolites for the adsorptive removal of a series of volatile organic compounds from air using molecular simulation. Phys. Chem. Chem. Phys. 17, 26451-26455. doi: 10.1039/C5CP04265H

Chiang, P.-C., Chiang, Y.-C., and Huang, C.-P. (2001). Effects of pore structure and temperatuare on VOC adsorption on activated carbon.Carbon 39, 523-534. doi: 10.1016/S0008-6223(00)00161-5

Chmelik, C., Heinke, L., Valiullin, R., and Kärger, J. (2010). A new view of diffusion in nanoporous materials. Chemie Ingenieur Technik 82, 779-804. doi: 10.1002/cite.201000038

Gorshunova, K. K., Travkina, O. S., and Kapustin, G. I. (2015). Effect of synthetic conditions on the adsorption properties of the resulting offretite-type zeolite. Russ. J. Phys. Chem. A. 89, 846-851. doi: 10.1134/S0036024415050167

Huang, H., Rong, W., and Yongyi, G. U. (2014). Adsorption and desorption of VOCs on the ZSM-5 zeolite. Acta Sci. Circumstantiae 34, 3144-3151. doi: $10.13671 /$ j.hjkxxb.2014.0739

Kim, K. J., and Ahn, H. G. (2012). The effect of pore structure of zeolite on the adsorption of VOCs and their desorption properties by microwave heating. Microporous Mesoporous Mater. 152, 78-83. doi: 10.1016/j.micromeso.2011.11.051

Kuo, C. P., Liao, H. T., Chou, C. C., and Wu, C. F. (2014). Source apportionment of particulate matter and selected volatile organic compounds with multiple time resolution data. Sci. Total Environ. 472, 880-887. doi: 10.1016/j.scitotenv.2013.11.114

Ling, Z., Peng, Y., Zhang, J., Chen, L., Meng, X., and Xiao, F. (2016). Adsorptive and catalytic properties in the removal of volatile organic compounds over zeolite-based materials. Chin. J. Catal. 37, 800-809. doi: 10.1016/S1872-2067(15)61073-7

Long, C., Liu, P., and Li, Y. (2011). Characterization of hydrophobic hypercrosslinked polymer as an adsorbent for removal of chlorinated volatile organic compounds. Environ. Sci. Technol. 45, 4506-4512. doi: $10.1021 /$ es $104250 \mathrm{j}$

Min, E. L., Jin, H. J., and Yun, Y. S. (2017). Synergistic catalytic effects of oxygen and nitrogen functional groups on active carbon electrodes for
Environment Science (No. 201903103), the Major Science and Technology Projects of Shanxi Province (No. 20181102017), the Open Project Program of State Key Laboratory of Petroleum Pollution Control (No. PPC2017010), CNPC Research Institute of Safety and Environmental Technology, and the Fundamental Research Funds for the Central Universities (No. 2009QH03). all-vanadium redox flow batteries. Rsc $A d v .7$, 43227-43232. doi: 10.1039/ C7RA08334C

Prajapati, Y. N., Bhaduri, B., Joshi, H. C., and Srivastava, A. (2016). Aqueous phase adsorption of different sized molecules on activated carbon fibers: effect of textural properties. Chemosphere 155, 62-69. doi: 10.1016/j.chemosphere.2016.04.040

Raj, C. J., Rajesh, M., Manikandan, R., Yu, K. H., Anusha, J. R., Ahn, J. H., et al. (2018). High electrochemical capacitor performance of oxygen and nitrogen enriched activated carbon derived from the pyrolysis and activation of squid gladius chitin. J. Power Sources 386, 66-76. doi: 10.1016/j.jpowsour.2018.03.038

Ramos, M. E., Bonelli, P. R., Cukierman, A. L., Ribeiro Carrottc, M. M., and Carrottc, P. J. (2010). Adsorption of volatile organic compounds onto activated carbon cloths derived from a novel regenerated cellulosic precursor. J. Hazard. Mater. 177, 175-182. doi: 10.1016/j.jhazmat.2009.12.014

Rioland, G., Nouali, H., and Daou, T. J. (2017). Adsorption of volatile organic compounds in composite zeolites pellets for space decontamination. Adsorption J. Int. Adsorption Soc. 23, 1-9. doi: 10.1007/s10450-017-9870-9

Son, H. K., Sivakumar, S., Rood, M. J., and kim, B. J. (2016). Electrothermal adsorption and desorption of volatile organic compounds on activated carbon fiber cloth. J. Hazard. Mater. 301, 27-34. doi: 10.1016/j.jhazmat.2015.08.040

Wang, S., Belmabkhout, Y., and Cairns, A. J. (2017). Tuning gas adsorption properties of zeolite-like supramolecular assemblies with gis topology via functionalization of isoreticular metal-organic squares. Appl. Mater. Interfaces 9, 33521-33527. doi: 10.1021/acsami.7b06010

Wei, W., Cheng, S., Li, G., Wang, G., and Wang, H. (2014a). Characteristics of volatile organic compounds (VOCs) emitted from a petroleum refinery in Beijing, China. Atmos. Environ. 89, 358-366. doi: 10.1016/j.atmosenv.2014.01.038

Wei, W., Wang, S., and Hao, J. (2014b). Trends of chemical speciation profiles of anthropogenic volatile organic compounds emissions in China, 2005-2020. Front. Environ. Sci. Eng. 8, 27-41. doi: 10.1007/s11783-012-0461-4

Yuan, G., Zhang, J., and Zhang, Y. (2015). Characterization of high-alumina coal fly ash based silicate material and its adsorption performance on volatile organic compound elimination. Korean J. Chem. Eng. 32, 436-445. doi: 10.1007/s11814-014-0264-3

Zhang, B., Chen, Y., Lin, W., and Zu, Z. (2012). Preparation of molecular sieve X from coal fly ash for the adsorption of volatile organic compounds. Microporous Mesoporous Mater. 156:36-39. doi: 10.1016/j.micromeso.2012.02.016

Zhou, L., Chen, Y. L., and Zhang, X. H. (2014). Zeolites developed from mixed alkali modified coal fly ash for adsorption of volatile organic compounds. Mater. Lett. 119, 140-142. doi: 10.1016/j.matlet.2013.12.097

Conflict of Interest Statement: The authors declare that the research was conducted in the absence of any commercial or financial relationships that could be construed as a potential conflict of interest.

Copyright (c) 2019 Zhu, Zhang, Han, Liu, Wang and Zhang. This is an open-access article distributed under the terms of the Creative Commons Attribution License (CC $B Y)$. The use, distribution or reproduction in other forums is permitted, provided the original author(s) and the copyright owner(s) are credited and that the original publication in this journal is cited, in accordance with accepted academic practice. No use, distribution or reproduction is permitted which does not comply with these terms. 


\section{OPEN ACCESS}

Edited by:

Benoit Louis,

UMR7515 Institut de Chimie et

Procédés pour l'Energie,

l'Environnement et la Santé (ICPEES), France

Reviewed by:

Wenbo Wang

Lanzhou Institute of Chemical Physics

(CAS), China

Subrahmanyam Challapalli,

Indian Institute of Technology

Hyderabad, India

*Correspondence:

Chunmao Chen

c.chen@cup.edu.cn

${ }^{\dagger}$ These authors have contributed equally to this work

Specialty section

This article was submitted to Green and Sustainable Chemistry, a section of the journal

Frontiers in Chemistry

Received: 21 February 2019 Accepted: 13 May 2019

Published: 31 May 2019

Citation

Xu Y, Wang Q, Yoza BA, Li QX, Kou Y, Tang Y, Ye H, Li Y and Chen C (2019) Catalytic Ozonation of Recalcitrant Organic Chemicals in Water Using Vanadium Oxides Loaded ZSM-5

Zeolites. Front. Chem. 7:384. doi: 10.3389/fchem.2019.00384

\section{Catalytic Ozonation of Recalcitrant Organic Chemicals in Water Using Vanadium Oxides Loaded ZSM-5 Zeolites}

\author{
Yingying $\mathrm{Xu}^{1 \dagger}$, Qinghong Wang ${ }^{1 \dagger}$, Brandon A. Yoza ${ }^{2}$, Qing X. $\mathrm{Li}^{3}$, Yue Kou ${ }^{1}$, Yuqi Tang ${ }^{1}$, \\ Huangfan $\mathrm{Ye}^{1}$, Yiming $\mathrm{Li}^{1}$ and Chunmao Chen ${ }^{1 *}$ \\ ${ }^{1}$ State Key Laboratory of Heavy Oil Processing, State Key Laboratory of Petroleum Pollution Control, China University of \\ Petroleum, Beijing, China, ${ }^{2}$ Hawaii Natural Energy Institute, University of Hawaii at Manoa, Honolulu, HI, United States, \\ ${ }^{3}$ Department of Molecular Biosciences and Bioengineering, University of Hawaii at Manoa, Honolulu, HI, United States
}

The discharge of wastewater having recalcitrant chemical compositions can have significant and adverse environmental effects. The present study investigates the application of a catalytic ozonation treatment for the removal of recalcitrant organic chemicals (ROCs) from the water. Novel catalytic materials using vanadium ( $V$ ) oxides deposited onto the surface of NaZSM-5 zeolites (V/ZSM) were found to be highly efficient for this purpose. The highly-dispersed $\mathrm{V}$ oxides $\left(\mathrm{V}^{4+}\right.$ and $\left.\mathrm{V}^{5+}\right)$ and $\mathrm{Si}-\mathrm{OH}-\mathrm{Al}$ framework structures were determined to promote the surface reaction and generation of hydroxyl radicals. The constructed $\mathrm{V}_{1} / \mathrm{ZSM}_{450}\left(0.7 \mathrm{wt} \%\right.$ of $\mathrm{V}$ loading and $450^{\circ} \mathrm{C}$ of calcination) exhibited the highest activity among the developed catalyst compositions. The $\mathrm{V} 1 / \mathrm{ZSM}_{450}-\mathrm{COP}$ increased the mineralization rate of nitrobenzene and benzoic acid by 50 and $41 \%$ in comparison to single ozonation. This study demonstrates the enhanced potential of V/ZSM catalysts used with catalytic ozonation process (COP) for the treatment of chemical wastewaters.

Keywords: ZSM-5 zeolites, catalytic ozonation, vanadium loadings, recalcitrant organic chemicals, wastewater treatment

\section{INTRODUCTION}

Chemical wastewaters generated during the industrial production of dyes, perfumes, pesticides, and pharmaceuticals pose a significant threat to the environment and human health $(\mathrm{Qu}$ et al., 2007; Ao et al., 2019). Chemicals found in these wastewaters, such as nitrobenzene and benzoic acid, are environmentally persistent, have poor biodegradability and are highly toxic (Mantis et al., 2005). Development of efficient technologies for the removal of these recalcitrant organic chemicals (ROCs) is needed (Güm and Akbal, 2017; Nawaz et al., 2017). The application of catalytic ozonation process (COP) has been investigated for the development of an efficient method for the removal of ROCs from water (Li et al., 2017). The catalysts in the process facilitate the decomposition of ozone into more active species such as free radicals, and/or for the adsorption of chemicals that can react with dissolved ozone (Dong et al., 2008; Chen et al., 2018).

A wide variety of zeolites have been used as catalysts in COP. Important considerations for the zeolite catalysts include hydrophilicity/hydrophobicity, silica to alumina ratio $\left(\mathrm{SiO}_{2} / \mathrm{Al}_{2} \mathrm{O}_{3}\right)$, surface area, and pore size (Amin et al., 2010; Jeirani and Soltan, 2017). The Y zeolites have been 
found to remove phenol and reduce chemical oxygen demand (COD) in solution, mainly via hydroxyl radicals $(\bullet \mathrm{OHs})$ mediated oxidation (Dong et al., 2008). The 4A zeolites enhanced the removal of paracetamol from water through an adsorptionmediated mechanism (Ikhlaq et al., 2018). The LTA zeolites improve the generation of $\bullet \mathrm{OHs}$ from ozone, promoting total organic carbon (TOC) removal from a 2, 4-dimethylphenol solution (Vittenet et al., 2014). The presence of transition metallic oxides in zeolites can catalyze the decomposition of ozone into highly active radicals, enhancing oxidation (Valdés et al., 2009). For the MCM-41 zeolites, the loading of manganese (Mn), iron $(\mathrm{Fe})$, or cerium (Ce) oxides increases the Lewis acid sites and surface hydroxyl groups (-OHs). The metals initiate ozone decomposition and generate $\bullet$ OHs that have been shown to mineralize nitrobenzene and $p$-chlorobenzoic acid (Bing et al., 2013). It is reported that Mn oxides loaded on SBA-15 zeolites significantly enhance mineralization of norfloxacin in COP (Sun et al., 2014). The protonated surface-OHs are the main reaction sites and promote $\bullet \mathrm{OHs}$ generation (Chen et al., 2018). Vanadium (V) oxides are also efficient catalysts in COP and the support properties also influence the conversion and selectivity of the ROC (Chetty et al., 2012). To our knowledge, V oxides loaded zeolites have not been developed for utilization in COP.

ZSM-5 zeolites as typical catalysts are widely used during fluid catalytic cracking due to a high activity, appropriate acid strength, regular pore structure, and good hydrothermal stability (Martínez and Corma, 2011). The potential use of ZSM-5 zeolites as catalysts in COP has recently been reported (Chen et al., 2007). High silica ZSM-5 zeolites significantly enhanced the removal of COD and TOC of dimethyl phthalate solution in an ozone/ultraviolet process via $\bullet \mathrm{OHs}$ oxidation (Chen et al., 2007). The ZSM-5 zeolite is a highly adsorbent, providing a large reaction surface area between ozone and phenol in water (Amin et al., 2010). Ozonation aided by ZSM-5 zeolites is speculated to be a non-radical mechanism. The ZSM-5 zeolites functions as ozone reservoirs and adsorbents of organic chemicals. This activity is dependent upon the ratio between $\mathrm{SiO}_{2}$ and $\mathrm{Al}_{2} \mathrm{O}_{3}$ or hydrophobicity rather than acidity or counter ions (Ikhlaq and Kasprzyk-Hordern, 2017). Our previous studies further determined that both NaZSM-5 and adsorption-saturated HZSM5 zeolites follow $\bullet$ OHs-mediated oxidation in COP of nitrobenzene. Surface $\mathrm{Si}-\mathrm{O}$ bonds and/or $\mathrm{Si}-\mathrm{O}(\mathrm{H})-\mathrm{Al}$ structures are the active sites of the ZSM-5 zeolites. The loading of Ce, Fe, or $\mathrm{Mn}$ oxides increase the catalytic activity relative to ZSM-5 zeolites alone (Chen et al., 2018). Efficiencies and mechanisms of ROCs mineralization using ZSM-5 zeolites catalyzed ozonation are not yet clearly identified. The $\mathrm{V}$ oxides supported on metallic oxides or carbon materials have been previously utilized to increase the efficiency for the advanced oxidation treatments of ROCs (Maddila et al., 2014; Rivoira et al., 2017). The V oxides loaded ZSM-5 zeolites (V/ZSM) as catalysts in COP for mineralization of ROCs have not been investigated.

In the present study, NaZSM-5 zeolites were loaded with $\mathrm{V}$ oxides and characterized. Mn supported NaZSM-5 zeolite was used as the reference considering the high catalytic activity of in COPs (Chen et al., 2018). Insights into catalytic efficiencies and mechanisms of those zeolites in COP for mineralizing nitrobenzene and benzoic acid in water were investigated for its potential application.

\section{EXPERIMENTAL}

\section{Materials}

NaZSM-5(30) zeolite (sodium $[\mathrm{Na}]$ type of counter ion, $\mathrm{SiO}_{2} / \mathrm{Al}_{2} \mathrm{O}_{3}$ ratio at 30 ) was selected as a parent catalyst (PZSM) and was purchased from Shanghai Sunny Molecular Sieve Plant, Shanghai, China. Nitrobenzene (99.8 wt\%), benzoic acid (99.5 wt\%), ammonium metavanadate $\left(\mathrm{NH}_{4} \mathrm{VO}_{3}, 99.95 \mathrm{wt} \%\right)$, oxalic acid $\left(\mathrm{H}_{2} \mathrm{C}_{2} \mathrm{O}_{4}, 99.6 \mathrm{wt} \%\right)$, sodium hydroxide $(\mathrm{NaOH}, 96 \mathrm{wt} \%)$, hydrochloric acid $(\mathrm{HCl}, 38 \mathrm{wt} \%)$, sodium bicarbonate $\left(\mathrm{NaHCO}_{3}\right.$, $99.5 \mathrm{wt} \%)$, manganese nitrate solution $\left(\mathrm{Mn}\left(\mathrm{NO}_{3}\right)_{2} ; 50 \mathrm{wt} \%\right)$ and disodium hydrogen phosphate $\left(\mathrm{Na}_{2} \mathrm{HPO}_{4}, 99\right.$ wt\%) were all obtained from Beijing Chemical Reagents Co., Ltd., Beijing, China. The ultrapure water $(18.2 \mathrm{~m} \Omega / \mathrm{cm})$ was produced by a Direct-Pure UP ultrapure water system (Rephile Shanghai Bioscience Co., Ltd., Shanghai, China).

\section{Catalyst Preparation}

The V/ZSM catalysts were prepared according to the incipient wetness impregnation method. Varying amounts of $\mathrm{NH}_{4} \mathrm{VO}_{3}$ and $4 \mathrm{~g}$ of $\mathrm{H}_{2} \mathrm{C}_{2} \mathrm{O}_{4}$ were added to $\sim 80 \mathrm{~g}$ of ultrapure water. The mixture was stirred for $30 \mathrm{~min}$ at $40^{\circ} \mathrm{C}$ to form a solution. Hundred gram of PZSM was saturated with the solution containing 2.4 or $4.0 \mathrm{~g}$ of $\mathrm{NH}_{4} \mathrm{VO}_{3}$. The impregnated samples were then calcinated at $450^{\circ} \mathrm{C}$ for $4 \mathrm{~h}$ in air after drying at $110^{\circ} \mathrm{C}$ for $12 \mathrm{~h}$ to yield $\mathrm{V} 1 / \mathrm{ZSM}_{450}$ and $\mathrm{V} 2 / \mathrm{ZSM}_{450}$, respectively. The calcination at $550^{\circ} \mathrm{C}$ was to yield $\mathrm{V} 1 / Z_{5 S} M_{50}$ and $\mathrm{V}_{2} / \mathrm{ZSM}_{550}$. The referenced catalyst of Mn supported NaZSM-5 zeolite (Mn/ZSM) with $1 \%$ Mn loading (by XRF) was prepared by the incipient wetness impregnation. An amount of $0.67 \mathrm{~g}$ of 50 wt $\% \mathrm{Mn}\left(\mathrm{NO}_{3}\right)_{2}$ solution was added with $3.0 \mathrm{~g}$ water followed by impregnation of $10 \mathrm{~g}$ NaZSM- 5 with the above solution. The resulting material was dried at $90^{\circ} \mathrm{C}$ for $4 \mathrm{~h}$ and calcined at $450^{\circ} \mathrm{C}$ for $4 \mathrm{~h}$.

\section{Characterization of the Catalysts}

The surface morphology was examined on a Quanta 200F scanning electron microscope (SEM) and a Tecnai G2 F20 transmission electron microscope (TEM) (FEI, Hillsboro, OR, USA). The crystals were observed by X-ray powder diffraction (XRD) with an XRD-6000 powder diffraction instrument (Shimadzu, Kyoto, Japan). The functional groups on the surface were identified with a Magna-IR 560 ESP FT-IR spectrometer (Nicolet, Madison, WI, USA). The surface area and pore volume were determined with an ASAP 2000 accelerated surface area and porosimetry system (Micromeritics, Norcross, GA, USA). The composition was determined with a ZSX100E X-ray fluorospectrometer (XRF) (Rigaku, Tokyo, Japan). Surface element distribution was recorded with a PHI Quantera SXM X-ray photoelectron spectrometer (XPS) (ULVAC-PHI, Chanhassen, MN, USA). The $\mathrm{pH}$ of point of zero charges $\left(\mathrm{pH}_{\mathrm{pzc}}\right)$ of catalysts was determined according to the $\mathrm{pH}$-drift procedure (El-Bahy et al., 2008). 


\section{Ozonation of Recalcitrant Organic Chemicals}

Nitrobenzene and benzoic acid are typical ROCs found in chemical wastewaters (Chen et al., 2018; Suryavanshi et al., 2018). In this study, nitrobenzene, and benzoic acid were utilized as model ROCs to investigate efficiencies and mechanisms of V/ZSM catalyzed ozonation (V/ZSM-COP). Nitrobenzene solution and benzoic acid solution were prepared with a concentration of $100 \mathrm{mg} / \mathrm{L}$ in ultrapure water. The initial TOC and $\mathrm{pH}$ values of nitrobenzene solution and benzoic acid solution were 55.9 or $67.5 \mathrm{mg} / \mathrm{L}$ and 6.5 or 3.5 , respectively.

The experimental ozonation system was constructed using a 40L of oxygen tank (Shandong Tianhai High Pressure Container Co., Ltd., Linyi, China), a COM-AD-02 ozone generator (Anseros Asvanced Oxidation Technologies Co., Ltd., Tübingen-Hirschau, Germany), two GM-6000-OEM ozone gas analyzers (Anseros Asvanced Oxidation Technologies Co., Ltd., Tübingen-Hirschau, Germany), a D07-7 mass flow controller (Beijing Sevenstar Flow Co., Ltd., Beijing, China), a D08-1F flow readout box (Beijing Sevenstar Flow Co., Ltd., Beijing, China), a 1,000 mL quartz column reactor and an exhaust gas collector. The reactor was placed on a ZNCL-BS intelligent magnetic stirrer (Shanghai Kankun Instrument Equipment Co., Ltd., Shanghai, China) at $800 \mathrm{rpm}$ to promote the mass transfer between ROCs, ozone and catalysts.

During ozonation experiments, an aliquot of $500 \mathrm{~mL}$ of nitrobenzene solution or benzoic acid solution and $0.5 \mathrm{~g}$ of catalyst was added into the reactor at $25^{\circ} \mathrm{C}$. The gaseous ozone was then introduced through a porous diffuser at the bottom of the reactor having a flow rate of $20 \mathrm{mg} \mathrm{min}^{-1}$. An aliquot of $10 \mathrm{~mL}$ of treated solution was extracted into a $20 \mathrm{~mL}$ of syringe when sampling. The solution in the syringe was then pressed through a $0.45 \mu \mathrm{m}$ end filter (Tianjin Jinteng Experimental Equipment Co., Ltd., Tianjin, China) to remove catalyst particles before further analysis. Adsorption experiments and single ozonation (SOP) were performed with the same experimental system as the COP. The initial $\mathrm{pH}$ values of solutions were adjusted with $1 \mathrm{~N} \mathrm{NaOH}$ or $\mathrm{HCl}$. Experiments were performed in triplicate.

The reaction rate constants $\left(k_{m}\right)$ of mineralization of nitrobenzene or benzoic acid in ozonation were calculated with equations (1) (Portela et al., 2001).

$$
\ln \left(\frac{T O C_{0}}{T O C}\right)=k_{m} t
$$

Where, $\mathrm{TOC}_{0}$, and TOC represent the TOC value of nitrobenzene solution and benzoic acid solution before and after ozonation. The $\bullet \mathrm{OH}$ quenching experiments were performed to identify the oxidation mechanism. As an $\bullet \mathrm{OH}$ scavenger, $\mathrm{NaHCO}_{3}$ was added into the solution at various concentrations prior to ozonation experiments.

The TOC and $\mathrm{pH}$ values of nitrobenzene solution and benzoic acid solution were measured on a TOC-L CPH CN 200 TOC analyzer (Shimadzu, Kyoto, Japan) and an MP $220 \mathrm{pH}$ meter (Mettler Toledo, Greisensee, Switzerland). Degradation products were analyzed by a 7890B gas chromatograph-5977B mass selective detector (GC-MS) (Agilent, Santa Clara, CA, USA) with a $30 \mathrm{~m} \times 0.25 \mu \mathrm{m} \times 0.25 \mathrm{~mm}$ DB-35 GC column. The sample pretreatment process was as follows: A $6 \mathrm{~mL}$ of solid-phase extraction cartridge (Sep-pak C18, $1 \mathrm{~g}$, Waters, Milford, MA, USA) was conditioned by rinsing with $10 \mathrm{~mL}$ of methanol followed by $10 \mathrm{~mL}$ of acidified ultrapure water $(\mathrm{pH}$ value at 2). The samples were first filtered through a $0.45 \mu \mathrm{m}$ Supor membrane filter (PALL, Ann Arbor, MI, USA) before pretreatment. A $10 \mathrm{~mL}$ of filtered sample was then pumped into the cartridge at $5 \mathrm{~mL} / \mathrm{min}$. The cartridge was rinsed with $20 \mathrm{~mL}$ of acidified ultrapure water ( $\mathrm{pH}$ value at 2 ) to remove salts. The cartridge was then eluted with $10 \mathrm{~mL}$ of methanol. The filtrate was concentrated to $1 \mathrm{~mL}$ using nitrogen blowing prior to GC$\mathrm{MS}$ analysis. The initial GC column temperature was remained at $65^{\circ} \mathrm{C}$ for $4 \mathrm{~min}$, ramped to $210^{\circ} \mathrm{C}$ at $5^{\circ} \mathrm{C} / \mathrm{min}$ and then kept for $5 \mathrm{~min}$. The ultra-pure helium was used as the carrier gas at $1.4 \mathrm{~mL}$ $\mathrm{min}^{-1}$. One microliter of concentrated sample was injected into the GC column using a splitless injector with a column head pressure of $10 \mathrm{psi}(69 \mathrm{kPa})$.

\section{RESULTS AND DISCUSSION \\ Characteristics of V/ZSM Catalysts}

The V/ZSM catalysts mainly exhibited XRD patterns at 2 theta of $7.86^{\circ}, 8.78^{\circ}, 23.18^{\circ}, 23.90^{\circ}$, and $24.40^{\circ}$, which are characteristic of crystal face diffraction of (011), (020), (051), (511), and (313), respectively. The XRD patterns of V/ZSM catalysts were similar to that of PZSM (Figure 1A). The peak intensities are however slightly decreased when compared with PZSM. The crystallinity

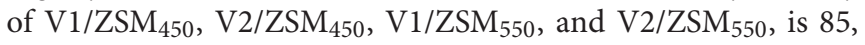
77,80 , and $73 \%$, relative to PZSM (100\%), respectively. A high calcination temperature and $\mathrm{V}$ loading can damage and overlay part of the ZSM-5 framework, reducing crystallinity. No prominent XRD diffraction peaks from $\mathrm{V}$ oxides are observed due to the high dispersion and low concentration (El-Bahy et al., 2008). The FT-IR spectra in a range of $450-2000 \mathrm{~cm}^{-1}$ for PZSM and V/ZSM catalysts are displayed in Figure 1B. The peaks at $451,553,797$, and $1,092 \mathrm{~cm}^{-1}$ are ascribed to the ZSM-5 framework (Zhao et al., 2015). Introduction of $\mathrm{V}$ oxides does not change the position of FT-IR peaks, however, decreases the intensity of characteristic peaks, suggesting a light collapse of the structure and/or the presence of $\mathrm{V}$ oxides on the surface. These results are in good accordance with the XRD analysis. PZSM and V/ZSM catalysts all are IV type of isotherms and show welldeveloped microporous structures (Figures 1C,D). The increase of calcination temperature and $\mathrm{V}$ loading decreases the surface area of V/ZSM catalysts (Table 1). Surface morphologies of $\mathrm{V} /$ ZSM catalysts remain unchanged by $\mathrm{V}$ loading (Figure 2). Irregular shapes of $\mathrm{V}$ oxides can be observed on the surface of V/ZSM catalysts by TEM (Figure 2). Further mapping focusing on $\mathrm{V} 1 / \mathrm{ZSM}_{450}$ confirmed that $\mathrm{V}$ is uniformly distributed for the $\mathrm{V} 1 / \mathrm{ZSM}_{450}$ (Figure 2F). The $\mathrm{V}$ contents determined by EDX are lower than those from XRF, suggesting a high bulk deposition (Table 1).

XPS spectra of Al2p, Si2p, and V2p of PZSM and V/ZSM catalysts are shown in Figure 3. The binding energies of Al2p at $74 \mathrm{eV}$ and $\mathrm{Si} 2 \mathrm{p}$ at $102 \mathrm{eV}$ are, respectively attributed to $\mathrm{Al}^{3+}$ and 

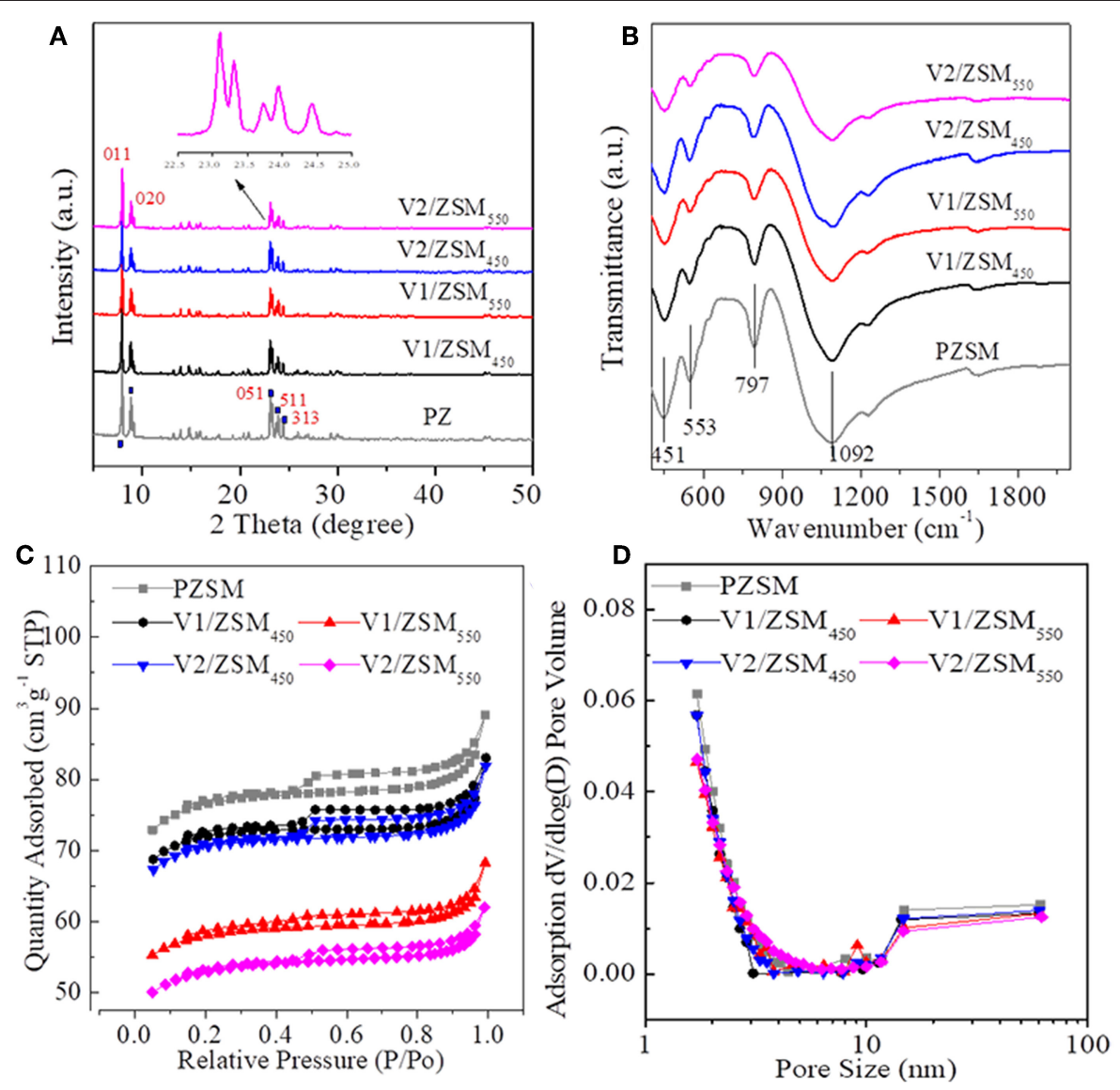

FIGURE 1 | XRD spectra (A), FT-IR (B) spectra, adsorption-desorption isotherms (C), and pore distributions (D) of ZSM-5 zeolites.

TABLE 1 | Surface areas and pore structures of ZSM- 5 zeolites by $\mathrm{N}_{2}$ adsorption-desorption and $\mathrm{V}$ content by EDX and XRF.

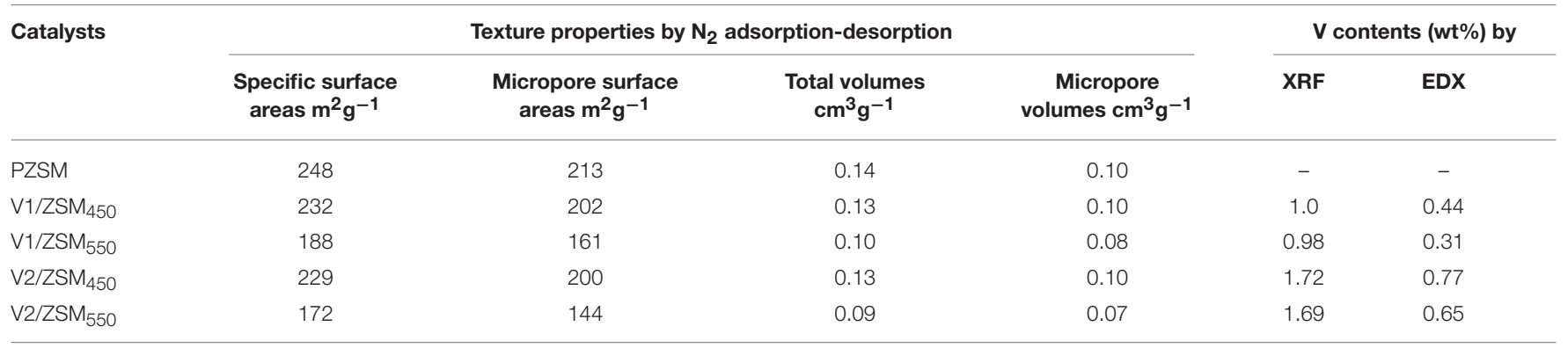

$\mathrm{Si}^{4+}$ oxides from Si-O-Al frameworks (Hadnadjev et al., 2008; Plymale et al., 2015) (Figures 3A,B). Surface Si and Al oxides of V/ZSM catalysts slightly decrease compared to PZSM due to the loading of $\mathrm{V}$ oxides. More $\mathrm{V}$ oxides are loaded onto the surface of $\mathrm{V} 2 / \mathrm{ZSM}_{450}$ and $\mathrm{V} 2 / \mathrm{ZSM}_{550}$, compared to $\mathrm{V} 1 / \mathrm{ZSM}_{450}$ and $\mathrm{V} 1 / \mathrm{ZSM}_{550}$ according to the peak intensity of $\mathrm{V} 2 \mathrm{p}$ spectra (Figure 3C). The XPS spectra from V2p mainly center at the ranges of 515-518 and 523-526 eV. The former was assigned to $\mathrm{V} 2 \mathrm{p}_{3 / 2}\left(\mathrm{~V}^{5+}\right)$ and $\mathrm{V} 2 \mathrm{p}_{3 / 2}\left(\mathrm{~V}^{4+}\right)$ oxides at 517.2 and $516.3 \mathrm{eV}$, and the latter associated with $\mathrm{V} 2 \mathrm{p}_{1 / 2}\left(\mathrm{~V}^{5+}\right)$ and $\mathrm{V} 2 \mathrm{p}_{1 / 2}\left(\mathrm{~V}^{4+}\right)$ oxides at 523.4 and $524.5 \mathrm{eV}$ (Silversmit et al., 2004) (Figures 3D,E).
The molar ratio of $\mathrm{V}^{5+}$ to $\mathrm{V}^{4+}\left(\mathrm{V}^{5+} / \mathrm{V}^{4+}\right.$ ratio) of $\mathrm{V} 1 / \mathrm{ZSM}_{450}$,

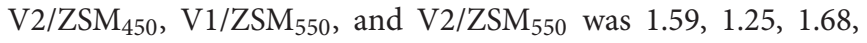
and 1.23 , respectively, according to $\mathrm{V} 2 \mathrm{p}_{3 / 2}$ peak fitting results. Overall, the $\mathrm{V}$ was found loaded on the surface of V/ZSM catalysts in forms of $\mathrm{V}^{5+}$ and $\mathrm{V}^{4+}$ oxides. The $\mathrm{V}$ loading or a high calcination temperature might result in coverage and partial collapse of the Si-O-Al frameworks. The $\mathrm{V}^{5+} / \mathrm{V}^{4+}$ ratio of used $\mathrm{V} 1 / \mathrm{ZSM}_{450}$ was 1.82 , higher than that (1.59) of parent $\mathrm{V} 1 / Z S M_{450}$. It suggests partial metal $\mathrm{V}^{4+}$ was oxidized to $\mathrm{V}^{5+}$. Besides, the peak intensity of $\mathrm{V} 2 \mathrm{p}$ for $\mathrm{V} 1 / \mathrm{ZSM}_{450}$ was decreased after COP, due to metal $\mathrm{V}$ loss. 
A

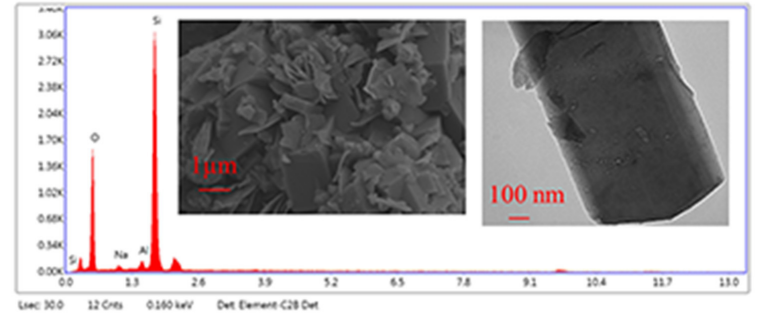

C

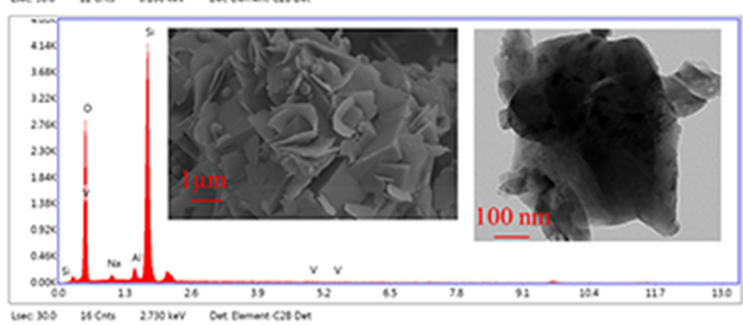

$\mathrm{E}$

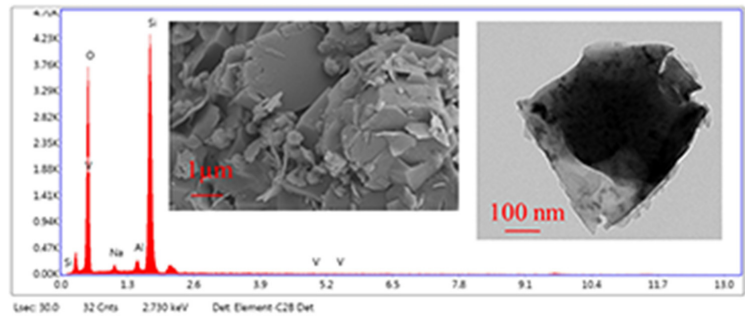

$\mathrm{B}$

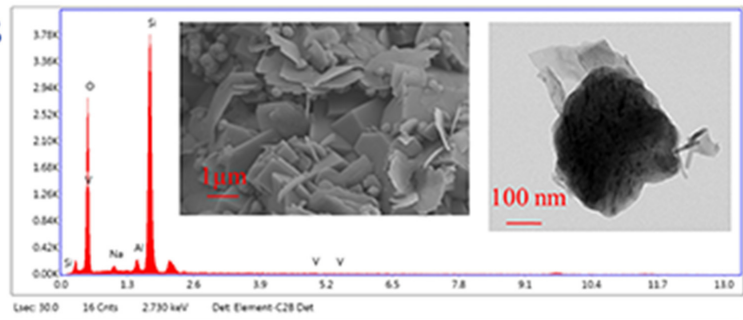

$\mathrm{D}$

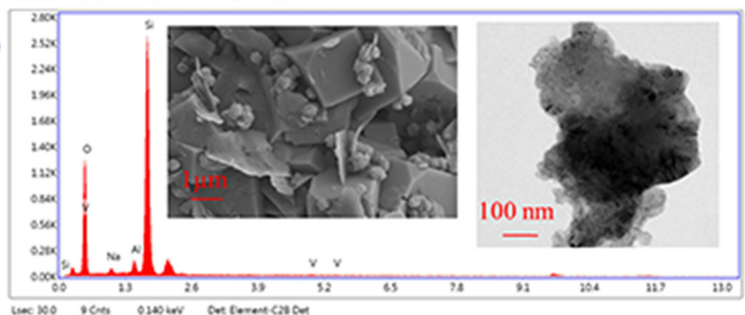

$\mathrm{F}$

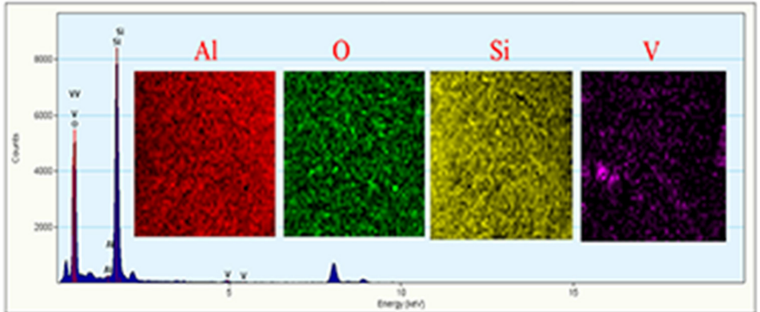

FIGURE 2 | SEM and TEM images (insert) and EDX spectra of ZSM-5 zeolites: PZSM (A), V1/ZSM 450 (B), V1/ZSM 550 (C), V2/ZSM 450 (D), and V2/ZSM550 (E) and element mapping-EDS spectra of $\mathrm{V} 1 / \mathrm{ZSM}_{450}$ (F).

\section{Removal Efficiencies of ZSM-5 Zeolites Catalyzed Ozonation TOC Removals of Adsorption SOP and COPs}

The PZSM and V/ZSM catalysts exhibit weak adsorption toward both nitrobenzene and benzoic acid in water. However, there was a significant difference in saturation time and TOC removal and between different chemicals. The adsorption reached saturation in $30 \mathrm{~min}$ for the nitrobenzene solution and in $15 \mathrm{~min}$ for the benzoic acid solution. PZSM and V/ZSM catalysts removed more TOC from the nitrobenzene solution (7.0-8.3\%) compared to the benzoic acid solution (2.5-4.4\%) within $30 \mathrm{~min}$ (Figure 4A). Nitrobenzene is polar relative to benzoic acid, therefore, is absorbed by the weakly hydrophobic NaZSM-5 (30) zeolite (Nakamoto and Takahashi, 1982). The loading of V oxides and calcination temperature used in this study had a negligible impact on the adsorption capacity of V/ZSM catalysts. Adsorption is more significantly influenced by the chemical nature of the compounds in the water, when compared with the effects from the catalyst surface area and pore volume (Table 1). SOP removes 35.3 and $49.5 \%$ of TOC from the nitrobenzene solution and benzoic acid solution after $30 \mathrm{~min}$ treatment (Figure 4B). COPs using ZSM-5 zeolites remove $45.5-85.4 \%$ and $61.3-88.3 \%$ of the TOC from the nitrobenzene solution and benzoic acid solution after $30 \mathrm{~min}$, respectively (Figure 4B). TOC removal upon application of PZSM-COP and V/ZSM-COPs are higher than the sums of their adsorption and SOP, confirming the catalytic activity of ZSM-5 zeolites. The dominant TOC removal during COPs using ZSM-5 zeolites results from ozonation rather than adsorption. PZSM-COP increased TOC removal of nitrobenzene from solution by $10.2 \%$ and benzoic acid from solution by $11.8 \%$ when compared to SOP. The degradation of nitrobenzene (99$100 \%)$ and benzoic acid (95-99\%) in solution were identical for both the COPs and SOP (Figure 4C) during the $30 \mathrm{~min}$ treatment. The concentration changes for the nitrobenzene and benzoic acid solution (Figure 4C) are different as determine by the changes in TOC (Figure 4B) during both SOP and COPs. Smaller molecular intermediates are initially generated during the oxidation of nitrobenzene and benzoic acid; COPs can effectively further mineralize these species, while SOP is usually ineffective.

The frameworks of PZSM are relevant to the catalytically active sites, promoting the mineralization of chemicals in COP. Acidic sites are usually thought to be active on the zeolites (Saeid et al., 2018). The Si-ONa-Al structure may be exchanged to SiOH-Al (Shirazi et al., 2008), as an active site for ZSM-5 zeolites. The V/ZSM-COPs increase TOC removal of nitrobenzene solution by $14.7-39.9 \%$ and benzoic acid solution by $12.3-27.0 \%$ in comparison with PZSM-COP. These differences indicate that by the loading of $\mathrm{V}$ oxides on PZSM the COP is improved. Surface distributed $\mathrm{V}$ oxides $\left(\mathrm{V}^{4+}\right.$ and $\left.\mathrm{V}^{5+}\right)$ function as major active sites of V/ZSM catalysts. Excessive loading of V oxides does not noticeably improve the TOC removal during V/ZSM-COPs. 

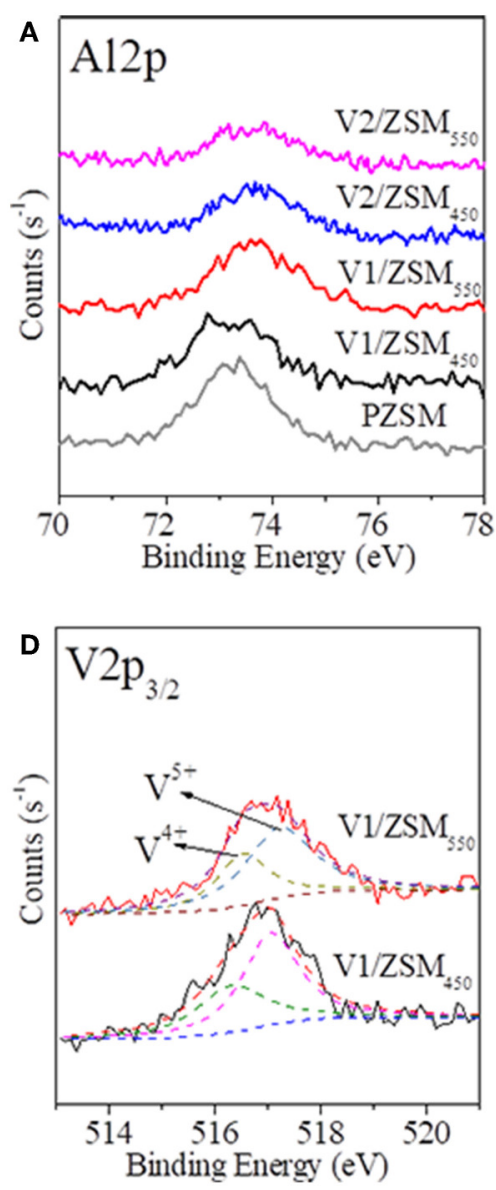
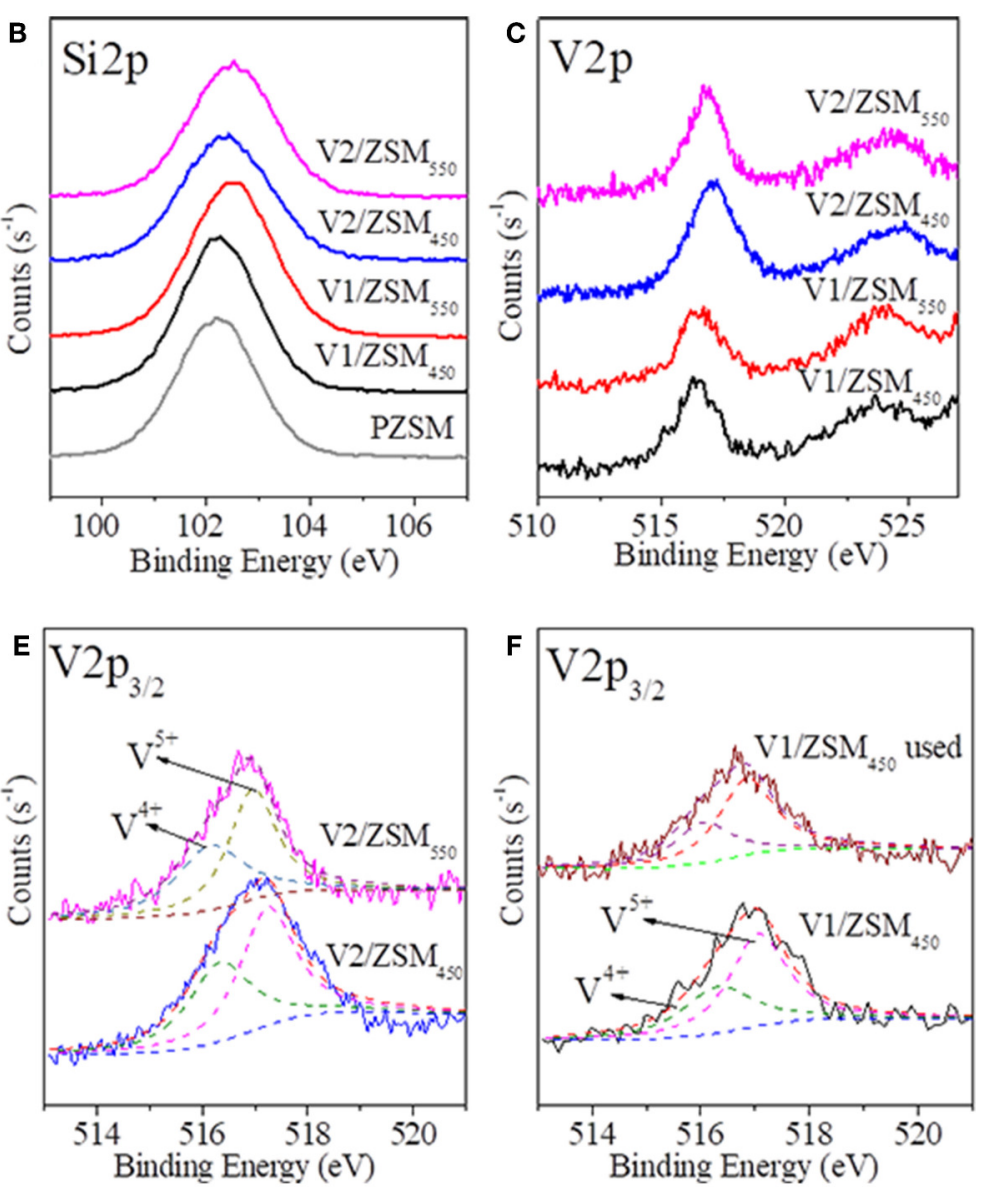

FIGURE 3 | XPS spectra of Al2p (A), Si2p (B), and V2p (C-F) for ZSM-5 zeolites.

Even though the loading of $\mathrm{V}$ oxide is doubled, the TOC removal of $\mathrm{V} 2 / \mathrm{ZSM}_{450}$ ( $85.4 \%$ for nitrobenzene and $88.3 \%$ for benzoic acid) was a little higher than that of $\mathrm{V} 1 / \mathrm{ZSM}_{450}(80.5 \%$ for nitrobenzene and $84.5 \%$ for benzoic acid). The V2/ZSM 550 (60.2\% for nitrobenzene and $74.2 \%$ for benzoic acid) and $\mathrm{V} 1 / Z S M_{550}$ (61.7\% for nitrobenzene and $73.6 \%$ for benzoic acid) have similar results. The excessive loading of metallic oxides may reduce active sites, weakening interactions between metallic oxides, and supports (Chen et al., 2017a). In this application, excessive $\mathrm{V}$ oxides may partially block $\mathrm{Si}-\mathrm{OH}-\mathrm{Al}$ structures, reducing activity. The increased activity from the active $\mathrm{V}$ oxides is partially offset by decreased $\mathrm{Si}-\mathrm{OH}$-Al sites. The $\mathrm{V} 1 / \mathrm{ZSM}_{450}$ and $\mathrm{V} 2 / \mathrm{ZSM}_{450}$ exhibit high TOC removal relative to $\mathrm{V} 1 / \mathrm{ZSM}_{550}$ and $\mathrm{V} 2 / \mathrm{ZSM}_{550}$. A high calcination temperature can decrease the catalytic activity of V/ZSM catalysts (Chen et al., 2017b). The V/ZSM catalysts that are calcinated at $550^{\circ} \mathrm{C}$ show lower crystallinity and surface areas than those at $450^{\circ} \mathrm{C}$, suggesting the loss of Si-OH-Al structures. The co-effect of various active sites coexisting on the support favors catalytic activity (Tu et al., 2012). For V/ZSM catalysts, its activity is dependent upon two kinds of active sites that coexist and interact cooperatively, the $\mathrm{V}$ oxides $\left(\mathrm{V}^{4+}\right.$ and $\left.\mathrm{V}^{5+}\right)$ and $\mathrm{Si}-\mathrm{OH}-\mathrm{Al}$ structures. The cooperative effects from $\mathrm{V}$ oxides and $\mathrm{Si}-\mathrm{OH}-\mathrm{Al}$ structures on $\mathrm{V} / \mathrm{ZSM}$ catalysts are however reduced by high temperature calcination, resulting in

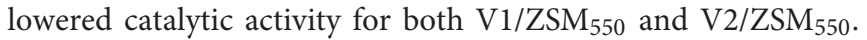
Among the V/ZSM catalysts, V1/ZSM 450 shows the high catalytic activity for the COP removal of nitrobenzene and benzoic acid in solution. By contrast, the TOC removal of the referenced $\mathrm{Mn} / \mathrm{ZSM}$ (72.2\% for nitrobenzene and $75.4 \%$ for benzoic acid) was a little lower than that of V1/ZSM 450 (80.5\% for nitrobenzene and $84.5 \%$ for benzoic acid). The result further reveals the advantage of $\mathrm{V} 1 / \mathrm{ZSM}_{450}$. The remainder of this study is focused on PZSM and $\mathrm{V} 1 / \mathrm{ZSM}_{450}$.

\section{Mineralization Kinetics of SOP and COPs}

The mineralization of nitrobenzene and benzoic acid both follow pseudo-first-order kinetics during SOP, PZSM-COP and

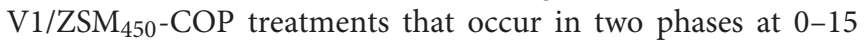
and 15-30 $\mathrm{min}$, respectively (Figure 4D). For the nitrobenzene solution, $k_{\mathrm{m}(0-15 \mathrm{~min})}$ values are $0.0197,0.0295$, and 0.0471 $\mathrm{min}^{-1}, k_{\mathrm{m}(15-30 \mathrm{~min})}$ values are $0.0891,0.0112$, and $0.061 \mathrm{~min}^{-1}$, over SOP, PZSM-COP, and V1/ZSM $450-C O P$, respectively. For benzoic acid solution, $k_{\mathrm{m}(0-15 \mathrm{~min})}$ are $0.0332,0.0446$, and $0.0757 \mathrm{~min}^{-1}, k_{\mathrm{m}(15-30 \mathrm{~min})}$ values are $0.0118,0.0192$, and $0.0496 \mathrm{~min}^{-1}$ over SOP, PZSM-COP and V1/ZSM $450-\mathrm{COP}$. PZSM-COP shows high $k_{\mathrm{m}}$ values relative to SOP, verifying 

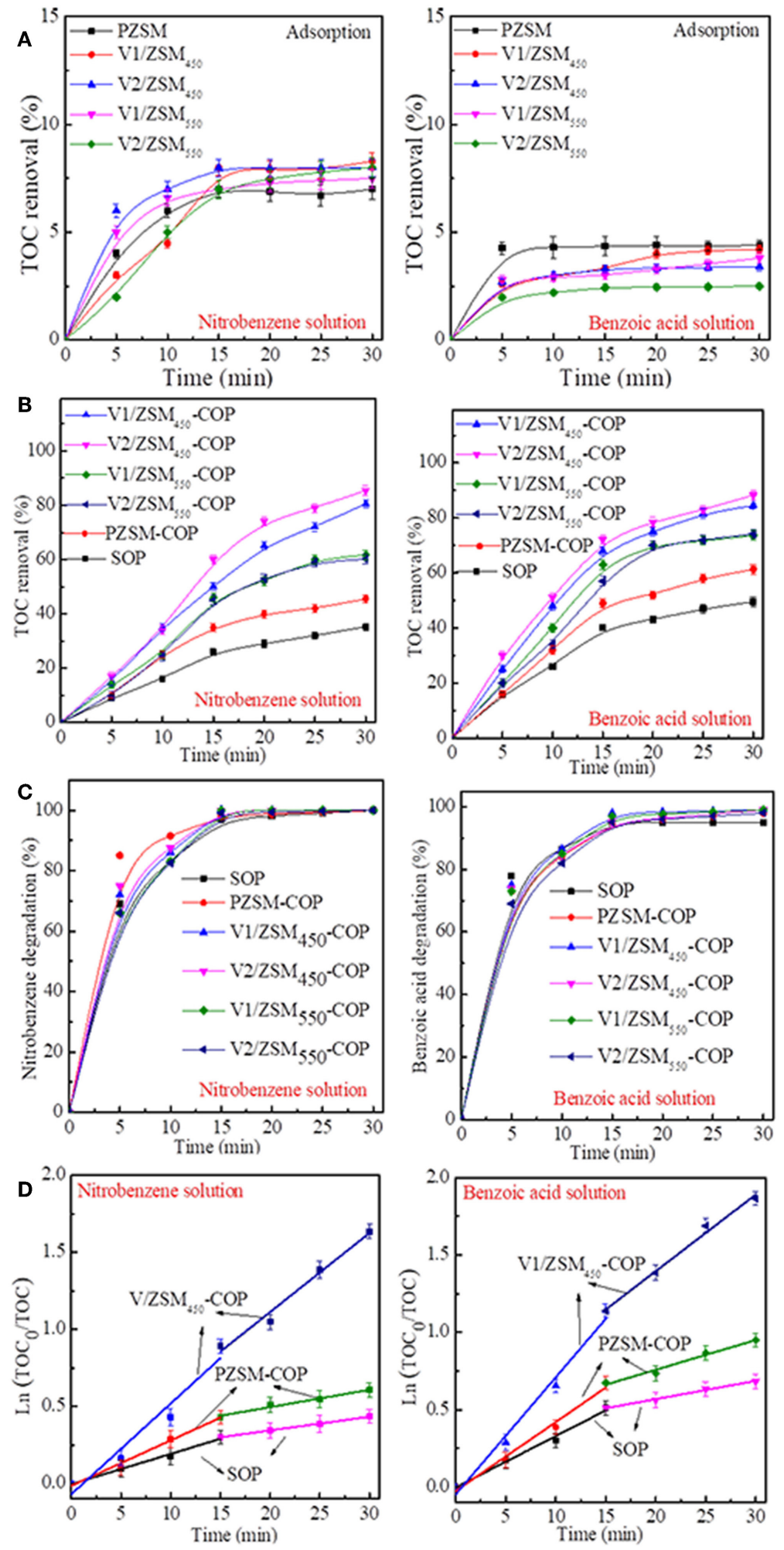

FIGURE 4 | TOC removal of nitrobenzene solution and benzoic acid solution during adsorption (A), SOP and COPs (B); concentration changes of nitrobenzene solution and benzoic acid solution upon SOP and COPs (C) using various ZSM-5 zeolites; Pseudo-first-order kinetics plots of SOP, PZSM-COP and V1/ZSM450-COP for nitrobenzene solution and benzoic acid solution (D). Note: Initial pH values of the nitrobenzene solution and benzoic acid solution are 6.5 and 3.5 . Initial pH values of the nitrobenzene solution and benzoic acid solution are 6.5 and 3.5 . 
the catalytic activity of PZSM. V1/ZSM 450 -COP has high $k_{\mathrm{m}}$ values compared to PZSM-COP and SOP, demonstrating the powerful catalytic activity of $\mathrm{V} 1 / \mathrm{ZSM}_{450}$. The $k_{\mathrm{m}}$ values of nitrobenzene are lower than those of benzoic acid during SOP, PZSM-COP, and V1/ZSM $450-C O P$, reflecting the ease of benzoic acid mineralization when compared with nitrobenzene. The $k_{\mathrm{m}(15-30 \mathrm{~min})}$ values are lower than the $k_{\mathrm{m}(0-15 \mathrm{~min})}$ values, suggesting that various mineralization mechanisms are involved. The reaction intermediates produced in solution add complexity toward understanding the mineralization process.

\section{Removal Mechanisms of ZSM-5 Zeolites Catalyzed Ozonation Changes of Solution pH Values in Adsorption, SOP, and COPs}

The changes in wastewater $\mathrm{pH}$ during the adsorption and ozonation treatments were measured for mechanistic insights. The $\mathrm{pH}$ values for the nitrobenzene (Figure 5A1) and benzoic acid solutions (Figure 5A2) rapidly increased during PZSM and $\mathrm{V} 1 / Z S M_{450}$ adsorption under acidic and nearly neutral conditions (initial $\mathrm{pH}$ values at 3.5 and 6.5) (Figure 5A). The increase in $\mathrm{pH}$ values result from the exchange between $\mathrm{H}^{+}$ in solutions and the $\mathrm{Na}^{+}$component of the ZSM-5 zeolites. Furthermore, the original Si-ONa-Al structures of the ZSM-5 zeolite are partly changed to $\mathrm{Si}-\mathrm{OH}-\mathrm{Al}$ structures. The observed changes in $\mathrm{pH}$ resulting from the PZSM and $\mathrm{V}_{1 / Z S M} \mathrm{ZS}_{40}$ adsorptions under alkaline conditions (initial $\mathrm{pH}$ values at 9 and 11) (Figure 5A), demonstrate that ion exchange did not occur. The two solutions both show a continuous $\mathrm{pH}$ decline during SOP treatment. However, this declining tendency is differentiated depending upon the initial $\mathrm{pH}$ value (Figure 5A). The $\mathrm{pH}$ values both exhibit downward trends under highly acidic (initial $\mathrm{pH}$ value at 3.5) and alkaline (initial $\mathrm{pH}$ value at 11 ) conditions. They all display rapid decreases during the initial $5 \mathrm{~min}$, then slowly decrease under weak acidity (initial $\mathrm{pH}$ value at 6.5) and alkaline (initial $\mathrm{pH}$ value at 9) conditions (Figure 5A). The extent of this decrease is less than those that occur under weakly acidic and alkaline conditions. The SOP produces acidic intermediates from the chemical degradation resulting in the decrease of solution $\mathrm{pH}$ values (Zhao et al., 2008). The SOP functions mainly via direct oxidation and only a small amount of $\bullet \mathrm{OHs}$ is involved with oxidation. Limited $\bullet \mathrm{OH}$ generation occurs at low $\mathrm{pH}$ values, and the $\bullet \mathrm{OH}$ are apt to dissociation at very high $\mathrm{pH}$ values (Beltrán et al., 1998), lowering the production rate of acidic intermediates. Therefore, the $\mathrm{pH}$ values only exhibit moderate reductions. Under weakly acidic and alkaline conditions ozone decomposition is the dominant process resulting in the generation of $\bullet \mathrm{OHs}$ (Elovitz et al., 2008). The production of acidic intermediates results in the rapid decline in $\mathrm{pH}$ values. The acidic solutions inhibit $\bullet \mathrm{OH}$ generation, also resulting in decreased acidic intermediate production.

The changes in $\mathrm{pH}$ value during the SOP, PZSM-COP, and $\mathrm{V} 1 / \mathrm{ZSM}_{450}$-COP treatments are similar when performed under highly alkaline conditions (initial $\mathrm{pH}$ value at 11 ). The SOP, PZSM-COP, and V1/ZSM $450-C O P$ follow direct oxidation mechanisms. The catalytic activity of the ZSM-5 zeolites is not significant in solutions having high initial $\mathrm{pH}$ values (11) Solutions ranging from strong acidity (initial $\mathrm{pH}$ value at 3.5) to weakly alkaline (initial $\mathrm{pH}$ value at 9), treated using PZSM$\mathrm{COP}$ and $\mathrm{V} 1 / \mathrm{ZSM}_{450}$-COP both exhibit decreased $\mathrm{pH}$ during the initial $15 \mathrm{~min}$ followed by an increase (Figure 5). The increased $\mathrm{pH}$ observed after $15 \mathrm{~min}$ implies that the acidic intermediates are being mineralized. The mineralization is usually associated with the generation of reactive oxidizing species (e.g., •OHs) or chemisorption at the surface (Andreozzi et al., 1996; Ikhlaq et al., 2018). The greater extent of the $\mathrm{pH}$ increase from $\mathrm{V} 1 / Z S M_{450}$-COP compared with PZSM-COP suggests a stronger mineralization effect (Figure 5A). At the same initial $\mathrm{pH}$ value, the increase in $\mathrm{pH}$ values for nitrobenzene is smaller than that with the benzoic acid solution (Figure 5A) demonstrating that the intermediates of benzoic acid are mineralized easily compared with those from nitrobenzene.

\section{Influences of Initial pH Values on TOC Removals of Adsorption, SOP, and COPs}

The initial $\mathrm{pH}$ values for the nitrobenzene and benzoic acid solutions had no impact on the adsorption capacity of PZSM and $\mathrm{V} 1 / Z S M_{450}$ (Figure 5B). They both minimally adsorbed nitrobenzene (Figure 5B1) and benzoic acid (Figure 5B2) from solution at various initial $\mathrm{pH}$ values. The initial $\mathrm{pH}$ values did however significantly influence the efficiencies of SOP, PZSM-COP, and V1/ZSM $450-C O P$ (Figure 5B). An appropriate concentration of hydroxide in solution may further promote ozone decomposition into $\bullet \mathrm{OHs}$ and improve mineralization (Elovitz et al., 2008). Therefore, the SOP efficiently removed TOC removal under weak alkaline (initial $\mathrm{pH}$ value at 9) condition compared to highly acidic (initial $\mathrm{pH}$ value at 3.5 ) and alkaline (initial $\mathrm{pH}$ value at 11 ).

The PZSM-COP and V1/ZSM 450 -COP more efficiently removed TOC relative to $S O P$ at initial $\mathrm{pH}$ values between 3.5 and 9. The TOC removal at acidic (initial $\mathrm{pH}$ value at 3.5 ) conditions using PZSM-COP was higher than those performed under weak acidity (initial $\mathrm{pH}$ value at 6.5) and weak alkalinity (initial $\mathrm{pH}$ value at 9). Under acidic conditions, the $\mathrm{Na}^{+}$in the $\mathrm{Si}-\mathrm{ONa}-\mathrm{Al}$ structures of ZSM-5 zeolites interacts with the $\mathrm{H}^{+}$in solution. The increased $\mathrm{pH}$ values of solutions during PZSM adsorption confirm the presence of this ion exchanges mechanism. The newly formed Si-OH-Al structures increase the acidity of ZSM5 zeolites, enhancing the catalytic activity. The V1/ZSM $450-C O P$ has high TOC removals relative to PZSM-COP under the initial $\mathrm{pH}$ values from between 3.5 and 9. Efficient TOC removal for the different chemicals occurs at different initial $\mathrm{pH}$ values.

Using the V1/ZSM 450 -COP the highest TOC removed from the nitrobenzene solution (Figure 5B1) occurred at an initial $\mathrm{pH}$ value of 9, which is close to the $\mathrm{pH}_{\mathrm{pzc}}$ value (9.25) of

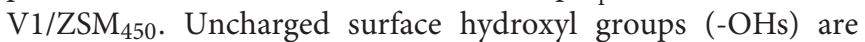
beneficial for ozone decomposition into $\bullet$ OHs (Zhao et al., 2008). The surface -OHs on the $\mathrm{V}$ oxides ( $\mathrm{V}-\mathrm{OHs}$ ) have a neutral charge at an alkaline $\mathrm{pH}$ value of 9, this increases the interactions that occur between the surface $\mathrm{V}-\mathrm{OH}$ and ozone. When the initial $\mathrm{pH}$ values are lower than the $\mathrm{pH}_{\mathrm{pzc}}$ value of $\mathrm{V} 1 / \mathrm{ZSM}_{450}$, a portion of surface - $\mathrm{OH}$ s on the $\mathrm{V}$ oxides are protonated $(\mathrm{V}$ $\mathrm{OH}_{2}{ }^{+}$) and the interaction between $\mathrm{V}$-OHs and ozone is reduced. 
A1

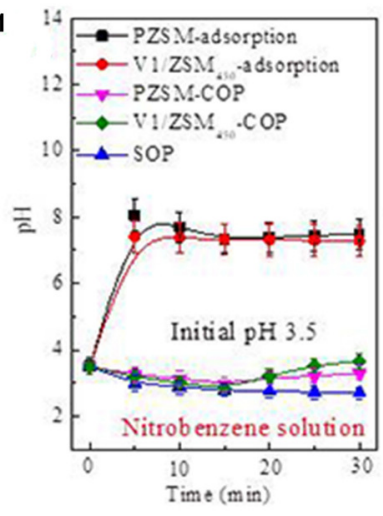

A2

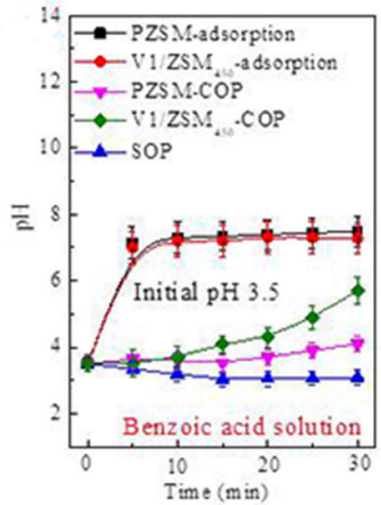

B1

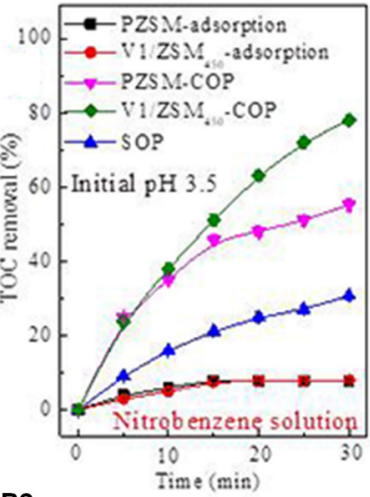

B2

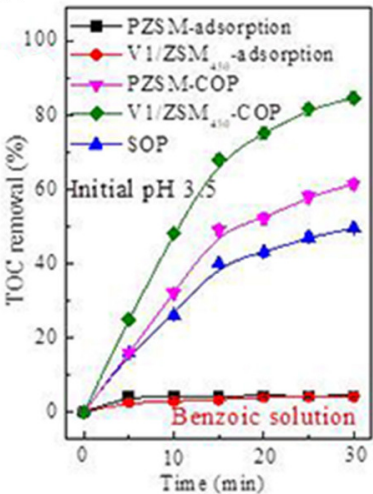

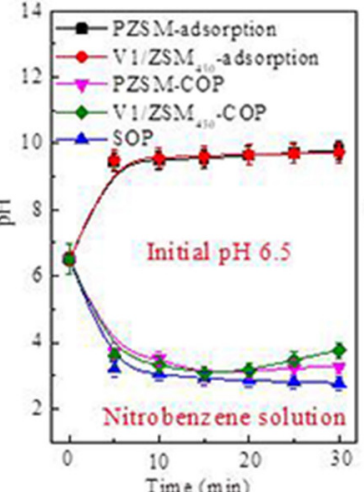
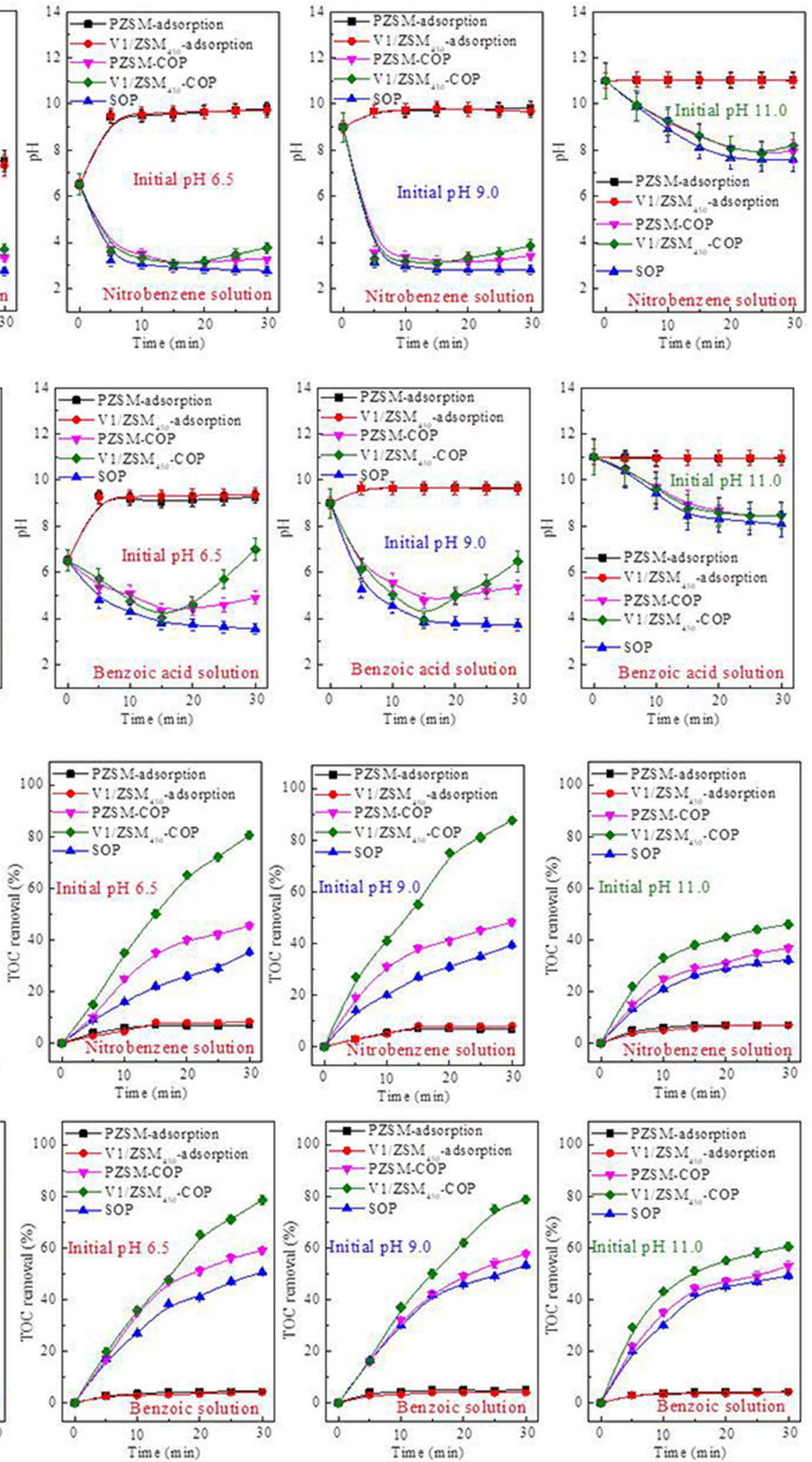

FIGURE 5 | pH value changes of the nitrobenzene solution (A1) and benzoic acid solution (A2) during adsorption, SOP, PZSM-COP and V1/ZSM $450-C O P$; Influence of the initial pH values on TOC removal of nitrobenzene solution (B1) and benzoic acid solution (B2) during adsorption, SOP, PZSM-COP, and V1/ZSM450-COP. 

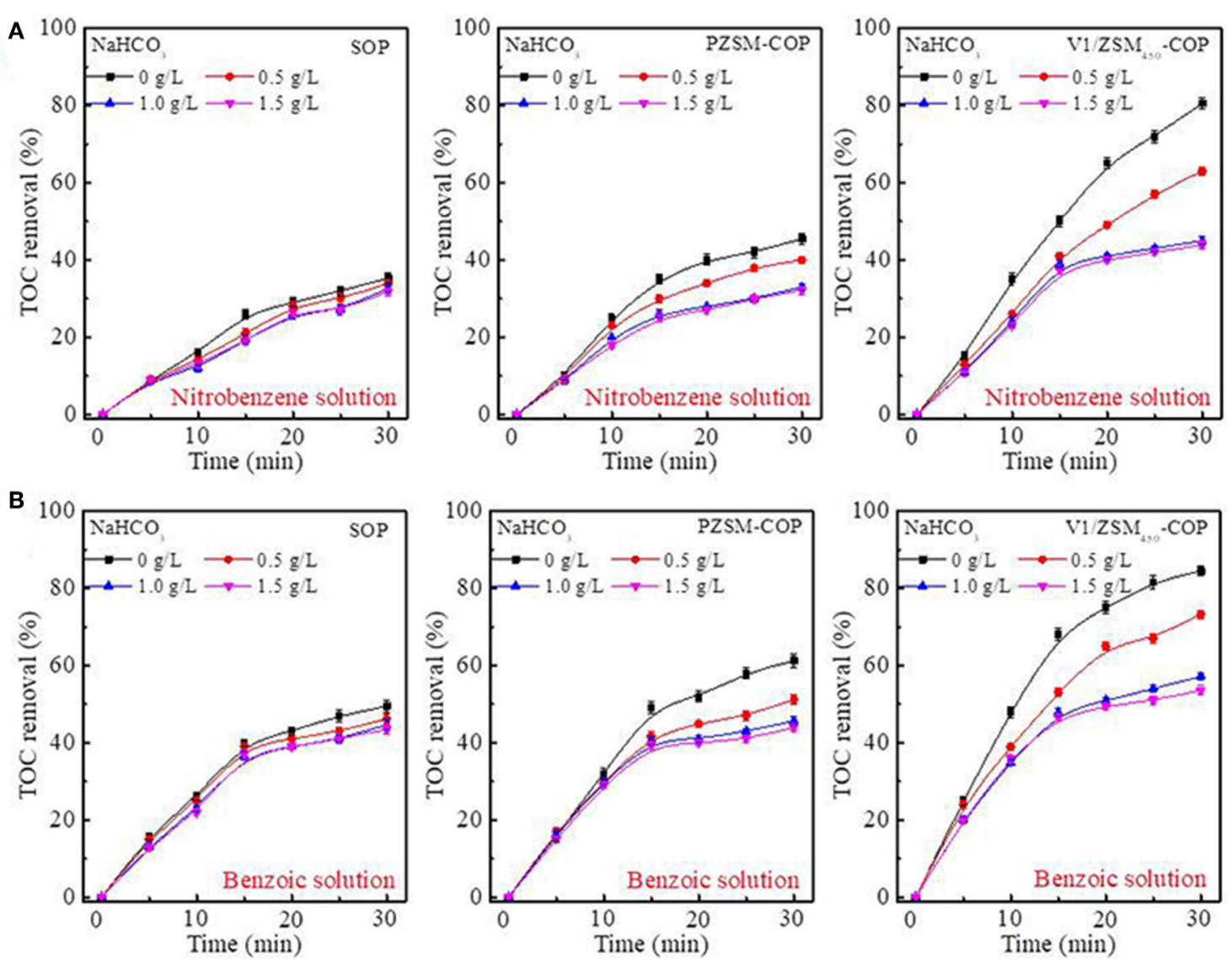

C

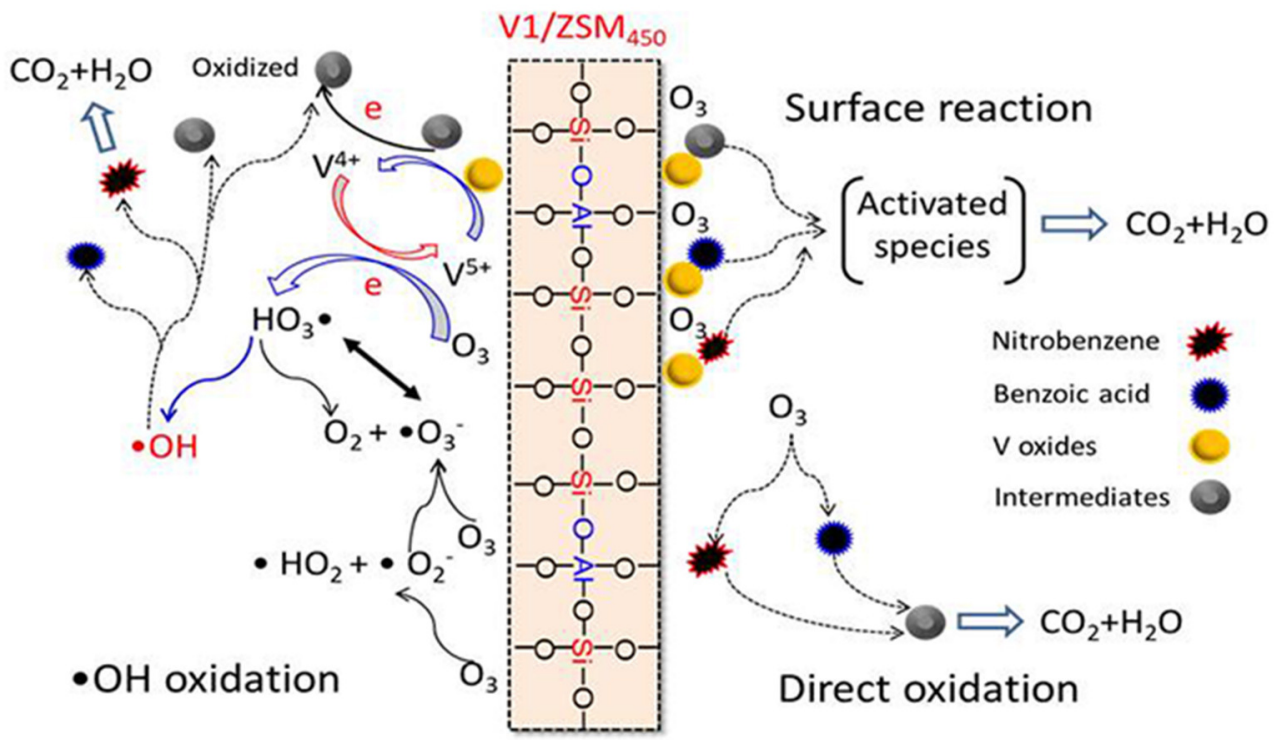

FIGURE 6 | Influences of $\mathrm{NaHCO}_{3}$ addition on the TOC removal of nitrobenzene solution (A) and benzoic acid solution (B) during SOP, PZSM-COP and

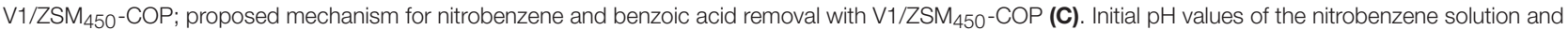
benzoic acid solution are 6.5 and 3.5 . 
This effect can be clearly observed from the experimental data generated at the lower $3.5 \mathrm{pH}$. The results are further influenced by the simultaneous formation of $\mathrm{Si}-\mathrm{OH}-\mathrm{Al}$ that occurs under acidic conditions, increasing the catalytic activity. Because of this, the use of $\mathrm{V} 1 / \mathrm{ZSM}_{450}-\mathrm{COP}$ results in nearly identical TOC removals that are observed at the $\mathrm{pH}$ values of 3.5 and 6.5. The pKa value of nitrobenzene in water is 11.9 , which is greater than the experimentally used initial $\mathrm{pH}$ values. The high $\mathrm{pKa}$ values and at lower operational $\mathrm{pHs}$ conditions mean that the nitrobenzene is not dissociated and exists in its molecular form (Langer et al., 2008). The surface catalytic oxidation of nitrobenzene is not significantly influenced by initial $\mathrm{pH}$, under our experimental conditions.

Using the $\mathrm{V} 1 / \mathrm{ZSM}_{450}$-COP for the treatment of benzoic acid (Figure 5B2), the interaction between surface $\mathrm{V}-\mathrm{OHs}$ and ozone are reduced at the initial $\mathrm{pH}$ value of 6.5 , relative to 9 . At the $\mathrm{pH}$ values of 6.5 and 9, benzoic acid exists mainly in an ionic state due to its $\mathrm{pKa}$ value of 4.2 .The protonated $\mathrm{V}_{-} \mathrm{OH}_{2}{ }^{+}$on the catalyst surface facilitates the interactions with benzoate at the $\mathrm{pH}$ value of 6.5 , increasing the surface oxidation reactions with benzoate compared to a $\mathrm{pH}$ value of 9 . The $\mathrm{V} 1 / \mathrm{ZSM}_{450}$ COP similarly removed TOC at the $\mathrm{pH}$ values of 6.5 and 9. Due to its $\mathrm{pKa}$, benzoic acid exists in its molecular state at $\mathrm{pH} 3.5$, reducing surface oxidation reactions between $\mathrm{V}-\mathrm{OH}_{2}{ }^{+}$ and benzoate. The active catalytic sites on $\mathrm{Si}-\mathrm{OH}-\mathrm{Al}$ are also simultaneously increased, promoting oxidation.

At an initial $\mathrm{pH}$ value of 11 the SOP and PZSM-COP comparably removed TOC. At this $\mathrm{pH}$, the catalytic activity of ZSM-5 zeolites is inhibited. Under strong alkaline conditions, $\mathrm{Si}-\mathrm{ONa}-\mathrm{Al}$ structures are dominant when compared with $\mathrm{Si}-\mathrm{OH}-$ Al. Therefore, the Si-OH-Al derived catalytic activity does not occur with PZSM and V1/ZSM 450 . At high $\mathrm{pH}$ values above the $\mathrm{pH}_{\mathrm{pzc}}$ (9.25) for $\mathrm{V} 1 / \mathrm{ZSM}_{450}$, a portion of surface -OHs on the $\mathrm{V}$ oxides are presented in a deprotonated form of ${\mathrm{V}-\mathrm{O}^{-}}^{-}$. The catalytic activity from the $\mathrm{V}-\mathrm{OH}$ and ozone interaction declines for $\mathrm{V} 1 / \mathrm{ZSM}_{450}$. The $\mathrm{V} 1 / \mathrm{ZSM}_{450}$-COP exhibits low TOC removal at $\mathrm{pH}$ value of 11 .

\section{Removal Mechanisms of Chemicals in ZSM-5 Zeolites Catalyzed Ozonation}

During the COP the generation of $\bullet \mathrm{OHs}$ are promoted by various catalysts and can facilitate the removal of ROC (Chen et al., 2018). During SOP, the introduction of $\mathrm{NaHCO}_{3}$ has an influence on the TOC removed from the nitrobenzene and benzoic acid containing solutions (Figures 6A,B). The SOP process removes the TOC mainly by direct oxidation and $\bullet \mathrm{OH}$ are not significantly generated. The TOC removed by PZSMCOP are nearly equal to the SOP after the addition of 0.5 and $1.0 \mathrm{~g} / \mathrm{L} \mathrm{NaHCO}_{3}$ (Figure 6A). The mineralization that occurs during the PZSM-COP is the result from both $\bullet \mathrm{OHs}$ mediated oxidation and direct oxidation. The addition of $\mathrm{NaHCO}_{3}$ significantly inhibits the $\mathrm{V} / \mathrm{ZSM}_{450}$-COPs activities relative to PZSM-COP (Figures 6A,B), suggesting that the loaded V oxides increases activity by generating $\bullet \mathrm{OH}$. Electron transfers between multivalent metallic oxides and ozone molecules accelerate ozone decomposition into active $\bullet$ OHs (Zhuang et al., 2014). Co-existing metal $\mathrm{V}$ oxides $\left(\mathrm{V}^{5+}\right.$ and $\left.\mathrm{V}^{4+}\right)$ further promote -OHs generation via electron transfer. Further inhibition of the $\mathrm{V} / \mathrm{ZSM}_{450}$-COPs activity was not observed at a higher concentration of $\mathrm{NaHCO}_{3}$, up to $1.5 \mathrm{~g} / \mathrm{L}$. The $\mathrm{V} / \mathrm{ZSM}_{450^{-}}$ COPs still exhibited high TOC removal rates relative to SOP (Figures 6A,B), suggesting that $\bullet \mathrm{OH}$ s oxidation is not the only mineralization process. It was previously determined that the degradation of chemicals in COPs can be enhanced by the formation of metallic oxides-chemicals complexes, such as $\mathrm{MnO}_{2}$-oxalic acid (Andreozzi et al., 1996) or CoO-carboxylic acid (Pines and Reckhow, 2003), on the catalyst surface. The compounds may be adsorbed onto the V/ZSM catalysts and are activated, forming highly reactive complexes that promote mineralization.

The removal mechanisms for nitrobenzene and benzoic acid with $\mathrm{V} 1 / \mathrm{ZSM}_{450}-\mathrm{COP}$ are illustrated in Figure 6C: (1) the compounds are mineralized or degraded to intermediates by direct ozonation. The compounds and intermediates may be partially adsorbed by $\mathrm{V} 1 / \mathrm{ZSM}_{450}$. (2) Dissolved ozone adsorbs on the $\mathrm{Si}-\mathrm{OH}-\mathrm{Al}$ active sites and then decomposed to $\bullet \mathrm{OH}$. (3) Dissolved ozone adsorbs on the $\mathrm{V}$-OHs active sites, where ozone oxidizes $\mathrm{V}^{4+}{ }_{-} \mathrm{OH}$ s to $\mathrm{V}^{5+}{ }_{-} \mathrm{OHs}$, along with the generation of -OHs. (4) Adsorbed chemicals and intermediates are oxidized or activated via electron-transfer reaction and reduce $\mathrm{V}^{5+}-\mathrm{OH}$ to $\mathrm{V}^{4+}$-OHs. (5) The oxidized or activated species are subsequently desorbed from the catalyst surface and further oxidized by $\bullet \mathrm{OH}$ and molecular ozone on the catalyst surface and in solution.

\section{Reaction Pathways of Chemicals in ZSM- 5 Zeolites Catalyzed Ozonation}

The degradation products of nitrobenzene and benzoic acid after V1/ZSM450-COP treatment at 5, 10, and $15 \mathrm{~min}$ were determined using GC-MS. For nitrobenzene, the products were o-nitrophenol, m-nitrophenol, p-nitrophenol, and phenol after 5 min treatment; 4-nitrocatechol and 1, 2, 4-trihydroxybenzene after 10 min treatment and; 1, 3, 4-trihydroxy-6-nitrobenzene, alcohols, aldehydes, and ketones after 15 min treatment. For benzoic acid, the products were phenol after 5 min treatment; 1, 2, 4-trihydroxybenzene after 10 min treatment; alcohols and; aldehydes and ketones after 15 min treatment.

Two reaction pathways for the mineralization of nitrobenzene and benzoic acid during $\mathrm{V} 1 / \mathrm{ZSM}_{450}-\mathrm{COP}$ are illustrated (Figure 7) based upon the observed intermediate products. For nitrobenzene, the $\bullet \mathrm{OH}$ interacts with nitrobenzene (pathway 1) via an electrophilic addition on a-, b-or g-carbons. Then $\mathrm{o}$-nitrophenol, $\mathrm{m}$-nitrophenol, and $\mathrm{p}$-nitrophenol are produced after 5 min (Di Paola et al., 2003). Nitro $\left(-\mathrm{NO}_{2}\right)$ is an electrondonating functional group, that can increase electron densities at the meta positions, facilitating the $\bullet \mathrm{OHs}$ electrophilic addition on $\alpha$ - $\beta$-or $\gamma$-carbons. The peak intensity of nitrophenols was quantitatively observed as: $\mathrm{m}$-nitrophenol $>\mathrm{o}$-nitrophenol $>\mathrm{p}$ nitrophenol. The $\bullet \mathrm{OHs}$ electrophilic addition on nitrophenols then produces 4-nitrocatechol and 1, 2, 4-trihydroxybenzene after 10 min treatment (Zhao et al., 2008). The $\bullet$ OHs electrophilic addition occurs continuously to 4-nitrocatechol, forming 1 , 3, 4-trihydroxy-6-nitrobenzene. Then a ring-opening reaction, generating alcohols, aldehydes, or ketones occurs after 15 min treatment. For benzoic acid, the $\bullet$ OHs electrophilic addition (pathway 1) occurs with benzoic acid and forms hydroxylbenzoic acids, dihydroxy-benzoic acids, trihydroxy-benzoic acid, 


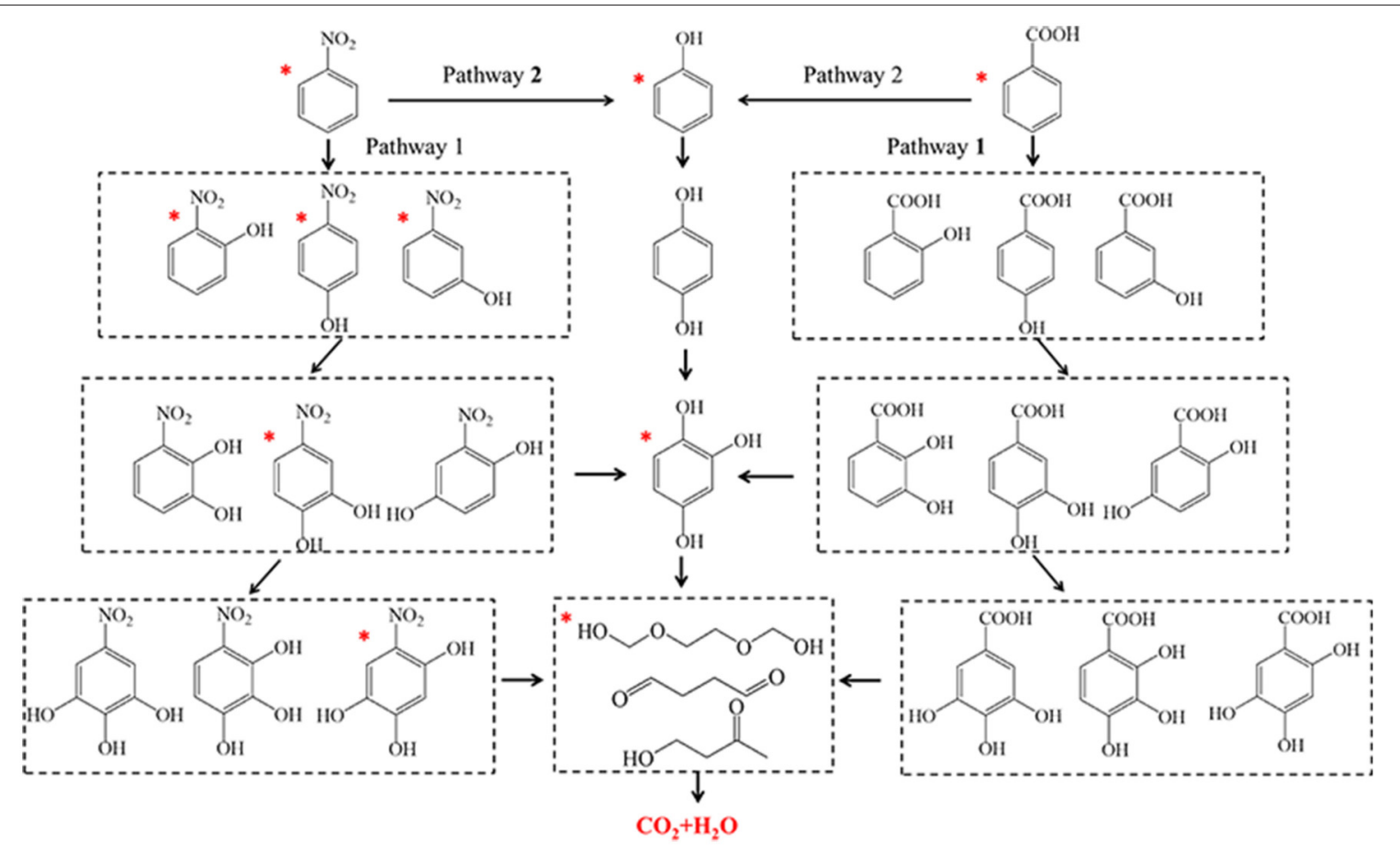

FIGURE 7 | The proposed general reaction pathways of nitrobenzene and benzoic acid in solution. The compounds with an asterisk have been detected.

and tetrahydroxy-benzoic acids (Albarrán and Mendoza, 2018). Nitrobenzene and benzoic acid both follow a similar degradation pathway (pathway 2). Molecular ozone attacks nitrobenzene and benzoic acid via a nucleophilic addition, producing phenol after 5 min (Kasprzyk-Hordern et al., 2003; Nawrocki and Fijołek, 2013). Additional electrophilic additions on the aromatic ring of phenol generate hydroquinone and trihydroxybenzene (Brillas et al., 1998; Goi et al., 2004). The stepwise hydroxylation of nitrobenzene, benzoic acids, and phenol is the dominant reaction process (Albarrán and Mendoza, 2018). The $\bullet \mathrm{OHs}$ and ozone then further react with the aromatic ring, forming alcohols, aldehydes, ketones, and carboxylic acids. The final step in this process results in mineralization to $\mathrm{CO}_{2}$ and $\mathrm{H}_{2} \mathrm{O}$. The surface reaction additionally contributes through surface adsorption.

\section{CONCLUSION}

V oxides modified NaZSM-5 zeolites (V/ZSM) were investigated for use in the COP treatment of nitrobenzene and benzoic acid in solution. V/ZSM-COPs significantly improved TOC removal in comparison to single ozonation, from its catalytic

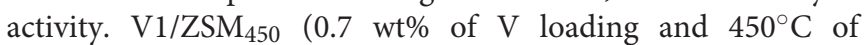
calcination) exhibited the highest activity among the developed

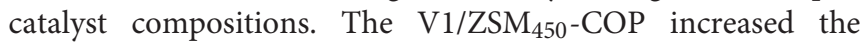
mineralization rate of nitrobenzene and benzoic acid by 50 and $41 \%$ in comparison to single ozonation. The catalytic activity of $\mathrm{V} / \mathrm{ZSM}$ catalysts result from a combination of surface multivalent $\mathrm{V}$ oxides, $\mathrm{Si}-\mathrm{OH}-\mathrm{Al}$ framework structures and the interactions that occur between them. The co-existing metal $\mathrm{V}$ oxides $\left(\mathrm{V}^{5+}\right.$ and $\mathrm{V}^{4+}$ ) are the main active sites that promote $\bullet \mathrm{OHs}$ generation via electron transfers between multivalent $\mathrm{V}$ oxides and ozone molecules. Indirect oxidation of $\bullet \mathrm{OHs}$, surface reactions and the direct oxidation by ozone are the mechanisms responsible for the TOC removal. This study shows the potential of V/ZSM zeolites in COPs of ROCs in water.

\section{DATA AVAILABILITY}

The raw data supporting the conclusions of this manuscript will be made available by the authors, without undue reservation, to any qualified researcher.

\section{AUTHOR CONTRIBUTIONS}

QW and CC conceived and designed the experiments. YX performed the experiments. BY, QL, YK, and YT interpreted and analyzed the data. $\mathrm{HY}$ and YL contributed reagents materials analysis tools. BY, QL, and CC wrote the manuscript.

\section{FUNDING}

This study was supported in part by the Independent Project Program of State Key Laboratory of Petroleum Pollution Control (Grant No. PPCIP2017004), the National Science and Technology Major Project of China (No. 2016ZX05040-003), the National Natural Science Foundation of China (No. 21776307), Science Foundation of China University of Petroleum, Beijing (No. 2462018BJB001) as well as grants N0001413-1-0463 and N00014-15-1-0028 from the U.S. Office of Naval Research. 


\section{REFERENCES}

Albarrán, G., and Mendoza, E. (2018). Ionizing radiation induced degradation of salicylic acid in aqueous solution. Radiat. Phys. Chem. 147, 27-34. doi: 10.1016/j.radphyschem.2018.01.025

Amin, N. A. S., Akhtar, J., and Rai, H. K. (2010). Screening of combined zeoliteozone system for phenol and COD removal. Chem. Eng. J. 158, 520-527. doi: 10.1016/j.cej.2010.01.042

Andreozzi, R., Insola, A., Caprio, V., Marotta, R., and Tufano, V. (1996). The use of manganese dioxide as a heterogeneous catalyst for oxalic acid ozonation in aqueous solution. Appl. Catal. A Gen. 138, 75-81. doi: 10.1016/0926-860X(95)00247-2

Ao, Z., Sun, H., and Fullana, A. (2019). Editorial: environmental catalysis and the corresponding catalytic mechanism. Front. Chem. 7:75. doi: $10.3389 /$ fchem. 2019.00075

Beltrán, F. J., Encinar, J. M., and Alonso, M. A. (1998). Nitroaromatic hydrocarbon ozonation in water. 1. single ozonation. Ind. Eng. Chem. Res. 37, 25-31. doi: $10.1021 /$ ie9704253

Bing, J., Wang, X., Lan, B., Liao, G., Zhang, Q., and Li, L. (2013). Characterization and reactivity of cerium loaded MCM-41 for pchlorobenzoic acid mineralization with ozone. Sep. Puri. Technol. 118, 479-486. doi: 10.1016/j.seppur.2013.07.048

Brillas, E., Mur, E., Sauleda, R., Sanchez, L., Peral, J., Domenech, X., et al. (1998). Aniline mineralization by AOP's: anodic oxidation, photocatalysis, electroFenton and photoelectro-Fenton processes. Appl. Catal. B Environ. 16, 31-42. doi: 10.1016/S0926-3373(97)00059-3

Chen, C., Chen, Y., Yoza, B. A., Du, Y., Wang, Y., Li, Q. X., et al. (2017a). Comparison of efficiencies and mechanisms of catalytic ozonation of recalcitrant petroleum refinery wastewater by $\mathrm{Ce}, \mathrm{Mg}$, and $\mathrm{Ce}-\mathrm{Mg}$ oxides loaded $\mathrm{Al}_{2} \mathrm{O}_{3}$. Catalysts 7:72. doi: 10.3390/catal7030072

Chen, C., Ma, W., Guo, S., Wang, Q., and Li, Q. X. (2017b). Mn-Fe-Mg-Ce loaded $\mathrm{Al}_{2} \mathrm{O}_{3}$ catalyzed ozonation for mineralization of refractory organic chemicals in petroleum refinery wastewater. Sep. Purif. Technol. 183, 1-10. doi: 10.1016/j.seppur.2017.03.054

Chen, C., Yan, X., Yoza, B. A., Zhou, T., Li, Y., Zhan, Y., et al. (2018). Efficiencies and mechanisms of ZSM-5 zeolites loaded with cerium, iron, or manganese oxides for catalytic ozonation of nitrobenzene in water. Sci. Total Environ. 612, 1424-1432. doi: 10.1016/j.scitotenv.2017.09.019

Chen, Y. H., Shang, N. C., and Hsieh, D. C. (2007). Decomposition of dimethyl phthalate in an aqueous solution by ozonation with high silica zeolites and UV radiation. J. Hazard. Mater. 157, 260-268. doi: 10.1016/j.jhazmat.2007. 12.091

Chetty, E. C., Dasireddy, V. B., Maddila, S., and Jonnalagadda, S. B. (2012). Efficient conversion of 1, 2-dichlorobenzene to mucochloric acid with ozonation catalyzed by $\mathrm{V}_{2} \mathrm{O}_{5}$ loaded metal oxides. Chem. Eng. J. 117-118, 18-28. doi: 10.1016/j.apcatb.2012.01.004

Di Paola, A., Augugliaro, V., Palmisano, L., Pantaleo, G., and Savinov, E. (2003). Heterogeneous photocatalytic degradation of nitrophenols. J. Photoch. Photobio. A 155, 207-214. doi: 10.1016/S1010-6030(02)00390-8

Dong, Y., Yang, H., He, K., Wu, X., and Zhang, A. (2008). Catalytic activity and stability of Y zeolite for phenol degradation in the presence of ozone. Appl. Catal. B Environ. 82, 163-168. doi: 10.1016/j.apcatb.2008.01.023

El-Bahy, Z. M., Mohamed, M. M., Zidan, F. I., and Thabet, M. S. (2008). Photo-degradation of acid green dye over Co-ZSM- 5 catalysts prepared by incipient wetness impregnation technique. J. Hazard. Mate. 153, 364-371. doi: 10.1016/j.jhazmat.2007.08.060

Elovitz, M. S., Gunten, U., and Kaiser, H. (2008). Hydroxyl radical/ozone ratios during ozonation processes. II. The effect of temperature, pH, alkalinity, and DOM properties. Ozone Sci. Eng. 22, 123-150. doi: 10.1080/01919510008547216

Goi, A., Trapido, M., and Tuhkanen, T. (2004). A study of toxicity, biodegradability, and some by-products of ozonised nitrophenols. Adv. Environ. Res. 8, 303-311. doi: 10.1016/S1093-0191(02)00102-8

Güm,üş, D., and Akbal, F. (2017). A comparative study of ozonation, iron coated zeolite catalyzed ozonation and granular activated carbon catalyzed ozonation of humic acid. Chemosphere 174, 218-231. doi: 10.1016/j.chemosphere.2017.01.106
Hadnadjev, M., Vulic, T., and Marinkovic-Neducin, R. (2008). The iron oxidation state in $\mathrm{Mg}$-Al-Fe mixed oxides derived from layered double hydroxides: an XPS study. Appl. Surf. Sci. 254, 4297-4302. doi: 10.1016/j.apsusc.2008.01.063

Ikhlaq, A., and Kasprzyk-Hordern, B. (2017). Catalytic ozonation of chlorinated VOCs on ZSM-5 zeolites and alumina: formation of chlorides. Appl. Catal. B Environ. 200, 274-282. doi: 10.1016/j.apcatb.2016.07.019

Ikhlaq, A., Waheed, S., Joya, K. S., and Kazmi, M. (2018). Catalytic ozonation of paracetamol on zeolite a: non-radical mechanism. Catal. Commun. 112, 15-20. doi: 10.1016/j.catcom.2018.01.010

Jeirani, Z., and Soltan, J. (2017). Improved formulation of Fe-MCM-41 for catalytic ozonation of aqueous oxalic acid. Chem. Eng. J. 307, 756-765. doi: 10.1016/j.cej.2016.08.141

Kasprzyk-Hordern, B., Ziółek, M., and Nawrocki, J. (2003). Catalytic ozonation and methods of enhancing molecular ozone reactions in water treatment. Appl. Catal. B Environ. 46, 639-669. doi: 10.1016/S0926-3373(03)00326-6

Langer, J., Dabkowsk, I., Zhang, Y., and Illenberger, E. (2008). Electron capture by pentafluoronitrobenzene and pentafluorobenzonitrile. Phys. Chem. Chem. Phys. 10, 1523-1531. doi: 10.1039/b714320f

Li, S., Tang, Y., Chen, W., Hu, Z., Li, X., and Li, L. (2017). Heterogeneous catalytic ozonation of clofibric acid using Ce/MCM-48: preparation, reaction mechanism, comparison with Ce/MCM-41. J. Colloid Interf. Sci. 504, 238-246. doi: 10.1016/j.jcis.2017.05.042

Maddila, S., Dasireddy, V. D. B. C., and Jonnalagadda, S. B. (2014). Ce-V loaded metal oxides as catalysts for dechlorination of chloronitrophenol by ozone. Appl. Catal. B Environ. 150-151, 305-314. doi: 10.1016/j.apcatb.2013.12.036

Mantis, I., Voutsa, D., and Samara, C. (2005). Assessment of the environmental hazard from municipal and industrial wastewater treatment sludge by employing chemical and biological methods. Ecotox. Environ. Safe. 62, 397-407. doi: 10.1016/j.ecoenv.2004.12.010

Martínez, C., and Corma, A. (2011). Inorganic molecular sieves: preparation, modification and industrial application in catalytic processes. Coordin. Chem. Rev. 255, 1558-1580. doi: 10.1016/j.ccr.2011.03.014

Nakamoto, H., and Takahashi, H. (1982). Hydrophobic natures of zeolite ZSM-5. Zeolites 2, 67-68. doi: 10.1016/S0144-2449(82)80002-X

Nawaz, F., Cao, H., Xie, Y., and Ghazi, Z. A. (2017). Selection of active phase of $\mathrm{MnO}_{2}$ for catalytic ozonation of 4-nitrophenol. Chemosphere. 168, 1457-1466. doi: $10.1016 /$ j.chemosphere.2016.11.138

Nawrocki, J., and Fijołek, L. (2013). Catalytic ozonation-effect of carbon contaminants on the process of ozone decomposition. Appl. Catal. B Environ. 142-143, 307-314. doi: 10.1016/j.apcatb.2013.05.028

Pines, D. S., and Reckhow, D. A. (2003). Solid phase catalytic ozonation process for the destruction of a model pollutant. Ozone Sci. Eng. 25, 25-39. doi: 10.1080/713610648

Plymale, N. T., Kim, Y. G., Soriaga, M. P., and Brunschwig, B. S. (2015). Synthesis, characterization, and reactivity of ethynyl- and propynyl-terminated $\mathrm{Si}(111)$ surfaces. J. Phys. Chem. C 119, 19847-19862. doi: 10.1021/acs.jpcc.5b05028

Portela, J. R., López, J., Nebot, E., and Martínez de la Ossa, E. (2001). Elimination of cutting oil wastes by promoted hydrothermal oxidation. J. Hazard. Mater. B 88, 95-106. doi: 10.1016/S0304-3894(01)00295-3

Qu, X., Zheng, J., and Zhang, Y. (2007). Catalytic ozonation of phenolic wastewater with activated carbon fiber in a fluid bed reactor. J. Colloid Interf. Sci. 309, 429-434. doi: 10.1016/j.jcis.2007.01.034

Rivoira, L., Juárez, J., Falcón, H., Costa, M. G., Anunziata, O., and Beltramone, A. (2017). Vanadium and titanium oxide supported on mesoporous CMK3 as new catalysts for oxidative desulfurization. Catal. Today 282, 123-132. doi: 10.1016/j.cattod.2016.07.003

Saeid, S., Tolvanen, P., Kumar, N. K., Eränen, K., Peltonen, J., Peurla, M., et al. (2018). Advanced oxidation process for the removal of ibuprofen from aqueous solution: a non-catalytic and catalytic ozonation study in a semi-batch reactor. Appl. Catal. B Environ. 230, 77-90. doi: 10.1016/j.apcatb.2018.02.021

Shirazi, L., Jamshidi, E., and Ghasemi, M. R. (2008). The effect of Si/Al ratio of ZSM-5 zeolite on its morphology, acidity and crystal size. Cryst. Res. Technol. 43, 1300-1306. doi: 10.1002/crat.200800149

Silversmit, G., Depla, D., Poelman, H., Marin, G. B., and Gryse, R. D. (2004). Determination of the V2p XPS binding energies for different vanadium oxidation states $\left(\mathrm{V}^{5+}\right.$ to $\left.\mathrm{V}^{0+}\right)$. J. Electron Spectrosc. $135,167-175$. doi: 10.1016/j.elspec.2004.03.004 
Sun, Q., Li, L., Yan, H., Hong, X., Hui, K. S., and Pan, Z. (2014). Influence of the surface hydroxyl groups of $\mathrm{MnOx} / \mathrm{SBA}-15$ on heterogeneous catalytic ozonation of oxalic acid. Chem. Eng. J. 242, 348-356. doi: 10.1016/j.cej.2013.12.097

Suryavanshi, R. D., Mohite, S. V., Bagade, A. A., Shaikh, S. K., Thorat, J. B., and Rajpure, K. Y. (2018). Nancrystalline immobilsed ZnO photocatalyst for degradation of benzoic acid and methyl blue dye. Mater. Res. Bull. 101, 324-333. doi: 10.1016/j.materresbull.2018.01.042

Tu, Y., Tian, S., Kong, L., and Xiong, Y. (2012). Co-catalytic effect of sewage sludgederived char as the support of Fenton-like catalyst. Chem. Eng. J. 185-186, 44-51. doi: 10.1016/j.cej.2012.01.008

Valdés, H., Farfána, V. J., Manolib, J. A., and Zaror, C. A. (2009). Catalytic ozone aqueous decomposition promoted by natural zeolite and volcanic sand. J. Hazard. Mater. 165, 915-922. doi: 10.1016/j.jhazmat.200 8.10 .093

Vittenet, J., Rodriguez, J., Petit, E., Cot, D., Mendret, J., Galarneau, A., et al. (2014). Removal of 2,4-dimethylphenol pollutant in water by ozonation catalyzed by SOD, LTA, FAU-X zeolites particles obtained by pseudomorphic transformation (binderless). Micropor. Mesopor. Mat. 189, 200-209. doi: 10.1016/j.micromeso.201 3.09.042

Zhao, L., Ma, J., Sun, Z., and Zhai, X. (2008). Catalytic ozonation for the degradation of nitrobenzene in aqueous solution by ceramic honeycomb-supported manganese. Appl. Catal. B Environ. 83, 256-264. doi: 10.1016/j.apcatb.2008.02.009

Zhao, X., Wei, L., Cheng, S., Cao, Y., Julson, J., and Gu, Z. (2015). Catalytic cracking of carinata oil for hydrocarbon biofuel over fresh and regenerated Zn/Na-ZSM-5. Appl. Catal. A Gen. 507, 44-55. doi: 10.1016/j.apcata.2015.09.031

Zhuang, H., Han, H., Hou, B., Jia, S., and Zhao, Q. (2014). Heterogeneous catalytic ozonation of biologically pretreated Lurgi coal gasification wastewater using sewage sludge based activated carbon supported manganese and ferric oxides as catalysts. Bioresoure Technol. 166, 178-186. doi: 10.1016/j.biortech.2014.05.056

Conflict of Interest Statement: The authors declare that the research was conducted in the absence of any commercial or financial relationships that could be construed as a potential conflict of interest.

Copyright (c) 2019 Xu, Wang, Yoza, Li, Kou, Tang, Ye, Li and Chen. This is an open-access article distributed under the terms of the Creative Commons Attribution License (CC BY). The use, distribution or reproduction in other forums is permitted, provided the original author(s) and the copyright owner(s) are credited and that the original publication in this journal is cited, in accordance with accepted academic practice. No use, distribution or reproduction is permitted which does not comply with these terms. 


\title{
Synthesis of ZSM-5/Siliceous Zeolite Composites for Improvement of Hydrophobic Adsorption of Volatile Organic Compounds
}

\author{
Renna Li ${ }^{1}$, Shijia Chong ${ }^{1}$, Naveed Altaf ${ }^{1}$, Yanshan Gao ${ }^{1 *}$, Benoit Louis ${ }^{2}$ and Qiang Wang ${ }^{1 *}$ \\ ${ }^{1}$ College of Environmental Science and Engineering, Beijing Forestry University, Beijing, China, ${ }^{2}$ ICPEES - Institut de Chimie \\ et Procédés pour l'Énergie, l'Environnement et la Santé, UMR 7515 CNRS - Université de Strasbourg, Strasbourg, France
}

In this research, we investigated the hydrophobicity and dynamic adsorption-desorption behaviors of volatile organic compounds (VOCs) by applying different optimized coating dosage (25, 50, and 75\%) on designed novel ZSM-5/MCM-41 and ZSM-5/Silicalite-1 hierarchical composites. The relatively large specific surface area and pore volume of adsorbents ZSM-5/MCM-41 and ZSM-5/Silicalite-1 composites with excellent stability

OPEN ACCESS

Edited by:

Svetlana Ivanova,

Universidad de Sevilla, Spain

Reviewed by:

Sujuan Xie,

Dalian Institute of Chemical Physics

(CAS), China

Luis F. Bobadilla

University of Seville, Spain

${ }^{*}$ Correspondence:

Yanshan Gao

yanshan_gao@bjfu.edu.cn

Qiang Wang

qiang.wang.ox@gmail.com;

qiangwang@bjfu.edu.cn

Specialty section:

This article was submitted to Green and Sustainable Chemistry, a section of the journal

Frontiers in Chemistry

Received: 14 May 2019

Accepted: 02 July 2019

Published: 16 July 2019

Citation:

Li R, Chong S, Altaf N, Gao Y, Louis B and Wang Q (2019) Synthesis of

ZSM-5/Siliceous Zeolite Composites for Improvement of Hydrophobic

Adsorption of Volatile Organic Compounds. Front. Chem. 7:505. doi: 10.3389/fchem.2019.00505 were affirmed by ex-situ XRD, FTIR, BET, SEM, and water contact angle analyses. Regarding, toluene adsorption-desorption investigation, ZSM-5/MCM-41 composite lead a longer stable toluene breakthrough time no matter under dry or $50 \%$ humid conditions. However, under different loading dosage condition, the breakthrough time of $75 \%$ coating ratio was the longest, which was 1.6 times as long as that of pure ZSM-5 under wet adsorption. Meanwhile, the complete elimination of toluene for ZSM-5/MCM-41-75\% was done by largest desorption peak area and the lowest desorption temperature of $101.9^{\circ} \mathrm{C}$, while, the largest contact angle of ZSM-5/MCM-41-75\% was $17.0^{\circ}$ higher than pure ZSM-5 zeolite. Therefore, we believe that the present hydrophobic sorbent will provide new insight with great research potential for removing low concentration of VOCs at industrial scale.

Keywords: toluene adsorption, composite materials, ZSM-5, siliceous zeolite, hydrophobicity evaluation

\section{INTRODUCTION}

With industrialization, volatile organic compounds (VOCs), as the significant precursors of photochemical smog and secondary organic aerosol (SOA), have raised stringent environmental threat for many industrial processes. Generally, VOCs originate from a wide range of manmade sources (e.g., industrial processes, vehicle emissions, solvent manufacturing, gasoline evaporation, fuel coatings manufacturing) and in a gaseous state at atmospheric pressure of $133.322 \mathrm{~Pa}$ (Okada et al., 2012). VOCs were promulgated to be composed of more than 500 compounds with different properties and most of them were demonstrated to be with high toxicity (Lewis et al., 2000). Being as an important photochemical oxidant of atmospheric environment, some of VOCs act as nerve agent could cause neurological disturbance and cell cancerization, bringing a great threat to human health (Atkinson, 2000). Therefore, the VOCs pollutants removal has already been one of the most urgent research areas.

In previous studies, several VOCs abatement technologies were developed, including oxidation (Johnsen et al., 2016; Zhang et al., 2016), biological treatment (Chen et al., 2012; Cheng et al., 2016), 
condensation (Khan and Ghoshal, 2000), absorption (Darracq et al., 2010; Hariz et al., 2017) and adsorption (Zhang et al., 2017). However, constrain was found in each technology during practical and industrial application. Such as, operating expense for VOCs extirpation by oxidation technology is extravagant due to high reaction temperature and longer retention time. As for biological treatment, the removal efficiency of VOCs is low, and the persistence time is relatively long. Condensation and absorption technologies would escalate the operating cost due to the secondary treatment of scrubbing liquids and adsorbents. Moreover, compared to these techniques, adsorption is more applicable for removing low concentration of VOCs due to its advantages (i.e., high efficiency, easy operation and low system operating costs) (Kim and Ahn, 2012; Tefera et al., 2014).

It is well-recognized that removal efficiencies by adsorption depend on the types and properties of adsorbents. Many materials have been widely accounted in adsorption of VOCs, containing carbon materials [e.g., activated carbon (Li et al., 2011; Qian et al., 2015), graphene (Shen et al., 2015) and activated carbon fiber Baur et al., 2015], oxygen adsorbents [e.g., zeolite (Li and Yu, 2014), silica gel (Adjimi et al., 2014) and metallic oxide Castaño et al., 2017], and polymeric adsorbents [e.g., polymer adsorption resin Wang et al., 2014]. Especially, activated carbon and zeolite are enumerated as main adsorbent controlled VOCs pollutants by the United States Environmental Protection Agency (USEPA). Withal, activated carbon materials (e.g., activated carbon, surface modified carbon) were profoundly applied owing to their strong adsorption selectivity for VOCs. However, the existence of fire and safety threat, stomatal blockage, and insufficient regenerative capacity of activated carbon materials limited their practical application (Zhao et al., 1998). Among these, microporous zeolites are good candidates for adsorbents of VOCs due to their unique properties such as simple synthesis, high adsorption capacity, high thermal stability and so on.

In our previous study (Li et al., 2018), although microporous zeolites (such as Y, ZSM-5 and TS-1) revealed and elucidated that high adsorption capacity for toluene, serious hydrophilicity of zeolites limits their application. Accordingly, the synthesis and application of hydrophobic zeolites have been appealing intense attentions. Therein, all-silicon zeolites may provide an opportunity to prepare relative hydrophobic zeolite due to resist the influence of some water vapor because of its pure silicon-type material (despite it contains a little the silanol on the amorphous walls surface) (Serrano et al., 2004; Dou et al., 2011). Therefore, pure siliceous zeolites are loaded on microporous zeolite ZSM5 , which can not only form multilayer porous materials, but also improve the hydrophobicity of microporous zeolite. Few reported researches work about synthesis of ZSM-5/all-silicon zeolites (e.g., MCM-41, $\mathrm{SiO}_{2}$, and Silicalite-1) composites. Most of the modified materials were used for catalytic properties, but few reports on removal adsorption of VOCs (Li et al., 2016; Pan et al., 2018; Xian et al., 2018).

Here, we aimed to synthesize hierarchically porous ZSM5/MCM-41 and ZSM-5/Silicalite-1 composites to improve the adsorption of microporous zeolite for toluene adsorption under humidity condition. To this end, ZSM-5/MCM-41 and ZSM-5/Silicalite-1 composites were synthesis and their adsorption properties for toluene under humidity condition were determined. Meanwhile, ZSM-5/MCM-41 and ZSM-5/Silicalite1 composites were characterized by ex-situ manner to prove the advantages of multiple pores zeolites.

\section{MATERIALS AND METHODS}

\section{Materials}

Cetyltrimethyl ammonium bromide (CTAB), sodium silicate $\left(\mathrm{Na}_{2} \mathrm{SiO}_{3} \cdot 9 \mathrm{H}_{2} \mathrm{O}\right)$ and tetrapropylammonium hydroxide (TPAOH) were bought from China Pharmaceutical Group Chemical Reagents Co., Ltd., the sodium hydroxide $(\mathrm{NaOH})$ was bought from Xilong Science Co., Ltd., sulphuric acid $\left(\mathrm{H}_{2} \mathrm{SO}_{4}\right)$ and tetraethylorthosilicate (TEOS) were purchased from Beijing Chemical Works and Aladdin, respectively.

\section{Preparation of Zeolites and Compounds}

Zeolite ZSM-5 was synthesized according to the previous study (Kustova et al., 2006). First, $0.3 \mathrm{~g} \mathrm{NaOH}$ and $0.3 \mathrm{~g} \mathrm{NaAlO}_{2}$ were dissolved in $9.8 \mathrm{~g}$ distilled water, then $19.4 \mathrm{~g}$ of TPAOH and $19.7 \mathrm{~g}$ TEOS were added into the above solution and stirred for $2 \mathrm{~h}$ at room temperature. The homogeneous gel was then transferred into a Teflon lined stainless steel autoclave and hydrothermal treated at $170^{\circ} \mathrm{C}$ for $72 \mathrm{~h}$. Then, the product was cooled and centrifugation with deionized water until $\mathrm{pH}$ was 7 . The product finally calcined at $550^{\circ} \mathrm{C}$ for $5 \mathrm{~h}$. The $\mathrm{Si} / \mathrm{Al}$ molar ratio of pure ZSM-5 was about 100 .

A pure silica MCM-41 was synthesized by a hydrothermal treatment (Serrano et al., 2004). Initially, $2.4 \mathrm{~g}$ of CTAB and $0.48 \mathrm{~g}$ of $\mathrm{NaOH}$ were dissolved in $60 \mathrm{~g}$ deionized water. Thereafter, $14.75 \mathrm{~g}$ of TEOS was added into solution and the mixture was stirred for $5 \mathrm{~h}$ at room temperature. After that, the resultant solution was loaded in a Teflon lined stainless steel autoclave, and treated during $48 \mathrm{~h}$ under static conditions at $110^{\circ} \mathrm{C}$. The obtained solid product was filtered, washed with distilled water. The calcination for removing the surfactant was performed at $550^{\circ} \mathrm{C}$ in air for $8 \mathrm{~h}$.

ZSM-5/MCM-41 composite was synthesized according to the following steps (Witsarut and Sirirat, 2016). First, $4.25 \mathrm{~g}$ of CTAB was dissolved in $40 \mathrm{~mL}$ of deionized water, then $1.2 \mathrm{~g}$ of ZSM5 was added to the solution with stirring for $24 \mathrm{~h}$ at $25^{\circ} \mathrm{C}$ to obtain slurry A. Solution B was obtained by dissolving $9.79 \mathrm{~g}$ of sodium silicate in $100 \mathrm{~mL}$ deionized water with $\mathrm{pH}$ was 11 adjusted by adding $6 \mathrm{M} \mathrm{H}_{2} \mathrm{SO}_{4}$. After stirring for several minutes, slurry A was dropwise added to solution $\mathrm{B}$, the mixture solution was stirred for $2 \mathrm{~h}$ at room temperature. Then the gel solutions were transferred into a Teflon lined stainless steel autoclave and heated at $120^{\circ} \mathrm{C}$ for $72 \mathrm{~h}$. Finally, the ZSM-5/MCM-41 compound was filtered, washed, dried, and calcined at $550^{\circ} \mathrm{C}$ for $6 \mathrm{~h}$.

Synthesis of ZSM-5/Silicalite-1 composite was followed by previous research steps (Deng et al., 2014). Specifically, $1.22 \mathrm{~g}$ of TPAOH was solved into $30 \mathrm{~mL}$ of deionized water, then $3.0 \mathrm{~g}$ of ZSM-5 zeolite was added to the mixture solution with ultrasonic treatment for $30 \mathrm{~min}$. Next, $2.14 \mathrm{~g}$ of TEOS was added drop by drop to above mixture with stirring for $3 \mathrm{~h}$ at $80^{\circ} \mathrm{C}$. The mixture was heated in an autoclave at $180^{\circ} \mathrm{C}$ under static condition for $48 \mathrm{~h}$. Finally, the composite was collected by centrifugation, then 
washing, drying and calcination at $550^{\circ} \mathrm{C}$ for $5 \mathrm{~h}$. Synthesis of Silicalite- 1 was the same as the above method, the only difference was removal of ZSM-5.

According to the above methods, the coating ratio of MCM-41 and Silicalite- 1 were $50 \%$. Composite materials with 25 and $75 \%$ MCM-41 or Silicalite-1 were synthesized by adjusting the dosage.

\section{Characterization}

$\mathrm{X}$-ray diffraction (XRD) analysis were measured on a Shimadzu $\mathrm{XRD}-7000$ instrument in reflection mode with $\mathrm{Cu} \mathrm{K} \alpha$ radiation. The diffraction patterns of low-angle and high-angle were obtained over the range of $1-8^{\circ}$ and $5-50^{\circ}$, with a scanning rate of $1^{\circ} \mathrm{min}^{-1}$ and $5^{\circ} \mathrm{min}^{-1}$, respectively. The 2 theta step was $0.02^{\circ}$. Infrared spectroscopic (IR) analysis was carried out on a Bruker Vertex 70 spectrophotometer with a wavenumber resolution of $\pm 4 \mathrm{~cm}^{-1}$ and scanning range from 4,000 to 400 $\mathrm{cm}^{-1}$, the number of scans used for the IR measurements was 32 times. Before test, the materials were blended with $\mathrm{KBr}$ and then pressed wafers. The nitrogen adsorption and desorption tests were conducted in Kubo-X1000 apparatus at $77 \mathrm{~K}$. The specific surface area of samples was obtained by the linear of the Brunauer-Emmett-Teller (BET) equation, and the pore size distribution of materials was determined from the nitrogen physisorption isotherms using the T-plot method and the BarretJoyner-Halenda (BJH) method. The surface morphology of products was measured using a scanning electron microscopy (SEM, Hitachi S-3400N II). Hydrophobicity of samples was evaluated through dynamic water contact angle analyses. The water contact angles of advancing and receding were gauged with a contact angle goniometer (Dataphysics OCA20) equipped with uEye digital camera. The syringe was filled with pure water, the droplet volume was $3 \mu \mathrm{L}$ and the drop speed was $5 \mu \mathrm{L} \mathrm{min}{ }^{-1}$. For accuracy, each sample was measured for 5 times.

\section{Measurement of Toluene Adsorption-Desorption Performance}

Toluene adsorption capacity of samples was evaluated using a fixed-bed reactor equipped with a GC apparatus (Agilent 7890A). The front detector used for gas chromatograph was a flame ion detector (FID) and the rear detector was a thermal conductivity detector (TCD). For each test, approximately $100 \mathrm{mg}$ pretreated sample was loaded into the stainless-steel reactor with inner diameter of $1 \mathrm{~cm}$. The samples pretreatment was done in the vacuum oven at $110^{\circ} \mathrm{C}$ for overnight to remove impurities and moisture before adsorption. Consequently, the testing condition is as follows: $400 \mathrm{ppm}$ toluene and $20 \% \mathrm{O}_{2}$, balanced by Ar with a total flow rate of $100 \mathrm{~mL} / \mathrm{min}$. For the wet condition, by winding heating belt outside the water vapor device and reaction tube to control the relative humidity of $50 \%$. The desorption test was conducted from 40 to $200^{\circ} \mathrm{C}$

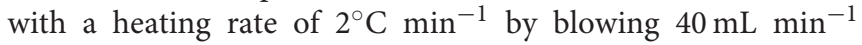
Ar. The thermal stability of adsorbed toluene was evaluated by a temperature programmed desorption (TPD) test. First, the sample was exposed to 2,000 ppm toluene with a flow

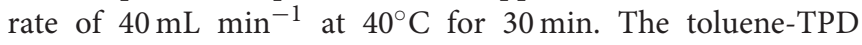
test was then implemented by heating the sample with a ramp of $10^{\circ} \mathrm{C} \mathrm{m^{-1 }}$ from 40 to $600^{\circ} \mathrm{C}$. The calculation of the saturated adsorption of toluene is according to the following formula (1):

$$
q=\frac{F^{*} C_{0}^{*} 10^{-9}}{W}\left[t_{s}-\int_{0}^{t_{s}} \frac{C_{t}}{C_{0}} d_{t}\right]
$$

where $\mathrm{q}(\mathrm{mg} / \mathrm{g})$ - adsorption capacity of toluene, $\mathrm{F}(\mathrm{mL} / \mathrm{min})$ - gas flow velocity,

$\mathrm{C}_{0}\left(\mathrm{mg} / \mathrm{m}^{3}\right)$-initial concentration of the intake,

$\mathrm{C}_{\mathrm{t}}\left(\mathrm{mg} / \mathrm{m}^{3}\right)$ - the concentration of gas at $\mathrm{t}$ minutes,

$\mathrm{W}(\mathrm{g})$ - the amount of adsorbent,

$\mathrm{t}$ ( $\mathrm{min}$ ) - the adsorption time,

$\mathrm{t}_{\mathrm{s}}(\mathrm{min})$ - the time of adsorption saturation.

\section{RESULTS AND DISCUSSION \\ Characterization of ZSM-5/Siliceous Zeolite Composites}

The low-angle and high-angle XRD patterns of ZSM-5, MCM-41, Silicalite-1, ZSM-5/MCM-41 composite and ZSM-5/Silicalite-1 composite are shown in Figure 1. As per Figure 1A of the lowangle XRD patterns, ZSM-5/MCM-41 composites exhibited the characteristic peak of (100), which belonged to the hexagonal mesopore structure of MCM-41, and the intensity of the peaks increased with the increasing of MCM-41 loading. Noteworthy, in comparison with pure MCM-41, the (100) diffraction peak of composites deviated to high-angle, which was more deviation as the load decreases and the diffraction peak of (200) became quite weak. This was due to the certain influence of alkali treatment on aggregated micelles during hydrothermal process and subsequent formation of mesopores (Sang et al., 2013). The result illustrates that the part of ZSM-5 particulates were disintegrated into $\mathrm{Si}-\mathrm{Al}$ nanoclusters then forming the hexagonal mesopore structure owing to the presence of CTAB templates (Tanaka et al., 2008). The high-angle XRD patterns of ZSM5 , Silicalite- 1 and all the compounds appeared the diffraction peaks at $2 \theta=7.9^{\circ}, 8.7^{\circ}, 23.1^{\circ}, 23.9^{\circ}$, and $24.4^{\circ}$, respectively, which corresponding to the reflections of (101), (020), (501), (151), and (303) planes (Figure 1B). The result demonstrates that all samples present a MFI-type zeolite structure (Sang et al., 2013). There was no presence of impurity phases in XRD curves, indicating the successful synthesis of ZSM-5/siliceous zeolite composites.

IR spectra of ZSM-5/MCM-41 and ZSM-5/Silicalite1 composites with different siliceous zeolite loading are shown in Figure 2. The strong band appeared at $1,080 \mathrm{~cm}^{-1}$ with a little shoulder at $1,230 \mathrm{~cm}^{-1}$ was assigned to the $\mathrm{T}-\mathrm{O}-\mathrm{T}$ ( $\mathrm{T}$ was $\mathrm{Si}$ or $\mathrm{Al}$ atom) asymmetric stretching mode. Consequently, the relatively weak band at $804 \mathrm{~cm}^{-1}$ and the strong band at $455 \mathrm{~cm}^{-1}$ was owing to the corresponding T-O-T symmetric stretching mode with plane bending character and the $\mathrm{T}-\mathrm{O}-\mathrm{T}$ rocking mode, respectively. Thus, the weaker absorption bond in region $700-500 \mathrm{~cm}^{-1}$ and the quite strong band at $554 \mathrm{~cm}^{-1}$ were typical MFI structural units (Dutta et al., 1991; Li et al., 2013). These IR spectra indicated that all compounds 

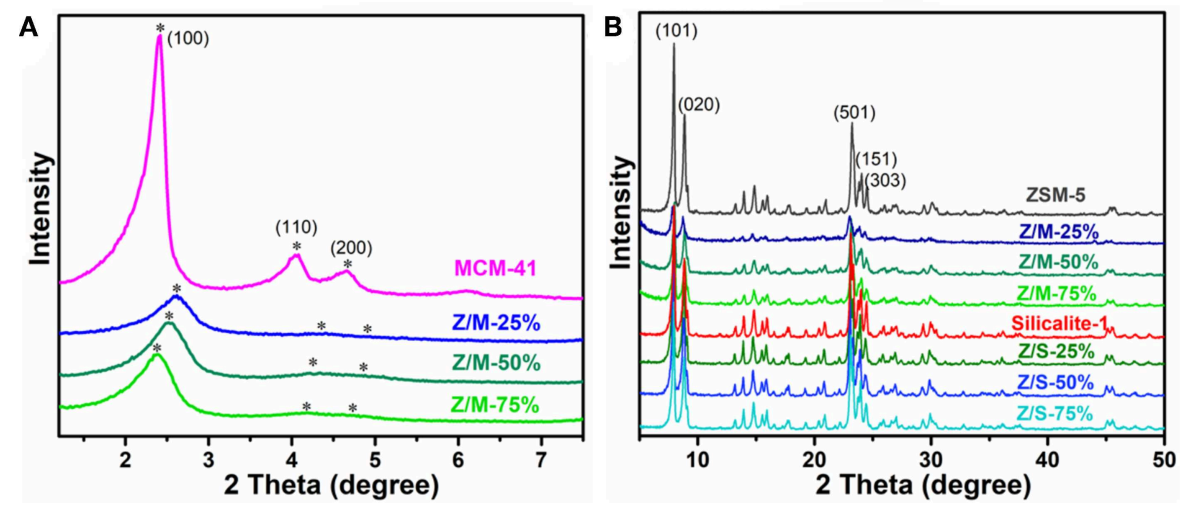

FIGURE 1 | XRD patterns of ZSM-5/siliceous zeolite composites at (A) low-angle and (B) high-angle.
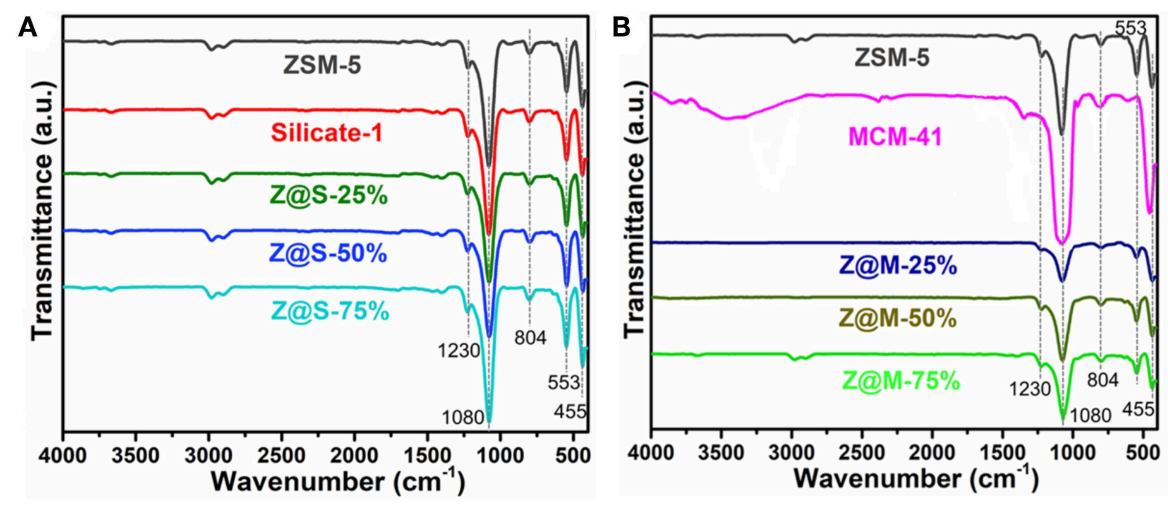

FIGURE 2 | IR spectra of (A) ZSM-5/MCM-41 (Z/M) and (B) ZSM-5/Silicalite-1 (Z/S) composites.

consistent with the above XRD results Figure 1, which contained the primary or secondary structure of ZSM-5 zeolite.

The $\mathrm{N}_{2}$ adsorption-desorption isotherms and pore distribution of ZSM-5, MCM-41, Silicalite-1 zeolite and different composites are depicted in Figure 2. Moreover, it can be explicated from Figure 3A, comparing with ZSM-5, the isotherms of ZSM-5/MCM-41 compounds were similar to type $\mathrm{I}$ in pressure range $\mathrm{P} / \mathrm{P}_{0}<0.05$, the adsorption capacity of $\mathrm{N}_{2}$ was below $140 \mathrm{~cm}^{3} / \mathrm{g}$, which was the amount of the microporous filling volume. However, the $\mathrm{N}_{2}$ adsorptiondesorption isotherms of ZSM-5/MCM-41 were belong to those of type IV in the pressure range $\mathrm{P} / \mathrm{P}_{0}>0.05$, which is typical for mesoporous zeolite and it illustrated the existence of mesopores. As per Figure 3B, there were two kinds of pore size distribution in all composites except microporous zeolite ZSM-5. The average diameter of the micropores was around $0.53 \mathrm{~nm}$, and mesopores with pore diameters of 2-3.5 $\mathrm{nm}$. However, as shown in Figure 3C, it can be found that the $\mathrm{N}_{2}$ adsorption isotherms of ZSM-5/Silicalite-1 were belong to type I as a whole, but there is a small hysteresis loop at the pressure range of $0.5-0.9$, which indicates the existence of mesopores in the composites. Such result was consistent with the pore size distribution in Figure 3D.
The BET parameters of pure ZSM-5, MCM-41, Slicalite-1, and all ZSM-5/siliceous zeolite composites were listed in Table 1, in which the specific surface area (SSA) of ZSM-5/MCM-41 composite zeolites with different dosage obey the larger specific surface area with increasing dosage ratio of MCM-41, however, ZSM-5/Silicalite-1 composites had the opposite order. Moreover, the same table also reflected that there were double-pore in all the ZSM-5/siliceous zeolite composites, but in fact, the mesopore of ZSM-5/Silicalite-1 composites was very weak, and it was still dominated by existing micropores, which was consistent with the information in Figure 3.

Moreover, Figure 4 demonstrated the SEM images of MCM41, ZSM-5, and the corresponding composite ZSM-5/MCM41, ZSM-5/Silicalite-1 with different dosage. Pure MCM-41 and ZSM-5 zeolite illustrated spherical particles and regular cubic particles, respectively. For ZSM-5/MCM-41 compounds, compared with the uniform morphology of pure ZSM-5, a lot of ZSM-5 particles were disintegrated and became irregular due to desilication phenomenon in the framework of ZSM-5 under basic conditions then destruction of silicon. It is worth noting that MCM-41 particles cannot be coated on the external surface of ZSM-5 because of the size of the particles, while it 

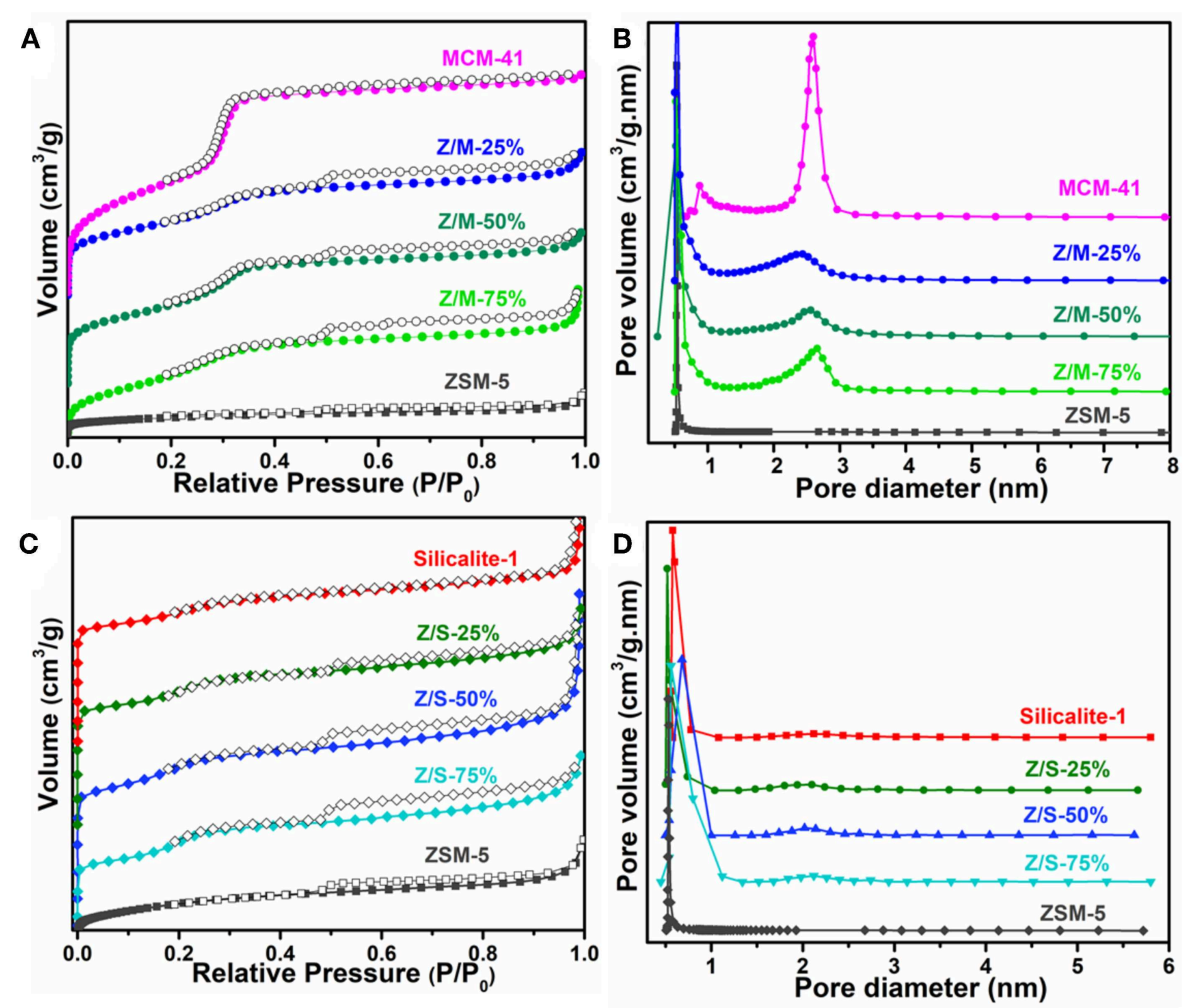

FIGURE 3 | N2 adsorption-desorption isotherms of (A) MCM-41, ZSM-5, ZSM-5/MCM-41 with different dosage and (C) Silicalite-1, ZSM-5/Silicalite-1 with different dosage. Pore size distribution curves of (B) MCM-41, ZSM-5, Slicalite-1 and (D) all ZSM-5/siliceous zeolite composites.

TABLE 1 | BET parameters of pure ZSM-5, MCM-41, Slicalite-1, and all ZSM-5/siliceous zeolite composites.

\begin{tabular}{|c|c|c|c|c|c|}
\hline Samples & $\mathrm{S}_{\mathrm{BET}}\left(\mathrm{m}^{2} / \mathrm{g}\right)$ & Pore size (nm) & $\mathrm{V}_{\text {total }}\left(\mathrm{cm}^{3} / \mathrm{g}\right)$ & $\mathrm{V}_{\text {micro }}\left(\mathrm{cm}^{3} / \mathrm{g}\right)$ & $V_{\text {meso }}\left(\mathrm{cm}^{3} / \mathrm{g}\right)$ \\
\hline ZSM-5 & 377 & 0.53 & 0.173 & 0.137 & 0.012 \\
\hline MCM-41 & 896 & 2.60 & 0.714 & 0.179 & 0.534 \\
\hline Z/M-25\% & 593 & $0.53,2.44$ & 0.475 & 0.261 & 0.210 \\
\hline Z/M-50\% & 645 & $0.52,2.56$ & 0.499 & 0.267 & 0.229 \\
\hline Z/M-75\% & 706 & $0.52,2.66$ & 0.563 & 0.288 & 0.273 \\
\hline Silicalite-1 & 361 & $0.60,2.12$ & 0.287 & 0.169 & 0.117 \\
\hline Z/S-25\% & 466 & $0.52,2.10$ & 0.412 & 0.211 & 0.198 \\
\hline Z/S-50\% & 439 & $0.68,2.02$ & 0.301 & 0.203 & 0.097 \\
\hline Z/S-75\% & 397 & $0.56,2.12$ & 0.276 & 0.187 & 0.088 \\
\hline
\end{tabular}

can only coexist with ZSM-5 to form microporous-mesoporous multilayer structure materials (Shen et al., 2018). With Silicalite-1 coating, the ZSM-5/silicalite-1 composites retain the big granular morphology but with the rough surfaces and the smooth corners, also it was apparent that there was a contiguous Silicalite-1 layer on the outer surface of ZSM-5 crystals, that the coating became thicker with the increase of dosage.

\section{Toluene Adsorption Properties of Materials}

The effect of siliceous zeolite coating for the toluene adsorption was systematically investigated under both dry and wet conditions. The toluene breakthrough curves are shown in Figure 5, the calculation of saturated adsorption capacity is based above Equation (1). Figure 5A clearly show that the breakthrough time of zeolite/MCM-41 composites became longer than that of parent zeolites no matter under dry or wet conditions. It was reported that a longer breakthrough time indicated a better adsorption capacity for a constant concentration. Under humidity conditions, the breakthrough curves of all microporous composites were greatly tilt, which was due to the adsorption sites occupied by water molecules lead the slow diffusion of toluene and longer saturation time. Figure 5B shows that all the adsorption curves take a quite long time from breakthrough to saturation, illustrating that a big mass transfer resistance. This was due to the main narrow micropore entrance within the microporous zeolites can lead to a low 


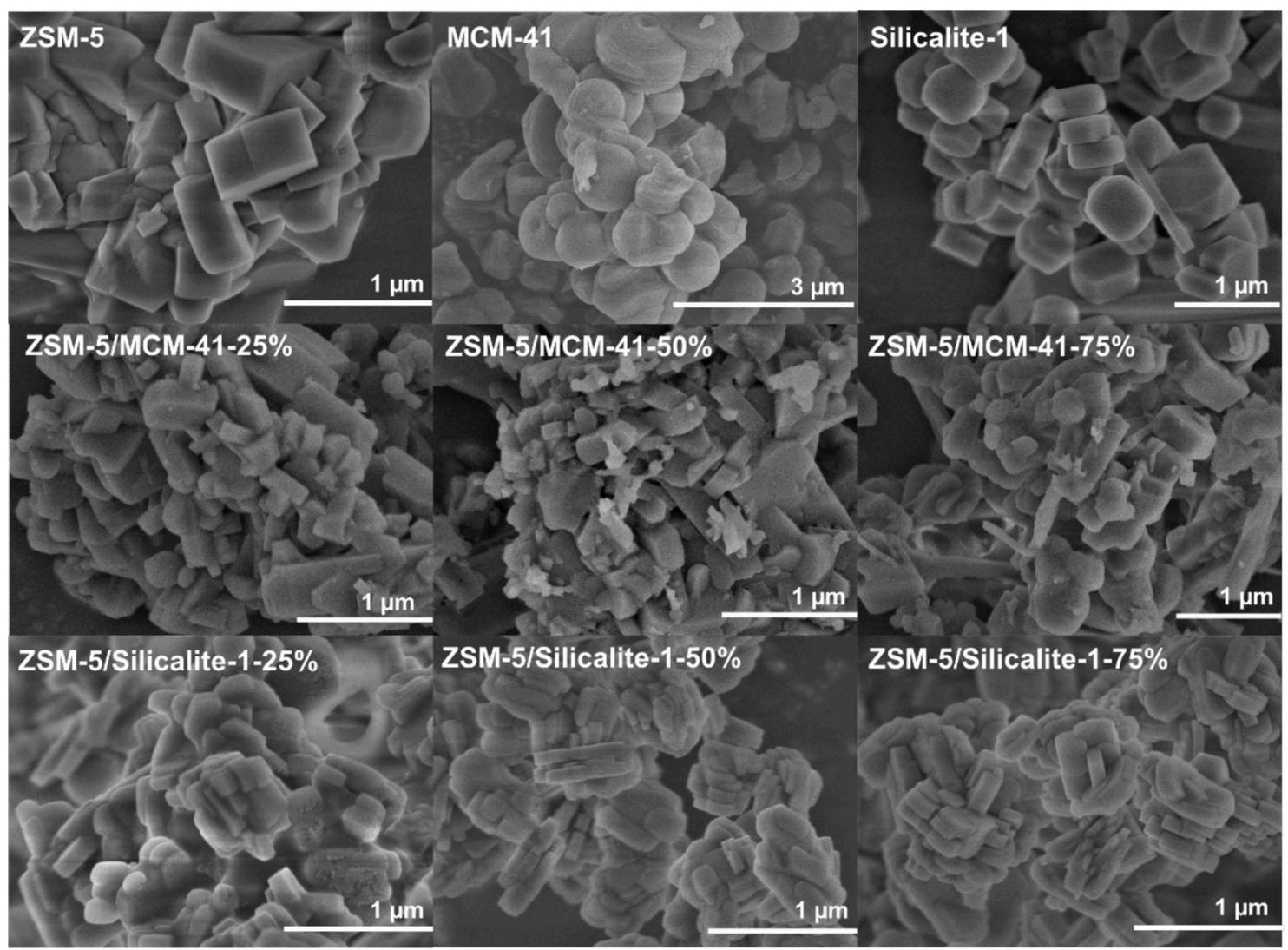

FIGURE 4 | SEM images of MCM-41, ZSM-5, Slicalite-1, and all ZSM-5/siliceous zeolite composites.
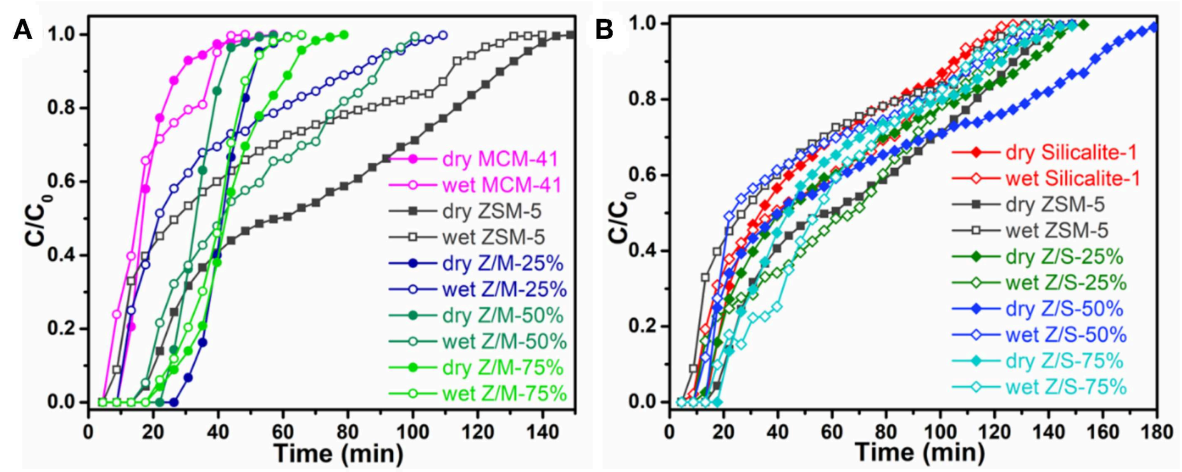

FIGURE 5 | Toluene breakthrough curve of (A) ZSM-5/MCM-41 and (B) ZSM-5/Silicalite-1 composites under dry and wet conditions.

diffusion rate (Kim and Ahn, 2012). Nevertheless, it also can be seen from the Figure 5 that all the ZSM-5/Silicalite-1 complexes have longer breakthrough time than ZSM-5 under 50\% relative humidity condition.

Table 2 elucidates the toluene adsorption properties of various samples under dry and wet conditions, which were obtained from the breakthrough curves in Figure 5. As a whole, ZSM-5/MCM41 compounds with different dosage gave a longer breakthrough time for toluene, while presented a lower adsorption capacity due to the lower saturation time. From Table 1, the specific surface area of ZSM-5/MCM-41 was also larger than major microporous zeolites. The adsorption capacity of microporous adsorbents was mainly affected by the specific surface area and pore volume, this result was consistent with gravimetric adsorption isotherm data (Huang et al., 2002). However, the longest breakthrough time decreased with the increasing of MCM-41 due to the 
TABLE 2 | The toluene adsorption properties of MCM-41, ZSM-5, Slicalite-1 and all ZSM-5/siliceous zeolite composites with different dosage.

\begin{tabular}{lccc}
\hline Samples & $\begin{array}{c}\text { Dry/Wet } \\
\text { Breakthrough time } \\
\text { (min) }\end{array}$ & $\begin{array}{c}\text { Dry/Wet } \\
\text { Saturation time(min) }\end{array}$ & $\begin{array}{c}\text { Dry/Wet } \\
\text { Saturated adsorption } \\
\text { capacity (mg/g) }\end{array}$ \\
\hline ZSM-5 & $18.6 / 7.1$ & $135.5 / 120.1$ & $111.1 / 73.6$ \\
MCM-41 & $9.9 / 5.4$ & $37.2 / 39.6$ & $31.1 / 30.5$ \\
Z/M-25\% & $28.2 / 9.7$ & $52.6 / 91.9$ & $71.5 / 58.7$ \\
Z/M-50\% & $24.0 / 17.6$ & $42.9 / 92.8$ & $58.0 / 78.9$ \\
Z/M-75\% & $23.1 / 18.5$ & $65.7 / 53.6$ & $75.9 / 64.1$ \\
Silicalite-1 & $14.5 / 9.6$ & $114.6 / 114.8$ & $78.4 / 85.1$ \\
Z/S-25\% & $14.0 / 9.4$ & $141.8 / 128.8$ & $97.1 / 104.1$ \\
Z/S-50\% & $14.2 / 10.7$ & $165.8 / 126.8$ & $108.9 / 79.4$ \\
Z/S-75\% & $19.5 / 15.5$ & $131.2 / 124.5$ & $96.0 / 100.6$ \\
\hline
\end{tabular}

poor adsorption property (only 9.9 under dry condition) of MCM-41. On the contrary, the adsorption properties increased with the increasing of MCM-41 or silicalite-1 under wet condition, this is mainly because of the better hydrophobic property of MCM-41 and silicalite-1. Both ZSM-5/MCM-41 and ZSM-5/Silicalite- 1 composite materials present the best toluene adsorption property with $75 \%$ MCM-41 or silicalite-1 loading. Under $50 \%$ humidity conditions, the breakthrough time of ZSM5/MCM-41-75\% and ZSM-5/Silicalite-1-75\% was 1.6 times and 1.2 times longer than that of pure ZSM-5, respectively. In most cases, the $=\mathrm{Si}-\mathrm{OH}$ groups on the surfaces of silica-based materials act as the adsorption sites for various VOCs molecules. The toluene adsorption by siliceous zeolite act through weak $\pi$-system hydrogen bonding with silanols on outer surface (Kosuge et al., 2007).

\section{Toluene-TPD of ZSM-5/Siliceous Compounds}

According to toluene-TPD test, toluene acting directly with the adsorption sites are desorbed by rising of the temperature. The desorption temperature is directly related to the intensity of adsorption adsorbents-adsorbates (Serrano et al., 2004). Figure 6 compares the toluene-TPD curve for three kinds of pure zeolites and two ZSM-5/siliceous-75\% composites. The tolueneTPD curves of all adsorbents show just one desorption peak, indicating that there was only one type of adsorption site. In fact, the main desorption temperature of ZSM-5/MCM-41$75 \%$ was $101.9^{\circ} \mathrm{C}$, which had the largest desorption peak area and the lowest desorption temperature, indicating that ZSM5/MCM-41-75\% was the best adsorbent among all the ZSM5/siliceous composites. However, we did Ar-TPD and desorption test of ZSM-5/MCM-41-75\%. Compare the curves of tolueneTPD and Ar-TPD, it is obvious that there was no peak for Ar-TPD (Figure S1A). Besides, one cyclic adsorption-desorption test was done by GC as well (Figure S1B). The result showed that there was no other desorption peak below $250^{\circ} \mathrm{C}$ except the one around $100^{\circ} \mathrm{C}$, which was consistent with tolueneTPD result $\left(101.9^{\circ} \mathrm{C}\right)$. Therefore, it can be confirmed that the peak around $101.9^{\circ} \mathrm{C}$ represent toluene. The desorption

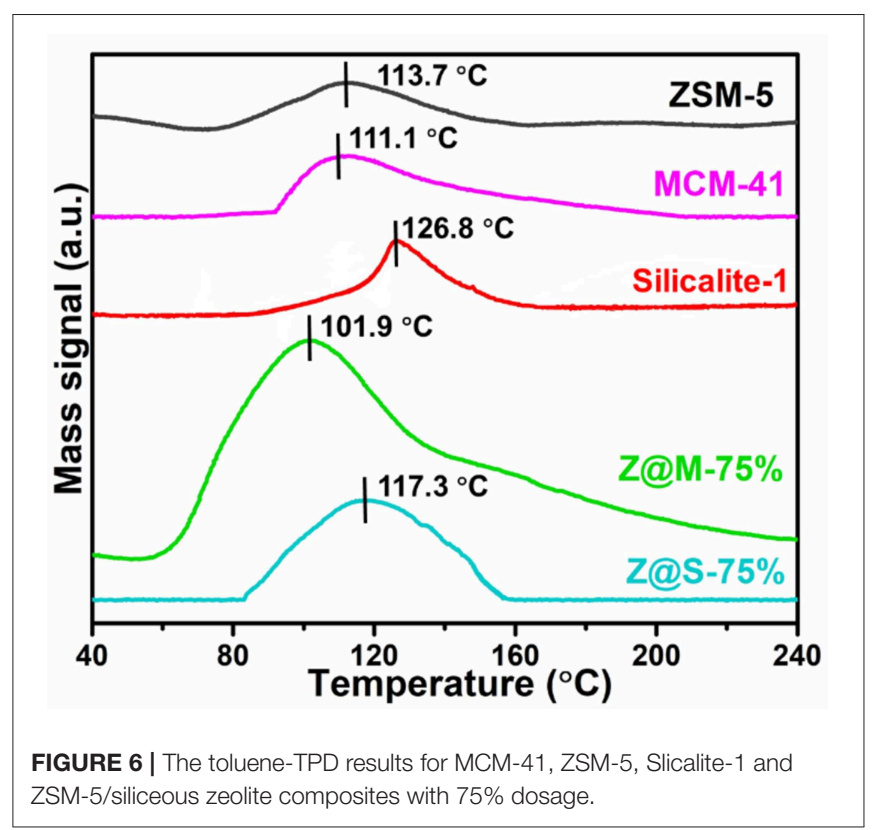

temperature results also indicated that $180^{\circ} \mathrm{C}$ was enough for toluene desorption for all the adsorbents. On the basis of TPD analysis, the cycling stability of ZSM-5 and ZSM-5/MCM-41-75\% for toluene adsorption was studied, and $180^{\circ} \mathrm{C}$ was chosen as the desorption temperature. The experimental results show that both the materials have good cycling stability (Figure S2).

\section{Hydrophobicity Evaluation}

Water contact angle can show hydrophilic or hydrophobic characteristics of the external surfaces directly. The images of the water drop on MCM-41, ZSM-5, Slicalite-1 and all ZSM5/siliceous zeolite composites surfaces are shown in Figure 7. The contact angles of ZSM-5/MCM-41-25\%, ZSM-5/MCM-41$50 \%$ and ZSM-5/MCM-41-75\% were $22.9^{\circ}, 27.2^{\circ}$, and $37.1^{\circ}$, respectively while the contract angles of ZSM-5/Silicalite-125\%, ZSM-5/Silicalite-1-50\% and ZSM-5/Silicalite-1-75\% were $23.3,25.9$, and $36.4^{\circ}$, respectively. Out of all the contact angle measured, ZSM-5 zeolite displayed the lowest contact angle $\left(20.1^{\circ}\right)$ due to its hydrophilic properties. When ZSM-5 zeolite coated with siliceous MCM-41 and Silicalite-1, the compounds showed the obvious improvement hydrophobicity with higher water contact angles than that of ZSM-5. In addition, ZSM5/MCM-41-75\% and ZSM-5/Silicalite-1-75\% showed the largest contact angle loading $75 \%$ dosage both composites, which was 37.1 and $36.4^{\circ}$, respectively. These results are in agreement with the previous results of toluene adsorption under wet condition. The higher hydrophobicity of composites with $75 \%$ dosage can be attributed to the combination of multiple scale surface roughness (Bernardoni and Fadeev, 2011). According to the SEM images (Figure 4), it is obvious that the surface of the ZSM-5/MCM41-75\% and ZSM-5/Silicalite-1-75\% composites was more roughness than that of pure zeolite. So the contact angle was larger than pure zeolite.

According to previous studies, microporous zeolite can be significantly improved hydrophobicity with coated all-siliceous 


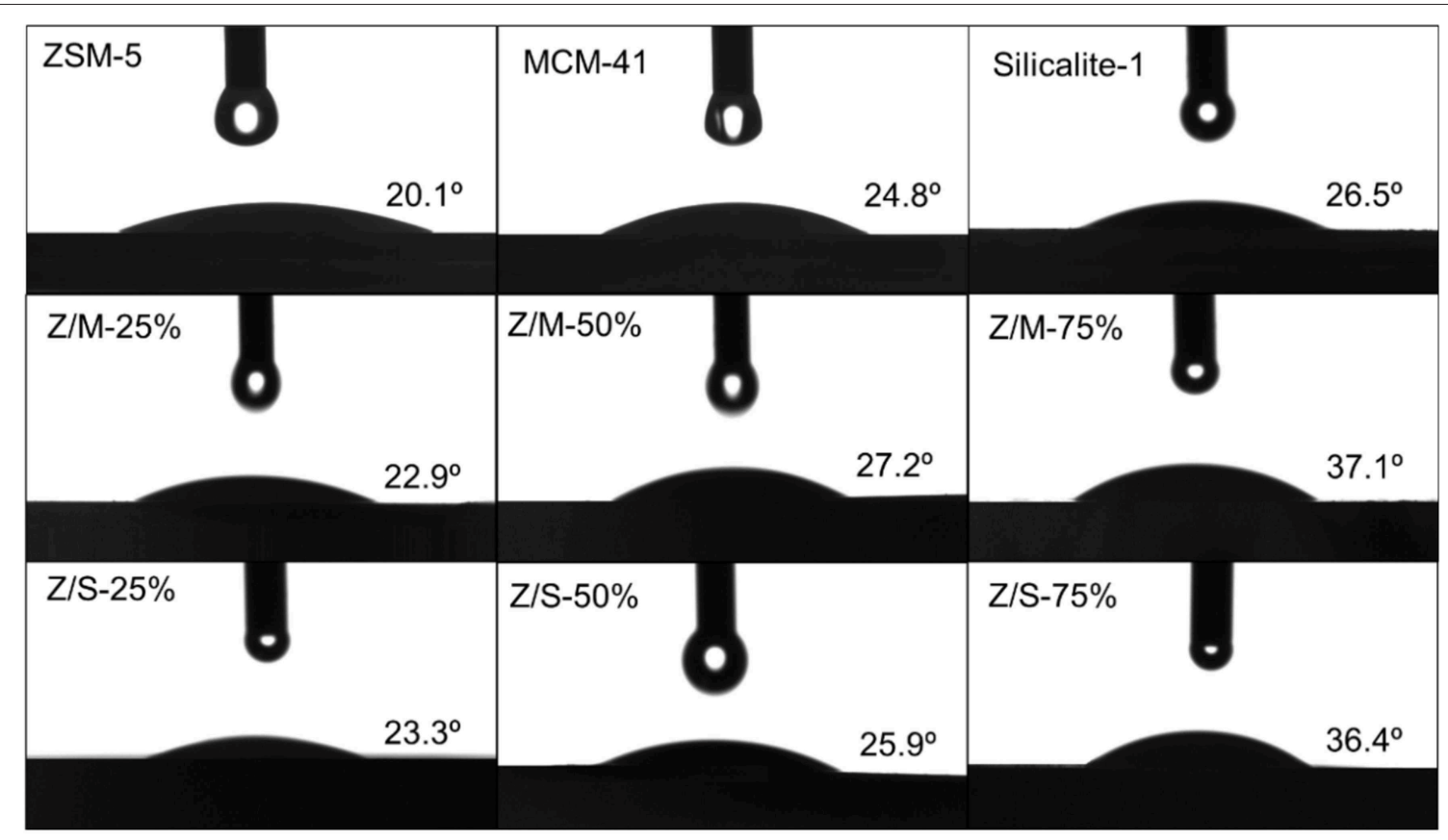

FIGURE 7 | Contact angle measurement of MCM-41, ZSM-5, Slicalite-1, and all ZSM-5/siliceous zeolite composites.

zeolite, the other mechanism of hydrophobicity was that the most stable of water molecules was combined to surface cations, next by hydrogen linked to coordinated water or silanol groups bonded to dissociative water. Therefore, surface cations or $\mathrm{Si}-\mathrm{OH}$ groups can make water molecules stay on the pore wall surface. However, free water weakly interacts with siliceous pore surface, because water molecules form amorphous groups through limited intermolecular hydrogen bonding (Cheng and Reinhard, 2006).

\section{CONCLUSIONS}

The hydrophobicity and dynamic toluene adsorption-desorption behaviors were investigated for ZSM-5/MCM-41 and ZSM5/Silicalite-1 hierarchical composites with different coating dosage, all of which had distinct characterization. Moreover, the crystal structure of ZSM-5/MCM-41 composites were somewhat destruction due to alkali treatment, which influence the formation of mesopores during hydrothermal process, and the existence of template destroyed orderliness of ZSM-5. On the contrary, ZSM-5/Silicalite-1 compounds showed better stability. For the study of toluene adsorption-desorption, the relatively large specific surface area and pore volume of ZSM-5/MCM41 composite presented a longer toluene breakthrough time no matter in dry or $50 \%$ humid conditions. Under different loading dosage, the breakthrough time of $75 \%$ coating ratio was the longest, which was 1.6 times as long as that of pure ZSM-5 under wet adsorption. The largest contact angle of ZSM-5/MCM- $41-75 \%$ was $17.0^{\circ}$ higher than pure ZSM5 zeolite. It was noteworthy, the reason for improvement of hydrophobic adsorption by coating siliceous zeolite was due to multiple scale surface roughness and free water form amorphous groups through finite intermolecular hydrogen bonds, so that water molecules interact weakly with the porous surface of siliceous materials.

\section{DATA AVAILABILITY}

All datasets generated for this study are included in the manuscript/Supplementary Files.

\section{AUTHOR CONTRIBUTIONS}

RL and SC involved in the sample synthesis and performance test and wrote the draft manuscript. YG revised the manuscript and analyzed the experimental result. NA revised the manuscript. $\mathrm{QW}$ and $\mathrm{BL}$ conceived the project. All authors contributed to manuscript preparation.

\section{FUNDING}

This work was supported by the Fundamental Research Funds for the Central Universities (BLX201724), the National Natural Science Foundation of China (51622801, 51572029, U1810209), and the National Research Program for Key Issues in Air Pollution Control (DQGG0201).

\section{SUPPLEMENTARY MATERIAL}

The Supplementary Material for this article can be found online at: https://www.frontiersin.org/articles/10.3389/fchem. 2019.00505/full\#supplementary-material 


\section{REFERENCES}

Adjimi, S., Sergent, N., Roux, J. C., Delpech, F., Pera-Titus, M., Chhor, K., et al. (2014). Photocatalytic paper based on sol-gel titania nanoparticles immobilized on porous silica for VOC abatement. Appl. Catal. B-Environ. 154-155, 123-133. doi: 10.1016/j.apcatb.2014.02.011

Atkinson, R. (2000). Atmospheric chemistry of VOCs and $\mathrm{NO}_{\mathrm{x}}$. Atmos. Environ. 34, 2063-2101. doi: 10.1016/s1352-2310(99)00460-4

Baur, G. B., Yuranov, I., Renken, A., and Kiwi-Minsker, L. (2015). Activated carbon fibers for efficient VOC removal from diluted streams: the role of surface morphology. Adsorption 21, 479-488. doi: 10.1007/s10450-015-9685-5

Bernardoni, F., and Fadeev, A. Y. (2011). Adsorption and wetting characterization of hydrophobic SBA-15 silicas. J. Colloid Interf. Sci. 356, 690-698. doi: 10.1016/j.jcis.2011.01.033

Castaño, M. H., Molina, R., and Moreno, S. (2017). Effect of $\mathrm{Mg}$ and $\mathrm{Al}$ on manganese oxides as catalysts for VOC oxidation. Mol. Catal. 443, 117-124. doi: 10.1016/j.mcat.2017.09.015

Chen, H., Yang, C., Zeng, G., Luo, S., and Yu, G. (2012). Tubular biofilter for toluene removal under various organic loading rates and gas empty bed residence times. Bioresour. Technol. 121, 199-204. doi: $10.1016 /$ j.biortech.2012.06.031

Cheng, H., and Reinhard, M. (2006). Sorption of trichloroethylene in hydrophobic micropores of dealuminated $\mathrm{Y}$ zeolites and natural minerals. Environ. Sci. Technol. 40, 7694-7701. doi: 10.1021/es060886s

Cheng, Y., He, H., Yang, C., Zeng, G., Li, X., Chen, H., et al. (2016). Challenges and solutions for biofiltration of hydrophobic volatile organic compounds. Biotechnol. Adv. 34, 1091-1102. doi: 10.1016/j.biotechadv.2016.06.007

Darracq, G., Couvert, A., Couriol, C., Amrane, A., Thomas, D., Dumont, E., et al. (2010). Silicone oil: an effective absorbent for the removal of hydrophobic volatile organic compounds. J. Chem. Technol. Biot. 85, 309-313. doi: $10.1002 /$ jctb. 2331

Deng, Y. Q., Zhou, W. F., Lv, H. M., Zhang, Y. Y., Au, C. T., and Yin, S. F. (2014). Synthesis of HZSM-5@silicalite-1 core-shell composite and its catalytic application in the generation of $\mathrm{p}$-xylene by methylation of toluene with methyl bromide. RSC Adv. 4, 37296-37301. doi: 10.1039/C4RA04126G

Dou, B., Hu, Q., Li, J., Qiao, S., and Hao, Z. (2011). Adsorption performance of VOCs in ordered mesoporous silicas with different pore structures and surface chemistry. J. Hazard. Mater. 186, 1615-1624. doi: 10.1016/j.jhazmat.2010.12.051

Dutta, P. K., Rao, K. M., and Park, J. Y. (1991). Correlation of Raman spectra of zeolites with framework architecture. J. Phys. Chem. 95, 6654-6656. doi: 10.1021/j100170a050

Hariz, R., del Rio Sanz, J. I., Mercier, C., Valentin, R., Dietrich, N., Mouloungui, Z., et al. (2017). Absorption of toluene by vegetable oil-water emulsion in scrubbing tower: experiments and modeling. Chem. Eng. Sci. 157, 264-271. doi: 10.1016/j.ces.2016.06.008

Huang, Z. H., Kang, F., Zheng, Y. P., Yang, J. B., and Liang, K. M. (2002). Adsorption of trace polar methy-ethyl-ketone and non-polar benzene vapors on viscose rayon-based activated carbon fibers. Carbon N. Y. 40, 1363-1367. doi: 10.1016/s0008-6223(01)00292-5

Johnsen, D. L., Emamipour, H., Guest, J. S., and Rood, M. J. (2016). Environmental and economic assessment of electrothermal swing adsorption of air emissions from sheet-foam production compared to conventional abatement techniques. Environ. Sci. Technol. 50, 1465-1472. doi: 10.1021/acs.est.5b05004

Khan, F. I., and Ghoshal, A. K. (2000). Removal of volatile organic compounds from polluted air. J. Loss Prevent. Proc. 13, 527-545. doi: 10.1016/S0950-4230(00)00007-3

Kim, K. J., and Ahn, H. G. (2012). The effect of pore structure of zeolite on the adsorption of VOCs and their desorption properties by microwave heating. Micropor. Mesopor. Mater. 152, 78-83. doi: 10.1016/j.micromeso.2011.11.051

Kosuge, K., Kubo, S., Kikukawa, N., and Takemori, M. (2007). Effect of pore structure in mesoporous silicas on VOC dynamic adsorption/desorption performance. Langmuir 23, 3095-3102. doi: 10.1021/la062 $616 \mathrm{t}$

Kustova, M. Y., Rasmussen, S. B., Kustov, A. L., and Christensen, C. H. (2006). Direct NO decomposition over conventional and mesoporous Cu-ZSM-5 and Cu-ZSM-11 catalysts: improved performance with hierarchical zeolites. Appl. Catal. B-Environ. 67, 60-67. doi: 10.1016/j.apcatb.2006.04.014
Lewis, A. C., Carslaw, N., Marriott, P. J., Kinghorn, R. M., Morrison, P., Lee, A. L., et al. (2000). A larger pool of ozone-forming carbon compounds in urban atmospheres. Nature 405, 778-781. doi: 10.1038/350 15540

Li, H., He, S., Ma, K., Wu, Q., Jiao, Q., and Sun, K. (2013). Micro-mesoporous composite molecular sieves H-ZSM-5/MCM-41 for methanol dehydration to dimethyl ether: effect of $\mathrm{SiO}_{2} / \mathrm{Al}_{2} \mathrm{O}_{3}$ ratio in H-ZSM-5 Appl. Catal. A-Gen. 450, 152-159. doi: 10.1016/j.apcata.2012.10.014

Li, L., Liu, S., and Liu, J. (2011). Surface modification of coconut shell based activated carbon for the improvement of hydrophobic VOC removal. J. Hazard. Mater. 192, 683-690. doi: 10.1016/j.jhazmat.2011.05.069

Li, N., Zhang, Y. Y., Chen, L., Au, C. T., and Yin, S. F. (2016). Synthesis and application of HZSM-5@silicalite-1 core-shell composites for the generation of light olefins from $\mathrm{CH}_{3} \mathrm{Br}$. Micropor. Mesopor. Mat. 227, 76-80. doi: 10.1016/j.micromeso.2016.02.017

Li, R., Xue, T., Bingre, R., Gao, Y., Louis, B., and Wang, Q. (2018). Microporous Zeolite@Vertically Aligned Mg-Al layered double hydroxide core@shell structures with improved hydrophobicity and toluene adsorption capacity under wet conditions. ACS Appl. Mater. Interfaces 10, 34834-34839. doi: $10.1021 /$ acsami.8b15118

Li, Y., and Yu, J. (2014). New stories of zeolite structures: their descriptions, determinations, predictions, and evaluations. Chem. Rev. 114, 7268-7316. doi: $10.1021 / \mathrm{cr} 500010 \mathrm{r}$

Okada, Y., Nakagoshi, A., Tsurukawa, M., Matsumura, C., Eiho, J., and Nakano, T. (2012). Environmental risk assessment and concentration trend of atmospheric volatile organic compounds in Hyogo Prefecture, Japan. Environ. Sci. Pollut. Res. 19, 201-213. doi: 10.1007/s11356-011-0550-0

Pan, D., Song, X., Yang, X., Gao, L., Wei, R., Zhang, J., et al. (2018). Efficient and selective conversion of methanol to para-xylene over stable $\mathrm{H}[\mathrm{Zn}, \mathrm{Al}] \mathrm{ZSM}-5 / \mathrm{SiO}_{2}$ composite catalyst. Appl. Catal. A-Gen. 557, 15-24. doi: 10.1016/j.apcata.2018.03.006

Qian, Q., Gong, C., Zhang, Z., and Yuan, G. (2015). Removal of VOCs by activated carbon microspheres derived from polymer: a comparative study. J. Loss Prevent. Proc. 21, 333-341. doi: 10.1007/s10450-015-9 673-9

Sang, Y., Liu, H., He, S., Li, H., Jiao, Q., Wu, Q., et al. (2013). Catalytic performance of hierarchical H-ZSM-5/MCM-41 for methanol dehydration to dimethyl ether. J. Energy Chem. 22, 769-777. doi: 10.1016/S2095-4956(13)60 102-3

Serrano, D. P., Calleja, G., Botas, J. A., and Gutierrez, F. J. (2004). Adsorption and hydrophobic properties of mesostructured MCM-41 and SBA-15 materials for volatile organic compound removal. Ind. Eng. Chem. Res. 43, 7010-7018. doi: $10.1021 /$ ie $040108 \mathrm{~d}$

Shen, Y., Fang, Q., and Chen, B. (2015). Environmental applications of threedimensional graphene-based macrostructures: adsorption, transformation, and detection. Environ. Sci. Technol. 49, 67-84. doi: 10.1021/es504 $421 \mathrm{y}$

Shen, Y., Wang, W., Liu, W., and Zhang, X. (2018). The preparation of $\mathrm{Fe}^{3+}$ ion-exchanged mesopore containing ZSM-5 molecular sieves and its high catalytic activity in the hydroxylation of phenol. J. Porous. Mat. 25, 1587-1595. doi: 10.1007/s10934-018-0572-9

Tanaka, S., Yuan, C., and Miyake, Y. (2008). Synthesis of silicalite-1 using an interspace of ordered mesoporous carbon-silica nanocomposites: introduction of mesoporosity in zeolite crystals. Micropor. Mesopor. Mat. 113, 418-426. doi: 10.1016/j.micromeso.2007.12.001

Tefera, D. T., Hashisho, Z., Philips, J. H., Anderson, J. E., and Nichols, M. (2014). Modeling competitive adsorption of mixtures of volatile organic compounds in a fixed-bed of beaded activated carbon. Environ. Sci. Technol. 48, 5108-5117. doi: $10.1021 / \mathrm{es} 404667 \mathrm{f}$

Wang, S., Zhang, L., Long, C., and Li, A. (2014). Enhanced adsorption and desorption of VOCs vapor on novel micro-mesoporous polymeric adsorbents. J. Colloid Interf. Sci. 428, 185-190. doi: 10.1016/j.jcis.2014.0 4.055

Witsarut, N., and Sirirat, J. (2016). Catalytic pyrolysis of waste tire using HY/MCM-41 core-shell composite. J. Anal. Nal. Appl. Pyrol. 121, 297-306. doi: 10.1016/j.jaap.2016.08.009

Xian, X., Ran, C., Yang, P., Chu, Y., Zhao, S., and Dong, L. (2018). Effect of the acidity of HZSM-5@MCM-41 hierarchical zeolite on its catalytic performance 
in supercritical catalytic cracking of n-dodecane- experiments and mechanism. Catal. Sci. Technol. 8, 4241-4256. doi: 10.1039/c8cy00908b

Zhang, X., Gao, B., Creamer, A. E., Cao, C., and Li, Y. (2017). Adsorption of VOCs onto engineered carbon materials: a review. J. Hazard. Mater. 338, 102-123. doi: 10.1016/j.jhazmat.2017.05.013

Zhang, Z., Jiang, Z., and Shangguan, W. (2016). Low-temperature catalysis for VOCs removal in technology and application: a state-of-the-art review. Catal. Today 264, 270-278. doi: 10.1016/j.cattod.2015.10.040

Zhao, X. S., Ma, Q., and Lu, G. Q. (1998). VOC Removal: Comparison of MCM41 with hydrophobic zeolites and activated carbon. Energ. Fuel. 12, 1051-1054. doi: $10.1021 /$ ef980113s
Conflict of Interest Statement: The authors declare that the research was conducted in the absence of any commercial or financial relationships that could be construed as a potential conflict of interest.

Copyright $\odot 2019$ Li, Chong, Altaf, Gao, Louis and Wang. This is an open-access article distributed under the terms of the Creative Commons Attribution License (CC $B Y)$. The use, distribution or reproduction in other forums is permitted, provided the original author(s) and the copyright owner(s) are credited and that the original publication in this journal is cited, in accordance with accepted academic practice. No use, distribution or reproduction is permitted which does not comply with these terms. 


\section{OPEN ACCESS}

Edited by:

Qiang Wang,

Beijing Forestry University, China

Reviewed by:

Brandon Yoza

University of Hawaii at Manoa,

United States

Wei Zhao,

Shenzhen University, China

*Correspondence:

Linhai Duan

Ihduan@126.com

Specialty section:

This article was submitted to

Inorganic Chemistry,

a section of the journal

Frontiers in Chemistry

Received: 22 May 2019

Accepted: 01 July 2019

Published: 16 July 2019

Citation:

Meng X, Lin C, Zhang Y, Qin H, Cao S and Duan L (2019) Mass Transfer

Behavior of Benzene in Hierarchically

Structured ZSM-5.

Front. Chem. 7:502.

doi: 10.3389/fchem.2019.00502

\section{Mass Transfer Behavior of Benzene in Hierarchically Structured ZSM-5}

\author{
Xiuhong Meng, Chunhui Lin, Youhua Zhang, Huibo Qin, Shui Cao and Linhai Duan* \\ Department of Chemical Engineering, Guangdong University of Petrochemical Technology, Maoming, China
}

A series of ZSM-5 zeolites with hierarchical porous structure were synthesized using $\mathrm{NaOH}$ solutions treatment method. The structural and acidity properties of hierarchical ZSM-5 zeolites as-synthesized were characterized by X-ray diffraction (XRD), $\mathrm{N}_{2}$ adsorption, scanning electron microscope (SEM), $\mathrm{NH}_{3}$-temperature programmed desorption (TPD), and pyridine Fourier transform infrared spectroscopy (Py-FTIR). The adsorption and diffusion performances of benzene in hierarchical ZSM-5 zeolites were studied by an intelligent gravimetric analyzer (IGA). It was found that mass transfer (adsorption and diffusion) performance of benzene was significantly affected by synergetic effect of hierarchical structure, acid amount, acidity, adsorption sites of ZSM-5 zeolites. After suitable alkali treatment, the crystal structure of ZSM-5 was retained and finely tailored. Hierarchical ZSM- 5 was obtained with a uniform size of mesoporous and microporous structure. Acidity of hierarchical ZSM-5 zeolites was improved, which produced more adsorption sites and thus increased the adsorption performance of benzene in hierarchical ZSM-5. As a result, connectivity in hierarchical ZSM-5 was improved with increasing of mesopores in hierarchical ZSM-5. Hierarchical ZSM-5 well-contributed to the adsorption performance of benzene on active sites and improved catalytic performance of hierarchical ZSM-5.

Keywords: alkali treatment, hierarchical porous, ZSM-5, adsorption, diffusion

\section{INTRODUCTION}

ZSM-5 are commonly used in industry due to the thermal stability and high surface area, appropriate pore size. ZSM-5 possesses unusual hydrophobicity, leading to potential applications in the separation of hydrocarbons from polar compounds, such as water and alcohols. These unique properties are responsible for their application as catalysts in many major chemical processes (Tang et al., 2006; Duan et al., 2013; Mu et al., 2013; Nandan et al., 2014; Hasan et al., 2015). The relatively narrow channels in ZSM-5, however, may lead to diffusion limitations for large reactant molecules. Several methods, such as synthesizing new zeolites with larger pores (Mu et al., 2013), synthesizing meso-microporous or micro-microporous composite zeolites (Corma, 2003; Christensen et al., 2007; Zhou et al., 2017), preparing smaller zeolite particles (Mitchell and Pérez-Ramírez, 2011), and modifying the pore structure of zeolites (Fernandez et al., 2010; Duan et al., 2012), have been proposed to overcome inherent diffusion limitations. Among these methods, desilication by innovative post-treatment method, has been extensively considered because that can enlarge the micropores of ZSM-5 slightly and shorten the diffusion path length of molecules in the micropores (Groen et al., 2006; Zhao et al., 2008; Chal et al., 2011; Lopez-Orozco et al., 2011; Sadowska et al., 2012; Mintova et al., 2013; Ma et al., 2019). This facilitates guest molecule to diffuse out of the ZSM-5 and form final liquid products rather than being adsorbed in the pores to form coke. 
As a consequence, it is highly needed to develop new materials with hierarchical architecture of porosity (van Donk et al., 2003;

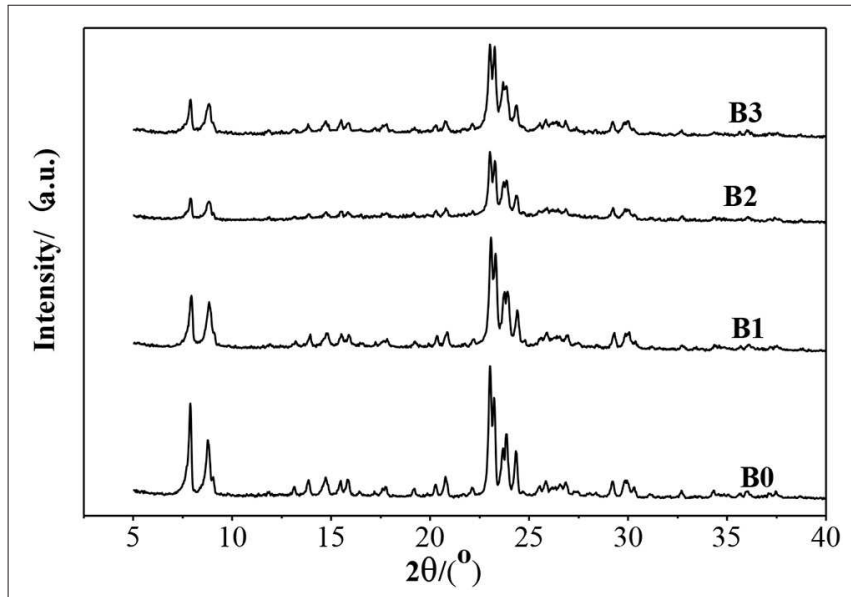

FIGURE 1 | XRD patterns of ZSM-5 and alkali-treatment zeolites.

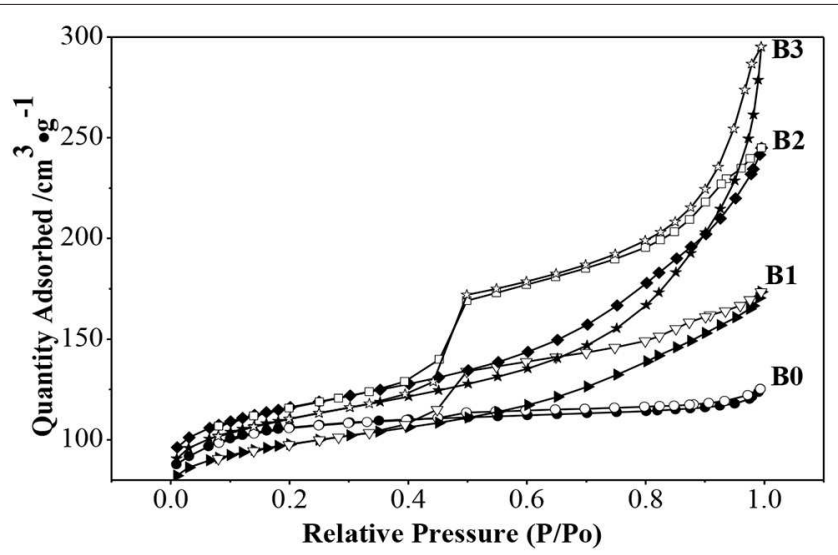

FIGURE 2 | $\mathrm{N}_{2}$ adsorption and desorption isotherms of alkali-treatment ZSM-5 at $-196^{\circ} \mathrm{C}$.

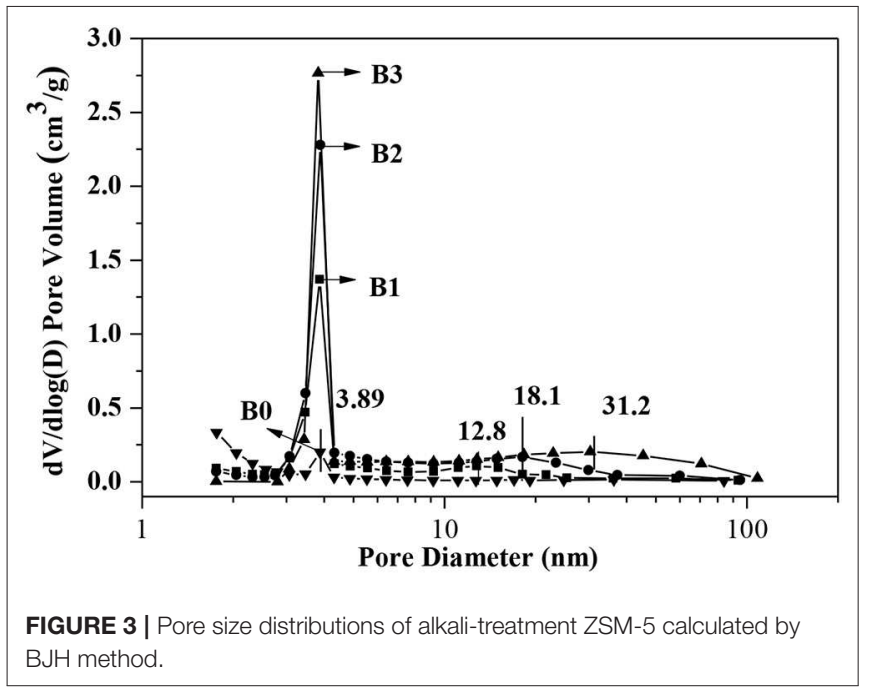

Ma et al., 2019). The large external surface provides more active sites, and moreover offers a short diffusion path for guest molecules (Mintova et al., 2013).

In order to improve the catalyst efficiency in chemical reactions, desilication by alkali-treatment was found to be a very effective and reproducible method for preparation of mesoporous zeolites without significant damages both in crystallinity and acidity (Groen et al., 2006; Chal et al., 2011; Lopez-Orozco et al., 2011). Previous studies showed that desilication of ZSM-5 can improve the accessibility of acid sites in zeolites, and results in redistribution of the framework $\mathrm{Al}$ atoms (Sadowska et al., 2012). Meanwhile, the diffusion capability of large molecules in zeolites channels can also be improved by the introduction of mesoporosity, which has been indirectly proven by enhanced catalytic performance. Zhao et al. (2008) reported that both the adsorption amount and the adsorption rate increased outstandingly in the mesopore structured ZSM-5 generated by alkali-treatment compared with the parent ZSM5. It was found that conversion of cumene in mesopore ZSM-5 catalyst has increased a lot compared with the conventional ZSM5 catalysts. These findings indicate that the catalytic selectivity, conversion rate are very relevant to the diffusion behavior in the zeolite. However, the relationship between the diffusion mechanism and adsorption sites is not well-understood. Ogura et al. (2001) proposed that the treated ZSM-5 in NaOH alkali solution can change the structure and acidic properties of ZSM5. The mesopores with a uniform size can be formed on the zeolite, while the microporous structure remained. The acidic property has very little change quantitatively or qualitatively, even though the catalytic activity for cracking of cumene was enhanced by the alkali-treatment due to that the adsorptive and diffusive performance of cumene are increased by the creation of mesopores in microporous ZSM-5.

Benzene, which can be synthesized to a series of derivatives of benzene, is very important to make chemical raw materials. Benzene is an important product in petrochemical industry for increasing aromatics production and octane number of gasoline. In this study, benzene was selected to study the mass transfer performance in hierarchically structured ZSM-5. However, the diffusion mechanism of aromatic hydrocarbons that result in increased catalytic conversion is not well-understood. Furthermore, the adsorption dynamic and thermodynamic such as the activation energy and adsorption heat, which are helpful in understanding the diffusion process and the catalytic performance, are not available for hierarchically ZSM-5. Our group has studied the adsorption property of several samples in

TABLE 1 | Chemical and physical properties of hierarchically ZSM-5.

\begin{tabular}{lcccccc}
\hline Sample & $\mathbf{D}_{\text {aver }}$ & $\mathbf{S}_{\text {BET }}$ & $\mathbf{S}_{\text {mic }}$ & $\mathbf{S}_{\text {Ext }}$ & $\mathbf{V}_{\mathbf{P}}$ & $\mathbf{V}_{\text {meso }}$ \\
\cline { 2 - 6 } & $\mathbf{n m}$ & $\mathbf{m}^{\mathbf{2}} / \mathbf{g}$ & $\mathbf{m}^{\mathbf{2}} \mathbf{g}$ & $\mathbf{m}^{\mathbf{2}} \mathbf{g}$ & $\mathbf{c m}^{\mathbf{3}} \mathbf{g}$ & $\mathbf{c m}^{\mathbf{3}} \mathbf{g}$ \\
\hline B0 & 2.85 & 327 & 212 & 115 & 0.194 & 0.080 \\
B1 & 4.59 & 306 & 189 & 118 & 0.268 & 0.168 \\
B2 & 5.27 & 367 & 212 & 155 & 0.379 & 0.267 \\
B3 & 6.62 & 350 & 201 & 149 & 0.456 & 0.350
\end{tabular}


zeolites and corresponding research (Meng et al., 2009; Sui et al., 2013; Qin et al., 2014a,b).

Hence, in this contribution we aims to reveal the intrinsic correlation between the mass transfer performance of benzene on hierarchical ZSM-5 and adsorption sites, as well as adsorption sites and acidic characteristics by using a high precision

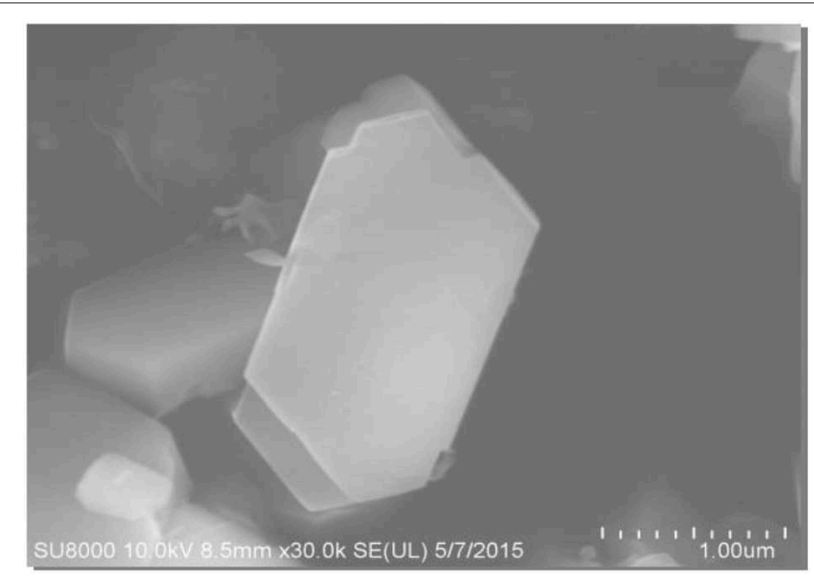

FIGURE 4 | SEM of fresh ZSM-5.

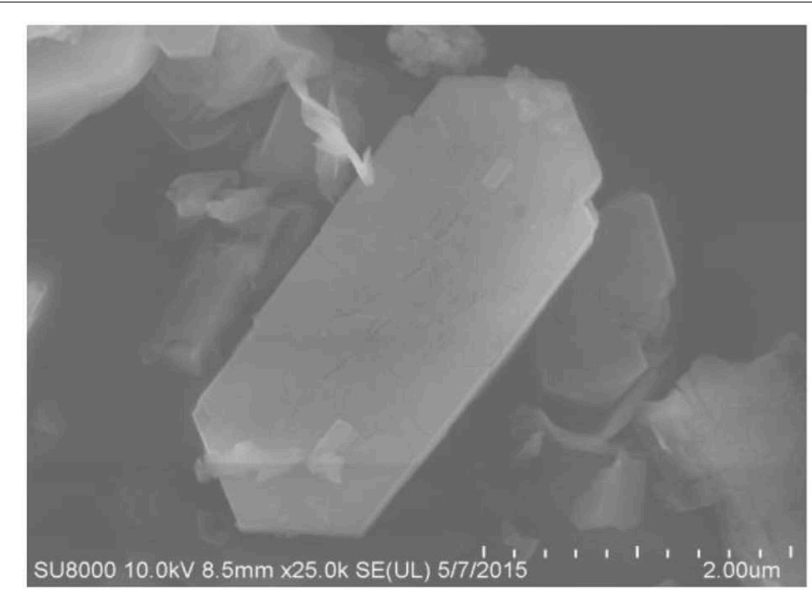

FIGURE 5 | SEM of alkali-treatment ZSM-5. intelligent gravimetric analyzer (IGA), pyridine adsorption Fourier-transform infrared spectroscopy (pyridine-IR) with hierarchical ZSM-5 as adsorbent and benzene as adsorbate.

\section{EXPERIMENT}

\section{Preparation of Mesoporous Zeolites}

Commercially available NaZSM-5 zeolite was used as parent material prepared by hydrothermal synthesis method. HZSM5 prepared by ion exchange with $\left(\mathrm{NH}_{4}\right)_{2} \mathrm{SO}_{4}$ aqueous solution was designated as "B0" in this work. Three groups were chosen as representative samples by orthogonal experiment design method. Group I was treated with $0.2 \mathrm{~mol} / \mathrm{L} \mathrm{NaOH}$ at $343 \mathrm{~K}$ for $3 \mathrm{~h}$. Group II was treated with $0.25 \mathrm{~mol} / \mathrm{L} \mathrm{NaOH}$ at $343 \mathrm{~K}$ for $4 \mathrm{~h}$. Group III was treated with $0.4 \mathrm{~mol} / \mathrm{L} \mathrm{NaOH}$ at $363 \mathrm{~K}$ for $5 \mathrm{~h}$. Firstly, conventional ZSM-5 was mixed with a series of $\mathrm{NaOH}$ aqueous solutions. After a certain period of alkali treatment, the slurry was cooled rapidly to room temperature in an ice bath, filtered and washed with distilled water until a neutral $\mathrm{pH}$ of filtrate was obtained. The remaining solid was dried in $393 \mathrm{~K}$ for $10 \mathrm{~h}$.

Alkali-treated NaZSM-5 was exchanged with $\left(\mathrm{NH}_{4}\right)_{2} \mathrm{SO}_{4}$ aqueous solution, followed by filtering and rinsing with distilled water to remove sodium ions. This procedure was repeated twice to obtain $\mathrm{NH}_{4} \mathrm{ZSM}-5$. After drying at $393 \mathrm{~K}$ for $10 \mathrm{~h}$,

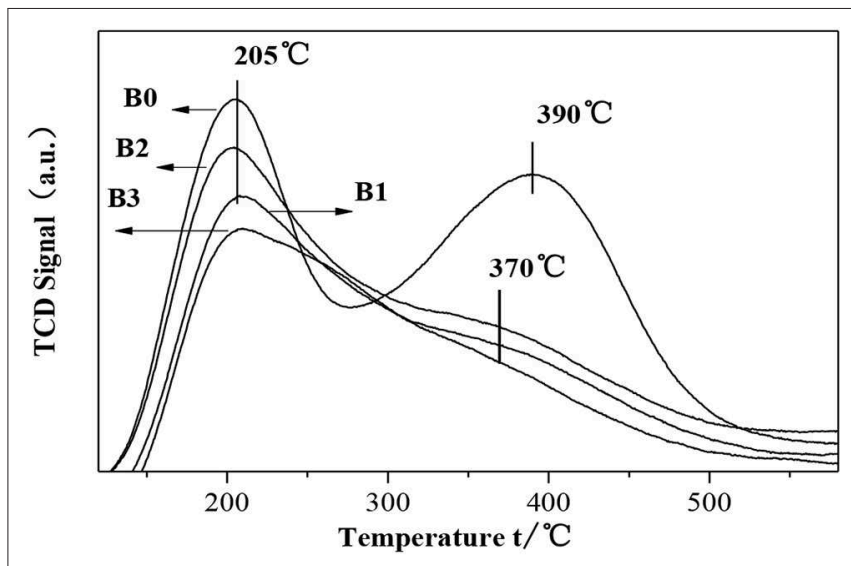

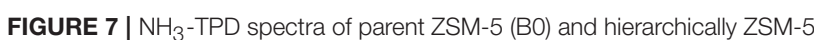
(B1, B2, B3).
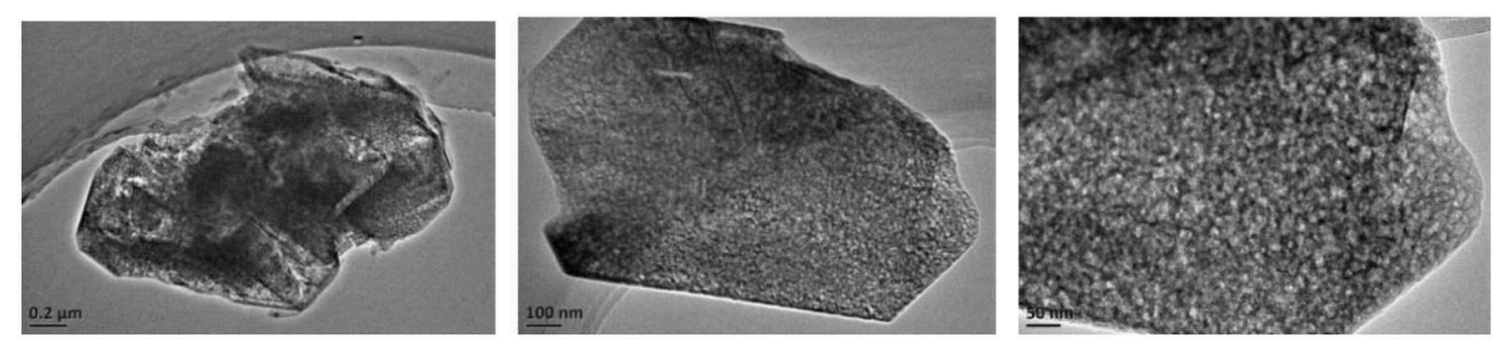

FIGURE 6 | TEM of alkali-treatment ZSM-5. 
$\mathrm{NH}_{4} \mathrm{ZSM}-5$ was calcined in static air at $823 \mathrm{~K}$ for $5 \mathrm{~h}$ to form the HZSM-5. These $\left(\mathrm{NH}_{4}\right)_{2} \mathrm{SO}_{4}$ treatment samples obtained at different conditions were designated by B1 [temperature $343 \mathrm{~K}$, time $3 \mathrm{~h},\left(\mathrm{NH}_{4}\right)_{2} \mathrm{SO}_{4}$ concentration $0.2 \mathrm{M}$ ], B2 [temperature $343 \mathrm{~K}$, time $4 \mathrm{~h}, \quad\left(\mathrm{NH}_{4}\right)_{2} \mathrm{SO}_{4}$ concentration $\left.0.25 \mathrm{M}\right], \quad \mathrm{B} 3$ [temperature $363 \mathrm{~K}$, time $5 \mathrm{~h}, \quad\left(\mathrm{NH}_{4}\right)_{2} \mathrm{SO}_{4}$ concentration $0.4 \mathrm{M}]$, respectively.

\section{Characterization}

The crystallinity of parent ZSM-5 and hierarchically ZSM-5 was characterized by X-ray diffraction. XRD measurements were taken in a XRD-6000 using $\mathrm{Cu} \kappa \alpha$ radiation at $100 \mathrm{~mA}$ and
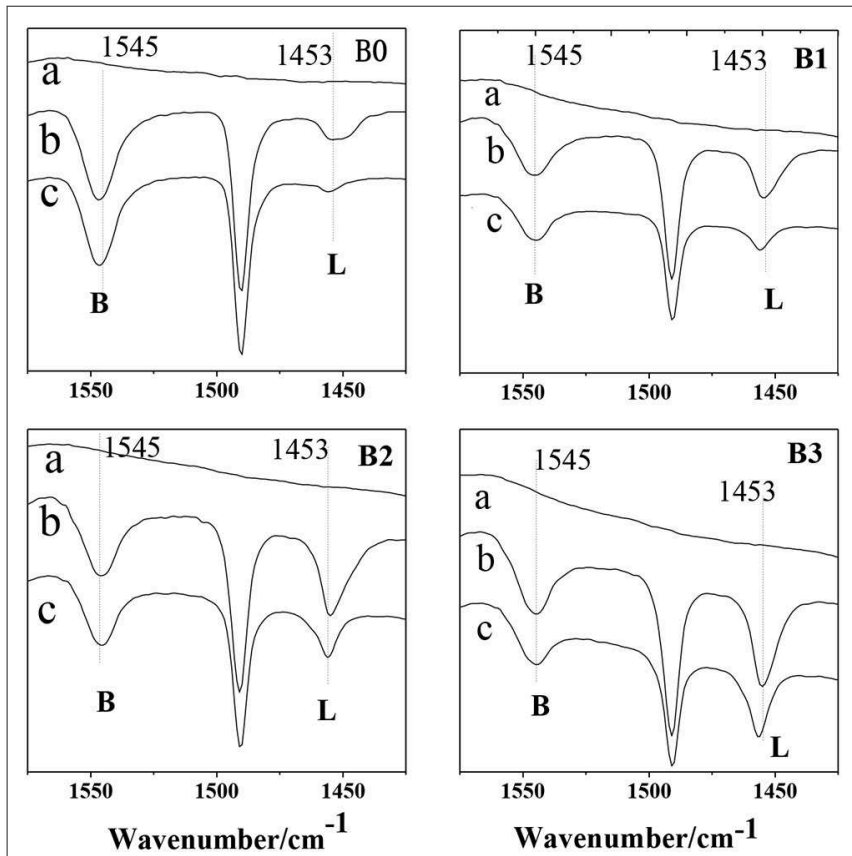

FIGURE 8 | Py-FTIR spectra of parent ZSM-5 (B0), hierarchically ZSM-5 (B1, B2, B3) at different temperatures. (a): background; (b): $150^{\circ} \mathrm{C}$; (c): $400^{\circ} \mathrm{C}$.

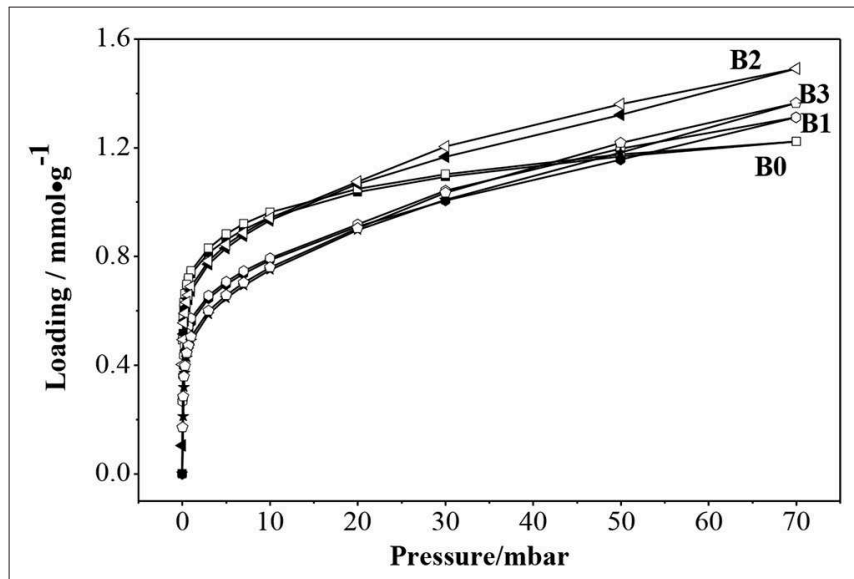

FIGURE 9 | Adsorption isotherms of benzene on fresh ZSM-5 and hierarchically ZSM-5 at $30^{\circ} \mathrm{C}$.
$30 \mathrm{mV} . \mathrm{N}_{2}$ adsorption/desorption isotherms were recorded on a Quanta chrome Autosorb Automated Gas Sorption analyzer ASAP2020 at $77 \mathrm{~K}$. The mesoporous volume and specific surface were evaluated by the t-plot method. The total surface area was calculated according to BET isotherms.

Temperature-programmed $\mathrm{NH}_{3}$ desorption $\left(\mathrm{NH}_{3}-\mathrm{TPD}\right)$ was measured by an automatic chemical adsorption instrument, aiming to investigate acidity distribution. The nature of acid sites was investigated using pyridine as the probe molecule. The FTIR spectra of pyridine adsorption were recorded using an FTIR spectrometer.

\section{RESULTS AND DISCUSSION}

\section{Textural and Features of the Alkali-Treated ZSM-5}

XRD (Figure 1) showed that the ZSM-5 structure was wellretained after alkali-treatment, but the intensity of most peaks decrease slightly, indicating that alkali-treatment did not destroy the crystal structure of ZSM-5, but the structure was finely modulated.

$\mathrm{N}_{2}$ adsorption isotherms and pores-size distribution curves of the samples are shown in Figures 2, 3 respectively. The hysteresis loop of the isotherm changed with different alkali-treatment conditions. $\mathrm{N}_{2}$ isotherms (Figure 2) clearly show that all the isotherms exhibit type IV, which are the typical characteristics of mesoporous materials (Verboekend and Pérez-Ramírez, 2011). The BET surface area data as well as the micro-and mesoporous volume determined by a t-plot method were shown in Table 1. Remarkably, the specific surface area of the alkali-treatment ZSM-5 showed an increasing trend and the mesoporous volume increased from 0.08 to $0.35 \mathrm{~cm}^{3} / \mathrm{g}$. This increase is due to the creation of the mesoporous with a slight decrease in the microspore volume $\left(0.114\right.$ vs. $0.106 \mathrm{~cm}^{3} / \mathrm{g}$ for fresh $\mathrm{H}-\mathrm{ZSM}$ 5 and hierarchically $\mathrm{H}-\mathrm{ZSM}-5$, respectively). The decrease in micropore volume was caused by desilication of ZSM-5 and thus induced the minor amorphization in the process of alkali-treatment (Verboekend et al., 2011). XRD patterns results showed the hierarchically structured ZSM-5 can be obtained by alkali-treatment methods while preserving the MFI micropore structure.

The SEM and TEM images of these samples are shown in Figures 4-6, respectively. The morphology of ZSM-5 is rectangular or hexagonal (Figure 4). With increase of the concentration of $\mathrm{NaOH}, \mathrm{ZSM}-5$ can still maintain its crystal structure, which is in accordance with the XRD results. The magnified SEM image shows that it has a mesoporous-like morphology, which is in accordance with the $\mathrm{N}_{2}$ adsorptiondesorption results.

\section{Effect of Alkali Treatment on Acidic Properties of ZSM-5}

The $\mathrm{NH}_{3}$-TPD results of fresh HZSM-5 and hierarchically HZSM-5 are shown in Figure 7. We can see that the desorption profiles of parent H-ZSM-5 shows two maxima, which are 
at 207 and $390^{\circ} \mathrm{C}$, respectively. The first maxima belongs to the weakly absorbed $\mathrm{NH}_{3}$ molecules, whereas the second one originates from $\mathrm{B}$ acid sites. In case of hierarchically HZSM5 , the strong acid sites are more pronounced than that in parent H-ZSM-5.

Figure 8 show the FITR spectra of HZSM-5 samples after desorption at difference temperatures. The adsorption at 1,545 and $1,453 \mathrm{~cm}^{-1}$ are assigned to the $B$ and $L$ acid sites, respectively. Apparently, a large number of $\mathrm{L}$ acid sites are formed in the zeolites after desilication. The results reveals that the weak acidity observed in $\mathrm{NH}_{3}$-TPD (Figure 7) has a clear Lewis nature and can be ascribed to $\mathrm{Al}$ in extraframework of hierarchically ZSM-5, which is produced during desilication. In summary, it can safely say that the higher the alkali concentration is, the stronger the Lewis acidity. For the hierarchically HZSM5 (B1, B2, B3), the acidity of B2 sample is the largest, which can provide more adsorption sites for molecular diffusion in hierarchically ZSM-5.

\section{Adsorption, Diffusion of Benzene on Hierarchically Structured ZSM-5}

Figure 9 showed the adsorption isotherms of benzene at $30^{\circ} \mathrm{C}$ in ZSM-5 (B0) and hierarchically ZSM-5 (B1, B2, B3). The isotherm of ZSM-5 showed typical Langmuir Type-I adsorption, which reached saturation at low pressure and increased slightly with further increase of pressure. The isotherms in hierarchically ZSM-5 (B1, B2, B3) showed hysteresis loops which are different from the isotherms in B0. It can be seen that the adsorption amount of benzene in B2 is higher than that in B1 and B3, the

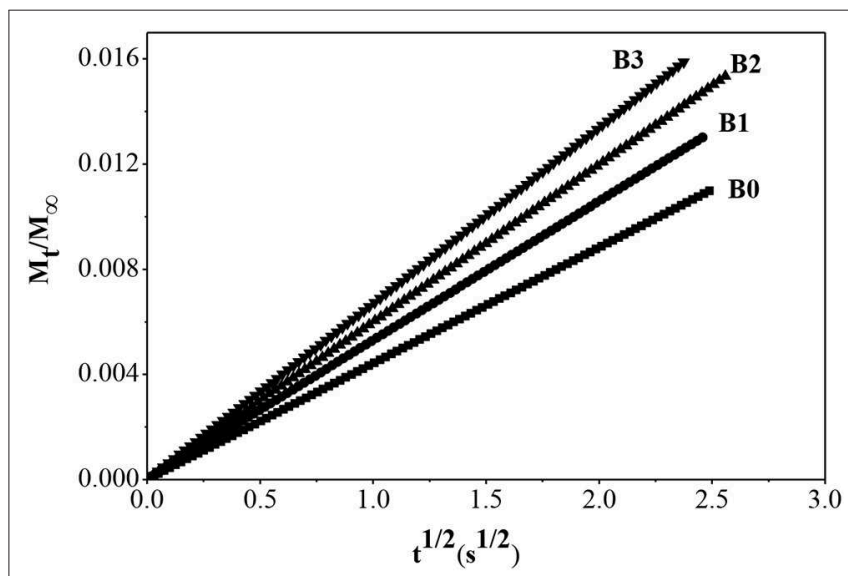

FIGURE 11 | Adsorption rate curve of benzene molecule in fresh ZSM-5 and hierarchically ZSM- 5 at $30^{\circ} \mathrm{C}$.
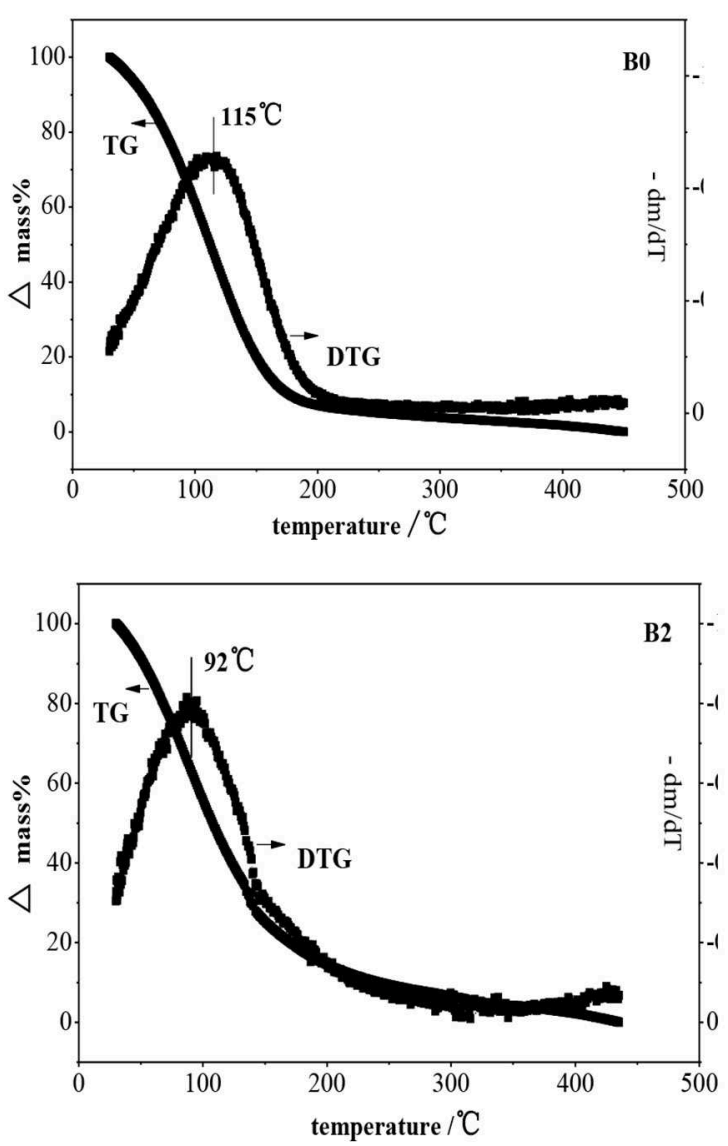
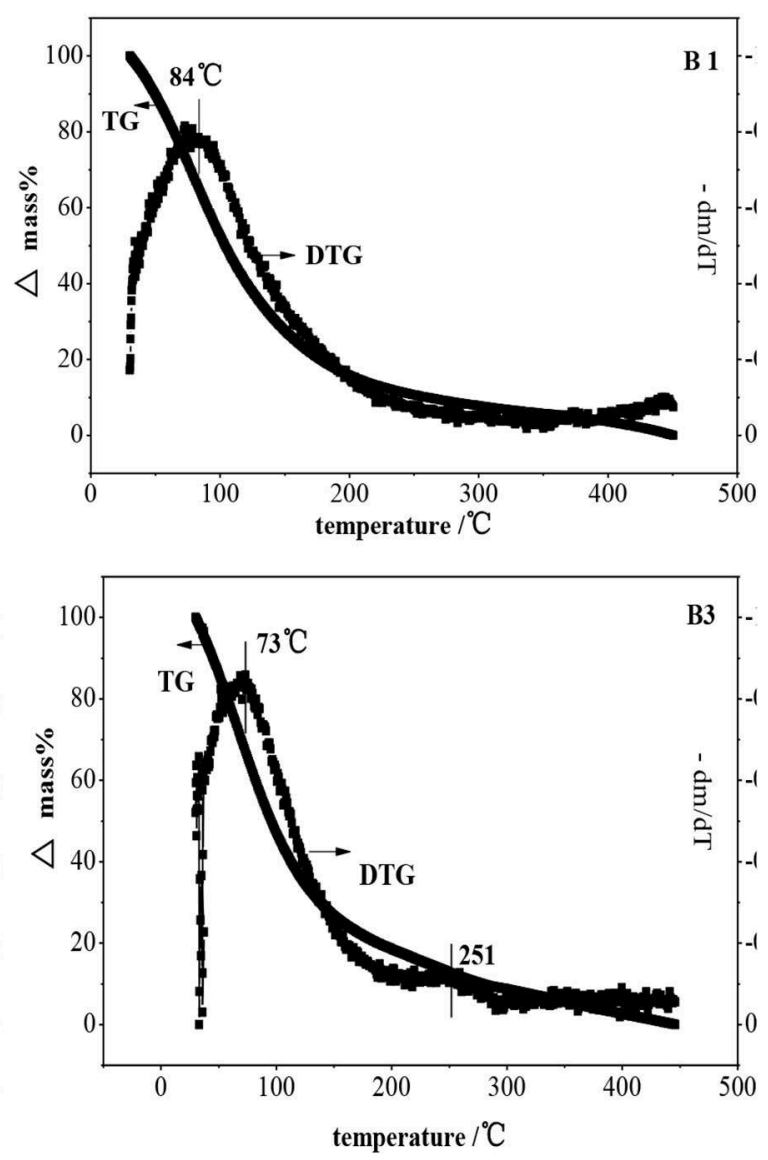

FIGURE 10 | Temperature programmed desorption of benzene in ZSM-5 and hierarchically ZSM-5. 
TABLE 2 | Diffusion time constants of benzene on ZSM-5 zeolites and hierarchically $\mathrm{ZSM}-5$ at $30^{\circ} \mathrm{C}$.

\begin{tabular}{lcccc}
\hline \multicolumn{5}{c}{$\mathbf{D} / \mathbf{r}^{\mathbf{2}}\left(\mathbf{S}^{-\mathbf{1}}\right)$} \\
Sample & B0 & B1 & B2 & B3 \\
Benzene & $4.21 \times 10^{-3}$ & $6.05 \times 10^{-3}$ & $7.76 \times 10^{-3}$ & $9.68 \times 10^{-3}$ \\
\hline
\end{tabular}

reason may be that the specific surface area of micro-mesoporous in $\mathrm{B} 2$ is higher than that in B1 and B3. The adsorption amount of benzene in $\mathrm{B} 2$ continued to increase with the increasing pressure. The obvious hysteresis loop in the adsorption and desorption isotherm was mainly caused by the capillary condensation of porous adsorbent.

It can be seen that the adsorption sites is increased in hierarchically ZSM-5 according to the benzene adsorption amount. The highest value of $\mathrm{S}_{\text {meso, }}$ as well as the highest total volume was obtained for B2. Benzene molecule prefers to adsorbe on the effective adsorption sites, which in accordance with the largest acid amount of B2. Although B3 has a broader mesoporous distribution, it initially promotes benzene molecules to enter its pore channels. When enough benzene molecules are adsorbed in the effective adsorption sites, the hierarchically ZSM-5 cannot accommodate more molecules due to the interaction forces between molecules and pore walls. So the adsorption performance of benzene on hierarchical ZSM-5 was correlated not only with the acidity of ZSM-5, but also with hierarchical structure.

The temperature programmed desorption of benzene in ZSM-5 and hierarchically ZSM-5 is shown in Figure 10. It can be seen that only one desorption peak is showed in the Derivative Thermogravimetry (DTG) curve of benzene in ZSM5 , suggesting that there is only one interaction mode between benzene and ZSM-5 before and after alkali-treatment. Benzene can be completely desorbed before $200^{\circ} \mathrm{C}$, indicating that the adsorption interaction belongs to physical adsorption (the van der Waals force) between benzene molecule and ZSM-5, which is relatively weak interaction. Compared with the hierarchically ZSM-5 zeolite, the parent ZSM-5 has stronger acidic center and larger acidity amount, i.e., more adsorption sites and larger interaction force, so the desorption temperature is relatively high. Moreover, the adsorption diffusion rate in parent ZSM-5 is the smallest. Because there is no much mesoporous and catalytic adsorption sites in it, the diffusion path is easily blocked.

With the increase of alkali concentration for preparing hierarchically ZSM-5, partial $\mathrm{Al}$ atoms can be removed from the framework of ZSM-5, which is adsorbed on the surface of hierarchically ZSM-5, and thus provided more L acid sites. Meanwhile, the mesopores and pore volume increased gradually, which provided more effective adsorption sites for benzene molecules and shortened the diffusion path. The adsorption kinetics of benzene molecule in fresh ZSM-5 and hierarchically ZSM-5 at $30^{\circ} \mathrm{C}$ are showed in Figure 11, and the diffusion time constants is showed in Table 2. It can be seen that the diffusion rate of benzene in hierarchically ZSM-5 increased significantly. B3 has more mesopores and pore volume in these three kinds of hierarchically ZSM-5 as synthesized, which provides a fast adsorption and diffusion path for benzene diffusion.
And thus, benzene has the largest adsorption capacity and the fastest diffusion rate in B3. While, the TG-DTG curve shows that the interaction force between benzene molecule and B3 is the smallest, suggesting that the adsorption and diffusion performance of benzene is not only depended on the structure of hierarchically ZSM-5 but also related to the effective adsorption sites in its channels. The TG-DTG curves of B2 show that the desorption temperature of $\mathrm{B} 2$ is highest in these three kinds of hierarchically ZSM-5, implying that the interaction force is greatest in B2. The percentages of mesopores in B2 is lower than $\mathrm{B} 3$, and so its micro-mesoporous connectivity is poorer than B3, so the diffusion time constant of benzene in B2 is smaller than that in B3. These results also imply that adsorption and diffusion performance of benzene is not only related to the connectivity of channels in hierarchically ZSM-5, but also depend on effective adsorption sites in it.

\section{CONCLUSION}

The hierarchically ZSM-5 with good connectivity was successfully synthesized by alkali treatment method. With the increase of alkali concentration, the mesoporous volume and surface area in hierarchically ZSM-5 gradually enhanced, and the adsorption surface area correspondingly increased, which reduced the diffusion resistance of molecules in the pore channels of hierarchically ZSM-5. By investigating the adsorption and diffusion properties of benzene in hierarchically ZSM-5, we can safely conclude that the adsorption capacity and diffusion rate in hierarchically ZSM-5 are not only related to the hierarchically pore structure, but also depended on the effective adsorption sites. Hierarchically ZSM-5 with high acidity has more effective adsorption sites and better performances, which are conducive to the adsorption and diffusion performances of benzene molecules. The good connectivity in hierarchical ZSM-5 improved the mass transfer performances of benzene, which was beneficial to the catalytic performance of ZSM-5 catalyst efficiently.

\section{DATA AVAILABILITY}

All datasets generated for this study are included in the manuscript/supplementary files.

\section{AUTHOR CONTRIBUTIONS}

All authors listed have made a substantial, direct and intellectual contribution to the work, and approved it for publication.

\section{FUNDING}

The financial supports received from the Natural Science Foundation of Guangdong province (Catalyst design and reaction mechanism of simultaneous removal of NOx and PM under lean combustion condition) and National Natural Science Foundation of China (No. 21476101) are gratefully acknowledged. 


\section{REFERENCES}

Chal, R., Gérardin, C., Bulut, M., and van Donk, S. (2011). Overview and industrial assessment of synthesis strategies towards zeolites with mesopores. ChemCatChem 3, 67-81. doi: 10.1002/cctc.201000158

Christensen, C. H., Johannsen, K., Törnqvist, E., Schmidt, I., Topsøe, H., and Christensen, C. H. (2007). Mesoporous zeolite single crystal catalysts: diffusion and catalysis in hierarchical zeolites. Catal. Today 128, 117-122. doi: 10.1016/j.cattod.2007.06.082

Corma, A. (2003). State of the art and future challenges of zeolites as catalysts. J. Catal. 216, 298-312. doi: 10.1016/S0021-9517(02)00132-X

Duan, L. H., Dong, X. Y., Wu, Y. Y., Li, H. L., Wang, L., and Song, L. J. (2013). Adsorption and diffusion properties of xylene isomers and ethylbenzene in metal-organic framework MIL-53(Al). J. Porous Mat. 20, 431-440. doi: 10.1007/s10934-012-9612-z

Duan, L. H., Meng, X. H., Wang, Q., Zhang, X. T., and Song, L. J. (2012). Adsorption, co-adsorption and reactions of sulfur compounds, aromatics, and olefins over Ce-exchanged Y zeolites. J. Phys. Chem. C 116, 25748-25756. doi: $10.1021 /$ jp $303040 \mathrm{~m}$

Fernandez, C., Stan, I., Gilson, J. P., Thomas, K., Vicente, A., Bonilla, A., et al. (2010). Hierarchical ZSM-5 zeolites in shape-selective xylene isomerization: role of mesoporosity and acid site speciation. Chem. Eur. J. 16, 6224-6233. doi: $10.1002 /$ chem. 200903426

Groen, J. C., Moulijn, J. A., and Pérez-Ramírez, J. (2006). Desilication: on the controlled generation of mesoporosity in MFI zeolites. J. Mater. Chem. 16, 2121-2131. doi: 10.1039/B517510K

Hasan, Z., Jun, J. W., Kim, C. U., Jeong, K. E., Jeong, S. Y., and Jhung, S. H. (2015). Desilication of ZSM-5 zeolites for mesoporosity development using microwave irradiation. Mater. Res. Bull. 61, 469-474. doi: 10.1016/j.materresbull.2014.10.058

Lopez-Orozco, S., Inayat, A., Schwab, A., Selvam, T., and Schwieger, W. (2011). Zeolitic materials with hierarchical porous structures. Adv. Mater. 23, 2602-2615. doi: 10.1002/adma.201100462

Ma, Z., Fu, T. J., Wang, Y. J., Shao, J., Ma, Q., Zhang, C. M., et al. (2019). Silicate-1 derivational desilication-recrystallization to prepare hollow nano-ZSM-5 and highly mesoporous micro-ZSM-5 catalyst for Methanol to hydrocarbons. Ind. Eng. Chem. Res. 58, 2146-2158. doi: 10.1021/acs.iecr.8b03858

Meng, X. H., Duan, L. H., Wang, Q., Chung, J. S., Song, L. J., and Sun, Z. L. (2009). Thermodynamics and kinetics study on the adsorption and diffusion of P-xylene in Silicalite-1. J. Non-Equil. Thermodyn. 34, 35-45. doi: 10.1515/JNETDY.2009.002

Mintova, S., Gilson, J. P., and Valtchev, V. (2013). Advances in nanosized zeolites. Nanoscale 5, 6693-6703. doi: 10.1039/c3nr01629c

Mitchell, S., and Pérez-Ramírez, J. (2011). Mesoporous zeolites as enzyme carriers: synthesis, characterization, and application in biocatalysis. Catal. Today 168, 28-37. doi: 10.1016/j.cattod.2010.10.058

Mu, X. H., Wang, D. Z., Wang, Y. R., Lin, M., Cheng, S. B., and Shu, X. T. (2013). Nanosized molecular sieves as petroleum refining and petrochemical catalysts. Chin. J. Catal. 34, 69-79. doi: 10.1016/S1872-2067(11)60462-2

Nandan, D., Saxena, S. K., and Nagabhatla, V. (2014). Synthesis of hierarchical ZSM-5 using glucose as a templating precursor. J. Mater. Chem. A 2, 1054-1059. doi: $10.1039 /$ C3TA13904B
Ogura, M., Shinomiya, S., Tateno, J., Nara, Y., Nomura, M., Kikuchi, E., et al. (2001). Alkali-treatment technique-new method for modification of structural and acid-catalytic properties of ZSM-5 zeolites. Appl. Catal. A Gen. 219, 33-43. doi: 10.1016/S0926-860X(01)00645-7

Qin, Y. C., Gao, X. H., Duan, L. H., Fan, Y. C., Yu, W. G., Zhang, H. T., et al. (2014a). Effects on adsorption desulfurization of $\mathrm{CeY}$ zeolites: acid catalysis and competitive adsorption. Acta Phys. Chim. Sin. 30, 544-550. doi: 10.3866/PKU.WHXB201401021

Qin, Y. C., Mo, Z. S., Yu, W. G., Dong, S. W., Duan, L. H., Gao, X. H., et al. (2014b). Adsorption behaviors of thiophene, benzene, and cyclohexene on FAU zeolites: comparison of $\mathrm{CeY}$ obtained by liquid-, and solid-state ion exchange. Appl. Surf. Sci. 292, 5-15. doi: 10.1016/j.apsusc.2013.11.036

Sadowska, K., Góra-Marek, K., and Datka, J. (2012). Hierarchic zeolites studied by IR spectroscopy: acid properties of zeolite ZSM-5 desilicated with $\mathrm{NaOH}$ and $\mathrm{NaOH} /$ tetrabutylamine hydroxide. Vib. Spectrosc. 63, 418-425. doi: 10.1016/.jvibspec.2012.09.007

Sui, P. P., Meng, X. H., Wu, Y. Y., Zhao, Y. Y., Song, L. J., Sun, Z. L., et al. (2013). Adsorption and diffusion of benzene and thiophene over Y/MCM-41 composite zeolite. Sci. Adv. Mater. 5, 1132-1138. doi: 10.1166/sam.2013.1564

Tang, K., Wang, Y. G., Song, L. J., Duan, L. H., Zhang, X. T., and Sun, Z. L. (2006). Carbon nanotube templated growth of nano-crystalline ZSM-5 and $\mathrm{NaY}$ zeolites. Mater. Lett. 60, 2158-2160. doi: 10.1016/j.matlet.2005.12.088

van Donk, S., Janssen, A. H., Bitter, J. H., and de Jong, K. P. (2003). Generation, characterization, and impact of mesopores in zeolite catalysts. Catal. Rev. 45 297-319. doi: 10.1081/CR-120023908

Verboekend, D., Mitchell, S., Milina, M., Groen, J. C., and Pérez-Ramírez, J. (2011). Full compositional flexibility in the preparation of mesoporous MFI zeolites by desilication. J. Phys. Chem. C 115, 14193-14203. doi: 10.1021/jp20 1671 s

Verboekend, D., and Pérez-Ramírez, J. (2011). Desilication mechanism revisited: highly mesoporous all-silica zeolites enabled through pore-directing agents. Chem. Eur. J. 17, 1137-1147. doi: 10.1002/chem.201002589

Zhao, L., Shen, B. J., Gao, J. S., and Xu, C. M. (2008). Investigation on the mechanism of diffusion in mesopore structured ZSM-5 and improved heavy oil conversion. J. Catal. 258, 228-234. doi: 10.1016/j.jcat.2008. 06.015

Zhou, F., Gao, Y., Wu, G., Ma, F. W., and Liu, C. T. (2017). Improved catalytic performance and decreased coke formation in post-treated ZSM-5 zeolites for methanol aromatization. Micropor. Mesopor. Mat. 240, 96-107. doi: 10.1016/j.micromeso.2016.11.014

Conflict of Interest Statement: The authors declare that the research was conducted in the absence of any commercial or financial relationships that could be construed as a potential conflict of interest.

Copyright $\odot 2019$ Meng, Lin, Zhang, Qin, Cao and Duan. This is an open-access article distributed under the terms of the Creative Commons Attribution License (CC $B Y)$. The use, distribution or reproduction in other forums is permitted, provided the original author(s) and the copyright owner(s) are credited and that the original publication in this journal is cited, in accordance with accepted academic practice. No use, distribution or reproduction is permitted which does not comply with these terms. 


\section{OPEN ACCESS}

Edited by:

Qiang Wang,

Beijing Forestry University, China

Reviewed by:

Peng Lu,

Ningbo University, China Yongming Luo,

Kunming University of Science and

Technology, China

*Correspondence:

Wha-Seung Ahn

whasahn@inha.ac.kr

Specialty section:

This article was submitted to Green and Sustainable Chemistry,

a section of the journal

Frontiers in Chemistry

Received: 09 May 2019

Accepted: 04 July 2019

Published: 17 July 2019

Citation:

Park MB, Park ED and Ahn W-S (2019) Recent Progress in Direct Conversion of Methane to Methanol

Over Copper-Exchanged Zeolites.

Front. Chem. 7:514.

doi: 10.3389/fchem.2019.00514

\section{Recent Progress in Direct}

\section{Conversion of Methane to Methanol Over Copper-Exchanged Zeolites}

\author{
Min Bum Park ${ }^{1}$, Eun Duck Park ${ }^{2}$ and Wha-Seung Ahn ${ }^{3 *}$ \\ ${ }^{1}$ Innovation Center for Chemical Engineering, Department of Energy and Chemical Engineering, Incheon National University, \\ Incheon, South Korea, ${ }^{2}$ Department of Chemical Engineering and Department of Energy Systems Research, Ajou University, \\ Suwon, South Korea, ${ }^{3}$ Department of Chemistry and Chemical Engineering, Inha University, Incheon, South Korea
}

The conversion of methane into an easily transportable liquid fuel or chemicals has become a highly sought-after goal spurred by the increasing availability of cheap and abundant natural gas. While utilization of methane for the production of syngas and its subsequent conversion via an indirect route is typical, it is cost-intensive, and alternative direct conversion routes have been investigated actively. One of the most promising directions among these is the low-temperature partial oxidation of methane to methanol over a metal-loaded zeolite, which mimics facile enzymatic chemistry of methane oxidation. Thus mono-, bi-, and trinuclear oxide compounds of iron and copper stabilized on ZSM-5 or mordenite, which are structurally analogous to those found in methane monooxygenases, have demonstrated promising catalytic performances. The two major problems of theses metal-loaded zeolites are low yield to methanol and batch-like non-catalytic reaction systems challenging to extend to an industrial scale. In this mini-review, attention was given to the direct methane oxidation to methanol over copper-loaded zeolite systems. A brief introduction on the catalytic methane direct oxidation routes and current status of the applied metal-containing zeolites including the ones with copper ions are given. Next, by analyzing the extensive experimental and theoretical data available, the consensus among the researchers to achieve the target of high methanol yield is discussed in terms of zeolite topology, active species, and reaction parameters. Finally, the recent efforts on continuous methanol production from the direct methane oxidation aiming for an industrial process are summarized.

Keywords: methane oxidation, methanol, zeolite, copper, process schemes

\section{INTRODUCTION}

Natural gas will be a major energy resource in the transition period from the current petroleum-based energy economy to a renewable energy society in the future. Natural gas is presently used as a fuel for power generation or transportation, but often merely flared to the atmosphere without being utilized. Various attempts have been made to convert methane, which 
accounts for $70-90 \%$ of natural gas, to a more useful liquid fuel or chemicals (Periana et al., 1998; McFarland, 2012; Sushkevich et al., 2017). Thus, syngas is produced by steam reforming of methane $\left(\mathrm{CH}_{4}+\mathrm{H}_{2} \mathrm{O} \rightarrow \mathrm{CO}+3 \mathrm{H}_{2}, \Delta \mathrm{H}_{298 \mathrm{~K}}^{0}=+206.2 \mathrm{~kJ}\right.$ $\mathrm{mol}^{-1}$ ), and this can be followed by either a Fischer-Tropsch process to hydrocarbons or methanol synthesis $\left(\mathrm{CO}+2 \mathrm{H}_{2} \rightarrow\right.$ $\mathrm{CH}_{3} \mathrm{OH}, \Delta \mathrm{H}_{298 \mathrm{~K}}^{0}=-90.7 \mathrm{~kJ} \mathrm{~mol}^{-1}$ ). However, this indirect route is highly energy consuming and also accompanied by multi-stage processes including a unit for water gas shift reaction $\left(\mathrm{CO}+\mathrm{H}_{2} \mathrm{O} \rightarrow \mathrm{CO}_{2}+\mathrm{H}_{2}, \Delta \mathrm{H}_{298 \mathrm{~K}}^{0}=-41.2 \mathrm{~kJ} \mathrm{~mol}^{-1}\right)$. Therefore, it is strongly desirable to develop a low-cost, smallscale direct conversion process that can replace the indirect route.

Methane is a highly stable molecule difficult to activate due to its low electron and proton affinity, low polarity, high ionization energy, and strong $\mathrm{C}-\mathrm{H}$ bond $(\sim 440 \mathrm{~kJ}$ $\mathrm{mol}^{-1}$ ) (Periana et al., 1998). The C-H bond of methane can be kinetically and thermodynamically activated by oxidation. However, the $\mathrm{C}-\mathrm{H}$ bond $\left(\sim 47 \mathrm{~kJ} \mathrm{~mol}^{-1}\right)$ in methanol which is one of the oxidative intermediates is weaker than that of methane, and thus completely oxidized to carbon dioxide under the reaction condition for methane activation. Therefore, it is desirable to develop an appropriate catalytic means to produce methanol selectively by direct methane oxidation. Methanol, incidentally, is a vital platform molecule to synthesize dimethyl ether, formaldehyde, light olefins, and even to gasoline through the methanol-to-gasoline (MTG) process (Tian et al., 2015; Yarulina et al., 2018).

One promising pathway for direct conversion of methane to methanol is via partial oxidation of methane over a metalcontaining zeolite catalyst $\left(\mathrm{CH}_{4}+0.5 \mathrm{O}_{2} \rightarrow \mathrm{CH}_{3} \mathrm{OH}, \Delta \mathrm{H}_{298 \mathrm{~K}}^{0}\right.$ $\left.=-126.2 \mathrm{~kJ} \mathrm{~mol}^{-1}\right)$, which mimics the methane oxidation by an enzyme (Kondratenko et al., 2017; Ravi et al., 2017; Tomkins et al., 2017; Dinh et al., 2018; Kulkarni et al., 2018; Mahyuddin et al., 2018a). As shown in Figure 1A, a mono-, bi- or tri-nuclear copper or iron complex similar to that of methane monooxygenases (MMOs) can be stabilized in the zeolite micropore structure such as ZSM-5 (framework type MFI) or mordenite (MOR) by ion-exchange of zeolite followed by successive activation with an oxidant (Snyder et al., 2018). The electrophilicity of the active metal oxide species allows methanol production by readily activating the strong $\mathrm{C}-\mathrm{H}$ bond of methane even at a relatively low temperature. However, these metal-containing zeolite systems exhibit stoichiometric and non-catalytic reaction characteristics destitute of the continuous desorption of product such that a high methanol selectivity can only be achieved under the conditions of methane conversions $<0.1 \%$ (Ravi et al., 2017; Dinh et al., 2018). These problems have to be resolved to extend the reaction to an industrial scale.

Although many studies on the direct conversion of methane over a zeolite containing transition metal ions of $\mathrm{Fe}, \mathrm{Co}, \mathrm{Ni}$, $\mathrm{Cu}$, and $\mathrm{Zn}$ and using $\mathrm{N}_{2} \mathrm{O}, \mathrm{H}_{2} \mathrm{O}_{2}, \mathrm{O}_{2}$, and recently $\mathrm{H}_{2} \mathrm{O}$ as oxidants have been reported, the Cu-zeolite system with $\mathrm{O}_{2}$ or $\mathrm{H}_{2} \mathrm{O}$ has been regarded to be most promising for industrial application (Sushkevich et al., 2017; Lee et al., 2018). Cu-zeolites can be activated by both $\mathrm{N}_{2} \mathrm{O}$ and $\mathrm{O}_{2}$, unlike the Fe-zeolites on which methane activation sites cannot be formed with $\mathrm{O}_{2}$. The

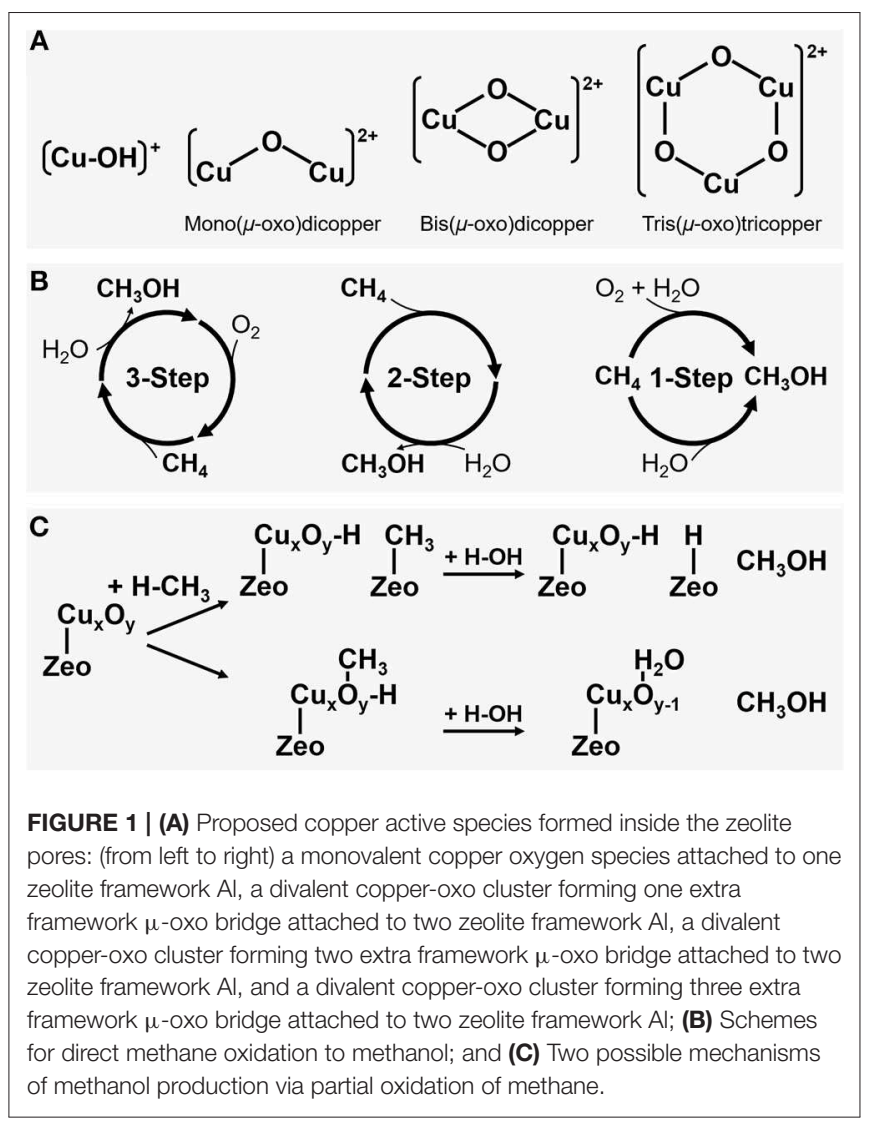

use of $\mathrm{N}_{2} \mathrm{O}$ and other oxidants (e.g., $\mathrm{HNO}_{3}, \mathrm{H}_{2} \mathrm{SO}_{4}, \mathrm{NaClO}$, $\mathrm{NaClO}_{2}, \mathrm{H}_{2} \mathrm{O}_{2}$, etc.) cannot compete against freely available and environmentally friendly $\mathrm{O}_{2}$ and $\mathrm{H}_{2} \mathrm{O}$. In this mini-review, therefore, the focus will be made on the direct methane oxidation to methanol on Cu-zeolite systems. After a short overview of this reaction system, the efforts made to obtain high methanol yields, and recent efforts for continuous methanol production are summarized.

\section{MULTISTEP METHANE PARTIAL OXIDATION OVER CU-ZEOLITES}

Copper has been used as a catalyst for various oxidation reactions and, in particular, $\mathrm{CuO}$ is well-known as a catalyst for methane oxidation (Elwell et al., 2017). As shown in Figure 1B, the initially proposed direct methane to methanol conversion over a Cu-zeolite is carried out by a three-step cyclic process of oxygen activation, methane reaction, and methanol extraction (Ravi et al., 2017; Tomkins et al., 2017). In typical operation, $\mathrm{Cu}$-zeolite is activated for several hours at near $450^{\circ} \mathrm{C}$ in an oxygen atmosphere and treated with an inert gas such as $\mathrm{He}$ to remove the $\mathrm{O}_{2}$ used in the activation of $\mathrm{Cu}$-zeolite. Then methane is reacted for some time at about $200^{\circ} \mathrm{C}$, and the produced methanol or methoxy group is desorbed or extracted from the $\mathrm{Cu}$-zeolite using a solvent such as water to obtain 
methanol. A variety of $\mathrm{Cu}$-zeolite catalysts have been evaluated during the last decade for such a multistep cyclic process, and the representative results are summarized in Table 1. An initial study using Cu-ZSM-5 showed a methanol yield of about $8.2 \mu \mathrm{mol} \mathrm{g}_{\text {cat }}^{-1}$ with a methanol selectivity of over $98 \%$ with negligible carbon dioxide and carbon monoxide (Groothaert et al., 2005). More recently, much higher methanol yields were achieved, for example, ca. 125 and $169 \mu \mathrm{mol} \mathrm{g} \mathrm{g}_{\text {cat }}^{-1}$ using $\mathrm{Cu}$ SSZ-13 (CHA) and Cu-mordenite, respectively (Pappas et al., 2017, 2018; Dyballa et al., 2019). The methanol selectivity close to $100 \%$ was attained as a result of inert gas treatment between the oxygen activation and the methane reaction to prevent the excess oxidation of generated methanol in an $\mathrm{O}_{2}$ free atmosphere.

The methanol formed inside the zeolite pores can be extracted by two processes (Kulkarni et al., 2018). As shown in Figure 1C, one is a process in which methanol is produced by hydrolysis of a Brønsted methoxy group bonded to a zeolite framework oxygen atom with water. The other is a process in which the methyl radical of methane activated at the $\mathrm{Cu}$-oxo site is directly adsorbed to a zeolite framework oxygen, and methanol is replaced by water used as a solvent. According to Kulkarni et al. who calculated the adsorption energies between methanol and different metal active species, it is difficult to spontaneously desorb the methanol molecules formed inside zeolite pores in most zeolite structures, but it is possible to desorb them using water. Theoretically, the adsorbed methanol could be desorbed with low water vapor pressure from almost any zeolite structures.

Although the structure of copper-oxo active species inside zeolite pores involved in the methanol production has been proposed since the beginning of the investigation, it remains controversial. The detailed spectroscopic and computational analyses for the active species are available in other reviews (Kulkarni et al., 2018; Snyder et al., 2018). Cu-mordenite, CuZSM-5, and Cu-SSZ-13 have been studied extensively, and various active species such as monocopper (e.g., $[\mathrm{CuOH}]^{+}$) (Grundner et al., 2015, 2016; Li et al., 2016), dicopper (e.g., mono( $\mu$-oxo)dicopper, $\left[\mathrm{Cu}_{2}(\mu \mathrm{O})_{2}\right]^{2+}$ and bis( $\mu$-oxo)dicopper, $\left.\left[\mathrm{Cu}_{2}(\mu \mathrm{O})\right]^{2+}\right)$ (Groothaert et al., 2005; Woertink et al., 2009; Tsai et al., 2014; Mahyuddin et al., 2018b,c), tricopper (e.g., tris( $\mu$ oxo)tricopper, $\left[\mathrm{Cu}_{3}(\mu \mathrm{O})_{3}\right]^{2+}$ ) (Grundner et al., 2015; Markovits et al., 2016; Vogiatzis et al., 2017; Dandu et al., 2018; Mahyuddin et al., 2018b,c), and even sub-nanometer copper oxide clusters (Tomkins et al., 2017; Doan et al., 2018) have been proposed (Figure 1A). An early study of Cu-ZSM-5 showed a peak in the UV/Vis spectrum at $22,700 \mathrm{~cm}^{-1}$ corresponding to a bis $(\mu$ oxo)dicopper site (Groothaert et al., 2005). On the other hand, using UV/Vis and Raman spectroscopies, the active species formed inside $\mathrm{Cu}-\mathrm{ZSM}-5$ pores was also claimed as a mono( $\mu$ oxo)dicopper site (Woertink et al., 2009). The UV/Vis result for $\mathrm{Cu}$-mordenite also detected the presence of the $\mu$-oxodicopper site, but other active species were also proposed to be involved in methanol production (Alayon et al., 2012). Recently, EXAFS analysis of $\mathrm{Cu}$-mordenite reported that a trinuclear copper-oxo cluster is the active species (Grundner et al., 2015;
Markovits et al., 2016). For other zeolites such as Cu-beta (*BEA) and $\mathrm{Cu}$-ferrierite (FER), despite only with a small amount of methanol formed, no active species like $\mu$-oxo-copper clusters were observed (Smeets et al., 2005). These different results seem to indicate that there could be various active species depending on the zeolite structure, composition, and activation conditions.

\section{METHANE REACTIVITY AND METHANOL YIELD IN CU-ZEOLITE SYSTEM}

Various factors such as structure and composition of the zeolite used, the structure of copper active species, and reaction conditions should be considered to produce methanol selectively by direct partial oxidation of methane. Depending on the structure of the zeolite, different environment in which oxygen or methane is stabilized at the active copper species can be formed (Kulkarni et al., 2016; Zhao et al., 2016; Pappas et al., 2017; Liu et al., 2018). The C-H bond activation barrier energy of methane depending on the type of metal active species present in the zeolite pores was estimated (Kulkarni et al., 2018). The activation barrier energy decreased significantly among the transition metals from left to the right in the periodic table (Fe, $\mathrm{Co}, \mathrm{Ni}$, and $\mathrm{Cu}$ ), and the energy by the $\mu$-oxo-dicopper species was $107 \mathrm{~kJ} \mathrm{~mol}^{-1}$ lower than that by iron. Therefore, it was predicted that copper ion has a better reactivity to methane than the other transition metal ions. It was also claimed that activation barrier energy changes depending on the zeolite structures; the aluminum position and its bonding structure with metal cations affected the M-O-M angle, which influenced the activation barrier energy.

Recently, Cu-zeolites with small-pores such as SSZ-13, SSZ16 (AFX), SSZ-39 (AEI), and SAPO-34 (CHA) were reported to exhibit better methane reactivity and methanol selectivity than the conventional Cu-ZSM-5 and Cu-mordenite (Wulfers et al., 2015; Ipek and Lobo, 2016; Kulkarni et al., 2016; Ipek et al., 2017; Pappas et al., 2017; Oord et al., 2018). These small-pore $\mathrm{Cu}$-zeolites produced almost twice as much methanol per $\mathrm{Cu}$-atom than the medium- and large-pore zeolites. It was reported that the activation energy necessary for breaking the $\mathrm{C}-\mathrm{H}$ bond of methane, which is the rate determining step in the methane conversion, is controlled by the $\mathrm{Cu}-\mathrm{O}-\mathrm{Cu}$ angle, which was dependent on the crystallographic location in a zeolite structure and copper active species (Mahyuddin et al., 2017, 2018b). DFT calculations indicated that the activation energies for $\mathrm{C}-\mathrm{H}$ bond dissociation by $\left[\mathrm{Cu}_{2}(\mu \mathrm{O}) 2\right]^{2+}$ formed inside the small-pore zeolites (SSZ-13, SSZ-16, and SSZ-39) are lower than those for medium- (Cu-ZSM-5) and large-pore ( $\mathrm{Cu}$-mordenite) zeolites. Also, the 8- ring side pocket of mordenite zeolite was claimed to stabilize the catalytically active trinuclear copper-oxo clusters owing to the structural environment similar to that of the MMO (Grundner et al., 2015).

Park et al. prepared $\mathrm{Cu}$-zeolites with 12 different structure types (i.e., MOR, EON, MAZ, MEI, BPH, FAU, LTL, MFI, HEU, FER, SZR, and CHA), and compared their methanol productivity by direct conversion of methane based on the 
TABLE 1 | Representative Cu-zeolite performances reported for the gas-phase direct methane oxidation to methanola .

\begin{tabular}{|c|c|c|c|c|c|c|c|c|}
\hline \multicolumn{3}{|c|}{ Cu-zeolite } & \multirow[t]{2}{*}{ Oxidant } & \multicolumn{2}{|c|}{ Temp., ${ }^{\circ} \mathbf{C}$} & \multicolumn{2}{|c|}{ Methanol yield } & \multirow[t]{2}{*}{ References } \\
\hline IZA code & $\mathrm{Cu}, \mathrm{wt} \%$ & $\mathrm{Cu} / \mathrm{Al}$ & & Activation & Reaction & $\mu \mathrm{mol} \mathrm{g}_{\mathrm{cat}}^{-1}$ & $\mathrm{~mol} \mathrm{~mol}_{\mathrm{Cu}}^{-1}$ & \\
\hline $\mathrm{MFI}$ & 4.0 & - & $\mathrm{O}_{2}$ & 450 & 200 & 8.2 & 0.01 & Groothaert et al., 2005 \\
\hline MOR & 4.3 & 0.4 & $\mathrm{O}_{2}$ & 450 & 200 & 13 & 0.02 & Alayon et al., 2012 \\
\hline MFI & 1.9 & - & NO & 150 & 150 & 0.63 & - & Sheppard et al., 2014 \\
\hline $\mathrm{CHA}$ & 4.9 & 0.4 & $\mathrm{O}_{2}$ & 450 & 200 & 31 & 0.04 & Wulfers et al., 2015 \\
\hline AEl & 2.5 & 0.3 & $\mathrm{O}_{2}$ & 450 & 200 & 36 & 0.09 & Wulfers et al., 2015 \\
\hline AFX & 5.0 & 0.3 & $\mathrm{O}_{2}$ & 450 & 200 & 39 & 0.05 & Wulfers et al., 2015 \\
\hline MOR & 3.2 & - & $\mathrm{O}_{2}$ & 450 & 200 & 160 & 0.32 & Grundner et al., 2015 \\
\hline $\mathrm{CHA}$ & 3.2 & 0.4 & $\mathrm{O}_{2}$ & 450 & 200 & 45 & 0.09 & Ipek and Lobo, 2016 \\
\hline $\mathrm{CHA}$ & 3.2 & 0.4 & $\mathrm{~N}_{2} \mathrm{O}$ & 450 & 200 & 35 & 0.07 & Ipek and Lobo, 2016 \\
\hline MOR & 3.0 & - & $\mathrm{O}_{2}$ & 200 & 200 & 56 & 0.12 & Tomkins et al., 2016c \\
\hline $\mathrm{MFI}$ & - & 0.3 & $\mathrm{O}_{2}$ & 550 & 210 & 82 & - & Narsimhan et al., 2016 ${ }^{\mathrm{d}}$ \\
\hline $\mathrm{MFI}$ & 3.3 & 0.5 & $\mathrm{O}_{2}$ & 450 & 200 & 89 & 0.17 & Markovits et al., 2016 \\
\hline MOR & 3.1 & 0.2 & $\mathrm{O}_{2}$ & 450 & 200 & 30 & 0.06 & Park et al., 2017 b \\
\hline $\mathrm{CHA}$ & 4.5 & 0.8 & $\mathrm{O}_{2}$ & 450 & 200 & 30 & 0.04 & Park et al., 2017b \\
\hline MAZ & 6.0 & 0.3 & $\mathrm{O}_{2}$ & 450 & 200 & 86 & 0.09 & Park et al., $2017^{\mathrm{b}}$ \\
\hline $\mathrm{CHA}$ & 3.9 & 0.5 & $\mathrm{O}_{2}$ & 500 & 200 & 125 & 0.20 & Pappas et al., 2017 \\
\hline MOR & 2.0 & 0.4 & $\mathrm{~N}_{2} \mathrm{O}$ & 600 & 150 & 97 & 0.31 & Kim et al., 2017 \\
\hline MOR & - & 0.4 & $\mathrm{H}_{2} \mathrm{O}$ & 400 & 200 & - & 0.20 & Sushkevich et al., $2017^{e}$ \\
\hline MOR & 3.1 & 0.3 & $\mathrm{H}_{2} \mathrm{O}$ & 350 & 350 & 161 & 0.33 & Lee et al., $2018^{f}$ \\
\hline MOR & 2.3 & 0.2 & $\mathrm{O}_{2}$ & 500 & 200 & 169 & 0.47 & Pappas et al., 2018 \\
\hline
\end{tabular}

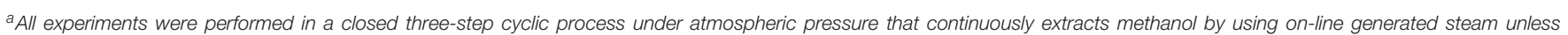
otherwise stated.

${ }^{b}$ Off-line methanol extraction with 1:1 water/acetonitrile mixture or water.

${ }^{c}$ Methane pressure of 37 bar.

${ }^{d}$ Methanol extraction by flowing a gas mixture comprised of $3.2 \mathrm{kPa}$ of $\mathrm{H}_{2} \mathrm{O}, 0.0025 \mathrm{kPa} \mathrm{O}$, and balance $\mathrm{CH}_{4}$.

${ }^{e}$ Activation in He flow.

${ }^{f}$ Continuous one-step methanol production using $33 \% \mathrm{CH}_{4}$ and $67 \% \mathrm{H}_{2} \mathrm{O}$.

copper content, activation temperature in an oxygen flow, zeolite structure, and zeolite precursor type (Park et al., 2017). The $\mathrm{Cu}$-omega with $\mathrm{MAZ}$ structure showed the highest methanol yield among the zeolites. This was explained as a result of copper-oxo active species distributed in the three-dimensional 8-ring small-pore channel only available in the MAZ structure. In-situ UV/Vis analysis after catalyst activation under high temperature and oxygen atmosphere revealed that there exist various copper active species rather than a single copper active state. Four main factors contributing to obtain high methanol yield were suggested: (i) highly dispersed copper-oxo active species, (ii) copper active species formed in small-pore channels, (iii) appropriate level of activation temperature, and (iv) $\mathrm{Cu}^{2+}$ ion-exchanged from an $\mathrm{H}^{+}$-form zeolite. $\mathrm{Cu}$-mordenite and $\mathrm{Cu}$-omega catalysts prepared from their $\mathrm{H}^{+}$-forms produced a substantial amount of methanol even at $200^{\circ} \mathrm{C}$ both applied for oxygen activation and methane reaction. It was also reported that the $\mathrm{Cu}$-mordenite prepared by liquid phase ion-exchange with its $\mathrm{H}^{+}$-form precursor showed the highest methanol yield compared to the other cation precursors (Dyballa et al., 2019). Furthermore, they suggested an optimum stoichiometry between $\mathrm{Si}, \mathrm{Al}$, and $\mathrm{Cu}$ of $\mathrm{Cu}$-mordenite (i.e., $\mathrm{Si} / \mathrm{Al}=7$ and $\mathrm{Cu} / \mathrm{Al}$ $=0.18$ ), which exhibited reproducible methanol productivity up to $169 \mu \mathrm{mol} \mathrm{g}$ cat .

\section{CONTINUOUS METHANOL PRODUCTION OVER A CU-ZEOLITE SYSTEM}

At the beginning of the investigation using a $\mathrm{Cu}$-zeolite system, an off-line extraction method was employed for methanol recovery. After the second step of methane reaction is completed, the reacted $\mathrm{Cu}$-zeolite was recovered from the reactor, and the methanol was extracted by adding a solvent such as water. Subsequently, a closed multistep cyclic process that continuously extracts methanol by using on-line generated steam was proposed (Alayon et al., 2012). The cycling experiments showed successful regeneration of $\mathrm{Cu}$-zeolite in a cyclic batch-wise operation; the catalyst deactivation can occur primarily due to sintering or leaching of $\mathrm{Cu}$ at high activation temperatures. The crucial problem of the multistep cyclic process was that these production steps proceed at different temperatures such that the first step of activating the copper in zeolite pores in an oxygen atmosphere is carried out at a high temperature of $450{ }^{\circ} \mathrm{C}$, and the contact with methane and extraction of methanol proceed at a relatively lower temperature of $200^{\circ} \mathrm{C}$. This low temperature was necessary to prevent the methanol from excessively oxidized to $\mathrm{CO}$ or $\mathrm{CO}_{2}$. Consequently, an isothermal closed multistep looping system using Cu-ZSM-5, NO oxidizer, and on-line steam extraction was suggested, where NO activation, methane reaction, and methanol 
extraction were all carried out under the same temperature at $150^{\circ} \mathrm{C}$, and a meaningful methanol yield of $0.63 \mu \mathrm{mol} \mathrm{g} \mathrm{g}_{\text {cat }}^{-1}$ was obtained (Sheppard et al., 2014).

Meanwhile, methane conversion using $\mathrm{Cu}$-mordenite and $\mathrm{O}_{2}$ at isothermal $200^{\circ} \mathrm{C}$, but with increased methane pressure was also attempted (Tomkins et al., 2016, 2017); practically no methanol was obtained under the $200^{\circ} \mathrm{C}$ activation with methane at the atmospheric pressure but methanol yield rapidly increased as the methane pressure was increased, and about $56 \mu \mathrm{mol} \mathrm{g}-1$ of methanol yield was achieved at 37 bar.

The methanol yield through the multistep cyclic looping process has been usually estimated and compared only by the amount of methanol produced per $\mathrm{Cu}-\mathrm{mol}$ or weight of the catalyst. To develop a commercial methanol production process, however, the amount of catalyst and the total process time necessary to produce a meaningful amount of methanol should be considered. Recently, it was reported that a total $21 \mathrm{~h}$ was spent for one cycle of the three-step reaction over Cu-ZSM-5 including the temperature control of $210-550^{\circ} \mathrm{C}$ to produce about $82 \mu \mathrm{mol}$ $\mathrm{g}_{\text {cat }}^{-1}$ of methanol (Narsimhan et al., 2016). This result corresponds to approximately $4 \mu \mathrm{mol} \mathrm{g} \mathrm{g}_{\mathrm{cat}}^{-1} \mathrm{~h}^{-1}$ of continuous methanol production under the assumption that catalyst deactivation does not occur during the repeated cycles. It will be necessary to optimize the time required for each step of the stepwise cyclic process and to speed up significantly the methanol production over the entire cycle for its application to an industrial operation.

It has been also reported that under the same conditions using $\mathrm{Cu}-\mathrm{ZSM}-5$, simultaneous introduction of methane, oxygen, and steam continuously produced methanol in a steady-state with the production rate of $1.8 \mu \mathrm{mol} \mathrm{g} \mathrm{gat}^{-1} \mathrm{~h}^{-1}$ methanol, which was about half the productivity obtained by the three-step process (Narsimhan et al., 2016; Dinh et al., 2018). Despite the copresence of methane and oxygen, methanol was not excessively oxidized and was produced with high selectivity by keeping oxygen concentration to a very low level around $100 \mathrm{ppm}$. While meaningful, the very low methane conversion due to the use of excess methane and the potential over-oxidation of methanol by the co-presence of oxygen is still problematic.

Also, it has been reported that methanol can be continuously produced from the simultaneous introduction of methane and steam without any oxidant by the oxidizing ability of $\mathrm{H}_{2} \mathrm{O}$ (Sushkevich et al., 2017; Lee et al., 2018). The produced methanol was not excessively oxidized since steam has lower oxidizing power than oxygen. The catalytic cycle over $\mathrm{Cu}$-mordenite under the co-presence of methane and steam at isothermal $350^{\circ} \mathrm{C}$ maintained stable methanol production for more than $500 \mathrm{~min}$ on stream, although the production rate of methanol

\section{REFERENCES}

Alayon, E. M., Nachtegaal, M., Ranocchiari, M., and van Bokhoven, J. A. (2012). Catalytic conversion of methane to methanol over $\mathrm{Cu}$-mordenite. Chem. Commun. 48, 404-406. doi: 10.1039/clcc15840f

Dandu, N. K., Reed, J. A., and Odoh, S. O. (2018). Performance of density functional theory for predicting methane-to-methanol conversion by a tri-copper complex. J. Phys. Chem. C 122, 1024-1036. doi: 10.1021/acs.jpcc.7b09284 was very low due to the thermodynamic limitation. For this reaction $\left(\mathrm{CH}_{4}(\mathrm{~g})+\mathrm{H}_{2} \mathrm{O}(\mathrm{g}) \rightarrow \mathrm{CH}_{3} \mathrm{OH}(\mathrm{g})+\mathrm{H}_{2}(\mathrm{~g})\right)$, there is a thermodynamic restriction with $\Delta \mathrm{G}_{298 \mathrm{~K}}^{\circ} \sim 117 \mathrm{~kJ} / \mathrm{mol}$, and the equilibrium methanol formation level is low.

\section{CONCLUSION AND OUTLOOK}

In this mini-review, we examined the recent progress in methanol synthesis by direct methane oxidation over a Cu-zeolite catalyst. There have been various characterization and computational studies to identify the $\mathrm{Cu}$-oxo active species involved in methanol production, and various types of mono-, di-, tricopper, and even sub-nanometer copper oxide clusters were proposed. Although there are several factors related to methane conversion, selection of a suitable zeolite is crucial to obtain the high methanol yield. It has been reported that $\mathrm{Cu}$-zeolites with small-pores have shown the higher methanol yields than medium- and largepore $\mathrm{Cu}$-zeolites. The activation of methane $\mathrm{C}-\mathrm{H}$ bond, which is considered to be the rate-determining step during the methane conversion, and $\mathrm{Cu}$-oxo formed in the small-pores was calculated to have the lowest $\mathrm{C}-\mathrm{H}$ bond activation energy. There has been considerable progress in continuous methanol production from direct methane conversion over $\mathrm{Cu}$-zeolites, i.e., steady-state cyclic reaction with the simultaneous introduction of methane and steam with or without oxygen. However, considering the hourly production rate, the current status is just around onehundredth of the methanol production rate via syngas from the commercially available indirect methane transformation. Therefore, it is necessary to both maximize the total number of copper active species in the zeolite catalyst and to reduce the time required for each cycle of the multistep process. There have been only limited attempts for isothermal oxidative activation and methane reaction, which can be an alternative but still needs a significant breakthrough for future implementation.

\section{AUTHOR CONTRIBUTIONS}

MP planned the contents and wrote the draft. EP did consulting and feedback on process data. W-SA initiated and supervised the work.

\section{FUNDING}

This work was financially supported by the C1 Gas Refinery Program through the National Research Foundation of Korea (NRF) funded by the Ministry of Science and ICT (2015M3D3A1A01064899).

Dinh, K. T., Sullivan, M. M., Serna, P., Meyer, R. J., Dincă, M., and Román-Leshkov, Y. (2018). Viewpoint on the partial oxidation of methane to methanol using Cuand Fe-exchanged zeolites. ACS Catal. 8, 8306-8313. doi: 10.1021/acscatal.8b 01180

Doan, H. A., Li, Z., Farha, O. K., Hupp, J. T., and Snurr, R. Q. (2018). Theoretical insights into direct methane to methanol conversion over supported dicopper oxo nanoclusters. Catal. Today 312, 2-9. doi: 10.1016/j.cattod.2018.03.063

Dyballa, M., Pappas, D. K., Kvande, K., Borfecchia, E., Arstad, B., Beato, P., et al. (2019). On how copper mordenite properties govern the framework stability 
and activity in the methane-to-methanol conversion. ACS Catal. 9, 365-375. doi: 10.1021/acscatal.8b04437

Elwell, C. E., Gagnon, N. L., Neisen, B. D., Dhar, D., Spaeth, A. D., Yee, G. M., et al. (2017). Copper-oxygen complexes revisited: structures, spectroscopy, and reactivity. Chem. Rev. 117, 2059-2107. doi: 10.1021/acs.chemrev.6b00636

Groothaert, M. H., Smeets, P. J., Sels, B. F., Jacobs, P. A., and Schoonheydt, R. A. (2005). Selective oxidation of methane by the bis( $\mu$-oxo)dicopper core stabilized on ZSM-5 and mordenite zeolites. J. Am. Chem. Soc. 127, 1394-1395. doi: $10.1021 /$ ja047158u

Grundner, S., Luo, W., Sanchez-Sanchez, M., and Lercher, J. A. (2016). Synthesis of single-site copper catalysts for methane partial oxidation. Chem. Commun. 52, 2553-2556. doi: 10.1039/c5cc08371k

Grundner, S., Markovits, M. A. C., Li, G., Tromp, M., Pidko, E. A., Hensen, E. J. M., et al. (2015). Single-site trinuclear copper-oxygen clusters in mordenite for selective conversion of methane to methanol. Nat. Commun. 6, 7546-7554. doi: $10.1038 /$ ncomms 8546

Ipek, B., and Lobo, R. F. (2016). Catalytic conversion of methane to methanol on Cu-SSZ-13 using $\mathrm{N}_{2} \mathrm{O}$ as oxidant. Chem. Commun. 52, 13401-13404. doi: $10.1039 /$ c6cc07893a

Ipek, B., Wulfers, M. J., Kim, H., Göltl, F., Hermans, I., Smith, J. P., et al. (2017). Formation of $\left[\mathrm{Cu}_{2} \mathrm{O}_{2}\right]^{2+}$ and $\left[\mathrm{Cu}_{2} \mathrm{O}\right]^{2+}$ toward $\mathrm{C}-\mathrm{H}$ bond activation in Cu-SSZ-13 and Cu-SSZ-39. ACS Catal. 7, 4291-4303. doi: $10.1021 /$ acscatal.6b03005

Kim, Y., Kim, T. Y., Lee, H., and Yi, J. (2017). Distinct activation of Cu-MOR for direct oxidation of methane to methanol. Chem. Commun. 53, 4116-4119. doi: $10.1039 / \mathrm{c} 7 \mathrm{cc} 00467 \mathrm{~b}$

Kondratenko, E. V., Peppel, T., Seeburg, D., Kondratenko, V. A., Kalevaru, N., Martin, A., et al. (2017). Methane conversion into different hydrocarbons or oxygenates: current status and future perspectives in catalyst development and reactor operation. Catal. Sci. Technol. 7, 366-381. doi: 10.1039/c6cy $01879 c$

Kulkarni, A. R., Zhao, Z.-J., Siahrostami, S., Nørskov, J. K., and Studt, F. (2016). Monocopper active site for partial methane oxidation in $\mathrm{Cu}$ exchanged 8MR zeolites. ACS Catal. 6, 6531-6536. doi: 10.1021/acscatal.6 b01895

Kulkarni, A. R., Zhao, Z.-J., Siahrostami, S., Nørskov, J. K., and Studt, F. (2018). Cation-exchanged zeolites for the selective oxidation of methane to methanol. Catal. Sci. Technol. 8, 114-123. doi: 10.1039/c7cy0 $1229 \mathrm{~b}$

Lee, S. H., Kang, J. K., and Park, E. D. (2018). Continuous methanol synthesis directly from methane and steam over $\mathrm{Cu}(\mathrm{II})$-exchanged mordenite. Korean J. Chem. Eng. 35, 2145-2149. doi: 10.1007/s11814-01 8-0150-5

Li, G., Vassilev, P., Sanchez-Sanchez, M., Lercher, J. A., Hensen, E. J. M., and Pidko, E. A. (2016). Stability and reactivity of copper oxo-clusters in ZSM5 zeolite for selective methane oxidation to methanol. J. Catal. 338, 305-312. doi: 10.1016/j.jcat.2016.03.014

Liu, X., Zhang, J., Huang, C., and Sun, X. (2018). Density functional theory study of Cu-ZSM-5-catalyzed C-H bond activation: the importance of active centers. J. Phys. Chem. C 122, 28645-28651. doi: 10.1021/acs.jpcc.8 b08137

Mahyuddin, M. H., Shiota, Y., Staykov, A., and Yoshizawa, K. (2018a). Theoretical overview of methane hydroxylation by copper-oxygen species in enzymatic and zeolitic catalysts. Acc. Chem. Res. 51, 2382-2390. doi: 10.1021/acs.accounts.8b00236

Mahyuddin, M. H., Staykov, A., Shiota, Y., Miyanishi, M., and Yoshizawa, K. (2017). Roles of zeolite confinement and $\mathrm{Cu}-\mathrm{O}-\mathrm{Cu}$ angle on the direct conversion of methane to methanol by $\left[\mathrm{Cu}_{2}(\mu-\mathrm{O})\right]^{2+}$-exchanged AEI, CHA, AFX, and MFI zeolites. ACS Catal. 7, 3741-3751. doi: 10.1021/acscatal.7b00588

Mahyuddin, M. H., Tanaka, T., Shiota, Y., Staykov, A., and Yoshizawa, K. (2018b). Methane partial oxidation over $\left[\mathrm{Cu}_{2}(\mu-\mathrm{O})\right]^{2+}$ and $\left[\mathrm{Cu}_{3}(\mu-\right.$ $\left.\mathrm{O}_{3}\right]^{2+}$ active species in large-pore zeolites. ACS Catal. 8, 1500-1509. doi: $10.1021 /$ acscatal.7b03389

Mahyuddin, M. H., Tanaka, T., Staykov, A., Shiota, Y., and Yoshizawa, K. (2018c). Dioxygen activation on Cu-MOR zeolite: theoretical insights into the formation of $\mathrm{Cu}_{2} \mathrm{O}$ and $\mathrm{Cu}_{3} \mathrm{O}_{3}$ active sites. Inorg. Chem. 57, 10146-10152. doi: 10.1021/acs.onorgchem.8b01329
Markovits, M. A. C., Jentys, A., Tromp, M., Sanchez-Sanchez, M., and Lercher, J. A. (2016). Effect of location and distribution of Al sites in ZSM-5 on the formation of $\mathrm{Cu}$-oxo clusters active for direct conversion of methane to methanol. Top. Catal. 59, 1554-1563. doi: 10.1007/s11244-016-0676-x

McFarland, E. (2012). Unconventional chemistry for unconventional natural gas. Science 338, 340-342. doi: 10.1126/science. 1226840

Narsimhan, K., Iyoki, K., Dinh, K., and Román-Leshkov, Y. (2016). Catalytic oxidation of methane into methanol over copper-exchanged zeolites with oxygen at low temperature. ACS Cent. Sci. 2, 424-429. doi: 10.1021/acscentsci.65b00139

Oord, R., Schmidt, J. E., and Weckhuysen, B. M. (2018). Methane-to-methanol conversion over zeolite Cu-SSZ-13, and its comparison with the selective catalytic reduction of $\mathrm{NO}_{\mathrm{x}}$ with $\mathrm{NH}_{3}$. Catal. Sci. Technol. 8, 1028-1038. doi: 10.1039/c7cy02461d

Pappas, D. K., Borfecchia, E., Dyballa, M., Pankin, I. A., Lomachenko, K. A., Martini, A., et al. (2017). Methane to methanol: structure-activity relationships for Cu-CHA. J. Am. Chem. Soc. 139, 14961-14975. doi: 10.1021/jacs.7b06472

Pappas, D. K., Martini, A., Dyballa, M., Kvande, K., Teketel, S., Lomachenko, K. A., et al. (2018). The nuclearity of the active site for methane to methanol conversion in Cu-mordenite: a quantitative assessment. J. Am. Chem. Soc. 140, 15270-15278. doi: 10.1021/jacs.8b08071

Park, M. B., Ahn, S. H., Mansouri, A., Ranocchiari, M., and van Bokhoven, J. A. (2017). Comparative study of diverse copper zeolites for the conversion of methane into methanol. ChemCatChem 9, 3705-3714. doi: $10.1002 /$ cctc. 201700768

Periana, R. A., Taube, D. J., Gamble, S., Taube, H., Satoh, T., and Fujii, H. (1998). Platinum catalysts for the high-yield oxidation of methane to a methanol derivative. Science 280, 560-564. doi: 10.1126/science.280.5363.560

Ravi, M., Ranocchiari, M., and van Bokhoven, J. A. (2017). The direct catalytic oxidation of methane to methanol-a critical assessment. Angew. Chem. Int. Ed. 56, 16464-16483. doi: 10.1002/anie.201702550.

Sheppard, T., Hamill, C. D., Goguet, A., Rooney, D. W., and Thompson, J. M. (2014). A low temperature, isothermal gas-phase system for conversion of methane to methanol over Cu-ZSM-5. Chem. Commun. 50, 11053-11055. doi: $10.1039 / \mathrm{c} 4 \mathrm{cc} 02832 \mathrm{e}$

Smeets, P. J., Grooehaert, M. H., and Schoonheydt, R. A. (2005). Cu based zeolites: a UV-Vis study of the active site in the selective methane oxidation at low temperature. Catal. Today 110, 303-309. doi: 10.1016/j.cattod.2005.09.028

Snyder, B. E. R., Bols, M. L., Schoonheydt, R. A., Sels, B. F., and Solomon, E. I. (2018). Iron and copper active sites in zeolites and their correlation to metalloenzymes. Chem. Rev. 118, 2718-2768. doi: 10.1021/acs.chemrev.7b00344

Sushkevich, V. L., Palagin, D., Ranocchiari, M., and van Bokhoven, J. A. (2017). Selective anaerobic oxidation of methane enables direct synthesis of methanol. Science 356, 523-527. doi: 10.1126/science.aam 9035

Tian, P., Wei, Y., Ye, M., and Liu, Z. (2015). Methanol to olefins (MTO): from fundamentals to commercialization. ACS Catal. 5, 1922-1938. doi: 10.1021/acscatal.5b00007

Tomkins, P., Mansouri, A., Bozbag, S. E., Krumeich, F., Park, M. B., Alayon, E. M. C., et al. (2016). Isothermal cyclic conversion of methane into methanol over copper-exchanged zeolite at low temperature. Angew. Chem. Int. Ed. 55, 5467-5471. doi: 10.1002/anie.201511065

Tomkins, P., Ranocchiari, M., and van Bokhoven, J. A. (2017). Direct conversion of methane to methanol under mild conditions over Cu-zeolites and beyond. Acc. Chem. Res. 50, 418-425. doi: 10.1021/acs.accounts.6b00534

Tsai, M.-L., Hadt, R. G., Vanelderen, P., Sels, B. F., Schoonheydt, R. A., and Solomon, E. I. (2014). [ $\left[\mathrm{Cu}_{2} \mathrm{O}\right]^{2+}$ active site formation in Cu-ZSM-5: geometric and electronic structure requirements for $\mathrm{N}_{2} \mathrm{O}$ activation. J. Am. Chem. Soc. 136, 3522-3529. doi: 10.1021/ja4113808

Vogiatzis, K. D., Li, G., Hensen, E. J. M., Gagliardi, L., and Pidko, E. A. (2017). Electronic structure of the $\left[\mathrm{Cu}_{3}(\mu-\mathrm{O})_{3}\right]^{2+}$ cluster in mordenite zeolite and its effects on the methane to methanol oxidation. J. Phys. Chem. C 121, 22295-22302. doi: 10.1021/acs.jpcc.7b08714.

Woertink, J. S., Smeets, P. J., Groothaert, M. H., Vance, M. A., Sels, B. F., Schoonheydt, R. A., et al. (2009). A $\left[\mathrm{Cu}_{2} \mathrm{O}\right]^{2+}$ core in Cu-ZSM-5, the active site in the oxidation of methane to methanol. Proc. Natl. Acad. Sci. U.S.A. 106, 18908-18913. doi: 10.1073/pnas.0910461106 
Wulfers, M. J., Teketel, S., Ipek, B., and Lobo, R. F. (2015). Conversion of methane to methanol on copper-containing small-pore zeolites and zeotypes. Chem. Commun. 51, 4447-4450. doi: 10.1039/c4cc09645b

Yarulina, I., Chowdhury, A. D., Meirer, F., Weckhuysen, B. M., and Gascon, J. (2018). Recent trends and fundamental insights in the methanol-tohydrocarbons process. Nat. Catal. 1, 398-411. doi: 10.1038/s41929-018-0078-5

Zhao, Z.-J., Kulkarni, A., Vilella, L., Nørskov, J. K., and Studt, F. (2016). Theoretical insights into the selective oxidation of methane to methanol in copper-exchanged mordenite. ACS Catal. 6, 3760-3766. doi: 10.1021/acscatal.6 b00440
Conflict of Interest Statement: The authors declare that the research was conducted in the absence of any commercial or financial relationships that could be construed as a potential conflict of interest.

Copyright (๑) 2019 Park, Park and Ahn. This is an open-access article distributed under the terms of the Creative Commons Attribution License (CC BY). The use, distribution or reproduction in other forums is permitted, provided the original author(s) and the copyright owner(s) are credited and that the original publication in this journal is cited, in accordance with accepted academic practice. No use, distribution or reproduction is permitted which does not comply with these terms. 


\section{OPEN ACCESS}

Edited by:

Pascal Granger,

Lille University of Science and

Technology, France

Reviewed by:

Carlos Adolfo Grande,

SINTEF Industry, Norway

Weiming Hua

Fudan University, China

Svetlana Ivanova,

University of Seville, Spain

*Correspondence: Cristina Megías-Sayago megiassayago@unistra.fr

Specialty section:

This article was submitted to Green and Sustainable Chemistry,

a section of the journal

Frontiers in Chemistry

Received: 17 April 2019

Accepted: 19 July 2019

Published: 06 August 2019

Citation:

Megías-Sayago C, Bingre R, Huang L, Lutzweiler G, Wang $Q$ and Louis $B$

(2019) $\mathrm{CO}_{2}$ Adsorption Capacities in

Zeolites and Layered Double

Hydroxide Materials.

Front. Chem. 7:551.

doi: 10.3389/fchem.2019.00551

\section{$\mathrm{CO}_{2}$ Adsorption Capacities in Zeolites and Layered Double Hydroxide Materials}

\author{
Cristina Megías-Sayago ${ }^{1 *}$, Rogéria Bingre ${ }^{1}$, Liang Huang ${ }^{1,2}$, Gaëtan Lutzweiler ${ }^{3}$, \\ Qiang Wang ${ }^{2}$ and Benoît Louis ${ }^{1}$
}

${ }^{1}$ ICPEES - Institut de Chimie et Procédés pour l'Energie, l'Environnement et la Santé, Energy and Fuels for a Sustainable Environment Team, UMR 7515 CNRS - Université de Strasbourg - ECPM, Strasbourg, France, ${ }^{2}$ Environmental Functional Nanomaterials (EFN) Laboratory, College of Environmental Science and Engineering, Beijing Forestry University, Beijing, China, ${ }^{3}$ INSERM, UMR 1121, Strasbourg, France

The development of technologies that allow us to reduce $\mathrm{CO}_{2}$ emissions is mandatory in today's society. In this regard, we present herein a comparative study of $\mathrm{CO}_{2}$ adsorption over three types of materials: zeolites, layered double hydroxides (LDH), and zeolites coated LDH composites. The influence of the zeolite Si/Al ratio on zeolites sorption capacity along with the presence of mesopores was investigated. By comparing these results with the well-known performance of LDHs, we aim to provide insights on the factors that may influence the $\mathrm{CO}_{2}$ capture capacity over zeolites, thus providing useful tools for tuning their properties upon post-treatments.

Keywords: $\mathrm{CO}_{2}$ adsorption, zeolite, LDH, zeolite@ LDH, Si/AI, hierarchical porosity

\section{INTRODUCTION}

The tremendous increase in the use of fossil fuels in the past 200 years has contributed to a steady rise of $\mathrm{CO}_{2}$ level in the atmosphere (Smil, 2017). Being the main actor responsible for the greenhouse effect, it led to reach a global warming never seen before, coming close to the pessimistic scenario (Stanley, 2003). Several efforts have been made to reduce those emissions, either by optimization of the current industrial processes, or by implementation of renewable energies where no $\mathrm{CO}_{2}$ is produced (Princiotta, 2011; Álvarez et al., 2017). However, the latter remain at a non-sufficiently mature state, hampered by high costs for their implementation and maintenance, mainly in developing countries (Mustapa et al., 2010; Horbach et al., 2014). Hence, this leads to the need to continue depleting fossil fuels to generate energy, and consequently, allow further release of $\mathrm{CO}_{2}$ in the atmosphere. Unfortunately, fossil fuels are not the unique factor increasing carbon footprint nowadays. A significant contribution comes from several industrial activities such as cement or steel production, whose $\mathrm{CO}_{2}$ emissions dramatically contribute to accelerate climate change.

$\mathrm{CO}_{2}$ capture technologies have been recently implemented in industries. However, the sole commercially mature technology to capture $\mathrm{CO}_{2}$ remains an amine-based scrubbing, but its high cost and hazardous by-products forces mankind to find out alternative technologies (Veltman et al., 2010; Vericella et al., 2015; Chen C. et al., 2017).

The development of new solid adsorbents / sorbents has flourished in the last decade, being preceded by Sircar's group work (Sircar et al., 1996). The latter sorbents can be classified into lowtemperature $\left(<200^{\circ} \mathrm{C}\right)$, intermediate-temperature $\left(200-400^{\circ} \mathrm{C}\right)$, and high-temperature $\left(>400^{\circ} \mathrm{C}\right)$ $\mathrm{CO}_{2}$ adsorbents/sorbents depending on their working temperature range (Wang et al., 2012, 2015; Cao et al., 2014). LDH, known as hydrotalcite-like compounds, are a class of layered 
materials which comprise mono- or di- and trivalent cations. To date, several studies have been dealing with the high potential of LDHs-derived $\mathrm{CO}_{2}$ adsorbents, especially conventional $\mathrm{Mg}$ $\mathrm{Al}$ LDHs, which demonstrated a great performance at high temperatures (Alpay and Ding, 2000; Hutson and Attwood, 2008; Sharma et al., 2008; Lwin and Abdullah, 2009; Chang et al., 2013). Likewise, zeolites have also been subjected to extensive research for the adsorption of $\mathrm{CO}_{2}$ due to their high capture capacity, low regeneration temperatures and high stability over several adsorption-desorption cycles (Siriwardane et al., 2005; Pham et al., 2014; Bande et al., 2015; Chen C. et al., 2017; Hasegawa and Matsumoto, 2017). Regarding sorbents working at intermediate temperature range, recent studies have shown a great potential from LDH coated zeolites (Li et al., 2018). A considerable increase in the adsorption of $\mathrm{CO}_{2}$ was observed after the coating of $\mathrm{LDH}$ over a zeolite core at temperatures ranging from 30 to $300^{\circ} \mathrm{C}$ (Othman et al., 2006).

Herein, we present a $\mathrm{CO}_{2}$ adsorption study comprising the three types of aforementioned materials. The impact of the zeolite $\mathrm{Si} / \mathrm{Al}$ ratio on its capture capacity, as well as the presence of mesopores has been highlighted. By comparing these results with the well-known performance of LDHs and LDH@zeolite composites, we aim to give insights on the factors that may influence the $\mathrm{CO}_{2}$ capture in zeolites, thus providing useful tools to tune their features upon different post-treatments (LDH coating, introduction of mesoporosity).

\section{EXPERIMENTAL}

\section{Synthesis}

\section{Large Crystal Zeolites}

$\mathrm{NH}_{4}$-ZSM-5 zeolites were directly synthesized via fluoridemediated route adapted from our former studies. In a typical synthesis, the Al-source (different amounts to reach the following Si/Al molar ratios: 200, 100, 50, and 25) was first weighted in a $150 \mathrm{~mL}$-Erlenmeyer flask where $50 \mathrm{~mL}$ of distilled water was added under vigorous stirring (700 rpm, r.t.). After complete dissolution, $\mathrm{TPABr}(0.498 \mathrm{~g})$ and $\mathrm{NH}_{4} \mathrm{~F}(1.103 \mathrm{~g})$ were consecutively added. Finally, $1.607 \mathrm{~g}$ of solid silica (Aeroperl $300 / 30$, Evonik) was slowly added during $5 \mathrm{~min}$. The gel was aged $2 \mathrm{~h}$ under vigorous stirring and finally autoclaved at $443 \mathrm{~K}$ for $144 \mathrm{~h}$. H-zeolite form was easily obtained after a single calcination at $823 \mathrm{~K}$ during $15 \mathrm{~h}$ in static air, needed to completely remove the template. The samples were named as H-ZSM-5-A, H-ZSM5-B, H-ZSM-5-C and H-ZSM-5-D, respectively, following the order related with the $\mathrm{Si} / \mathrm{Al}$ molar ratio (usually denoted as SAR) decrease.

\section{Zeolite Derived Materials}

Commercial ZSM-5 zeolite (CBV3020E) having Si/Al molar ratio of 15 was purchased from Zeolyst in its ammonium form. The zeolite was either calcined at $600^{\circ} \mathrm{C}$ for $4 \mathrm{~h}$ to produce its proton form, named $\mathrm{R} 0-\mathrm{H}$, or subjected to a cationic exchange to produce its sodium form $\mathrm{R} 0-\mathrm{Na}$. The latter was performed by exchanging three times the zeolite with $\mathrm{NaCl} 1 \mathrm{M}$ at $80^{\circ} \mathrm{C}$ for $1 \mathrm{~h}$, followed by filtration and drying. To prepare the mesoporous zeolite, $200 \mathrm{mg}$ of the commercial powder in its proton form was subjected to an alkaline treatment with $0.15 \mathrm{~mL}$ of $0.2 \mathrm{M}$ of $\mathrm{NaOH}$ at $65^{\circ} \mathrm{C}$ for $30 \mathrm{~min}$. The solution was filtered, dried and added to a $30 \mathrm{~mL}$ solution of tetraethylammonium hydroxide $(\mathrm{TEAOH}$, $0.1 \mathrm{M}$ ) and $100 \mathrm{mg}$ of alkali lignin (Aldrich). After stirring, the solution was transferred to an autoclave and placed in an oven at $150^{\circ} \mathrm{C}$ for $10 \mathrm{~h}$, followed by filtration, drying and calcination at $550^{\circ} \mathrm{C}$ for $15 \mathrm{~h}$ ( $1 \mathrm{~h}$ ramp to burn off the templates). The sample was treated three times with $1 \mathrm{M}$ of $\mathrm{NH}_{4} \mathrm{Cl}$ at $80^{\circ} \mathrm{C}$, followed by filtration, drying and calcination at $550^{\circ} \mathrm{C}$ to release $\mathrm{NH}_{3}$ to ensure the proton form of the zeolite. The sample was named $\mathrm{R} 0$-meso-H. Following the same procedure as for $\mathrm{R} 0-\mathrm{H}$, the mesoporous sample was subjected to another cationic exchange to leave its sodium form R0-meso-Na.

$\mathrm{R} 0-\mathrm{H}$ material was also coated with $\mathrm{Mg}-\mathrm{Al} \mathrm{LDH}$ using a co-precipitation method. It should be noted that based on the obtained results (H-ZSM-5-D vs. R0-H), only the commercial sample was chosen for the coating procedure. Firstly, $200 \mathrm{mg}$ of zeolite was dispersed in $40 \mathrm{~mL}$ of distilled water for $30 \mathrm{~min}$, followed by the addition of $0.212 \mathrm{~g}$ of sodium carbonate and dispersion for additional $20 \mathrm{~min}$. Then, a $40 \mathrm{~mL}$ aqueous solution containing $1.918 \mathrm{mmol}$ of magnesium nitrate hexahydrate $\left(\mathrm{Mg}\left(\mathrm{NO}_{3}\right)_{2} \cdot 6 \mathrm{H}_{2} \mathrm{O}\right)$ and $0.955 \mathrm{mmol}$ of aluminium nitrate nonahydrate $\left(\mathrm{Al}\left(\mathrm{NO}_{3}\right)_{3} .9 \mathrm{H}_{2} \mathrm{O}\right)$ was added drop-wise to the previous solution for around $1 \mathrm{~h}$ under vigorous stirring. The $\mathrm{pH}$ of the solution was kept constant at 10 by adding $1 \mathrm{M}$ of sodium hydroxide. After stirring for $4 \mathrm{~h}$, the solid was filtered and washed. The sample was stirred for another $4 \mathrm{~h}$ in $40 \mathrm{~mL}$ of ethanol, and then filtered and dried. The composite was calcined at $400^{\circ} \mathrm{C}$ for $5 \mathrm{~h}$ to obtain the LDO (layered double oxide) and named finally R0@LDH.

\section{LDHs}

$\mathrm{MgAl}$ and $\mathrm{CaAl} \mathrm{LDH}$ were prepared using the co-precipitation method. All chemicals were purchased from Acros Organics, VWR and Sigma-Aldrich. In brief, a salt solution containing a mixture of $\mathrm{M}^{2+}$ precursor and $\mathrm{Al}\left(\mathrm{NO}_{3}\right)_{3} \quad 9 \mathrm{H}_{2} \mathrm{O}$ was added dropwise to an alkaline solution $(100 \mathrm{~mL})$ containing $\mathrm{Na}_{2} \mathrm{CO}_{3}$ $\left(\mathrm{NaNO}_{3}\right.$ for $\left.\mathrm{CaAl} \mathrm{LDHs}\right)$ and additives. The $\mathrm{pH}$ of the precipitation solution was kept constant at 10 (or 11 for $\mathrm{CaAl}$ LDHs) by addition of $\mathrm{NaOH}(4 \mathrm{M})$ solution. The resulting mixture was aged at room temperature for $12 \mathrm{~h}$ under continuous stirring. The aged mixture was then filtered and washed with deionized water followed by drying at $100^{\circ} \mathrm{C}$ in an oven. In order to study the impact of structural degradation (LDO formation), $\mathrm{MgAl} \mathrm{LDH}$ sample was finally calcined at $400^{\circ} \mathrm{C}$ during $5 \mathrm{~h}$ in static air. Meanwhile, $\mathrm{CaAl} \mathrm{LDH}$ was treated at $750^{\circ} \mathrm{C}$ during $5 \mathrm{~h}$ in the same atmosphere. Samples were named as $\mathrm{LDH}$ fresh or LDH calcined.

\section{Characterization}

Powder X-ray diffraction (XRD) patterns of zeolites were acquired using a Bruker D8 $(\mathrm{Cu} \mathrm{K} \alpha)$ diffractometer operated at $40 \mathrm{kV}$ and $40 \mathrm{~mA}$. XRD patterns were recorded in the $2 \theta=5-60^{\circ}$ range with a step size of $0.05^{\circ}$. XRD patterns of $\mathrm{LDH}$ materials were acquired over a Rigaku Ultima IV apparatus using $\mathrm{CuK} \alpha$ radiation $(\lambda=0.15418 \mathrm{~nm})$, operated at $40 \mathrm{kV}$ and $20 \mathrm{~mA}$. Scans were performed at $2^{\circ} \mathrm{min}^{-1}$ in the $3-70^{\circ}$ range. 
SEM images were acquired in a JEOL FEG-6700F microscope working at a $9 \mathrm{kV}$ accelerating voltage. Bulk elemental analyses were determined by X-ray fluorescence (XRF) using a XEPOS (AMETEK) device equipped with a $\mathrm{Rh}$ radiation tube.

The textural properties were analyzed by means of nitrogen physisorption using Micromeritics ASAP 2420 equipment. Samples were pre-treated in-situ at $200^{\circ} \mathrm{C}$ under vacuum prior to the analyses. Surface areas were determined using the BET method and pore size distributions were obtained using the adsorption branch of the isotherms (BJH method).

Zeolite acid site density was evaluated by temperature programmed ammonia desorption ( $\left.\mathrm{NH}_{3}-\mathrm{TPD}\right)$ by using a Micromeritics AutoChem II chemisorption analyzer equipped with TCD detector. Samples were pre-treated in-situ at $550^{\circ} \mathrm{C}$ during $1 \mathrm{~h}$ under helium atmosphere. After that, samples were cooled down to room temperature and a $5 \% \mathrm{NH}_{3} / \mathrm{He}$ flow was passed through the reactor. Once physisorbed ammonia was removed, the temperature gradually increased to $550^{\circ} \mathrm{C}$.

The hydrophilicity of the zeolites has been determined by contact angle measurements as follows: $20 \mathrm{mg}$ of powder was placed under an hydraulic press, and let under 12 bar for $30 \mathrm{~s}$ to obtain a compact pellet. Wetting properties of the samples were determined by static contact angle using an optical tensiometer (Attension theta, Biolin Scientific). A $2 \mu \mathrm{l}$ drop of purified water (milli Q) was deposited on the pellet surface and the angle was recorded by the camera mounted on the device.

\section{Evaluation of $\mathrm{CO}_{2}$ Adsorption Capacity}

Thermogravimetric sorption of $\mathrm{CO}_{2}$ on zeolites, LDHs and composites was measured using a TGA analyzer (Q500 TA Instrument). All solids were first calcined in a muffle furnace at a temperature comprised between 400 and $600^{\circ} \mathrm{C}$ for $5 \mathrm{~h}$, before transferring the samples to the TGA analyzer. To avoid any error, the test was done immediately after the first calcination. Finally, the samples were further calcined in situ for $1 \mathrm{~h}$ in $\mathrm{N}_{2}$ prior to the measurement. $\mathrm{CO}_{2}$ adsorption experiments were carried out at 1 atm with a constant flow of $\mathrm{CO}_{2}\left(40 \mathrm{~mL} \mathrm{~min}^{-1}\right)$.

\section{RESULTS AND DISCUSSION}

\section{Large Zeolite Crystals}

Fluoride-mediated synthesis of ZSM-5 zeolite crystals provides mild conditions, thus facilitating the formation of few nuclei under diluted conditions as consequence of a slow release of $\mathrm{SiO}_{\mathrm{x}} \mathrm{F}_{\mathrm{y}}^{-}$species (Flanigen et al., 1986; Losch et al., 2017). The latter renders possible the formation of highly crystalline zeolites characterized by larger crystals (usually tenths of microns) with less defects and more open structures than in alkaline medium (Xu et al., 1990). This, together with the high Si/Al ratio that can be obtained, entails the formation of more

TABLE 1 | Chemical composition, acid site density and textural properties of as-synthetized H-ZSM-5 zeolites.

\begin{tabular}{|c|c|c|c|c|}
\hline Sample & $\begin{array}{c}\text { SAR } \\
\text { (XRF) }\end{array}$ & $\begin{array}{c}\text { Acid site density } \\
\left(\mathrm{mmol}\left(\mathrm{H}^{+}\right) / \mathrm{g} \text { zeolite }\right)^{\mathrm{a}}\end{array}$ & $\begin{array}{l}\mathrm{S}_{\mathrm{BET}} \\
{\left[\mathrm{m}^{2} / \mathrm{g}\right]}\end{array}$ & $\begin{array}{c}V_{\text {pore }} \\
\left(\mathrm{cm}^{3} / \mathrm{g}\right)\end{array}$ \\
\hline H-ZSM-5-A & 226 & 0.110 & 355 & 0.178 \\
\hline H-ZSM-5-B & 115 & 0.168 & 296 & 0.184 \\
\hline H-ZSM-5-C & 55 & 0.297 & 348 & 0.178 \\
\hline H-ZSM-5-D & 43 & 0.309 & 347 & 0.181 \\
\hline
\end{tabular}

a Determined by $\mathrm{NH}_{3}-\mathrm{TPD}$.

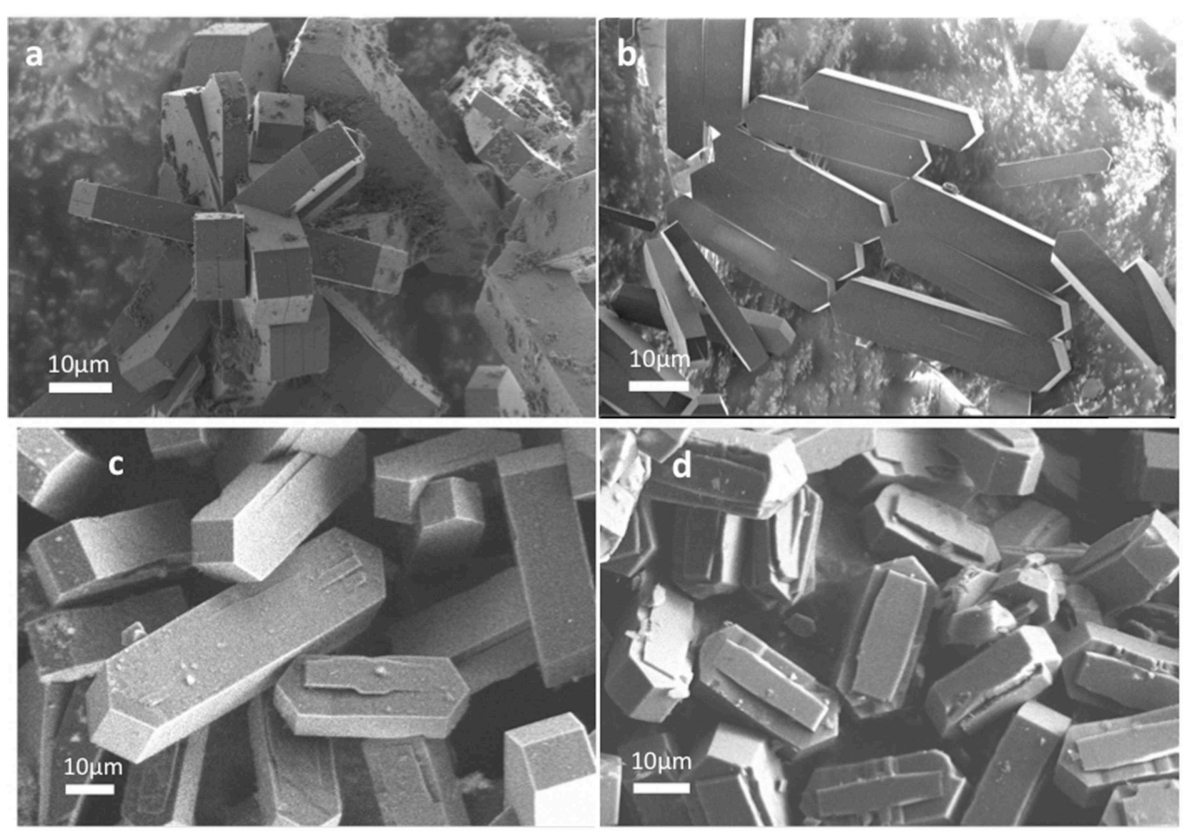

FIGURE 1 | SEM images of as-synthetized H-ZSM-5 zeolites. (a) H-ZSM-5-A, (b) H-ZSM-5-B, (c) H-ZSM-5-C, and (d) H-ZSM-5-D. 
hydrophobic materials. Therefore, the possible effect of both the hydrophobicity and crystal size can be evaluated in terms of $\mathrm{CO}_{2}$ capture capacity.

The XRD patterns of each zeolite (Figure S1) confirmed the presence of the sole MFI structure (Ocampo et al., 2009, 2010). Whatever the aluminum content in the framework, all syntheses led to the formation of large prismatic crystals (Figure 1) having between 30 and $60 \mu \mathrm{m}$ in size. Lower $\mathrm{Al}$ containing zeolites have, in general, narrow crystal size distributions (Figures 1a,b) differing from zeolites with higher $\mathrm{Al}$ content (Figure 1c). A difference in the crystal morphology can be observed for H-ZSM5-D (possessing the lowest SAR, Table 1).

Table 1 summarizes the Si/Al ratios, the total number of Brønsted acid sites and the textural properties of as-prepared zeolites. XRF values together with $\mathrm{NH}_{3}$-TPD experiments confirm a successful variation of acidic properties, i.e., aluminum content, within the series while neither influencing the specific surface areas, nor the pore volumes.

$\mathrm{CO}_{2}$ capture capacities of large crystals H-ZSM-5 zeolites were evaluated using a TGA analyzer in order to monitor the weight changes of each sample under a constant $\mathrm{CO}_{2}$ flow. Prior to analysis, the sample surface was cleaned by means of two calcination steps in situ under inert flow. Afterwards, $\mathrm{CO}_{2}$ capture abilities were evaluated at low temperature $\left(40^{\circ} \mathrm{C}\right)$ and intermediate-temperature $\left(200^{\circ} \mathrm{C}\right)$ and presented in Figure 2. The data acquired at low temperature strongly depend on the $\mathrm{Si} / \mathrm{Al}$ content in zeolites (Figure 2A) which is in agreement with former literature reports (Chen $\mathrm{H}$. et al., 2017). $\mathrm{CO}_{2}$ adsorption capacity was enhanced while diminishing the $\mathrm{Si} / \mathrm{Al}$ ratio. This can be attributed to the presence of more $\mathrm{Al}$ atoms in the framework. $\mathrm{CO}_{2}$ interaction with zeolites is governed by the hard Lewis base character of oxygen atoms (Pham et al., 2014) that strongly interact with hard Lewis acid sites as $\mathrm{Al}^{3+}$. One may therefore a priori expect that lower $\mathrm{Si} / \mathrm{Al}$ ratio may induce a higher quantity of $\mathrm{CO}_{2}$ adsorbed. Indeed this trend could be verified over large MFI zeolite crystals. In addition, lower $\mathrm{Si} / \mathrm{Al}$ implies superior ion exchange ability due to the presence of more charge compensation cations. Finally, zeolites with lower Si/Al ratio are expected to be more hydrophilic. Indeed, contact angle measurements have been performed and hopefully confirmed this statement. H-ZSM-5-D, having the lowest SAR (43), exhibited the smaller contact angle with the water drop, $22.6^{\circ}$ in comparison with $28.5^{\circ}$ for H-ZSM-5-C (SAR 55), 55.0 for H-ZSM-5-B (SAR 115) and $67.0^{\circ}$ for H-ZSM-5-A (SAR 226), respectively.

To summarize, the higher $\mathrm{CO}_{2}$ sorption capacity has been obtained over zeolites which are more hydrophilic, thus possessing more $\mathrm{Al}$-atoms in the frame.

The adsorption capacity at intermediate-temperature $\left(200^{\circ} \mathrm{C}\right)$ was also evaluated over H-ZSM-5-D (lowest SAR zeolite) and presented in Figure 2A. The adsorption capacity diminished from 1.033 to $0.056 \mathrm{mmol}_{\mathrm{CO} 2} / \mathrm{g}$, limiting the application of large ZSM-5 crystals at higher temperatures. The latter result points out the importance of physisorption phenomena in zeolites at low temperatures. In contrast at higher temperatures, $\mathrm{CO}_{2}$ sorption should be only ruled by
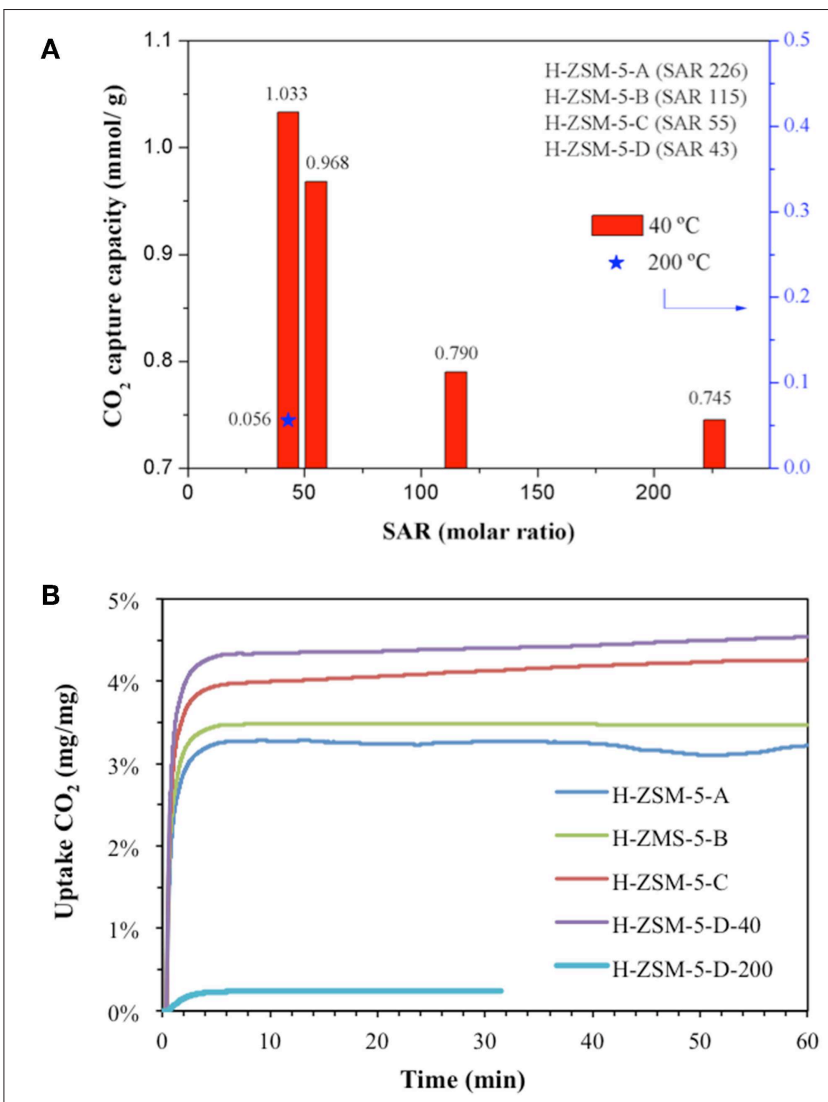

FIGURE 2 | (A) $\mathrm{CO}_{2}$ capture capacity as a function of $\mathrm{Si} / \mathrm{Al}$ mole ratio and sorption temperature. (B) $\mathrm{CO}_{2}$ uptake curves.

chemical interactions, which unfortunately diminishes the sorption capacity.

$\mathrm{CO}_{2}$ uptake curves as function of time are shown in Figure 2B. The sorbents displayed fast $\mathrm{CO}_{2}$ sorption kinetics for a very short absorption time period (less than $3 \mathrm{~min}$ ). The latter could be attributed to the high specific surface area and the microporous network which provide a higher availability of active sites. In general, two stages concerning the sorption process can be differentiated in the solids. Firstly, a fast uptake reaction occurs at the initial stage of $\mathrm{CO}_{2}$ absorption (less than $3 \mathrm{~min}$ ). Secondly, a later long-period stage usually appears where it is possible to distinguish a continuous (but considerably slower) increase in the sample weight. The first stage is directly related to the chemical reaction control whilst the second one is more likely attributed to a diffusional control (Chang et al., 2013). By careful comparing these uptake curves obtained at $40^{\circ} \mathrm{C}$ (Figure 2B), it is noteworthy that the sorption process is controlled by the chemical reaction for low $\mathrm{Al}$ content H-ZSM5-A (SAR 226) and H-ZSM-5-B (SAR 115) zeolites. In contrast, H-ZSM-5-C (SAR 55) and H-ZSM-5-D (SAR 43) seem to suffer from diffusional limitations. These results are in line with the adsorption capacity values presented in Figure 2A. As aluminum content increases in the materials, a larger amount of $\mathrm{CO}_{2}$ molecules diffuse and absorb within the pores, thus hindering the 


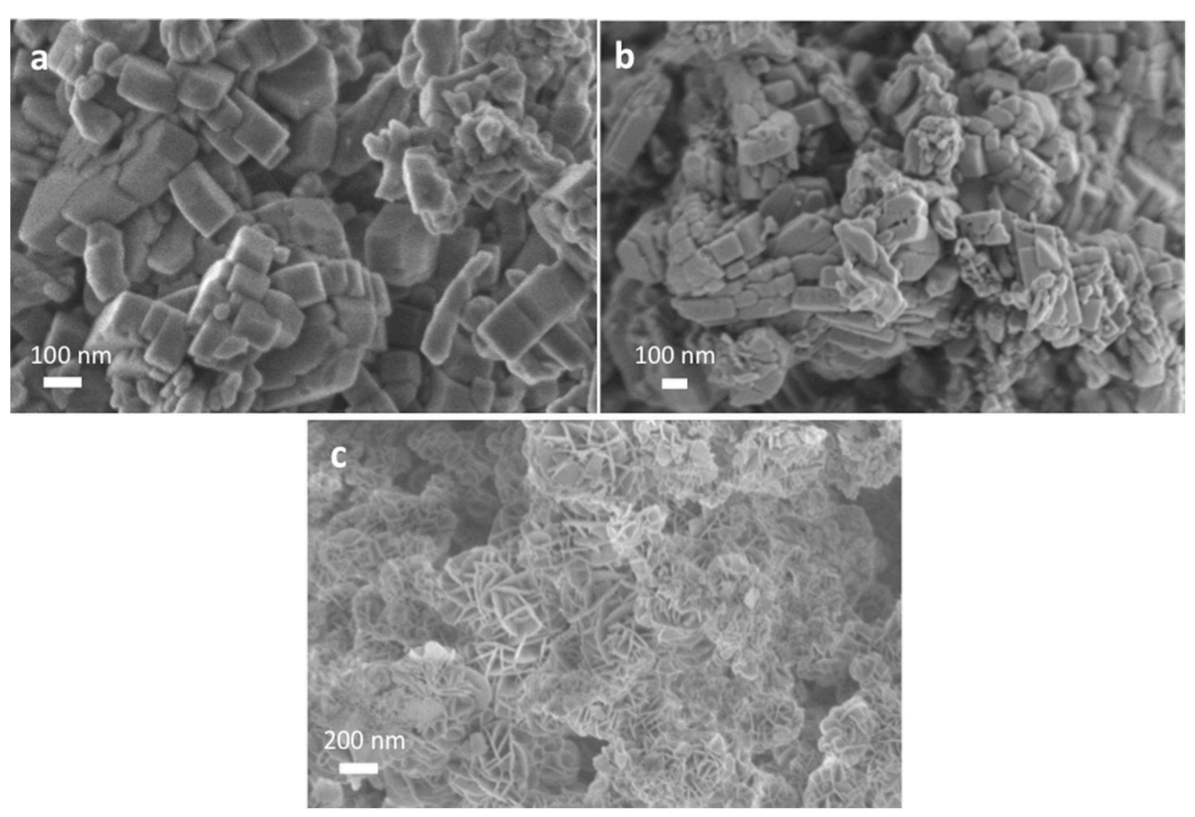

FIGURE 3 | SEM pictures of (a) RO-H, (b) RO-meso H, and (c) RO@LDH composite.

$\mathrm{CO}_{2}$ diffusion along the cavities. This phenomenon is discarded at $200^{\circ} \mathrm{C}$ due to the lower uptake capacity at higher temperatures.

\section{Core-Shell LDH@zeolite Composites}

The diffraction patterns of commercial $\mathrm{R} 0-\mathrm{H}$ zeolite and core-shell LDH@zeolite material confirm the sole presence of MFI structure (Figure S2). Neither the presence of mesopores nor the coating of LDH led to different diffraction peaks. The LDH presence is evidenced by SEM analysis as shown in Figure 3. R0-H sample possess regular nanosized morphology (Figure 3a) with smooth surface which became rough when the mesopores were created (Figure 3b). After coating with $\mathrm{LDH}$, the composite retains the original shape of pristine zeolite together with uniform flower-like shaped edges (Figure 3c). A core-shell LDH@ZSM-5 zeolite composite has therefore been successfully obtained, as already reported by Wang et al. (Li et al., 2018).

The textural properties of commercial $\mathrm{R} 0-\mathrm{H}$ and postmodified materials are summarized in Table 2 . The specific surface area of both zeolites (commercial and meso) is close to $360-370 \mathrm{~m}^{2} / \mathrm{g}$, not being affected by the presence of mesopores. A slight decrease of about $20 \%$ in BET surface could be observed after the coating with LDH, R0@LDH sample, whilst the total pore volume almost doubled.

In order to gain more insights on those samples porosity, $\mathrm{BJH}$ pore profiles are shown in Figure 4. The pore size variation toward the mesoporous range among the samples is verified while ranging from $\mathrm{R} 0-\mathrm{H}$ to $\mathrm{R} 0$-meso $\mathrm{H}$ and R0@LDH. Pristine zeolite is characterized by the sole presence of micropores (Figure 4A) together with mesopores having $4-6 \mathrm{~nm}$ being assigned to intercrystalline porosity. The pore diameter profile changes for R0-meso $\mathrm{H}$ (Figure 4B)
TABLE 2 | Textural properties of commercial $\mathrm{RO}-\mathrm{H}$ and zeolite derived materials.

\begin{tabular}{lcccc}
\hline Sample & $\mathbf{S}_{\text {BET }}\left[\mathbf{m}^{\mathbf{2}} / \mathbf{g}\right]$ & $\mathbf{S}_{\text {meso }}\left[\mathbf{m}^{\mathbf{2}} / \mathbf{g}\right]$ & $\mathbf{V}_{\text {total }}\left(\mathbf{c m}^{\mathbf{3}} \mathbf{g}\right)$ & $\mathbf{V}_{\text {micro }}\left(\mathbf{c m}^{\mathbf{3}} \mathbf{g}\right)$ \\
\hline RO-H & 369 & 147 & 0.23 & 0.109 \\
R0-meso H & 362 & 144 & 0.26 & 0.107 \\
R0@LDH & 298 & 142 & 0.43 & 0.076 \\
\hline
\end{tabular}

highlighting the presence of mesopores of about $12 \mathrm{~nm}$, demonstrating the mesoporous character of this sample. Regarding the zeolite coated with LDH (Figure 4C), the pore sizes further increased in the mesoporous range. The presence of macropores could also be evidenced, being probably due to the presence of LDHs at the zeolite crystals surface ( $\mathrm{Li}$ et al., 2018). Zeolite micropores might be still accessible during nitrogen adsorption after the LDH coating procedure but the diffusion might be partially hindered. In any case, the use of zeolite for the synthesis of the LDH@ZSM-5 nanocomposite allows enhancing the specific surface area in comparison to pristine $\mathrm{LDH}$.

$\mathrm{CO}_{2}$ capture capacities of as-prepared samples are presented in Figure 5A. In order to evaluate the cation nature influence along with the mesopore presence, $\mathrm{R} 0-\mathrm{H}$ and $\mathrm{R} 0$ meso- $\mathrm{H}$ samples were subjected to cationic exchange to get their sodium form. In principle, the $\mathrm{CO}_{2}$ sorption capacity raises when the protons are exchanged with sodium cations (R0-H vs. R0-Na and R0 meso$\mathrm{H}$ vs. R0 meso-Na, respectively). Although some differences could be observed due to mesopores presence, a higher capacity could be achieved over Na-zeolite forms. Previous studies have underlined that the main interaction between the zeolite surface and $\mathrm{CO}_{2}$ is the field gradient-quadrupole interaction 

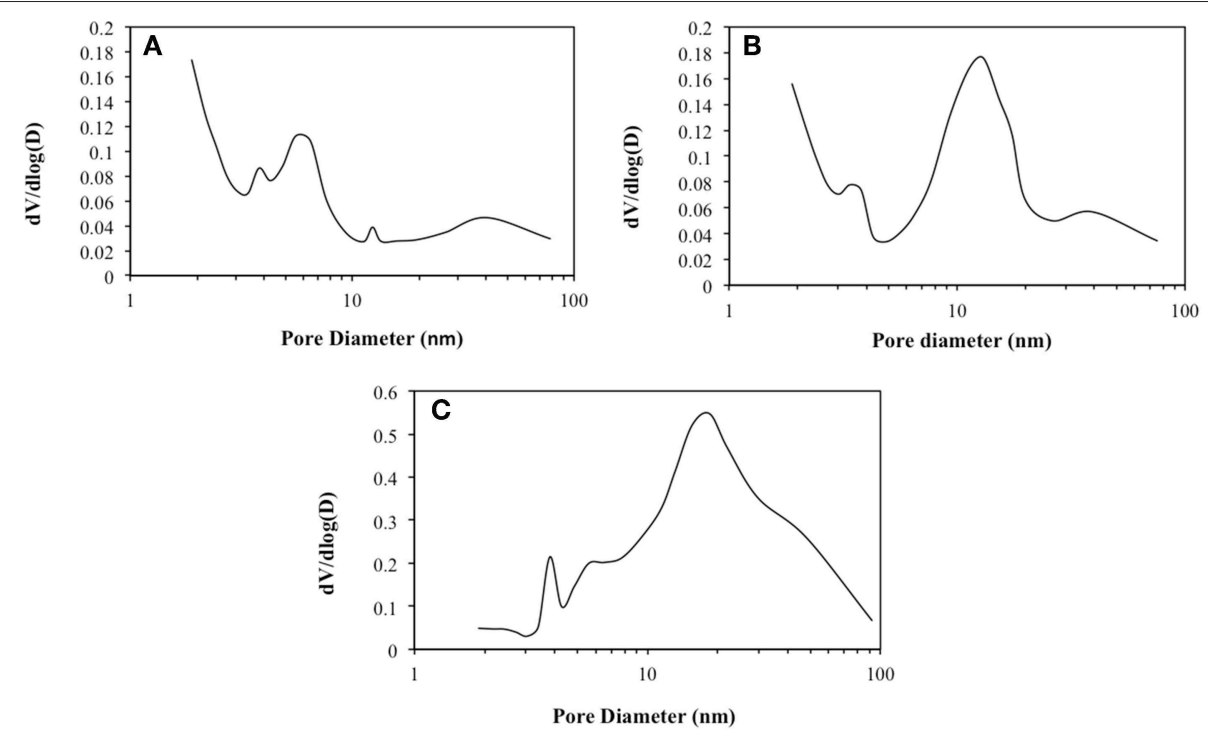

FIGURE 4 | BJH pore profiles of (A) RO-H, (B) RO-meso H, and (C) RO@LDH.

A
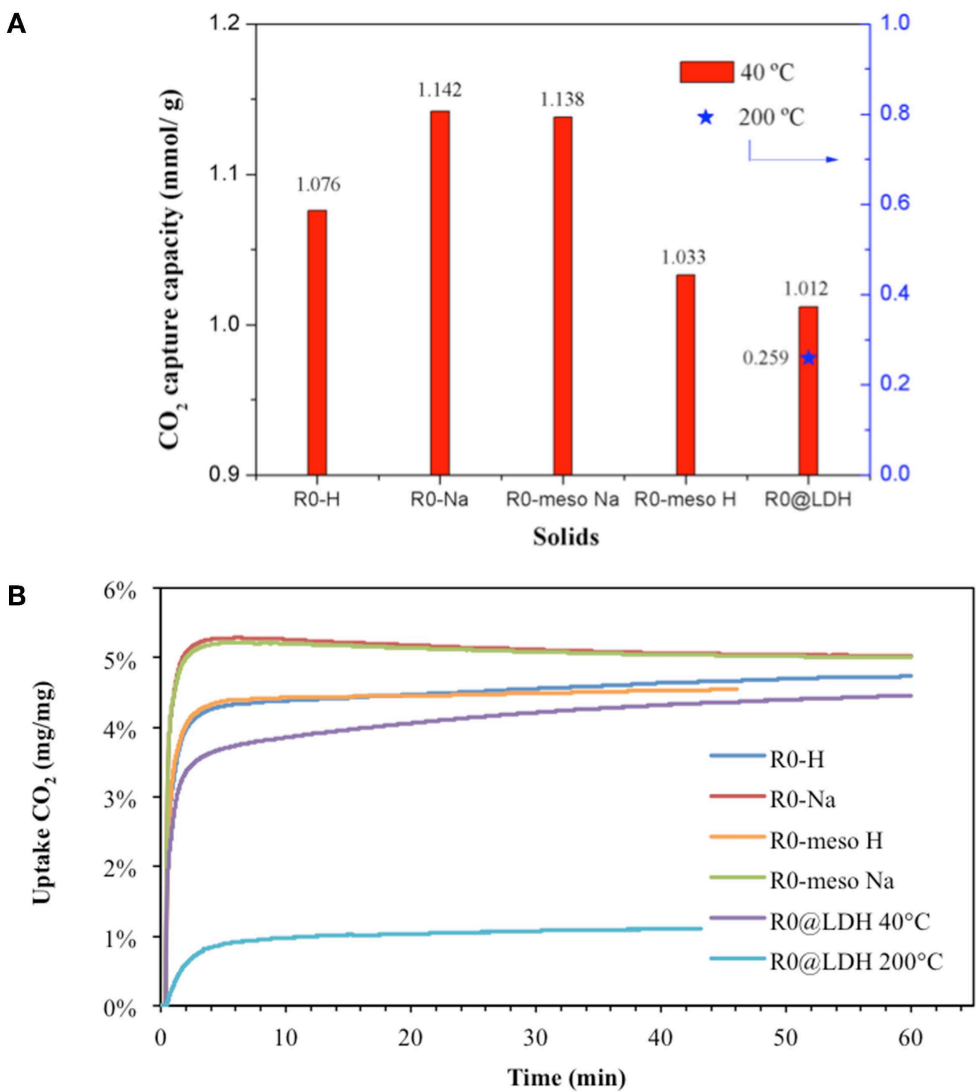

FIGURE 5 | (A) $\mathrm{CO}_{2}$ capture capacity of zeolites and LDH-based materials as function of sorption temperature. (B) $\mathrm{CO}_{2}$ uptake curves.

(Hasegawa and Matsumoto, 2017) which is proportional to $r^{-3}$ and the valence of the cation, $z$. Since the ionic radius of $\mathrm{H}^{+}$is the smallest, the ion- $\mathrm{CO}_{2}$ distance is the shortest and therefore the interaction would be the strongest. Carbon dioxide molecules in small and medium-pore zeolites are strongly adsorbed, possibly hindering the diffusion of other molecules inside the pores, resulting in smaller $\mathrm{CO}_{2}$ uptake capacities. The latter explains the lower observed uptakes for 
acidic R0 and R0-meso samples in comparison to their Naexchanged counterparts.

The presence of mesopores (R0-H vs. R0-meso H) led to lower sorption capacities, in contrast to what could be expected taking into account mass transfer limitations. A possible explanation could be based on the removal of Al-atoms during the creation of the mesopores, diminishing therefore the number of potential adsorption sites for carbon dioxide molecules. Indeed, the sorption capacity achieved over R0-meso $\mathrm{H}$ sample is 1.033 $\mathrm{mmolCO}_{2} / \mathrm{g}$, being exactly the same value reached over H-ZSM5 -D. The later zeolite has a $\mathrm{Si} / \mathrm{Al}=43$, which is almost the triple than for $\mathrm{R} 0-\mathrm{H}(\mathrm{Si} / \mathrm{Al}=15)$. This effect is partially suppressed after exchanging the zeolite with $\mathrm{Na}^{+}$, probably due to a better diffusion of carbon dioxide molecules through the narrow zig-zag channels, hence enabling an easier access to the active sites.

When the acidic R0 zeolite is coated with LDH, a lower sorption capacity is obtained. As observed in the $\mathrm{BJH}$ profiles, zeolite micropores seem to be blocked (at least partially) after LDH coating, suggesting that only the LDH part could interact with $\mathrm{CO}_{2}$. Although LDHs have demonstrated to be efficient $\mathrm{CO}_{2}$ adsorbents (Chang et al., 2013), the quantity used in this composite is smaller when compared to bare LDH material. At higher temperature $\left(200^{\circ} \mathrm{C}\right)$, the capacity value diminishes from 1.012 to $0.259 \mathrm{mmol}_{\mathrm{CO} 2} / \mathrm{g}$ (which supposes $76 \%$ capacity loss), as expected by the exclusion of physisorption phenomenon at higher temperatures. However, this decrement is low in comparison with the 95\% registered for H-ZSM-5-D zeolite (previous section) which points out the beneficial effect of LDH coating.

Figure 5B shows the $\mathrm{CO}_{2}$ uptake curves as a function of time for each sample. It is worthy to mention that $\mathrm{Na}$-exchanged samples and acidic zeolites follow the similar trend, being different from LDH coated sample. All samples are characterized by a fast adsorption process (less than $3 \mathrm{~min}$ ) followed by a diffusional control effect depending on the material. Slight differences can be observed over micro- and mesoporous $\mathrm{H}$ zeolites ( $\mathrm{R} 0-\mathrm{H}$ vs. $\mathrm{R} 0$-meso $\mathrm{H}$ ) regarding the second adsorption stage, i.e., the later long-period stage. For $\mathrm{R} 0-\mathrm{H}$, it is possible to distinguish a continuous but considerably slower weight increase contrarily to R0-meso H sample. This effect suggests that the mesopores presence may avoid diffusional problems during the adsorption process. Likewise for Na-exchanged samples, a continuous decrease in the sample weight is observed, thus indicating that a small fraction of $\mathrm{CO}_{2}$ molecules are fastly and weakly adsorbed on the zeolite surface. The impact of diffusion is more pronounced over R0@LDH at $40^{\circ} \mathrm{C}$, being limited at $200^{\circ} \mathrm{C}$.

\section{LDHs}

The diffraction patterns of $\mathrm{MgAl}$ and $\mathrm{CaAl}$ based samples are presented in Figure S3. Highly crystalline $\mathrm{Mg}-\mathrm{Al}-\mathrm{NO}_{3}$ and Ca-Al- $-\mathrm{NO}_{3}$ were successfully prepared using co-precipitation method leading to pure LDHs phases (Wang et al., 2015) with characteristic peaks at $11.7^{\circ}, 23.7^{\circ}, 34.7^{\circ}$, and $39.3^{\circ}$, corresponding to the basal planes of (003), (006), (009) and (015) reflections (Climent et al., 2004). Since LDH derived materials will be activated by thermal treatment before $\mathrm{CO}_{2}$ sorption, XRD patterns were also recorded after calcination. LDHs usually lose their layered structure, turning into layered double oxides (LDOs) which possess three kinds of active sites. The structure and composition changes are probably the most important parameters to take into account for an application as sorbent. It can be deduced from TGA curves (Figure S4), that structural changes occur at different temperatures for $\mathrm{MgAl}$ and $\mathrm{CaAl}$ LDHs. MgAl LDH first loses its interlayer water until $200^{\circ} \mathrm{C}$. From this temperature, the dehydroxylation of the octahedral layers takes place as well as the interlayer charge compensation nitrate anions removal, which last up to $400^{\circ} \mathrm{C}$. The same two weight loss steps can be differentiated for CaAl LDH, being in this case $550^{\circ} \mathrm{C}$ the final temperature. Based on that and in order to ensure $\mathrm{LDO}$ formation, $\mathrm{MgAl}$ and $\mathrm{CaAl} \mathrm{LDHs}$ were calcined at $400^{\circ} \mathrm{C}$ and $750^{\circ} \mathrm{C}$ during $5 \mathrm{~h}$, respectively, and XRD diffraction patterns presented in Figure S3. As expected, after calcination,

TABLE 3 | Textural properties of fresh and calcined LDHs.

\begin{tabular}{lcccccc}
\hline Sample & $\begin{array}{c}\mathrm{S}_{\mathrm{BET}} \\
{\left[\mathrm{m}^{2} / \mathrm{g}\right]} \\
\text { fresh }\end{array}$ & $\begin{array}{c}\mathrm{S}_{\mathrm{BET}} \\
{\left[\mathrm{m}^{2} / \mathrm{g}\right]} \\
\text { calcined }\end{array}$ & $\begin{array}{c}\text { Pore } \\
\text { size } \\
(\mathbf{n m}) \\
\text { fresh }\end{array}$ & $\begin{array}{c}\text { Pore } \\
\text { size } \\
(\mathbf{n m}) \\
\text { calcined }\end{array}$ & $\begin{array}{c}\mathbf{V}_{\text {pore }} \\
\left(\mathrm{cm}^{3} / \mathbf{g}\right) \\
\mathrm{Fresh}\end{array}$ & $\begin{array}{c}\mathbf{V}_{\text {pore }} \\
\left(\mathbf{c m}^{3} / \mathbf{g}\right) \\
\text { calcined }\end{array}$ \\
\hline $\begin{array}{l}\mathrm{MgAl} \\
\mathrm{LDH}\end{array}$ & 50 & 224 & 9.0 & 13.3 & 0.19 & 0.63 \\
$\mathrm{CaAl}$ & 21 & 26 & 10.4 & 10.0 & 0.04 & 0.06
\end{tabular}

$\mathrm{LDH}$

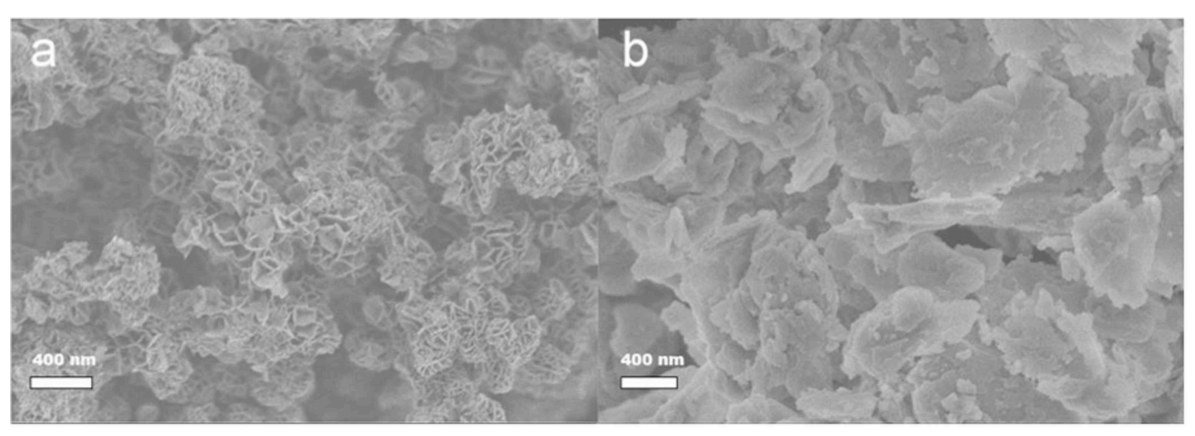

FIGURE 6 | SEM images of (a) MgAl LDH and (b) CaAI LDH. 
the samples lost their original structure and changed to pure mixed-metal oxide phases, $\mathrm{MgAl}_{2} \mathrm{O}_{4}$ and $\mathrm{CaAl}_{2} \mathrm{O}_{4}$, respectively.

SEM images of LDH samples are presented in Figure 6. $\mathrm{MgAl}$ LDH exhibits a typical spheroidal rose-like morphology different from $\mathrm{CaAl} \mathrm{LDH}$ where only regular aggregates could be observed.

The textural properties of fresh (LDH) and calcined (LDOs) solids are presented in Table 3. MgAl LDH specific surface area is more than twice higher than $\mathrm{CaAl}$ one. In both cases, the $S_{\mathrm{BET}}$ increased after calcination, although the increment is much higher for $\mathrm{MgAl}$, reaching $224 \mathrm{~m}^{2} / \mathrm{g}$. The pore sizes are similar for both samples, increasing for $\mathrm{MgAl}$ after calcination. Likewise to the pore volume, important differences between the samples could be detected, MgAl exhibiting a much higher pore volume. In both cases, the values increased after calcination, becoming more important for $\mathrm{MgAl}$ sample.

Carbon dioxide capacity values are presented for both samples in Figure 7A. The superiority of $\mathrm{MgAl}$ sample is evidenced at both temperatures, which seems logical taking into account the higher specific surface area and pore volume. Likewise for the uptake curves (Figure 7B), both samples are characterized by a fast adsorption (superior to the zeolites) and diffusional impediment in a second stage, being evidenced by a continuous weight increase as a function of time.

\section{Comparison of the Sorbents}

In general, $\mathrm{CO}_{2}$ sorption capacity depends on different factors as discussed throughout this contribution. A careful control of these

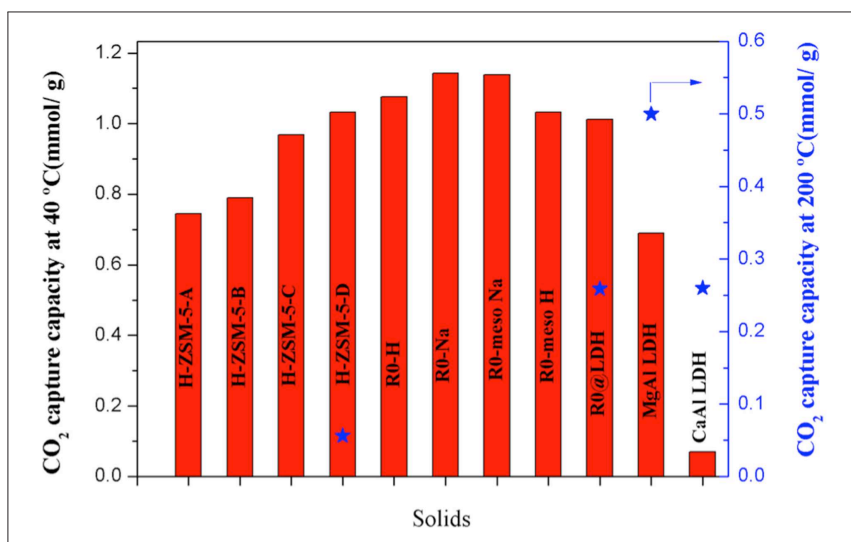

FIGURE 8 | $\mathrm{CO}_{2}$ capture capacities comparison at different temperatures.

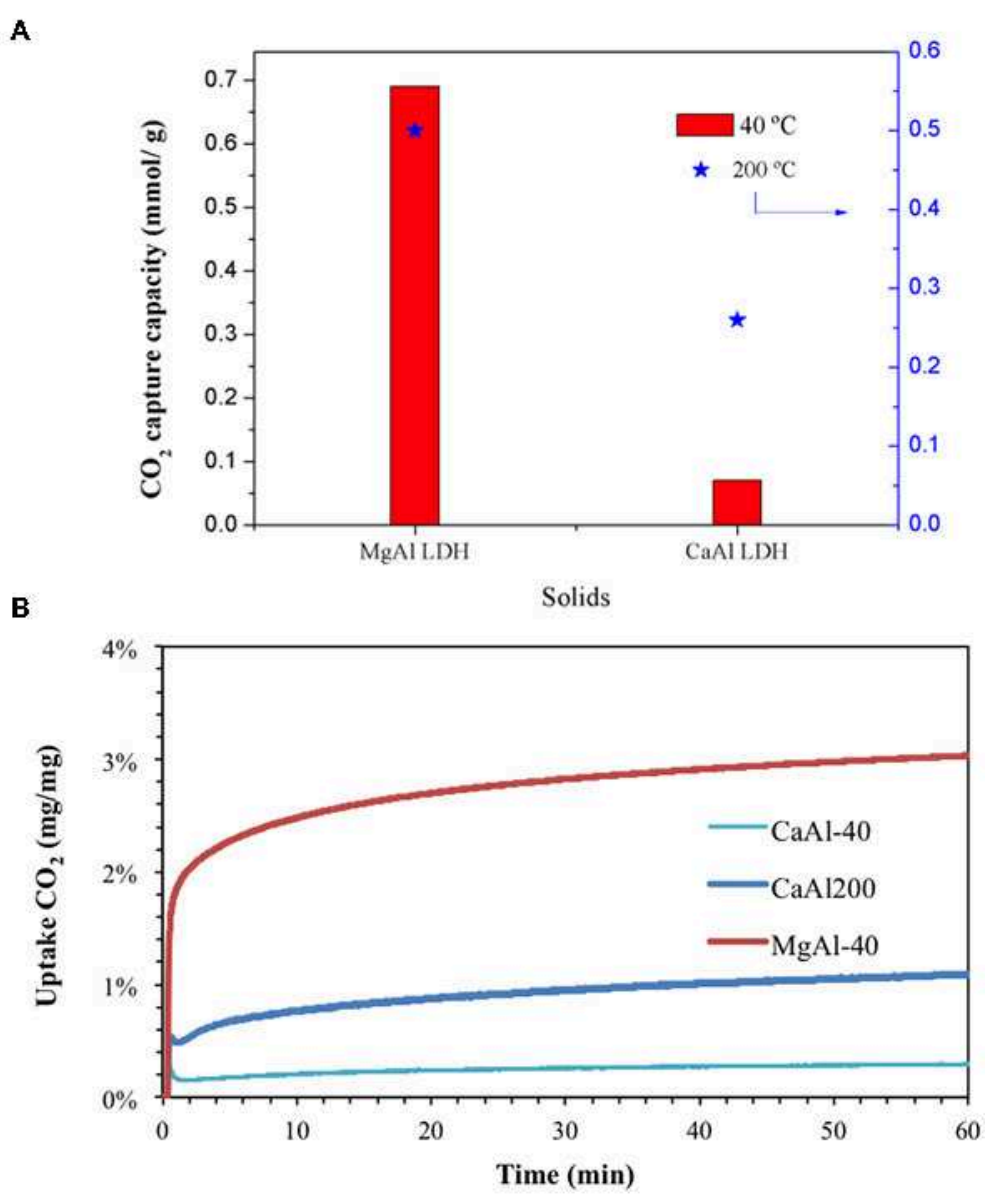

FIGURE 7 | (A) $\mathrm{CO}_{2}$ capture capacity of calcined $\mathrm{LDH}$ as function of sorption temperature (B) $\mathrm{CO}_{2}$ uptake curves. 
parameters for different materials is an effective tool to select the suitable application for the right material.

In order to summarize and properly compare, $\mathrm{CO}_{2}$ capture capacities of all materials are presented in Figure 8. At low temperature, the highest sorption values are registered for $\mathrm{Na}$-exchanged zeolites. As aforementioned, the presence of mesopores did not have an important impact, contrarily to the $\mathrm{Si} / \mathrm{Al}$ ratio and the cation nature. The impact of $\mathrm{Si} / \mathrm{Al}$ ratio has been demonstrated for the large zeolite crystals (H-ZSM5-A to H-ZSM-5-D samples). Likewise, the cation nature effect has been evidenced whatever the crystal size. While raising the temperature, the superior performance of LDHs is clear. Although at $40^{\circ} \mathrm{C}$, R0@LDH's capacity remained lower than pristine zeolite ( $\mathrm{R} 0-\mathrm{H}$ and $\mathrm{R} 0-\mathrm{Na})$, at higher temperature the LDH coating led to a more efficient sorbent material, comparable to $\mathrm{CaAl} \mathrm{LDH}$. Nevertheless, the best potential sorbent at intermediate temperature remains $\mathrm{MgAl} \mathrm{LDH}$.

\section{CONCLUSION}

The synthesis and characterization of large ZSM-5 zeolite crystals and $\mathrm{LDH}$ derived materials have been successfully performed. Those materials demonstrated efficient $\mathrm{CO}_{2}$ sorption capacity. It has been clearly shown that $\mathrm{CO}_{2}$ capture strongly depends on the concentration of Al-atoms in the zeolite framework as well as

\section{REFERENCES}

Alpay, E., and Ding, Y. (2000). Equilibria and kinetics of $\mathrm{CO}_{2}$ adsorption on hydrotalcite adsorbent. Chem. Eng. Sci. 55, 3461-3474. doi: 10.1016/S0009-2509(99)00596-5

Álvarez, A., Bansode, A., Urakawa, A., Bavykina, A. V., Wezendonk, T. A., Makkee, M., et al. (2017). Challenges in the greener production of formates/formic acid, methanol, and DME by heterogeneously catalyzed $\mathrm{CO}_{2}$ hydrogenation processes. Chem. Rev. 117, 9804-9838. doi: 10.1021/acs.chemrev.6b00816

Bande, R. I., Sadhana, R., and Rashami, S. D. (2015). $\mathrm{CO}_{2}$ adsorption and desorption studies for zeolite 4A. Res. J. Mater. Sci. 3, 7-13.

Cao, Y., Zhao, Y., Song, F., and Zhong, Q. (2014). Alkali metal cation doping of metal-organic framework for enhancing carbon dioxide adsorption capacity. J. Energy Chem. 23, 468-474. doi: 10.1016/S2095-4956(14)60173-X

Chang, P. H., Lee, T. J., Chang, Y. P., and Chen, S. Y. (2013). $\mathrm{CO}_{2}$ Sorbents with Scaffold-like Ca-Al layered double hydroxides as precursors for $\mathrm{CO}_{2}$ capture at high temperatures. ChemSusChem 6, 1076-1083. doi: $10.1002 /$ cssc. 201200910

Chen, C., Zhang, S., Row, K. H., and Ahn, W. S. (2017). Amine-silica composites for $\mathrm{CO}_{2}$ capture: a short review. J. Energy Chem. 26, 868-880. doi: 10.1016/j.jechem.2017.07.001

Chen, H., Wang, W., Ding, J., Wei, X., and Lu, J. (2017). $\mathrm{CO}_{2}$ adsorption capacity of FAU zeolites in presence of $\mathrm{H}_{2} \mathrm{O}$ : a monte carlo simulation study. Energy Proc. 105, 4370-4376. doi: 10.1016/j.egypro.2017.03.929

Climent, M. J., Corma, A., Iborra, S., Epping, K., and Velty, A. (2004). Increasing the basicity and catalytic activity of hydrotalcites by different synthesis procedures. J. Catal. 225, 316-326. doi: 10.1016/j.jcat.2004.04.027

Flanigen, E. M., Lok, B. M., Patton, R. L., Wilson, S. T. (1986). New Developments in Zeolite Science and Technology. Tokyo: Co-Published by Kodansha LTD; Elsevier.

Hasegawa, K., and Matsumoto, A. (2017). Role of cation in target adsorption of carbon dioxide from $\mathrm{CO}_{2}-\mathrm{CH}_{4}$ mixture by low silica $\mathrm{X}$ zeolites. AIP Conf. Proc. 1865:020002. doi: 10.1063/1.4993321

Horbach, J., Chen, Q., Rennings, K., and Vögele, S. (2014). Environmental innovation and societal transitions do lead markets for clean coal technology its cation nature. In contrast, the mesoporous character did not seem to induce an important effect.

For LDHs, high specific surface area combined with high pore volume appear as a determining factor for achieving high adsorption. When comparing different materials, the highest sorption values at low temperature were registered for sodium-exchanged zeolites. When enhancing the temperature up to $200^{\circ} \mathrm{C}$, the superiority of LDHs has been clearly evidenced.

\section{DATA AVAILABILITY}

All datasets generated for this study are included in the manuscript and/or the Supplementary Files.

\section{AUTHOR CONTRIBUTIONS}

All authors listed have made a substantial, direct and intellectual contribution to the work, and approved it for publication.

\section{SUPPLEMENTARY MATERIAL}

The Supplementary Material for this article can be found online at: https://www.frontiersin.org/articles/10.3389/fchem. 2019.00551/full\#supplementary-material

follow market demand? A case study for China, Germany, Japan and the US. Environ. Innov. Soc. Transit. 10, 42-58. doi: 10.1016/j.eist.201 3.08 .002

Hutson, N. D., and Attwood, B. C. (2008). High temperature adsorption of $\mathrm{CO}_{2}$ on various hydrotalcite-like compounds. Adsorption 14, 781-789. doi: 10.1007/s10450-007-9085-6

Li, R., Xue, T., Bingre, R., Gao, Y., Louis, B., and Wang, Q. (2018). Microporous Zeolite@vertically aligned Mg-Al layered double hydroxide Core@Shell structures with improved hydrophobicity and toluene adsorption capacity under wet conditions. ACS Appl. Mater. Interfaces 10, 34834-34839. doi: 10.1021/acsami.8b15118

Losch, P., Pinar, A. B., Willinger, M. G., Soukup, K., Chavan, S., Vincent, B., et al. (2017). H-ZSM-5 Zeolite model crystals : structure- diffusionactivity relationship in methanol- to-olefins catalysis. J. Catal. 345, 11-23. doi: 10.1016/j.jcat.2016.11.005

Lwin, Y., and Abdullah, F. (2009). High temperature adsorption of carbon dioxide on $\mathrm{Cu}-\mathrm{Al}$ hydrotalcite-derived mixed oxides: kinetics and equilibria by thermogravimetry. J. Therm. Anal. Calorim. 97, 885-889. doi: 10.1007/s10973-009-0156-7

Mustapa, S. I., Leong Yow, P., and Hashim, A. H. (2010). "Issues and challenges of renewable energy development: a Malaysian experience," in Proceedings of the International Conference on Energy and Sustainable Development: Issues and Strategies (ESD 2010) (Chiang Mai: IEEE), 1-6. doi: 10.1109/ESD.2010.55 98779

Ocampo, F., Cunha, J. A., Santos, M. R., de, L., Tessonnier, J. P., Pereira, M. M., and Louis, B. (2010). Synthesis of zeolite crystals with unusual morphology: application in acid catalysis. Appl. Catal. A Gen. 390, 102-109. doi: 10.1016/j.apcata.2010.09.037

Ocampo, F., Yun, H. S., Pereira, M. M., Tessonnier, J. P., and Louis, B. (2009). Design of MFI zeolite-based composites with hierarchical pore structure: a new generation of structured catalysts. Cryst. Growth Des. 9, 3721-3729. doi: $10.1021 / \operatorname{cg} 900425 r$

Othman, M. R., Rasid, N. M., and Fernando, W. J. N. (2006). Mg-Al Hydrotalcite coating on zeolites for improved carbon dioxide adsorption. Chem. Eng. Sci. 61, 1555-1560. doi: 10.1016/j.ces.2005.09.011 
Pham, T. D., Hudson, M. R., Brown, C. M., and Lobo, R. F. (2014). Molecular basis for the high $\mathrm{CO}_{2}$ adsorption capacity of chabazite zeolites. ChemSusChem 7, 3031-3038. doi: 10.1002/cssc.201402555

Princiotta, F. (2011). Global Climate Change - The Technology Challenge (Advances in Global Change Research 38). Springer.

Sharma, U., Tyagi, B., and Jasra, R. V. (2008). Synthesis and characterization of $\mathrm{Mg}-\mathrm{Al}-\mathrm{CO}_{3}$ layered double hydroxide for $\mathrm{CO}_{2}$ adsorption. Ind. Eng. Chem. Res. 47, 9588-9595. doi: 10.1021/ie800365t

Sircar, S., Golden, T. C., and Rao, M. B. (1996). Activated carbon for gas separation and storage. Carbon N. Y. 34, 1-12. doi: 10.1016/0008-6223(95)00128-X

Siriwardane, R. V., Shen, M. S., Fisher, E. P., and Losch, J. (2005). Adsorption of $\mathrm{CO}_{2}$ on zeolites at moderate temperatures. Energy Fuels 19, 1153-1159. doi: 10.1021/ef040059h

Smil, V. (2017). Energy Transitions: Global and National Perspectives, 2nd Edn. Santa Bárbara, CA: Praeguer.

Stanley, M. (2003). The Economics of Climate Change-A Primer. The Congress of the United States. Avialable online at: https://www.cbo.gov

Veltman, K., Singh, B., and Hertwich, E. G. (2010). Human and environmental impact assessment of postcombustion $\mathrm{CO}_{2}$ capture focusing on emissions from amine-based scrubbing solvents to air. Environ. Sci. Technol. 44, 1496-1502. doi: 10.1021/es902116r

Vericella, J. J., Baker, S. E., Stolaroff, J. K., Duoss, E. B., Hardin, J. O., Lewicki, J., et al. (2015). Encapsulated liquid sorbents for carbon dioxide capture. Nat. Commun. 6, 1-7. doi: 10.1038/ncomms7124
Wang, J., Mei, X., Huang, L., Zheng, Q., Qiao, Y., Zang, K., et al. (2015) Synthesis of layered double hydroxides/graphene oxide nanocomposite as a novel high-temperature $\mathrm{CO}_{2}$ Adsorbent. J. Energy Chem. 24, 127-137. doi: 10.1016/S2095-4956(15)60293-5

Wang, Q., Tay, H. H., Zhong, Z., Luo, J., and Borgna, A. (2012). Synthesis of hightemperature $\mathrm{CO}_{2}$ adsorbents from organo-layered double hydroxides with markedly improved $\mathrm{CO}_{2}$ capture capacity. Energy Environ. Sci. 5, 7526-7530. doi: 10.1039/c2ee21409a

$\mathrm{Xu}$, Y., Maddox, P. J., and Couves, J. W. (1990). The Synthesis of SAPO-34 and CoSAPO-34 from a Triethylamine-hydrofluoric acid-water system. J. Chem. Soc. Faraday Trans. 86, 425-429. doi: 10.1039/FT99086 00425

Conflict of Interest Statement: The authors declare that the research was conducted in the absence of any commercial or financial relationships that could be construed as a potential conflict of interest.

Copyright (c) 2019 Megías-Sayago, Bingre, Huang, Lutzweiler, Wang and Louis. This is an open-access article distributed under the terms of the Creative Commons Attribution License (CC BY). The use, distribution or reproduction in other forums is permitted, provided the original author(s) and the copyright owner(s) are credited and that the original publication in this journal is cited, in accordance with accepted academic practice. No use, distribution or reproduction is permitted which does not comply with these terms. 
OPEN ACCESS

Edited by:

Qiang Wang,

Beijing Forestry University, China

Reviewed by:

Zifeng Yan,

China University of Petroleum, China

Tao Zhu,

School of Chemical and Environmental

Engineering, China University of

Mining and Technology (Beijing), China

*Correspondence:

Xianliang Meng

meng27@cumt.edu.cn

Specialty section:

This article was submitted to

Inorganic Chemistry,

a section of the journal

Frontiers in Chemistry

Received: 19 June 2019 Accepted: 04 September 2019

Published: 18 September 2019

Citation:

Chu R, Yang D, Meng X, Yu S, Wan Y, Wu J and Wang J (2019) Effect of

Surface Structure and Adsorption

Activity on Implanting of b-Oriented

ZSM-5 Zeolite Film on Modified

$\alpha$-Quartz Substrate.

Front. Chem. 7:636

doi: 10.3389/fchem.2019.00636

\section{Effect of Surface Structure and}

\section{Adsorption Activity on Implanting of b-Oriented ZSM-5 Zeolite Film on Modified $\alpha$-Quartz Substrate}

\author{
Ruizhi Chu ${ }^{1,2}$, Deguang Yang ${ }^{2}$, Xianliang Meng ${ }^{1,2 *}$, Shi Yu${ }^{2}$, Yongzhou Wan ${ }^{1,2}$, Jiaxing $W^{2}$ \\ and Jian Wang ${ }^{2}$ \\ ${ }^{1}$ Key Laboratory of Coal Processing and Efficient Utilization of Ministry of Ministry of Education, Xuzhou, China, ${ }^{2}$ School of \\ Chemical Engineering and Technology, China University of Mining and Technology, Xuzhou, China
}

b-oriented ZSM-5 zeolite film was synthesized on the macropore $\alpha$-quartz substrate modified with titanium dioxide $\left(\mathrm{TiO}_{2}\right)$, polyvinyl acetate (PVA), and chitosan (CTS) by hydrothermal crystallization. By comparing the binding energy and b-oriented angle of zeolite film on each modified $\alpha$-quartz substrate, the orientations, and combinations derived from structure-adsorption relationship were investigated with Material Studio simulation. Furthermore, the effects of calcination temperature and ultraviolet (UV) irradiation time on the surface structure and adsorption activity of $\mathrm{TiO}_{2}$ coating were studied. The increase adsorption potential energy and the formation of Ti-O-Si bind between zeolite crystal phase and substrate facilitate the continuous and uniform zeolite film growth. The $\mathrm{TiO}_{2}$ interlayer with anatase phase after $U V$ irradiation presents a smooth surface with high Ti-OH density, consequently to high selectivity of b-orientation growth for the ZSM-5 crystals. Compared with the traditional ZSM-5, the higher stability has been exhibited with b-oriented ZSM- 5 film $/ \mathrm{TiO}_{2} / \alpha$-quartz in the MTA reaction, and the methanol conversion and BTX selectivity remained higher than 90 and 70\%, after 6 h reaction.

Keywords: b-oriented ZSM-5 zeolite film, $\alpha$-quartz substrate, modification, surface structure, adsorption activity

\section{HIGHLIGHTS}

- The b-oriented ZSM-5 zeolite film was prepared on the substrate of modified $\alpha$-quartz.

- The modification-structure-adsorption relationship of modifiers and $\alpha$-quartz surface were investigated.

- The orientations and combinations derived from structures and adsorption between modified $\alpha$-quartz and ZSM-5-crystallites were studied.

\section{INTRODUCTION}

Aromatic hydrocarbons, especially light aromatic hydrocarbons such as benzene, toluene, and xylene (BTX) are important raw materials for organic chemicals and polymer industry (Ye et al., 2019). The production of light aromatic hydrocarbons BTX by methanol conversion (MTA) is of great significance to realize the low-cost synthesis of value-added chemicals via non-oil routes and 


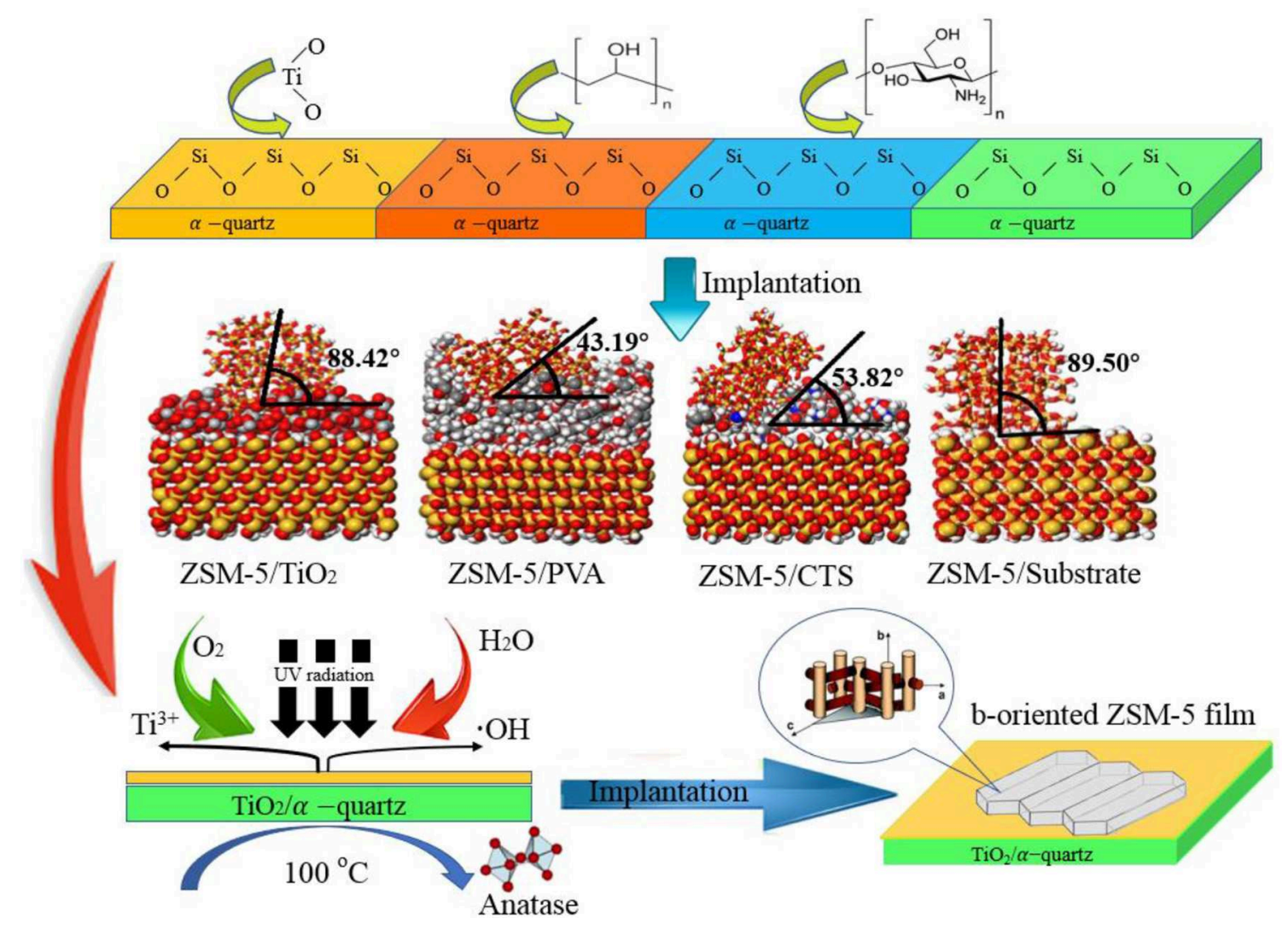

GRAPHICAL ABSTRACT | Surface modification mechanism of $\alpha$-quartz substrate.

to expand the application of methanol (Ali et al., 2015; Bozzano and Manenti, 2016; Mitsuyoshi et al., 2017).

At present, some MTA studies are reported and the main reaction catalysts are ZSM-5 (Na et al., 2018), ZSM-22 (Catizzone et al., 2017), MCM-22 (Lacarriere et al., 2011), MCM-36 (Lacarriere et al., 2011), and H-Beta molecular sieve (Svelle et al., 1999) etc. ZSM-5 exhibits excellent shape-selectivity catalysis for BTX aromatic hydrocarbons due to the suitable diameter of the tunnel, therefore it becomes the most widely studied catalyst for MTA reaction (Li et al., 2003; Khodakov et al., 2010). However, aromatic hydrocarbon selectivity and carbon deposition on ZSM5 remain as the core issues which make it difficult to scale-up for MTA industry deployment.

Significant efforts have been attempted to address the carbon deposition issue on catalysts during MTA reaction, for example, some studies have proposed to synthesize nanometer acicular c-axis ZSM-5 catalyst (Shen et al., 2013). The length of the main reaction channel of $a, b$ orientation is in favor of strengthen the diffusion process, thereby suppresses carbon deposition. For example, Shen et al. (2013, 2014). Used acidtreatment to slowly dissolve the aluminum and silicon from natural dolomite, and formed the $\mathrm{Al}-\mathrm{Si}-\mathrm{O}$ structural unit in the catalyst synthesis. Without directing agent, the Al-Si-O structural unit was self-assembled and crystallized into a ZSM5 acicular nanometer powder along c-axis, The MTA reactivity of this acicular ZSM-5 nanoparticles was evaluated and it is found that the reaction molecules were able to rapidly diffuse through the micropores in the short axes of a and $b$, thus the diffusion limit is lowered. Compared with the traditional non-b-oriented ZSM-5, the residence time of the reaction molecules in the pores of this novel materials is shortened, therefore the carbon deposition on the catalyst is significantly reduced, which contributes to the prolonged catalyst life and improved BTX selectivity. However, the study also found that the crystals of acicular molecular sieves are so brittle, which limits their industrial application due to the difficulties for storage and transportation.

To solve above-mentioned issues, our group proposed to utilize the adsorption and diffusion advantages of ZSM-5 in the boriented straight channel (Lai et al., 2010; Zhou et al., 2013). The b-oriented ZSM-5 one-dimensional molecular sieve was loaded on the nanospheres with mesoporous pore structure to construct the b-oriented ZSM-5 nanosphere shell material with micromesoporous pore structure. The micropores of the material will become the active center of the MTA catalyst with excellent carbon deposition resistance and BTX selectivity, meanwhile the mesopores work as fast channels for the diffusion of aromatic BTX small molecules.

It was found that the pore structure and surface activity of the substrate exhibit significant effects on film orientation 

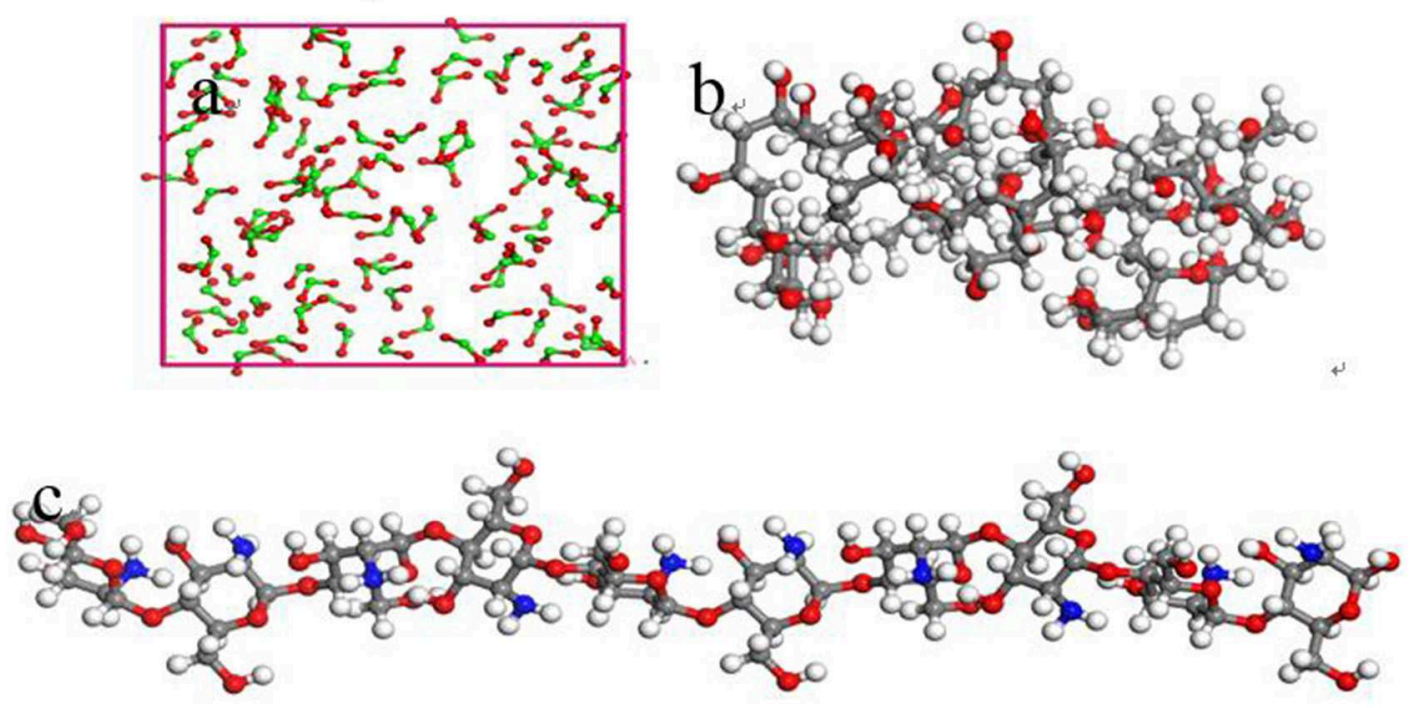

FIGURE 1 | Schematic diagram of modifier model (a) Inorganic modifier $\mathrm{TiO}_{2}$, (b) grid structure organic modifier PVA, and (c) linear organic modifier CTS (Gray, white, red, and green represent $\mathrm{C}, \mathrm{H}, \mathrm{O}$, and $\mathrm{Ti}$, respectively).

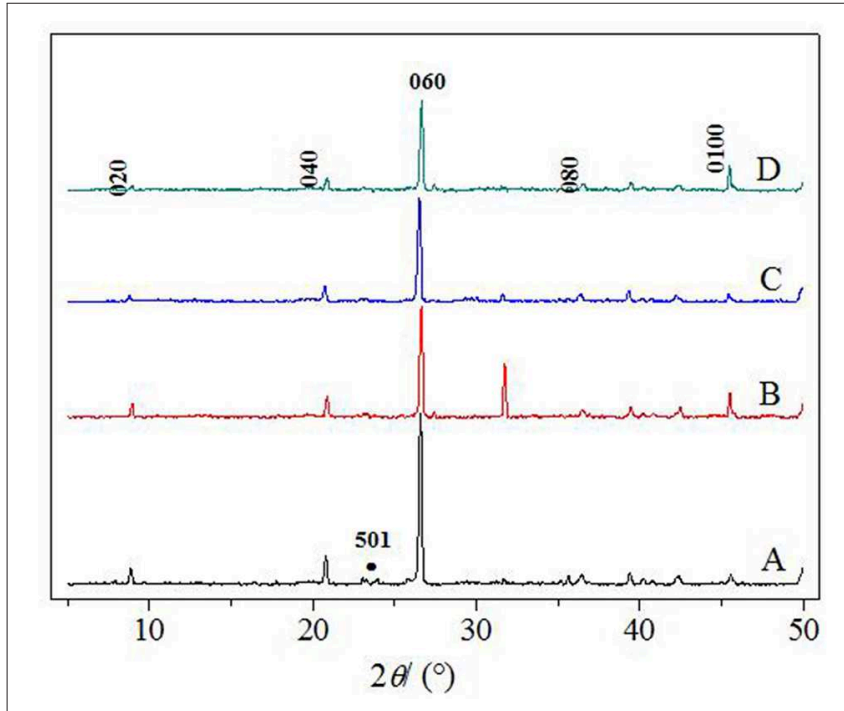

FIGURE 2 | XRD patterns of ZSM-5 zeolite film on (A) uncoated, (B) $\mathrm{TiO}_{2}$, (C) CTS, and (D) PVA coating.

and adhesion strength (Wei and Yen, 2007). Therefore, to improve the binding force between the crystal nucleus and the substrate surface, some attempts are made to increase the surface activity and adsorption strength of the substrate by employing suitable coupling agents or modifiers. For example, Lee et al. (2000b) used 3-Aminopropyltriethoxysilane and 3-Glycidoxypropyltrimethoxysilane as coupling agents to synthesize the ZSM-5 with a great b-oriented crystal layer on the glass surface. In addition, this repeatable synthesis of the molecular sieve onto the substrate was demonstrated by similar mechanism (Lee et al., 2000a, 2001; Park et al., 2002; Jin et al., 2006). Yeung et al. (Jlh et al., 2000) assembled randomly oriented silicalite-1 molecular sieves on the surface of stainless steel. Fu et al. (2018) prepared a silicalite-1 molecular sieve onto the ceramic surface by manual assembly method, and obtained dense seed layer of b-oriented crystals. However, due to the lack of fundamental understanding, the research is still mainly in the sample screening stage with different substrates and modifiers via trail-and-error approach. Different from other chemical processes, the surface of the colloidal microspheres is not destroyed during the loading of the crystal nucleus on the surface of the substrate. The nanocrystal nucleus firstly adsorbs on the colloidal microsphere surface, whose structure and properties can then affect the formation process of ZSM5 crystal nuclei. Therefore, the surface structure and properties of colloidal microspheres were introduced and investigated in the molecular design and synthesis system of microspheres with core-shell structure. The effects of the surface structure of colloidal microspheres, as well as the surface properties of nanocrystal cores and modifier molecules were studied. To achieve the fundamental understanding of the directed growth of molecular sieve crystals, the effect of structural on the b-oriented adsorption of nanocrystal nuclei on the surface of colloidal microspheres was investigated. It is of important significance for both the theoretical and practical design of novel core-shell molecular sieve.

In addition, another goal of synthesis the b-oriented ZSM5 zeolite is to increase the bonding force of the crystal nucleus on the substrate surface. The substrate materials with limited pore channels are reported in most present studies, which greatly restricts the application of molecular sieve film in separation and catalysis. Therefore, the design strategy to obtain monodisperse oriented molecular sieve film on the multi-channel substrate 

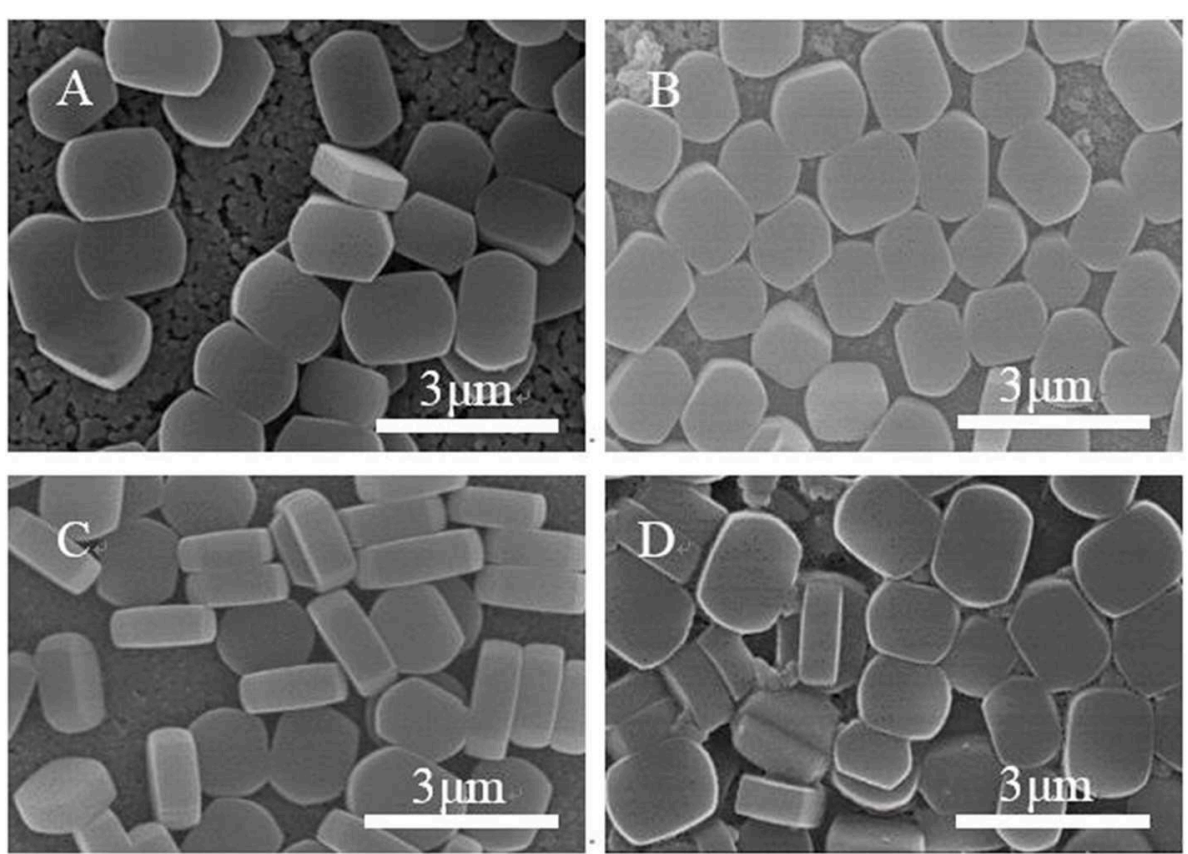

FIGURE 3 | SEM images of ZSM-5 zeolite film on (A) uncoated, (B) $\mathrm{TiO}_{2}$, (C) CTS, and (D) PVA coating.
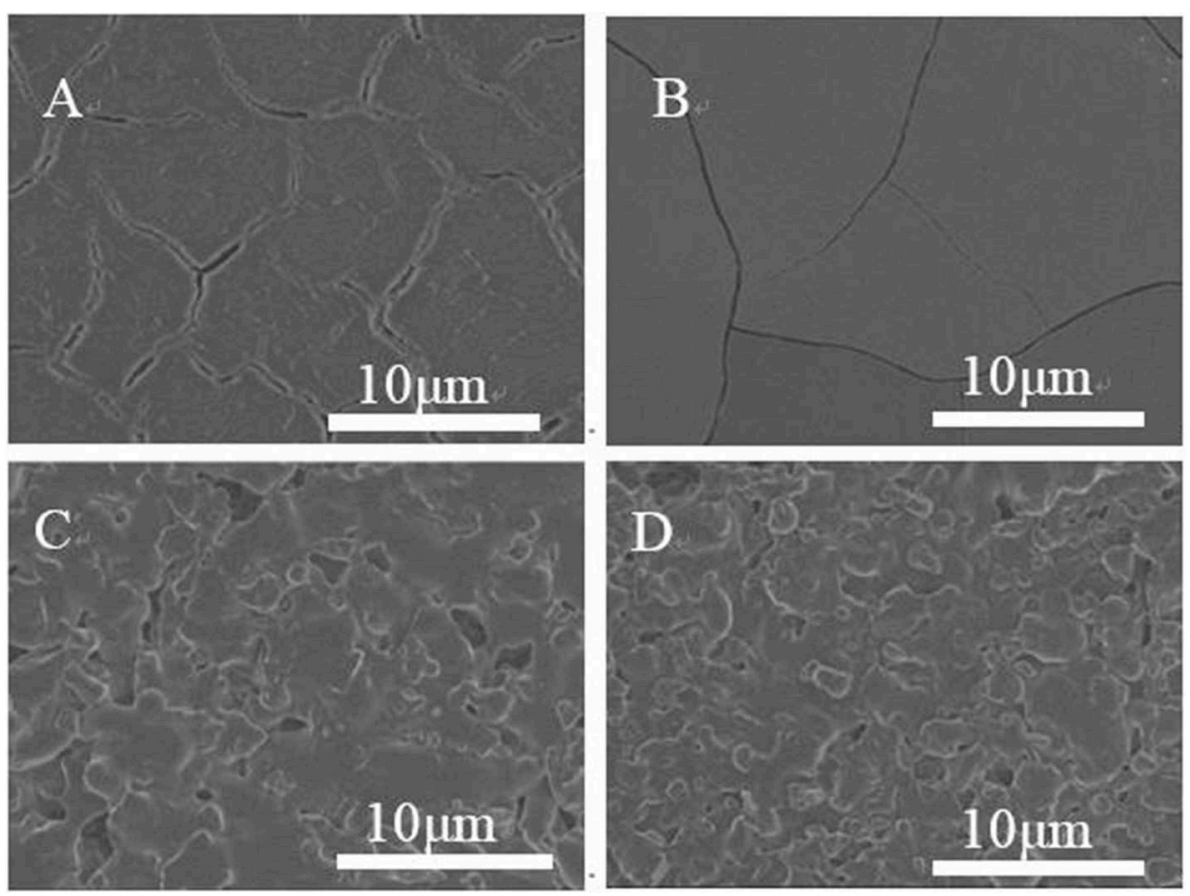

FIGURE 4 | SEM diagram of substrate coated with different modifiers (A) uncoated, (B) TiO2, (C) CTS, and (D) PVA.

surface has become a challenging and important research topic in the field of oriented film materials.

Furthermore, as for the preparation of b-oriented ZSM5 zeolite film on the surface of macropore substrate, the influencing factors of the oriented growth and assembly of nanocrystalline core are regarded as the essential points for the preparation process. In this paper, a series of ZSM- 5 zeolite films anchoring on the $\alpha$-quartz substrate surface will be synthesized by hydrothermal crystallization. Both organic (polyvinyl acetate and chitosan) and inorganic (titanium dioxide) modifiers are 
TABLE 1 | Adsorption characteristics of ZSM-5 nanocrystalline crystal (010) surface and modifier surface/substrate.

\begin{tabular}{lcccc}
\hline & Substrate & TiO $_{\mathbf{2}}$ & CTS & PVA \\
\hline b-oriented Angle $\left(^{\circ}\right)$ & 89.5 & 88.42 & 53.82 & 43.19 \\
Binding energy $(\mathrm{Kcal} / \mathrm{mol})$ & -218.64 & -752.17 & -335.00 & -458.35
\end{tabular}

applied to coat on the prepared samples. Considering the macropore $\alpha$-quartz substrate, the effects of substrate surface structure and adsorption activity on the b-oriented adsorption of nanocrystal nuclei will be investigated.

\section{EXPERIMENTAL SECTION}

\section{Simulation of Substrate Surface Modification and ZSM-5 Zeolite Combination Process}

The inorganic modifier titanium dioxide $\left(\mathrm{TiO}_{2}\right)$ and organic modifier polyvinyl acetate (PVA) and chitosan (CTS) were modeled by 3 Dviewer in Material Studio software. In order to make the simulation conditions close to the molecular weight and polymerization degree of the organic modifier in the experiment, the polymerization degrees of PVA and CTS were set to 40 and 10 (Razmimanesh et al., 2015; Wei et al., 2017), respectively. The repeating unit of the $\mathrm{TiO}_{2}$ molecule was set to 100 (Baguer et al., 2009). The model is shown in Figure 1. Molecular dynamics simulation of the adsorption process of ZSM-5(010) crystal plane on the modified surface was performed under NVT system at $450 \mathrm{~K}$, with a step size of $1 \mathrm{fs}$ and simulation time of $1,000 \mathrm{ps}$ using the Universal force field of Forcite module.

\section{Substrate Surface Modification Experiment}

The surface of the substrate was modified by inorganic modifier $\left(\mathrm{TiO}_{2}\right)$ and organic modifier (PVA and CTS). $\mathrm{TiO}_{2}$ (10wt.\%, Hang Zhou Wan Jing new materials co., LTD.) precursor oxides sols were coated on the substrate surface by sol-gel method, and dried for $12 \mathrm{~h}$ at $50^{\circ} \mathrm{C}$, then roasted for $2 \mathrm{~h}$ at $100^{\circ} \mathrm{C}$. Chitosan (0.5 wt.\%, Sinopharm Chemical Reagent Co., Ltd.) and PVA (4Wt.\%, Sinopharm Chemical Reagent Co., Ltd.) were coated on the surface of the substrate for three times. It was dried at $30^{\circ} \mathrm{C}$ and $60 \%$ relative humidity for $12 \mathrm{~h}$ subsequently dried at $60^{\circ} \mathrm{C}$ for $2 \mathrm{~h}$.

In order to study the effect of $\mathrm{Ti}-\mathrm{OH}$ species and its concentration on the substrate surface of the supported ZSM-5 crystal layer, the samples substrate loaded with $\mathrm{TiO}_{2}$ coating was calcined in muffle furnace at $100,300,600$, and $900^{\circ} \mathrm{C}$, irradiated with UV for $2,4,6$, and $8 \mathrm{~h}$, respectively.

\section{Preparation of b-Oriented ZSM-5 Zeolite Film}

The ZSM-5 zeolite film was supported on the $\alpha$-quartz substrate by hydrothermal synthesis. A prescribed amount of Tetrapropylammonium Hydroxide (TPAOH) (10 wt.\%, Sinopharm Chemical Reagent Co., Ltd.) was added to the DI water followed by dropwise adding Ethyl Orthosilicate (TEOS)
(Xiyu Chemical Co., Ltd.) and aluminum nitrate. Subsequently the mixture was aged for $24 \mathrm{~h}$ to obtain a clear and uniform solution. The synthesis mole composition was $0.32 \mathrm{TPAOH}$ : $1 \mathrm{SiO}_{2}: 0.005 \mathrm{Al}_{2} \mathrm{O}_{3}: 165 \mathrm{H}_{2} \mathrm{O}$. The substrate was vertically inserted into a hydrothermal crystallization vessel with a Teflon liner, and the synthesis solution was added to the crystallization vessel without passing through the substrate. After heating to $165^{\circ} \mathrm{C}$ for $80 \mathrm{~min}$, the obtained catalyst then is slowly rinsed for several times with DI water. Finally, the catalysts are calcinated at $550^{\circ} \mathrm{C}$ for $2 \mathrm{~h}$ in a tubular furnace with a heating rate of $0.5^{\circ} \mathrm{C} / \mathrm{min}$.

\section{Characterizations}

The microstructure of the modified substrate and the surface of the ZSM-5 film was characterized by scanning electron microscopy. Prior to the test, the sample was subjected to gold spray treatment. XRD data was obtained on a VERTEX $80 \mathrm{v}$ $\mathrm{X}$-ray diffractometer using $\mathrm{Cu} \mathrm{K} \alpha$ radiation $(k=0.15418 \mathrm{~nm})$, scanning speed $2^{\circ} / \mathrm{min}$, scanning range $5^{-} 50^{\circ}$, tube current and tube voltage of $150 \mathrm{~mA}, 40 \mathrm{kV}$, respectively. The contact angle was measured by the JC2000C4 contact angle meter and measured by a synthetic liquid solid drop method. Each contact angle was an average value of multiple measurements at different positions on the surface at room temperature. Nitrogen $\left(\mathrm{N}_{2}\right)$ adsorption/desorption isotherms were measured with a physical adsorption instrument (ASAP2010) at $-196^{\circ} \mathrm{C}$. The textural properties of $\alpha$-quartz substrate was determined by the highperformance automatic mercury intrusion meter (AutoPore IV 9510). The total pore volume $\left(\mathrm{V}_{\text {total }}\right)$ was derived from the amount of $\mathrm{N}_{2}$ adsorbed at $\mathrm{p} / \mathrm{p}_{0}=0.99$, the BET method was applied to determine the total surface area $\left(S_{\text {total }}\right)$, the $t$-plot method is specifically used to identify micropores, and the $\mathrm{BJH}$ method was used to estimate the size distribution.

\section{The Catalytic Activity and Selectivity of ZSM-5 Zeolite in MTA Reaction}

The catalytic activity and selectivity in MTA reaction were studied in a fixed-bed reactor. $0.5 \mathrm{~g}$ of catalyst was carried out in a reaction tube with an inner diameter of $10 \mathrm{~mm}$, the catalyst was activated for $2 \mathrm{~h}$ at $450^{\circ} \mathrm{C}$, and the methanol was introduced at a space velocity (WHSV) of $2.85 \mathrm{~h}^{-1}$ under normal pressure at $470^{\circ} \mathrm{C}$, the concentration of the components was analyzed using a gas chromatograph.

\section{RESULTS AND DISCUSSION}

\section{Effect of Modifier Species on Preparation of b-Oriented ZSM-5 Zeolite Film} Characterization of ZSM-5 Zeolite Film: Composition, Morphology

In this paper, $\mathrm{TiO}_{2}, \mathrm{PVA}$, and CTS coatings were used to modify the surface of macropore $\alpha$-quartz substrate, and the addition of intermediate oxide layer, to change the directional growth of ZSM-5 zeolite film on the substrate. Figure 2 shows the XRD patterns of ZSM-5 zeolite film with various coatings. There are five diffraction peaks at $2 \theta=8.89^{\circ}, 17.81^{\circ}, 26.82^{\circ}, 36.06^{\circ}$, and $45.46^{\circ}$, attributed to the (020), (040), (060), (080), and (0100) crystal faces of MFI zeolite. The results indicate that 

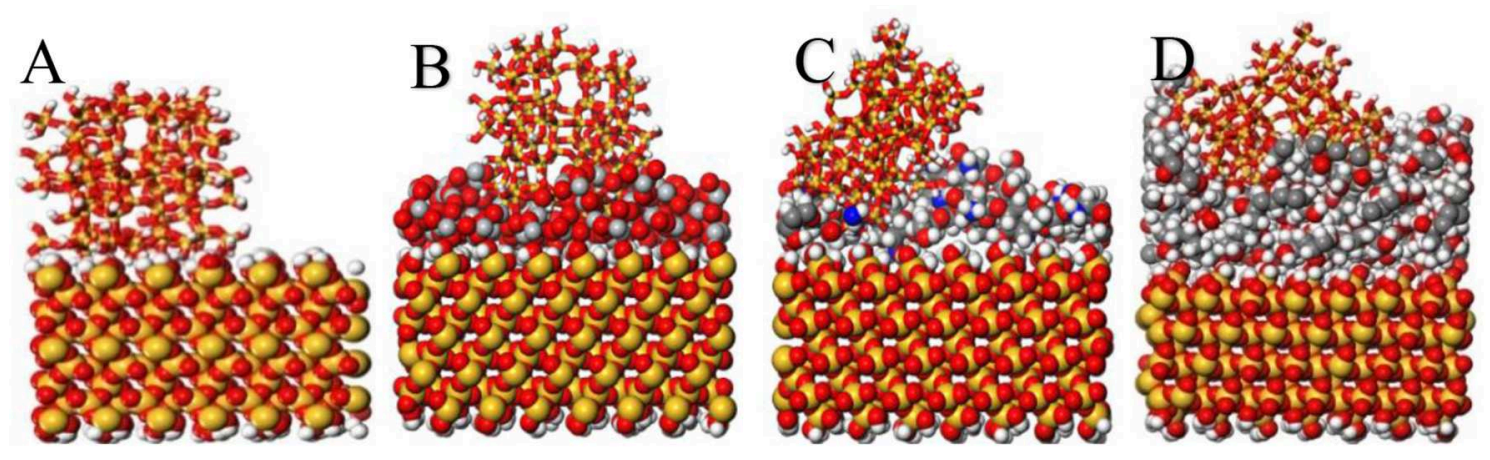

FIGURE 5 | Adsorption simulation of ZSM-5 nanometer crystal (010) on the surface of modifier (A) substrate, (B) TiO2, (C) CTS, and (D) PVA.

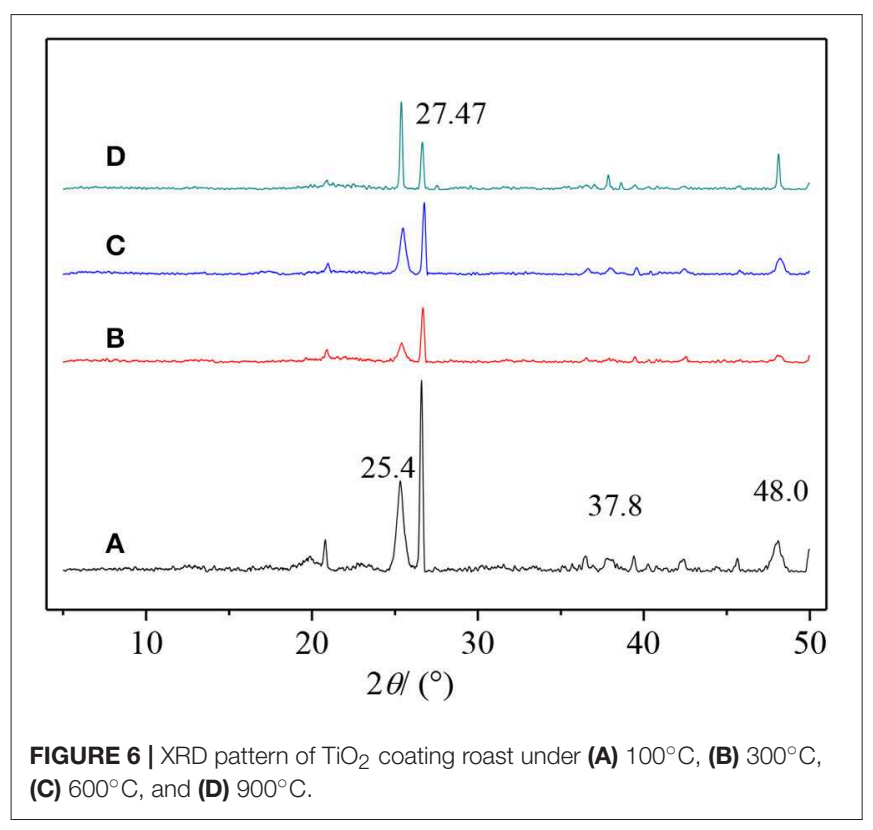

ZSM-5 zeolite film with b-oriented crystals perpendicular to the substrate surface was formed. Compared with the other three modifiers, Figure 2B (0h0) shows the strongest diffraction peak intensity, implying the $\mathrm{TiO}_{2}$ is more favorable for the growth of b-oriented ZSM-5 zeolite film. In addition, the uncoated substrate exhibits a weak characteristic peak at $2 \theta=23.3^{\circ}$ (Figure 2A), attributed to the (501) crystal plane which was identified as ZSM-5 in the a-axis (Chu et al., 2016), indicating the presence of the small amount of a-axis crystals.

Figure 3 shows SEM images of ZSM-5 zeolite film synthesized on the surface of substrates with different modifiers. Most of the ZSM-5 zeolite crystals grow in the b-orientation with coffin shape, and the effective $\mathrm{TiO}_{2}$ modification is clearly observed. Compared with the unmodified matrix (Figure 3A), others show that the ZSM-5 crystals increase significantly. This indicates that in the presence of the intermediate modification layer, the ZSM5 molecular sieve nucleus can be more easily anchored and grown on the substrate, exhibiting higher coverage, and better film formation property. Moreover, the crystals on the substrate coated with organic modifiers (CTS and PVA) exhibit greater superposition and non-b-orientation than that with $\mathrm{TiO}_{2}$. Part of the ZSM- 5 crystals are embedded in the intermediate modifier layer during growth, with the uneven crystals distribution and low coverage. Besides, the degree of orientation is inconsistent due to the difference in surface structure and adsorption activity between the surface of the ZSM-5 zeolite film and the substrate.

\section{Substrate Surface Structure Analysis}

It is found that the microstructure of the substrate is one of the important factors affecting the orientation growth of the crystal on the substrate. Figure 4 shows the SEM morphology of the substrates to analyze their microstructures with different coatings. The inorganic oxides in the nanosized particles can be effectively coated on flat surface (Figure 4B), in contrast the organic modifier film in a mesh or linear is tightly attached to form an uneven surface (Figures 4C,D), This observation indicates that the smooth nanocrystalline core-substrate interface promotes the growth of ZSM-5 zeolite film., Di et al. modified the surface of the smooth glass substrate by sol-gel method to obtain different surface coverages of silicalite-1 film (Di et al., 2011). Previous studies have shown that $-\mathrm{OH}$-rich substrate with smooth surface does not own the effective adsorption through hydrogen bonding, and this may be cause by the structural differences between the surfaces of the material ( Fu et al., 2018). We characterized a series of substrate materials (dispersed in deionized $\mathrm{H}_{2} \mathrm{O}$ ) using $\zeta$-potential measurements. It is found that both $\mathrm{SiO}_{2}$ and silicalite-1 exhibit negative surface charges, and the mixture of these two materials shows a $-34.6 \mathrm{mV} \zeta$-potential value, which lies between the values of their individual components, $\zeta$-potential value of $\mathrm{TiO}_{2}$ is close to zero, revealing the weak interactions on adsorption. This electrostatic adsorption potential of smooth inorganic $\mathrm{TiO}_{2}$ surface results in the growth of ZSM-5 zeolite film. For organic modifiers, the film surface is positively charged and covered by large number of $-\mathrm{OH}$ and $-\mathrm{NH}_{2}$ active groups. In the meantime, the organic modifier is dehydrated during the coating process, the colloidal particles are aggregated due to the intermolecular force and chemical force, resulting in the uneven distribution of the surface active group on the matrix 

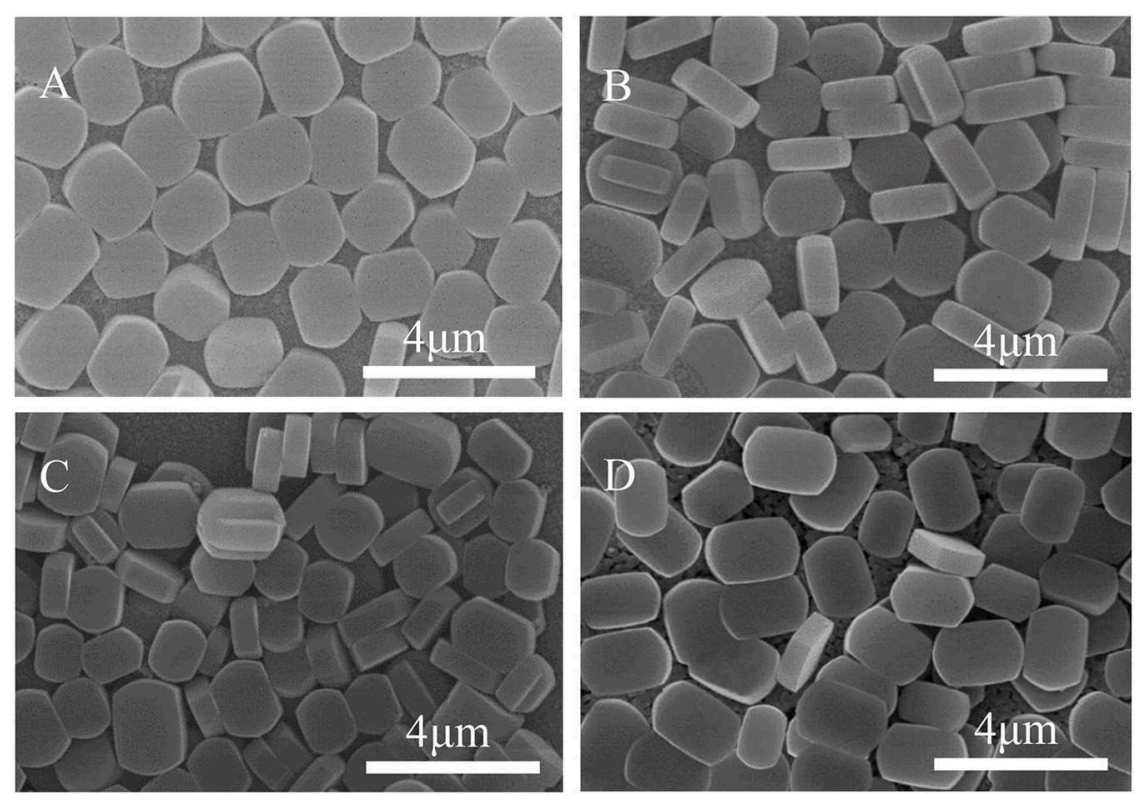

FIGURE 7 | SEM images of ZSM-5 zeolite film on $\mathrm{TiO}_{2}$ coating calcine under (A) $100^{\circ} \mathrm{C}$, (B) $300^{\circ} \mathrm{C}$, (C) $600^{\circ} \mathrm{C}$, and (D) $900^{\circ} \mathrm{C}$.

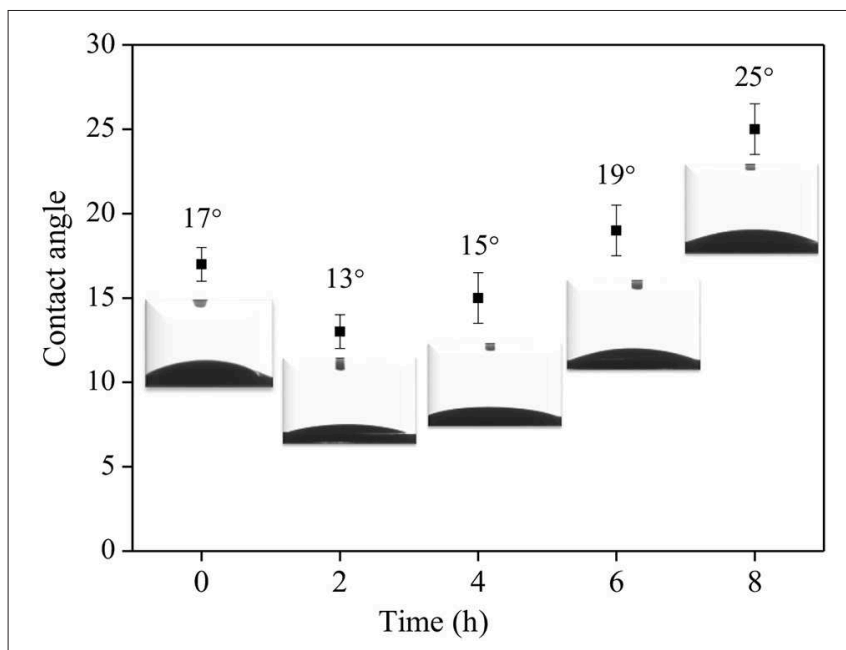

FIGURE 8 | The relationship of UV irradiation time and the contact angles of synthesis solution droplets on $\mathrm{TiO}_{2}$ coated substrate.

and different physical adsorptions. Thereby it further explains the degree of accumulation and aggregation of ZSM- 5 crystals on the organic modifier surface.

\section{Adsorption Activity}

There is significant difference of the adsorption force (van der Waals force) between the modifier interface and the zeolite crystal phase (silica particles), this adsorption force can be characterized by non-zero frequency Hamaker constant $A_{v>0}$ to evaluate the ability of various substrates to initiate surface gelation. According to the literature (Ji et al., 2012), the Hamaker constant $\mathrm{A}_{\mathrm{v}>0}$ of $\mathrm{SiO}_{2}-\mathrm{SiO}_{2}$ and $\mathrm{SiO}_{2}-\mathrm{TiO}_{2}$ interaction are 0.35 $\times 10^{-20}$ and $3.1 \times 10^{-20}$, respectively. The values suggest the silica-silica adsorption force is much weaker than silica-titanium adsorption force, which further explains that the poorer quality of the ZSM-5 film on substrate than that on $\mathrm{TiO}_{2}$ layer. According to the expressions and constants of the literature (Lai et al., 2000), we estimate the Hamaker constant $\mathrm{A}_{\mathrm{v}>0}$ of $\mathrm{SiO}_{2}-\mathrm{PVC}$ and $\mathrm{SiO}_{2}$-CTS interaction are $1.82 \times 10^{-20}$ and $1.53 \times 10^{-20}$, respectively. By comparison, it is proved that the adsorption force of the substrate surface coated with $\mathrm{TiO}_{2}$ is obviously larger than that of the other modifiers. Thus, it can be concluded that the substrate with strong adsorption force is favorable for the loading of the crystals.

ZSM-5 was pre-planted in the b-direction on the surface of $\mathrm{TiO}_{2}, \mathrm{CTS}$, and PVA coated substrates, the orientation angle are $43.19,53.82$, and $88.42^{\circ}$ (Table 1 ), respectively, indicating that the orientation angles of ZSM- 5 grown on the modifier in the b-orientation decreases in the order: $\mathrm{TiO}_{2}>\mathrm{CTS}>$ PVA. The CTS and PVA are rich in $-\mathrm{OH}$ groups and $-\mathrm{NH}_{2}$ groups, which can generate hydrogen bonds at the interface between ZSM-5 and the substrate, thereby generating interaction forces. However, with the help of kinetic simulation in Figures 5C,D, it is found that although there is a strong interaction between macromolecules of CTS/PVA and the substrates, a small range of cross-linking or agglomeration will occur on the surface of the substrates. Therefore, the exposed surfaces of the CTS and PVA modifiers are always accompanied by a slight roughness, resulting in a certain inclination angle. As shown in Figure 5A, when the ZSM- 5 coated with $\mathrm{TiO}_{2}$ modification on the substrate for the plant, ZSM-5 embedded in the modified layer with borientation. As small molecule, $\mathrm{TiO}_{2}$ does not agglomerate on the surface of the substrate, meanwhile a strong interaction 

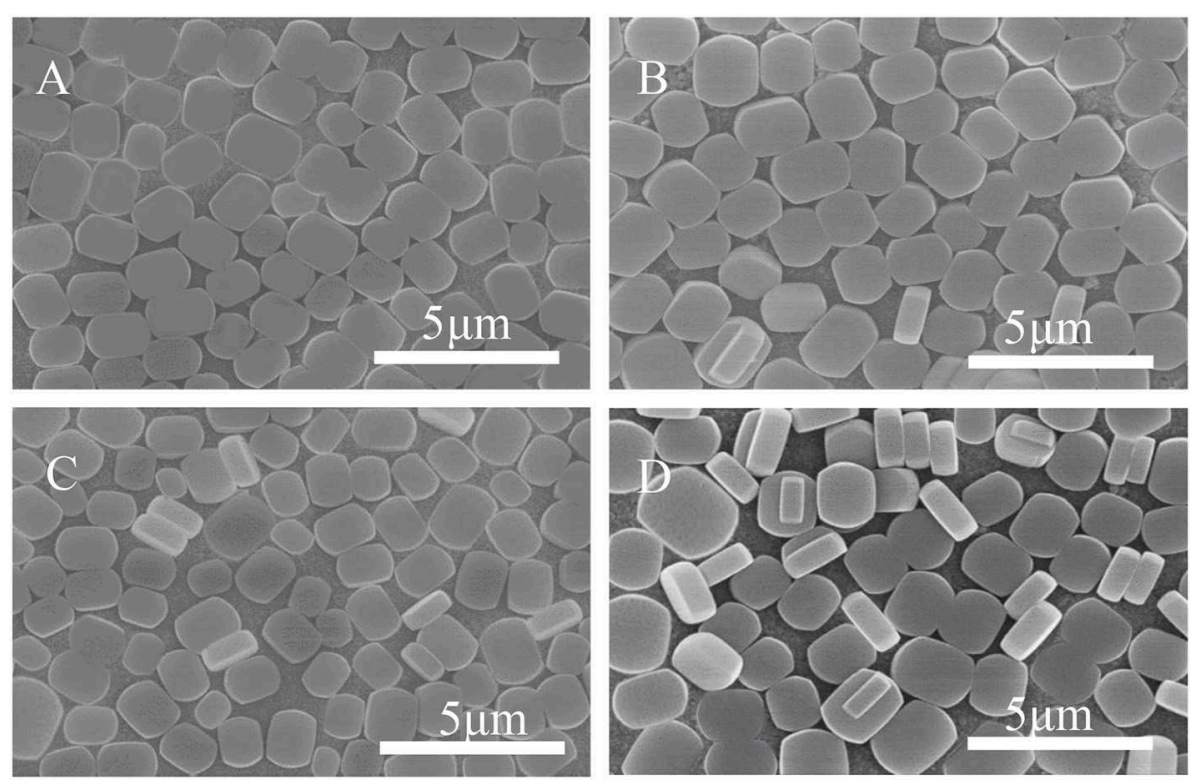

FIGURE 9 | SEM images of ZSM-5 zeolite film on $\mathrm{TiO}_{2}$ coated substrate after UV irradiation for (A) $2 \mathrm{~h}$, (B) $4 \mathrm{~h}$, (C) 6 h, and (D) 8 h.

force can be maintained between $\mathrm{TiO}_{2}$ molecules, thereby a dense and uniform modification layer can be formed on the substrate. Further, stable Ti-O-Si bond was formed due to the interaction between $\mathrm{Ti}-\mathrm{OH}$ with $\mathrm{Si}-\mathrm{OH}$, which facilitated the ZSM-5 embedded in the $\mathrm{TiO}_{2}$ modified layer. However, the Si$\mathrm{O}-\mathrm{Si}$ bond was not formed at the uncoated substrate effectively, and the van der Waals force becomes the main adsorption force in the interfaces, resulting in failure to form an effective preplanted (Figure 5B). Consequently, the b-oriented ZSM-5 is best pre-planted on the substrate coated by $\mathrm{TiO}_{2}$.

Meanwhile, even though the $\mathrm{TiO}_{2}$ modifier can provide the great b-oriented angle and maximum interaction energy, the Figure 3B shows that the ZSM-5 zeolite film still has a small amount of non-b-orientation ones, which may be caused by the differences in the species and density of - $\mathrm{OH}$ groups on the substrate surface. Moreover, the layer of $\mathrm{TiO}_{2}$ was modified to study the effect of Ti-OH species and their density on the crystal orientation as well as surface coverage of ZSM-5 zeolite film.

\section{Effect of $\mathrm{TiO}_{2}$ Coating on Preparation of b-Oriented ZSM-5 Zeolite Film}

\section{Temperature of Calcination}

The Ti-OH species on the substrate surface can be altered by calcining the $\mathrm{TiO}_{2} /$ substrate. Figure 6 shows the XRD results, pure anatase peaks appear at $2 \theta=25.4,37.8$, and $48.0^{\circ}$ at $100^{\circ} \mathrm{C}$, and the characteristic peak intensity increases with temperature. At $900^{\circ} \mathrm{C}$, the diffraction peak is sharp and symmetrical, and the half-width $\beta$ is narrowed. The crystal form of titanium oxide changes from anatase to rutile with increasing temperature (Liu et al., 2012; Mashimo et al., 2017). Anatase and rutile Ti-OH are more hydrophilic than $\mathrm{Ti}-\mathrm{OH}$ in mixed crystalline form. The seeds of anatase and rutile $\mathrm{TiO}_{2}$ with strong hydrophilicity grow along high b-orientation, and the distribution of crystals on anatase $\mathrm{TiO}_{2}$ is very uniform (Figures 7A,B). The thermal treatment is capable of changing the crystal structure of $\mathrm{TiO}_{2}$, resulting in various $\mathrm{Ti}-\mathrm{OH}$ species and different water molecules adsorption mechanisms. The mixed crystal phase (including anatase- and rutile- $\mathrm{TiO}_{2}$ ) is low hydrophilic, and when the temperature rises to $300^{\circ} \mathrm{C}$, the intermolecular adsorption mode is converted from non-dissociative adsorption to dissociative adsorption. The $\mathrm{TiO}_{2}$ intermolecular force is reduced and partially dissociated, causing a relatively sparse density of $\mathrm{TiO}_{2}$ coating on the surface of the substrate. Eventually, the amount of anatase-type $\mathrm{Ti}-\mathrm{OH}$ is reduced, resulting in partial nucleation to grow along non-b-orientation (Figures 7C,D).

\section{Time of UV Irradiation}

The effect of surface Ti-OH density on the crystal orientation of ZSM-5 zeolite film is investigated in this section. According to research reports, the hydrophilicity of $\mathrm{TiO}_{2}$ films can be tuned by photocatalysis (Mohamad et al., 2015; Barbieriková et al., 2018). In detail, the Ti-OH concentration on the substrate surface was adjusted by irradiating the substrate with ultraviolet light (Wu et al., 2012; Lian and Park, 2016). With the increased UV treatment time, the contact angle of the $\mathrm{TiO}_{2}$ coating is gradually reduced, inferring the ultraviolet light irradiation can enhance the hydroxyl concentration on the substrate. Figure 8 shows the contact angle is the smallest when irradiated for $2 \mathrm{~h}$, namely, the hydrophilicity of the substrate is the strongest. $\mathrm{TiO}_{2}$ is firstly excited by photons to generate hole-electron pairs $\left(\mathrm{h}^{+}\right.$ and $\mathrm{e}^{-}$) (Equation 1), then the bridge oxygen and the positively charged holes $\left(\mathrm{h}^{+}\right)$react on the surface to cause the breakage of Ti-O bond, and later the bridge oxygens leave the surface to generate oxygen vacancies (Equation 2). At the same time, in order to maintain the surface electrical neutrality, $\mathrm{Ti}^{4+}$ is 
TABLE 2 | Specific surface area and pore volume of samples.

\begin{tabular}{|c|c|c|c|c|c|c|}
\hline & \multicolumn{3}{|c|}{ Area } & \multicolumn{3}{|c|}{ Volume } \\
\hline$\alpha$-quartz & 108.5 & - & - & 0.6735 & - & - \\
\hline ZSM-5 & 353.6 & 73.8 & 279.8 & 0.4132 & 0.0843 & 0.3289 \\
\hline FC zeolite & 325.3 & 136.6 & 188.7 & 0.5802 & 0.3455 & 0.2347 \\
\hline
\end{tabular}

a The data are obtained by BET method.

${ }^{b}$ The data are obtained by $t$-plot method.

${ }^{c}$ The data are the difference between total pore and micropore.
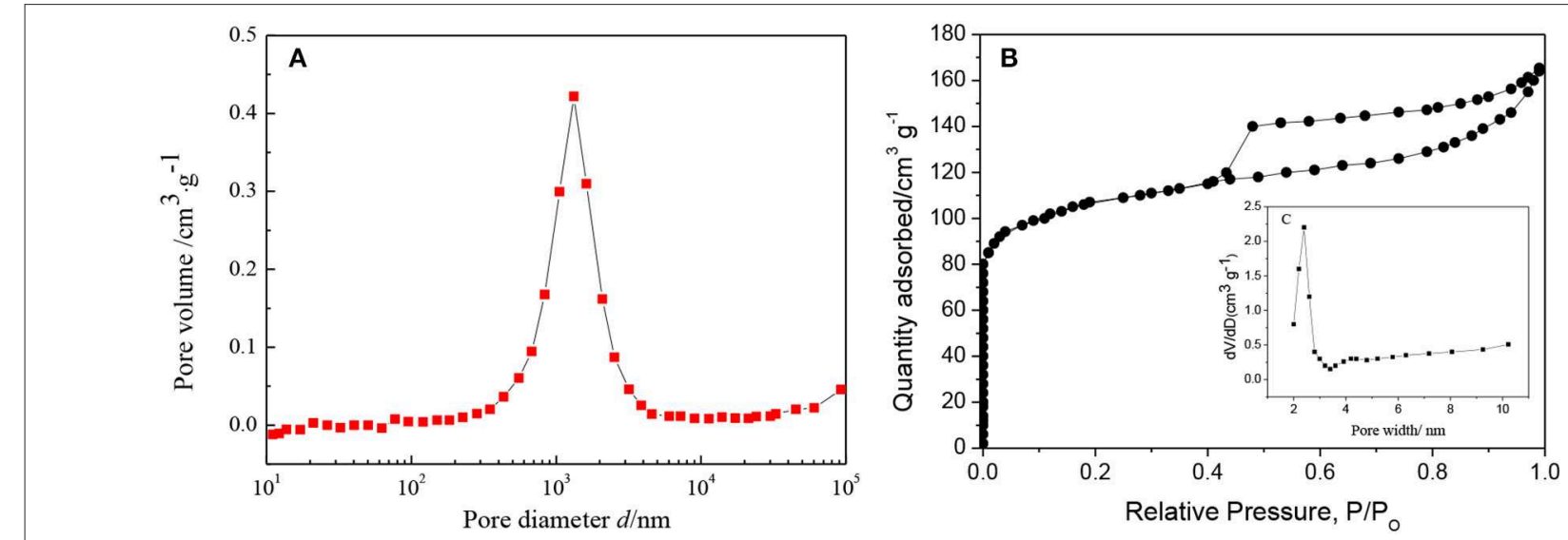

FIGURE 10 | (A) Pore size distribution of $\alpha$-quartz substrate, (B) $\mathrm{N}_{2}$ adsorption and desorption isotherm for FC zeolite, (C) Pore size distribution of ZSM-5 zeolite film.

reduced to $\mathrm{Ti}^{3+}$ (Equation 3), and then the water molecules enter the oxygen vacancy and react to form an adsorbed hydroxyl group (Equation 4). This reaction process can be expressed by the following equations:

$$
\begin{gathered}
\text { Photon energy } \rightarrow \mathrm{e}^{-}+\mathrm{h}^{+} \\
\mathrm{O}(\mathrm{O})^{2-}+2 \mathrm{~h}^{+} \rightarrow \mathrm{V}(\mathrm{O})+0.5 \mathrm{O}_{2} \\
\mathrm{Ti}^{4+}+\mathrm{e}^{-} \rightarrow \mathrm{Ti}^{3+} \\
\mathrm{O}_{\text {neighbor }}+\mathrm{V}(\mathrm{O})+\mathrm{H}_{2} \mathrm{O} \rightarrow 2 \mathrm{OH}
\end{gathered}
$$

Figure 9 shows SEM morphology of the crystal layer synthesized on the $\mathrm{TiO}_{2}$ coating irradiated by ultraviolet light at different times. As it can be seen from the figure, the zeolite film is highly uniform with b-orientation on the substrate. When the irradiation time reaches $8 \mathrm{~h}$, a small part of the seed crystal grows on the substrate in the non-b- oriented direction. The extra irradiation results in a decrease in the hydroxyl concentration on the surface of the substrate (Ehhalt and Rohrer, 2000). From Figure 3B, the surface seed crystals without ultraviolet treatment are evenly distributed, but the crystals are not dense enough. In contrast, from Figure 9A, it is found that the crystals on the surface of the substrate are uniformly and densely formed after treated by $2 \mathrm{~h}$ ultraviolet irradiation. From Figure 8, it can be seen that under the condition of ultraviolet light irradiation for $2 \mathrm{~h}$, the contact angle is the smallest and the surface hydrophilicity is the strongest, which greatly enhances the Ti-OH concentration and makes the b-oriented ZSM- 5 crystal growth denser.

In summary, surface structure and adsorption activity play a crucial role in the orientation and combination of ZSM5 zeolite film. The introduction of $\mathrm{TiO}_{2}$ modification layer provides a great substrate-modification growth interface for ZSM-5 crystal, and enhances the adsorption activity on the substrate and promotes the b-oriented growth of the ZSM-5 zeolite film.

\section{Textural Properties and Catalytic Performance of $\mathrm{ZSM}-5 / \mathrm{TiO}_{2} / \alpha-$ Quartz Zeolite}

\section{Textural Properties}

The change in porosity of the $\mathrm{ZSM}-5 / \mathrm{TiO}_{2} / \alpha$-quartz zeolite (FC) was confirmed by nitrogen adsorption and desorption, Table 2 summarizes the textural properties of the ZSM-5 zeolite before and after loading onto $\alpha$-quartz substrate, a wide peak (centered around $103 \mathrm{~nm}$ ) was observed clearly (Figure 10A), The macroporous $\alpha$-quartz substrate provides 


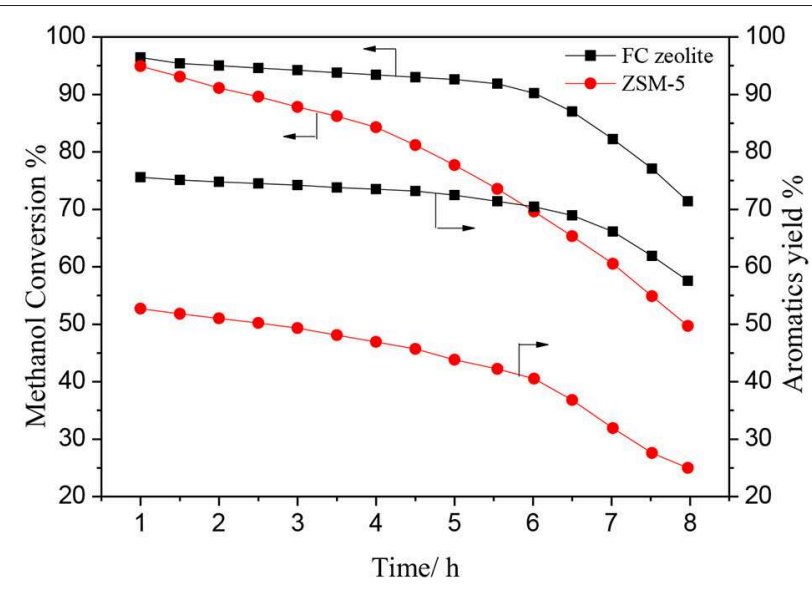

FIGURE 11 | Methanol conversion and aromatics yield of ZSM-5 and FC zeolite in MTA reaction.

a low-resistance mass transfer channel for the raw reactants and products. The FC zeolite exhibits a type IV nitrogen adsorption-desorption isotherm with a low uptake at low relative pressures (Figure 10B), which is consistent with the presence of micropores. And the ZSM-5 pore size distribution agrees with it (Figure 10C). At the same time, there is a typical H4 hysteresis loop in the isotherm at high relative pressure, which is the result of the adsorption and desorption of $\mathrm{N}_{2}$ in the mesoporous (Han and Liu, 2015; Chu et al., 2016). During the preparation of FC zeolite, the specific surface area $\left(S_{\text {total }}\right)$ and micropore volume $\left(\mathrm{V}_{\text {micro }}\right)$ have different degrees of reduction, but the mesoporous specific surface area $\left(\mathrm{S}_{\text {meso }}\right)$ and mesopore volume $\left(V_{\text {meso }}\right)$ increased to $136.6\left[\mathrm{~m}^{2} \mathrm{~g}^{-1}\right], 0.3455\left[\mathrm{~m}^{3} \mathrm{~g}^{-1}\right]$, respectively, this can greatly facilitate the rapid diffusion of the product to the catalyst surface and reduce the formation of coke.

\section{Catalytic Performance}

Figure 11 shows the methanol conversion and aromatics yield over ZSM-5 and FC zeolite with the reaction time in the MTA reaction. The methanol conversion was similar in the beginning of the reaction, however, after $6 \mathrm{~h}$, the methanol conversion over ZSM-5 was rapidly decreased to $68 \%$, while a slight decrease was observed over b-oriented ZSM-5. Meantime, the aromatics yield over b-oriented ZSM-5 (71\%) was much higher than ZSM-5 (40\%). The FC zeolite shortens the diffusion path and reduces diffusion resistance for the methanol, alkanes, and aromatic hydrocarbons to rapidly diffuses to the catalyst surface by the mesoporous. However, the single microporous structure has a negative impact on the ZSM-5 catalytic process due to its extremely narrow and elongated microchannel arrangement which limits mass transfer and facilitated coke formation (Groen et al., 2010; Chu et al., 2019). The introduction of $\mathrm{TiO}_{2}$ coating greatly promotes the formation of a dense and uniform b-oriented ZSM-5 zeolite film. The suitable pore structure ensures that the reactants and products in the pore is more conducive to the formation of BTX hydrocarbons, short residence time can reduce the degree of side reaction, thereby maintaining high catalytic activity and selectivity.

\section{CONCLUSION}

Hydrothermal crystallization method was used to prepare the b-oriented ZSM-5 zeolite film material on the macropore $\alpha$ quartz substrate. The effects of surface structure and adsorption activity on b-oriented implanting of ZSM-5 nucleus on porous $\alpha$-quartz substrates were investigated. Simulations of the loading process of ZSM-5 on different modified substrates with $\mathrm{TiO}_{2}$, PVA, CTS modifiers were carried out by Forcite module in Material Studio. And we obtained the b-oriented angle and adsorption potential energy though simulations. In the presence of $\mathrm{TiO}_{2}$ coating, the $\zeta$-potential energy of the interface of $\mathrm{TiO}_{2}$-substrate is zero, forming stable Ti-O-Si bond and strong adsorption potential energy, it turns out to be the most beneficial to ZSM-5 zeolite film loading and growth along the borientation.

Moreover, the $\mathrm{TiO}_{2}$ coating is subjected to different calcination temperature and ultraviolet irradiation time. With $100^{\circ} \mathrm{C}$ calcination temperature and $2 \mathrm{~h}$ irradiation time, the $\mathrm{Ti}-\mathrm{OH}$ concentration in the anatase crystal phase reaches the maximum. It is conclusive that the $\mathrm{TiO}_{2}$ coating provides a smooth nucleus-substrate growth interface for ZSM-5 zeolite film. Consequently, the interaction between the substrate surface and the ZSM-5 zeolite film is increased and the uniform distribution of the ZSM-5 zeolite film growing along the boriented direction is obtained.

Finally, we successfully prepared a FC zeolite with a suitable micro-mesoporous structure. it exhibits excellent catalytic activity and selectivity in MTA reactions and will be valuable material for further application.

\section{DATA AVAILABILITY STATEMENT}

The datasets generated for this study are available on request to the corresponding author.

\section{AUTHOR CONTRIBUTIONS}

All authors have contributed in various degrees to the analytical methods used, to the research concept, to the experiment design, to the acquisition of data, or analysis, and interpretation of data, to draft the manuscript or to revise it critically for important intellectual content.

\section{FUNDING}

This work was supported by the Fundamental Research Funds for the Central Universities (2017XKQY067). 


\section{REFERENCES}

Ali, K. A., Abdullah, A. Z., and Mohamed, A. R. (2015). Recent development in catalytic technologies for methanol synthesis from renewable sources: a critical review. Renew. Sust. Energ. Rev. 44, 508-518. doi: 10.1016/j.rser.2015.01.010

Baguer, N., Georgieva, V., Calderin, L., Todorov, L., Gils, S. V., and Bogaerts, A. (2009). Study of the nucleation and growth of $\mathrm{TiO} 2$ and $\mathrm{ZnO}$ thin films by means of molecular dynamics simulations. J. Cryst. Growth. 311, 4034-4043. doi: $10.1016 /$ j.jcrysgro.2009.06.034

Barbieriková, Z., PliŽingrová, E., Motlochová, M., Bezdička, P., Boháček, J., Dvoranová, D., et al. (2018). N-doped titanium dioxide nanosheets: preparation, characterization and UV/visible-light activity. Appl. Catal. B Environ. 232, 397-408. doi: 10.1016/j.apcatb.2018.03.053

Bozzano, G., and Manenti, F. (2016). Efficient methanol synthesis: perspectives, technologies and optimization strategies. Prog. Energ. Combust. Sci. 56, 71-105. doi: $10.1016 /$ j.pecs.2016.06.001

Catizzone, E., Cirelli, Z., Aloise, A., Lanzafame, P., Migliori, M., and Giordano, G. (2017). Methanol conversion over ZSM-12, ZSM-22 and EU1 zeolites: from DME to hydrocarbons production. Catal. Today 304, 39-50. doi: $10.1016 /$ j.cattod.2017.08.037

Chu, R., Wang, J., Meng, X., Yu, S., Zhang, G., Wang, M., et al. (2019). Molecular simulation of hydrodesulfurization of coal tar using $\mathrm{Pd} / \mathrm{ZSM}-5 / \gamma-\mathrm{Al}_{2} \mathrm{O}_{3}$ catalyst. Asia-Pacific J. Chem. Eng. 14:e2304. doi: 10.1002/apj.2304

Chu, R., Xu, T., Meng, X., Hou, W., and Miao, Z. (2016). Improved catalytic performance of C-axis oriented HZSM- 5 nanobunches synthesized by re-aging. Catal. Lett. 146, 1965-1972. doi: 10.1007/s10562-016-1835-1

Chu, R. Z., Xu, T. T., Meng, X. L., and Wu, G. G. (2016). Mechanism of reaction of $\mathrm{CeO} 2-\mathrm{CaO}-\mathrm{Pd} / \mathrm{HZSM} 5$ catalyst in the syngas process in the presence of sulfurcontaining impurities. Prog. React. Kinet. Mech. 41, 1965-1972. doi: 10.3184/146867816X14702288 640948

Di, J., Cong, Z., Yan, W., Wang, X., Yu, J., and Xu, R. (2011). Direct in situ crystallization of highly oriented silicalite-1 thin films on a surface sol-gel process modified substrate. Microporous Mesoporous Mater. 145, 104-107. doi: 10.1016/j.micromeso.2011.04.032

Ehhalt, D. H., and Rohrer, F. (2000). Dependence of the $\mathrm{OH}$ concentration on solar UV. J. Geophys. Res. 105, 3565-3571. doi: 10.1029/1999JD9 01070

Fu, D., Schmidt, J. E., Pletcher, P., Karakiliç, P., Ye, X., Vis, C. M., et al. (2018). Uniformly oriented zeolite ZSM-5 membranes with tunable wettability on a porous ceramic. Angew. Chem. Int. Edn. 57, 12458-12462. doi: 10.1002/anie.201806361

Groen, J. C., Peffer, L. A., Moulijn, J. A., and Pérez-Ramírez, J. (2010). Mechanism of hierarchical porosity development in MFI zeolites by desilication: the role of aluminium as a pore-directing agent. Chem. A Eur. J. 11, 4983-4994. doi: $10.1002 /$ chem. 200500045

Han, J., and Liu, D. (2015). Influence of synthesis conditions on the mesopore distribution and morphology control of hierarchical ZSM-5 zeolites synthesized by double-acyloxy organosilane surfactants. Eur. J. Inorg. Chem. 2015, 5081-5088. doi: 10.1002/ejic.201500735

Ji, M., Liu, G., Chen, C., Wang, L., and Zhang, X. (2012). Synthesis of highly b -oriented ZSM-5 membrane on a rough surface modified simply with TiO 2 by in situ crystallization. Microporous Mesoporous Mater. 155, 117-123. doi: 10.1016/j.micromeso.2011.12.037

Jin, S. P., Lee, G. S., and Yoon, K. B. (2006). Micropatterned monolayer assembly of zeolite microcrystals on glass by ionic linkages. Microporous Mesoporous Mater. 96, 1-8. doi: 10.1016/j.micromeso.2006.06.002

Jlh, C., Tellez, C., Yeung, K. L., and Ho, K. (2000). The role of surface chemistry in zeolite membrane formation. J. Membrane Sci. 164, 257-275. doi: 10.1016/S0376-7388(99)00214-8

Khodakov, A. Y., Chu, W., and Fongarland, P. (2010). Advances in the development of novel cobalt fischer\&mdash;tropsch catalysts for synthesis of long-chain hydrocarbons and clean fuels. Chem. Rev. 38, 1692-1744. doi: 10.1002/chin.200733255

Lacarriere, A., and Luck, F., Swierczynski, D., Fajula, F., and Hulea, V. (2011). Methanol to hydrocarbons over zeolites with MWW topology: effect of zeolite texture and acidity. Appl. Catal. A Gen. 402, 208-217. doi: 10.1016/j.apcata.2011.06.003
Lai, R., Yan, Y., and Gavalas, G. R. (2000). Growth of ZSM-5 films on alumina and other surfaces. Microporous Mesoporous Mater. 37, 9-19. doi: 10.1016/S1387-1811(99)00188-2

Lai, Z. P., Tsapatsis, M., and Nicolich, J. P. (2010). Siliceous ZSM-5 membranes by secondary growth of b-oriented seed layers. Adv. Funct. Mater. 14, 716-729. doi: $10.1002 /$ adfm.200400040

Lee, G. S., Lee, Y. J., Choi, S. Y., Park, Y. S., and Yoon, K. B. (2000a). Self-assembly of $\beta$-glucosidase and d-glucose-tethering zeolite crystals into fibrous aggregates. J. Am. Chem. Soc. 122, 12151-12157. doi: 10.1021/ja0028222

Lee, G. S., Lee, Y. J., Ha, K., and Yoon, K. B. (2000b). Orientationcontrolled monolayer assembly of zeolite crystals on glass using terephthaldicarboxaldehyde as a covalent linker. Tetrahedron 56, 6965-6968. doi: 10.1016/S0040-4020(00)00517-2

Lee, G. S., Lee, Y. J., and Yoon, K. B. (2001). Layer-by-Layer assembly of zeolite crystals on glass with polyelectrolytes as ionic linkers. J. Am. Chem. Soc. 123, 9769-9779. doi: 10.1021/ja010517q

Li, S., Demmelmaier, C., Itkis, M. E., Liu, Z., Haddon, R. C., and Yan, Y. (2003). Micropatterned oriented zeolite monolayer films by direct in situ crystallization. Chem. Mater. 15, 2687-2689. doi: 10.1021/cm034362s

Lian, X., and Park, S. S. (2016). Preparation of titanium dioxide films on etched aluminum foil by vacuum infiltration and anodizing. Appl. Surf. Sci. 388, 245-251. doi: 10.1016/j.apsusc.2016.01.166

Liu, F., Liu, C. L., Hu, B., Kong, W. P., and Qi, C. Z. (2012). Hightemperature hydrothermal synthesis of crystalline mesoporous $\mathrm{TiO} 2$ with superior photo catalytic activities. Appl. Surf. Sci. 258, 7448-7454. doi: 10.1016/j.apsusc.2012.04.059

Mashimo, T., Bagum, R., Ogata, Y., Tokuda, M., Okube, M., Sugiyama, K., et al. (2017). Structure of single-crystal rutile (TiO2) prepared by high-temperature ultracentrifugation. Cryst. Growth Des. 17, 1460-1464. doi: $10.1021 /$ acs.cgd.6b01818

Mitsuyoshi, D., Kuroiwa, K., Kataoka, Y., Nakagawa, T., Kosaka, M., Nakamura, K., et al. (2017). Shape selectivity in toluene disproportionation into para-xylene generated by chemical vapor deposition of tetramethoxysilane on MFI zeolite catalyst. Microporous Mesoporous Mater. 242, 118-126. doi: 10.1016/j.micromeso.2017.01.022

Mohamad, M., Haq, B. U., Ahmed, R., Shaari, A., Ali, N., and Hussain, R. (2015). A density functional study of structural, electronic and optical properties of titanium dioxide: characterization of rutile, anatase and brookite polymorphs. Mater. Sci. Semiconduct. Process. 31, 405-414. doi: 10.1016/j.mssp.2014.12.027

$\mathrm{Na}$, L., Chen, M., and Liu, D. (2018). Deactivation kinetics with activity coefficient of the methanol to aromatics process over modified ZSM-5. Fuel 233, 283-290. doi: $10.1016 /$ j.fuel.2018.06.044

Park, J. S., Lee, G. S., Lee, Y. J., Park, Y. S., and Yoon, K. B. (2002). Organization of microcrystals on glass by adenine-thymine hydrogen bonding. J. Am. Chem. Soc. 124, 13366-13367. doi: 10.1021/ja0270569

Razmimanesh, F., Amjad-Iranagh, S., and Modarress, H. (2015). Molecular dynamics simulation study of chitosan and gemcitabine as a drug delivery system. J. Mol. Model. 21:165. doi: 10.1007/s00894-015-2705-2

Shen, K., Ning, W., Qian, W., Cui, Y., and Wei, F. (2014). Atmospheric pressure synthesis of nanosized ZSM-5 with enhanced catalytic performance for methanol to aromatics reaction. Catal. Sci. Technol. 4, 3840-3844. doi: $10.1039 / \mathrm{C} 4 \mathrm{CY} 01010 \mathrm{H}$

Shen, K., Qian, W., Wang, N., Zhang, J., and Wei, F. (2013). Direct synthesis of caxis oriented ZSM-5 nanoneedles from acid-treated kaolin clay. J. Mater. Chem. A 1, 3272. doi: $10.1039 / \mathrm{c} 3 \mathrm{ta} 01479 \mathrm{~g}$

Svelle, S., Joensen, F., Nerlov, J., Olsbye, U., Lillerud, K. P., Kolboe, S., et al. (1999). The conversion of methanol to hydrocarbons over zeolite H-beta. Microporous Mesoporous Mater. 29, 173-184. doi: 10.1016/S1387-1811(98) 00329-1

Wei, C., and Yen, J. Y. (2007). Effect of film thickness and interlayer on the adhesion strength of diamond like carbon films on different substrates. Diamond Relat. Mater. 16, 1325-1330. doi: 10.1016/j.diamond.2007.02.003

Wei, Q., Zhang, Y., Wang, Y., and Yang, M. (2017). A molecular dynamic simulation method to elucidate the interaction mechanism of nano-SiO 2 in polymer blends. J. Mater. Sci. 52, 12889-12901. doi: 10.1007/s10853-017-1330-0

Wu, M. C., Tóth, G., Sápi, A., Leino, A. R., Kónya, Z., Kukovecz, A., et al. (2012). Synthesis and photocatalytic performance of titanium dioxide nanofibers 
and the fabrication of flexible composite films from nanofibers. J. Nanosci. Nanotechnol. 12, 1421-1424. doi: 10.1166/jnn.2012.4655

Ye, J., Bai, L., Liu, B., Tian, H., Hu, J., Polo-Garzon, F., et al. (2019). Fabrication of a pillared ZSM-5 framework for shape selectivity of ethane dehydroaromatization. Ind. Eng. Chem. Res. 58, 7094-7106. doi: 10.1021/acs.iecr.8b04965

Zhou, X., Chen, H., Zhu, Y., Song, Y., Chen, Y., Wang, Y., et al. (2013). Dual-mesoporous ZSM-5 zeolite with highly b-axisoriented large mesopore channels for the production of benzoin ethyl ether. Chemistry 19, 10017-10023. doi: 10.1002/chem.201 300245
Conflict of Interest: The authors declare that the research was conducted in the absence of any commercial or financial relationships that could be construed as a potential conflict of interest.

Copyright $(0) 2019$ Chu, Yang, Meng, Yu, Wan, Wu and Wang. This is an open-access article distributed under the terms of the Creative Commons Attribution License (CC $B Y)$. The use, distribution or reproduction in other forums is permitted, provided the original author(s) and the copyright owner(s) are credited and that the original publication in this journal is cited, in accordance with accepted academic practice. No use, distribution or reproduction is permitted which does not comply with these terms. 
OPEN ACCESS

Edited by:

Qiang Wang,

Beijing Forestry University, China

Reviewed by:

Takashi Okubo,

Kindai University, Japan

Linhai Duan,

Guangdong University of

Petrochemical Technology, China

${ }^{*}$ Correspondence:

Qibin Xia

qbxia@scut.edu.cn

Qi-Hui Wu

qihui_wu@xmu.edu.cn

Specialty section:

This article was submitted to

Inorganic Chemistry,

a section of the journal

Frontiers in Chemistry

Received: 16 June 2019 Accepted: 11 September 2019

Published: 27 September 2019

Citation:

Sun X, Gu X, Xu W, Chen W-J, Xia Q,

Pan X, Zhao X, Li Y and WU Q-H

(2019) Novel Hierarchical Fe(III)-Doped

Cu-MOFs With Enhanced Adsorption

of Benzene Vapor.

Front. Chem. 7:652.

doi: 10.3389/fchem.2019.00652

\section{Novel Hierarchical Fe(III)-Doped Cu-MOFs With Enhanced Adsorption of Benzene Vapor}

\author{
Xuejiao Sun ${ }^{1}$, Xiulian $\mathrm{Gu}^{1}$, Wentao Xu ${ }^{1}$, Wen-Jie Chen ${ }^{1}$, Qibin Xia ${ }^{2 *}$, Xiaoyang Pan ${ }^{1}$, \\ Xiaojing Zhao ${ }^{1}$, Yi Li ${ }^{3}$ and Qi-Hui $W^{4 *}$ \\ ${ }^{1}$ School of Chemical Engineering and Materials Science, Quanzhou Normal University, Quanzhou, China, ${ }^{2}$ School of \\ Chemistry and Chemical Engineering, South China University of Technology, Guangzhou, China, ${ }^{3}$ Jiangsu Key Laboratory of \\ Advanced Functional Polymer Designand Application, Department of Polymer Science and Engineering, College of \\ Chemistry, Chemical Engineering and Materials Science, Soochow University, Suzhou, China, ${ }^{4}$ College of Mechanical and \\ Energy Engineering, Jimei University, Xiamen, China
}

New hierarchical Fe(III)-doped Cu-MOFs (Fe-HK) were developed via introduction of $\mathrm{Fe}^{3+}$ ions during HKUST-1 synthesis. The obtained products were characterized by $\mathrm{N}_{2}$ adsorption, $\mathrm{X}$-ray diffraction, scanning electron microscopy, energy dispersive spectroscopy, FIIR spectroscopy, and thermal analysis. The adsorption isotherms and kinetics of benzene vapor were measured and consecutive adsorption-desorption cycles were performed. It was found that the hierarchical-pore Fe-HK-2 exhibited optimal textural properties with high BET surface area of $1,707 \mathrm{~m}^{2} / \mathrm{g}$ and total pore volume of $0.93 \mathrm{~cm}^{3} / \mathrm{g}$, which were higher than those of the unmodified HKUST-1. Significantly, the hierarchical-pore Fe-HK-2 possessed outstanding benzene adsorption capacity, which was 1.5 times greater than the value on HKUST-1. Benzene diffusivity of Fe-HK-2 was 1.7 times faster than that of parent HKUST-1. Furthermore, the benzene adsorption on Fe-HK-2 was highly reversible. The hierarchical-pore Fe-HK-2 with high porosity, outstanding adsorption capacity, enhanced diffusion rate, and excellent reversibility might be an attractive candidate for VOCs adsorption. This may offer a simple and effective strategy to synthesize hierarchical-pore MOFs by doping with other metal ions.

Keywords: HKUST-1, hierarchical-pore, adsorption, benzene, VOC

\section{INTRODUCTION}

Volatile organic compounds (VOCs) as hazardous air pollutants are the precursors of ozone and smog (Zhang et al., 2019). They are derived from various industrial processes and applications of chemical products. The emissions of VOCs have caused severe environmental and healthy issues causing cancer and death (Zhu et al., 2016, 2019; Meng et al., 2019). Therefore, the reduction of VOCs emissions is of great significance. Adsorption with appropriate materials as VOC adsorbent has been known as an energy-efficient and promising strategy (Vellingiri et al., 2017; Zhang et al., 2017; Sui et al., 2019). 
Metal-organic frameworks (MOFs), as novel adsorbents, have been attracted considerable attention owing to their excellent specific surface and porosity, as well as tunable topologies (Sun et al., 2014; Ahmed and Jhung, 2016; Li et al., 2018; Lin et al., 2018). Importantly, MOFs have been developed as attractive candidates for VOCs adsorption (Duan et al., 2013; Vellingiri et al., 2016, 2017; Wang et al., 2018). Hu et al. (2018) reported that $\mathrm{UiO}-66$ had the high adsorption capacities of chlorobenzene (4.94 mmol/g) and acetaldehyde $(9.42 \mathrm{mmol} / \mathrm{g})$. Xian et al. (2015) indicated that the uptakes of 1,2-dichloroethane and ethyl acetate (EA) on MIL-101(Cr) were separately 9.71 and $5.79 \mathrm{mmol} / \mathrm{g}$. Previously, our results also implied that: (1) MIL101(Cr) exhibited excellent uptakes of a series of aromatics and $n$-alkanes (7.2-16.3 mmol/g) (Sun et al., 2014, 2017); and (2) MOF-5 possessed high uptakes of linear alkanes $n \mathrm{C}_{4}-n \mathrm{C}_{7}$ (8.0-11.5 mmol/g) (Lv et al., 2017). However, most MOFs (e.g., UiO-66, HKUST-1, MOF-5) are microporous with pore sizes $<20 \AA$, which does not benefit molecule diffusion and mass transport (Huang et al., 2015; Yang et al., 2018), inhibiting their applications in VOCs adsorption separation.

Recently, hierarchical-pore MOFs (H-MOFs) are attracting wide attention because of their exceptional properties, including that the micropores can facilitate high surface area, and the mesopores or macropores can enhance molecule diffusion and mass transport (Duan et al., 2018a).Various strategies have been developed to prepare hierarchical porous MOFs, including ligand extension method, mixed ligands method, post-modification method, and template method (Bradshaw et al., 2014; He et al., 2016; Yuan et al., 2017; Chen et al., 2019). Whereas, most of these methods need rigorous experimental conditions and complicated post-treatments (Yang et al., 2018). Moreover, these strategies are disrupted by other disadvantages, such as the high cost of larger ligands, the random copolymerization of mixed ligands, the interpenetrated structures, the collapse of framework after template removal and so on (Yuan et al., 2017; Duan et al., $2018 b)$. Therefore, it is imperative to develop a new strategy to synthesize H-MOFs with high VOCs adsorption capacities.

Notably, HKUST-1 (Cu-BTC) is a potential adsorbent for VOCs due to its high porosity, accessible unsaturated metallic sites, good thermal stability, and easy production (Sun et al., 2015; Wu et al., 2015; Vellingiri et al., 2016). HKUST-1 contains $3 \mathrm{D}$ intersectional pores with a window size of $6.0 \AA$ and cage size of $9.0 \AA$ (Zhao et al., 2015). These micropores can offer strong adsorption affinity toward VOCs molecules, but limit their diffusion rate, especially for large ones. Recently, Duan et al. prepared hierarchical-pore HKUST-1 by employing organic amines or dual-functional surfactant as template and investigated its catalytic activity (Duan et al., 2018b,c). Nevertheless, the hierarchical-pore HKUST-1 exhibited lower BET surface area (584-1,241 $\mathrm{m}^{2} / \mathrm{g}$ ) compared to the parent HKUST-1(1,425 m²/g). Mao et al. (2015) developed a ligand-assisted etching process to prepare the hierarchical porous HKUST-1 with BET surface area of $1,462 \mathrm{~m}^{2} / \mathrm{g}$, which showed the enhanced $\mathrm{CO}_{2}$ adsorption capacity and improved diffusion rate. Chuah et al. (2017) synthesized hierarchically structured HKUST-1 nanocrystals with BET surface area of $1,328 \mathrm{~m}^{2} / \mathrm{g}$ to improve the $\mathrm{SF}_{6}$ uptake and adsorption kinetics. However, these approaches are still complicated and BET surface areas of the hierarchical-pore HKUST-1 need to be further improved. Thus, it is imperative to develop a facile approach to synthesize hierarchical-pore HKUST-1 with high BET surface area and enhanced VOCs adsorption capacity.

In this work, we initiated a simple and effective method to synthesize hierarchical-pore HKUST-1 by introducing $\mathrm{Fe}^{3+}$ ions in the HKUST-1 synthesis process. The obtained hierarchicalpore products were characterized, and subsequently their benzene adsorption isotherms and kinetics were measured. Consecutive adsorption-desorption cycles were performed to evaluate the reversibility of benzene adsorption. Importantly, hierarchical-pore HKUST-1 exhibited high porosities with micropores and mesopores. In a result, the hierarchical-pore HKUST-1 showed outstanding benzene adsorption capacities, enhanced diffusion rate and excellent reversibility. Current work indicated that the hierarchical-pore HKUST-1 might be an attractive candidate for VOCs adsorption applications.

\section{EXPERIMENTAL}

\section{Materials}

Copper nitrate trihydrate $\left[\mathrm{Cu}\left(\mathrm{NO}_{3}\right)_{2} \cdot 3 \mathrm{H}_{2} \mathrm{O}, 99 \%\right]$, ferric trichloride hexahydrate $\left(\mathrm{FeCl}_{3} \cdot 6 \mathrm{H}_{2} \mathrm{O}, 99 \%\right)$, and $\mathrm{N}, \mathrm{N}-$ dimethylformamide (DMF, 99.5\%) were purchased from Shanghai Macklin Biochemical Co., Ltd. Benzenetricarboxylic acid $\left(\mathrm{H}_{3} \mathrm{BTC}, 99 \%\right)$ was provided from Beijing J\&K Chemical Technology Co., Ltd.

\section{Synthesis of Fe-Doped HKUST-1}

HKUST-1 was prepared according to the previous report with some modifications (Duan et al., 2018b). In general, copper nitrate trihydrate $(1.45 \mathrm{~g}, 6 \mathrm{mmol})$ and $\mathrm{H}_{3} \mathrm{BTC}(0.84 \mathrm{~g}, 4 \mathrm{mmol})$ were dissolved in $36 \mathrm{~mL}$ DMF. The mixture was then transferred to a Teflon-lined autoclave and heated at $383 \mathrm{~K}$ for $21 \mathrm{~h}$. The products were filtered and sequently washed with DMF and ethanol. Fe-doped HKUST-1 (Fe-HK) samples with different

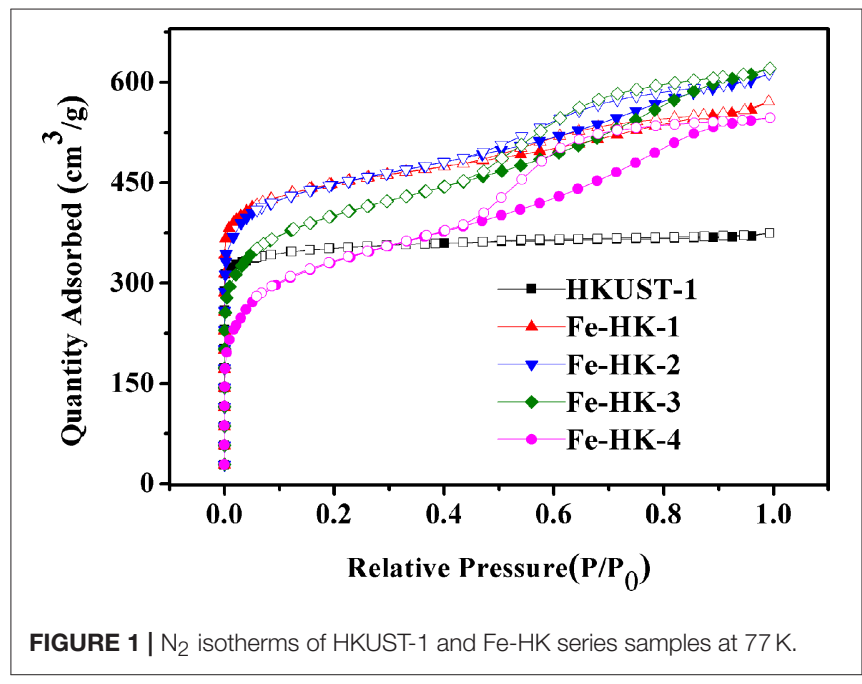



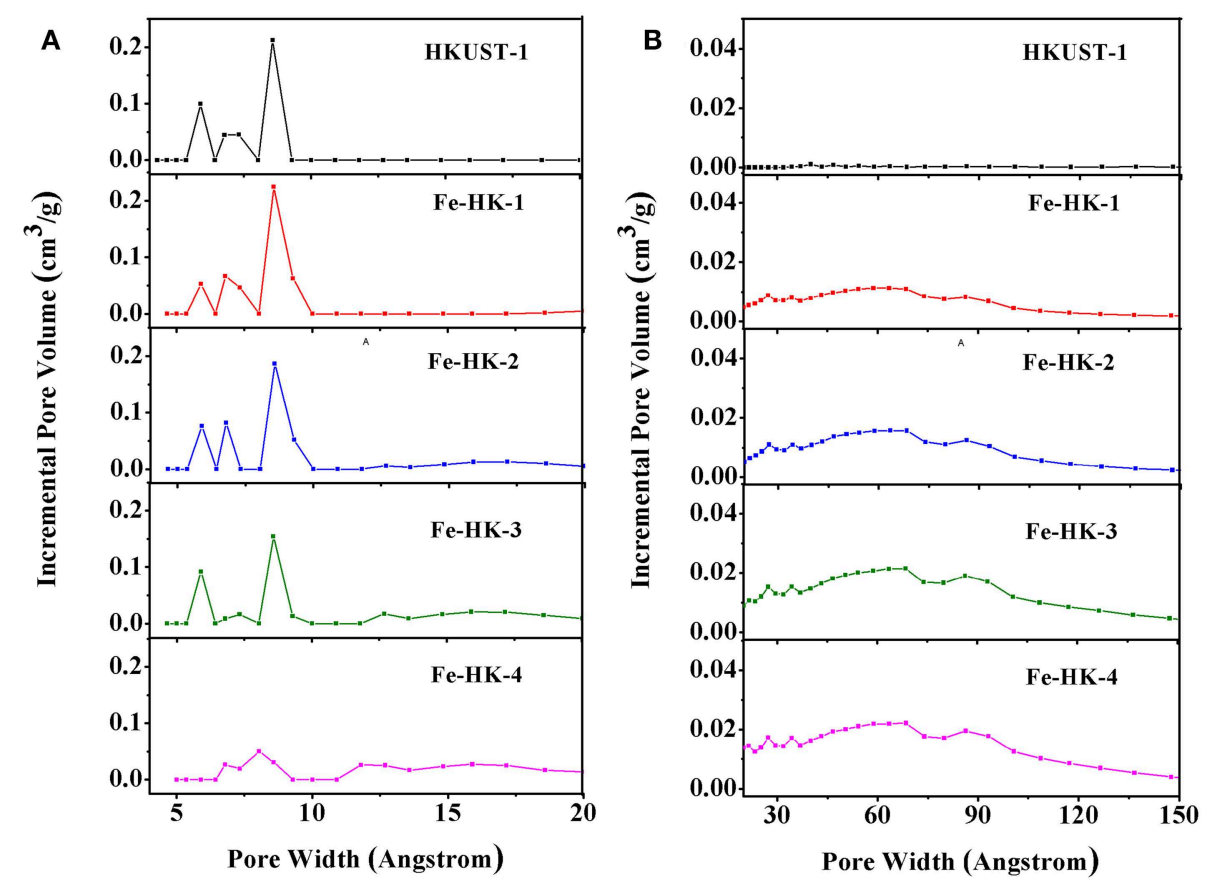

FIGURE 2 | Pore size distribution curves of HKUST-1 and Fe-HK samples (A) micropore and (B) mesopore.

TABLE 1 | Pore structure parameters of HKUST-1 and Fe-HK samples.

\begin{tabular}{|c|c|c|c|c|}
\hline \multirow[t]{2}{*}{ Sample } & \multirow{2}{*}{$\frac{\text { Surface Area }\left(\mathrm{m}^{2} / \mathrm{g}\right)}{\text { BET }}$} & \multicolumn{3}{|c|}{ Pore Volume $\left(\mathrm{cm}^{3} / \mathrm{g}\right)$} \\
\hline & & Total & Micropore & Mesopore \\
\hline HKUST-1 & 1400 & 0.56 & 0.48 & 0.08 \\
\hline Fe-HK-1 & 1729 & 0.86 & 0.64 & 0.22 \\
\hline Fe-HK-2 & 1707 & 0.93 & 0.62 & 0.31 \\
\hline $\mathrm{Fe}-\mathrm{HK}-3$ & 1495 & 0.95 & 0.53 & 0.42 \\
\hline Fe-HK-4 & 1226 & 0.84 & 0.41 & 0.43 \\
\hline
\end{tabular}

$\mathrm{Fe}^{3+} / \mathrm{Cu}^{2+}$ molar ratios were synthesized following the similar procedure of HKUST-1, in which the total mole value $(6 \mathrm{mmol})$ of $\mathrm{Fe}^{3+}$ and $\mathrm{Cu}^{2+}$ was constant by substitution of copper nitrate trihydrate with ferric trichloride hexahydrate. Herein, Fe-HK samples were synthesized with initial $\mathrm{Fe}^{3+} / \mathrm{Cu}^{2+}$ molar ratios of $0.15,0.20,0.33$, and 0.50, and labeled as Fe-HK-1, Fe-HK-2, $\mathrm{Fe}-\mathrm{HK}-3$, and Fe-HK-4, respectively.

\section{RESULTS AND DISCUSSION \\ Physical Characteristics}

Figure 1 shows the $N_{2}$ isotherms of HKUST-1 and four FeHK samples at $77 \mathrm{~K}$. The isotherm of HKUST-1 exhibits the typical type-I characteristic, indicating the existence of micropores. Whereas, all the Fe-HK samples exhibit typical type-IV isotherms with apparent hysteresis loops, implying the presence of mesopores. These results are further confirmed by NLDFT pore-size distribution curves of these materials. As shown in Figure 2, HKUST-1 only presents micropores below 10 $\AA$. The pore size below $10 \AA$ is also observed in all Fe-HK samples, suggesting that the porous structure of HKUST-1 is remained in the Fe-HK samples. Comparing to HKUST-1, there are also new micropores (10-20 $)$ and mesopores in Fe-HK samples. On one hand, the coordination between $\mathrm{Fe}^{3+}$ and carboxylic groups in the BTC can form new micropores and smaller mesopores. On the other hand, $\mathrm{Fe}^{3+}$ ions can coordinate with BTC ligand and compete with $\mathrm{Cu}^{2+}$ ions to result in the formation of defects and larger mesopores (Horcajada et al., 2014; Zhou et al., 2016). Moreover, the volumes of mesopores increase with $\mathrm{Fe}^{3+}$ contents in the Fe-HK samples. These results indicate that $\mathrm{Fe}-\mathrm{HK}$ samples exhibit hierarchical porous structures.

Table 1 lists the textural properties of HKUST-1 and the FeHK samples. Fe-HK-1-3 samples possess higher BET surface areas, micropore volumes and mesopore volumes than HKUST1, suggesting that the small addition of $\mathrm{Fe}^{3+}$ can enhance the porosities of $\mathrm{Fe}-\mathrm{HK}$ samples. This may be ascribed to the formation of new microporous and mesoporous structures owing to the introduction of $\mathrm{Fe}^{3+}$ (Horcajada et al., 2014; Zhou et al., 2016). Additionally, with the increase of molar ratio of $\mathrm{Fe}^{3+} / \mathrm{Cu}^{2+}$ from 0.15 to 0.33 , the BET surface areas and micropore volumes of the three Fe-HK samples (Fe-HK-13) gradually decrease from 1,729 to $1,495 \mathrm{~m}^{2} / \mathrm{g}$ and $0.64-0.53$ $\mathrm{cm}^{3} / \mathrm{g}$, respectively. In contrast, the total pore volumes, mesopore volumes of the three samples increase with the molar ratio of $\mathrm{Fe}^{3+} / \mathrm{Cu}^{2+}$, and could separately reach 0.95 and $0.42 \mathrm{~cm}^{3} / \mathrm{g}$. However, Fe-HK-4 $\left(\mathrm{Fe}^{3+} / \mathrm{Cu}^{2+}=0.5\right)$ shows lower BET surface area than HKUST-1, which is possibly attributed to the formation 
of the serious crystal defects owing to the excess $\mathrm{Fe}^{3+}$ (Zhou et al., 2016). After comprehensive consideration, Fe-HK-2 $\left(\mathrm{Fe}^{3+} / \mathrm{Cu}^{2+}\right.$ $=0.20$ ) was chosen as the optimal sample, which presents BET surface area of $1,707 \mathrm{~m}^{2} / \mathrm{g}$ and total pore volume of $0.93 \mathrm{~cm}^{3} / \mathrm{g}$, higher than the previously reported values for hierarchical-pore HKUST-1 prepared with different methods (Mao et al., 2015; Duan et al., 2018b,c).

Figure 3 shows the PXRD patterns of HKUST-1 and the Fe-HK samples. The PXRD patterns of Fe-HK-1-3 samples

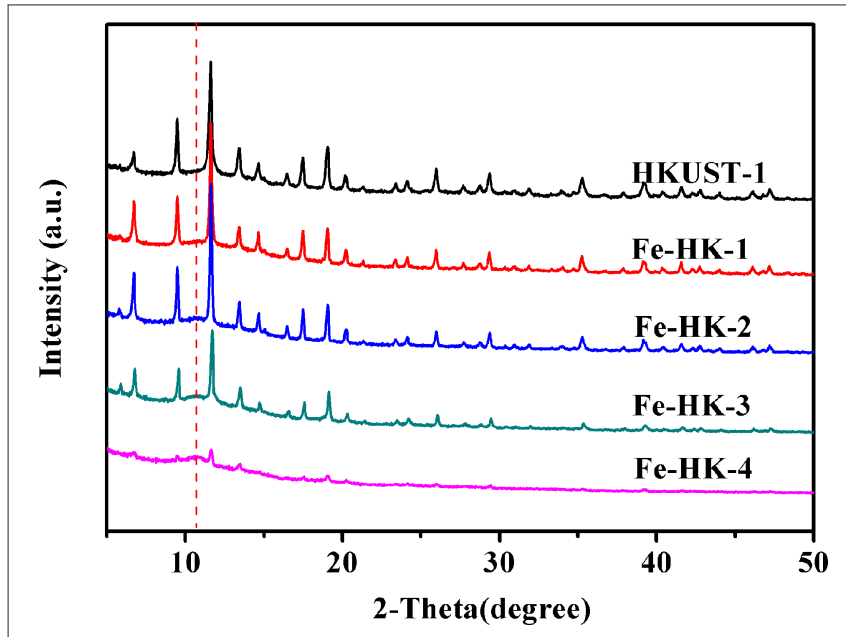

FIGURE 3 | PXRD patterns of HKUST-1 and the Fe-HK samples. exhibit the main characteristic peaks at $9.4^{\circ}, 11.6^{\circ}, 17.5^{\circ}$, and $19.1^{\circ}$, which are identical to that of HKUST-1. It indicates that the Fe-HK-1-3 samples preserve the crystalline characters of HKUST-1, whereas, Fe-HK-4 shows very weak characteristic peaks of HKUST-1 and a new characteristic peak at $10.7^{\circ}$ appears. It suggests that when the $\mathrm{Fe}^{3+}$ content is higher than certain number, the growth of the HKUST-1 structure would be prevented (Ebrahim and Bandosz, 2013; Zhou et al., 2016). This conclusion is in agreement with the above BET results. Additionally, the new peak at $10.7^{\circ}$ may be due to the interaction between $\mathrm{Fe}^{3+}$ and carboxylic groups in the BTC.

SEM images of HKUST-1 and the Fe-HK samples are presented in Figure S1. It indicates that HKUST-1 has octahedral morphology. The Fe-HK-1-3 samples maintain octahedral structure and their surfaces become rough due to the incorporation of $\mathrm{Fe}^{3+}$. Similar results were also found for other metal ion doping MOFs (Ebrahim and Bandosz, 2013). EDS mapping of the Fe-HK-2 sample was selected as a representative to verify the existence and dispersion of iron ions. As shown in Figure 4, the existence of Fe element is clearly confirmed. It is also observed that the $\mathrm{Fe}$ and $\mathrm{Cu}$ elements are well-dispersed in the Fe-HK-2 crystals, indicating that the iron ions were incorporated successfully into the HKUST-1 framework. The EDS results of $\mathrm{Fe} / \mathrm{Cu}$ atomic ratios for all $\mathrm{Fe}-\mathrm{HK}$ samples are listed in Table S1. It indicates that the atomic ratios of $\mathrm{Fe} / \mathrm{Cu}$ in Fe-HK-1, Fe-HK-2, Fe-HK-3 and Fe-HK-4 are 0.17, 0.21, 0.31, and 0.53 , respectively, which are very close to their design values.

Figure 5 displays FTIR spectra of HKUST-1 and the Fe-HK samples. These FTIR spectra are nearly similar, which present
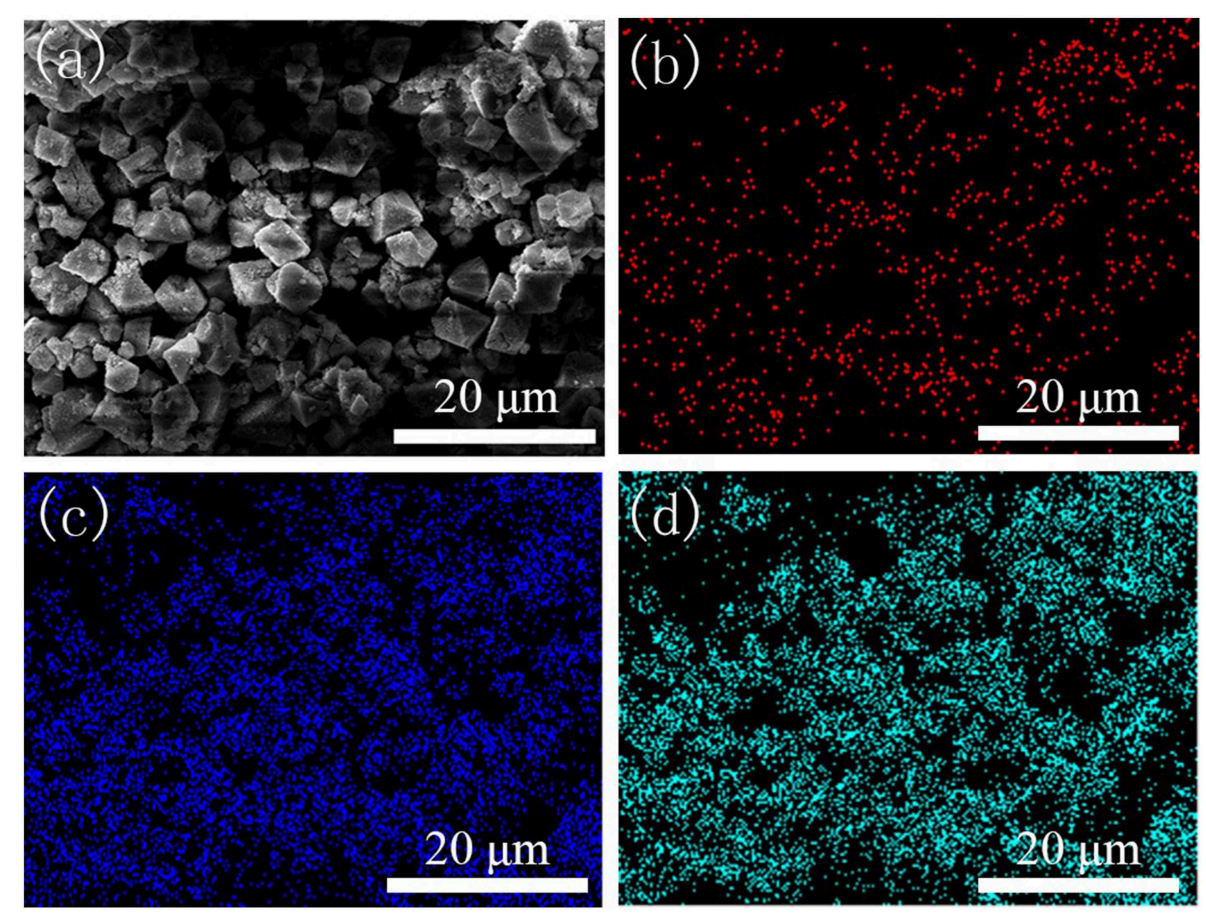

FIGURE 4 | EDS mapping of Fe-HK-2 sample. SEM image (a) and the corresponding elemental distributions of Fe (b), Cu (c), and O (d). 


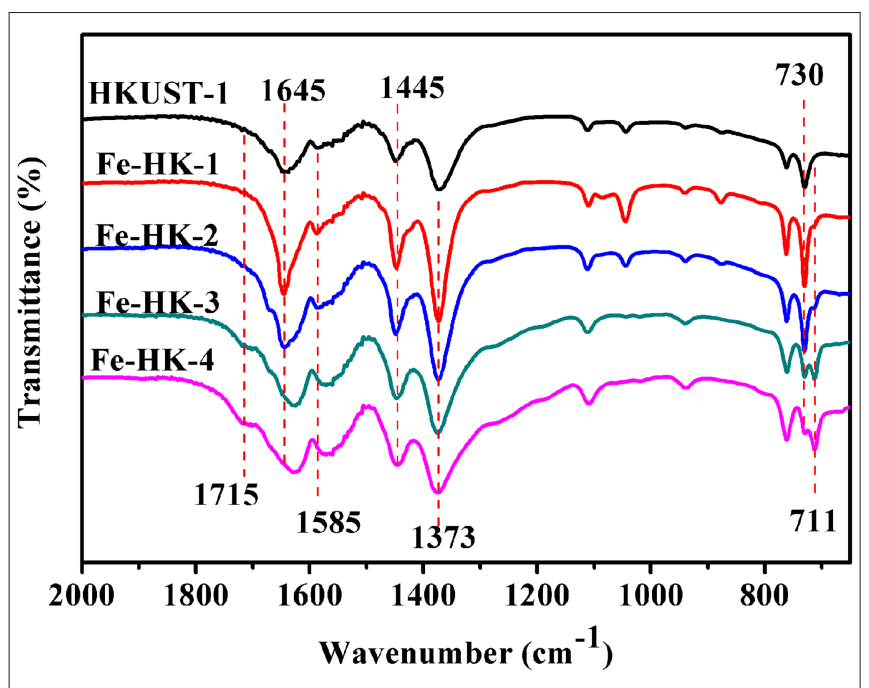

FIGURE 5 | FTIR spectra of HKUST-1 and Fe-HK samples.

the asymmetric vibrations of carboxylate groups at 1,645/1,585 $\mathrm{cm}^{-1}$ and the symmetric vibrations at $1,445 / 1,373 \mathrm{~cm}^{-1}$ (Petit et al., 2012; Sun et al., 2015). However, it is noticed that for FeHK-3 and Fe-HK-4, the two bands at 1,645/1,585 $\mathrm{cm}^{-1}$ shift to lower wavenumbers, and a new band appears at $1,715 \mathrm{~cm}^{-1}$ belonged to the partially coordinated trimesic acid (Majano et al., 2014). Moreover, the band at $730 \mathrm{~cm}^{-1}$ is ascribed to the vibration of $\mathrm{Cu}-\mathrm{O}$, in which copper ions coordinate with the carboxylate groups of BTC (Lin et al., 2014). A new band appears at $711 \mathrm{~cm}^{-1}$, which is ascribed to the vibration of $\mathrm{Fe}-$ $\mathrm{O}$, indicating that iron ions coordinate with the carboxylate groups of BTC (Tan et al., 2015; Abdpour et al., 2018). The peak intensity at $711 \mathrm{~cm}^{-1}$ becomes stronger, while the peak intensity at $730 \mathrm{~cm}^{-1}$ becomes weaker as the increase of molar ratio of $\mathrm{Fe} / \mathrm{Cu}$.

Figure 6 exhibits TG and DTG curves of HKUST-1 and the Fe-HK samples. It is apparent that HKUST-1 and the Fe-HK samples present the different weight loss patterns. HKUST-1 exhibits two weight loss steps. The first weight loss below $373 \mathrm{~K}$ corresponds to the loss of guest molecules. The second weight loss between 523 and $673 \mathrm{~K}$ is assigned to the removal of BTC ligands coordinated to $\mathrm{Cu}^{2+}$ and the formation of $\mathrm{CuO}$ (Lin et al., 2012). Interestingly, all the Fe-HK samples exhibit four weight loss steps in Figure 6B. The first peak is similar to that of HKUST-1. The second peak broadens after the incorporation of $\mathrm{Fe}^{3+}$ ions. Thus, the second weight loss of the Fe-HK samples can correspond to the decomposition of organic ligands linked to $\mathrm{Cu}^{2+}$ and $\mathrm{Fe}^{3+}$ ions to form $\mathrm{CuO}$ and $\mathrm{Fe}_{3} \mathrm{O}_{4}$ at the same time (Petit and Bandosz, 2012). Additionally, a new peak as the third weight loss reveals between 673 and $800 \mathrm{~K}$, which is ascribed to the reduction of $\mathrm{Fe}_{3} \mathrm{O}_{4}-\mathrm{Fe}_{2} \mathrm{O}_{3}$ (Petit and Bandosz, 2012). Another new peak as the fourth weight loss occurs between 800 and $1,000 \mathrm{~K}$, which is due to the reduction of $\mathrm{Fe}_{2} \mathrm{O}_{3}$ to $\mathrm{FeO}$ (Petit and Bandosz, 2012).
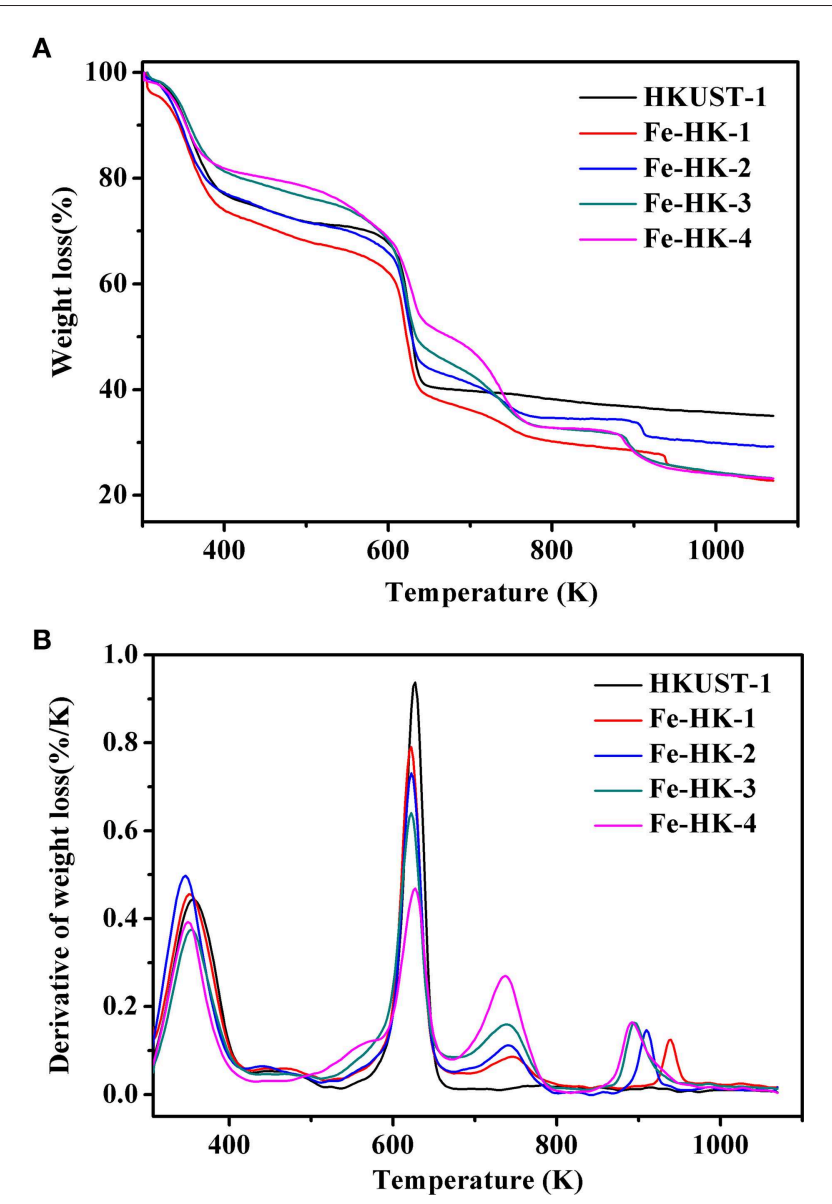

FIGURE 6 | TG (A) and DTG (B) curves of HKUST-1 and Fe-HK samples.

\section{Adsorption Isotherms of Benzene}

Figure 7 presents adsorption isotherms of benzene on HKUST1 and the optimal sample Fe-HK-2 at $298 \mathrm{~K}$. It is observed that benzene adsorption capacities of HKUST-1 and Fe-HK-2 exhibit a sharp rise at low pressure $(<0.5 \mathrm{kPa})$, which is ascribed to the micropore adsorption owing to the metal $-\pi$ interactions between benzene molecules and the metal cations as well as the $\pi-\pi$ stacking and electrostatic interactions between benzene molecules and the organic ligand (Sun et al., 2017). Subsequently, benzene adsorption capacity of HKUST-1 reaches a plateau followed by a slight increase at $8 \mathrm{kPa}$, which is related to the intermolecular $\pi-\pi$ interactions of benzene (Zhu et al., 2017). Nevertheless, benzene adsorption capacity of Fe-HK-2 presents a gradual increase at high pressure, which is mainly attributed to the mesopore filling due to the $\pi-\pi$ and electrostatic interactions between benzene molecules and the organic ligand as well as the intermolecular benzene-benzene interactions (Sun et al., 2017). Moreover, the Fe-HK sample exhibits higher saturated adsorption capacity of benzene than HKUST-1. The maximum adsorption capacity of benzene on Fe-HK-2 is up to $11.4 \mathrm{mmol} / \mathrm{g}$, which is 1.5 times higher than that on HKUST- $1(7.5 \mathrm{mmol} / \mathrm{g})$. The great increase in benzene capacity of Fe-HK-2 can be 


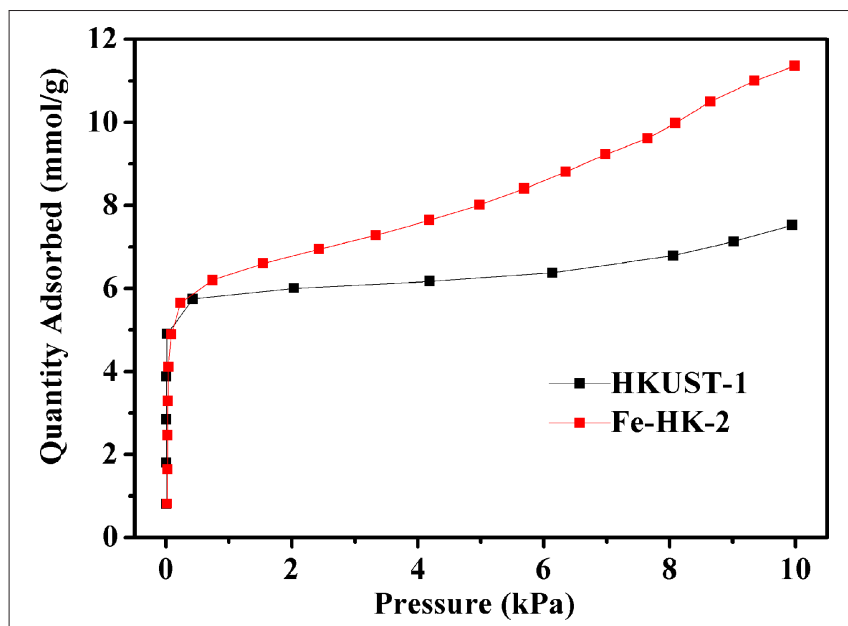

FIGURE 7 | Adsorption isotherms of benzene on HKUST-1 and Fe-HK-2 at 298 K.

attributed to its higher BET surface area and pore volume than HKUST-1.

For comparison, the adsorption capacities of benzene on some typical porous materials at 0.3 and $10 \mathrm{kPa}$ are shown in Figure 8. It indicates that the synthesized HKUST-1 and Fe-HK2 possess much higher benzene capacities than the conventional adsorbents, e.g., ZSM-5 (Jhung et al., 2007), MCM-48 (Hartmann and Bischof, 1999), BPL(AC) (Zhao et al., 1998) and Zeolite Y (Zhao et al., 1998). It is also seen that the uptake of benzene on Fe-HK-2 at high pressure $10 \mathrm{kPa}$ is lower than some MOFs [i.e., MIL-101 (Sun et al., 2017)], whereas, the benzene adsorption capacity of $5.7 \mathrm{mmol} / \mathrm{g}$ on the Fe-HK-2 at low pressure $0.3 \mathrm{kPa}$ is 3 times larger than that of MIL-101(1.9 mmol/g). One reason might be that Fe-HK-2 with smaller micropore size is favored for benzene adsorption at low pressure in comparison with MIL-101. Therefore, the hierarchical Fe-HK-2 exhibits certain advantages over some conventional adsorbents or MOFs.

\section{Adsorption Kinetics of Benzene}

Figure 9 shows the kinetic curves of benzene on HKUST-1 and Fe-HK-2 at 298 and 308 K. Compared to HKUST-1, equilibrium uptakes of benzene on Fe-HK-2 are achieved in a shorter time owing to the presence of mesopores. In order to obtain the intracrystalline diffusion coefficient of benzene on HKUST-1 and Fe-HK-2, the plots of fractional uptake $\left(q_{t} / q_{\mathrm{e}}\right)$ of benzene vs. the square root of adsorption time at 298 and $308 \mathrm{~K}$ are presented in Figure 10. The diffusion time constants $\left(D_{\mathrm{M}} / r_{\mathrm{c}}^{2}\right.$, $\mathrm{s}^{-1}$ ) were obtained from the slope of $q_{t} / q_{\mathrm{e}}$ vs. $\sqrt{t}$ based on the diffusion model (Equation 1) (Sui et al., 2013; Zhu et al., 2017). Their activation energy $\left(E_{\mathrm{a}}\right)$ was estimated by Arrhenius equation (Equation 2) (Hu et al., 2018).

$$
\begin{array}{r}
\frac{q_{t}}{q_{e}} \cong \frac{6}{r_{c}} \sqrt{\frac{D_{M} t}{\pi}} \\
1 n D_{M}=1 n A-\frac{E_{a}}{R T}
\end{array}
$$

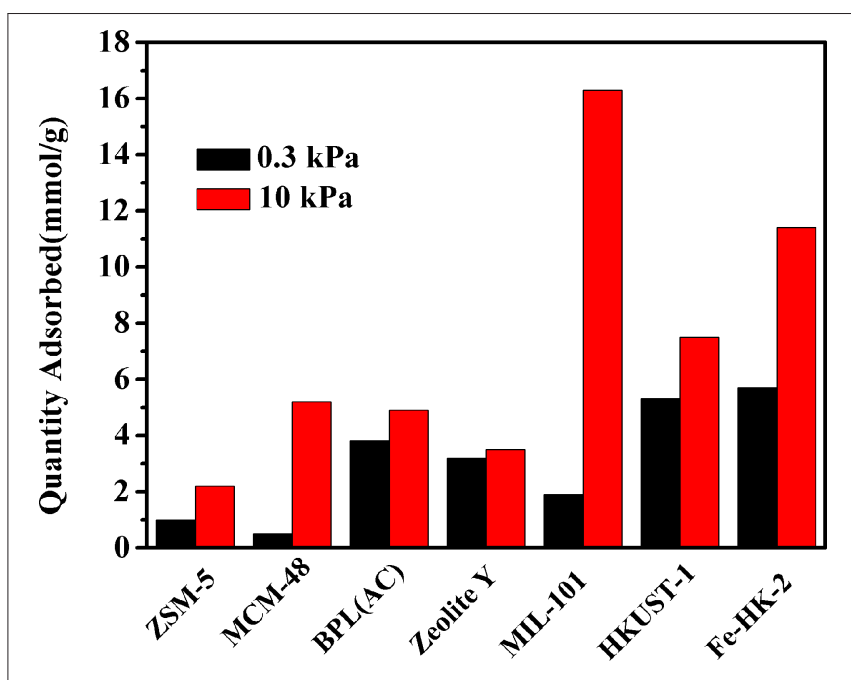

FIGURE 8 | Adsorption capacity comparison of benzene on some adsorbents at same conditions.

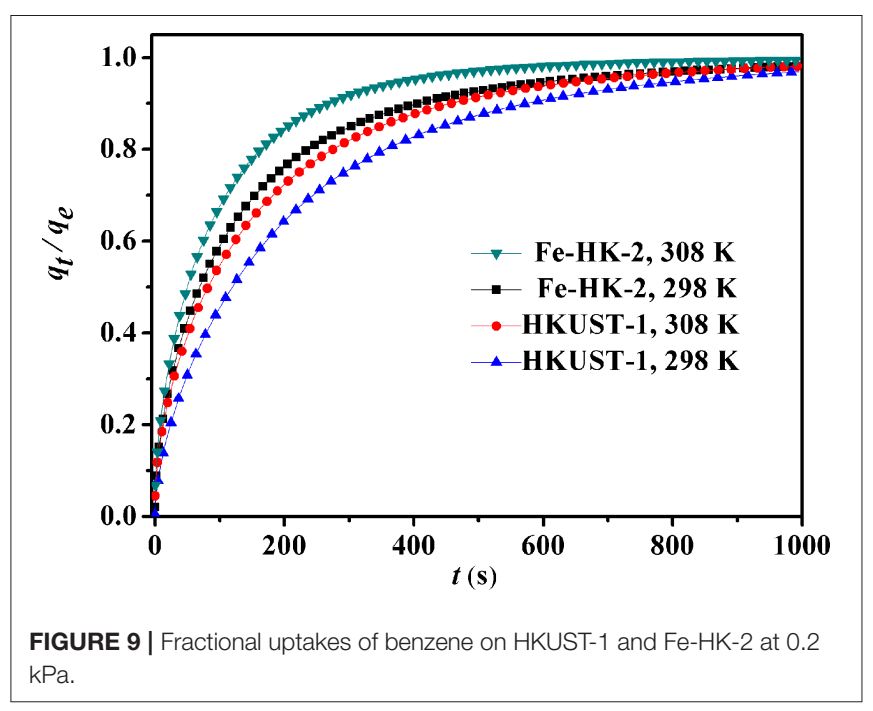

where $q_{\mathrm{e}}(\mathrm{mg} / \mathrm{g})$ and $q_{t}(\mathrm{mg} / \mathrm{g})$ are the uptakes of benzene on adsorbent per gram at equilibrium and time $t, D_{\mathrm{M}}\left(\mathrm{cm}^{2} / \mathrm{s}\right)$ is the intracrystalline diffusion coefficient, $r_{\mathrm{c}}(\mathrm{cm})$ is the crystal radius, $\mathrm{R}$ is the gas constant and $\mathrm{A}$ is the Arrhenius factor.

Table S2 lists benzene diffusivity parameters and the activation energies of HKUST-1 and Fe-HK-2. The high regression coefficients $\left(R^{2}>0.996\right)$ suggests that the diffusion model can fit the kinetic curves of benzene well. The diffusion time constants $\left(D_{\mathrm{M}} / r_{\mathrm{c}}^{2}\right)$ of benzene on the HKUST-1 and $\mathrm{Fe}-\mathrm{HK}-2$ are in the range of $(1.78-2.54) \times 10^{-4}$ and (3.02$4.23) \times 10^{-4} \mathrm{~s}^{-1}$, respectively. Corresponding diffusion coefficients $\left(D_{\mathrm{M}}\right)$ using the average particle radius $r_{\mathrm{c}}$ of $4 \mu \mathrm{m}$ (Figure S1) are (2.85-4.07) $\times 10^{-11}$ and (4.83-6.76) $\times 10^{-11} \mathrm{~cm}^{2} / \mathrm{s}$ for HKUST-1 and Fe-HK-2, respectively. The diffusivity value of $\mathrm{Fe}-\mathrm{HK}-2$ is 1.7 times faster than that of parent HKUST-1. It is also noticed from Table S2 that the activation energy $E_{\mathrm{a}}$ for diffusion of benzene on 


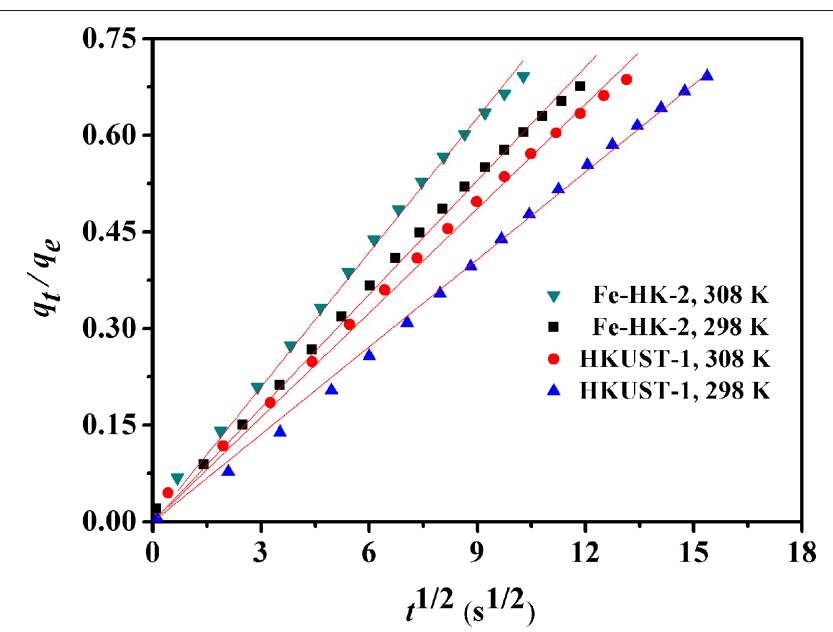

FIGURE 10 | Plots of the fractional benzene uptakes $\left(q_{t} / q_{\mathrm{e}}\right)$ against the square root of adsorption time at 298 and $308 \mathrm{~K}$.

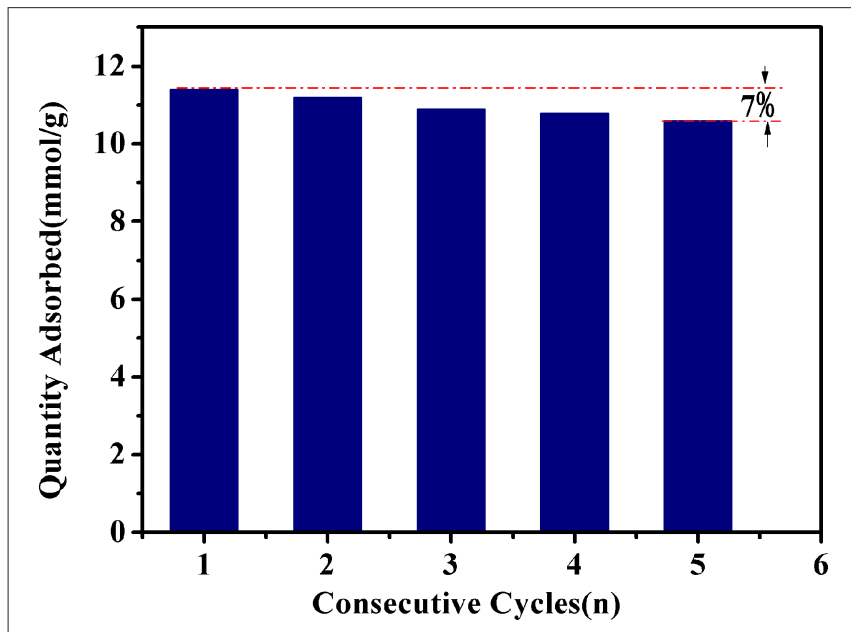

FIGURE 11 | Adsorption capacities of benzene after consecutive cycles on Fe-HK-2 at $298 \mathrm{~K}$

Fe-HK-2 is about $25.78 \mathrm{~kJ} / \mathrm{mol}$, which is smaller than that on HKUST-1 owing to faster benzene diffusion on Fe-HK2. These results indicate that the Fe-HK-2 with mesopores exhibits the enhanced diffusion and mass transport than HKUST-1.

\section{Recycling Performance of Fe-HK-2 for Benzene Adsorption}

The reversibility of $\mathrm{Fe}-\mathrm{HK}-2$ for benzene adsorption was also tested in this work. Adsorption was measured at $10 \mathrm{kPa}$, then desorption was performed at $373 \mathrm{~K}$ under high vacuum. Figure 11 presents adsorption capacities of benzene after consecutive cycles on Fe-HK-2 at $298 \mathrm{~K}$. After five consecutive cycles, the adsorption capacities of benzene on Fe-HK-2 decreases by only 7\%, indicating that the Fe-HK-2 possesses an outstanding reversibility of VOCs adsorption.

\section{CONCLUSIONS}

In summary, we proposed a facile strategy to prepare novel hierarchical $\mathrm{Fe}$ (III)-doped $\mathrm{Cu}-\mathrm{MOF}$ materials with enhanced benzene adsorption. The characterizations showed that the introduction of $\mathrm{Fe}^{3+}$ ions could form new mesopores in $\mathrm{Fe}$ HK. The hierarchical-pore Fe-HK-2 exhibited high BET surface area of $1,707 \mathrm{~m}^{2} / \mathrm{g}$, mesopore volume of $0.31 \mathrm{~cm}^{3} / \mathrm{g}$ and total pore volume of $0.93 \mathrm{~cm}^{3} / \mathrm{g}$, which are much higher than those of the original HKUST-1. This improves benzene adsorption capacity of Fe-HK-2, showing 1.5 times greater than that on HKUST-1. Fe-HK-2 also exhibited faster diffusivity and excellent reversibility of benzene adsorption. Thus, the hierarchical-pore Fe-HK-2 could be a promising adsorbent for VOCs adsorption. The results also indicate that metal ion doping can be a facile strategy to synthesize hierarchical-pore MOFs with enhanced adsorption performance.

\section{DATA AVAILABILITY STATEMENT}

The datasets generated for this study are available on request to the corresponding author.

\section{AUTHOR CONTRIBUTIONS}

XS, XG, WX, and W-JC have provided substantial contribution to the acquisition, interpretation and analysis of data, as well as to the drafting of the work. QX, XP, XZ, YL, and Q-HW performed essential work regarding to the conception and design of the research presented and to its critical revision for important intellectual content. They all approve the version to be published and agree to be accountable to investigate and resolve any question related to the accuracy or integrity of any part of the work.

\section{FUNDING}

This work was supported by the National Natural Science Foundation of China (Nos. 21606144, 21878101), the Program for the Cultivation of Outstanding Young Scientific Talents in Fujian Province University, the Natural Science Foundation of Fujian Province (No. 2017J05026), and Quanzhou City Science \& Technology Program of China (Nos. 2017G022, 2017Z028, and 2018C127R).

\section{SUPPLEMENTARY MATERIAL}

The Supplementary Material for this article can be found online at: https://www.frontiersin.org/articles/10.3389/fchem. 2019.00652/full\#supplementary-material 


\section{REFERENCES}

Abdpour, S., Kowsari, E., Moghaddam, M. R. A., Schmolke, L., and Janiak, C. (2018). Mil-100 (Fe) nanoparticles supported on urchin like $\mathrm{Bi}_{2} \mathrm{~S}_{3}$ structure for improving photocatalytic degradation of rhodamine-B dye under visible light irradiation. J. Solid State Chem. 266, 54-62. doi: 10.1016/j.jssc.2018.07.006

Ahmed, I., and Jhung, S. H. (2016). Remarkable adsorptive removal of nitrogencontaining compounds from a model fuel by a graphene oxide/MIL-101 composite through a combined effect of improved porosity and hydrogen bonding. J. Hazard. Mater. 314, 318-325. doi: 10.1016/j.jhazmat.2016.04.041

Bradshaw, D., El-Hankari, S., and Lupica-Spagnolo, L. (2014). Supramolecular templating of hierarchically porous metal-organic frameworks. Chem. Soc. Rev. 43, 5431-5443. doi: 10.1039/C4CS00127C

Chen, X., Jiang, X., Yin, C., Zhang, B., and Zhang, Q. (2019). Facile fabrication of hierarchical porous ZIF-8 for enhanced adsorption of antibiotics. J. Hazard. Mater. 367, 194-204. doi: 10.1016/j.jhazmat.2018.12.080

Chuah, C. Y., Goh, K., and Bae, T. H. (2017). Hierarchically structured HKUST1 nanocrystals for enhanced $\mathrm{SF}_{6}$ capture and recovery. J. Phys. Chem. 121, 6748-6755. doi: 10.1021/acs.jpcc.7b00291

Duan, C., Li, F., Li, L., Zhang, H., Wang, X., Xiao, J., et al. (2018a). Hierarchically structured metal-organic frameworks assembled by hydroxy double salttemplate synergy with high space-time yields. CrystEngComm 20, 1057-1064. doi: 10.1039/C7CE01843F

Duan, C., Li, F., Luo, S., Xiao, J., Li, L., and Xi, H. (2018b). Facile synthesis of hierarchical porous metal-organic frameworks with enhanced catalytic activity. Chem. Eng. J. 334, 1477-1483. doi: 10.1016/j.cej.2017.11.086

Duan, C., Zhang, H., Peng, A., Li, F., Xiao, J., Zou, J., et al. (2018c). Synthesis of hierarchically structured metal-organic frameworks by a dual-functional surfactant. Chem. Select. 3, 5313-5320. doi: 10.1002/slct.201800571

Duan, L. H., Dong, X. Y., Wu, Y. Y., Li, H. L., Wang, L., and Song, L. J. (2013). Adsorption and diffusion properties of xylene isomers and ethylbenzene in metal-organic framework MIL-53(Al). J. Porous Mat. 20, 431-440. doi: 10.1007/s10934-012-9612-z

Ebrahim, A. M., and Bandosz, T. J. (2013). Ce(III) doped Zr-based MOFs as excellent $\mathrm{NO}_{2}$ adsorbents at ambient conditions. ACS Appl. Mater. Inter. 5, 10565-10573. doi: 10.1021/am402305u

Hartmann, M., and Bischof, C. (1999). Mechanical stability of mesoporous molecular sieve MCM-48 studied by adsorption of benzene, n-heptane, and cyclohexane. J. Phys. Chem. 103, 6230-6235. doi: 10.1021/jp991103a

He, S., Chen, Y., Zhang, Z., Ni, B., He, W., and Wang, X. (2016). Competitive coordination strategy for the synthesis of hierarchical-pore metal-organic framework nanostructures. Chem. Sci. 7, 7101-7105. doi: 10.1039/C6SC02272C

Horcajada, P., Chevreau, H., Heurtaux, D., Benyettou, F., Salles, F., Devic, T., et al. (2014). Extended and functionalized porous iron(iii) tri- or dicarboxylates with MIL-100/101 topologies. Chem. Commun. 50, 6872-6874. doi: $10.1039 / \mathrm{c} 4 \mathrm{cc} 02175 \mathrm{~d}$

Hu, P., Liang, X., Yaseen, M., Sun, X., Tong, Z., Zhao, Z., et al. (2018). Preparation of highly-hydrophobic novel N-coordinated UiO-66 ( $\mathrm{Zr}$ ) with dopamine via fast mechano-chemical method for (CHO-/Cl-)-VOCs competitive adsorption in humid environment. Chem. Eng. J. 332, 608-618. doi: 10.1016/j.cej.2017.09.115

Huang, H., Li, J. R., Wang, K., Han, T., Tong, M., Li, L., et al. (2015). An in situ self-assembly template strategy for the preparation of hierarchicalpore metal-organic frameworks. Nat. Commun. 6:8847. doi: 10.1038/ ncomms 9847

Jhung, S. H., Lee, J. H., Yoon, J. W., Serre, C., Férey, G., and Chang, J. S. (2007). Microwave synthesis of chromium terephthalate MIL-101 and its benzene sorption ability. Adv. Mater. 19, 121-124. doi: 10.1002/adma.200601604

Li, H., Wang, K., Sun, Y., Lollar, C. T., Li, J., and Zhou, H. C. (2018). Recent advances in gas storage and separation using metal-organic frameworks. Mater. Today 21, 108-121. doi: 10.1016/j.mattod.2017.07.006

Lin, K. S., Adhikari, A. K., Ku, C. N., Chiang, C. L., and Kuo, H. (2012). Synthesis and characterization of porous HKUST-1 metal organic frameworks for hydrogen storage. Int. J. Hydrogen Energ. 37, 13865-13871. doi: 10.1016/j.ijhydene.2012.04.105

Lin, R. B., Li, L. B., Zhou, H. L., Wu, H., He, C. H., Li, S., et al. (2018). Molecular sieving of ethylene from ethane using a rigid metal-organic framework. Nat. Mater. 17, 1128-1133. doi: 10.1038/s41563-018-0206-2
Lin, S., Song, Z., Che, G., Ren, A., Li, P., Liu, C., et al. (2014). Adsorption behavior of metal-organic frameworks for methylene blue from aqueous solution. Micropor. Mesopor. Mat. 193, 27-34. doi: 10.1016/j.micromeso. 2014.03.004

Lv, D., Chen, Y., Li, Y., Shi, R., Wu, H., Sun, X., et al. (2017). Efficient mechanochemical synthesis of MOF-5 for linear alkanes adsorption. J. Chem. Eng. Data 62, 2030-2036. doi: 10.1021/acs.jced.7b00049

Majano, G., Martin, O., Hammes, M., Smeets, S., Baerlocher, C., and PerezRamirez, J. (2014). Solvent-mediated reconstruction of the metal-organic framework HKUST-1 $\left(\mathrm{Cu}_{3}(\mathrm{BTC})_{2}\right)$. Adv. Funct. Mater. 24, 3855-3865. doi: $10.1002 / \mathrm{adfm} .201303678$

Mao, Y., Chen, D., Hu, P., Guo, Y., Ying, Y., Ying, W., et al. (2015). Hierarchical mesoporous metal-organic frameworks for enhanced $\mathrm{CO}_{2}$ capture. Chem. Eur. J. 21, 15127-15132. doi: 10.1002/chem.201502515

Meng, X. H., Lin, C. H., Zhang, Y. H., Qin, H. B., Cao, S., and Duan, L. H. (2019). Mass transfer behavior of benzene in hierarchically structured ZSM-5. Front. Chem. 7:502. doi: 10.3389/fchem.2019.00502

Petit, C., and Bandosz, T. J. (2012). Exploring the coordination chemistry of MOFgraphite oxide composites and their applications as adsorbents. Dalton T. 41, 4027-4035. doi: 10.1039/c2dt12017h

Petit, C., Levasseur, B., Mendoza, B., and Bandosz, T. J. (2012). Reactive adsorption of acidic gases on MOF/graphite oxide composites. Micropor. Mesopor. Mat. 154, 107-112. doi: 10.1016/j.micromeso.2011.09.012

Sui, H., Liu, J. J., He, L., Li, X. G., and Jani, A. (2019). Adsorption and desorption of binary mixture of acetone and ethyl acetate on silica gel. Chem. Eng. Sci. 197, 185-194. doi: 10.1016/j.ces.2018.12.010

Sui, P. P., Meng, X. H., Wu, Y. Y., Zhao, Y. Y., Song, L. J., Sun, Z. L., et al. (2013). Adsorption and diffusion of benzene and thiophene over Y/MCM-41 composite zeolite, Sci. Adv. Mater. 5, 1132-1138. doi: 10.1166/sam.2013.1564

Sun, X., Li, H., Li, Y., Xu, F., Xiao, J., Xia, Q., et al. (2015). A novel mechanochemical method for reconstructing the moisture-degraded HKUST1. Chem. Commun. 51, 10835-10838. doi: 10.1039/C5CC02809D

Sun, X., Lv, D., Chen, Y., Wu, Y., Wu, Q., Xia, Q., et al. (2017). Enhanced adsorption performance of aromatics on a novel chromiumbased MIL-101@graphite oxide composite. Energ. Fuel. 31, 13985-13990. doi: 10.1021/acs.energyfuels.7b02665

Sun, X. J., Li, Y. J., Xi, H. X., and Xia, Q. B. (2014). Adsorption performance of a MIL-101(Cr)/graphite oxide composite for a series of n-alkanes. RSC Adv. 4, 56216-56223. doi: 10.1039/C4RA08598A

Tan, F., Liu, M., Li, K., Wang, Y., Wang, J., Guo, X., et al. (2015). Facile synthesis of size-controlled MIL-100 (Fe) with excellent adsorption capacity for methylene blue. Chem. Eng. J. 281, 360-367. doi: 10.1016/j.cej.2015.06.044

Vellingiri, K., Kumar, P., Deep, A., and Kim, K. H. (2017). Metal-organic frameworks for the adsorption of gaseous toluene under ambient temperature and pressure. Chem. Eng. J. 307, 1116-1126. doi: 10.1016/j.cej.2016.09.012

Vellingiri, K., Szulejko, J. E., Kumar, P., Kwon, E. E., Kim, K. H., Deep, A., et al. (2016). Metal organic frameworks as sorption media for volatile and semi-volatile organic compounds at ambient conditions. Sci. Rep. 6:27813. doi: $10.1038 /$ srep27813

Wang, D., Wu, G., Zhao, Y., Cui, L., Shin, C. H., Ryu, M. H., et al. (2018). Study on the copper(II)-doped MIL-101(Cr) and its performance in VOCs adsorption. Environ. Sci. Pollut. R. doi: 10.1007/s11356-018-2849-6

Wu, Y., Liu, D., Chen, H., Qian, Y., Xi, H., and Xia, Q. (2015). Enhancement effect of lithium-doping functionalization on methanol adsorption in copper-based metal-organic framework. Chem. Eng. Sci. 123, 1-10. doi: $10.1016 /$ j.ces.2014.10.010

Xian, S., Yu, Y., Xiao, J., Zhang, Z., Xia, Q., Wang, H., et al. (2015). Competitive adsorption of water vapor with VOCs dichloroethane, ethyl acetate and benzene on MIL-101(Cr) in humid atmosphere. RSC Adv. 5, 1827-1834. doi: 10.1039/C4RA10463C

Yang, X., Wu, S., Wang, P., and Yang, L. (2018). Hierarchical 3D ordered meso-/macroporous metal-organic framework produced through a facile template-free self-assembly. J. Solid State Chem. 258, 220-224. doi: 10.1016/j.jssc.2017.10.020

Yuan, S., Zou, L., Qin, J. S., Li, J., Huang, L., Feng, L., et al. (2017). Construction of hierarchically porous metal-organic frameworks through linker labilization. Nat. Commun. 8:15356. doi: 10.1038/ncomms15356

Zhang, X. D., Yang,Y., Lv, X. T., Wang, Y. X., Liu, N., Chen, D., et al. (2019). Adsorption/desorption kinetics and breakthrough of gaseous toluene 
for modifed microporous-mesoporous UiO-66 metal organic framework. J. Hazard. Mater. 366, 140-150. doi: 10.1016/j.jhazmat.2018.11.099

Zhang, X. Y., Gao, B., Creamer, A. E., Cao, C. C., and Li, Y. C. (2017). Adsorption of VOCs onto engineered carbon materials: a review. J. Hazard. Mater. 338, 102-123. doi: 10.1016/j.jhazmat.2017.05.013

Zhao, X., Ma, Q., and Lu, G. (1998). VOC removal: comparison of MCM-41 with hydrophobic zeolites and activated carbon. Energ. Fuel. 12, 1051-1054. doi: $10.1021 /$ ef980113s

Zhao, Z. X., Wang, S., Yang, Y., Li, X. M., Li, J., and Li, Z. (2015). Competitive adsorption and selectivity of benzene and water vapor on the microporous metal organic frameworks (HKUST-1). Chem. Eng. J. 259, 79-89. doi: 10.1016/j.cej.2014.08.012

Zhou, Z., Mei, L., Ma, C., Xu, F., Xiao, J., Xia, Q., et al. (2016). A novel bimetallic MIL-101(Cr, Mg) with high $\mathrm{CO}_{2}$ adsorption capacity and $\mathrm{CO}_{2} / \mathrm{N}_{2}$ selectivity. Chem. Eng. Sci. 147, 109-117. doi: 10.1016/j.ces.2016. 03.035

Zhu, M., Hu, P., Tong, Z., Zhao, Z., and Zhao, Z. (2017). Enhanced hydrophobic MIL (Cr) metal-organic framework with high capacity and selectivity for benzene VOCs capture from high humid air. Chem. Eng. J. 313, 1122-1131. doi: 10.1016/j.cej.2016.11.008
Zhu, M., Tong, Z., Zhao, Z., Jiang, Y., and Zhao, Z. (2016). A microporous graphitized biocarbon with high adsorption capacity toward benzene volatile organic compounds (VOCs) from humid air at ultralow pressures. Ind. Eng. Chem. Res. 55, 3765-3774. doi: 10.1021/acs.iecr.6b00056

Zhu, T., Zhang, X., Han, Y., Liu, T., Wang, B., and Zhang, Z. (2019). Preparation of zeolite $\mathrm{X}$ by the aluminum residue from coal fly ash for the adsorption of volatile organic compounds. Front. Chem. 7:341. doi: $10.3389 /$ fchem.2019.00341

Conflict of Interest: The authors declare that the research was conducted in the absence of any commercial or financial relationships that could be construed as a potential conflict of interest.

Copyright (๑) 2019 Sun, Gu, Xu, Chen, Xia, Pan, Zhao, Li and Wu. This is an open-access article distributed under the terms of the Creative Commons Attribution License (CC BY). The use, distribution or reproduction in other forums is permitted, provided the original author(s) and the copyright owner(s) are credited and that the original publication in this journal is cited, in accordance with accepted academic practice. No use, distribution or reproduction is permitted which does not comply with these terms. 


\section{OPEN ACCESS}

Edited by:

Benoit Louis,

UMR7515 Institut de Chimie et Procédés pour l'Energie,

l'Environnement et la Santé (ICPEES), France

Reviewed by: Richard Walton,

University of Warwick, United Kingdom Christoph Janiak

Heinrich Heine University of

Düsseldorf, Germany

*Correspondence: Alvaro Mayora amayora/@shanghaitech.edu.cn Isabel Diaz idiaz@icp.csic.es

Specialty section:

This article was submitted to Inorganic Chemistry,

a section of the journal

Frontiers in Chemistry

Received: 22 May 2019 Accepted: 04 October 2019 Published: 22 October 2019

Citation:

Mahugo R, Mayoral A, Sánchez-Sánchez M and Diaz I (2019) Observation of Ag Nanoparticles in/on Ag@MIL-100(Fe) Prepared Through Different Procedures.

Front. Chem. 7:686. doi: 10.3389/fchem.2019.00686

\section{Observation of Ag Nanoparticles in/on Ag@MIL-100(Fe) Prepared Through Different Procedures}

\author{
Rubén Mahugo ${ }^{1}$, Alvaro Mayoral ${ }^{2 *}$, Manuel Sánchez-Sánchez ${ }^{1}$ and Isabel Diaz ${ }^{1 *}$ \\ ${ }^{1}$ Instituto de Catálisis y Petroleoquímica (ICP), CSIC, Madrid, Spain, ${ }^{2}$ Center for High-Resolution Electron Microscopy, \\ School of Physical Science and Technology (SPST), ShanghaiTech University, Shanghai, China
}

Loading of active metals, metal clusters, and/or metal nanoparticles in Metal Organic Frameworks (MOFs) is an emergent field with applications in sensors, catalysis, medicine, and even in the polymeric industry. In the present work, MIL-100(Fe) has been synthesized and reacted with $\mathrm{AgNO}_{3}$ through liquid and incipient wetness, and also through solid-state reaction or solid grinding. The aim of this study is to evaluate whether the MIL-100 would uptake metal particles using a similar principle as that of the ion exchange in zeolites, or else, their inherent humidity would favor the "dissolution" of the metal salt, thus yielding very small metal particles. The immobilization of Ag nanoparticles inside the MOF pores was identified by $\mathrm{C}_{\mathrm{s}}$-corrected scanning transmission electron microscopy $\left(\mathrm{C}_{\mathrm{s}}\right.$-corrected STEM) techniques.

Keywords: Ag@MIL-100(Fe), MOF, impregnation, STEM/HAADF, TEM

\section{INTRODUCTION}

The study of porous materials is one of the main disciplines in material science, due to their industrial and potential applications, which have even increased in the last few decades (Hermes et al., 2005). Metal Organic Frameworks (MOFs) are the most recent family of ordered porous materials formed by metal nodes connected by organic linkers. These particular building units increase the possibilities of generating new materials with different pore sizes, shapes and topologies that, together with their vast framework chemistry, facilitate the versatility in applications as gas storage (Orcajo et al., 2012; Dutta et al., 2018), catalysis (Wang et al., 2019), sensors (Peng et al., 2016; Bagheri et al., 2018), or redox processes (Moon et al., 2005), among others (Li et al., 2016). Our interest in MOFs relies on the use of facile synthesis methods with low energy and reagents demand. Using this approach, we have obtained highly crystalline and small particle MOFs, suitable for catalytic processes (Díaz-García et al., 2014; Getachew et al., 2014; Ruano et al., 2015; SánchezSánchez et al., 2015; Guesh et al., 2017). The immobilization of metals in MOFs brings a new challenge in supported catalysts (Dhakshinamoorthy and García, 2012), not only in terms of the immobilization efficiency but also in the identification of the metal cluster trapped in the porous network (Houk et al., 2009; Esken et al., 2010; Meilikhov et al., 2010). In this sense, and mainly due to the negative charges introduced by the $\mathrm{Al}$ units into zeolite frameworks, the presence of exchangeable cations have facilitated the metal-incorporation chemistry of zeolites that have been dominating this field (Mayoral and Anderson, 2007; Mayoral et al., 2016). Typically, metals are aimed to form nanoparticles or clusters (Mayoral et al., 2011, 2013; Corma et al., 2013; Moliner et al., 2016; Wang et al., 2016) with controllable size, morphology, and composition; however, their trend is to sinter in reactive atmospheres, such as oxidative or reducing environments, humidity, 
variable temperature, light, or even air. In order to be able to increase the activity, the life-time and therefore the efficiency of the metal, the confined certain space of the MOF pores can be used to control the size of the clusters or nanoparticles and to locate them along the MOF.

Among the many characterization techniques, Transmission Electron Microscopy (TEM) is one of the most adequate to characterize these materials, particularly metal-containing porous solids where the metals are not periodically distributed over the framework. Using TEM, it is possible to characterize both the framework and the guest species by high-resolution imaging combined with electron diffraction, as well as spectroscopic measurements to obtain chemical information. In the particular case of MOFs, the poor stability under the electron beam makes their study significantly complex as they disintegrate under conventional irradiation in just a few seconds (Mayoral et al., 2015, 2018; Zhu et al., 2017; Zhang et al., 2018). Despite these difficulties, we have been able to show evidences of metal cluster trapped inside the porosity of MIL-100(Fe) using spherical aberration corrected $\left(\mathrm{C}_{\mathrm{s}}\right.$-corrected) scanning transmission electron microscopy (STEM) in low dose conditions (Mayoral et al., 2017), coupled with an annular dark field detector (ADF). By carefully controlling the e-beam dose, it is not only possible to acquire high-resolution information, but even the formation of metal nanoparticles or even nanowires can be produced (Mayoral and Anderson, 2007; Mayoral et al., 2011). Furthermore, various metals have been supported over different MOFs using different methods (Dhakshinamoorthy and García, 2012). The main challenge in this case remains in obtaining clusters or particles below $5 \mathrm{~nm}$, taking advantage of the flexibly and mobility offered by the porous network of MOFs.

We have focused our study on the incorporation of silver nanoparticles within MIL-100(Fe), because it contains meso-sized cavities and it can be prepared with small particle size and high crystallinity. MIL- $100(\mathrm{Fe})$ is formed by cavities large enough to immobilize $\mathrm{Ag}$ inside its pores (Horcajada et al., 2007). Silver was selected because of its catalytic capacity and its application in different fields (Dadashi et al., 2018). Different loading approaches can be beneficial, depending on the required synthesis conditions, and/or on the targeted materials. Although impregnation methods are the most common technique (Rösler and Fischer, 2015; Agundez et al., 2018), solid grinding has resulted into the formation of $2 \mathrm{~nm}$ gold metal nanoparticles in certain MOFs (Peng et al., 2016).

In this study, silver nanoparticles have been immobilized over MIL-100(Fe) through different techniques: solid grinding or solid-state reaction, incipient wetness, and ion exchange liquid impregnation. The resulted materials have been studied by different characterization techniques and more in depth by $\mathrm{C}_{\mathrm{s}}$-corrected STEM as a tool to obtain direct information of the nanoparticle distribution within the support. Indeed, this technique has proved to be the most powerful one to evaluate which method yields to the desired Ag@MIL-100(Fe) composite material.

\section{MATERIALS AND METHODS MIL-100(Fe)}

MIL-100(Fe) was synthesized at room temperature following the procedure developed in our previous work (Guesh et al., 2017). In a first solution, $1.68 \mathrm{~g}$ of trimesic acid $\mathrm{H}_{3} \mathrm{BTC}$ ( $8 \mathrm{mmol}$, SigmaAldrich) was dissolved in $26.9 \mathrm{~mL}$ of $1 \mathrm{M} \mathrm{NaOH}$ under agitation for $30 \mathrm{~min}$. A second solution was prepared by dissolving $2.38 \mathrm{~g}$ $\mathrm{FeCl}_{2} \cdot 4 \mathrm{H}_{2} \mathrm{O}$ (12 mmol, Sigma-Aldrich) into $97.2 \mathrm{~mL}$ of water. This second solution was added dropwise into the first one, and the resultant mixture was allowed to react under stirring for $24 \mathrm{~h}$. The molar composition of the mixture was $1.0 \mathrm{H}_{3} \mathrm{BTC}$ : $1.5 \mathrm{Fe}: 3.48 \mathrm{NaOH}: 860 \mathrm{H}_{2} \mathrm{O}$. Afterwards, the solid obtained was recovered by centrifugation and washed three times with excess of deionized water.

\section{Anionic sod-ZMOF}

Anionic sod-ZMOF was prepared following the reported literature (Calleja et al., 2010) but carrying out the crystallization under microwaved-assisted (computer-controlled Milestone ETHOS ONE microwave equipment) heating, in order to reduce the crystal size of the material to make both the ion exchange procedure and their characterization easier by means of transmission electronic microscopy. 4,5-Imidazoledicarboxylic acid $\left(\mathrm{H}_{3} \operatorname{ImDC}\right)$ was used as a linker, $\operatorname{In}\left(\mathrm{NO}_{3}\right)_{3} \cdot \mathrm{xH}_{2} \mathrm{O}$ as metal source, dimethylformamide (DMF) and acetonitrile $\left(\mathrm{CH}_{3} \mathrm{CN}\right)$ as solvents, nitric acid $\left(\mathrm{HNO}_{3}\right)$ as modulator, and imidazole (Im) as the structure-directing agent, to give a mixture of the following molar composition: 1 In: $3 \mathrm{H}_{3} \mathrm{ImDC}$ : $6.9 \mathrm{Im}: 24 \mathrm{HNO}_{3}$ : 446 DMF: $220 \mathrm{CH}_{3} \mathrm{CN}$. This mixture was heated up to $85^{\circ} \mathrm{C}$ for $12 \mathrm{~h}$ (nucleation step) and then up to $105^{\circ} \mathrm{C}$ for $23 \mathrm{~h}$ (crystallization step). The resultant solid was collected by centrifugation and dried at room temperature.

\section{Impregnation of $\mathrm{AgNO}_{3}$}

Impregnation of $\mathrm{AgNO}_{3}$ was attempted using three methods: Solid state Reaction (SR), Incipient Wetness impregnation (IW), and Ion Exchange in aqueous solution (IE). In all experiments the silver source was $\mathrm{AgNO}_{3}$ (Sigma-Aldrich). In the first method, solid-state reaction, a given amount of $\mathrm{MOF}$ and $\mathrm{AgNO}_{3}$ were ground using mortar and pestle until a homogeneous brown color solid was achieved. Three ratios were tested using Fe: $\operatorname{Ag}\left(\mathrm{AgNO}_{3}\right)$ molar ratios of 1:1, 5:1, and 10:1. The samples were labeled SR-1:1, SR-5:1, and SR-10:1. In the case of the incipient wetness impregnation method, the solution volume necessary to reach the incipient point was previously determined using pure distilled water as a adsorbate. Such determined volume of solutions with different $\mathrm{AgNO}_{3}$ concentrations were added dropwise to the warm MIL-100(Fe) sample, which had been dehydrated at $180^{\circ} \mathrm{C}$ for $24 \mathrm{~h}$. The resulting samples were named IW-5:1, IW-10:1 and IW-100:1, according to their corresponding Fe:Ag ratio. The Ion Exchange in aqueous solution was tested for comparison purposes. Aiming similar Fe to Ag ratios, $3 \mathrm{~mL}$ of two solutions of $\mathrm{AgNO}_{3}: 0.003 \mathrm{M}$ and $0.24 \mathrm{M}$, were tested. The mixtures were stirred for $5 \mathrm{~h}$, and the final solid was recovered by centrifugation. The final samples were named IE-10:1 and IE100:1. Finally, the anionic sod-ZMOF was ion exchanged under 
TABLE 1 | Fe/Ag molar ratios of the Ag@MIL-IOO(Fe) materials prepared by different methods.

\begin{tabular}{ll}
\hline Sample code and molarFe:Ag & SEM/EDX Molar Fe/Ag \\
\hline SR-1:1 & - \\
SR-5:1 & $<$ dect. limit \\
SR-10:1 & $<$ dect. limit \\
IW-5:1 & 5 \\
IW-10:1 & 8 \\
IW-100:1 & 259 \\
IE-10:1 (0.24 M) & 15 \\
IE-100:1 (0.003 M) & 97 \\
\hline
\end{tabular}

the conditions used for sample IE-10:1 and called IE-SOD. All the samples were heated to $150^{\circ} \mathrm{C}$ for $12 \mathrm{~h}$ following a $2^{\circ} \mathrm{C} / \mathrm{min}$ ramp.

\section{Characterization Techniques}

Powder X-Ray Diffraction (PXRD) patterns were collected in an X-Ray Polycrystalline X'Pert Pro PANalytical diffractometer using $\mathrm{CuK}_{\alpha}$ radiation $(\lambda=1.5406 \AA)$, with accelerating voltage and current of $45 \mathrm{kV}$ and $40 \mathrm{~mA}$, respectively. $\mathrm{N}_{2}$ adsorption measurements were conducted at $-196^{\circ} \mathrm{C}$ using a Micrometrics ASAP 2420 sorptometer to determine textural properties. All samples were pre-treated at $150^{\circ} \mathrm{C}$ for $16 \mathrm{~h}$. Pore size distributions were determined from the adsorption branches of isotherms, using the Barrett-Joyner-Halenda (BJH) following the Kruk-Jaroniec-Sayari model. Scanning electron microscopy and EDX analyses were carried out on a Hitachi TM1000 microscope equipped with EDX detector. Samples were observed without coating. Scanning transmission electron microscopy (STEM) analyses were performed in a cold FEG JEOL GrandARM 300 operated at $300 \mathrm{kV}$. The microscope is equipped with a double spherical aberration corrector from JEOL. The spatial resolution at $300 \mathrm{kV}$ was $0.7 \AA$. The microscope is also fitted with a JEOL EDS system and a Gatan Quantum Energy Filter. Typically, the beam current employed was set between 1 and $2 \mathrm{pA}$, with a total exposure time of $6 \mathrm{~s}$. In prior observation, the samples were crushed using mortar and pestle for $3 \mathrm{~min}$, suspended in ethanol and sonicated. A few drops of the suspension were placed onto holey carbon copper grids.

\section{RESULTS AND DISCUSSION}

Metal incorporation within MOF materials opens up new possibilities of use for these materials, as additional properties can be granted increasing their multifunctional behavior. Silver is of particular interest in catalysis, optical devices, and as antibacterial compounds. In order to evaluate the efficiency of the impregnation of silver, a comparison between the different molar ratios was tested. Table 1 collects the different Ag molar ratios contained in the MOF using the three different approaches. Powder X-ray diffraction (PXRD) was used to evaluate the crystallinity of the support prior and after metal incorporation to corroborate if any of the reactions caused any structural damage and if any evidence of metal loading could be extracted.
Figure 1-left shows all PXRD profiles of the as-synthesized materials in addition to the pristine MIL-100(Fe), black color. The comparison between all high-angle XRD profiles with that of the Ag-free MIL-100(Fe) evidences that, after the reaction, most of major diffraction peaks were preserved, suggesting that the crystallinity of the MOF prevailed. Nevertheless, it is noteworthy to mention that certain $\mathrm{Ag}$ incorporation processes induced a decrease on the general intensity of the diffraction peaks mainly those corresponding to SR-5:1 and both ion exchanged samples. This observation can be attributed either to partial loss of crystallinity or to the successful incorporation of the metals within the pore system. Additional peaks, which do not belong the MIL- $100(\mathrm{Fe})$, were identified at $2 \theta=38^{\circ}$ and $44^{\circ}$, marked by asterisks in Figure 1-left, that were attributed to $\mathrm{Ag}^{0}$ (in particular, they correspond to 111 and 200 reflections, respectively). It is remarkable that these peaks have only been observed in the case of the solid state reaction, suggesting that this approach may incorporate a higher amount of silver, and also that the formation of larger metal isolated particles occurred. Due to the large lattice cell parameters of MIL$100(\mathrm{Fe})$ a $\approx 73.34 \AA$, which falls within the mesoscopic range, low-angle PXRD was also registered (Figure 1-right) as the dspacing of the 111,200 , and 311 lattice planes are below $4.5^{\circ}$ $2 \theta$. It must be noted that such XRD reflections correspond to interplanar d-spacing involving the mesocages of the MOFs (Sanchez-Sanchez et al., 2015; Guesh et al., 2017). In other words, the relative intensity of such reflections, with respect to the intensity of the other reflections found at higher $2 \theta$ angle, are very sensitive to the presence of chemical species inside of the cavities, particularly if such species are bulky and formed by heavy atoms, like Ag nanoparticles. The significant changes in the relative intensity between these peaks suggest that some structural transformations (or rather, efficient filling of the mesocages) took place, with special emphasis in the samples SR-10:1, IW-5:1, IW-10:1, and IE-10:1. If the intensity of the low-angle XRD reflections is affected by the presence of Ag species within the MIL-100(Fe) pores, it is expected that textural properties of the Ag@MIL-100(Fe) materials are also modified with respect these of the pristine MIL-100(Fe). Figure SI1 shows the adsorption/desorption $\mathrm{N}_{2}$ isotherms of the different Ag@MIL-100(Fe) samples. Regardless of both metal content and metal incorporation method, all Ag-containing samples lost certain pore volume and surface area, which must be attributed to the presence of Ag species in the sample but not necessarily within the MOF pores. Interestingly, the porosity does not vary systematically with Ag content of the samples, suggesting that Ag incorporation by different methods and even different amounts of Ag incorporated by a given method leads to different efficiency in pore filling. Figure $\mathbf{2}$ compares the $\mathrm{BJH}$ pore size distribution (PSD) curves of the MIL-100(Fe) and the different Ag@MIL$100(\mathrm{Fe})$ samples prepared by wetness impregnation method. The two peaks correspond to the pore diameter of the MIL100 (Fe) meso-sized cavities. These diameters (21 and $24 \AA$ ) are slightly smaller than the real ones ( 25 and $29 \AA$ ) due to the well-known underestimation of the mesopore size by the $\mathrm{BJH}$ method (Sanchez-Sanchez et al., 2015; Guesh et al., 2017). Ag incorporation to the sample does not modify the position neither 

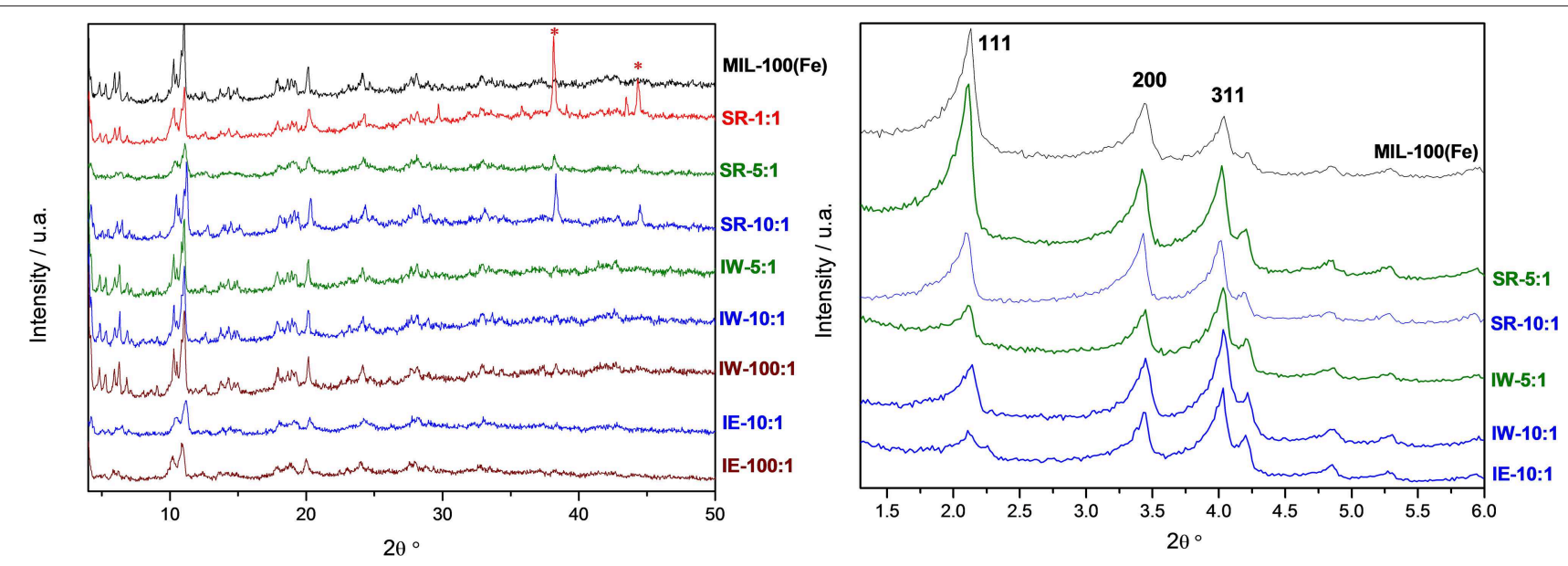

FIGURE 1 | Wide-angle (Left) and low angle (Right) powder XRD patterns of the Ag-free (top, black line) and Ag@ MIL-100(Fe) samples incorporated by different methodologies and with different Ag loadings. Asterisks at $2 \theta$ near $38^{\circ}$ and $44^{\circ}$ indicate the presence of $\mathrm{Ag}^{\circ}$.

the broadening of the PSD peaks, but it entails their intensity decrease, particularly that of the largest cavity, suggesting that Ag species preferably occupied this cavity. Unexpectedly, the intensity decrease is more significant for samples containing less Ag. To deepen this a priori anomalous behavior and the XRD features, we further characterize the samples by means of advanced electron microscopy techniques. Scanning electron microscopy, using backscattered electrons detector, coupled with Energy dispersive X-ray spectroscopy (SEM/EDX) was employed to study the homogeneity of the samples. This mode allows for identifying isolated Ag particles in brighter contrast due to higher atomic number (Figure SI2). The aim of using this technique was to evaluate, at a glance, the formation of isolated Ag-rich particles, i.e., the homogeneity achieved in each loading method, taking advantage of the backscattered electrons detector, which is sensitive to the atomic number. Besides, some rough estimation of the $\mathrm{Fe} / \mathrm{Ag}$ ratios of the Ag@MIL-100(Fe) particles was taken from EDX spectroscopy. In spite of the fact that EDX in a SEM machine is at most semi quantitative, it is very powerful when it comes to analyzing molar ratios in isolated particles, rather than obtaining a bulk elemental analysis (ICP-OES, for instance) that would not differentiate between the Ag present inside or outside the porous network. The qualitative $\mathrm{Fe} / \mathrm{Ag}$ ratios given in Table 1 were analyzed over particles showing weaker contrast, that is, over particles mainly formed by the MOF, avoiding brighter particles due to the presence of the isolated/segregated Ag particles. As expected from the PXRD results, samples obtained via solid state reaction, such as SR 5:1 and SR10:1, showed physical mixtures and abundant presence of isolated $\mathrm{Ag}$ particles, with very low presence of $\mathrm{Ag}$ in the MOF particles, or even below the detection limit. On the other hand, incipient wetness (IW) and ion exchange (IE) gave a very homogeneous distribution of $\mathrm{Ag}$ within the MOF crystals, although outer separated small Ag particles could be found in all the samples. Very little difference could be observed in IW5:1 and IW 10:1 samples, yielding very homogenous and high incorporation of $\mathrm{Ag}$, indicating that this method is very efficient

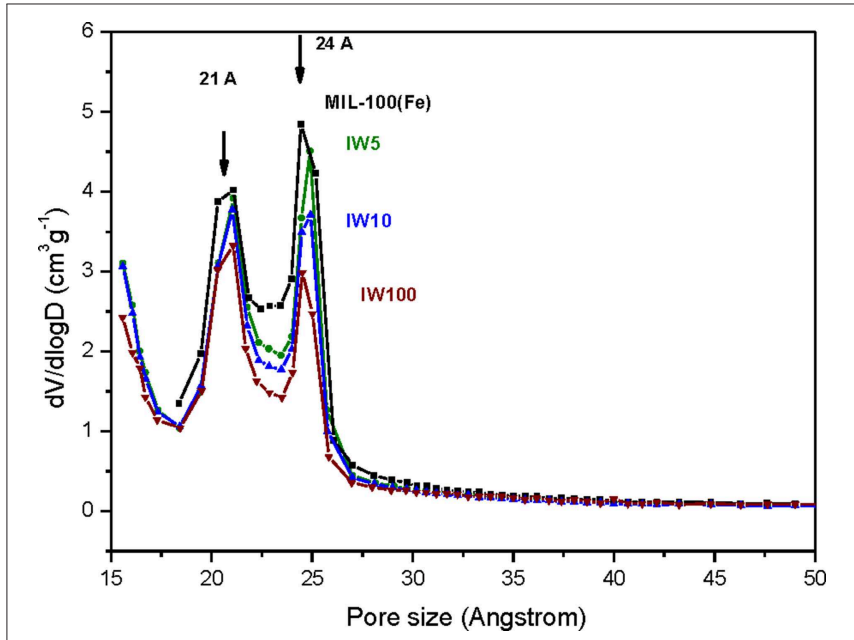

FIGURE 2 | Pore size distribution curves of the pristine MIL-100(Fe) (black) and the different Ag@MIL-100(Fe) samples prepared by wetness impregnation method (IW-5:1, IW-10:1, and IW 100:1).

in incorporating higher loadings of $\mathrm{AgNO}_{3}$. The same trend is obtained for ion exchange conditions with a clear tendency following the theoretical values. In the sample with low levels of loading 100:1, the presence of Ag is hardly detected being below the detection limit.

With the intention of further investigating the structure of the support, together with the presence (or absence) of the metal, its shape, its size and its location, TEM analyses were carried out. To do this, spherical aberration corrected $\left(\mathrm{C}_{\mathrm{s}}\right.$-corrected) STEM, coupled with an annular dark field detector (ADF), was chosen. This technique has already produced outstanding results on the characterization of beam sensitive nanoporous solids, which, by the use of the ADF detector, also gives direct chemical information as the contrast depends on the atomic number of the elements, thus allowing the clear visualization of the metal with respect to the lighter support. Figure 3 presents 

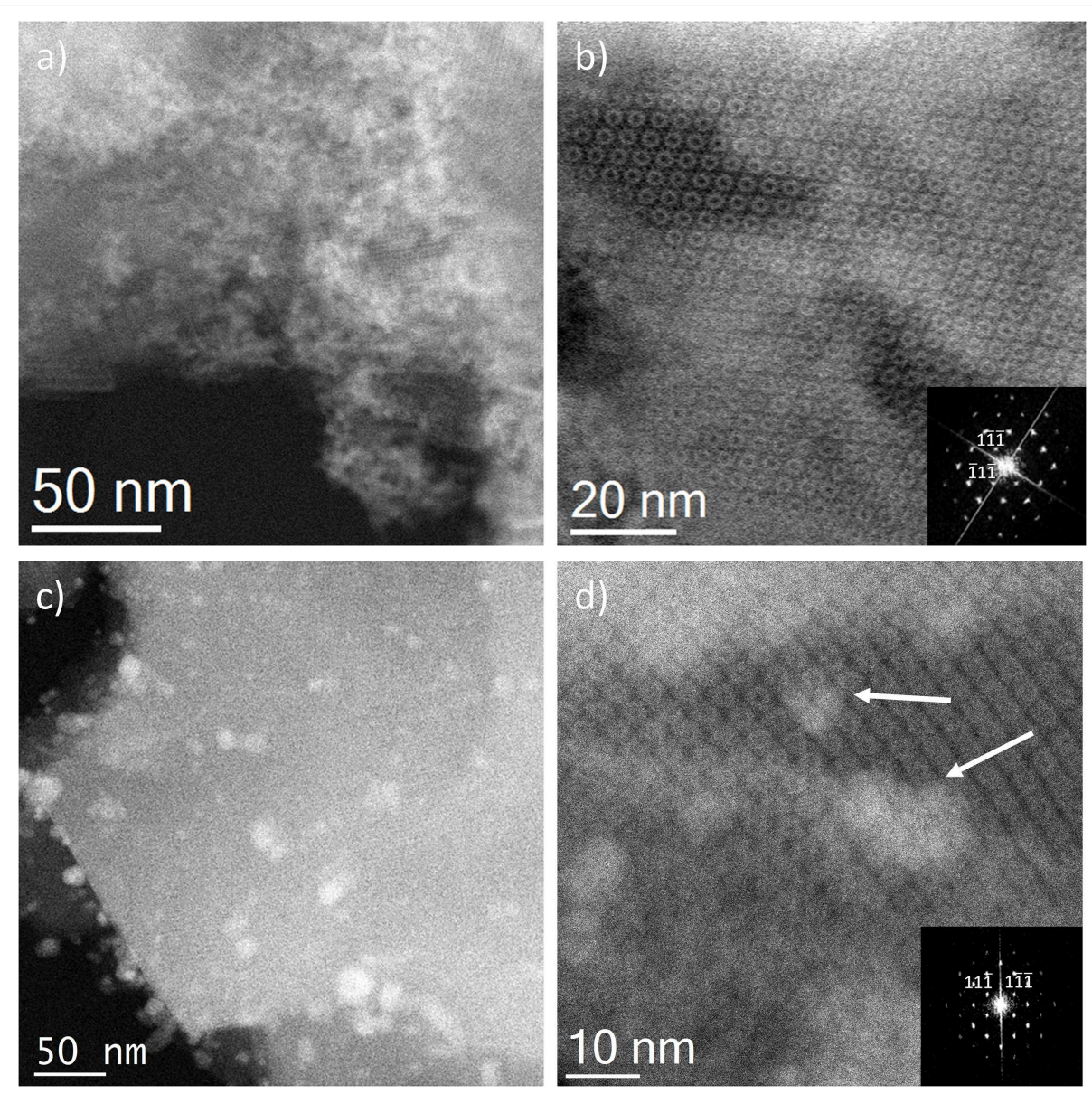

FIGURE 3 | $\mathrm{C}_{\mathrm{S}}$-corrected STEM-ADF observations for the solid state reactions. (a,b) SR-1:1 low magnification and high resolution images, respectively. The Fourier diffractogram (FD) is shown inset of (b). (c) Low magnification image of SR-5:1 and (d) closer observation of the pore system, where the Ag introduced in the pores is marked by white arrows, the FD inset.

the results of the solid-state reaction for the different molar ratios studied. Figures $\mathbf{3 a}$, b show low and high magnification images, respectively, of the samples SR-1:1. In Figure 3a, large domains of $\mathrm{Ag}$ (brighter region) with no particular structure, predominant size or morphology on the outer surface of the MOF particles having been clearly identified, as expected from the observation of $\mathrm{Ag}^{0}$ peaks in the PXRD (Figure 1). A closer look, Figure $3 \mathbf{b}$, allows clear visualization of the porous framework, proving the good crystallinity of the support after reaction. In this case, a MIL-100(Fe) crystallite is observed sitting on the [110] orientation, which is the most adequate for the visualization of the two types of cavities that form this structure (Mayoral et al., 2017). The contrast variations observed on this projection correspond to the existence of Ag. It is complicated to assess whether $\mathrm{Ag}$ is inside, on top or below the MOF. However, the significant changes in the diffraction peaks observed in the PXRD and PSD results, suggest that Ag may be occluded inside the MOF cages, at least to some extent.

In the lower metal content sample, SR-5:1, Figure 3c, the low magnification observation reveals the formation of nanoparticles, which are significantly less agglomerated on the surface of the MIL-100(Fe). The mean size obtained was $12 \pm 5 \mathrm{~nm}$ (see Figure 4A), much larger than the cavities which have diameters of 2.9 and $2.5 \mathrm{~nm}$. Even though silver can be observed outside the MIL-100(Fe), a closer look at the pore system suggests that silver has also gone inside, as the contrast observed matches very well with the porous frameworks (indicated by arrows in Figure 3d). From the comparison of these observations with the PXRD profiles and textural characterization obtained from the solid-state reactions, it can be deduced that crystallinity of the MOF is not affected by the conditions employed here, $210^{\circ} \mathrm{C}$. This temperature is below the melting point of the salt and it was chosen to guarantee the preservation of the framework. Under these conditions, the salt should be in solid-state form; however, the presence of the MOF, together with some water that may be allocated in the pores, may induce the melting of the salt at lower temperatures, which is beneficial for its application. Based on electron microscopy observations, it is thus confirmed that the structure did not suffer major alterations and that the diffraction intensity variations in the low angle XRD patterns 

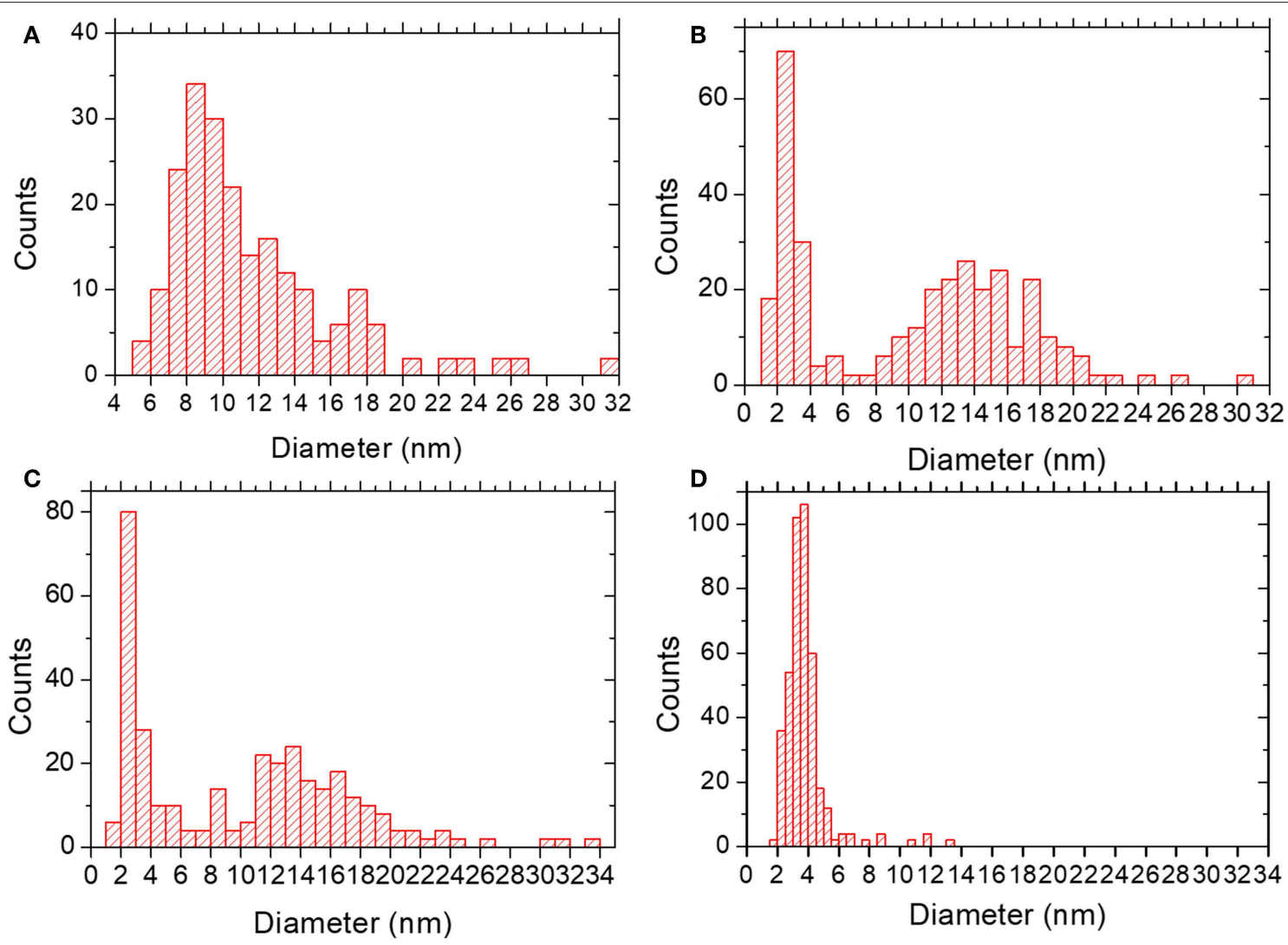

FIGURE 4 | Particle size distribution for (A) SR-5:1; mean diameter $12 \pm 5 \mathrm{~nm}$. (B) IW-10:1; mean diameter of $10 \pm 6 \mathrm{~nm}$. (C) IE-10:1; mean diameter of $10 \pm 7 \mathrm{~nm}$. (D) IE-SOD; mean diameter of $4 \pm 1 \mathrm{~nm}$.

and $\mathrm{N}_{2}$ isotherms owed to the introduction of $\mathrm{Ag}$ inside the MIL-100(Fe) cages.

Incipient Wetness impregnation was also explored as a possibility of $\mathrm{Ag}$ incorporation in MIL-100(Fe). In this case, the method requires a low amount of a liquid phase where the salt would be dissolved prior to getting in contact with the dried MOF. As in the previous case, the wide-angle PXRD displayed very good crystallinity after the reaction, which significantly altered some low-angle diffraction peaks and the intensity of the PSD peaks. Figure 5 displays the same analysis as for the $\mathrm{SR}$ materials. The samples with different Fe/Ag ratios have been combined in Figure 5, as no differences were found between the 3 samples as expected from SEM. This is in good agreement with the data obtained by PXRD, being the patterns very similar to that of the pristine MOF, except for the systematic changes in the relative intensity at low angle $(111,200$, and 311 reflections). Figure 5a presents a low magnification typical image of MIL-100(Fe) where the Ag particles are on the surface. As occurred for the solid-state reaction, for these samples it was also possible to visualize the MIL-100(Fe) network, confirming that the crystallinity was preserved, see Figure $\mathbf{5 b}$. In this image, it is possible to index the FD along the [110] orientation, assuming the $F d-3 m$ symmetry, see inset. By gently defocusing that image and increasing the electron dose at the cost of certain beam damage, Ag nanoparticles of around $2 \mathrm{~nm}$, smaller than the pore size of MIL-100, are clearly visualized, Figure 5c, marked by red circles, confirming that the MOF materials can act as hosts for the local confinement of silver inside its structure. The analysis of the particle size distribution, Figure 4B, presents and average size of $10 \pm 6 \mathrm{~nm}$, similar to the solid-state reaction. However, in this case, two clear domains are identified: (i) one population centered at $\approx 2.5 \mathrm{~nm}$, and (ii) the second one at $\approx 13 \mathrm{~nm}$, which is in good agreement with the high-resolution electron microscopy observations.

Ion Exchange in aqueous solution (IE) was the third type of metal incorporation method studied in this work. The relative intensity of the diffraction patterns has decreased in comparison to the parent MOF but still retains a good degree of crystallinity. The low angle analysis also shows clear evidence of structural changes by the decrease in relative intensity of the 111 diffraction peak in comparison with the 200 and 311, which may suggest once again that metal is present inside the porous network. As occurred for the wet impregnation, very similar PXRD results were obtained for the different Fe/Ag ratios. Figure 6a depicts a typical image of the IE-100:1, where it is possible to observe the presence of Ag due to its higher contrast, but with no defined morphology. It seems that for this low amount of silver, the metal may form very small sized nanoparticles embedded in the 

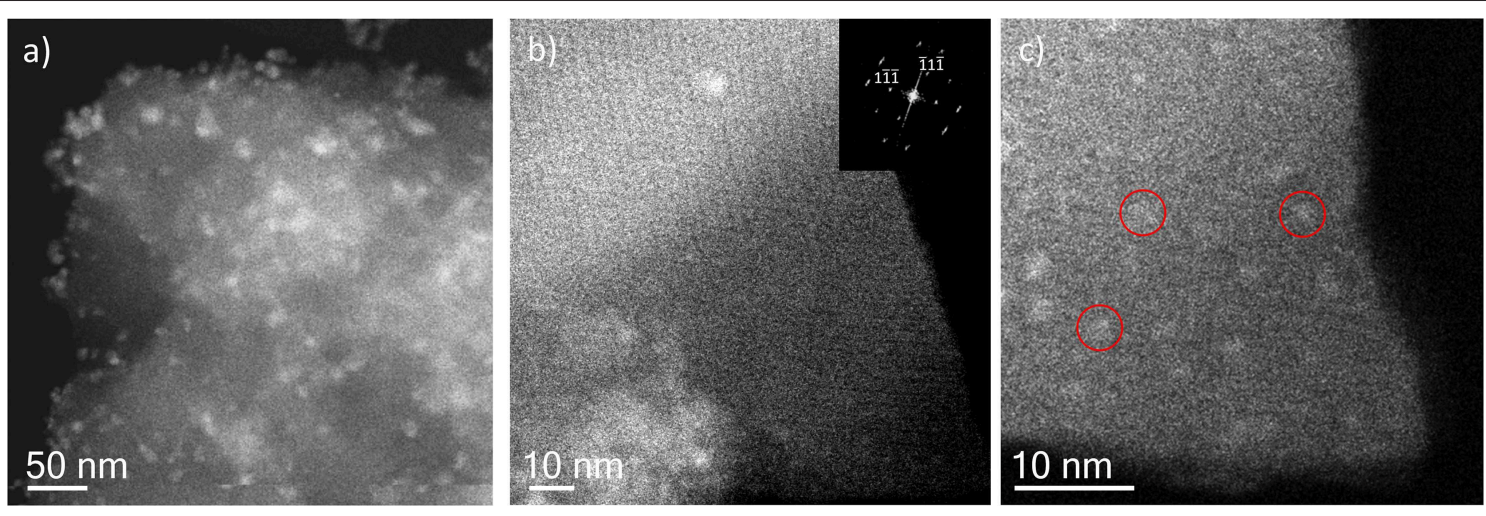

FIGURE 5 | $\mathrm{C}_{\mathrm{S}}$-corrected STEM-ADF analysis of IW-10:1. (a) Low magnification image where several Ag nanoparticles are observed. (b) High-resolution image of the framework with the Fourier diffractogram inset. (c) A closer look of the edge of the MIL-100(Fe) crystallite where the smallest Ag nanoparticles are marked by red circles.
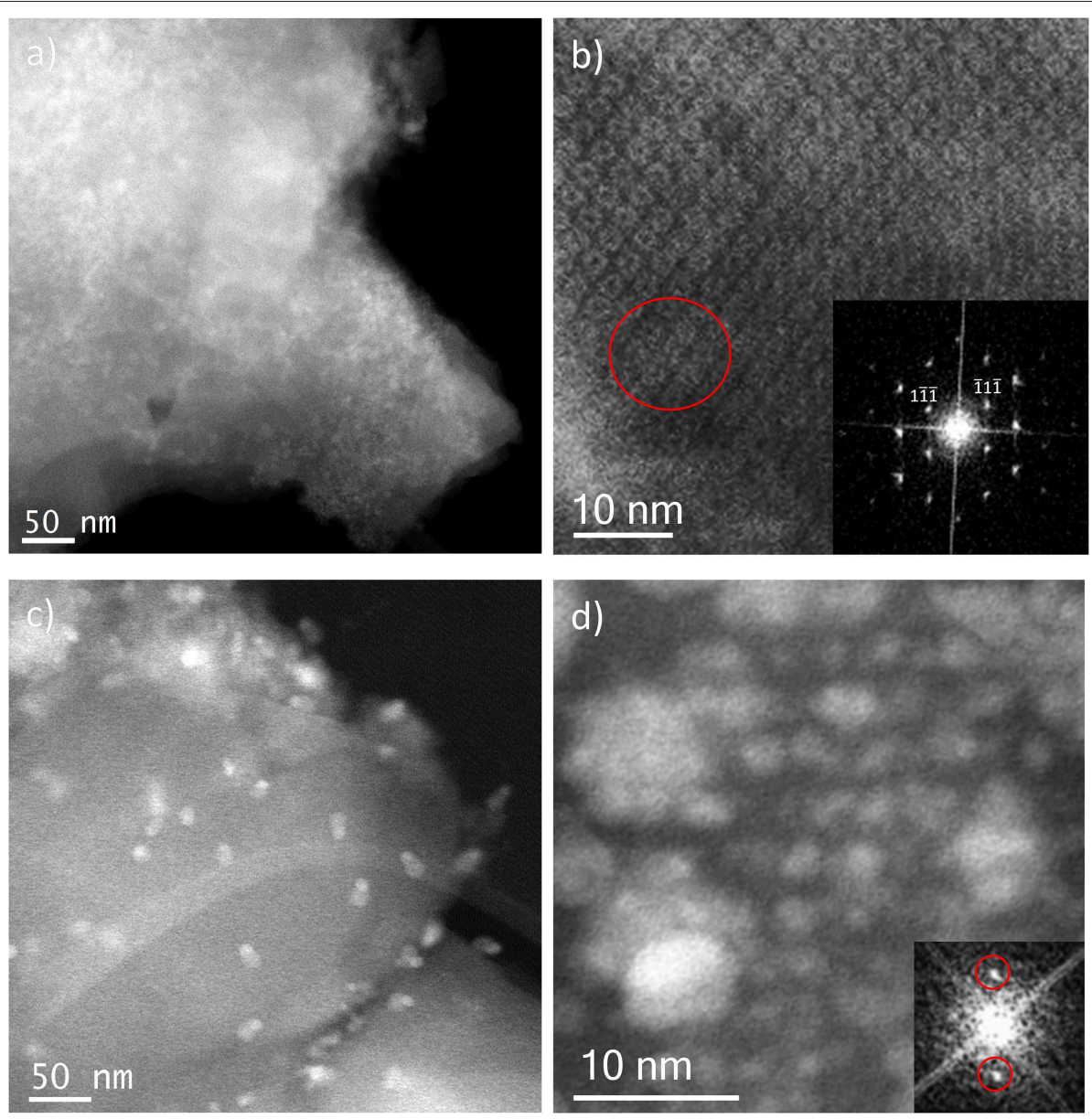

FIGURE 6 | $\mathrm{C}_{\mathrm{s}}$-corrected STEM-ADF analysis of: (a) IE-100:1 low magnification image and (b) IE-100:1 high-resolution micrograph along the [110] orientation with the FD shown inset; and (c) IE-10:1 low magnification image where the large Ag nanoparticles can be observed and (d) IE-10:1 closer observation of a MIL-100(Fe) crystal with the small Ag nanoparticles in a perfect array that matches with the pore system. The FD obtained from that metal distribution is shown inset.

structure. The high-resolution image along the [110] orientation is shown in Figure 6b, where the contrast variations are owed to the presence of the $\mathrm{Ag}$ within the pores. Figure $\mathbf{6} \mathbf{b}$ shows that $\mathrm{Ag}$ occupies the cages and that adjacent cages could be filled with metal, giving the impression of larger formations as indicated by the red circle. 
Sample IE-10:1 contains 10 times higher Ag loading, which was evident from the STEM observations. Figure $\mathbf{6 c}$ presents the low magnification micrograph, clearly showing the formation of Ag nanoparticles on the surface of the MIL-100(Fe). The average particle size was estimated in $10 \pm 7 \mathrm{~nm}$, with two populations clearly identified. A narrow distribution centered around $2.5 \mathrm{~nm}$ and a second wider one of $\sim 13 \mathrm{~nm}$ (Figure $4 \mathrm{C}$ ) resembling what was observed in the samples prepared by the wet impregnation method. Interestingly, for this material it was also observed how the small nanoparticles, which would fit the pore size, entirely filled the MOF crystal as depicted in Figure 6d. It was observed how $2 \mathrm{~nm} \mathrm{Ag} \mathrm{nanoparticles} \mathrm{were} \mathrm{periodically} \mathrm{aligned} \mathrm{compacted}$ in a MIL-100(Fe) crystallite, corroborating the confinement effect thanks to the introduction of the metal inside the cages. The Fourier diffractogram corresponding to that array is shown inset, where the diffraction spots are denoted by red circles situated at a distance of $\approx 37.20 \AA$, which would correspond to the d-spacing of the $\{200\}$ planes MIL-100(Fe).

A very particular aspect only observed for the sample IW10:1, with sufficient amount of Ag, was the morphology of the nanoparticles situated on the surface of the MOFs. In many cases, different contrast was appreciated within the NPs. Keeping in mind that the contrast is $\mathrm{Z}$ dependent, it needs to be explained in terms of different composition. Figure 7a shows the highresolution image of a typical example, where the nanoparticle is composed by two regions that crystallized in different structures, as confirmed by the high-resolution image and by the FDs. Indexing the $\mathrm{FD}$ of the lower contrast region gives an interplanar distance of $3.16 \AA$ in agreement with the $\mathrm{d}_{111}$ planes of $\mathrm{AgCl}$ obtaining a unit cell value of $\mathrm{a}=5.47 \AA$. The FD of the brightest area numbered as 2, can be indexed as pure Ag on the [110] projection obtained a $d_{111}$ of $2.35 \AA$ to give a lattice constant of $\mathrm{a}=4.07 \AA$. The chemical analysis performed by EELS, Figure $\mathbf{7 b}$, corroborated the brightest region correspond to pure Ag, yellow map, while the lighter one is formed by $\mathrm{AgCl}$, orange color. Both spectra, corresponding to the $\mathrm{Cl}-\mathrm{L}_{2,3}$ and the Ag-M signals, are presented in the bottom part of Figure $7 \mathbf{b}$. Further chemical spectra imaging was recorded over a larger region (Figure 7c) displaying similar results.

Every studied method has successfully introduced Ag in different forms in the pores of MIL-100(Fe), and they have also resulted in the formation of small nanoparticles on the surface of the porous materials. In this aspect, although some nanoparticles were outside the framework, their formation were also affected by the presence of the porous network. In the solid-state reactions, a high content of salt yielded the introduction of Ag in many cages but with no particular morphology. This is the case of sample SR1:1 where the excess of Ag was spread over the porous particles, even in some regions on their surface. Among the possibilities of how metals were introduced into the framework, cations may be transferred through vapor phase or surface diffusion (Karge, 2008). In our case, surface diffusion may be the process that took place as the temperature used did not even reach the melting point of the salt and, therefore, an intimate contact between the salt in its molten form and the MOF, may favor the introduction of the metal within the pores followed by the self-reduction of $\mathrm{Ag}$ at this temperature in the presence of light. In the samples with higher loading, Ag seems to occupy many contiguous pores and that is the reason for the contrast variations within the framework. Furthermore, due to the high salt content, not all the salt penetrated into the system and larger domains of noncrystalline $\mathrm{Ag}^{0}$ were formed. When Ag concentration decreased, the process occurred in a similar way and the MIL-100(Fe) facilitated the diffusion of the metal along its porosity, allowing Ag to nucleate, forming Ag NPs (nanoparticles) whose size may be restricted by the Ag reservoir. In this case, the available Ag is significantly lower in comparison with the sample SR-1:1, so well-defined Ag nanoparticles were formed, in many cases on the surface of crystallites.

As a general trend, the two cases involving liquid media, wet impregnation and liquid ion exchange IE-(10:1), produced similar results. The dissolved $\mathrm{Ag}$, forming separated $\mathrm{Ag}^{+}$ cations would enter in the pores and nucleate as $\mathrm{Ag}$ clusters/nanoparticles that fill certain pores. In addition, owing to the high mobility of silver along the framework, silver nanoparticles were found on the surface of the MOF particles. In this case, some $\mathrm{Ag}^{+}$may migrate onto the surface where it began to nucleate forming larger particles, as no structural constrains were present; these two types of Ag entities were made clear through the particle size analysis, which presented a bimodal behavior in both cases: (i) the formation of one family of nanoparticles of size around $2.5 \mathrm{~nm}$ that would fit the pore cages of MIL-100(Fe), and (ii) the second one with much larger size (of ca. $\approx 13 \mathrm{~nm}$ of diameter) that was observed outside the framework. This indicates that MIL-100(Fe) structure limits the size of the Ag clusters growing in its pores, as the outside Ag trends to form (around five times) larger particles.

The excess of water in the ion exchange solution assured that silver cations are separated from their counter ions and this aspect facilitated their in-going process; in this case the cavities acted as confined space limiting the formation of larger nanoparticles and allowing the formation of an array of nanoparticles within the pores. In fact, this sufficient presence of separated silver cations also derivate into their reaction with $\mathrm{Cl}^{-}$, whose origin must be related to residual counter ion from the $\mathrm{Fe}$ source $\left(\mathrm{FeCl}_{2}\right)$ used in the synthesis of MIL-100(Fe).

Finally, for comparison purposes, a charged In-based sodZMOF was also tested with the intention of evaluating the additional functionalization through the presence of a negative charge into the framework. Unlike MIIL-100(Fe), sod-ZMOF is a microporous material, lacking any mesoporosity (Liu et al., 2006; Calleja et al., 2010). Figure 8 shows the most representative cavities of both MOFs. From correctly interpreting this figure, it is clear that the scale of the pore size is noteworthy, revealing the enormous difference in this feature. The anionic sod-ZMOF material has the topology of the zeolite sodalite and is formed by indium as the isolated (non-clustered) metal node, 4,5-imidazoledicarboxylate as the organic linker and imidazole as structure-directing agent. Its negative charge is compensated by imidazolium in the as-synthesized form. Fortunately, these cations are at least partially exchangeable by more conventional and smaller cations, increasing its available porosity. The condition of anionic framework was expected to favor the attraction of silver cations in a similar manner as 

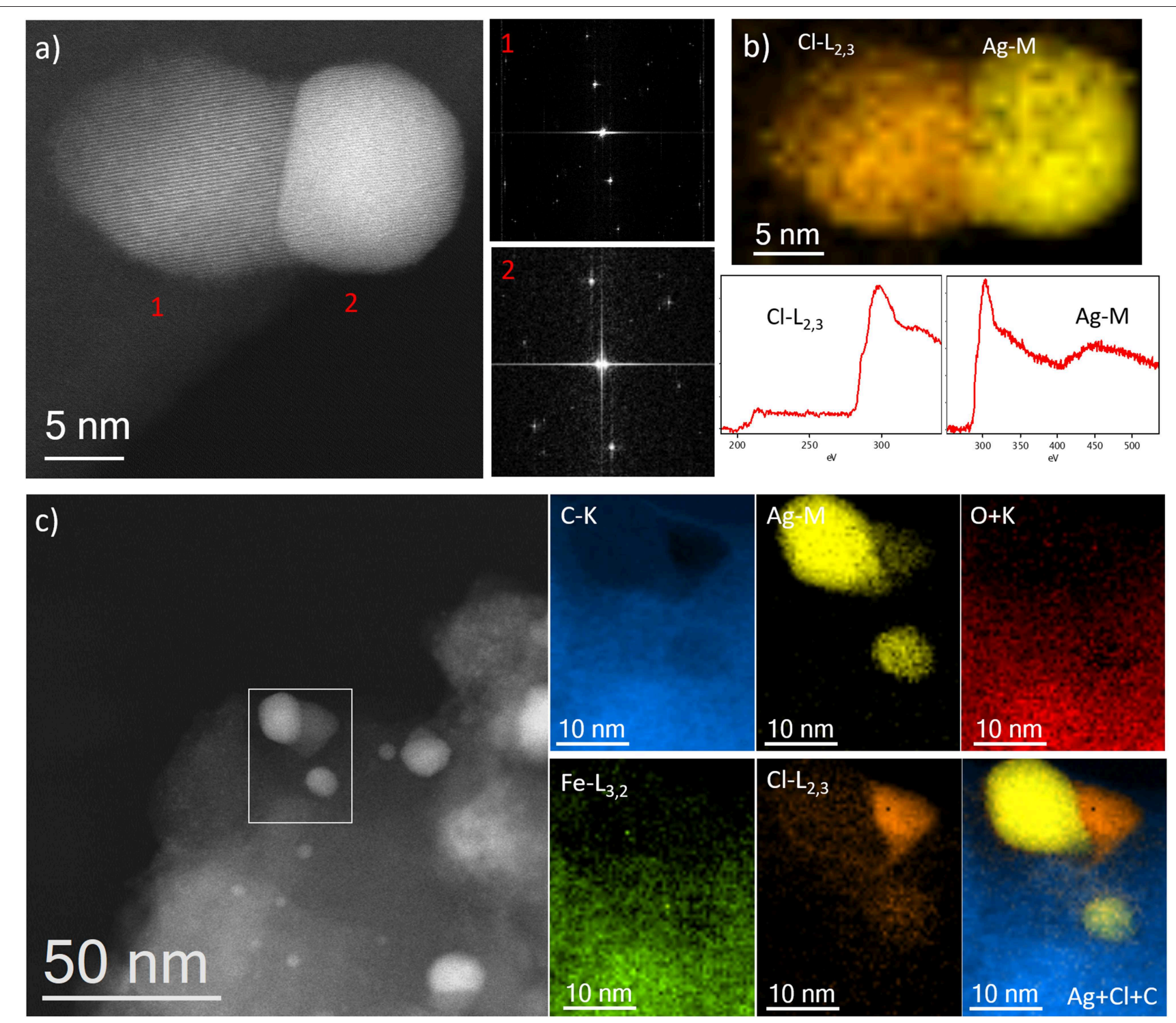

FIGURE 7 | (a) Cs-corrected STEM-ADF image showing a particle with two different regions marked as 1 and 2. The FDs are also shown to the correspondent regions. (b) EEL spectrum imaging with $\mathrm{Cl}$ as orange and $\mathrm{Ag}$ as yellow, the correspondent spectra of each edge are shown below. (c) Cs-corrected STEM-ADF image where the area of analysis is marked by a white rectangle. The different compositional maps are presented separately. Additionally, the $\mathrm{Ag}, \mathrm{Cl}$, and $\mathrm{C}$ map is also shown.

occurs for zeolitic materials with $\mathrm{Al}$ ions incorporated within the framework. Even single Ag atoms could be potentially formed, favored by the presence of the negatively-charge framework (Liu et al., 2006; Calleja et al., 2010; Chen et al., 2011). A low magnification image of a IE-SOD sample (Figure 9a), after incorporating $\mathrm{Ag}$ by ion exchange (IE) procedure, shows the formation of $\mathrm{Ag}$ nanoparticles. However, there is a major difference compared with previous experiments. In this case, the particle size is very homogeneous, see Figure 4D, and the diameter is significantly smaller than the former ones with a mean value of $4 \pm 1 \mathrm{~nm}$. Such size is quite different to the $13 \mathrm{~nm} \mathrm{Ag}$ particles formed outside MIL-100(Fe) by the same method, which suggests that chemistry of the MOF surface (composition, defects, charge, hydrophilic character, etc.) could determine the $\mathrm{Ag}$ aggregation trend and, therefore, the $\mathrm{Ag}$ nanoparticles size, even if they are not formed within their pores. Figures $9 \mathbf{b}, \mathbf{c}$ display the high-resolution data of the IE-SOD along the [110] and [111] orientations with the corresponding Fourier diffractograms indexed in agreement with its $F d-3 c$ space group symmetry. These two images allow the visualization of the porous system along with brighter signals that correspond to the Ag occluded inside the pores, marked by red arrows. The narrow pore distribution obtained for this material, together with the small particle size $(4 \pm 1 \mathrm{~nm})$, can give some hints as to the particle formation mechanism as previously discussed. Clearly, the MOF material acts as a host for the metal during the reaction 

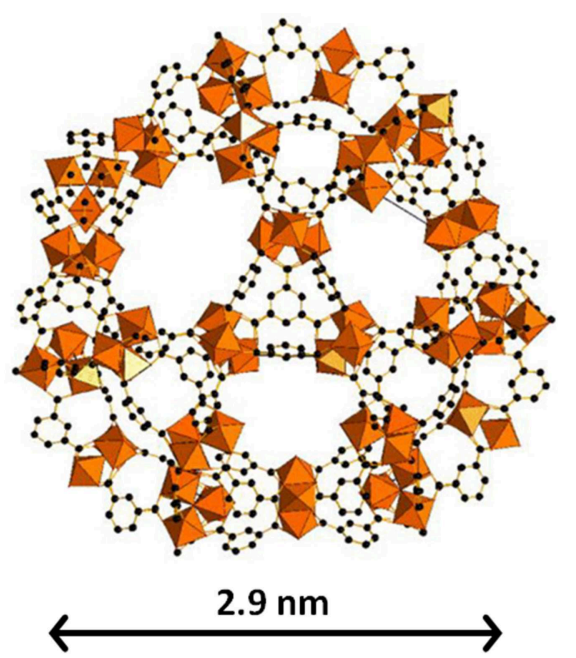

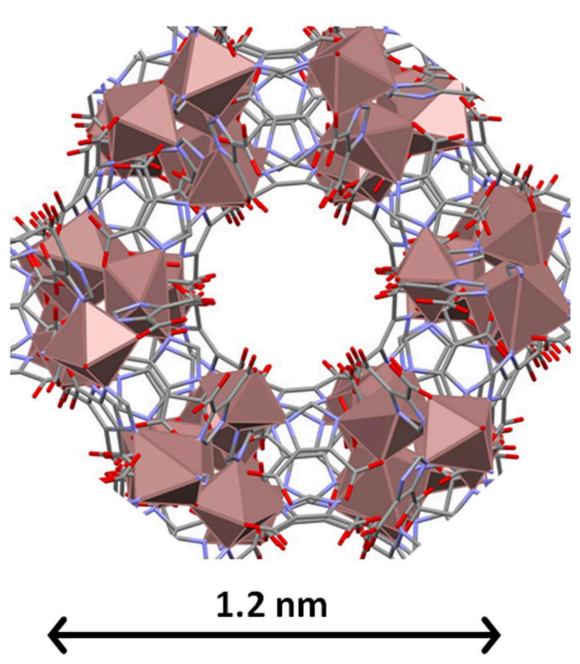

FIGURE 8 | The biggest cages in both MIL-100(Fe) (Left) and sod-ZMOF (Right) materials. Note that they are at different scales, which is evidenced by the different scale bar and by the size of the metal (Fe and In, respectively) polyhedra. The inner diameter of the cavities is 2.9 and $1.2 \mathrm{~nm}$, and they are accessible through windows with apertures of 0.86 and $0.41 \mathrm{~nm}$. In the case of sod-ZMOF, the compensation cations have been omitted to highlight the porosity.
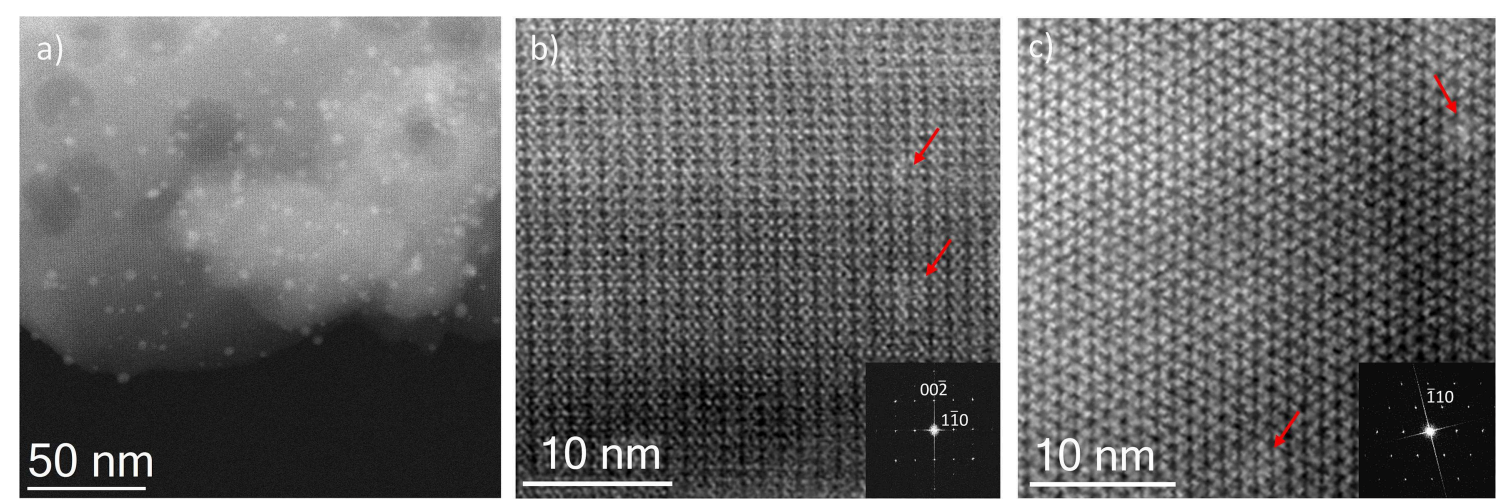

FIGURE 9 | $\mathrm{C}_{\mathrm{s}}$-corrected STEM-ADF observation IE-SOD MOF. (a) Low magnification micrograph showing the presence of Ag NPs. (b) Closer observation on the [110] orientation, where some pores are filled with Ag. The FD is shown inset indexed in the Fd-3c space group. (c) High resolution data on the [111] that also confirms the presence of $\mathrm{Ag}$ within the pores, the indexed FD is shown inset.

between the porous material and the metal-containing solution. Eventually, the metal may migrate onto the surface where it begins to nucleate and grow into small nanoparticles. The size of these nanoparticles may be limited by the amount of metal accessible to migrate and the growing process is limited by the amount of metal within the pores. In the case of negatively charged MOFs, more silver was initially occluded into the framework in a more homogenous manner, that allowed the formation of many nucleation points with similar Ag reservoir accessible to them, leading to the formation of many welldistributed metal nanoparticles of relatively small size.

\section{CONCLUSIONS}

Different simple methods to incorporate Ag clusters/nanoparticles in a mesoporous MIL-100(Fe) support, prepared under sustainable conditions, have been studied. Some different characterization techniques could provide indirect features of the resultant samples, particularly regarding the Ag particles. However, electron microscopy with the most advanced $\mathrm{C}_{\mathrm{s}}$-corrected and detector technologies provides direct and reliable information regarding the location of the metal nanoparticles inside the porous network, in spite of the low structural stability of the MOFs under the electron beam. Supported by other valuable techniques, such as XRD, $\mathrm{N}_{2}$ adsorption/desorption isotherms and EDX, TEM characterization was able to unequivocally identify both the location and the size of the resultant clusters and/or nanoparticles (or even potentially atoms). Attempts to incorporate $\mathrm{Ag}$ by simple solid state reaction of $\mathrm{AgNO}_{3}$ with the MOF almost exclusively led to the formation of relatively large and heterogeneously-sized Ag nanoparticles on the external 
surface of the MOF; scarce Ag was incorporated within the MOF pores. Both wetness impregnation and ion exchange approaches incorporated a significant amount of Ag clusters within the pores, in addition to external Ag nanoparticles, more homogeneous in size than by the solid state reaction approach. The size of such Ag clusters $(2.5 \mathrm{~nm}$ of diameter with narrow distribution) observed inside of the MOF mesopores (2.5 and $2.9 \mathrm{~nm}$ ) indicates that the MOF plays an effective role of steric constrain for Ag clusters, which makes MIL-100(Fe) a good candidate to act as a guest of metal nanoparticles in different applications.

Although the here-presented experimental procedures for efficiently creating Ag clusters in MOF pores could be widely improved, this work makes clear that simple experimental modifications can have an important influence in both chemistry and location of the $\mathrm{Ag}$ species. More importantly, the advanced TEM techniques developed in this study have shown enormous potential to characterize, in depth and in detail, this particular Ag@MIL-100(Fe) system or, more generally, any metal@MOF system.

\section{DATA AVAILABILITY STATEMENT}

The datasets generated for this study will be made available by the authors, without any undue reservation, to any qualified researcher.

\section{REFERENCES}

Agundez, J., Martin, L., Mayoral, A., and Pérez-Pariente, J. (2018). Gold nanoclusters prepared from an eighteenth century two-phases procedure supported on thiol-containing SBA-15 for liquid phase oxidation of cyclohexene with molecular oxygen. Catal. Today 304, 172-180. doi: 10.1016/j.cattod.2017.09.045

Bagheri, N., Khataee, A., Hassanzadeh, J., and Habibi, B. (2018). Visual detection of peroxide-based explosives using novel mimetic Ag nanoparticle/ZnMOF nanocomposite. J. Hazard. Mater. 360, 233-242. doi: 10.1016/j.jhazmat.2018.08.013

Calleja, G., Botas, J. A., Sánchez-Sánchez, M., and Orcajo, M. G. (2010). Hydrogen adsorption over Zeolite-like MOF materials modified by ion exchange. Int $J$ Hydr. Energ. 35, 9916-9923. doi: 10.1016/j.ijhydene.2010.02.114

Chen, C., Kim, J., Yang, D. A., and Ahn, W. S. (2011). Carbon dioxide adsorption over zeolite-like metal organic frameworks (ZMOFs) having a sod topology: structure and ion-exchange effect. Chem. Eng. J. 168, 1134-1139. doi: 10.1016/j.cej.2011.01.096

Corma, A., Concepcion, P., Boronat, M., Sabater, M. J., Navas, J., Jose-Yacaman, M., et al. (2013). Exceptional oxidation activity with size-controlled supported gold clusters of low atomicity. Nat. Chem. 5, 775-781. doi: 10.1038/nchem.1721

Dadashi, M., Arabi, F. A., Gh, S. M. S., Rahimpour, A., and Soroush, M. (2018). A novel nanocomposite with superior antibacterial activity: a silver-based metal organic framework embellished with graphene oxide. Adv. Mater. Interfaces 5:1701365. doi: 10.1002/admi.201701365

Dhakshinamoorthy, A., and García, H. (2012). Catalysis by metal nanoparticles embedded on metal-organic frameworks. Chem. Soc. Rev. 41, 5262-5284. doi: $10.1039 / \mathrm{c} 2 \mathrm{cs} 35047 \mathrm{e}$

Díaz-García, M., Mayoral, A., Díaz, I., and Sánchez-Sánchez, M. (2014). Nanoscaled M-MOF-74 materials prepared at room temperature. Cryst. Growth Des. 14, 2479-2487. doi: 10.1021/cg500190h

\section{AUTHOR CONTRIBUTIONS}

All authors listed have made a substantial, direct and intellectual contribution to the work, and approved it for publication.

\section{FUNDING}

This work has been funded by the Spanish State Research Agency (AEI) and the European Regional Development Fund (FEDER) through the Project MAT2016-77496-R (AEI/FEDER, UE), the Centre for High-resolution Electron Microscopy (CћEM), supported by SPST of ShanghaiTech University under contract No. EM02161943, and National Natural Science Foundation of China (NSFC) through the projects NFSC-21850410448 and NSFC-21835002.

\section{ACKNOWLEDGMENTS}

We acknowledge support of the publication fee by the CSIC Open Access Publication Support Initiative through its Unit of Information Resources for Research (URICI).

\section{SUPPLEMENTARY MATERIAL}

The Supplementary Material for this article can be found online at: https://www.frontiersin.org/articles/10.3389/fchem. 2019.00686/full\#supplementary-material

Dutta, G., Jana, A. K., Singh, D. K., Eswaramoorthy, M., and Natarajan, S (2018). Encapsulation of silver nanoparticles in an amine-functionalized porphyrin metal-organic framework and its use as a heterogeneous catalyst for CO2 fixation under atmospheric pressure. Chem. Asian 13, 2677 -2684. doi: 10.1002/asia.201800815

Esken, D., Turner, S., Lebedev, O. I., Tendeloo, G. V., and Fischer, R. A. (2010). Au@ZIFs: stabilization and encapsulation of cavity-size matching gold clusters inside functionalized zeolite imidazolate frameworks, ZIFs. Chem. Mater. 22, 6393-6401. doi: 10.1021/cm102529c

Getachew, N., Chebude, Y., Sánchez-Sánchez, M., and Diaz, I. (2014). Room temperature synthesis of metal organic framework MOF-2. J. Porous Mat. 21, 769-773. doi: 10.1007/s10934-014-9823-6

Guesh, K., Caiuby, C. D., Mayoral, A., Díaz-García, M., Díaz, I., and Sanchez-Sanchez, M. (2017). Sustainable preparation of MIL-100(Fe) and its photocatalytic behavior in the degradation of methyl orange in water. Cryst. Growth Des. 17, 1806-1813. doi: 10.1021/acs.cgd.6b01776

Hermes, S., Schröter, M. K., Schmid, R., Khodeir, L., Muhler, M., Tissler, A., et al. (2005). Metal@MOF: loading of highly porous coordination polymers host lattices by metal organic chemical vapor deposition. Angew. Chem. Int. Ed 44, 6237-6241. doi: 10.1002/anie.200462515

Horcajada, P., Surblé, S., Serre, C., Hong, D. Y., Seo, Y. K., Chang, J. S., et al. (2007). Synthesis and catalytic properties of MIL-100(Fe), an iron(III) carboxylate with large pores. Chem. Commun. 2007, 2820-2822. doi: 10.1039/ B704325B

Houk, R. J. T., Jacobs, B. W., Gabaly, F. E., Chang, N. N., Talin, A. A., Grahan, D. D., et al. (2009). Silver cluster formation, dynamics, and chemistry in metal-organic frameworks. Nano Lett. 9, 3413-3418. doi: 10.1021/nl901397k

Karge, H. G. (2008). "Solid State Ion Exchange in Zeolites," in Handbook of Heterogenous Catalysis, eds G. Ertl, H. Knözinger, F. Schüth, and J. Weitkamp (Wiley, WA: VCH Verlag GmbH \& Co.), 484-512. doi: 10.1002/9783527610044.hetcat0023 
Li, B., Wen, H. M., Cui, Y., Zhou, W., Qian, G., and Chen, B. (2016). Emerging multifunctional metal-organic framework materials. Adv. Mater. 28, 8819-8860. doi: 10.1002/adma.201601133

Liu, Y., Kravtsov, V. C., Larsen, R., and Eddaoudi, M. (2006). Molecular building blocks approach to the assembly of zeolite-like metal-organic frameworks (ZMOFs) with extra-large cavities. Chem. Commun. 2006, 1488-1490. doi: $10.1039 / \mathrm{b} 600188 \mathrm{~m}$

Mayoral, A., and Anderson, P. A. (2007). Production of bimetallic nanowires through electron beam irradiation of copper- and silver-containing zeolite A. Nanotechnology 18:165708. doi: 10.1088/0957-4484/18/16/165708

Mayoral, A., Carey, T., Anderson, P. A., and Diaz, I. (2013). Atomic resolution analysis of porous solids: a detailed study of silver ion-exchanged zeolite A. Micropor. Mesopor. Mater. 166, 117-122. doi: 10.1016/j.micromeso.2012.04.033

Mayoral, A., Carey, T., Anderson, P. A., Lubk, A., and Diaz, I. (2011). Atomic resolution analysis of silver ion-exchanged zeolite A. Angew. Chem. Int. Ed. 50, 11230-11233. doi: 10.1002/anie.201105450

Mayoral, A., Hall, R. M., Jackowska, R., and Readman, J. E. (2016). Imaging the atomic position of light cations in a porous network and the Europium(III) ion exchange capability by aberration-corrected electron microscopy. Angew. Chem. Int. Ed. 55, 16127-16131. doi: 10.1002/anie.201609094

Mayoral, A., Ma, Y., and Terasaki, O. (2018). Some efforts toward understanding structural features of MOF/COF. Isr. J. Chem. 58, 1157-1163. doi: 10.1002/ijch.201800125

Mayoral, A., Mahugo, R., Sanchez-Sanchez, M., and Diaz, I. (2017). Cs-corrected STEM imaging of both pure and Ag-supported metal-organic framework MIL-100(Fe). Chem. Cat. Chem. 22, 3497-3502. doi: 10.1002/cctc.201700519

Mayoral, A., Sanchez-Sanchez, M., Alfayate, A., Perez-Pariente, J., and Diaz, I. (2015). Atomic observations of microporous materials highly unstable under the electron beam: the cases of Ti-doped AlPO4-5 and Zn-MOF-74. Chem. Cat. Chem. 7, 3719-3724. doi: 10.1002/cctc.201500617

Meilikhov, M., Yusenko, K., Esken, D., Turner, S., Tendeloo, G. V., and Fischer, R. A. (2010). Metals@MOFs - loading MOFs with metal nanoparticles for hybrid functions. Eur J. Inorg. Chem. 2010, 3701-3714. doi: 10.1002/ejic.201000473

Moliner, M., Gabay, J. E., Kliewer, C. E., Carr, R. T., Guzman, J., Casty, G. L., et al. (2016). Reversible transformation of Pt nanoparticles into single atoms inside high-silica chabazite zeolite. J. Am. Chem. Soc. 138, 15743-15750. doi: 10.1021/jacs.6b10169

Moon, H. R., Kim, J. H., and Suh, M. P. (2005). Redox active porous metal-organic framework producing silver nanoparticles from AgI ions at room temperature. Angew. Chem. Int. Ed 44, 1261-1265. doi: 10.1002/anie.200461408

Orcajo, M. G., Botas, J. A., Calleja, G., and Sánchez-Sánchez, M. (2012). Materiales MOF para el almacenamiento de hidrógeno. An. Quim. 108, 13-20.

Peng, Z., Jiang, Z., Huang, X., and Li, Y. (2016). A novel electrochemical sensor of tryptophan based on silver nanoparticles/metal-organic framework composite modified glassy carbon electrode. RSC Adv. 6, 13742-13748. doi: 10.1039/C5RA25251B

Rösler, C., and Fischer, R.A. (2015). Metal-organic frameworks as hosts for nanoparticles. CrystEngComm 17, 199-217 doi: 10.1039/C4CE $01251 \mathrm{H}$

Ruano, D., Díaz-García, M., Alfayate, A., and Sánchez-Sáchez, M. (2015). Nanocrystalline M-MOF-74 as heterogeneous catalysts in the oxidation of cyclohexene: correlation of the activity and redox potential. ChemCatChem 7, 674-681. doi: 10.1002/cctc.201402927

Sanchez-Sanchez, M., Asua, I. D., Ruano, D., and Diaz, K. (2015). Direct synthesis, structural features, and enhanced catalytic activity of the basolite F300like semiamorphous Fe-BTC framework. Cryst. Growth Des. 15, 4498-4506. doi: 10.1021/acs.cgd.5b00755

Sánchez-Sánchez, M., Getachew, N., Díaz, K., Díaz-Garcia, M., Chebude, Y., and Díaz, I. (2015). Synthesis of metal-organic frameworks in water at room temperature: salts as linker sources. Green Chem. 17, 1500-1509. doi: 10.1039/C4GC01861C

Wang, C., An, B., and Lin, W. (2019). Metal-organic frameworks in solid-gas phase catalysis. ACS Catal. 9, 130-146. doi: 10.1021/acscatal.8b 04055

Wang, N., Sun, Q., Bai, R., Li, X., Guo, G., and Yu, J. (2016). In situ confinement of ultrasmall pd clusters within nanosized silicalite-1 zeolite for highly efficient catalysis of hydrogen generation. J. Am. Chem. Soc. 138, 7484-7487. doi: 10.1021/jacs.6b03518

Zhang, D., Zhu, Y., Liu, L., Ying, X., Hsiung, C. E., Sougrat, R., et al. (2018). Atomic-resolution transmission electron microscopy of electron beam-sensitive crystalline materials. Science 359, 675-679. doi: 10.1126/science.aao0865

Zhu, Y., Ciston, J., Zheng, B., Miao, X., Czarnik, C., Pan, Y., et al. (2017). Unravelling surface and interfacial structures of a metal-organic framework by transmission electron microscopy. Nat. Mater. 16, 532-536. doi: $10.1038 /$ nmat 4852

Conflict of Interest: The authors declare that the research was conducted in the absence of any commercial or financial relationships that could be construed as a potential conflict of interest.

Copyright (c) 2019 Mahugo, Mayoral, Sánchez-Sánchez and Diaz. This is an openaccess article distributed under the terms of the Creative Commons Attribution License (CC BY). The use, distribution or reproduction in other forums is permitted, provided the original author(s) and the copyright owner(s) are credited and that the original publication in this journal is cited, in accordance with accepted academic practice. No use, distribution or reproduction is permitted which does not comply with these terms. 


\section{OPEN ACCESS}

Edited by:

Pascal Granger,

Lille University of Science and

Technology, France

Reviewed by:

Gregory Scott Patience,

École Polytechnique de Montréal, Canada

Konstantinos Triantafyllidis,

Aristotle University of

Thessaloniki, Greece

*Correspondence: Marcelo Maciel Pereira macie/@iq.ufrj.br

Specialty section: This article was submitted to Green and Sustainable Chemistry,

a section of the journal

Frontiers in Chemistry

Received: 21 June 2019 Accepted: 10 October 2019 Published: 01 November 2019

Citation:

Pinto J, Pedrosa I, Linhares C, San Gil RAS, Lam YL and Pereira MM (2019) Ketal Sugar Conversion Into Green Hydrocarbons by Faujasite Zeolite in a Typical Catalytic Cracking

Process. Front. Chem. 7:720 doi: 10.3389/fchem.2019.00720

\section{Ketal Sugar Conversion Into Green Hydrocarbons by Faujasite Zeolite in a Typical Catalytic Cracking Process}

\author{
Joana Pinto, Igor Pedrosa, Camila Linhares, Rosane A. S. San Gil, Yiu Lau Lam and \\ Marcelo Maciel Pereira*
}

Universidade Federal do Rio de Janeiro, Instituto de Química, Rio de Janeiro, Brazil

Fluidized catalytic cracking (FCC) converts hydrocarbons in the presence of a catalyst based on faujasite zeolite (USY and REY). While hydrocarbon is poorly reactive, biomass and its derived compounds are highly functionalized and not suitable to a typical FCC process. To overcome this limitation biomass was first converted into a dense and stable bio-crude composed mainly of ketal-sugar derivatives by using acetone in diluted acid. Here, a representative compound of this bio-crude, 1,2:3,5-di-O-isopropylidene- $\alpha$-D-xylofuranose (DX) in n-hexane, was converted by USY and a commercial FCC catalyst containing USY, at $500^{\circ} \mathrm{C}$, in a fixed bed and fluidized bed reactors, respectively. Faujasite $Y$ is very efficient in converting DX. More than 95\% conversion was observed in all tests. Over $60 \mathrm{wt}$ \% was liquid products, followed by gas products and only around $10 \%$ or less in coke. The higher the catalyst activity the greater the aromatics in the liquid products and yet higher coke yields were observed. In particular, simulating more practical application conditions: using deactivated catalyst in a fluidized bed reactor, improved green hydrocarbons production (mono-aromatic up to 10 carbons and light hydrocarbon up to eight carbons) and unprecedented lower coke yield $(\approx 5 \mathrm{wt} . \%)$ for bio-feeds. The present results further suggest that catalyst will play a primary role to convert the bio-crude into target hydrocarbons and overcome the transition of a non-renewable to a renewable refinery feed.

Keywords: sugar ketals, biocrude, USY, hydrocarbons, aromatics

\section{INTRODUCTION}

Energy needs have been increasing substantially since the industrial revolution due to population growth and goods demand. Today oil, natural gas, and coal are the main sources for chemicals, fuel and energy production (Smil, 2004; Conti et al., 2016). But the unrestrained exploitation of these non-renewable resources almost doubled the greenhouse gas concentration in the atmosphere in the last 100 years (Russ and Criqui, 2007; North and Styring, 2015). Among several alternatives to reduce the carbon footprint, the production of green-fuels for typical refinery process can shorten our transition of a non- to a renewable refinery. As a huge ready-to-use structure for fuel products and distribution is available, and also requires simple modifications to the fuel-legislation and no adaptation in motors. Besides, simultaneously this avoids building an entire new structure (Goldthau, 2017). Thus, the conversion of biomass into regular fuel using a typical refinery is one of the most important issues that chemistry now faces (Ragauskas et al., 2006). 
A major process of a typical refinery is fluidized catalytic cracking (FCC). This process produces gasoline, liquefied petroleum gas (LPG), light olefins and light cycle oil. The FCC process consists of three distinct steps: reaction, separation, and regeneration. The reaction occurs in the riser reactor in a few seconds under a reducing atmosphere due to the presence of hydrocarbons and hydrogen. After this step, catalyst and reaction products are separated by means of cyclones and a stripper. Finally, the spent catalyst with coke content in the range of 0.6 to $2.0 \mathrm{wt} . \%$ is directed to the regenerator vessel. The catalyst regeneration occurs at high temperature (above $700^{\circ} \mathrm{C}$ ) and in the presence of $\mathrm{O}_{2}, \mathrm{H}_{2} \mathrm{O}$, and other gases ( $\mathrm{O}^{\prime}$ Connor and Pouwels, 1994; Wen et al., 2002). The presence of steam can remarkably affect the catalyst properties (Escobar et al., 2005; Cerqueira et al., 2008) and a central point to develop laboratory test more close to typical FCC condition is to use deactivated or equilibrium catalysts. Also, the reaction-regeneration feature of the FCC makes this process eligible to co-process oil and renewable feeds (O'Connor, 2007).

The arrival of first generation of biofuels, such as bioethanol and bio-diesel allowed a partial replacement of fossil resources, also mitigate $\mathrm{CO}_{2}$ emissions. These new generation transport fuels are now facing key environmental and strategic questions, such as the fact that, they are derived from agricultural commodities that compete with food crops. In contrast, lignocellulosic biomass of forest and industrial waste are an attractive raw material to produce of renewable fuels (Ladanai and Vinterbäck, 2009; Langholtz et al., 2016). Biomass comprising cellulose, hemicellulose and lignin are commonly referred to as second generation biomass of and typically derived from non-edible residues such as bagasse and others from food industries. However, biomasses have low density and a broad diversity in functionalized components compared to hydrocarbons. Thus, it is mandatory to improve density and adjust the reactivity of any bio-feed prior to its conversion in a typical refinery process.

There are some strategies to introduce second-generation biomass in refineries (Huber et al., 2006; Serrano-Ruiz and Dumesic, 2011; Jong and Ommen, 2015). Pyrolysis and fast pyrolysis (Lappas et al., 2002; Oasmaa et al., 2003; Oasmaa and Meier, 2005; Mendes et al., 2016) have generally been accepted as primary processes for this transformation for further conversion into refinery (Adjaye and Bakhshi, 1995; Samolada et al., 1998). Pyrolysis can be performed in the presence of a catalyst (CPO) (French and Czernik, 2010; Graça et al., 2011), or post-treated by a hydro-deoxygenation (HDO) process (Saidi et al., 2014; Talmadge et al., 2014). The oils produced by these processes are typically dark, dense, viscous and composed of a complex mixture of different oxygen-containing molecules in function of the pyrolysis process, like phenols, sugars, carboxylic acids and 15-30 wt.\% of water (Sfetsas et al., 2011; Silva et al., 2016). Thus, bio-oil is non-miscible with hydrocarbon, highly acid and corrosive. These bio-oils result in increase coke during coprocessing with conventional feeds in FCC (Pereira and Benoit, 2013; Talmadge et al., 2014) and hence could be co-processed in very low concentration (Thegarid et al., 2014; Pinho et al., 2015). For instance, even after a severe hydrotreatment ( $\mathrm{H} / \mathrm{C}$ in bio-oil
TABLE 1 | Yield of oil products, gas, and coke used to convert bio-oil and oxygenated model compounds.

\begin{tabular}{lcccll}
\hline Bio feed, catalysts, temp. & $\begin{array}{c}\text { Liquid } \\
\text { wt. } \%\end{array}$ & $\begin{array}{c}\text { Carbon }^{\star} \\
\text { wt. } \%\end{array}$ & $\begin{array}{c}\text { Gas } \\
\text { wt. } \%\end{array}$ & References \\
\hline Raw bio-oil, ZSM-5, $490^{\circ} \mathrm{C}$ & 7 & 19 & 44 & Vitolo et al., 1999, 2001 \\
$20 \%$ hydro-treated & 40 & $6-12$ & $20-40$ & Samolada et al., 1998 \\
bio-oil/80\% gasoil, HY $500^{\circ} \mathrm{C}$ & & & & \\
Raw bio-oil & 26 & 32 & - & Vispute et al., 2010 \\
Hydro-treated Wood Bio-oil & $80^{\star \star *}$ & 13 & 22 & Vispute et al., 2010 \\
\hline
\end{tabular}

*Include coke, char, and Tar.

${ }^{\star *} 100$ bar of $\mathrm{H}_{2}, 330^{\circ} \mathrm{C}$, one hydrogen per carbon in feed.

${ }^{* * *}$ Several classes of compounds.

$\approx 1$ ), high amounts of coke and gas was recorded (Table 1 ). The pyrolysis process solves the density, but not the reactivity problem of a bio-feed for further co-conversion at typical refinery conditions. However, bio-oil can be transformed into products by a coupling process, like hydrogen and synthesis gas (Trane et al., 2012) or fuels (Bulushev and Ross, 2011).

Recently, we proposed an alternative approach to fuel production from second generation biomass in two steps (Batalha et al., 2014). The biomass was firstly converted in mild conditions into a bio-crude (density of $1.1 \mathrm{gmL}^{-1}$ and $\mathrm{CHO}$ composition $\approx 58,7$, and $35 \%$ by weight, respectively) combining acid catalyzed hydrolysis with organic reactions such as ketalization (Garrett et al., 2015; de Souza et al., 2017) and acetylation (Durange et al., 2015). The biocrude is composed by a mixture of isopropylidene ketals containing mono and polyshacharides-ketals (Garrett et al., 2015). For instance 1,2:3,5-di-O-isopropylidene- $\alpha$-D-xylofuranose (DX) and 1,2: 5,6- Isopropylidene- $\alpha$-D -glucofuranose (DG) were produced in high concentration, 50 wt.\%. A later publication also applied similar condition to depolymerization wood biomass and avoided undesirable reaction of sugars (Questell-Santiago et al., 2018).

Secondly, the feasibility of producing hydrocarbons, especially aromatics, using typical model components of the ketal-biocrude such as DX and DG were shown by a simplified catalytic protocol (Batalha et al., 2014, 2016). Our approach of circular economy for producing green-aromatics can be illustrated in Figure 1.

The present work is focused on the catalyst and the catalytic testing conditions, using $\mathrm{Y}$ zeolite, the workhorse, active component of the FCC catalyst. First, with a fixed bed reactor, using pure USY zeolites comprehensively characterized, we showed that the DX in hexane was efficiently converted and the transformation was sensitive to catalysts properties. For example, USY was covered by silica to demonstrate that the catalyst controls the DX conversion. Then, approaching the conditions in commercial practice, a mixture of $30 \mathrm{wt} . \%$ of DX in $n$-hexane were converted in the presence of a commercial FCC catalyst, fresh or deactivated, in a fluidized bed reactor. For each process an overall view of the material balance and product distribution in gas, liquid and coke fractions, are discussed. The 


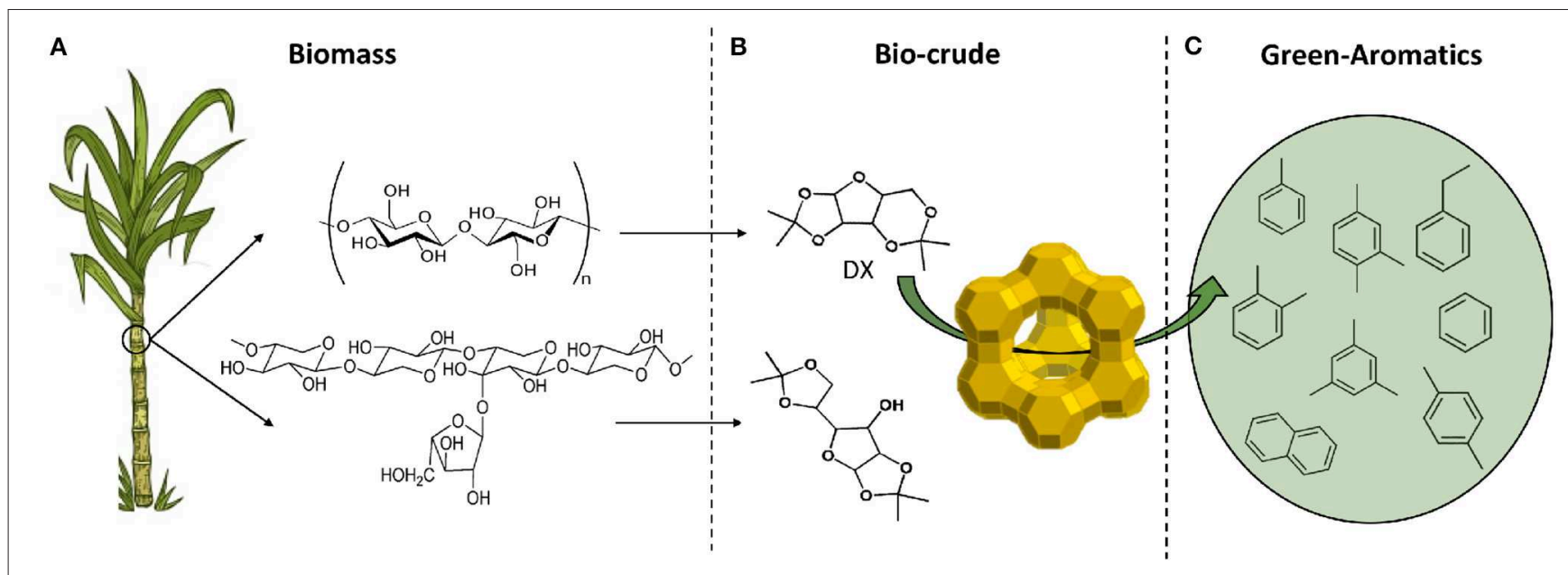

FIGURE 1 | Circular economy based on second generation biomass converted into green-aromatics and -light hydrocarbons in three steps: (A) biomass production, sugarcane bagasse: the residue of ethanol and sugar industry, as feed; (B) biomass conversion into biocrude: sugar-ketal, ex. DX, DG, and polysaccharides-ketal (Garrett et al., 2015); (C) biocrude conversion into hydrocarbons.

products distribution and catalytic properties provided insights of DX conversion into hydrocarbons.

\section{EXPERIMENTAL SECTION}

\section{Catalysts}

The faujazite zeolite USY (provided by Petrobras) was thermal treated in a furnace and the temperature increased from room temperature to 500 at a rate of $10^{\circ} \mathrm{C} \mathrm{min}^{-1}$. At the final temperature, deionized water was pumped at $1 \mathrm{~mL} \mathrm{~min}^{-1}$ for $1 \mathrm{~h}$. The catalyst obtained through this procedure was named USY-D500. The commercial catalyst was provided by Fabrica Carioca de Catalisadores S.A. and it was used as provided and after thermal-treatment (at a final temperature of $720^{\circ} \mathrm{C}$ and following the same procedure of the USY used in the fixed bed test). An additional treatment process was carried out at the USYD500: $4 \mathrm{~g}$ of catalyst was dispersed under magnetic stirring in $100 \mathrm{~mL}$ of $\mathrm{n}$-hexane and heated to $70^{\circ} \mathrm{C}$ under reflux. When the mixture reached $70^{\circ} \mathrm{C}, 0.6 \mathrm{~mL}$ of tetraethylorthosilicate (TEOS) was added. After $1 \mathrm{~h}$, the mixture was filtered and the sample dried at $100^{\circ} \mathrm{C}$. After $24 \mathrm{~h}$, the catalyst was calcinated at $500^{\circ} \mathrm{C}$ for $3 \mathrm{~h}$. This procedure resulted in the catalyst namely USY-D500Silica. Prior to use, the zeolite was submitted to ion exchange using a $\mathrm{NH}_{4} \mathrm{NO}_{3} 2 \mathrm{M}$ solution, at $80^{\circ} \mathrm{C}$, for $1 \mathrm{~h}$. The ion exchange procedure was performed 4 times, followed by calcination at $450^{\circ} \mathrm{C}$ for $4 \mathrm{~h}$ under airflow. This procedure resulted in no sodium being detected in the final sample as previously reported in the literature.

\section{Catalytic Cracking}

The $\mathrm{n}$-hexane cracking in differential reactor was carried out in a high throughput unit (Ferreira et al., 2014). All experiments were conducted at room pressure (open reactor) in a continuous down flow fixed-bed micro reactor. Prior to catalyst evaluation, all the catalyst were heated simultaneously under $\mathrm{N}_{2}$ flow from room temperature to the desired temperature $(773 \mathrm{~K})$, at a rate of 10
$\mathrm{K} / \mathrm{min}$. Then the reactor flow was modified to a mixture of $\mathrm{n}$ Hexane $10 \% \mathrm{v} / \mathrm{v}$ in $\mathrm{N}_{2}(30 \mathrm{~mL} / \mathrm{min})$ for all catalytic tests. A typical run was carried out with $0.01 \mathrm{~g}$ of catalyst and reaction products were analyzed on-line after three distinct times on stream ( $3 \mathrm{~min}$, $17 \mathrm{~min}$ and $32 \mathrm{~min}$ ) by gas chromatography using a Shimadzu GC-2010 (Maia et al., 2010). The activities and selectivity were presented as the average result obtained after $17 \mathrm{~min}$ and $32 \mathrm{~min}$ on stream. The error in conversion and selectivity of n-hexane test was determined in previous working and are $<5$ and $2 \%$, respectively (Ferreira et al., 2014).

Reactions performed in a fixed bed reactor (Figure S1) occurred at $500^{\circ} \mathrm{C}$, under atmospheric pressure and nitrogen flow $\left(100 \mathrm{~mL} \mathrm{~min}^{-1}\right)$ and $400 \mathrm{mg}$ of catalyst. Prior to reaction, the catalyst was heated under a nitrogen flow $\left(100 \mathrm{~mL} \mathrm{~min}^{-1}\right)$ from room temperature to $500^{\circ} \mathrm{C}$ at a rate of $10^{\circ} \mathrm{C} \mathrm{min}{ }^{-1}$, remaining at this final temperature for $30 \mathrm{~min}$. During the reaction, a $0.2 \mathrm{~mL}$ $\min ^{-1}$ liquid flow of DX in n-hexane, at room temperature, was directly to the reactor entrance and mixed with $\mathrm{N}_{2}(100 \mathrm{~mL}$ $\left.\min ^{-1}\right)$. For comparison, pristine $n$-hexane cracking was carried out with the same reaction protocol and catalyst mass. The fluid catalytic cracking unit used to convert the new bio-feed in this study is presented in Figures S2, S3 (Pinto et al., 2017). The tests were carried out by using $10 \mathrm{~mL}$ of feed (pristine $\mathrm{n}$ hexane and mixtures of DX of $30 \mathrm{wt} . \%$ in n-hexane) injected over $1 \mathrm{~min}$, and $20 \mathrm{~g}$ of the fresh and deactivated catalyst were used in the catalytic bed. Before the reaction, the catalyst was activated in a nitrogen atmosphere for $12 \mathrm{~h}$ at $773 \mathrm{~K}$. Nitrogen flow was calibrated at room temperature, and nitrogen flow at $200 \mathrm{~mL} \mathrm{~min}{ }^{-1}$ (estimated at $500^{\circ} \mathrm{C}$ using the state equation of ideal gas) was used to fluidize the catalyst. The reactor was operated in between 450 and $500^{\circ} \mathrm{C}$ considering the height of the fluidized catalytic bed (Figure S3). OPAL is a fresh commercial FCC catalyst supplied for this work by Fábrica Carioca de Catalisadores S.A., and was used with particle diameter 115-200 mesh equivalent to a particle size diameter of $0.125-0.08 \mathrm{~mm}$, respectively, but the composition is unknown. 
The reaction products were distributed in: liquid, gas and coke. Three tests were carried out in the presence of the catalyst USY-D500 to provided an estimative of the error (Table S1). These values were 5, 4, and $6 \%$ for gas, liquid and coke, respectively. An error of $6 \%$ for all fractions was assumed as presented in Figure 5. The liquid fraction was obtained through condensation $\left(-15^{\circ} \mathrm{C}\right.$ in fixed bed and $-18^{\circ} \mathrm{C}$ in the FCC test) by means of a condenser placed right after the reactor exit. The liquid amount was obtained directly by weight difference of the condenser before and after the reaction.

The liquid faction from the cracking reactions were analyzed off-line by both GCMS and CGFID. The determination of liquid products was obtained based on GCMS and the quantification was carried out in a GCFID. The GCMS system is an Agilent Technologies 7890A CG coupled to a 5975C MS in electron impact mode, an Agilent HP-5MS column was used and the oven temperature kept at $303 \mathrm{~K}$ for $7 \mathrm{~min}$ followed by a ramp to $443 \mathrm{~K}$ for $40 \mathrm{~min}$, helium was used as carrier gas. At the inlet, a split ratio of 20:1, 14 psi pressure and $563 \mathrm{~K}$ was used. The GCFID system is an Agilent Technologies 7890A GC and the same method as GCMS was used.

The liquid products were obtained by subtracting the liquid mass by the mass of non-reacted $n$-hexane (determined according Text S1). The wt.\% of each aromatic compounds in the liquid fraction was obtained multiplied the FID area $(\%), \mathrm{AR}_{\mathrm{i}}$, by the respective chromatographic factor $\left(f_{i}\right)$ that is 0.82 for aromatic compounds. The wt.\% of the remaining products were equal to each FID area (\%) by assuming $\mathrm{f}_{\mathrm{i}}=1$. Remaining products, $P_{j}$, are determined by the sum of all olefins (containing five or more carbons), all hydrocarbons (containing five or more carbons), all light compounds (containing four or fewer carbons), heavy (assuming $f=1$ ) and non-determined compounds (assuming $f=1$ ). The total area of liquid products was determined by the sum of aromatics (corrected by each aromatic factor) and $\mathrm{P}_{j}$ (total of the remaining products), equation 1-a. The aromatic/total products ratio $\left(\mathrm{S}_{\mathrm{AR}}\right)$ was as presented in equation 1-b. These ratios are $S_{\text {ole }}$ (obtained by equation 1-c), $S_{\text {sat }}$ (equation 1-d), and $S_{\text {light }}$ (equation 1-e). Yields were obtained by multiplying the above ratios by the mass liquid products (obtained by discounting the amount of n-hexane, not reacted).

\begin{tabular}{|c|c|c|}
\hline Equation & Parameter in the liquid product & Formula \\
\hline $1-\mathrm{a}$ & Total liquid product, in wt.\% & $\sum A R_{i} \cdot f_{i}+P_{j}$ \\
\hline $1-b$ & Aromatic fraction $\mathrm{S}_{\mathrm{AR}}$ & $\frac{\sum A R_{i} \cdot f_{i}}{\sum A R_{i} \cdot f_{i}+P_{j}}$ \\
\hline $1-c$ & $\begin{array}{l}\text { Olefin fraction } S_{\text {ole }} \\
\text { Having more than six carbons }\end{array}$ & $\frac{\sum \text { Olefin }_{j}}{\sum A R_{i} \cdot f_{i}+P_{j}}$ \\
\hline $1-d$ & $\begin{array}{l}\text { Heavy saturated hydrocarbon } \\
\text { fraction, } S_{\text {sat }}\end{array}$ & $\frac{\sum \text { Saturated Hydrocarbons }(c \geq 5)_{j}}{\sum A R_{i} \cdot f_{i}+P_{j}}$ \\
\hline $1-e$ & $\begin{array}{l}\text { Light (saturated and olefin) } \\
\text { hydrocarbon fraction containing } \\
\text { four and less carbons Slight }\end{array}$ & $\frac{\sum \text { Hydrocarbons }(c \leq 4)_{j}}{\sum A R_{i} \cdot f_{i}+P_{j}}$ \\
\hline
\end{tabular}

The gas products composition $\left(\mathrm{H}_{2}, \mathrm{CO}, \mathrm{CO}_{2}\right.$ methane, and hydrocarbon up to $\mathrm{C}_{4}$ ) were analyzed on-line using an Agilent Technologies Micro-GC 490. The amount of gas produced during the reaction was determined by the difference of water displaced during the reaction and the one in pure nitrogen flow (always quantified before reaction). The gas composition obtained was estimated using the average of 5 injections made on-line during time on stream of the reaction.

The amount of coke in the spent catalysts was determined through thermogravimetric analysis (Netzsch TG-IRIS). The samples were heated, under helium atmosphere, from 35 to $250^{\circ} \mathrm{C}$ at a rate of $10^{\circ} \mathrm{C} \mathrm{min}^{-1}$ under $\mathrm{N}_{2}$ atmosphere. The temperature was kept at $250^{\circ} \mathrm{C}$ for $30 \mathrm{~min}$, after which the atmosphere was changed to synthetic air $\left(20.9 \% \mathrm{O}_{2}\right.$ in $\left.\mathrm{N}_{2}\right)$

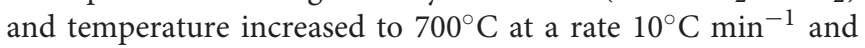
afterwards it stayed on an isotherm for $30 \mathrm{~min}$. The amount of coke in the catalyst corresponded to the weight lost at temperatures higher than $250^{\circ} \mathrm{C}$ and the coke yield was estimated comparing this value (considering the amount of catalyst in each reaction) to the total feed introduced into the reactor.

The 1,2:3,5-di-O-isopropylidene- $\alpha$-D-xylofuranose (DX) was synthesized through the reaction of $D$-xylose (98.5\%, VETEC, $20 \mathrm{~g}$ ) with acetone (99\%, VETEC, $400 \mathrm{~mL}$ ) in the presence of sulfuric acid (P.A., VETEC, $16 \mathrm{~mL}$ ). The reaction was carried out at $0^{\circ} \mathrm{C}$ and under mechanic stirring. The sulfuric acid was slowly added to the xylose/acetone suspension to avoid any changes to the mixture temperature. Once all acid was added, the mixture was stirred for $5 \mathrm{~h}$ at $0^{\circ} \mathrm{C}$, and then a solution of $\mathrm{NaOH}$ (50 wt.\%) was added until pH of 5. Complete neutralization was obtained with sodium bicarbonate (VETEC). After neutralization, the solution was filtered and all acetone removed under vacuum. The remaining liquid was dissolved in ethyl acetate (99\%, VETEC) and the organic phase washed with distilled water. The solvent from the organic phase was removed under vacuum and the remaining liquid was dissolved in $\mathrm{n}$-hexane (VETEC 99\%). The part that was insoluble in $\mathrm{n}$-hexane was discarded. $\mathrm{N}$-hexane was then evaporated to obtain pure DX, which was weight (yield around 25\%) and dissolved once more in n-hexane to obtain the mixtures used in the reactions (10 and $30 \mathrm{wt} . \%$ in n-hexane). This mixture was kept at $5^{\circ} \mathrm{C}$ to avoid n-hexane evaporation and DX degradation. The purity of the final compound was verified after each batch synthesis, through GCMS analysis.

\section{RESULTS AND DISCUSSION \\ Catalyst Characterization Used in the Fixed Bed Test}

Fresh and modified USY by thermal treatment and silication are presented in Table 2. The thermal treatment in steam at $500^{\circ} \mathrm{C}$ slightly reduced both BET and external area compared to the USY precursor. The silication process of the USY-D500 (USY-D500-Silica) produced further decreases in the textural properties. Figure $2 \mathrm{~A}$ shows typical type IV isotherms (IUPAC classification) of USY zeolite, with the occurrence of hysteresis cycle in the range of relative pressures $0.45<\mathrm{P} / \mathrm{P}_{0}<0.95$ associated with capillary condensation which occurs in mesopores. The X-ray diffraction, Figure 2B, confirms the presence of $\mathrm{Y}$ zeolite based on Crystallography Open Database (COD). 
TABLE 2 | Properties of USY, USY-D500, and USY-D500-Silica.

\begin{tabular}{|c|c|c|c|c|c|c|c|c|}
\hline Catalyst & $A_{\text {BET }}\left(m^{2} g^{-1}\right)$ & $A_{\text {ext. }}\left(m^{2} g^{-1}\right)$ & Micro. vol. $\left(\mathrm{cm}^{3} / \mathrm{g}\right)$ & XRD int. $2 \Theta=23.8^{\circ \star \star}$ & $\mathrm{Si} / \mathrm{Al}_{\mathrm{NMR}}$ & EFAL \%* & Silica \%* & $\mathrm{Si} / \mathrm{Al}$ XPS \\
\hline USY & 627 & 67 & 0.26 & 100 & 8.7 & 15 & 4.3 & 1.2 \\
\hline USY-D500 & 597 & 64 & 0.25 & 85 & 14.5 & 40 & 7.6 & 1.0 \\
\hline USY-D500-Silica & 522 & 53 & 0.21 & 77 & 12.7 & 41 & 11.8 & 1.1 \\
\hline
\end{tabular}

${ }^{\star} \mathrm{Al}$ as EFAL species and Si as amorphous silica are presented in molar \% of aluminum and silica respectively, from MAS-NMR.

${ }^{\star *}$ Normalized using USY as $100 \%$.

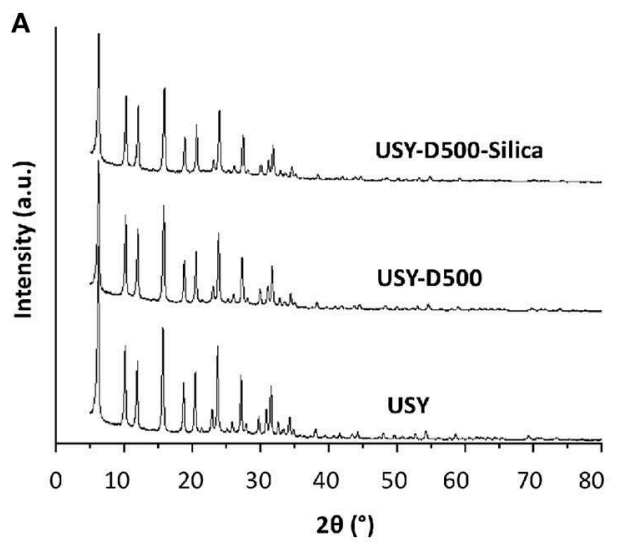

C

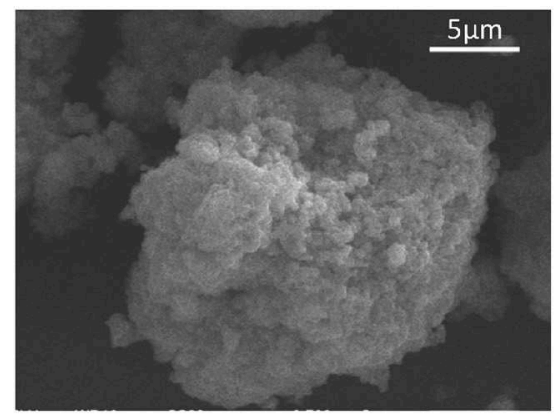

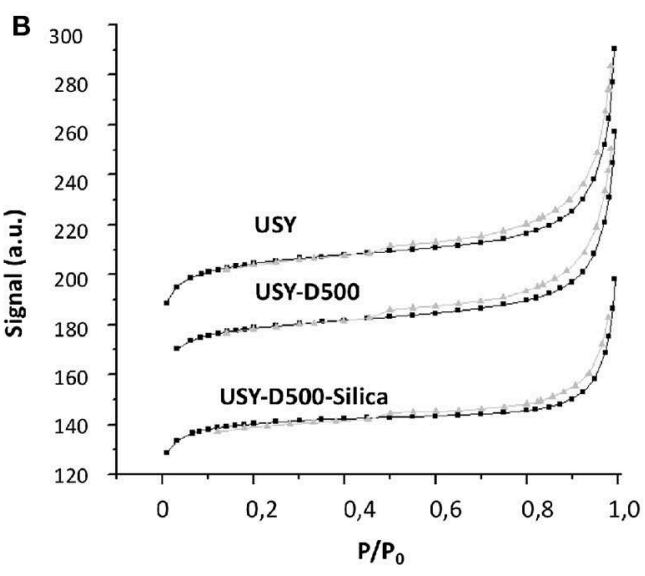

D

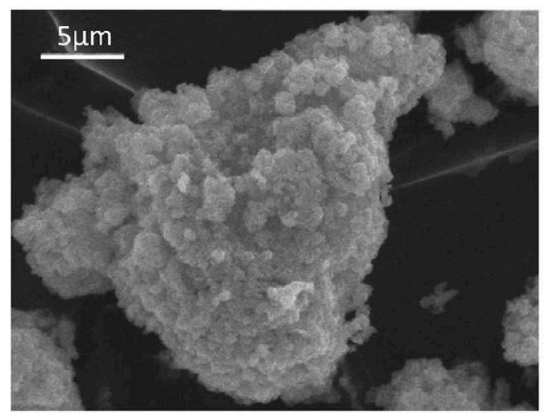

FIGURE 2 | (A) XRD diffraction, (B) nitrogen isotherm for USY, USY-D500, and USY-D500-silica, (C) SEM of USY, and (D) SEM of USY-D500-Silica.

The XRD intensity was estimated based on the peak at $2 \Theta=$ $23.8^{\circ}$, this signal decreased to both USY-D500 and USY-D500Silica. Additionally, both USY and USY-500-silica showed very similar SEM microscopy (Figures 2C,D, respectively), thus the silication did not aggregate the zeolite crystals.

The ${ }^{27} \mathrm{Al}$ RMN-MAS spectra for all catalysts, Figure 3, shows 3 signals with maxima at approximately 60, 30, and 0 ppm for all USY catalysts. These values are related to framework $\mathrm{Al}^{\mathrm{IV}}$, extra-latent $\mathrm{Al}^{\mathrm{VI}}$ sites with distorted symmetry and extra framework Al, EFAL (Moreno and Poncelet, 1997; Lisboa et al., 2008; Agostini et al., 2010), respectively. USY-500-silica and USY-500 catalysts showed similar intensity of both extra-latent and EFAL and higher than USY catalyst. The ${ }^{29}$ Si MAS-NMR spectrum, Figure 3, showed signals -110, -104, -97, and -92 ppm and the number of aluminum coordinated with silica is indicated in Figure 3B. The former is assigned to an amorphous silica phase this signal increased after thermal treatment (USY-D500) compared to USY. Thermal treatment decreased the framework aluminum, thus increasing the SAR and also increased the amount of amorphous silica on USY-D500 compared with USY. The USY-D500-Silica catalyst showed an increase in the amorphous silica but similar SAR compared to USY-D500.

The Si/Al molar ratio estimated by XPS was also presented in Table 2. This value decreased from USY to USY-D500, thus suggest that the amount of aluminum increased in the outer surface of the catalyst, most probably as extra framework aluminum species (EFAL) formed during the hydrothermal treatment. By adding silica (USY-D500silica), the $\mathrm{Si} / \mathrm{Al}$ ratio increased compared to USY-D500 confirming that siliceous species are located in the outer surface of the catalyst. The quantification of total acidity was estimated based on the total ammonium desorption as presented in Figure S4, USY, USYD500, and USY-D500-silica showed 1399, 799, and $669 \mu \mathrm{mol}$ of $\mathrm{NH}_{3} \mathrm{~g}_{\text {cat }}^{-1}$. Hence, these 

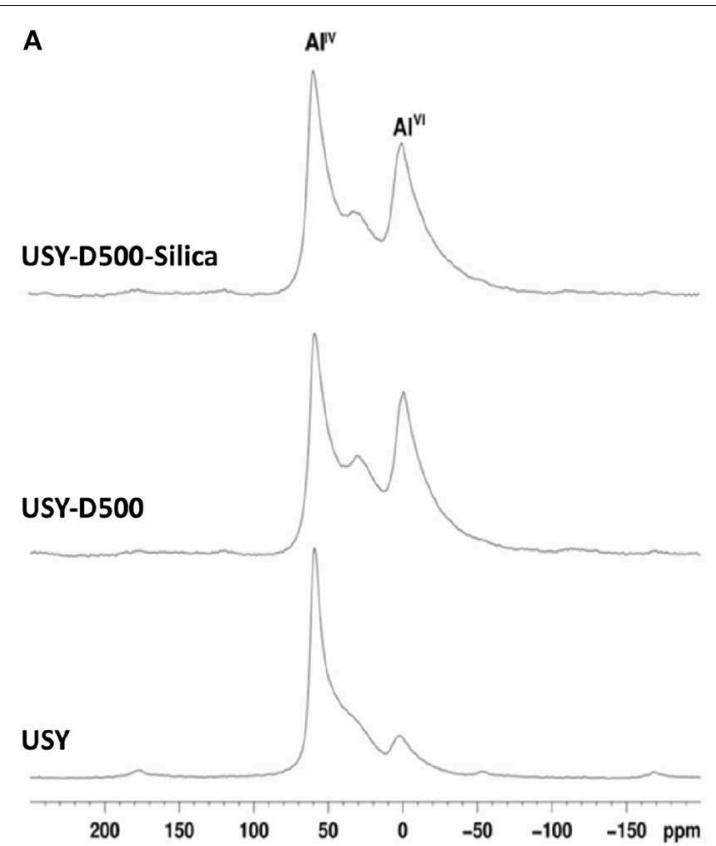

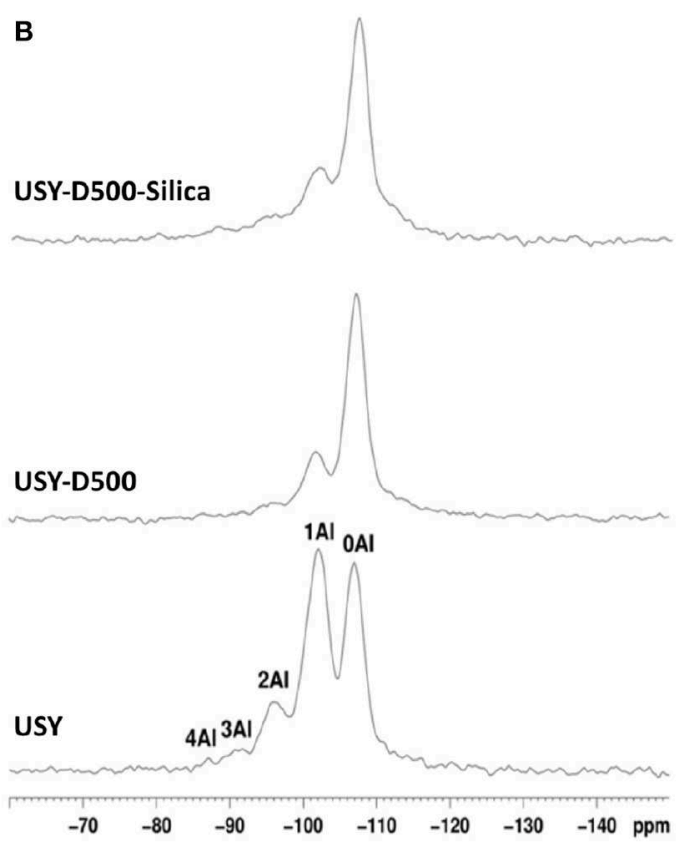

FIGURE 3 | MAS-NMR spectra obtained for the catalysts studied. (A) ${ }^{27}$ Al MAS-NMR; (B) ${ }^{29}$ Si MAS-NMR (the areas of ${ }^{27}$ Al MAS-NMR signals are listed in Table S2, whereas the areas of ${ }^{29}$ Si MAS-NMR signals are listed in Table S3).

TABLE 3 | n-hexane cracking in differential conditions in the presence of USY catalysts used in the fixed bed tests.

\begin{tabular}{lccccc}
\hline Catalyst & $\begin{array}{c}\text { Rate }_{\mathbf{n}-\mathbf{c 6}} \\
\left(\mathbf{m m o l} / \mathbf{g}_{\text {cat }} \text { min) }\right.\end{array}$ & $\begin{array}{c}\text { Conv }_{\mathbf{n}-\mathrm{C6}} \\
\mathbf{( \% )}\end{array}$ & $\begin{array}{c}\text { Propylene/ } \\
\text { propane }\end{array}$ & $\begin{array}{c}\text { TOF } \\
\mathbf{m i n}^{\mathbf{1}}\end{array}$ & $\begin{array}{c}\text { Total } \\
\text { olefin/paraffin }\end{array}$ \\
\hline USY & 2.00 & 9.8 & 1.1 & 1.15 & 1.11 \\
USY-D500 & 0.81 & 3.9 & 1.6 & 0.74 & 1.37 \\
USY-D500Silica & 0.46 & 2.5 & 2.3 & 0.29 & 1.45 \\
\hline
\end{tabular}

results confirm the intended modifications that the USY was submitted.

The n-hexane cracking was carried out in differential condition (low conversion, n-hexane/ catalyst ratio 1.18 and in the presence of $10 \mathrm{mg}$ of catalyst), as presented in Table 3. The differential condition is sensitive to catalysts acidity, and a remarkable reduction (higher than 2-fold) was observed after thermal treatment of the catalysts. Further reduction was observed in the presence of USY-D500-silica compared to USYD500. The TOF (Frequency of turnover), Table 3, was calculated based on the quantity of the framework aluminum calculated by NMR, that is, corresponding to the Brønsted sites. Roughly USY, USY-D500 showed similar TOF values (around 1), but TOF decreased $75 \%$ in the USY 500-D00Silica compared to USY. This reduction is much higher when compared to the decreased in BET area and should be related to lower accessibility of n-hexane caused by the external porous blocking by siliceous species.

n-Hexane cracking in differential conditions produces exclusively light hydrocarbons (Guisnet and Pinard, 2018) as presented in a simplified reaction pathway in Figure 4. After the protolytic reaction (Kotrel et al., 2000) (in low conversion and differential conditions) n-hexane is converted into molecular propylene/propane, ethylene/butanes and ethane/butenes ratios close to one. Higher rate of hydrogen transfer reaction decreases the olefin concentration (Miyaji et al., 2015) and both propylene/propane and total light olefins/total light paraffins (in wt.\%) ratio may be used to indicate the hydrogen transfer (HT) reaction. Both ratios increased from USY to USY-D500 and further increased were observed to USY-D500-Silica. As the USY catalyst is gave much higher conversion; we would only compare USY-D500 with USY-D500-Silica to avoid the conversion effect on the extent of secondary reaction of hydrogen transfer. But in this case, we observed that the silicate USY had a large increase in olefin/paraffin ratio, more than expected.

\section{Co-conversion of $10 \% \mathrm{DX}$ in $\mathrm{n}$-Hexane in Fixed Bed Reactor}

The material balances of the fixed bed tests, given by the sum of the gas, liquid, and coke fractions were higher than $94 \%$ (as presented in Table S1). The product yields distribution were hence normalized (each product was divided by the sum of all weights) as presented in Table 4.

Pure n-hexane showed the highest conversion in the presence of the USY catalyst, conversion decreased for the remaining catalysts. The decrease is consistent with the catalysts features as previously discussed. In the presence of $10 \mathrm{wt} \% \mathrm{DX}$, the n-hexane conversion decreased similarly in both USY and USY-D500, by $\sim 10 \%$. Yet higher decrease was observed for USY-D500-Silica catalyst $\sim 20 \%$. In contrast, DX is almost fully converted in all tests, so its conversion not being sensitive to the 


\section{Primary Products}

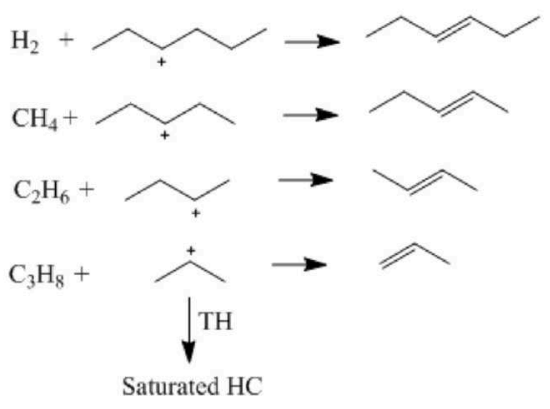

Sequential reactions of olefins (ex: ethene)

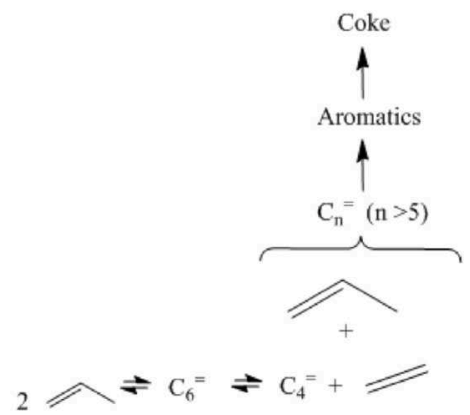

FIGURE 4 | n-Hexane conversion into hydrocarbons, primary products are hydrogen, methane, light hydrocarbons up to 6 carbons (paraffins and olefins), secondary products involves a combination of several reactions, for instance olefins condensation produces larger olefins which can be sequentially converted to aromatics and coke.

TABLE 4 | Gas, liquid, and coke yield for fixed bed catalytic test using pure n-hexane and DX 10 wt.\%.

\begin{tabular}{|c|c|c|c|c|c|c|}
\hline \multirow[t]{2}{*}{ Catalyst } & \multirow[t]{2}{*}{ Feed } & Gas & Liquid & Coke & \multirow[t]{2}{*}{ Conv $\mathrm{nC}_{6}(\%)$} & \multirow[t]{2}{*}{ Conv. DX (\%) } \\
\hline & & \multicolumn{3}{|c|}{ Normalized wt\% } & & \\
\hline \multirow[t]{2}{*}{ USY } & $n-C_{6}$ & 35.5 & 62.5 & 2.1 & 41 & - \\
\hline & $10 \% \mathrm{DX}$ & 29.5 & 66.5 & 4.1 & 30 & 100 \\
\hline \multirow[t]{2}{*}{ USY-D500 } & $n-C_{6}$ & 27.9 & 70.9 & 1.2 & 29 & - \\
\hline & $10 \% \mathrm{DX}$ & 19.9 & 76.9 & 3.2 & 20 & 100 \\
\hline \multirow[t]{2}{*}{ USY-D500Silica } & $n-C_{6}$ & 25.2 & 74.2 & 0.7 & 30 & - \\
\hline & $10 \% \mathrm{DX}$ & 13.5 & 83.5 & 3.0 & 11 & 98 \\
\hline
\end{tabular}

modification in the USY properties. n-Hexane demands highly active catalytic sites (Haag et al., 1984; Narbeser et al., 1995), and the presence of DX could decrease the amount of available sites for $n$-hexane, thus suggest that the competition between $\mathrm{n}$-hexane and DX put n-hexane at disadvantage.

The gas yield of pure $n$-hexane followed the behavior of $n$ hexane conversion, i.e., gas yield was higher in the presence of catalyst USY and decreased to similar values for the remaining catalysts. For the cracking of $10 \%$ DX in n-hexane, the yield of gaseous products slightly decreased compared to the cracking of pure $n$-hexane. In the presence of all catalysts the decrease in gas yield correlated with the decrease in the n-hexane conversion. The amount of $\mathrm{CO}$ and $\mathrm{CO}_{2}$, produced from $\mathrm{DX}$ are up to approximately $20 \mathrm{wt} . \%$.

Coke in spent catalyst is produced by several consecutive reactions (Cerqueira et al., 2000, 2005; Bayraktar and Kugler, 2002; Occelli, 2002; Reyniers et al., 2002), coke amount in wt.\% of total products reduced as the activity of the catalyst was reduced, such as by thermal treatment. USY-D500-silica catalyst produced less coke. Coke increased roughly 2 wt. \% by converting 10 wt.\% DX in $\mathrm{n}$-hexane in the presence of all catalyst, thus deactivation did not affect the conversion of DX into coke in fixed bed reactor.
Yet, it is interesting to point out that in the MAS-NMR and XPS results indicate that the USY-D500Silica contained siliceous species that may be covering some EFAL. With less accessible Lewis sites, coke formation may be reduced compared to USY-D500 catalyst as Lewis sites can improve coke formation (Humphries et al., 1993).

The n-hexane and DX experiments were carried out in the presence of $0.5 \mathrm{~g}$ of catalyst and a $\mathrm{n}$-hexane/catalyst ratio close to 3.6 , as we aim to the verify the performance of the catalyst in full DX conversion.

Hydrogen and methane are produced in small amounts when converting pure $n$-hexane. With the addition of DX, n-hexane conversion decreased, hydrogen production also decreased and in contrast methane increased. Hydrogen and methane are produced from protolysis of $\sigma \mathrm{C}-\mathrm{H}$ and $\mathrm{C}-\mathrm{C}$ and bonds, respectively as presented in Figure 4, thus producing a carbenium ion that originates a catalytic cycle (Louis et al., 2010). It is important to point out that DX is more active than nhexane, as in all tests it was fully converted. As methane did not follow the decreased in the n-hexane conversion, DX could contribute to methane, like for example by the protolytic reaction of isopropylidene groups.

The DX deoxygenates produce $\mathrm{CO}$ and $\mathrm{CO}_{2}$, also carbon dioxide are almost double of carbon monoxide in all tests. A higher concentration of $\mathrm{CO}_{2}$ compared to $\mathrm{CO}$ indicates that less carbon (from DX) is loosed during the decarbonization and the decarboxylation process. These products increased from USY to less active catalyst. This behavior is related to lower $\mathrm{n}$-hexane conversion, thus the relative concentration of $\mathrm{CO}$ and $\mathrm{CO}_{2}$ increased.

The main products of $n$-hexane are light olefins and saturated hydrocarbons. The former are more reactive than n-hexane and can undergo sequential reaction like hydrogen transfer reaction, alkylation, cyclization, producing a broad type of products. For instance, aromatics were produced in the presence of high amount of catalyst and absent in the n-hexane cracking in differential conversion. Thus, the propylene/propane ratio decreased 3 -fold in these experiments compared to the 
TABLE 5 | Selectivity (Wt.\%) of the gaseous products for USY, USY 500, and USY 500-Silica*.

\begin{tabular}{llcccccc}
\hline & & $\mathbf{H}_{\mathbf{2}}$ & $\mathbf{C H}_{\mathbf{4}}$ & $\mathbf{C O}$ & $\mathbf{C O}_{\mathbf{2}}$ & $\mathbf{C}_{\mathbf{3}} / \mathbf{C}_{\mathbf{3}}$ & Olef/sat \\
\hline \multirow{2}{*}{ USY } & Hexane & 0.05 & 0.9 & - & - & 0.34 & 0.31 \\
\multirow{3}{*}{ USY 500 } & 10\% DX & 0.02 & 1.1 & 1 & 2.2 & 0.43 & 0.37 \\
& Hexane & 0.04 & 0.6 & - & - & 0.47 & 0.40 \\
\multirow{2}{*}{ USY 500Silica } & Hexane & 0.03 & 0.8 & - & - & 0.55 & 0.48 \\
& 10\%DX & 0.02 & 1.7 & 2.3 & 4 & 0.69 & 0.55 \\
\hline
\end{tabular}

${ }^{\star}$ Detail gas products in Table $\mathbf{S 4}$.

ones carried out in differential conditions. On DX and nhexane test condition the propylene/propane ratio for pure $\mathrm{n}$-hexane was 0.3 , as propylene is consumed in sequential reaction, this ratio slightly increased to 0.47 in the presence of USY-D500. Less active catalyst decreases hydrogen transfer reaction, as fewer acid sites are available for sequential reactions. The propylene/propane and olefin/total saturated hydrocarbons ratios increased for DX and n-hexane mixture compared to pure n-hexane to both USY and USY-D500 (Table 5). Further increase is observed in the presence of USY-D500-Silica compared to USY-D500.

The increased in light olefins selectivity in the presence of the less active catalyst and particularly in the presence of DX is discussed considering that these products are related exclusively to $\mathrm{n}$-hexane then included the contribution of DX. The olefin/paraffin ratio and n-hexane conversion showed opposite tendencies and as the conversion of nhexane also decreases in the presence of DX prevents a more conclusive analysis. However, the effect in olefins formation taking into consideration that DX is present in small amounts could be related to some contribution of DX to these products or a mutual interaction between DX and n-hexane. Related to the latter proposition the olefin/paraffin ratio could be affected by decreasing olefins consumption (for instance by a competition with acid sites with oxygenated compounds), or by increasing olefin production due to hydrogen transfer reaction (between the hydrocarbon and the oxygenated derivatives).

The liquid yield is affect by mainly two features, non-reacted n-hexane and amount of aromatics. The liquid yield decreased with $\mathrm{n}$-hexane conversion. It was lowest for USY, as this was a more active catalyst, and was highest in conversion of DX in n-hexane over USY-D500-Silica, Figure 5.

The liquid fraction was analyzed qualitatively to verify oxygenate compounds (GCMS) and quantitatively for hydrocarbons (GCFID). As explained in the experimental section the reaction products are grouped by class and the focus here was to show that DX is mainly transformed to aromatics (Table 6). Pure n-hexane converted in the presence of USY produced mainly saturated hydrocarbons (in the liquid fraction light hydrocarbons are solubilized and paraffin and olefins up to seven carbons were observed) followed by a significant amounts of aromatics. The mixture of $10 \mathrm{wt} \% \mathrm{DX}$ converted in the presence of USY more than doubled the aromatic/total liquid

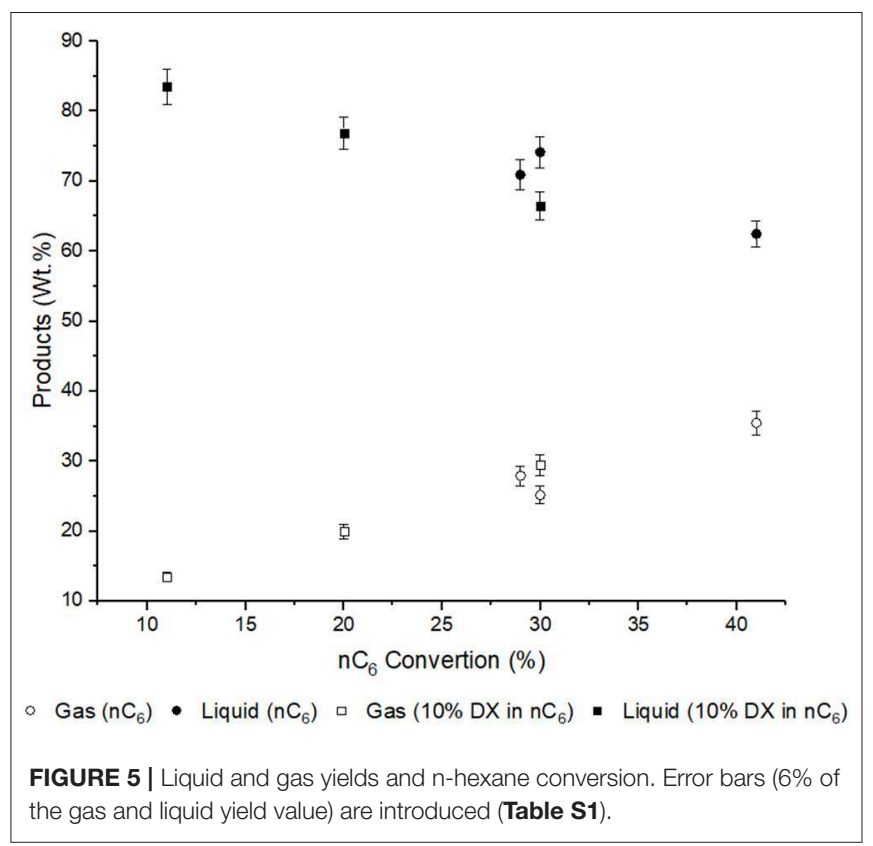

TABLE 6 | Aromatic selectivity, percentage of n-hexane conversion for the cracking tests with pristine $n$-hexane and for the mixture of $10 \% \mathrm{DX}$ in $n$-hexane.

\begin{tabular}{lcccccc}
\hline & \multicolumn{2}{c}{ USY } & \multicolumn{2}{c}{ USY-D500 } & \multicolumn{2}{c}{ USY-D500-Silica } \\
\hline $\mathrm{S}_{\mathrm{Ar}} \%$ & 29 & 57 & 22 & 41 & 32 & 51 \\
$\mathrm{AR}$ yield \% & 1.4 & 3.8 & 2.9 & 4.6 & 4.0 & 8.2 \\
$\mathrm{DX}$ conv. \% & - & 97 & - & 97 & - & 95 \\
$\mathrm{nC}_{6}$ conv. \% & 41 & 30 & 29 & 20 & 30 & 11 \\
\hline
\end{tabular}

products compared to pure n-hexane. This marked increase in aromatics when DX in n-hexane was used instead of pure n-hexane was observed for all other zeolites. This indicates a strong tendency in generating aromatics from DX.

When converting DX and n-hexane in the presence of USY-D500 catalyst the aromatic/total liquid products decreased around $30 \%$ compared to USY. Aromatics are secondary products of $\mathrm{n}$-hexane and produced from cyclization, hydrogen transfer and light olefins re-conversion. Thus, fewer aromatics are produced in the presence of a less active catalyst. Similar explanations could be applied for the decrease in aromatics from USY to USY-D500Silica observed in conversion of DX and n-hexane mixture.

But from the XPS and MAS-NMR results: the effect of blocking some EFAL sites and reducing diffusivity due to silication could increase bimolecular reaction thus enhancing aromatic production of USY D500-Silica compared to USY-D500.

The yield of each aromatic compound is presented in Figure 6. n-Hexane produced mainly, toluene and xylene regardless the catalyst. In general similar aromatic distributions are observed for USY and USY-D500 while USY-D500-Silica enhance benzene and three-methyl-benzene. Further, the aromatic distribution is quite similar to n-hexane and DX n-hexane mixture. 


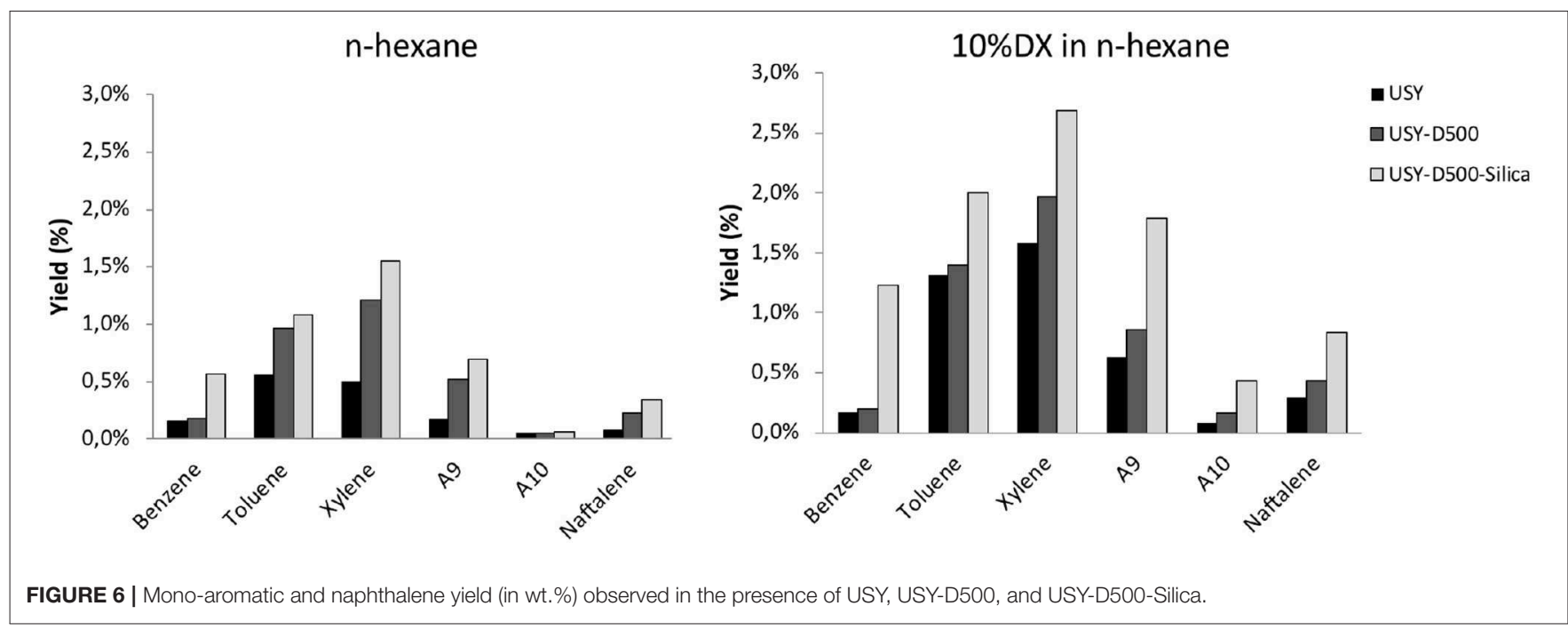

The modification of USY by thermal treatment combined with silication leads to significant change in the catalyst properties compared to fresh catalyst that resulted in a improvement in green aromatic yields (higher than 2-fold). However, coke formation from DX was apparently less affected by the type of catalyst, al least by converting $10 \mathrm{wt}$.\% DX in $\mathrm{n}$-hexane in fixed bed tests.

In short, $\mathrm{Y}$ zeolite converted efficiently DX, a model compound of the bio-crude, mainly into a liquid product in particular aromatics. Also, part of DX left as light gases, CO, $\mathrm{CO}_{2}$, and coke. The gas and coke decreased while the aromatic liquid product increased when the activity of USY was reduced. To explore these results in selectivity for applications, we have to reduce more drastically the activity of the USY and increase the catalyst to feed ratio. The later to ensure maximum removal of the oxygenated groups. Hence, we resort to using a fluidized bed reactor and real commercial FCC catalyst containing USY zeolite. Testing the adequately hydrothermally treated FCC catalyst in fluidized bed indeed bring us to a regime close to conditions in FCC in industrial practice.

\section{Conversion DX in n-Hexane Under Fluidized Catalytic Cracking Conditions With Deactivated Commercial FCC Catalyst}

Herein we demonstrate an example of DX and n-hexane conversion in a typical condition. A mixture of $30 \mathrm{wt} . \%$ of DX in n-hexane was converted by a commercial FCC catalyst fresh [Cat or hydrothermally treated at $720^{\circ} \mathrm{C}($ Cat D)]. The properties of the commercial FCC catalyst are presented in Table 7, and XRD for both catalysts are presented in Figure S5.

The material balance of the fluidized catalytic cracking is obtained as in the fixed bed test and was in the range of 91-106. The products yields were done by normalizing the coke, gas and liquid fractions to $100 \%$, likewise in the fixed bed test.

Pure n-hexane showed the highest conversion with fresh Cat and decreased with deactivated catalyst (Cat D) as expected
TABLE 7 | Properties of the FCC commercial catalyst, Cat as provided by FCC S.A.

\begin{tabular}{ll}
\hline Properties & \\
\hline Area BET $\left(\mathrm{m}^{2} / \mathrm{g}\right)$ & 250 \\
Density $\left(\mathrm{gL}^{-1}\right)$ & 0.82 \\
Pore volume $\left(\mathrm{mL} \mathrm{g}^{-1}\right)$ & 0.35 \\
$\mathrm{Re}_{2} \mathrm{O}_{3}$ (wt.\%) & 0.54 \\
$\mathrm{Al}_{2} \mathrm{O}_{3}$ (wt.\%) & 59.2 \\
$\mathrm{Fe}($ wt.\%) & 0.62 \\
$\mathrm{Na}($ wt.\%) & 0.31 \\
$\mathrm{P}_{2} \mathrm{O}_{5}$ (wt.\%) & 0.07
\end{tabular}

TABLE 8 | Conversion of $n$-hexane and DX and global product distribution in the fluidized bed test using pure $\mathrm{n}$-hexane and DX 30 wt.\%.

\begin{tabular}{|c|c|c|c|c|c|c|c|}
\hline & \multirow[t]{2}{*}{ Feed } & \multicolumn{3}{|c|}{ Yields wt\% (normalized) } & \multirow{2}{*}{$\begin{array}{l}\text { Coke on cat. } \\
\text { (wt. \%) }\end{array}$} & \multirow{2}{*}{$\begin{array}{c}\text { Conv. } \mathrm{nC}_{6} \\
(\%)\end{array}$} & \multirow{2}{*}{$\begin{array}{l}\text { Conv. } \\
\text { DX (\%) }\end{array}$} \\
\hline & & Gas & Liquid & Coke & & & \\
\hline \multirow[t]{2}{*}{ Cat } & $\mathrm{n}-\mathrm{C}_{6}$ & 29 & 70 & 6.6 & 2.1 & 40 & - \\
\hline & $30 \%$ DX & 30 & 60 & 13.2 & 4.6 & 32 & 99.7 \\
\hline \multirow[t]{2}{*}{ Cat D } & $\mathrm{n}-\mathrm{C}_{6}$ & 9 & 90 & 1.8 & 0.6 & 19 & - \\
\hline & $30 \%$ DX & 23 & 78 & 3.9 & 1.4 & 11 & 99.6 \\
\hline
\end{tabular}

(Table 8). In mixture with 30\% DX, n-hexane decreased 20\% in conversion reacting on fresh catalyst and this decrease was notably more drastic on Cat D.

Thus, n-hexane conversion was affected by the type of the catalyst and DX. In contrast, DX was almost fully converted in all tests. The more drastic decrease in n-hexane conversion in the case of mixture with DX over deactivated catalyst suggest that DX was more successful in competing for the active sites of the catalysts than $\mathrm{n}$-hexane.

The conversion of pure $n$-hexane with fresh Cat produced high amount of coke. Further increase in the coke yield 
TABLE 9 | Hydrogen, methane, $\mathrm{CO}, \mathrm{CO}_{2}$, propylene/propane, and light olefins/light paraffins ratios (in wt.\% of total gas) in the presence of Cat and Cat D.

\begin{tabular}{llllllcc}
\hline Catalyst & Feed & $\mathbf{H}_{\mathbf{2}}$ & $\mathbf{C H}_{\mathbf{4}}$ & $\mathbf{C O}$ & $\mathbf{C O}_{\mathbf{2}}$ & $\begin{array}{c}\text { Propylene/ } \\
\text { propane }\end{array}$ & $\begin{array}{c}\text { Olefin/ } \\
\text { paraffin }\end{array}$ \\
\hline Cat & n-hexane & 0.1 & 3.4 & 0.0 & 0.0 & 0.33 & 0.41 \\
& 30\% DX & 0.1 & 6.4 & 5.0 & 6.0 & 0.58 & 0.68 \\
Cat D & n-hexane & 0.1 & 3.0 & 0.0 & 0.0 & 0.38 & 0.47 \\
& 30\% DX & 0.1 & 11.2 & 12.0 & 10.0 & 1.67 & 2.03 \\
\hline
\end{tabular}

was observed by converting the mixture of 30 wt.\% of DX in $\mathrm{n}$-hexane. High coke yield is a consequence of excessive reconversion of the products and a fresh catalyst did not represent a typical FCC condition. Thus, after hydrothermal treatment, Cat D obtained gave 3-fold decrease in coke yield. At any rate, considering this coke yield is from test using a laboratory reactor, it was remarkably and encouragingly low comparing to values presented in Table 1. More discussions will be put forward later.

Methane, hydrogen, $\mathrm{CO}, \mathrm{CO}_{2}$, propylene/propane and olefins/paraffins ratios are presented in Table 9 and the detail gas products in Table S5. Pure n-hexane produced low hydrogen and methane in both Cat and Cat-D. Both tests showed similar hydrogen, methane and propylene/propane ratio. The methane and propylene/propane ratio doubled when converting 30 wt.\% DX in n-hexane compared to pure n-hexane in the presence of Cat. In the presence of Cat D these properties increased 4-fold compared to pure n-hexane. These results support that DX contributed to methane and light olefins formation, similarly as observed in the fixed bed tests. The $\mathrm{CO} / \mathrm{CO}_{2}$ ratio was close to one while in the fixed bed tests was around 0.5 .

The amount of oxygen contained in both $\mathrm{CO}$ and $\mathrm{CO}_{2}$ was estimated for Cat and Cat D as 20 and 30\%, respectively. The amount of gas products in the DX and n-hexane mixture was discounted from $\mathrm{CO}$ and $\mathrm{CO}_{2}$ and also considering that n-hexane behaves equally when pure and mixture with DX. Firstly, DX contributes to light hydrocarbons in the gas phase and mainly to light olefins, judging by the increased in the olefins in the presence of DX and as sequentially presented in Figure 7.

The liquid fraction is separated into six main classes as presented in Table 10. The aromatic/total liquid products ratio $\mathrm{S}_{\mathrm{Ar}}$ increased 6-fold by converting $\mathrm{DX}$ and n-hexane in the presence of Cat compared to pure n-hexane, and further increase was observed in the presence of Cat D. By contrast, the fraction of light saturated hydrocarbons decreased in converting DX and $\mathrm{n}$-hexane in the presence of Cat compared to pure n-hexane, and further decrease was observed in the presence of Cat D. Nonaromatic was produced in low amount in all tests. Light products decreased 2-and 4-folds in the presence of DX for Cat and Cat $\mathrm{D}$, respectively. Acetone was detected and quantify whenever DX was being transformed. Finally non-identified compounds were recorded in the presence of DX. In short, the outstanding observation in the liquid fraction was the high contents in aromatic products. The aromatic distribution is presented in

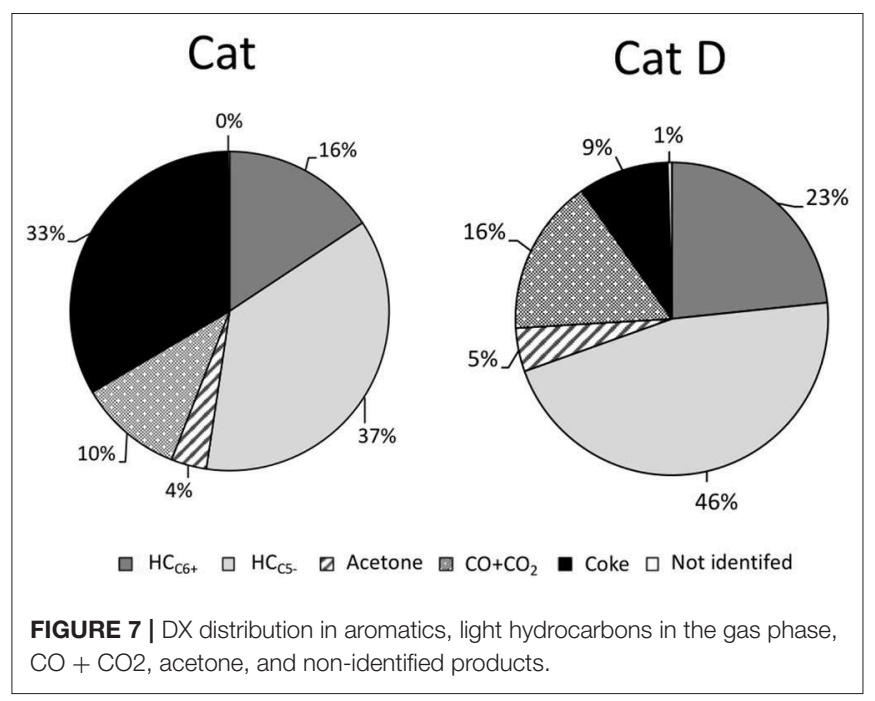

TABLE 10 | Liquid products distribution with Cat and Cat D.

\begin{tabular}{|c|c|c|c|c|}
\hline \multirow[t]{2}{*}{ Class/total products } & \multicolumn{2}{|c|}{ Cat } & \multicolumn{2}{|c|}{ Cat D } \\
\hline & $n-C_{6}$ & $\begin{array}{c}30 \% \text { DX in } \\
\text { n-hexane }\end{array}$ & $n-C_{6}$ & $\begin{array}{c}30 \% \text { DX in } \\
\text { n-hexane }\end{array}$ \\
\hline $\mathrm{S}_{\mathrm{Ar}} \%$ & $7 \%$ & $41 \%$ & $6 \%$ & $56 \%$ \\
\hline $\mathrm{S}_{\text {nonAr }} \%$ & $4 \%$ & $6 \%$ & $9 \%$ & $6 \%$ \\
\hline$S_{\text {light }}\left(\mathrm{C5}^{-}\right) \%$ & $89 \%$ & $39 \%$ & $84 \%$ & $22 \%$ \\
\hline $\mathrm{S}_{\text {Heavy }} \%$ & $0 \%$ & $3 \%$ & $0 \%$ & $3 \%$ \\
\hline SAcetone \% & $0 \%$ & $6 \%$ & $0 \%$ & $6 \%$ \\
\hline$S_{\text {Noidentified } \%}$ & $0 \%$ & $11 \%$ & $0 \%$ & $12 \%$ \\
\hline n-hexane conv. \% & $40 \%$ & $32 \%$ & $19 \%$ & $11 \%$ \\
\hline
\end{tabular}

TABLE 11 | Aromatic distribution with Cat and Cat D.

\begin{tabular}{lcccccc}
\hline & \multicolumn{3}{c}{ Cat } & & \multicolumn{2}{c}{ Cat D } \\
\cline { 2 - 3 } \cline { 5 - 6 } \cline { 5 - 6 } & n-hexane & $\mathbf{3 0 \%} \mathbf{~ D X}$ & & n-hexane & 30\% DX \\
\hline Benzene & 1.2 & 5.7 & & 0.0 & 7.0 \\
Toluene & 1.2 & 18.0 & & 3.4 & 22.9 \\
Xylene & 4.2 & 13.7 & & 2.8 & 21.3 \\
3Mbenzene & 0.8 & 3.8 & & 0.0 & 5.0 \\
4Mbenzene & 0.0 & 0.0 & & 0.0 & 0.0 \\
Naftalene & 0.0 & 2.8 & & 0.4 & 2.9 \\
\hline
\end{tabular}

Table 11 and in all cases the main products were xylene and toluene followed by $\mathrm{C}_{3}$-phenyl, benzene and naphthalene.

\section{Considerations on Potential in Co-processing This New Feed With Gasoil The Coke Issue}

The coke in the spent Cat D showed a value similar to a typical spent FCC catalyst converting hydrocarbon feed (in general around 1-1.5 wt.\%). This value is remarkably lower compared to pyrolysis bio-crude converted in the presence of an acid catalyst 
in typical cracking conditions (Fogassy et al., 2011; Graça et al., 2013; Pereira and Benoit, 2013).

A commercial FCC unit operates in the temperature range of $500-535^{\circ} \mathrm{C}$ and the reaction occurs within short contact times, i.e., 3 to $7 \mathrm{~s}$ (Haag et al., 1984; O'Connor, 2007). In our tests for Cat and Cat D, the catalyst/feed ratio was three times lower and the contact time was $60 \mathrm{~s}$. These condition are regularly applied in laboratory fluidized units and increasing the coke yield up to 3 -folds compared to the FCC unit operating in typical condition (Occelli, 2002; Cerqueira et al., 2005). Hence, the coke yield of $1.4 \%$ is expected to show further reduction in a FCC unit- to an unprecedented low value, most probably similar to those observed for hydrocarbon feed like heavy gasoil. This scenario supports that biocrude based on ketal-sugar derivative could be co-converted in higher concentration with gasoil. In contrast, the co-process of pyrolysis oil in FCC increases coke and gas compared to hydrocarbons (Table 1). Also, lower carbon is incorporated in the final products (around $20-30 \%$ ) and phenol derivatives and not fully converted (Pinho et al., 2015). Thus limits the amount of this bio-feed around $10 \mathrm{wt} . \%$ during coprocess with gasoil feed in the FCC process (Pinho et al., 2015).

\section{Bio-Crude to Hydrocarbon: Carbon-Hydrogen Efficiency, Example From DX}

For a first approach, the products yields from DX were estimated assuming that n-hexane behaves equally when pure or mixed with DX. Hence, the contribution of $n$-hexane could be subtracted from total product based on the observed conversion of $\mathrm{n}$-hexane and the product distribution when it is converted pure. The results are presented in Figure 7. They are grouped into green hydrocarbons containing six or more carbons, $\mathrm{C}_{6+}$ (aromatics, naphthalene, olefins and paraffins); hydrocarbons containing five or less carbons, $\mathrm{C}_{5-}$ (methane, paraffin, and mainly olefins); acetone, $\mathrm{CO}+\mathrm{CO}_{2}$, non-identified compounds and coke.

In the presence of fresh catalyst $53 \%$ of DX was converted into green hydrocarbon $\left(\mathrm{C}_{6+}+\mathrm{C}_{5-}\right)$ and $1 / 3$ of $\mathrm{DX}$ was converted to coke. Besides acetone, $\mathrm{CO}$ and $\mathrm{CO}_{2}$ were formed. The green hydrocarbons in carbon and hydrogen bases of DX are estimated dividing 53 by 65 ( $35 \mathrm{wt} . \%$ of DX is oxygen) and resulted in $81 \%$. In the presence of a more representative catalyst of a typical FCC process, coke yield remarkably decreased (almost 4 -folds), and around of $69 \mathrm{wt} . \%$ of DX was converted into green hydrocarbons $\left(\mathrm{C}_{6+}+\mathrm{C}_{5-}\right)$. This value is similar to the carbon and hydrogen contents in the DX (65 wt.\%).

To interpret the above findings we noted, first, that higher green hydrocarbons yield were observed for both fresh and deactivated catalysts than expected since a considerable amount of carbon from DX was loss as coke, $\mathrm{CO}$ and $\mathrm{CO}_{2}$.

Second, it is important to point out that the hypothesis of DX distribution into products was done assuming that $\mathrm{n}$ hexane behaves equally when converted pure or during coprocess. Bimolecular reactions like alkylation, condensation and hydrogen transfer reaction are well-documented in hydrocarbon chemistry (Watson et al., 1997; Miyaji et al., 2015). For co-feeding DX and $\mathrm{n}$-hexane, DX is more reactive than $\mathrm{n}$-hexane and could de assumed to convert first. Then $n$-hexane (or its products) could undergo reactions with products from DX. For instance, the presence of DX could increase the hydrogen transfer reaction between $\mathrm{n}$-hexane (or its products) and products derived from DX. This scenario could enhance the contribution of $n$-hexane to light olefins and aromatics during co-process.

Thus, on one hand, higher amount of carbon from DX is converted into hydrocarbons but the assumptions for the previous calculation of $\mathrm{C}-\mathrm{H}$ efficiency are rough approximations. On the other hand, the possibilities that of the co-processed hydrocarbon participating in the overall conversion motivates further studies on the effect of the co-feed hydrocarbon and catalyst properties. Higher amount of bio-feed maybe able to be co-processed and better product slates may be obtained.

It is also important to point out some consideration on the reaction pathway of DX into aromatics. Olefins selectivity increase in the presence of DX. Therefore, the inter-conversion of olefins could respond partially to the aromatic formation, likewise in hydrocarbon chemistry (Liu et al., 2014). However, we cannot rule out a direct conversion of DX into aromatic without go through light olefins. A detailed work devoted to mechanism has yet to be performed in further works.

\section{A Consideration on the Operation and Results of the Two Different Tests: FB and FCC}

It is opportune to compare the results obtained using the simple fixed bed tests (FB) with that of the fluidized bed tests (FCC), even though it is not our intention to compare the operations of the two different units with distinct running conditions. Table 12 below first summarizes the operational parameters of the two tests, FB and FCC. We would like to point particularly the advantage of the FCC: that one could operate with a high catalyst to feed ratio. Hence, one obtains results from catalysts that are much less active per unit mass. If one uses the same catalyst to feed ratio in the present FB set up, diffusional and pressure drop problem will be encountered using powder catalysts.

First, from the fixed bed tests we observed that $\mathrm{Y}$ zeolites are effective in transforming DX into useful products, especially benzene, toluene and xylene, with only small generation of coke. More interesting is the observation that the less active the USY zeolite, more selective it is for aromatics and produces less light gases. The tendency of yielding less coke is observed, but it is not very sensitive to the properties of the catalyst for the samples used.

This prompted the use of much less active catalyst for its selectivity. But we still wanted to convert as much DX and remove as much oxygenates as possible. Using the FCC reactor one compensated the conversion of the low activity catalyst by increasing its amount (which was no longer constrained). As a consequence of both of these factors, as shown in Table 12, very high amount in aromatics and low coke yield was attained with almost complete conversion of DX. Needless to say, this test condition can be more readily related to industrial applications.

\section{On Catalysts Deactivation and Optimization}

The deactivated catalyst (Cat D) still fully transformed all DX in the feed, so it was reasonably active. However, a significant amount of light hydrocarbons and acetone were found. Yet, it was important to point out in this specific test that the catalyst 
TABLE 12 | A brief comparison between the operational parameters and results on DX conversion for the fixed bed (FB) and fluidized bed (FCC) tests.

\begin{tabular}{|c|c|c|c|}
\hline & Fixed bed: FB & Fluidized bed: FCC & Observations \\
\hline \multicolumn{4}{|l|}{ On operational parameters } \\
\hline Feed rate in DX & $0.34 \mathrm{~g} / \mathrm{g}$ cat min & $0.36 \mathrm{~g} / \mathrm{g}$ cat $\mathrm{min}$ & Similar \\
\hline $\mathrm{T}^{\circ}$ and pressure & $500^{\circ} \mathrm{C}$, atmospheric & $450-500^{\circ} \mathrm{C}$, atmospheric & Similar \\
\hline $\begin{array}{l}\text { Catalyst/ feed ratio ( } \mathrm{g} / \mathrm{g} \text { relative } \\
\text { to DX) }\end{array}$ & $\begin{array}{l}0.2 \text { (Diffusion and pressure drop } \\
\text { problem if increased) }\end{array}$ & $\begin{array}{l}3 \text { (Cat/feed ratio } 5 \text { or above } \\
\text { routinely practiced) }\end{array}$ & Advantage for FCC \\
\hline Execution time & Short, $3 \mathrm{~h}$ per sample & One day per sample & Advantage for FB \\
\hline Material balance & Satisfactory & Satisfactory & Similar \\
\hline \multicolumn{4}{|l|}{ On dx conversion, findings } \\
\hline Performance of $Y$ zeolite & $\begin{array}{l}\text { Near total conversion of } 10 \% \text { DX in } \\
\text { n-hexane }\end{array}$ & $\begin{array}{l}\text { Near total conversion of } 30 \% \text { DX in } \\
\text { n-hexane }\end{array}$ & $\begin{array}{l}\text { FCC confirmed FB on the efficiency of } \\
\text { Y zeolite in converting DX }\end{array}$ \\
\hline Aromatics in liquid & Indication of DX increase aromatics & Marked increase in presence of DX & FCC clear confirmation of FB results \\
\hline Major aromatics & Benzene, toluene and xylenes & Benzene, toluene and xylenes & Confirmation of results \\
\hline Selectivity in coke & Not clear due to catalyst variation & Decrease in less active catalyst & FCC: more information \\
\hline Gas amount and composition & $\begin{array}{l}\mathrm{CH}_{4} \text { increased, } \mathrm{CO} \text { and } \mathrm{CO}_{2} \\
\text { formed with } \mathrm{DX} \text { feed }\end{array}$ & $\begin{array}{l}\text { Same observation, but the } \mathrm{CO} / \mathrm{CO}_{2} \\
\text { ratio varied }\end{array}$ & $\begin{array}{l}\text { The difference in } \mathrm{CO}_{2} / \mathrm{CO} \text { ratio still } \\
\text { has to be interpreted }\end{array}$ \\
\hline \multirow[t]{2}{*}{ Sensitive to catalyst properties } & \multicolumn{3}{|c|}{ Both showed sensibility to catalyst properties, such as acidity } \\
\hline & \multicolumn{3}{|c|}{ Additional results of variations due to different zeolites recorded in FB (de Souza et al., 2017) } \\
\hline
\end{tabular}

to oil ratio was only $<2.5$ (since $20 \mathrm{~g}$ of catalyst was used for $10 \mathrm{ml}$ feed, taking the density of the feed as $0.8 \mathrm{~g} / \mathrm{ml}$.) while in typical FCC operation in practice, the catalyst to oil ratio was easily above 5 . That is, there is a lot of room to operate the deactivated catalyst to further convert light olefins, acetone and most probably, the non-identified products that could be oxygenated intermediates.

Moreover, the tests showed that the transformation of DX and n-hexane mixtures are responsive to the catalyst properties. Indeed, the catalyst activity could still be increased by changing the catalyst composition, such as the amount of zeolites and zeolite type. Besides, there is a competition for an acid site in the presence of a less active catalyst (in the co-cracking). Two points deserve consideration. Firstly nhexane is a product of the FCC process and not converted in the presence of an equilibrium FCC catalyst, thus remarkable less reactive than large hydrocarbons. Thus, for converting DX in the presence of a gasoil feed composed of larger hydrocarbons it is expected less decrease in the gasoil conversion by the presence of DX. Secondly, mixtures of DX and light hydrocarbons could be used itself as a process for producing green-hydrocarbons, thus light hydrocarbons (like n-hexane) should be used as a solvent for DX in the presence of less active catalyst. Further, we would also point out a different consideration in the mode of operation for producing light olefins and/or aromatics thanks to the flexibility and adjust the reactivity of DX to be transformed in typical FCC process.

\section{CONCLUSION}

The present work is a proof of concept that biomass can be converted into green hydrocarbon, in typical refinery conditions, by using the approach of protective reaction.
Using a fixed bed reactor, Y zeolite showed efficient conversion of a model compound of bio-crude, DX. The gas and coke decreased while the aromatic liquid product increased when the activity of USY was reduced. Aromatics were the main product.

These results were confirmed and extended to a regime close to conditions in FCC in industrial practice. Mixtures of DX (up to 30 wt.\%) in n-hexane, were converted by fresh and deactivated commercial FCC catalysts in fluidized process. The deactivated catalyst increased the green hydrocarbons products and decreased coke yield compared to the fresh one. DX was mainly converted into green aromatic and light hydrocarbon (mainly olefins) yet gave only a very small amount of coke in the presence of a deactivated catalyst.

The test also showed that the transformations of DX and n-hexane mixtures were responsive to the catalyst properties. Thus, it is expected that catalyst will play a key role in further improving the conversion of sugar-ketal derivatives in the refinery.

\section{DATA AVAILABILITY STATEMENT}

All datasets generated for this study are included in the article/Supplementary Material.

\section{AUTHOR CONTRIBUTIONS}

JP made the catalytic tests in fixed bed and fluidized bed, the calculations, and the development of the article. IP carried out tests in the fixed bed. CL performed n-hexane cracking tests. RS performed and interpreted the NMR analyzes. YL assisted the interpretation of the results. MP writes the manuscript and manages the work. 


\section{FUNDING}

The authors declare that this study received funding from Coordenação dos programa de pós graduação (CAPES), conselho nacional de desenvolvimento (CNPq), and Fundação Carlos Chagas Filho de Amparo à Pesquisa do Rio de Janeiro (FAPERJ). CAPES and CNPq by providing scholarships to JP and IP, and FAPERJ (E-26/010001516-24) by providing partially funds to the project. The funders had no role in study design, data

\section{REFERENCES}

Adjaye, J. D., and Bakhshi, N. N. (1995). Production of hydrocarbons by catalytic upgrading of a fast pyrolysis bio-oil. Part II: comparative catalyst performance and reaction pathways. Fuel Proc. Technol. 45, 185-202. doi: 10.1016/0378-3820(95)00040-E

Agostini, G., Lamberti, C., Palin, L., Milanesio, M., Danilina, N., Xu, B., et al. (2010). In situ XAS and XRPD parametric rietveld refinement to understand dealumination of Y zeolite catalyst. JACS 132, 667-678. doi: 10.1021/ja907696h

Batalha, N., Pinto, J., Ferreira, H., Baptista, D. C., Miranda, L. S. M., and Pereira, M. M. (2016). Biohydrocarbons production under standard refinery conditions by means of a representative ketal compound of biocrude. Energy Technol. 5, 428-441. doi: 10.1002/ente.201600313

Batalha, N., Silva, A. V. D., Souza, M. O. D., Costa, B. M. C. D., Gomes, E. S., Silva, T. C., et al. (2014). Gasoline from biomass through refineryfriendly carbohydrate-based bio-oil produced by ketalization. ChemSusChem 7, 1627-1636. doi: 10.1002/cssc.201301242

Bayraktar, O., and Kugler, E. L. (2002). Characterization of coke on equilibrium fluid catalytic cracking catalysts by temperature-programmed oxidation. Appl. Cataly. A Gen. 233, 197-213. doi: 10.1016/S0926-860X(02)00142-4

Bulushev, D. A., and Ross, J. R. H. (2011). Catalysis for conversion of biomass to fuels via pyrolysis and gasification: a review. Cataly. Today 171, 1-13. doi: 10.1016/j.cattod.2011.02.005

Cerqueira, H. S., Ayrault, P., Datka, J., and Guisnet, M. (2000). Influence of coke on the acid properties of a USHY zeolite. Micro Mesopor. Mater. 38, 197-205. doi: 10.1016/S1387-1811(99)00304-2

Cerqueira, H. S., Caeiro, G., Costa, L., and Ribeiro, F. R. (2008). Deactivation of FCC catalysts. J. Mol. Catal. A Chem. 292, 1-13. doi: 10.1016/j.molcata.2008.06.014

Cerqueira, H. S., Sievers, C., Joly, G., Magnoux, P., and Lercher, J. A. (2005). Multitechnique characterization of coke produced during commercial resid FCC operation. Industr. Eng. Chem. Res. 44, 2069-2077. doi: 10.1021/ie048963k

Conti, J., Holtberg, P., Diefenderfer, J., LaRose, A., Turnure, J. T., and Westfall, L. (2016). International Energy Outlook 2016. USEI Administration, 276. doi: $10.2172 / 1296780$

de Souza, M. O., Garrett, R., Pereira, M. M., and Miranda, L. S. M. (2017). Use of Kappaphycus alvarezii biomass for the production of carbohydrate isopropylidene-ketal-based biocrude. Energy Fuels 31, 9422-9428. doi: 10.1021/acs.energyfuels.7b00765

Durange, J. A. C., de Souza, M. O., Santos, M. R. L., Nele, M., Caramão, E. B., Carvalho, N. M. F., et al. (2015). Valorization of sugar cane bagasse and Jatropha curcas cake: production of a biocrude by acetylation reaction under microwave radiation. Energy Fuels 29, 917-921. doi: 10.1021/ef502598j

Escobar, A., Pereira, M., Pimenta, R., Lau, L., and Cerqueira, H. (2005). Interaction between $\mathrm{Ni}$ and $\mathrm{V}$ with USHY and rare earth $\mathrm{HY}$ zeolite during hydrothermal deactivation. Appl. Catal. A General 286, 196-201. doi: 10.1016/j.apcata.2005.03.002

Ferreira, A. D. F., Maia, A. J., Guatiguaba, B., Herbst, M. H., Rocha, P. T. L., Pereira, M. M., et al. (2014). Nickel-doped small pore zeolite bifunctional catalysts: a way to achieve high activity and yields into olefins. Catal. Today 226, 67-72. doi: 10.1016/j.cattod.2013.10.033

Fogassy, G., Thegarid, N., Schuurman, Y., and Mirodatos, C. (2011). From biomass to bio-gasoline by FCC co-processing: effect of feed composition collection, and analysis, decision to publish, or preparation of the manuscript.

\section{SUPPLEMENTARY MATERIAL}

The Supplementary Material for this article can be found online at: https://www.frontiersin.org/articles/10.3389/fchem. 2019.00720/full\#supplementary-material

and catalyst structure on product quality. Energy Environ. Sci. 4, 5068-5076 doi: $10.1039 / \mathrm{clee} 02012 \mathrm{a}$

French, R., and Czernik, S. (2010). Catalytic pyrolysis of biomass for biofuels production. Fuel Process. Technol. 91, 25-32. doi: 10.1016/j.fuproc.2009.08.011

Garrett, R., Barros, T. G., de Souza, M. O., da Costa, B. M. C., Pereira, M. M., and Miranda, L. S. M. (2015). Unveiling the chemical composition of sugar cane biocrudes by liquid chromatography-tandem mass spectrometry. Energy Fuels 29, 8082-8087. doi: 10.1021/acs.energyfuels.5b02317

Goldthau, A. (2017). The G20 must govern the shift to low-carbon energy. Nature 546, 203-205. doi: 10.1038/546203a

Graça, I., Fernandes, A., Lopes, J. M., Ribeiro, M. F., Laforge, S., Magnoux, P., et al. (2011). Bio-oils and FCC feedstocks co-processing: impact of phenolic molecules on FCC hydrocarbons transformation over MFI, Fuel 90, 467-476. doi: 10.1016/j.fuel.2010.09.028

Graça, I. S., Lopes, J. M., Cerqueira, H. S., and Ribeiro, M. F. (2013). Bio-oils upgrading for second generation biofuels. Ind. Eng. Chem. Res. 52, 275-287. doi: $10.1021 /$ ie $301714 \mathrm{x}$

Guisnet, M., and Pinard, L. (2018). Characterization of acid-base catalysts through model reaction. Cataly. Rev. 60, 337-436. doi: 10.1080/01614940.2018.1446683

Haag, W. O., Lago, R. M., and Weisz, P. B. (1984). The active site of acidic aluminosilicate catalysts. Nature 309, 589-591. doi: 10.1038/309589a0

Huber, G. W., Iborra, S., and Corma, A. (2006). Synthesis of transportation fuels from biomass: chemistry, catalysts and engineering. Chem. Rev. 106, 4044-4098. doi: 10.1021/cr068360d

Humphries, A., Harris, D. H., and O'Connor, P. (1993). Chapter 2 the nature of active sites in zeolites: influence on catalyst performance. Stud. Surface Sci. Cataly. 76, 41-82. doi: 10.1016/S0167-2991(08)63825-2

Jong, W. D., and Ommen, J. R. V. (2015). Biomass as a Sustainable Energy Source for the Future: Fundamentals of Conversion Processes. Hoboken: NJ AIChE Wiley, John Wiley \& Sons, Inc. doi: 10.1002/9781118916643

Kotrel, S., Knozinger, H., and Gates, B. C. (2000). The Haag-Dessau mechanism of protolytic cracking of alkanes. Micro. Mesopor. Mater. 35-36, 11-20. doi: 10.1016/S1387-1811(99)00204-8

Ladanai, S., and Vinterbäck, J. (2009). Global Potential of Sustainable Biomass for Energy. SLU., Swedish University of Agricultural Sciences Department of Energy and Technology, 29.

Langholtz, M. H., Stokes, B. J., and Eaton, L. M. (2016). 2016 Billion-Ton Report: Advancing Domestic Resources for a Thriving Bioeconomy. U.S. Department of Energy, 411.

Lappas, A. A., Samolada, M. C., Iatridis, D. K., Voutetakis, S. S., and Vasalos, I. A. (2002). Biomass pyrolysis in a criculating fluid bed reactor for the production os fuels and chemicals. Fuel 81, 2087-2095. doi: 10.1016/S0016-2361(02) 00195-3

Lisboa, O., Sánchez, M., and Ruette, F. (2008). Modeling extra framework aluminum (EFAL) formation in the zeolite ZSM-5 using parametric quantum and DFT methods. J. Mol. Cataly. A Chem. 294, 93-101. doi: 10.1016/j.molcata.2008.08.003

Liu, D., Choi, W. C., Kang, N. Y., Lee, Y. J., Park, H. S., Shin, C.-H., et al. (2014). Inter-conversion of light olefins on ZSM-5 in catalytic naphtha cracking condition. Cataly. Today 226, 52-66. doi: 10.1016/j.cattod.2013.09.060

Louis, B., Pereira, M. M., Santos, F. M., Esteves, P. M., and Sommer, J. (2010). Alkane activation over acidic zeolites: the first step. Chemistry 16, 573-578. doi: 10.1002/chem.200901737 
Maia, A. J., Louis, B., Lam, Y. L., and Pereira, M. M. (2010). Ni-ZSM-5 catalysts: detailed characterization of metal sites for proper catalyst design. J. Cataly. 269, 103-109. doi: 10.1016/j.jcat.2009.10.021

Mendes, F. L., Ximenes, V. L., de Almeida, M. B. B., Azevedo, D. A., Tessarolo, N. S., and de Rezende Pinho, A. (2016). Catalytic pyrolysis of sugarcane bagasse and pinewood in a pilot scale unit. J. Analyt. Appl. Pyroly. 122, 395-404. doi: 10.1016/j.jaap.2016.08.001

Miyaji, A., Iwase, Y., Nishitoba, T., Long, N. Q., Motokura, K., and Baba, T. (2015). Influence of zeolite pore structure on product selectivities for protolysis and hydride transfer reactions in the cracking of n-pentane. Phys. Chem. Chem. Phys. 17, 5014-5032. doi: 10.1039/C4CP04438J

Moreno, S., and Poncelet, G. (1997). Dealumination of small- and largeport mordenites: a comparative study. Microporous Mater. 12, 197-222. doi: 10.1016/S0927-6513(97)00067-9

Narbeser, T. F., Vinek, H., and Lercher, J. A. (1995). Monomolecular Conversion of light Alkanes over H-ZSM-5, Journal of Cataly. 157, 388-395. doi: $10.1006 /$ jcat.1995.1304

North, M., and Styring, P. (2015). Perspectives and visions on CO2 capture and utilisation. Faraday Discuss 183, 489-502. doi: 10.1039/C5FD90077H

Oasmaa, A., Kuoppala, E., and Solantausta, Y. (2003). Fast pyrolysis of forestry residue. 2. Physicochemical composition of product liquid. Energy Fuels 17, 433-443. doi: 10.1021/ef020206g

Oasmaa, A., and Meier, D. (2005). Norms and standards for fast pyrolysis liquids. J. Analyt. Appl. Pyroly. 73, 323-334. doi: 10.1016/j.jaap.2005.03.003

Occelli, M. (2002). The location and effects of coke deposition in fluid cracking catalysts during gas oil cracking at microactivity test conditions. J. Cataly. 209, 385-393. doi: 10.1006/jcat.2002.3639

O'Connor, P. (2007). "Catalytic cracking: the future of an evolving process," in: Fluid Catalytic Cracking VII: Materials, Methods and Process Innovations, ed M. L. Occelli (Amsterdam: Elsevier B.V.), 227-250. doi: 10.1016/S0167-2991(07)80198-4

O'Connor, P., and Pouwels, A. C. (1994). FCC catalyst deactivation: a review and directions for further research. Stud. Surface Sci. Catal. 88, 129-144. doi: 10.1016/S0167-2991(08)62734-2

Pereira, M. M., and Benoit, L. (2013). "Carbon dioxide, chemical valorization, and mitigation in the refinery," in New and Future Developments in Catalysis: Catalysis for Remediation and Environmental Concerns, ed S. L. Suib (Amsterdam: Elsevier), 535-562. doi: 10.1016/B978-0-444-53870-3.00020-4

Pinho, A. D. R., de Almeida, M. B. B., Mendes, F. L., Ximenes, V. L., and Casavechia, L. C. (2015). Co-processing raw bio-oil and gasoil in an FCC unit. Fuel Process. Technol. 131, 159-166. doi: 10.1016/j.fuproc.2014.11.008

Pinto, J. F., Miranda, L. S. M., and Marcelo, P. M. (2017). "Petroleum refining and oil well drilling," in Problems, Process and Industry Prospects, ed K. F. Olson (New York, NY: Nova Science Publishers), 314.

Questell-Santiago, Y. M., Zambrano-Varela, R., Talebi Amiri, M., and Luterbacher, J. S. (2018). Carbohydrate stabilization extends the kinetic limits of chemical polysaccharide depolymerization. Nat. Chem. 10, 1222-1228. doi: 10.1038/s41557-018-0134-4

Ragauskas, A. J., Williams, C. K., Davison, B. H., Britovsek, G., Cairney, J., Eckert, C. A., et al. (2006). The path forward for biofuels. Science 311, 484-489. doi: $10.1126 /$ science. 1114736

Reyniers, M.-F., Beirnaert, H., and Marin, G. B. (2002). Influence of coke formation on the conversion of hydrocarbons I. Alkanes on a USY-zeolite. Appl. Cataly. A Gen. 202, 49-63. doi: 10.1016/S0926-860X(00)00450-6

Russ, P., and Criqui, P. (2007). Post-Kyoto CO2 emission reduction: the soft landing scenario analysed with POLES and other world models. Energy Policy 35, 786-796. doi: 10.1016/j.enpol.2006.03.010

Saidi, M., Samimi, F., Karimipourfard, D., Nimmanwudipong, T., Gates, B. C., and Rahimpour, M. R. (2014). Upgrading of lignin-derived biooils by catalytic hydrodeoxygenation. Energy Environ. Sci. 7, 103-129. doi: 10.1039/C3EE43081B
Samolada, M. C., Baldauf, W., and Vasalos, I. A. (1998). Production of a bio-gasoline by upgrading biomass flash pyrolysis liquids via hydrogen processing and catalytic cracking. Fuel 77, 1667-1675. doi: 10.1016/S0016-2361(98)00073-8

Serrano-Ruiz, J. C., and Dumesic, J. A. (2011). Catalytic routes for the conversion of biomass into liquid hydrocarbon transportation fuels Energy Environ. Sci. 4, 83-99. doi: 10.1039/C0EE00436G

Sfetsas, T., Michailof, C., Lappas, A., Li, Q., and Kneale, B. (2011). Qualitative and quantitative analysis of pyrolysis oil by gas chromatography with flame ionization detection and comprehensive two-dimensional gas chromatography with time-of-flight mass spectrometry. J. Chromatogr. A 1218, 3317-3325. doi: 10.1016/j.chroma.2010.10.034

Silva, R. V. S., Tessarolo, N. S., Pereira, V. B., Ximenes, V. L., Mendes, F. L., de Almeida, M. B. B., et al. (2016). Quantification of real thermal, catalytic, and hydrodeoxygenated bio-oils via comprehensive two-dimensional gas chromatography with mass spectrometry. Talanta 164:626-635. doi: 10.1016/j.talanta.2016.11.005

Smil, V. (2004). "World history and energy", in Encyclopedia of Energy, ed C. Cleveland (Elsevier), 549-561. doi: 10.1016/B0-12-176480-X/ 00025-5

Talmadge, M. S., Baldwin, R. M., Biddy, M. J., McCormick, R. L., Beckham, G. T., Ferguson, G. A., et al. (2014). A perspective on oxygenated species in the refinery integration of pyrolysis oil. Green Chem. 16, 407-453. doi: 10.1039/C3GC41951G

Thegarid, N., Fogassy, G., Schuurman, Y., Mirodatos, C., Stefanidis, S., Iliopoulou, E. F., et al. (2014). Second-generation biofuels by co-processing catalytic pyrolysis oil in FCC units. Appl. Cataly. B Environ. 145, 161-166. doi: 10.1016/j.apcatb.2013.01.019

Trane, R., Dahl, S., Skjøth-Rasmussen, M. S., and Jensen, A. D. (2012). Catalytic steam reforming of bio-oil. Int. J. Hydrogen Energy 37, 6447-6472. doi: 10.1016/j.ijhydene.2012.01.023

Vispute, T. P., Zhang, H., Sanna, A., Xiao, R., and Huber, G. W. (2010). Renewable chemical commodity feedstocks from integrated catalytic processing of pyrolysis oils. Science 330, 1222-1227. doi: 10.1126/science.11 94218

Vitolo, S., Bresci, B., Seggiani, M., and Gallo, M. G. (2001). Catalytic upgrading of pyrolytic oils over HZSM-5 zeolite: behaviour of the catalyst when used in repeated upgrading-regenerating cycles. Fuel 80, 17-26. doi: 10.1016/S0016-2361(00)00063-6

Vitolo, S., Seggiani, M., Frediani, P., Ambrosini, G., and Politia, L. (1999). Catalytic upgrading of pyrolytic oils to fuel over different zeolites. Fuel 78, 1147-1159. doi: 10.1016/S0016-2361(99)00045-9

Watson, B. A., Klein, M. T., and Harding, R. H. (1997). Catalytic cracking of alkylcyclohexanes: modeling the reaction pathways and mechanisms. Int. J. Chem. Kinetcs 29, 545-560. doi: 10.1002/(SICI)1097-4601(1997)29:7<545::AID-KIN9>3.0.CO;2-U

Wen, B., He, M., and Costello, C. (2002). Simultaneous catalytic removal of NOx, SOx, and CO from FCC regenerator. Energy Fuels 16, 1048-1053. doi: 10.1021/ef010268r

Conflict of Interest: The authors declare that the research was conducted in the absence of any commercial or financial relationships that could be construed as a potential conflict of interest.

Copyright (C) 2019 Pinto, Pedrosa, Linhares, San Gil, Lam and Pereira. This is an open-access article distributed under the terms of the Creative Commons Attribution License (CC BY). The use, distribution or reproduction in other forums is permitted, provided the original author(s) and the copyright owner(s) are credited and that the original publication in this journal is cited, in accordance with accepted academic practice. No use, distribution or reproduction is permitted which does not comply with these terms. 


\section{OPEN ACCESS}

Edited by:

Benoit Louis,

UMR7515 Institut de Chimie et

Procédés pour l'Energie,

l'Environnement et la Santé

(ICPEES), France

Reviewed by:

Tilo Söhnel,

The University of Auckland,

New Zealand

Cristina Megías-Sayago,

Université de Strasbourg, France

*Correspondence:

Ruizhi Chu

4038@cumt.edu.cn

Specialty section:

This article was submitted to

Inorganic Chemistry,

a section of the journal

Frontiers in Chemistry

Received: 20 June 2019

Accepted: 17 October 2019

Published: 06 November 2019

Citation:

Wu J, Meng X, Chu R, Yu S, Wan Y, Song C, Zhang $G$ and Zhao T (2019) Molecular Dynamics Simulation of the Implantation of b-Oriented ZSM-5 Film Modified $\alpha$-Quartz Substrate Surface With Different Modifiers.

Front. Chem. 7:746

doi: 10.3389/fchem.2019.00746

\section{Molecular Dynamics Simulation of the Implantation of $b$-Oriented ZSM-5 Film Modified $\alpha$-Quartz Substrate Surface With Different Modifiers}

\author{
Jiaxin $W u^{1}$, Xianliang Meng ${ }^{1,2}$, Ruizhi Chu ${ }^{1,2 *}$, Shi Yu ${ }^{1}$, Yongzhou Wan ${ }^{1,2}$, \\ Chengcheng Song ${ }^{1}$, Guifeng Zhang ${ }^{1}$ and Tong Zhao ${ }^{1}$ \\ ${ }^{1}$ School of Chemical Engineering and Technology, China University of Mining and Technology, Xuzhou, China, ${ }^{2}$ Key \\ Laboratory of Coal Processing and Efficient Utilization of Ministry of Ministry of Education, Xuzhou, China
}

In this study, we investigated the structure-absorption relationship of common surface modifiers of chitosan (CTS), polyvinyl acetate (PVA), and titanium dioxide $\left(\mathrm{TiO}_{2}\right)$ with $\alpha$-quartz surface using molecular dynamics simulation. And the orientations and combinations derived from structures between modified $\alpha$-quartz and ZSM- 5 crystallites were also investigated. The results show that PVA is a non-linear organic macromolecule with a large amount of hydroxyl groups on its surface, which easily adhere to the surface of the substrate and agglomerate. CTS is a straight-chain structure containing a large number of hydroxyl and amino groups, which easily accumulate and spread on the surface of the substrate. $\mathrm{TiO}_{2}$ not only forms hydrogen bonds and complexes with the substrate but also interacts with each other to form a dense modifier layer. We observed that a large number of stable Ti-O-Si chemical bonds formed between the modified layer of inorganic small-molecule $\mathrm{TiO}_{2}$ and the surface of $\alpha$-quartz, which compacted and stabilized the attached ZSM-5 film. Moreover, the orientation angle of the ZSM-5 nanocrystalline nucleus on the modified $\alpha$-quartz was computed, which confirmed that the $b$-axis orientation of the ZSM- 5 nanocrystalline nucleus was the highest on the surface of the substrate modified by $\mathrm{TiO}_{2}$. We discussed the influence of the modified temperature of modifiers in the constructed materials, and we have observed the adsorption state differences of $\mathrm{TiO}_{2}$ at different modified temperatures. We also discussed the catalytic properties of the materials prepared by the corresponding methods in conversion of methanol-to-aromatics (MTA) reaction. These results agree with our previous experimental data. By employing molecular dynamics simulation, we have obtained more precise conclusive information of the $b$-oriented growth of ZSM- 5 crystallites, which highly depends on the surface modifiers.

Keywords: $b$-oriented ZSM-5 film, modified $\alpha$-quartz, implantation, molecular dynamics simulation, MTA reaction 


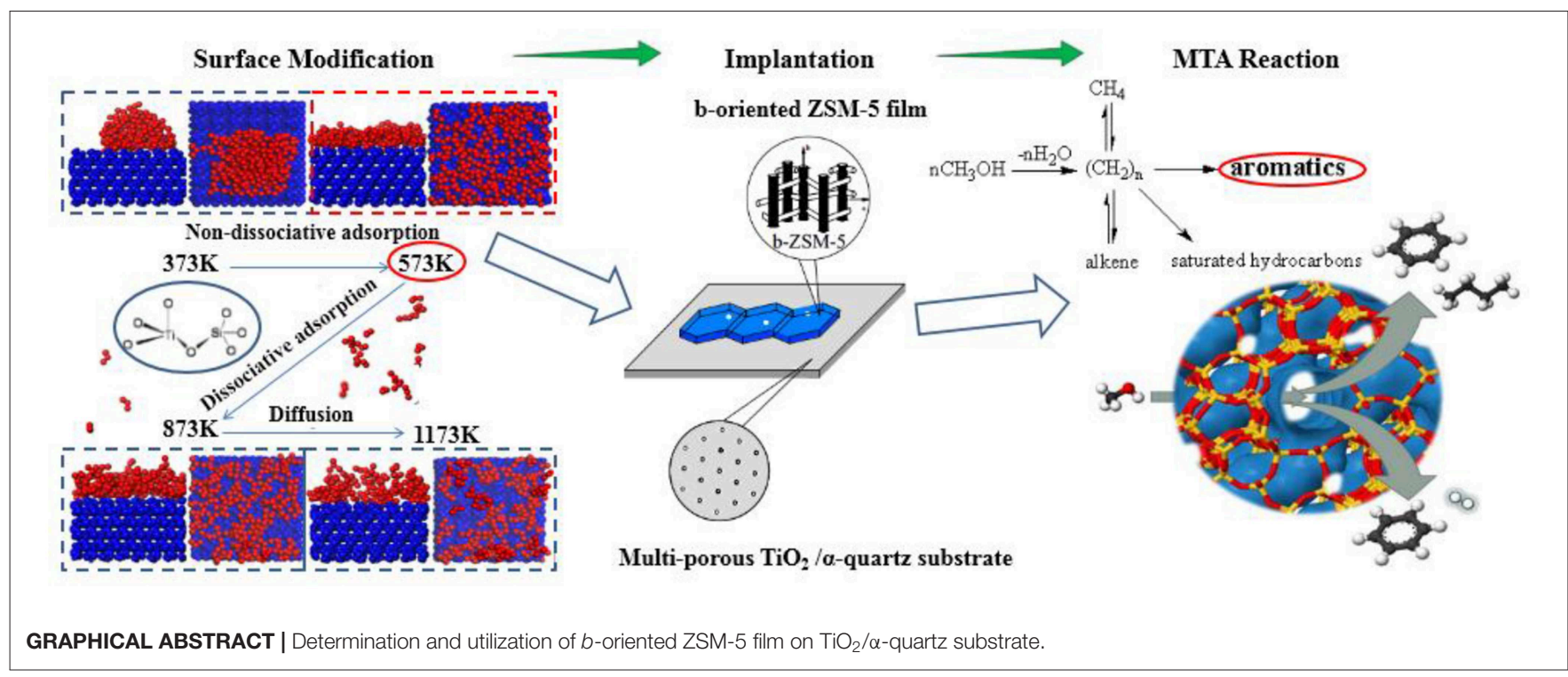

\section{HIGHLIGHTS}

- Model building and optimization of b-oriented ZSM$5 /$ modifiers/substrate film by molecular dynamics simulation. - Effect of orientations and combinations of implantation of $b$ oriented ZSM- 5 film modified $\alpha$-quartz substrate surface with different modifiers.

- $b$-Oriented $\mathrm{ZSM}-5 / \mathrm{TiO}_{2} /$ substrate catalyst significantly improved methanol conversion, aromatic hydrocarbon yield, and lifetime.

\section{INTRODUCTION}

ZSM-5 belongs to the MFI topology zeolite and has a threedimensional pore structure. The growth in the vertical direction is the $b$-axis ZSM-5 (b-ZSM-5) zeolite. The straight-channel structure of the $b$-axis $\left(\begin{array}{lll}0 & 1 & 0\end{array}\right)$ of ZSM-5 enables the molecules to rapidly diffuse in a one-dimensional straight channel, shortening the molecular diffusion path, thereby reducing the possibility of deep side reactions of the product and inhibiting the formation of carbon deposits. ZSM-5 molecular sieves have high stability, have high specific surface area and selective catalytic function, and is often used in methanol-to-aromatics (MTA), methanol-toolefins (MTO), and methanol-to-hydrocarbon (MTH) reactions. Since Feng and Bein (1994) realized the control of molecular sieve crystal orientation for the first time, MFI molecular sieve membranes with $a$-axis orientation, $b$-axis orientation, $c$-axis orientation and composite orientation have been prepared on various carriers by controlling the interaction between carrier and molecular sieve crystal.

Since researchers proposed that the structure and physicochemical properties of the substrate surface would affect the nucleation and growth of molecular sieves (Koegler et al., 1997), they thought that the synthetic liquid would first form a gel layer on the surface of the silicon-rich silicon hydroxyl, and the supersaturation was larger at the interface between the gel layer and the liquid main interface. The nuclei form at the interface between the two phases, and then the crystals grow on the surface of the $b$-axis orientation carrier through hydrogen bonding force to form $b$-axis orientation molecular sieve films. The high orientation molecular sieve materials were obtained by modifying the surface of the substrate with modifiers. Lee et al. (2003) prepared three orientations of pure silicon MFI (silicalite-1) molecular sieve crystal $a-, b$-, and $c$-axes by pre-coating a highly ordered polyurethane film modifier on the glass surface. When the surface groups are randomly oriented polyurethane films, only a randomly oriented silicalite-1 film can be obtained. Obviously, the functional groups and their ordered alignment on the surface of polyimide films are the key to achieving directional guidance and to obtaining ordered alignment of molecular sieve arrays. Lang et al. (2009) synthesized silicalite-1 molecular sieve membrane with $b$-axis orientation on the surface of chitosan (CTS)-modified porous silica-zirconium composite membrane carrier (average pore diameter is $8 \mathrm{~nm}$ ). A silicalite-1 molecular sieve membrane with continuous coverage and $b$-axis orientation formed on the surface of the silica-zirconium composite interlayer modified by soluble carboxymethyl CTS (CMCTS). Wang and Yan (2001) found that the material and roughness of the substrate had a great influence on the orientation of molecular sieve membranes. Silicalite-1 molecular sieve membranes with $b$-axis orientation could be synthesized on polished smooth stainless steel substrates. In summary, the material control of ZSM-5 molecular sieve membranes with high preference in orientation mainly focused on the surface modification of the substrate. The modifiers used for substrate modification are mainly organic and inorganic modifiers. The common organic modifiers are polyvinyl acetate (PVA), CTS, etc. (Wang et al., 2010; Wei et al., 2017), and inorganic modifiers are $\mathrm{TiO}_{2}, \mathrm{SiO}_{2}$, etc. (Liu et al., 2011; Cheng et al., 2014). The surface of PVA has a large number of hydroxyl functional groups, which easily adhere to the 
surface of quartz substrate to form active groups and easily form hydrogen bonds with ZSM-5 nanocrystalline nuclei to promote binding. There are a large number of hydroxyl, amino, and ether bonds on the surface of CTS, which easily form hydrogen bonds with ZSM-5 nanocrystalline nuclei. As a small molecule, $\mathrm{TiO}_{2}$ can form a smooth dressing layer on the surface of the substrate, and various crystal structures formed at different temperatures, which enhances the $b$-axis orientation growth of the seed.

At present, the synthesis of $b$-ZSM-5 composites faces difficulties. Experimental conditions are hard to control accurately for the traditional method. The interface effects of $b$-ZSM-5 molecular sieves, modifier, and substrate cannot be studied in detail. Therefore, the design of new ZSM-5 molecular sieve membrane materials cannot be guided. Molecular dynamics (MD) simulation overcomes the shortcomings of experiments and can simulate the system at atomistic scale. In recent years, many researchers have successfully used MD calculation to explain the interface effect between systems. Yan et al. (2016) simulated the interactions between PVA and poly(methyl methacrylate) (PMMA) on $\alpha$-quartz surface by MD. Liu et al. (2015) studied the adsorption of DDA, ether amine, and AC1210 on $\alpha$-quartz at different acidity and alkalinity by a universal force field (UFF) in MD simulations. MD simulation has been used in the design of composite molecular sieve materials. It has been reported that the epitaxial growth evidence of $\mathrm{ZnO}, \mathrm{Fe}-\mathrm{B}$, and carbon nanotube (Fang et al., 2006; Tarabaev and Esin, 2007; Sharma et al., 2015) can be well-explained by MD simulation, and the results are basically consistent with the experiment. Brinkmann et al. (2011) has focused on the interfacial effects between ZSM-5 and quartz with different gap sizes by MD simulation.

In this work, we attempt to design a model system to investigate the thermodynamic behaviors of $b$-ZSM- 5 implanted on the surface of $\alpha$-quartz substrate with organic and inorganic modifiers (PVA, CTS, and $\mathrm{TiO}_{2}$ ) at a molecular level. Equilibrium all-atom MD simulations were used to study the whole system in vacuum. Mean square displacement (MSD), diffusion coefficient, relative concentration distribution, and hydrogen bonds were analyzed to investigate the preplantation mechanisms of $b$-ZSM5 on the surface of modified $\alpha$-quartz, and the orientation angle (Zeng Y. Q. et al., 2015) between $b$-ZSM-5 and modified substrate is also calculated to explain the orientation degree between $b$ ZSM-5 and the substrate surface. Our long-term goal is to fully understand the binding between $b$-ZSM-5, modifiers, and $\alpha$ quartz and how the reactive functional groups affect the binding processes, which is vital for the preparation of ZSM-5 catalyst materials designed with high $b$-axis orientation.

\section{MATERIALS AND METHODS}

\section{Material Synthesis}

Preparation of Modified $\alpha$-Quartz

(1) Substrate surface modification

The $\alpha$-quartz sieve from the coal mine of Zhouyuanshan was crushed and then passed through a 200 -mesh sieve. The $\alpha$-quartz powder was calcined in a muffle furnace at $850^{\circ} \mathrm{C}$ for $2 \mathrm{~h}$ and then compression-molded to obtain the raw substrate, before acid treatment that consisted of $15 \% \mathrm{HCl}$ and $\mathrm{H}_{2} \mathrm{SO}_{4}$ with a volume ratio of $1: 1$. The raw substrate was calcined in a muffle furnace at $1,123 \mathrm{~K}$ for $1 \mathrm{~h}$. The side of the $\alpha$-quartz substrate was polished with 1000\#, 1500\#, and 2000\# sandpaper until the surface is smooth, and the $\alpha$-quartz substrate was placed for ultrasonic cleaning for $10 \mathrm{~min}$.

An aqueous solution of 4\% PVA and an acetic acid solution of $0.5 \%$ CTS were used to modify the substrate for several times by the dip-coating method, and then the dip-coating substrate was dried at $333 \mathrm{~K}$ for $12 \mathrm{~h}$. Ethanol sol at $10 \% \mathrm{TiO}_{2}$ was applied to modify the substrate at $373 \mathrm{~K}$ by the sol-gel method, and the modified substrate was dried for $12 \mathrm{~h}$. After $\mathrm{TiO}_{2}$ dip-coating, the substrate was calcined at $573 \mathrm{~K}$.

\section{(2) $b$-ZSM-5 seed layer loading on the modified substrate}

A certain amount of tetrapropylammonium hydroxide (TPAOH) and ionized water was weighed with an Erlenmeyer with stirring, and tetraethyl orthosilicate (TEOS) was slowly added to the mixture solution and aging for $24 \mathrm{~h}$. The precursor was crystallized at a temperature of $450 \mathrm{~K}$ for $80 \mathrm{~min}$, before the growth of the crystal was stopped with quenching treatment. The material prepared was calcined in a tube furnace with air atmosphere for $2 \mathrm{~h}$ at $823 \mathrm{~K}$, and the temperature rise-and-fall rate was $0.5 \mathrm{~K} / \mathrm{min}$.

\section{Material Characterization}

(1) Powder X-ray diffraction (XRD) patterns were recorded with a D8 ADVANCE instrument equipped with a graphite monochromator operating at $40 \mathrm{kV}$ and $150 \mathrm{~mA}$ using $\mathrm{Cu}$ $\mathrm{K} \alpha$ radiation $(\lambda=0.15 \mathrm{~mm})$. The powder diffractograms were recorded at $0.02^{\circ}$ intervals from $5^{\circ}$ to $50^{\circ}$ with a scanning rate of $2^{\circ} / \mathrm{min}$.

(2) The morphology and size of the sample were tested by Hitachi's Su8010 scanning electron microscope (SEM), including the morphology, crystal morphology, and size of the substrate surface. To avoid discharge, the sample was subjected to gold spray treatment before the test.

(3) Bruker's VERTEX 80v model Fourier transform infrared spectroscopy (FTIR) was used to detect the condition of the organic modifier-modified $\alpha$-quartz substrate; because it was organically modified on the surface of the substrate, the total reflection infrared spectroscopy attenuated total reflectance (ATR) test was used with a wavelength range from 600 to $4,500 \mathrm{~cm}^{-1}$.

\section{Simulation Molecule Models}

Potential parameters were taken from Universal, which is parameterized by Johnson et al. (2006). All MD simulations were performed by the program Material Studio (Accelrys). The force field used was of importance in MD simulation. The UFF is an all-atom force field that has parameterizations for every atom of the periodic table with an atomic number lower than 103. The van der Waals interactions are described by the Lennard-Jones potential. Electrostatic interactions are 


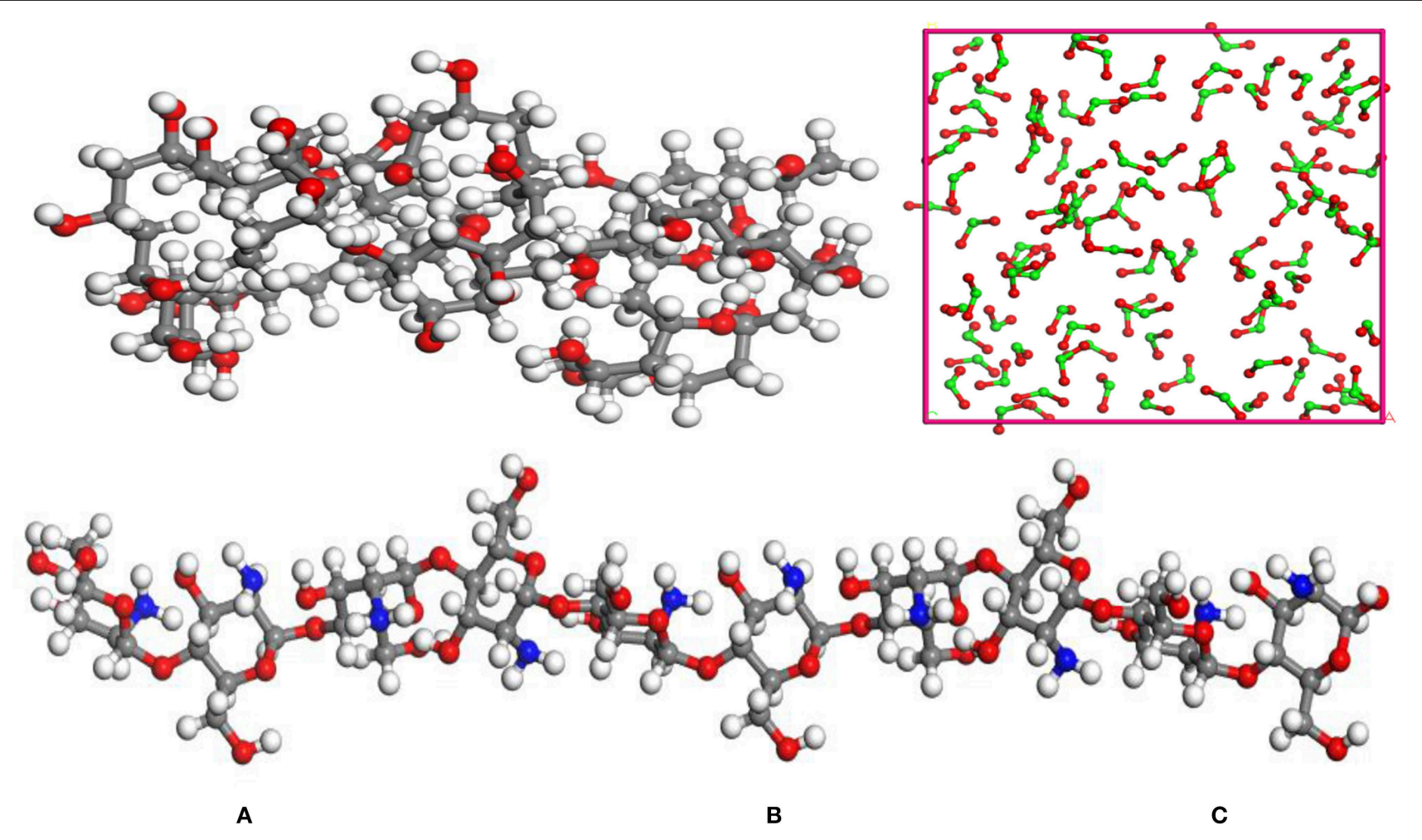

FIGURE 1 | Molecular model of the modifiers: (A) polyvinyl acetate (PVA); (B) chitosan (CTS); (C) TiO 2 (Gray, red, white, and green represent C, O, H, and Ti, respectively).

described by atomic monopoles and a screened (distancedependent) Coulombic term. This force field enables accurate and simultaneous prediction of structural, conformational, and thermophysical properties for silicate compound (Rappe et al., 1992; Froudakis, 2001; Coupry et al., 2017). So UFF is applied to describe the interface and atomic interaction in our simulation. The charge equilibration (QEQ) method is utilized to calculate the charge distributions based on geometry and connectivity throughout the course of the simulation. The ZSM-5 model is derived from the all-silicon MFI molecular sieve that comes from Material Studio (Accelrys). ZSM-5 is designed as a cluster model (Dahl and Kolboe, 1994), retaining the primitive skeleton structure. The suspended silicon atoms are saturated with the hydroxyl group, and the suspended oxygen atoms are saturated with hydrogen atoms. The $\left(\begin{array}{lll}1 & 0 & 0\end{array}\right)$ crystallographic face of $\alpha$-quartz was used to model the solid substrate. To obtain a chemically realistic surface, all the non-bridging oxygen atoms were saturated by $\mathrm{H}$ atom.

$\mathrm{TiO}_{2}, \mathrm{PVA}$, and CTS were modeled by Material Studio software (Accelrys). In order to make the simulation conditions closer to the molecular weight and agglomeration degree of PVA and CTS in the experiment, the agglomeration degrees of PVA and CTS were set to 40 and 10, respectively, and the repeating unit of the $\mathrm{TiO}_{2}$ molecule was set to 100 , which is shown in Figure 1.
Periodic models of PVA, CTS, and $\mathrm{TiO}_{2}$ were constructed at Amorphous Cell module in Material Studio 8.0. In order to increase the modification degree and improve the flatness of the substrate surface, the periodic model consisting of PVA and CTS with one to five repeat units was built. The PVA-and-CTS molecular model was then added over the $\alpha$-quartz surface, and there is a distance of $3 \AA$ maintained between the substrate and the modifiers. In addition, in order to eliminate the effects of the upper structure on the model, a vacuum layer of $10 \mathrm{~nm}$ is placed above the model. First, $100 \mathrm{TiO}_{2}$ molecules were placed on the substrate surface and at a distance of $3 \AA$ was kept between $\mathrm{TiO}_{2}$ and the substrate. Preplanting of ZSM-5 on the modified substrate surface is carried out by placing the $b$-ZSM- 5 on the surface of the modified substrate with a distance of $3 \AA$ between the ZSM-5 and modified substrate.

\section{Simulation Details}

MD simulation for PVA and CTS/substrate: The structure optimization was carried out in the Forcite module to minimize the energy of the system, in which the UFF and the cutoff radius of $12.5 \AA$ were used. MD simulation was carried out in Material Studio 8.0 as follows: at $333 \mathrm{~K}$, with the NVT ensemble and a step size of $1 \mathrm{fs}$ and simulation time of $500 \mathrm{ps}$ using the UFF under the periodic boundary condition.

MD simulation for $\mathrm{TiO}_{2} /$ substrate: The adsorption state of $\mathrm{TiO}_{2}$ on the substrate surface at different temperatures is 


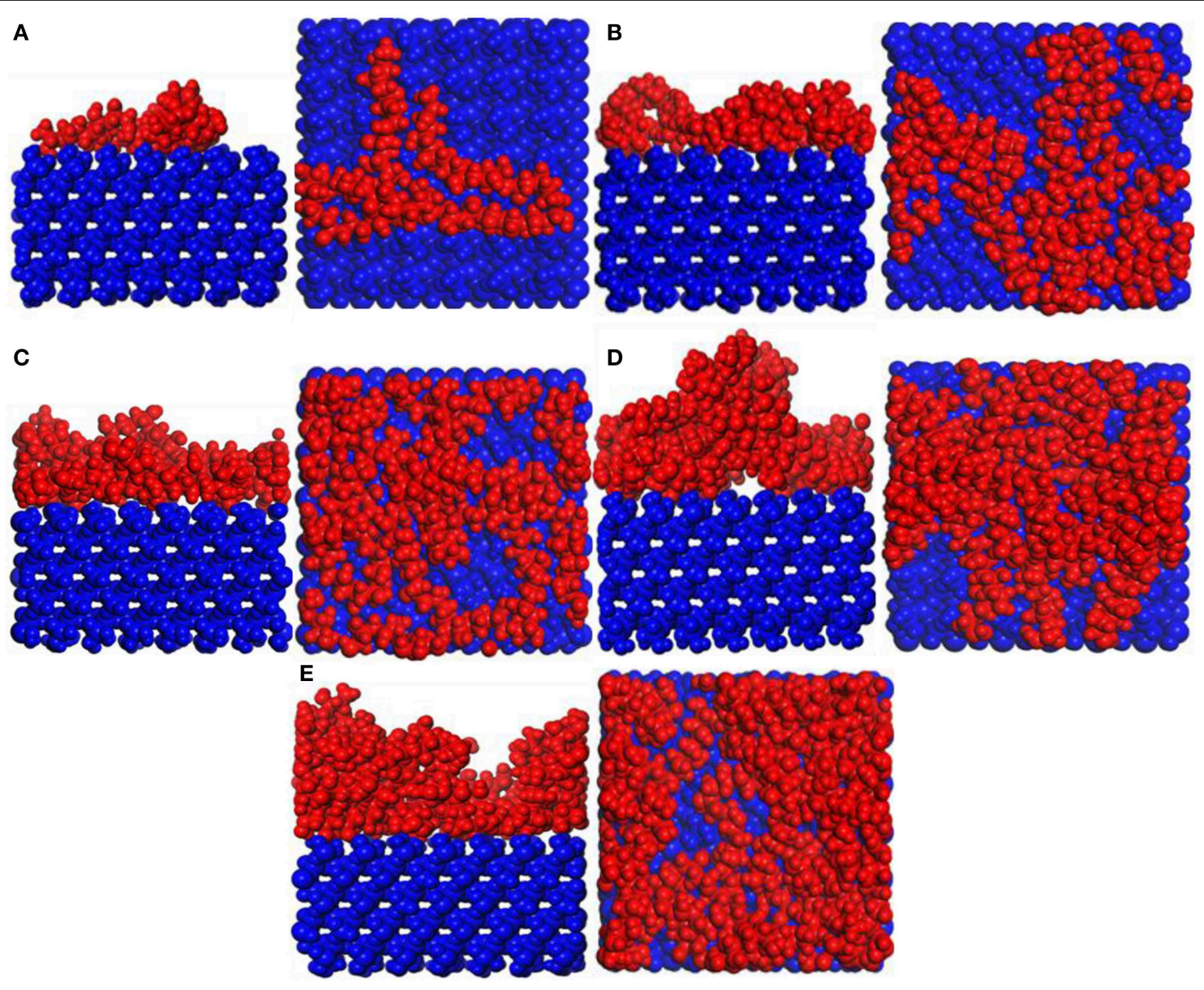

FIGURE 2 | Snapshot diagrams of polyvinyl acetate (PVA)/ $\alpha$-quartz under molecular dynamics simulation: (A-E) the repeat units for 1-5.

considered. First, $100 \mathrm{TiO}_{2}$ molecular repeat units were loaded on the surface, and a distance of $3 \AA$ was kept between the surface and $\mathrm{TiO}_{2}$. After the structure is optimized to minimize the energy of the system, the MD simulations were performed at 373, 573, 873 , and $1,173 \mathrm{~K}$ under the NVT ensemble, with a time step size of $1 \mathrm{fs}$ and simulation time of 1,000 ps using the UFF.

MD simulation for ZSM-5/modifier/substrate: After the structure optimization using the Forcite module to minimize the energy of the system, MD simulations were then performed under an NVT ensemble at $450 \mathrm{~K}$, with a step size of $1 \mathrm{fs}$ and simulation time of 1,000 ps using the UFF.

\section{RESULTS AND DISCUSSION}

\section{b-ZSM-5/PVA/Substrate MD Simulation Adsorption of PVA on Substrate Surface}

Figure 2 shows the snapshots of the PVA/ $\alpha$-quartz system. PVA spontaneously adheres to the surface of the substrate because of hydrogen bonding. The PVA molecular configuration is a nonlinear structure, so agglomeration occurs on the surface of the substrate (Yan et al., 2016). It can be seen that as the PVA repeat unit increases, the agglomeration of PVA becomes more and more obvious, especially when the number of PVA is equal to 4-5; the irregularity is formed on the surface of the substrate.

The higher the value of the MSD and $D$, the stronger is the mobility of the PVA on the surface of the substrate, indirectly indicating the weaker interaction between the surface of the substrate and the PVA (Dai et al., 2017). MSD and D (diffusion coefficient) are shown in Figures 3A,B. The MSD curve and the $D$ value at different PVA numbers are relatively small, indicating a strong interaction between the PVA and the substrate surface. The order of $D$ values of different PVA molecules is $1>4 \approx$ $5 \approx 3>2$, indicating that PVA has the strongest interaction ability when the number is equal to 2 . The relative concentration distribution of PVA on the surface of the substrate is shown in Figure 3C. When the number of molecules is 1 and 2, the peak value and the peak shape remain the same and show a single peak, indicating that a single modified layer with a thickness of $10 \AA$ is formed. However, when the number of molecules exceeds 3 , small peaks are formed, indicating that a single modified layer was destroyed and the formed modified layer is not uniform. It can also be seen from Figure 3D that the largest number of hydrogen bonds was formed when the number of PVA is equal to 2 . Above all, the substrate is 

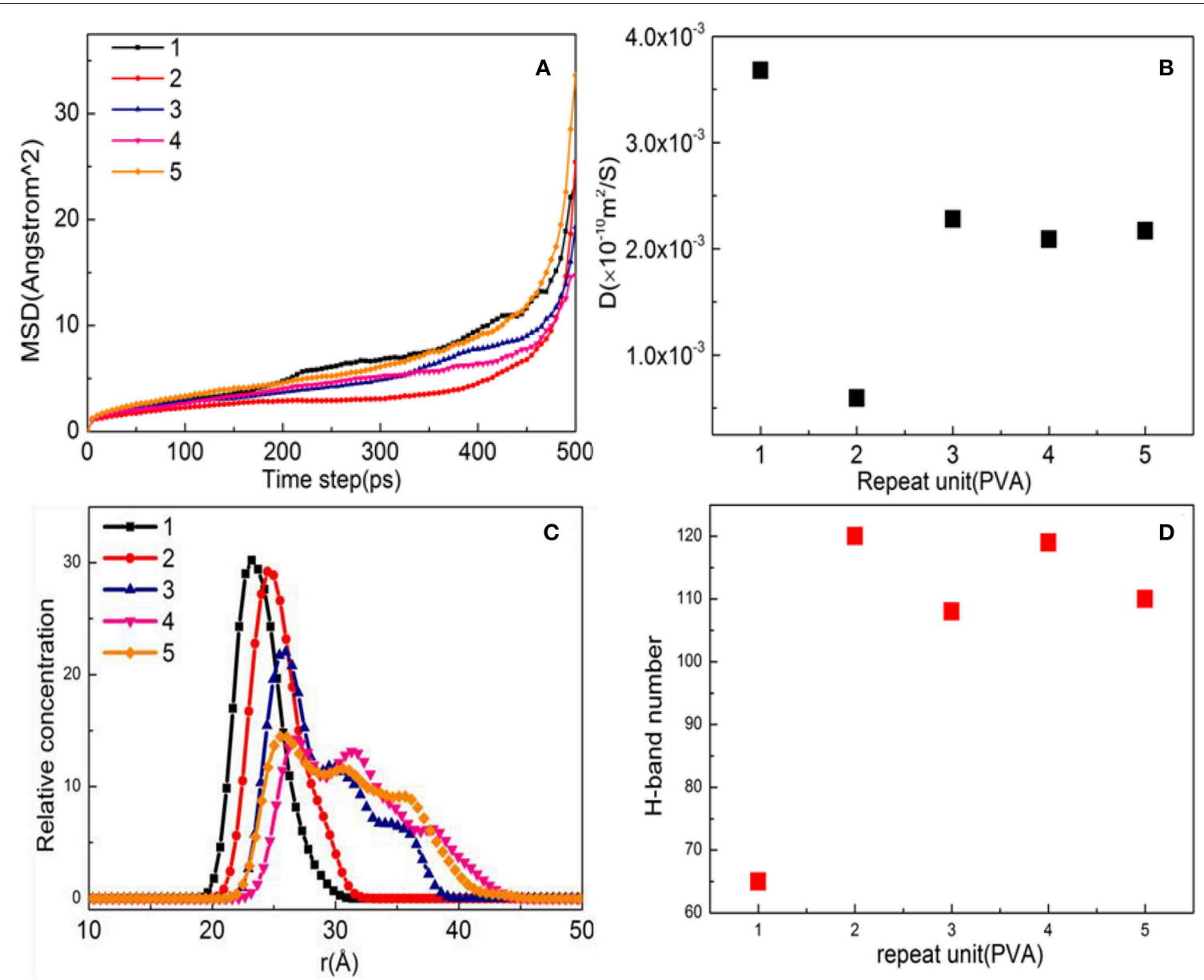

FIGURE 3 | Property analysis of polyvinyl acetate (PVA)/ $\alpha$-quartz substrate after equilibrium of molecular dynamics simulation: (A) mean square displacement (MSD); (B) diffusion coefficient; (C) hydrogen bond number; and (D) relative concentration profile.

fully modified with the 10 - $\AA$ thickness as the PVA number is 2 .

\section{Adsorption of b-ZSM-5 on PVA/Substrate Surface}

The snapshot diagrams of the $b$-ZSM-5 on the PVA/substrate surface is displayed in Figure 4. When the number of PVA is $1, b$-ZSM-5 can adsorb on the modified surface. However, due to insufficient modification, ZSM-5 tilts on the modified surface, and ZSM-5 with $b$-orientation cannot form. When the number of PVA molecules is 2, due to the surface having been sufficiently modified with a single-layer structure, ZSM-5 can be stably implanted with $b$-axial orientation on the modified substrate. However, when the number of PVA molecules is $3-5$, due to the agglomeration of PVA to form irregularity, ZSM-5 is tilted or embedded in the PVA-modified layer, so that ZSM-5 with $b$-axial orientation cannot form.

In order to further show the orientation degree of ZSM-5 with $b$-axial orientation implanted in the substrate, the orientation angle of the ZSM-5 with substrate is calculated, which is shown in Figure 5A; the orientation angle order with the PVA increasing is $2>3>1>4>5$, indicating that with the PVA having a molecule number of 2, ZSM-5 has the highest degree of $b$ axis orientation and an orientation angle of $84.81^{\circ}$. However, the theoretical orientation angle is $90^{\circ}$, because the hydroxyl groups of PVA promotes interaction with ZSM-5. Although a uniform layer of modifier formed, the distribution of hydroxyl groups exposed on the surface of the PVA was not uniform (Figure 5B), and the distribution of force with ZSM-5 was uneven, resulting in ZSM-5 not being completely implanted with $b$-axial orientation.

The interaction energies of ZSM- 5 and PVA/substrate models can be calculated using

$$
E_{\text {inter }}=E_{\text {total }}-E_{\mathrm{PVA} / \text { substrate }}-E_{\mathrm{ZSM}-5}
$$

where $E_{\text {total }}$ is the energy of the ZSM-5/PVA/substrate, $E_{\mathrm{PVA} / \text { substrate }}$ is the energy of the PVA/substrate, and $E_{\mathrm{ZSM}-5}$ is the energy of ZSM-5. The interaction energies are given in Table 1.

It can be seen from the table that when ZSM-5 is implanted on the surface of the substrate which is not fully modified by PVA, the interaction energy is lower than that of ZSM-5 of the PVAfree-modified substrate. When the surface of the substrate is fully 


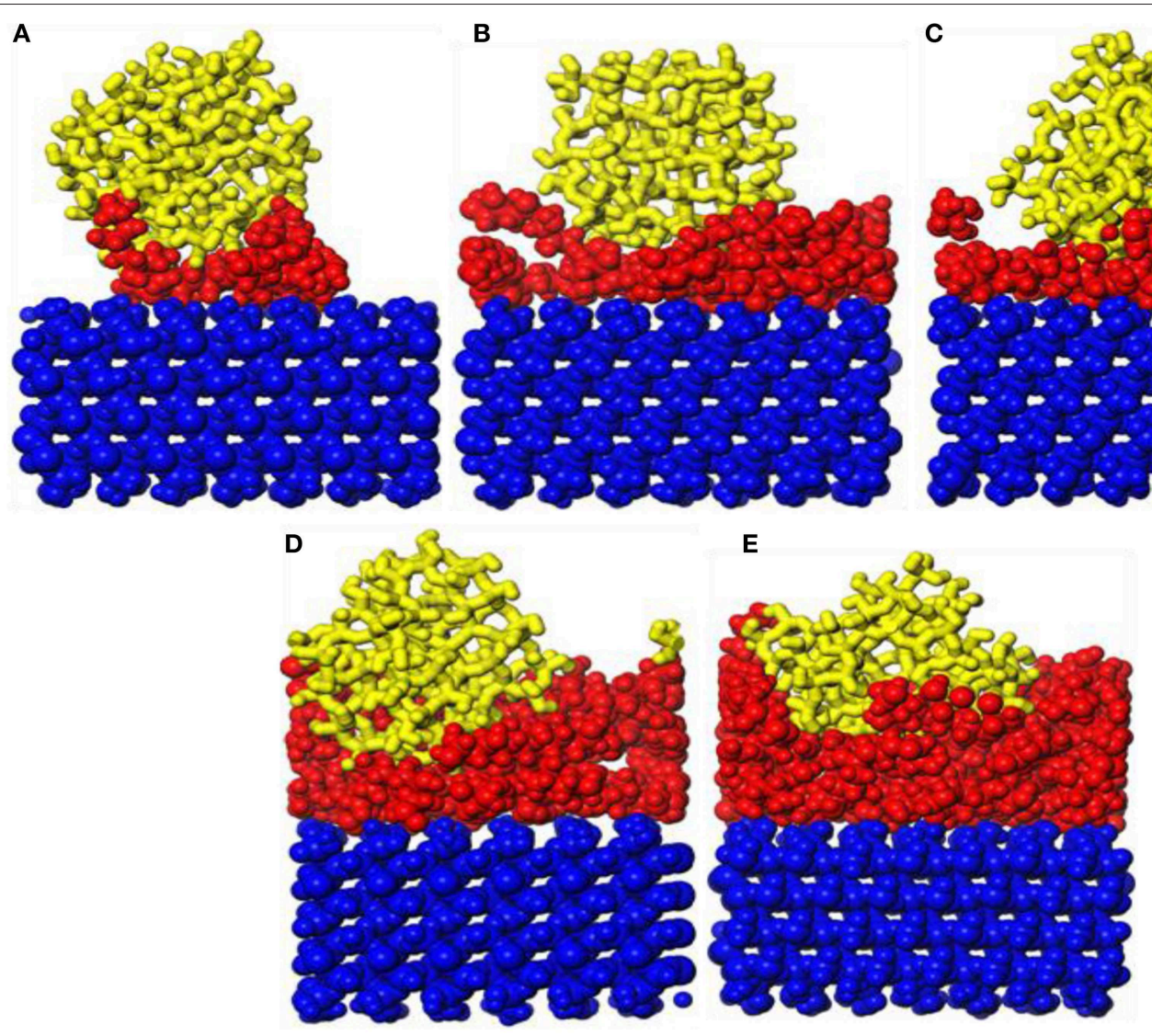

FIGURE 4 | Snapshot diagrams of ZSM-5/polyvinyl acetate (PVA)/ $\alpha$-quartz under molecular dynamics simulation: (A-E) the PVA repeat units from 1 to 5.
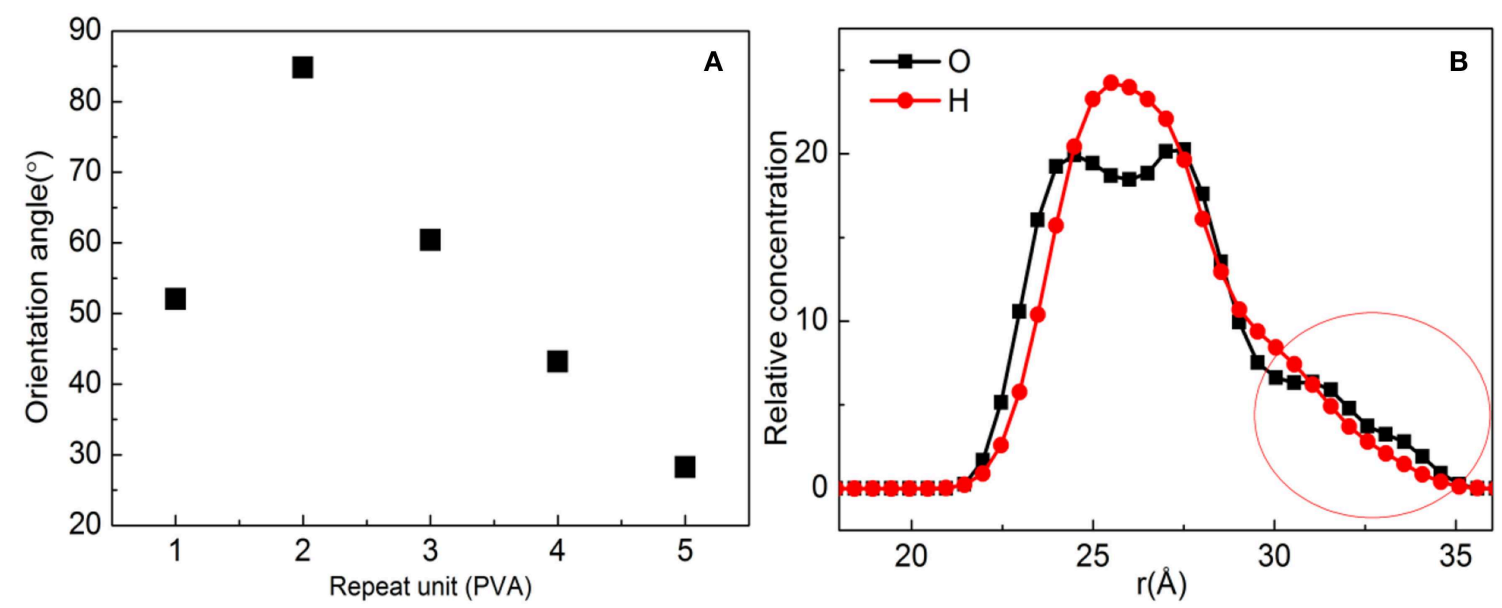

FIGURE 5 | (A) Orientation angle between polyvinyl acetate (PVA)/substrate and ZSM-5 with centroid along the b-axial direction. (B) Concentration profile for H and O atoms with the PVA repeat unit for 2.

preimplanted with a modifier, the interaction energy is higher than that of ZSM-5 without a PVA-modified substrate. However, it can be seen from the table that the order of interaction energy is $5>3>4>2>1$ with the increase of the number of PVA repeat units. This is because when the number of PVA molecules exceeds 3 (the thickness is $10 \AA$ ), ZSM-5 is embedded in the modifier layer and the contact area with the modifier increases, which leads to the increase of interaction potential. ZSM-5 is stably implanted 
TABLE 1 | Interaction energies of ZSM-5/polyvinyl acetate (PVA)/substrate (kcal/mol).

\begin{tabular}{lllllll}
\hline $\begin{array}{l}\text { System } \\
\text { (PVA unit) }\end{array}$ & None & 1 & 2 & 3 & 4 & 5
\end{tabular}

$E_{\text {inter }}(\mathrm{kcal} / \mathrm{mol}) \quad-329.92-283.12-447.83-540.218-458.352-633.141$

with $b$-orientation when the number of PVA molecules is 2 , and the contact area is small, resulting in low interaction energy.

\section{b-ZSM-5/CTS/Substrate MD Simulation Adsorption of CTS on the Substrate Surface}

Figure 6 shows snapshot diagrams of the CTS/substrate. Different from the PVA structural unit, the CTS molecular model is linear (Razmimanesh et al., 2015; Asghari et al., 2017), which is hard to agglomerate on the substrate surface. Therefore, it can be seen from Figure 6 that CTS can be stably adsorbed and accumulated on the substrate surface by hydrogen bonding. when the number of molecules is 1-4, the modified layer of CTS on the surface of the substrate is uniform. In contrast, when the number of molecules reaches 5, irregularity formed, because the bulk density of the CTS is too high. It can be also seen that when the number of CTS molecules is 3-4, some atoms in the CTS interface have adhered to the substrate surface.

As shown in Figure 7A, the MSD with three repeat units is much steeper than that of other molecules, which is hard to preplant on the substrate. When the number of molecules is 1 , 2,4 , and 5 , the diffusion degree is not intense due to the influence of steric hindrance, indicating that it can be stably adsorbed on the surface of the substrate. When the $D$ values in Figure $7 \mathbf{B}$ are compared, the order is found to be $3>5>2>4>1$, indicating that the CTS for a repeat unit of 1 has a strong interaction with substrate, while the repeat unit of 4 comes second.

Figure 7C shows the aggregation morphology of CTS on the substrate surface. When the number of molecules is $1-3$, the shape of the peak remains basically the same, and all show a single peak. That is, CTS forms a single modified layer with a thickness of $12 \AA$. However, when the number of molecules reaches 4 , symmetrical peaks are formed at 26.5 and $28.5 \AA$, indicating that CTS no longer exists as a single modified layer on the surface of the substrate but forms a uniform two-layered layer with a thickness of $20 \AA$. When the number of molecules is 5 , the main peak appears at $26.2 \AA$ and the shoulder peak is formed at 34.4 $\AA$. It can also be seen from Figure 6C that the peak value at 26.2 and $34.4 \AA$ is different, indicating that the modified layer is not uniform. It can be clearly be found from Figure 6D that as the number of molecules increases, the order of hydrogen bond generation is $4>2>5 \approx 3>1$. When the number of molecules is $1-2$, the number of hydrogen bonds is small due to insufficient modification. When the number of molecules is 3-4, CTS can fully modify the substrate, so the number of hydrogen bonds formed is the most at the repeat unit of 4 (Figure 7D). However, at the repeat unit of 3 , due to the strong degree of CTS movement, the diffusion coefficient is fast, resulting in a decrease in hydrogen bonding, which is consistent with the law of diffusion coefficient illustrated in Figure 7B.

\section{Adsorption of b-ZSM-5 on CTS/Substrate Surface}

It can be found in Figure 6 that the surface of the substrate cannot be sufficiently modified at the repeat unit of 1 . Therefore, the preplanting study of $b$-ZSM-5 on CTS/substrate is focused on the repeat units of 2-5. It can be seen from Figure 8 that ZSM5 can adsorb on the surface of the CTS-modified layer. When the number of molecules is 2, surface modification is insufficient, resulting in ZSM-5 inclining on the modified surface. When the number of CTS molecules is 3, the surface of the substrate is sufficiently modified, and a single modified layer of the structure is maintained. Therefore, it can be seen from Figure $\mathbf{8 B}$ that ZSM-5 can be stably implanted with $b$-axial orientation. When the number of molecules is 4 (Figure 8C), ZSM-5 can also be implanted with the $b$-orientation due to a double-layered layer. In contrast, when the number of molecules is 5 (Figure 8D), due to the cross-linking of CTS to form irregularity, ZSM-5 is embedded in the CTS-modified layer and cannot form a $b$-axis orientation preplanting. The relative concentration distribution (Figure 7C) displayed that when the number of molecules is 3-4, the thickness of the modifier layer is 12 and $20 \AA$, so that $b$-ZSM-5 preplanting can be formed either as the thickness of the modifier layer is below 12 Å or beyond $20 \AA$.

Figure 9A shows the orientation angle between the $b$-ZSM5 and the CTS/substrate surface. The orientation angle order is $4>3>5>2$, indicating that ZSM-5 has the best $b$-axial orientation and its orientation angle is $85.65^{\circ}$ with a molecule number of 4 . However, when the number of molecules is 3 , the orientation angle is $80.58^{\circ}$, indicating the double-layered modified layer is more suitable for $b$-ZSM-5 preplanting than the single modified layer.

This is because the interacting atoms between CTS and ZSM5 are $\mathrm{H}, \mathrm{N}$, and $\mathrm{O}$. It can be seen from Figure $9 \mathrm{~B}$ that the concentration distribution of $\mathrm{H}$ atoms is relatively uniform, but the concentrations of $\mathrm{N}$ and $\mathrm{O}$ are quite different. When the number of molecules is 3 , due to the strong movement of CTS on the substrate surface, the concentration of $\mathrm{N}$ atoms interacting between the CTS layer and substrate is much higher than the concentration of $\mathrm{N}$ atoms interacting between the ZSM-5 and CTS layer, indicating that interaction between CTS and ZSM-5 is weak, while when the number of molecules is 4 , the peaks of $\mathrm{N}$ atoms and $\mathrm{O}$ atoms at the molecule number of 3 are much higher than three molecules, and $\mathrm{N}$ atoms form a symmetric peak. It is indicated that the main reason that the two-layered modified layer is stronger than the single modified layer is the uniform distribution and concentration distribution of the exposed $\mathrm{N}$ and $\mathrm{O}$ atoms.

The order of interaction between ZSM-5 and the CTS/substrate surface is as follows: $5>3>4>2$; this conclusion can also be obtained by observing their interfacial interaction models after MD simulation (Figures 6, 8). When CTS is insufficiently modified on the substrate (CTS $<2$ ), the interaction energy is less than the interaction energy of ZSM-5 implanted on the surface without the PVA-modified substrate. When CTS is sufficiently modified on the substrate (CTS $>2$ ), the interaction energy is greater than the interaction energy of ZSM-5 implanted on the surface without the PVA-modified substrate. When the number of CTS molecules is five, ZSM-5 is 


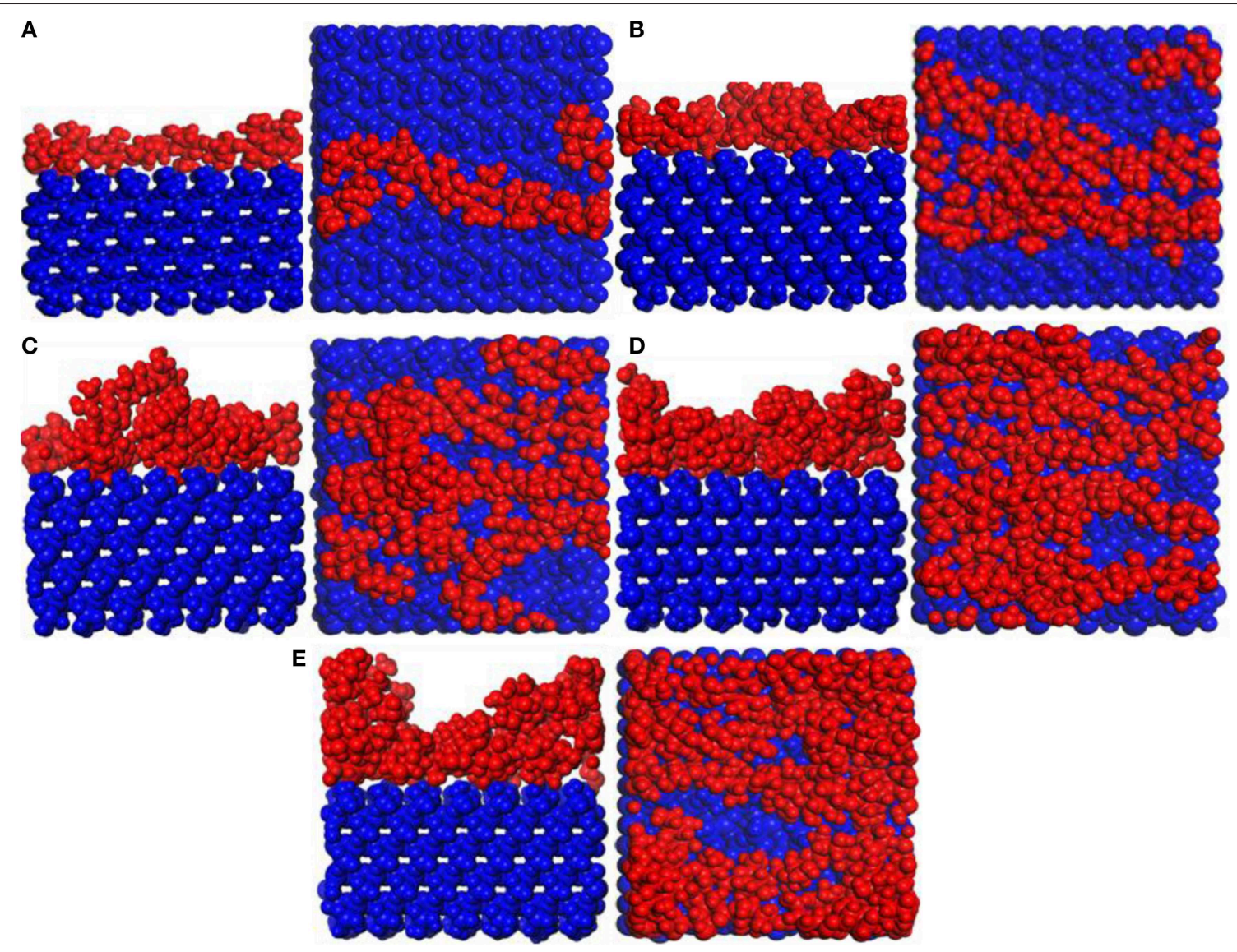

FIGURE 6 | Snapshot diagrams of chitosan (CTS)/ $\alpha$-quartz substrate under molecular dynamics simulation: (A-E) the polyvinyl acetate (PVA) repeat units from 1 to 5.

embedded to cause an increase in energy. At the same time, it can be found from Table 2 that the interaction energy of the double modifier (CTS = 4) formed by ZSM-5 and CTS on the surface of the substrate is larger than that of the single modified layer (CTS $=3$ ), which is consistent with the results of Figure 9B analysis.

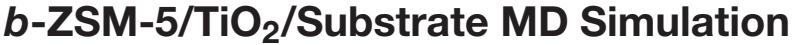 Adsorption of $\mathrm{TiO}_{2}$ on Substrate Surface}

Snapshot diagrams of $\mathrm{TiO}_{2} /$ substrate is shown in Figure 10. After MD simulation, the $\mathrm{TiO}_{2}$ molecules at different temperatures exhibit different formations. At $373-573 \mathrm{~K}$, the adsorption of $\mathrm{TiO}_{2}$ on the surface of the substrate belongs to non-dissociative adsorption (Baguer et al., 2009), where the $\mathrm{TiO}_{2}$ molecules not only interact with the substrate but also interact with the $\mathrm{TiO}_{2}$ molecules to prevent $\mathrm{TiO}_{2}$ from separating on the substrate surface to form a dense modified layer. At 873 and $1,173 \mathrm{~K}$, some $\mathrm{TiO}_{2}$ molecules are free in the box and cannot be adsorbed on the surface of the substrate, indicating that the adsorption of $\mathrm{TiO}_{2}$ belongs to dissociative adsorption. It can also be seen from Figure 10 that because the temperature is low and the kinetic energy necessary for the movement of the $\mathrm{TiO}_{2}$ molecule is insufficient at $373 \mathrm{~K}$ (Figure 10A), it only shrinks with the formation of the "island" structure on the substrate surface. At $573 \mathrm{~K}$ (Figure 10B), $\mathrm{TiO}_{2}$ has formed a dense modified monolayer, and the inner $\mathrm{TiO}_{2}$ molecules have been embedded in the surface of the substrate. Therefore, Ti-O-Si are easily formed between $\mathrm{Ti}$ and $\mathrm{Si}\left(\mathrm{SiO}_{4}\right.$ in the substrate surface) (Sang, 2004). At $873 \mathrm{~K}$ (Figure 10C), although most of the $\mathrm{TiO}_{2}$ is still adsorbed on the surface of the substrate, a small amount of $\mathrm{TiO}_{2}$ has been released in the vacuum box, indicating that the kinetic energy is greater than the energy between the $\mathrm{TiO}_{2}$ molecules, leading to $\mathrm{TiO}_{2}$ dissociation. At $1,173 \mathrm{~K}$ (Figure 10D), most of the $\mathrm{TiO}_{2}$ molecules have dissociated and the distance between $\mathrm{TiO}_{2}$ has become longer, indicating that the kinetic energy is greater than the energy sum for $\mathrm{TiO}_{2}$ with substrate and between $\mathrm{TiO}_{2}$ molecules. Therefore, the modified layer formed on the surface of the substrate is sparse.

Figure 11A shows the MSD of $\mathrm{TiO}_{2}$ on the substrate surface. $\mathrm{TiO}_{2}$ as a small molecule is sterically hindered, and the intermolecular interaction is weak, so the MSD curve of $\mathrm{TiO}_{2}$ is steep. When the temperature is from 373 to $573 \mathrm{~K}$, the MSD curve of $\mathrm{TiO}_{2}$ has a little change, while from 573 to $1173 \mathrm{~K}$, the MSD curve steepness becomes larger. It can also be seen from Figure 11B that the $\mathrm{D}$ value is $D_{(373 \mathrm{~K})}$ $\approx D_{(573 \mathrm{~K})}, D_{(873 \mathrm{~K})}=6 D_{(573 \mathrm{~K})}$, and $D_{(1,173 \mathrm{~K})}=21 D_{(573 \mathrm{~K})}$, indicating that $573 \mathrm{~K}$ is the critical temperature for molecules to form non-dissociative adsorption between $\mathrm{TiO}_{2}$. When the temperature is higher than $573 \mathrm{~K}$, the kinetic energy of the $\mathrm{TiO}_{2}$ 

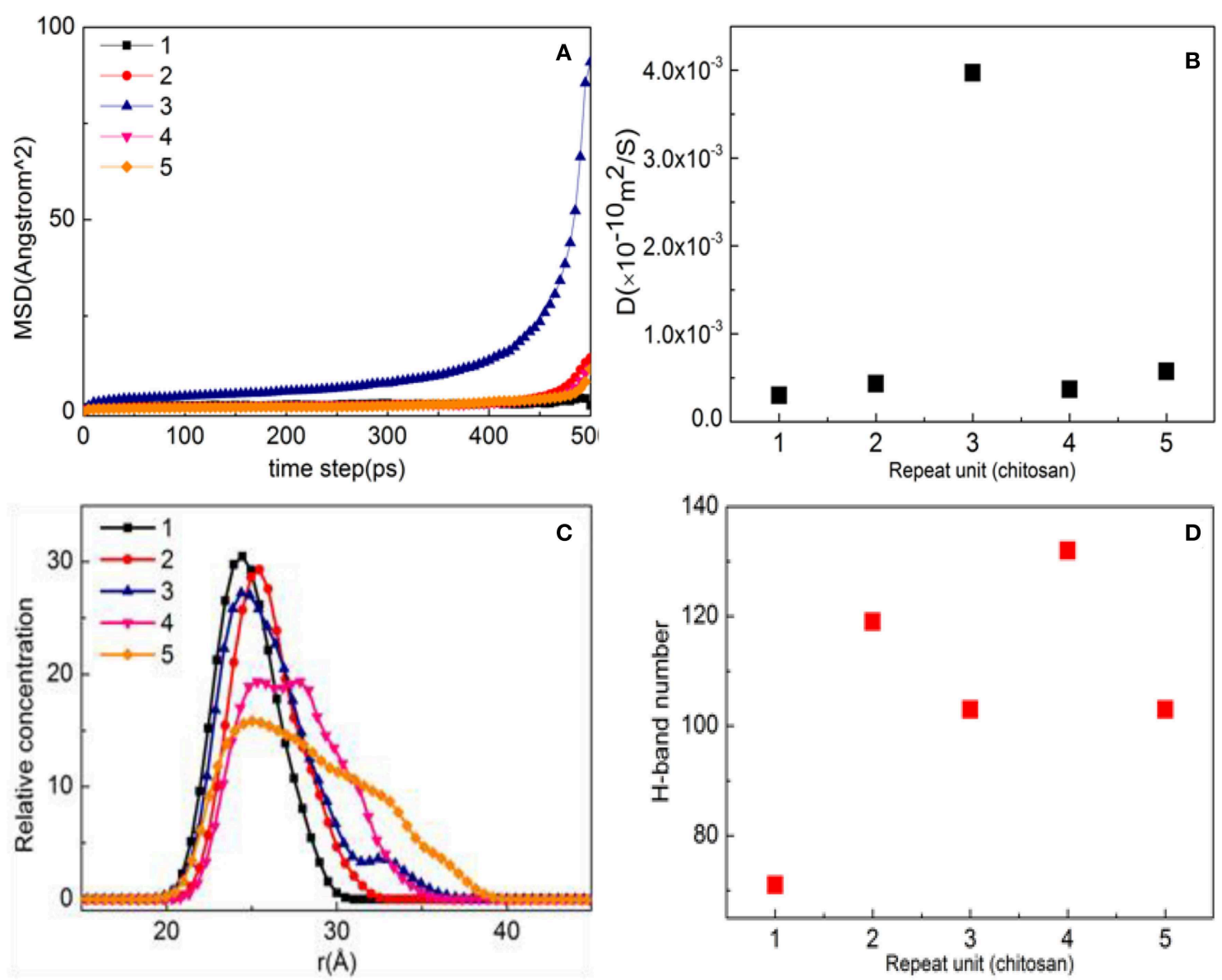

FIGURE 7 | Property analysis of chitosan (CTS)/ $\alpha$-quartz $\left(\begin{array}{lll}1 & 0 & 0\end{array}\right)$ substrate after equilibrium. (A) Mean square displacement (MSD), (B) diffusion coefficient, (C) hydrogen bond number, and (D) relative concentration profile.

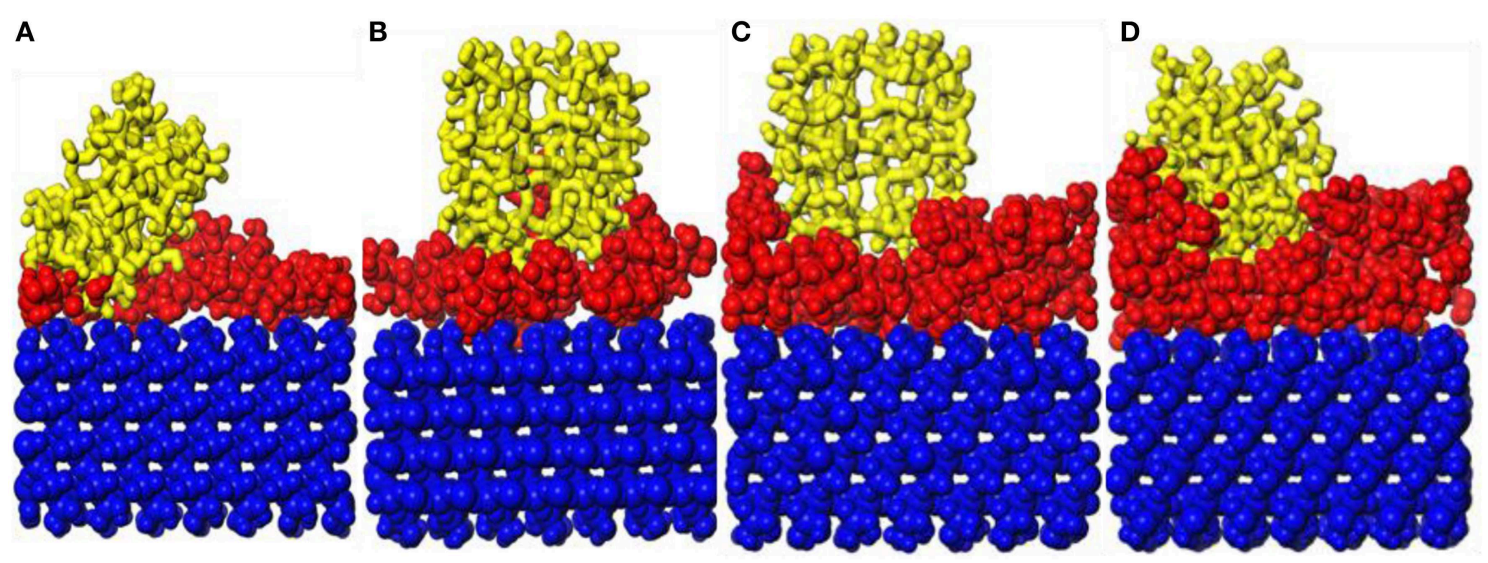

FIGURE 8 | Snapshot diagrams of ZSM-5/chitosan (CTS)/ $\alpha$-quartz under molecular dynamics simulation: (A-D) the polyvinyl acetate (PVA) repeat units from 2 to 5.

molecule increase leads to the destruction of the non-dissociative adsorption and even desorption (Figure 10), resulting in the $D$ value increasing drastically. With the increase of temperature,
$\mathrm{TiO}_{2}$ has undergone the non-dissociation adsorption stage $\rightarrow$ dissociation adsorption stage $\rightarrow$ desorption stage on the surface of the substrate. This phenomenon can be visually 

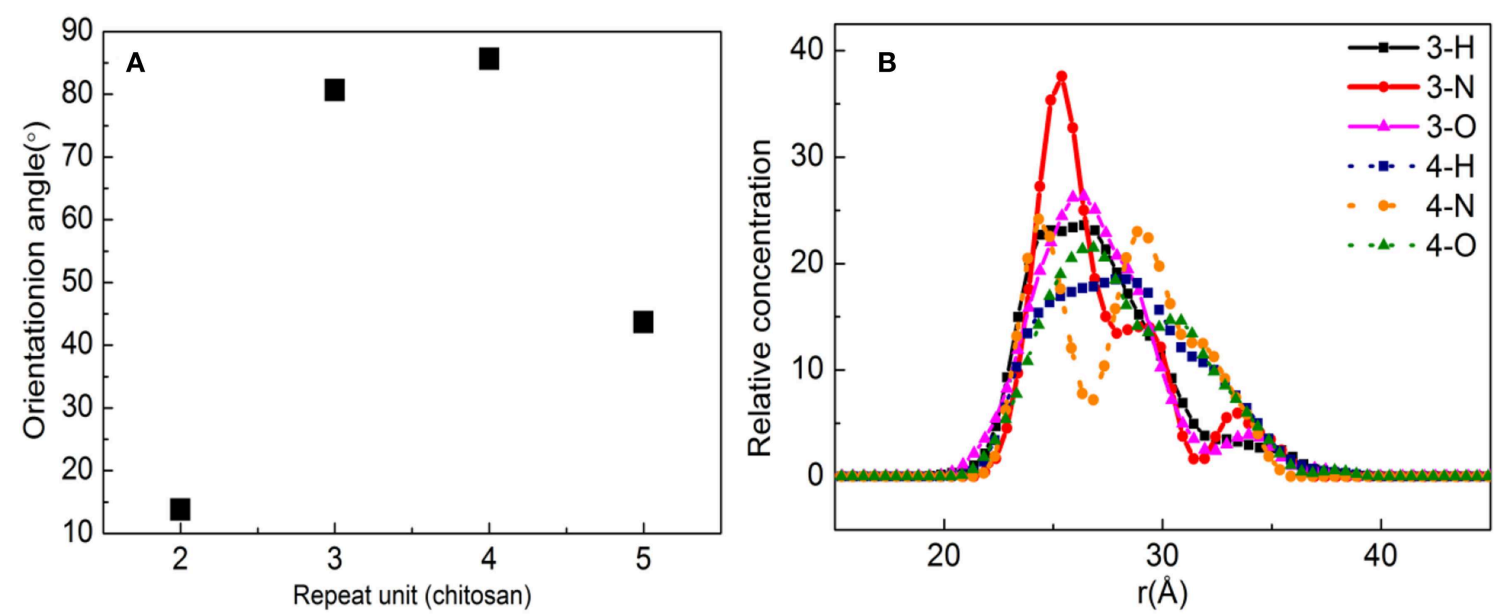

FIGURE 9 | (A) Orientation angle between chitosan (CTS)/ $\alpha$-quartz substrate and ZSM-5 with centroid along the b-axial direction. (B) Concentration profile for H, N, and $\mathrm{O}$ atoms with the polyvinyl acetate (PVA) repeat units of 2 and 3.

TABLE 2 | Interaction energies of the ZSM-5/CTS/substrate.

\begin{tabular}{lccccc}
\hline $\begin{array}{l}\text { System } \\
\text { (chitosan unit) }\end{array}$ & None & $\mathbf{2}$ & $\mathbf{3}$ & $\mathbf{4}$ & $\mathbf{5}$ \\
\hline$E_{\text {inter }} / \mathrm{kcal} / \mathrm{mol}$ & -329.92 & -360.01 & -484.99 & -506.29 & -557.38 \\
\hline
\end{tabular}

observed from Figures 11C,D as the temperature increases. The first peak and peak shape are changing. When the temperature is below $573 \mathrm{~K}$, the modified layer still maintains a uniform single modified layer, and the number of hydrogen bonds formed is also increasing, which belongs to a nondissociation adsorption stage. At $873 \mathrm{~K}$, a symmetrical double peak appeared in the concentration profile, which formed a double modified layer, indicating that the $\mathrm{TiO}_{2}$ movement was more intense. Based on the observation of Figure 10D, the number of hydrogen bonds greatly reduced from 573 to $875 \mathrm{~K}$, leading to a great reduction of the interaction between $\mathrm{TiO}_{2}$ and the substrate surface, indicating that $\mathrm{TiO}_{2}$ is at the dissociative adsorption phase. At $1,173 \mathrm{~K}$, it can be seen from the concentration profile that $\mathrm{TiO}_{2}$ peaks appear at 20$120 \AA$, indicating that hydrogen bonding disappears and that the interaction between $\mathrm{TiO}_{2}$ and the surface of the substrate becomes weak. In summary, at $573 \mathrm{~K}, \mathrm{TiO}_{2}$ is most easily adsorbed on the substrate, and the modified layer maintains uniform flatness.

\section{Adsorption of b-ZSM-5 on $\mathrm{TiO}_{2} /$ Substrate Surface}

Through the above MD simulation at different temperatures (Zeng Y. et al., 2015), it is known that $\mathrm{TiO}_{2}$ maintains the stage of desorption and dissociation at 1,173 K, so the study for ZSM-5 preplanting on the $\mathrm{TiO}_{2}$ /substrate surface is focused on 373,573 , and $873 \mathrm{~K}$.

Figure 12 shows snapshot diagrams of the $b$-ZSM-5 on the $\mathrm{TiO}_{2} /$ substrate surface after $\mathrm{MD}$ relaxation. Since the preimplantation temperature of ZSM-5 is $450 \mathrm{~K}$, it can be seen from Figure 12A that the adsorption morphology of $\mathrm{TiO}_{2}$ is also changed from the previous island structure to the layer structure. However, when the $b$-ZSM-5 is implanted on $\mathrm{TiO}_{2} /$ substrate performed under $\mathrm{MD}$ simulation at $373 \mathrm{~K}$, the kinetic energy of $\mathrm{TiO}_{2}$ is strengthened and the $\mathrm{TiO}_{2}$ molecule flows on the substrate surface, so that ZSM-5 was not implanted on its surface at steady state, resulting in the tilt of ZSM-5 on the surface of the substrate (Figure 12A). When $b$-ZSM-5 is implanted on $\mathrm{TiO}_{2} /$ substrate performed under $\mathrm{MD}$ simulation at $573 \mathrm{~K}$, it can be seen from Figure 11B that ZSM-5 can be stably implanted with $b$-axial orientation, and the inner layer of ZSM5 is embedded in the $\mathrm{TiO}_{2}$ modifier layer, indicating that $\mathrm{Si}-$ $\mathrm{OH}$ (ZSM-5) and Ti are prone to bonding, while when the $b$ ZSM-5 is implanted on $\mathrm{TiO}_{2}$ /substrate performed under MD simulation at $873 \mathrm{~K}$, it can be seen from Figure $12 \mathrm{C}$ that the modified layer has transitioned from the dissociation adsorption stage to the non-dissociation adsorption stage. However, what is similar to the state performed under MD simulation at $373 \mathrm{~K}$ is that ZSM-5 tilts on the substrate surface due to the failure to preplant in the steady state. In summary, ZSM-5 is more easily implanted with $b$-axial orientation performed under MD simulation at $573 \mathrm{~K}$.

Figures 13A,B show the orientation angle and concentration profile. The order of orientation angle is $573>873>373 \mathrm{~K}$, indicating that the modifier layer at $573 \mathrm{~K}$ is most suitable for $b$-ZSM-5 preplanting, which is $88.42^{\circ}$. Combined with the concentration distribution of $\mathrm{TiO}_{2}$ in Figure 13B, the peak of ZSM-5 is high and narrow when $b$-ZSM-5 is implanted under $573 \mathrm{~K}$, indicating that the interaction between ZSM-5 and $\mathrm{TiO}_{2}$ results in a denser modification layer. For preplantation at $373 \mathrm{~K}$, as the temperature increased from 373 to $450 \mathrm{~K}$, the kinetic energy of $\mathrm{TiO}_{2}$ enhances the movement of $\mathrm{TiO}_{2}$, but the concentration and peak shape of $\mathrm{TiO}_{2}$ did not change, indicating that the kinetic energy of $\mathrm{TiO}_{2}$ was so insufficient at $450 \mathrm{~K}$ that part of the "island" structure still exists. Therefore, $b$-ZSM-5 is tilted on the substrate surface. However, as shown 


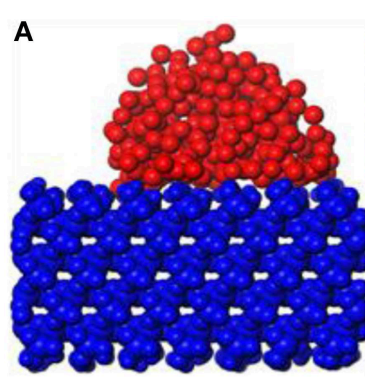

C
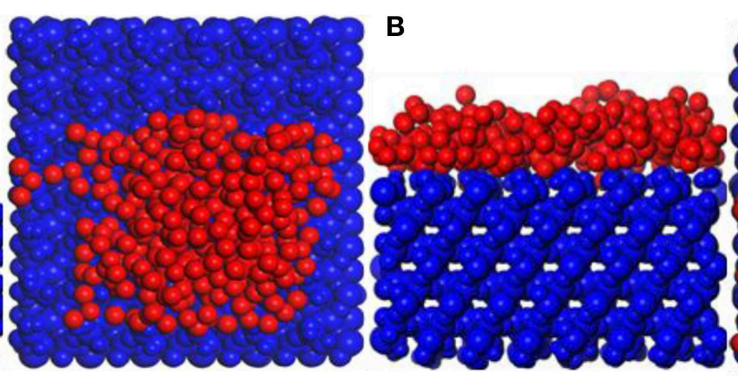

D
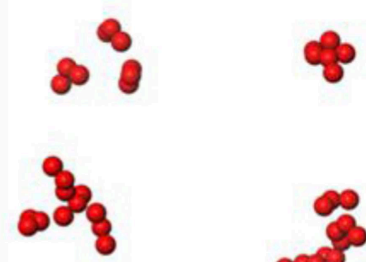

8

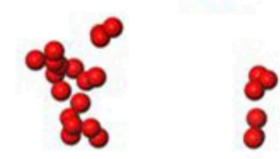

\section{8}

8
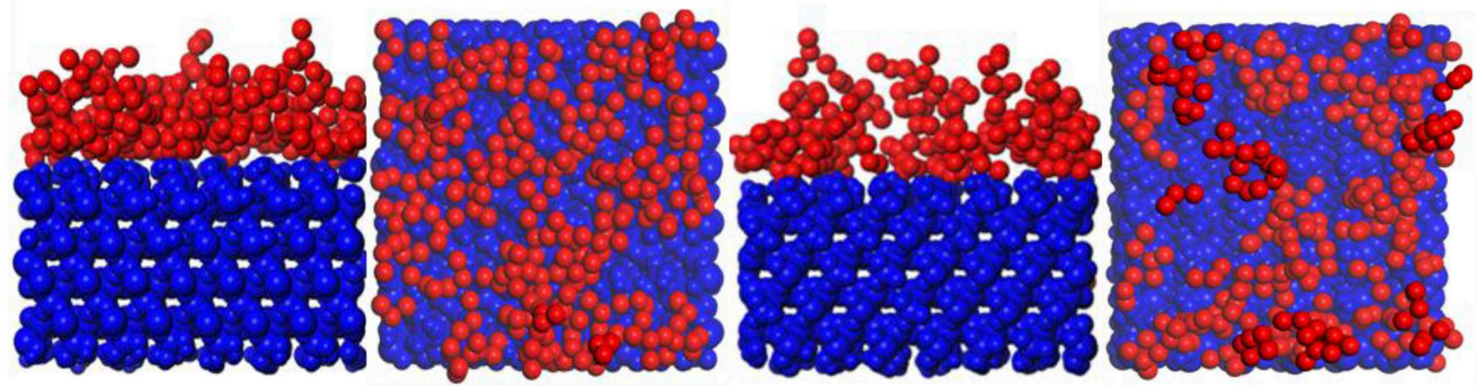

FIGURE 10 | Snapshot diagrams of $\mathrm{TiO}_{2} / \alpha$-quartz substrate under molecular dynamics simulation: (A) 373 , (B) 573 , (C) 873 , and (D) $1,173 \mathrm{~K}$.

in Figure 12B, when the temperature was reduced from 873 to $450 \mathrm{~K}$, the concentration of $\mathrm{TiO}_{2}$ after preplanting was much higher than that before preplanting, which was basically the same as that at $573 \mathrm{~K}$, indicating that the adsorption process of $\mathrm{TiO}_{2}$ changed from the dissociative adsorption phase to the non-dissociation adsorption phase. However, due to the flow of $\mathrm{TiO}_{2}, \mathrm{ZSM}-5$ could not be implanted in the steady state, resulting in the tilt of ZSM-5 on the surface of the $\mathrm{TiO}_{2}$ modified layer.

Interaction energies of $\mathrm{ZSM}-5 / \mathrm{TiO}_{2} /$ substrate are given in Table 3.

The order of interaction energy between ZSM-5 and $\mathrm{TiO}_{2} /$ substrate is $373>873>573 \mathrm{~K}$. This is because $\mathrm{TiO}_{2}$ forms anatase and rutile structures when $\mathrm{TiO}_{2}$ is $<573$ and $>873 \mathrm{~K}$, respectively, and the activation property of anatase is higher than that of rutile. The interaction energy of ZSM5 and $\mathrm{TiO}_{2}$ /substrate surface preplanting is consistent with that of ZSM-5 in PVA and CTS surface modification and is affected by the orientation degree of $b$-oriented preplanting. The higher the degree of orientation of the $b$-ZSM- 5 preplant, the smaller the interaction energy. However, unlike PVA and CTS, since $\mathrm{TiO}_{2}$ belongs to a small molecular structure, ZSM5 is not embedded in the modifier layer, and $\mathrm{TiO}_{2}$ easily bonds with $\mathrm{Si}-\mathrm{O}-\mathrm{H}$ on ZSM-5, resulting in much higher energy than that of ZSM-5 implanted on the surface of an unmodified substrate. 

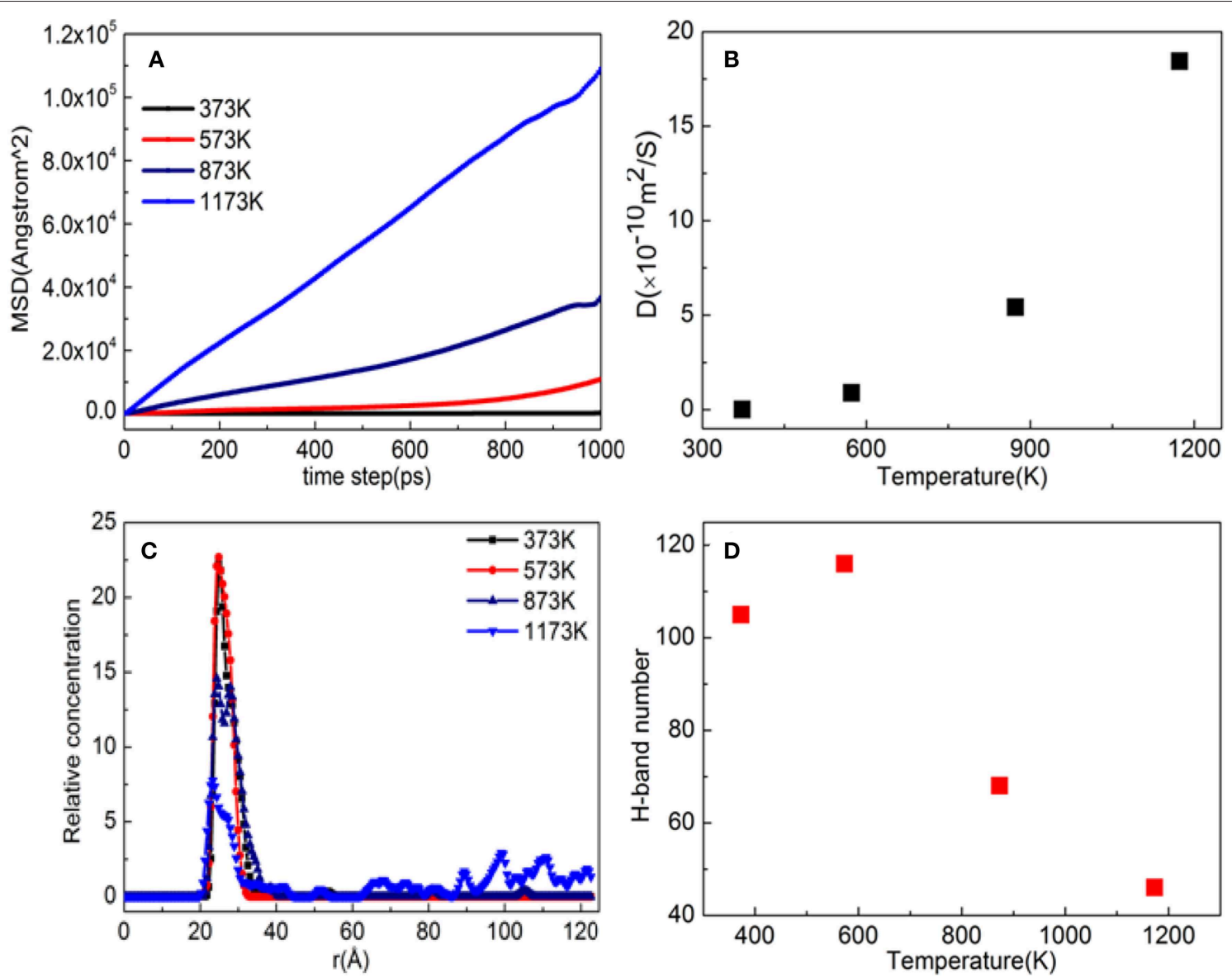

FIGURE 11 | Property analysis of $\mathrm{TiO}_{2} / \alpha$-quartz substrate after equilibrium of molecular dynamics simulation. (A) Mean square displacement (MSD), (B) diffusion coefficient, (C) hydrogen bond number, and (D) relative concentration profile.

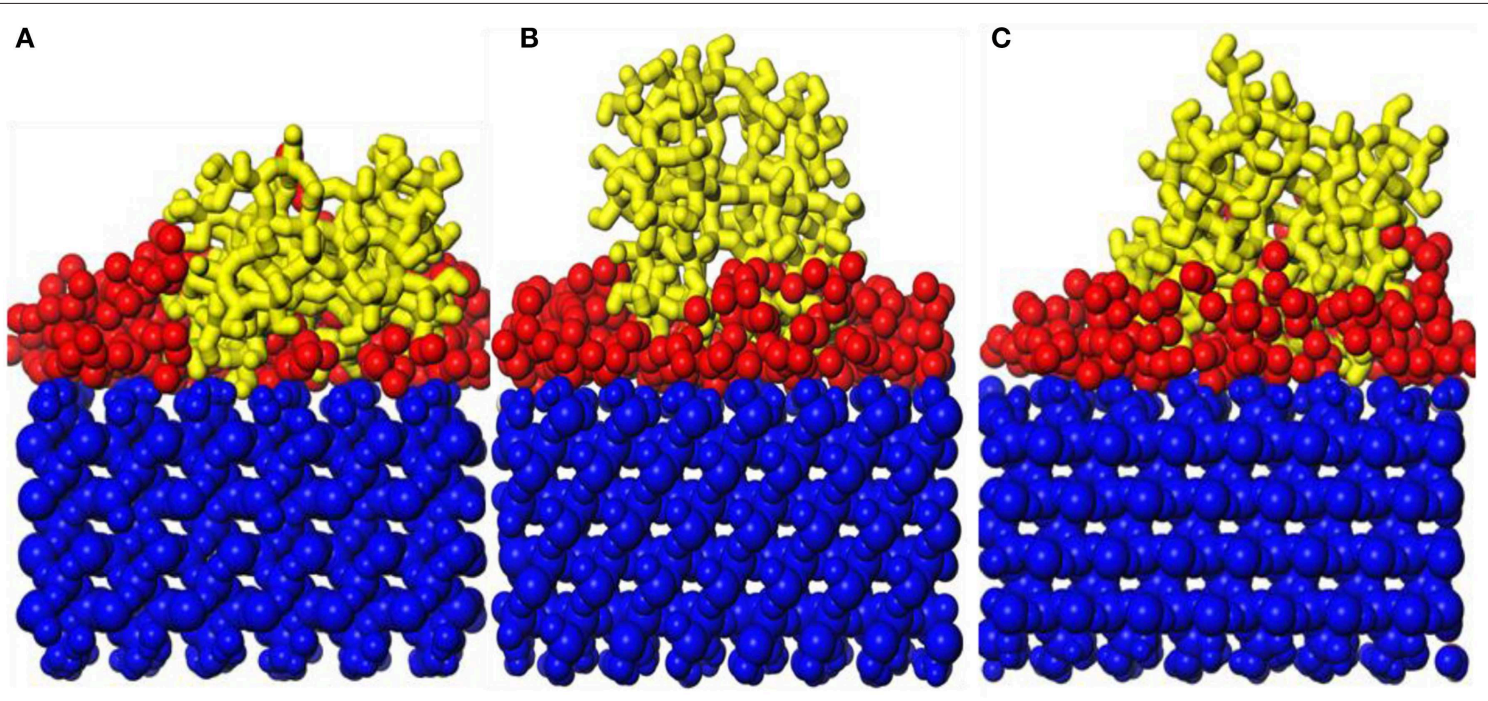

FIGURE 12 | Snapshot diagrams of $Z \mathrm{SM}-5 / \mathrm{TiO}_{2} / \alpha$-quartz under molecular dynamics relaxation: (A) 573, (B) 873, and (C) 1,173 K. 

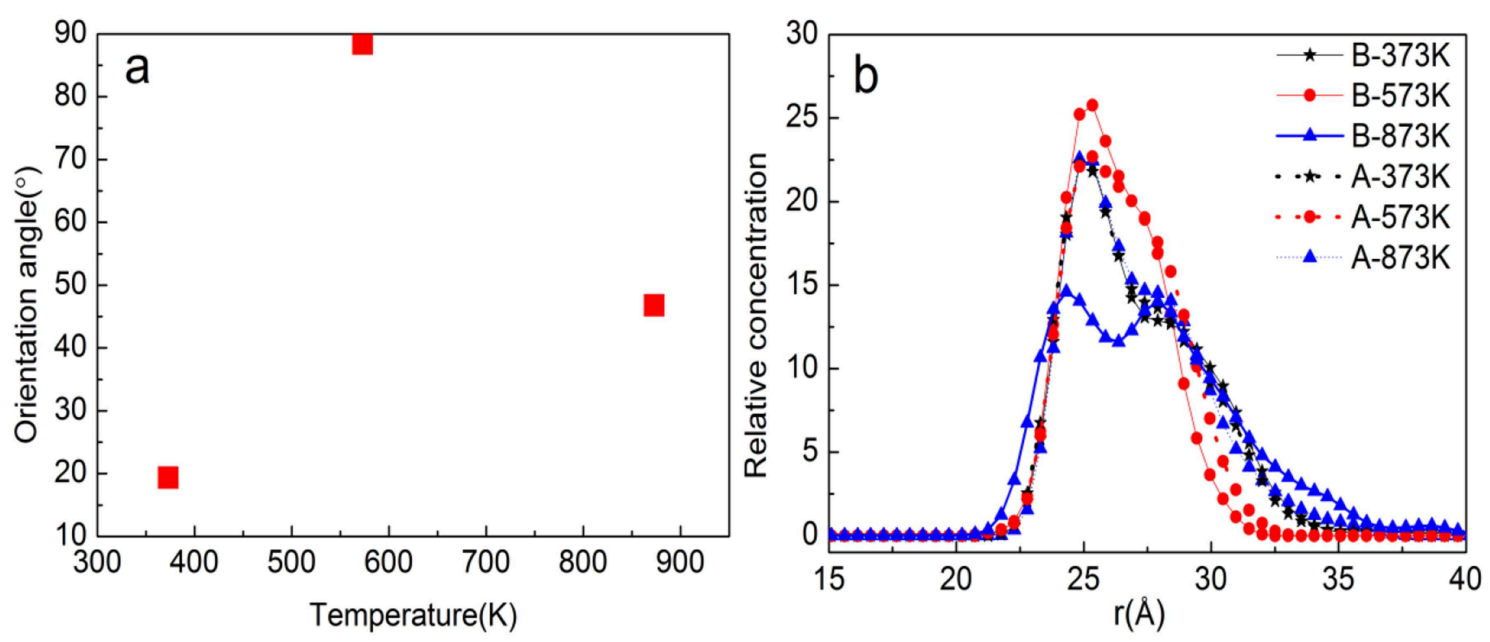

FIGURE 13 | (a) Orientation angle between $\mathrm{TiO}_{2} / \alpha$-quartz substrate and $\mathrm{ZSM}-5$ with centroid along the $b$-axial direction. (b) $\mathrm{TiO}_{2}$ concentration profile.

TABLE 3 | Interaction energies of $\mathrm{ZSM}-5 / \mathrm{TiO}_{2} /$ substrate( $\left.\mathrm{kcal} / \mathrm{mol}\right)$

\begin{tabular}{lcccc}
\hline $\begin{array}{l}\text { System } \\
\left(\mathrm{TiO}_{2} / \text { temperature }\right)\end{array}$ & None & $\mathbf{3 7 3}$ & $\mathbf{5 7 3}$ & $\mathbf{8 7 3}$ \\
\hline$E_{\text {inter }} / \mathrm{kcal} / \mathrm{mol}$ & -329.92 & $-1,119.59$ & -752.17 & -879.61 \\
\hline
\end{tabular}

\section{MTA Reaction Test of Materials}

ZSM-5 zeolite catalysts are good catalysts for converting methanol into the hydrocarbons of petroleum-range products. All methanol disappears on HZSM-5 or modified HZSM-5 zeolite in a lot of literature reports. However, the one-pass yield of aromatic hydrocarbons is not necessarily high (Wei et al., 2015; Yang et al., 2017a,b). Surprisingly, in this study, we found that the $b$ - ZSM- $5 / \mathrm{TiO}_{2} /$ substrate catalyst produced high benzene, toluene, and xylene (BTX) hydrocarbons (Figure 14A) and exhibited long lifetimes (Figure 14B) in the MTA reaction, although the conversion of methanol decreased slightly. We speculate that this performance of the catalysts can be attributed to two aspects. On the one hand, while in the MTA reaction, methanol is first dehydrated to form dimethyl ether, then the equilibrium product of methanol, dimethyl ether, and water is converted to light olefin, and then light olefins are further reacted to form alkanes and a large number of aromatic hydrocarbons (Dahl and Kolboe, 1994). If the product does not move out of the catalyst surface quickly, the product will react further to form carbon deposit and result in deactivation. In this paper, the dense and uniform $b$-ZSM-5 zeolite films synthesized can provide suitable pore structures and ensure that the residence time of reactants and products in the pore is more conducive to the formation of BTX hydrocarbons. On the other hand, the effective component of ZSM-5 zeolite film supported by quartz carrier is only $5 \%$ of that of conventional ZSM- 5 solid catalyst at the same catalyst loading volume, but its catalytic activity can still reach $95 \%$, only $5 \%$ lower than that of the conventional ZSM-5 solid catalyst. This indicates that the $b$-ZSM-5 zeolite film catalyst can provide more active centers and has better catalytic activity in MTA reaction. Combined with the previous simulation data, we found that the methanol conversion of the catalysts modified by different modifiers correlated with the energy of binding force (Figure 14D) and that BTX selection correlates with the $b$-axis orientation angle of the ZSM-5 film (Figure 14C). Hence, the larger the binding force, the denser the molecular zeolite film is synthesized. In addition, the more appropriate the $b$-axis orientation of the molecular zeolite film, the better the product diffusivity, as the more active sites of olefins are converted into aromatic hydrocarbons. Then the residence time of the aromatic hydrocarbon products is shorter in the catalyst pores, and the aromatic hydrocarbon selectivity becomes higher.

\section{CONCLUSION}

By employing MD simulation, we have obtained more precise conclusive information of $b$-oriented growth of ZSM-5 crystallites, which highly depends on the surface modifiers. The organic modification mainly forms a modifier layer by cross-linking the hydrogen bond with the substrate, and the flatness of the modified layer is greatly affected by the type and concentration of the modifier. The inorganic modifier not only forms a hydrogen bond and a complex interaction with the substrate but also interacts with others to form a dense layer of modifier, and the degree of tightness of the layer is significantly affected by temperature. PVA is a non-linear organic macromolecule with a large amount of hydroxyl groups on the surface, which easily adheres to the surface of the substrate and agglomerates. When PVA forms a uniform single modified layer of 10- $\AA$ thickness, crosslinking takes place, and the modification agent layer is not uniform. CTS is a straight-chain structure with a large amount of hydroxyl and amino groups, which easily accumulate and spread out on the substrate surface, and forms a single modified agent layer of $12-\AA$ thickness and double 

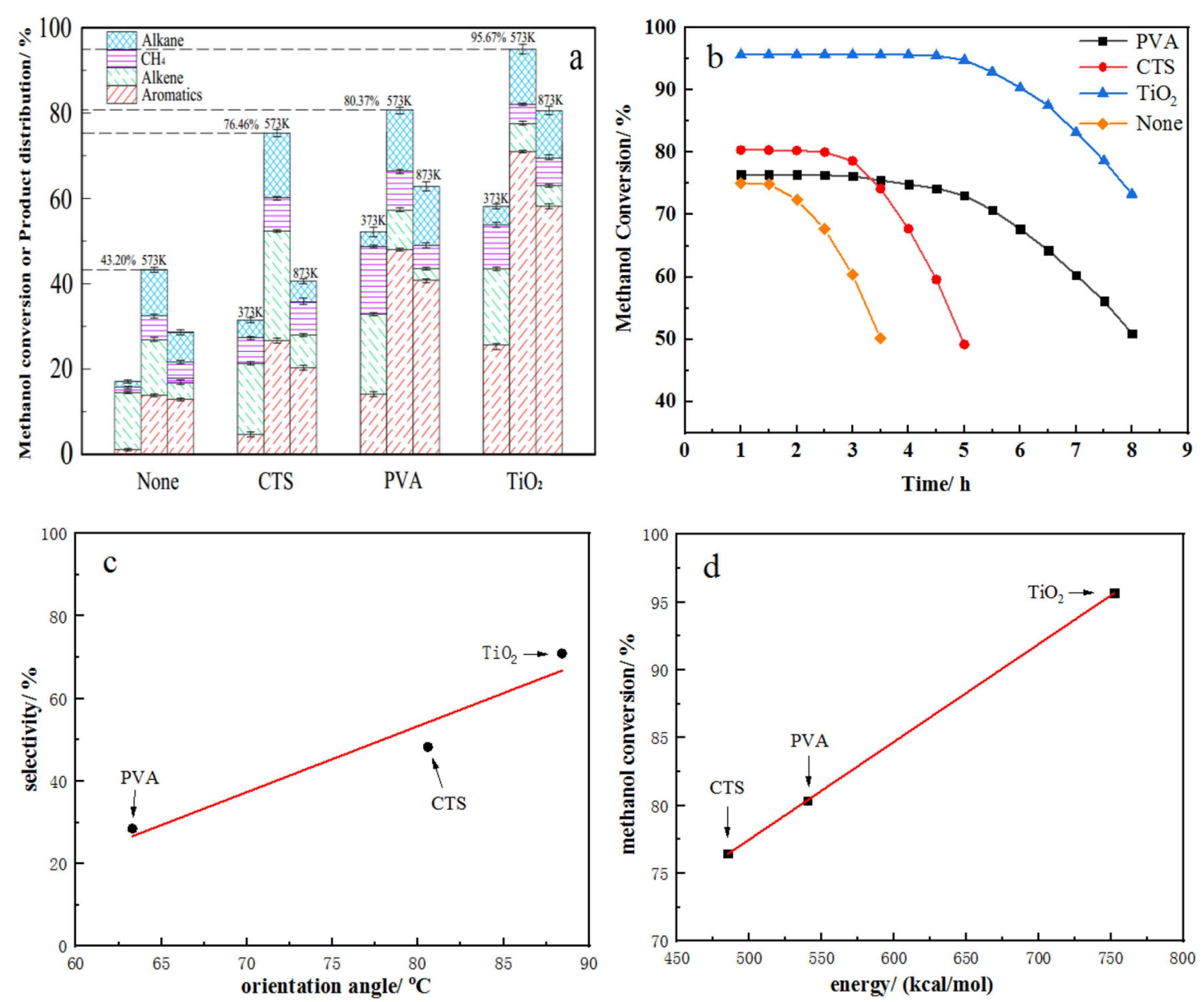

FIGURE 14 | (a) Activity and (b) lifetime of b-oriented ZSM-5 film in methanol-to-aromatics (MTA) reaction. (c) Linear fitting curve between orientation angle and selectivity and (d) between energy and conversion.

with 20 - $\AA$ thickness. $\mathrm{TiO}_{2}$ undergoes an island-like $(373 \mathrm{~K})$ to layered $(573 \mathrm{~K})$ to diffusion-free $(>573 \mathrm{~K})$ process on the surface of the substrate, indicating that $\mathrm{TiO}_{2}$ undergoes a process of non-dissociative adsorption to dissociation adsorption to diffusion on the surface of the substrate. At $573 \mathrm{~K}, \mathrm{ZSM}-5$ is embedded in the modified layer with a $b$-axis orientation, and the binding ability is the strongest. The order of implantation orientation angle of the $b$-axis orientation ZSM-5 on PVA, CTS, and $\mathrm{TiO}_{2}$-modified substrate surface is as follows: $\mathrm{TiO}_{2}$ (88.42) > CTS (85.65) > PVA (84.81). It shows that ZSM-5 has the best $b$-axis orientation on the surface of the substrate after $\mathrm{TiO}_{2}$ modification. In MTA reaction, we found that the $b$-ZSM$5 / \mathrm{TiO}_{2} /$ substrate catalyst produced high BTX hydrocarbons and exhibited long lifetimes. And the orientation angle is linearly correlated with aromatic hydrocarbon selectivity. Meanwhile, the interaction energy is linearly correlated with methanol conversion.

\section{DATA AVAILABILITY STATEMENT}

The datasets generated for this study are available on request to the corresponding author.

\section{AUTHOR CONTRIBUTIONS}

RC contributed significantly to the conception of the study. JW performed the data analyses and wrote the whole manuscript. $\mathrm{XM}$ and SY helped perform the analysis with constructive discussions. YW contributed reagents, materials, and analysis tools. CS, GZ, and TZ contributed to manuscript preparation.

\section{FUNDING}

This work was supported by the Fundamental Research Funds for the Central Universities (2017XKQY066). 


\section{REFERENCES}

Asghari, M., Sheikh, M., Afsari, M., and Asghari, M. (2017). Molecular simulation and experimental investigation of temperature effect on CSnanosilica supported mixed substrate membranes for dehydration of ethanol via pervaporation. J. Mol. Liquids 246, 7-16. doi: 10.1016/j.molliq.2017.09.045

Baguer, N., Georgieva, V., Calderin, L., Todorov, I., Gils, S. V., and Bogaerts, A. (2009). Study of the nucleation and growth of $\mathrm{TiO}_{2}$ and $\mathrm{ZnO}$ thin films by means of molecular dynamic simulations. J. Crystal Growth 311, 4034-4043. doi: $10.1016 /$ j.jcrysgro.2009.06.034

Brinkmann, A., Langer, F., Scholler, F., Shan, Z., Wilmers, J., Zhao, Y., et al. (2011). Molecular dynamic simulation of interfaces and surfaces in structures derived from a-quartz and ZSM-5crystallites. Phys. B 15-16, 2931-2947. doi: 10.1016/j.physb.2011.02.074

Cheng, Z. L., Liu, Z., and Wang, S. (2014). Preparation of MFI membrane on mesoporous-layer-modified macroporous $\mathrm{Al}_{2} \mathrm{O}_{3}$ substrate by secondary growth method and its permeation property. Appl. Mech. Mater. 633-634, 417-421. doi: 10.4028/www.scientific.net/AMM.633-634.417

Coupry, D. E., Addicoat, M. A., and Heine, T. (2017). Explicit treatment of hydrogen bonds in the universal force field: validation and application for metal-organic frameworks, hydrates, and host-guest complexes. J. Chem. Phys. 147, 276-8566. doi: 10.1063/1.4985196

Dahl, I. M., and Kolboe, S. (1994). On the reaction mechanism for hydrocarbon formation from methanol over SAPO-34: I. Isotopic labeling studies of the co-reaction of ethene and methanol. J. Catal. 149, 458-464. doi: $10.1006 /$ jcat. 1994.1312

Dai, S. S., Liu, Y., Zhang, J. H., Zhang, T., Huang, Z., and Zhao, X. (2017). Molecular dynamic simulation of core-shell structure: study of the interaction between modified surface of nano- $\mathrm{SiO}_{2}$, and PAMAA in vacuum and aqueous solution. Composite Interfaces 24, 897-914. doi: 10.1080/09276440.2017.1302398

Fang, T. H., Chang, W. J., and Chiu, J. W. (2006). Study on coalescent properties of $\mathrm{ZnO}$ nanoclusters using molecular dynamic simulation and experiment. Microelectr. J. 37, 722-727. doi: 10.1016/j.mejo.2005.12.007

Feng, S., and Bein, T. (1994). Growth of oriented molecular sieve crystals on organophosphonate films. Nature 368, 834-836. doi: 10.1038/368834a0

Froudakis, G. E. (2001). Hydrogen interaction with single-walled carbon nanotubes: a combined quantum-mechanics/molecular-mechanics study. Nano Lett. 1, 179-182. doi: 10.1021/nl015504p

Johnson, K. J., Cygan, R. T., and Fein, J. B. (2006). Molecular simulations of metal adsorption to bacterial surfaces. Geochimica Et Cosmochimica Acta 70, 5075-5088. doi: 10.1016/j.gca.2006.07.028

Koegler, J. H., Bekkum, H. V., and Jansen, J. C. (1997). Growth model of oriented crystals of zeolite Si-ZSM-5. Zeolites 19, 262-269. doi: 10.1016/S0144-2449(97)00088-2

Lang, L., Liu, X. F., and Zhang, B. Q. (2009). Controlling the orientation and coverage of silica-MFI zeolite films by surface modification. Appl. Surface Sci. 255, 4886-4890. doi: 10.1016/j.apsusc.2008.12.030

Lee, J. S., Lee, Y. J., Tae, E. L., Park, Y. S., and Yoon, K. B. (2003). Synthesis of zeolite as ordered multicrystal arrays. Science 301, 818-821. doi: $10.1126 /$ science. 1086441

Liu, A., Fan, J. C., and Fan, M. Q. (2015). Quantum chemical calculations and molecular dynamics simulations of amine collector adsorption on quartz $\left(\begin{array}{lll}0 & 0 & 1\end{array}\right)$ surface in the aqueous solution. Int. J. Mineral Process. 134, 1-10. doi: 10.1016/j.minpro.2014.11.001

Liu, Y., Wang, D., Peng, Q., Chu, D., Liu, X., and Li, Y. (2011). Directly assembling ligand-free $\mathrm{ZnO}$ nanocrystals into three-dimensional mesoporous structures by oriented attachment. Inorg Chem 50, 5841-5847. doi: 10.1021/ic2009013

Rappe, A. K., Casewit, C. J., Colwell, K. S., Goddard, W. A., and Skiff, W. M. (1992). UFF, a full periodic table force field for molecular mechanics and molecular dynamics simulations. J. Am. Chem. Soc. 114, 10024-10035. doi: $10.1021 /$ ja00051a040

Razmimanesh, F., Amjad-Iranagh, S., and Modarress, H. (2015). Molecular dynamic simulation study of CS and gemcitabine as a drug delivery system. J. Mol. Model. 21:165. doi: 10.1007/s00894-015-2705-2

Sang, L. X. (2004). Preparation of Supported Composite Semiconductor and Photocatalytic Performance of Methane and Water Reaction. Tianjin: Tianjin University.

Sharma, S., Chandra, P., Kumar, R., and Kumar, N. (2015). Thermo-mechanical characterization of multi-walled carbon nanotube reinforced polycarbonate composites: a molecular dynamic approach. Compt. Rendus Mécanique 343, 371-396. doi: 10.1016/j.crme.2015.03.002

Tarabaev, L. P., and Esin, V. O. (2007). Computer simulation of the crystal morphology and growth rate during ultrarapid cooling of an Fe-B Melt. Russian Metallurgy 2007, 478-483. doi: 10.1134/S0036029507060079

Wang, Z. B., and Yan, Y. S. (2001). Oriented zeolite MFI monolayer films on metal substrates by in situ crystallization. Micropor. Mesopor. Mater. 48, 229-238. doi: 10.1016/S1387-1811(01)00357-2

Wang, Z. X., Yan, W. F., Tian, D. Y., Cao, X. J., and Xu, R. R. (2010). Preparation of high b-oriented silicalite-1 molecular sieve membrane. J. Phys. Chem. 26, 2044-2048. doi: 10.3866/PKU.WHXB20100714

Wei, H., Xie, S., Liu, K., Xin, W., Li, X., Liu, S., et al. (2015). CTAB modification of MCM-49 zeolite containing HMI and its acylation of anisole. Chinese J. Catal. 36, 1766-1776. doi: 10.1016/S1872-2067(15)60887-7

Wei, Q. H., Zhang, Y., Wang, Y. F., and Yang, M. (2017). A molecular dynamic simulation method to elucidate the interaction mechanism of nano- $\mathrm{SiO}_{2}$ in polymer blends. J. Mater. Sci. 52, 12889-12901. doi: 10.1007/s10853-017-1330-0

Yan, L., Yang, Y., Jiang, H., Zhang, B., and Zhang, H. (2016). The adsorption of methyl methacrylate and vinyl acetate polymers on $\alpha$ quartz surface: a molecular dynamic study. Chem. Phys. Lett. 643, 1-5. doi: 10.1016/j.cplett.2015.11.006

Yang, L., Liu, Z., Liu, Z., Peng, W., Liu, Y., and Liu, C. (2017a). Product distribution and catalytic performance of nano-sized H-ZSM- 5 zeolites in the methanol-to-aromatics (MTA) reaction. Petroleum Sci. Technol. 35, 955-962. doi: 10.1080/10916466.2017.1292293

Yang, L., Liu, Z., Liu, Z., Peng, W., Liu, Y., and Liu, C. (2017b). Correlation between H-ZSM-5 crystal size and catalytic performance in the methanol-to-aromatics reaction. Chinese J. Catalysis 38, 683-690. doi: 10.1016/S1872-2067(17) 62791-8

Zeng, Y., Tao, B., Chen, J., and Yin, Z. (2015). Temperature-dependent orientation study of the initial growth of pentacene on amorphous $\mathrm{SiO}_{2}$ by molecular dynamic simulations. J. Crystal Growth 429, 35-42. doi: 10.1016/j.jcrysgro.2015.07.033

Zeng, Y. Q., Tao, B., Chen, J., and Yin, Z. (2015). Temperature-dependent orientation study of the initial growth of pentacene on amorphous $\mathrm{SiO}_{2}$ by molecular dynamics simulations. J. Crystal Growth 429, 35-42. doi: 10.1016/j.jcrysgro.2015.07.033

Conflict of Interest: The authors declare that the research was conducted in the absence of any commercial or financial relationships that could be construed as a potential conflict of interest.

Copyright (๑) $2019 \mathrm{Wu}$, Meng, Chu, Yu, Wan, Song, Zhang and Zhao. This is an open-access article distributed under the terms of the Creative Commons Attribution License (CC BY). The use, distribution or reproduction in other forums is permitted, provided the original author(s) and the copyright owner(s) are credited and that the original publication in this journal is cited, in accordance with accepted academic practice. No use, distribution or reproduction is permitted which does not comply with these terms. 
OPEN ACCESS

Edited by:

Qiang Wang,

Beijing Forestry University, China

Reviewed by:

Clara S. B. Gomes,

New University of Lisbon, Portugal

Peng Lu,

Ningbo University, China

*Correspondence: Nicholas M. Musyoka nmusyoka@csir.co.za

Specialty section This article was submitted to Inorganic Chemistry, a section of the journa

Frontiers in Chemistry

Received: 22 May 2019 Accepted: 28 November 2019 Published: 17 December 2019

Citation:

Molefe LY, Musyoka NM, Ren J, Langmi HW, Mathe $M$ and Ndungu PG (2019) Polymer-Based

Shaping Strategy for Zeolite Templated Carbons (ZTC) and Their

Metal Organic Framework (MOF) Composites for Improved Hydrogen Storage Properties.

Front. Chem. 7:864.

doi: $10.3389 /$ fchem.2019.00864

\section{Polymer-Based Shaping Strategy for Zeolite Templated Carbons (ZTC) and Their Metal Organic Framework (MOF) Composites for Improved Hydrogen Storage Properties}

\author{
Lerato Y. Molefe $^{1,2}$, Nicholas M. Musyoka ${ }^{1,2 *}$, Jianwei Ren ${ }^{1}$, Henrietta W. Langmi ${ }^{1,3}$, \\ Mkhulu Mathe ${ }^{1}$ and Patrick G. Ndungu ${ }^{2}$ \\ ${ }^{1}$ HySA Infrastructure Centre of Competence, Energy Centre, Council for Scientific and Industrial Research (CSIR), Pretoria, \\ South Africa, ${ }^{2}$ Department of Chemical Sciences, University of Johannesburg, Johannesburg, South Africa, ${ }^{3}$ Department of \\ Chemistry, University of Pretoria, Pretoria, South Africa
}

Porous materials such as metal organic frameworks (MOFs), zeolite templated carbons (ZTC), and some porous polymers have endeared the research community for their attractiveness for hydrogen $\left(\mathrm{H}_{2}\right)$ storage applications. This is due to their remarkable properties, which among others include high surface areas, high porosity, tunability, high thermal, and chemical stability. However, despite their extraordinary properties, their lack of processability due to their inherent powdery nature presents a constraining factor for their full potential for applications in hydrogen storage systems. Additionally, the poor thermal conductivity in some of these materials also contributes to the limitations for their use in this type of application. Therefore, there is a need to develop strategies for producing functional porous composites that are easy-to-handle and with enhanced heat transfer properties while still retaining their high hydrogen adsorption capacities. Herein, we present a simple shaping approach for ZTCs and their MOFs composite using a polymer of intrinsic microporosity (PIM-1). The intrinsic characteristics of the individual porous materials are transferred to the resulting composites leading to improved processability without adversely altering their porous nature. The surface area and hydrogen uptake capacity for the obtained shaped composites were found to be within the range of $1,054-2,433 \mathrm{~m}^{2} \mathrm{~g}^{-1}$ and $1.22-1.87 \mathrm{H}_{2}$ wt. \%, respectively at 1 bar and $77 \mathrm{~K}$. In summary, the synergistic performance of the obtained materials is comparative to their powder counterparts with additional complementing properties.

Keywords: hydrogen storage, physisorption, polymers of intrinsic microporosity, zeolite templated carbon, metal organic frameworks

\section{INTRODUCTION}

The current state-of-the-art for hydrogen $\left(\mathrm{H}_{2}\right)$ storage in fuel cell vehicles is compression at 700 bar of which the storage tank is heavy, expensive and can also cause safety problems. Typically, type IV cylinder in fuel cell vehicles can store $\geq 5$ wt. \% of $\mathrm{H}_{2}$ at 700 bar (Hua et al., 2017). Therefore, strategies for developing alternative effective and efficient methods for storing $\mathrm{H}_{2}$ still 


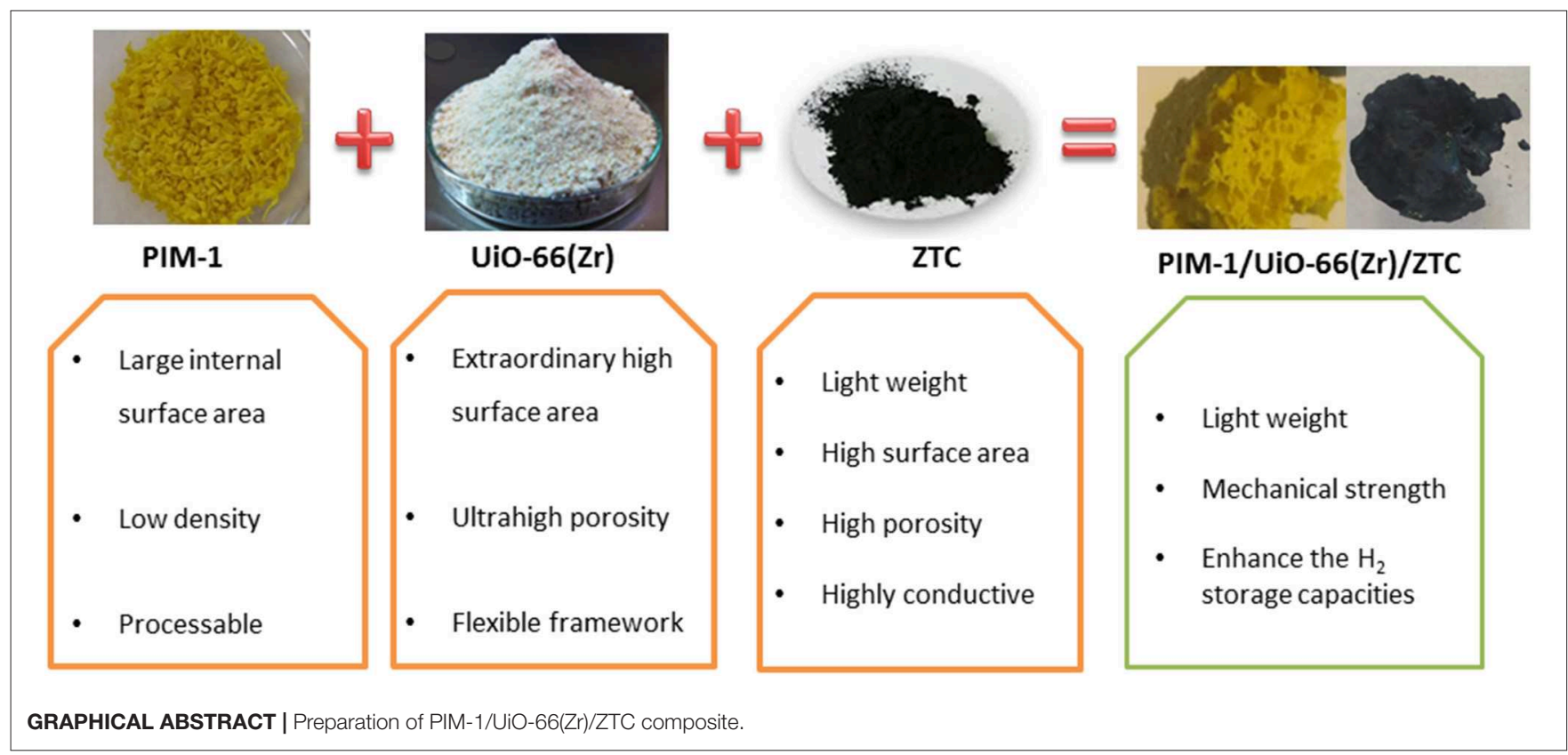

remain a challenge. The proposed 2020 United States Department of Energy (DOE) targets for on-board $\mathrm{H}_{2}$ storage systems (include valves, pressure containment, cooling systems, etc.) are $4.5 \mathrm{wt}$. $\%$ and $0.030 \mathrm{~kg} \mathrm{H}_{2} / \mathrm{L}$ for gravimetric and volumetric storage, respectively (US Department of Energy, 2018). The tremendous research progress made in nanoporous materials for hydrogen storage applications shows great promise. Materials with high surface areas such as metal organic frameworks, carbons and porous polymers can store hydrogen through physisorption at safer low pressures and possess good reversibility as well as fast kinetics (Yang et al., 2011). Moreover, high gravimetric $\mathrm{H}_{2}$ capacities up to 8.9 wt. \% at $77 \mathrm{~K}$ and 30 bar on activated carbons (Blankenship et al., 2017) and a maximum total of $10 \mathrm{wt}$. \% on NOTT-112 MOFs can be achieved at $77 \mathrm{~K}$ and 77 bar (Yan et al., 2009). Whereas, at low pressures, maximum amounts of $\mathrm{H}_{2}$ adsorbed on MOFs are slightly lower and have been reported to be around 2.5 wt. \% (Rowsell and Yaghi, 2006) while carbons such as CA-4700 have 3.9 wt \% at $77 \mathrm{~K}$ and 1 bar (Blankenship et al., 2017). However, volumetric capacities remain low at same conditions (Kaye et al., 2007). Therefore, the properties of these adsorbents must be improved to achieve high gravimetric and volumetric capacities at both low and ambient temperatures to become practically viable for their inclusion into an on-board $\mathrm{H}_{2}$ storage system. Furthermore, nanoporous materials need modifications in order to enhance other physical properties such as thermal conductivity that is required for fast heat dissipation and mechanical strength required for better handling. These additional properties are crucial in practical applications.

Metal organic frameworks (MOFs) are a class of crystalline and highly porous hybrid materials consisting of metallic ions and organic ligands (Férey, 2008). The properties of MOFs can be tuned by using a variety of metal ions and organic linkers during synthesis (Hu and Zhao, 2015). Besides application in drug delivery, gas separation and catalysis, MOFs not only exhibit interesting properties for gas adsorption and storage but can also be used as sensors, among other applications (Murray et al., 2009; Della Rocca et al., 2011; Kreno et al., 2011; Stavila et al., 2014). In this study, the interest of zirconium-carboxylate Universitetet i Oslo (UiO-66(Zr)) MOF was due to its excellent mechanical, chemical, and thermal stabilities (Cavka et al., 2008). In addition to MOFs, conductive carbon nanostructured materials such as zeolite templated carbons (ZTCs) whose structure consists of a three-dimensional network of buckybowl-like nanographene (Nishihara et al., 2009) have emerged as attractive materials for $\mathrm{H}_{2}$ storage applications due to their high surface area, high porosity, light weight and high thermal conductivity (Yang et al., 2016).

The synthesis of porous composites has emerged as an attractive strategy for enhancing the intrinsic properties of the individual materials. For instance, Musyoka et al. (2017) investigated the in-situ compositing of the zirconium based $\mathrm{UiO}$ 66 MOF with reduced graphene oxide (rGO) and observed an increased surface area coupled with enhanced hydrogen uptake capacity for the rGO/Zr-MOF composite in comparison to pristine $\mathrm{Zr}$-MOF. The mechanism of hydrogen adsorption in carbon material was reported to be through dissociation and chemisorption of hydrogen on the carbon sites with isolated hydrogen being easier to diffuse on the carbon materials (Wang et al., 2016). Particularly, composites of MOFs with carbon materials are of great interest because carbon materials have high thermal conductivity, which is beneficial for heat management during hydrogen cycling (Ngene et al., 2017). However, despite their enhanced hydrogen sorption behavior, $\mathrm{MOF} /$ Carbon composites still have processing challenges. Hence recently, fabrication of various types of polymer based carbon 
and MOF composites have been investigated and identified as an interesting strategy not only for improving the performance but also for shaping of these materials.

On the other hand, a highly processable polymer of intrinsic microporosity (PIM-1) is an attractive adsorbent material that is soluble in common solvents and it can be casted into mechanically stable structures (Budd et al., 2004). However, most focus has been on improving the adsorptive properties of these materials for high uptake capacities and very little effort has been done on tailoring the materials for large scale applications properties. In a recent study by Tien-Binh et al. (2018) defect-free mixed matrix membranes (MMM) made up of PIM-1 and UiO$66-\mathrm{NH}_{2}$ filler were prepared by in-situ chemical cross-linking of UiO-66- $\mathrm{NH}_{2}$ with PIM-1 during polymer synthesis to improve the poor polymer-filler adhesion. It was reported that the in-situ chemical reaction between 1,4-dicyanotetrafluorobenzene monomer and amine groups of UiO-66(Zr) MOF lead to direct grafting of PIM-1 onto the MOF surface and thus enhancing polymer-filler adhesion and gas separation performance (higher permeability and selectivity for all the gases tested).

There have been other several studies on PIM-1/UiO-66 MMM (Khdhayyer et al., 2017; Tien-Binh et al., 2018; Yu et al., 2019), however their scope was limited to membranes for gas separation applications. Several other studies have also reported on other types of MOF/Carbon composites such as MOF-5/expanded natural graphite (ENG) (Liu et al., 2012), MIL101(Cr)/ZTC (Musyoka et al., 2016) and HKUST-1/graphene platelets (Hassan et al., 2019). Additionally, other MOF/polymer composites such as PIM-1/MIL-101 (Cr) (Khdhayyer et al., 2019), PIM-1/UiO-66 (Khdhayyer et al., 2017), PIM-1/UiO-66$\mathrm{NH}_{2}$ (Tien-Binh et al., 2018), PIM-1/UiO-66-CN (Yu et al., 2019) and Matrimid/UiO-66 MMMs (Marti et al., 2018) have been reported. However, no work has been done on composites materials consisting of the three pristine materials (carbon/polymer/MOF) for $\mathrm{H}_{2}$ adsorption applications. In our previous work (Molefe et al., 2019) we reported that upon increasing the MOF loading in PIM-1/MIL-101(Cr) composites, the surface area, pore volume and $\mathrm{H}_{2}$ adsorption capacity increased significantly. Our findings showed that $80 \mathrm{wt} \%$ loading of MIL-101(Cr) onto PIM-1 exhibits enhanced $\mathrm{H}_{2}$ uptake with no pore blocking effects. Hence, the optimized filler loading of 80 wt $\%$ was also chosen for the current study. However, the polymer/MOF composites still lacked thermal conductivity. Therefore, it is on this basis that the current study presents the merging of physico-chemical properties of ZTC, PIM-1 and UiO66(Zr) MOF into mouldable functional composites. In as much as all the three pristine materials can serve as individual $\mathrm{H}_{2}$ adsorbents, ZTC in this case serves as the thermal conductivity enhancer whereas the PIM-1 also serves as the binder material.

\section{MATERIALS AND METHODS}

\section{Chemicals}

In this study, the Potassium carbonate $\mathrm{N}, \mathrm{N}$-dimethylformamide

following

$\left(\mathrm{K}_{2} \mathrm{CO}_{3}\right.$,

(DMF, chemicals were used: Sigma-Aldrich, $99+\%)$, Sigma-Aldrich, 99.8\%),

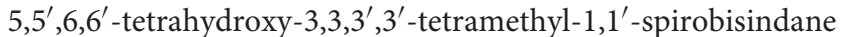
(TTSBI, Sigma-Aldrich), 1,2,2-tetrachloroethane (TCE, SigmaAldrich, 98.0+\%), 2,3,5,6 tertrafluoroterephthalonitrile (TFTPN, Sigma-Aldrich, 99\%), 13X powder (Sigma-Aldrich, $\sim 2 \mu \mathrm{m}$ average particle size), furfuryl alcohol (FA, Sigma-Aldrich, $97+\%)$, hydrofluoric acid (HF, Ace chemicals, 97+\%), hydrochloric acid ( $\mathrm{HCl}$, Ace chemicals, 37+\%), Anhydrous chloroform $\left(\mathrm{CHCl}_{3}\right.$, Sigma-Aldrich, 99.9+\%), Zirconium chloride $\left(\mathrm{ZrCl}_{4}\right.$, Sigma-Aldrich, 99.5+\%), terephthalic acid (BDC, Sigma-Aldrich, 98\%), formic acid ( $\mathrm{HCOOH}$, SigmaAldrich, 99.5+\%), methanol $\left(\mathrm{CH}_{3} \mathrm{OH}\right.$, Sigma-Aldrich, 99.9+\%), ethanol (Ace chemicals, 90\%) and de-ionized water were purchased and used without further purification. Hydrogen and nitrogen $\left(\mathrm{N}_{2}\right)$ gases of ultra-high purity grade purchased from Afrox Company, South Africa were used for sample analysis.

\section{Experimental Procedure Synthesis of ZTC}

In this study, the synthesis of ZTC was prepared based on the previously reported two step procedure involving furfuryl alcohol impregnation of zeolite $13 \mathrm{X}$ followed by its chemical vapor deposition (Masika and Mokaya, 2013; Musyoka et al., 2016). In summary, zeolite $13 \mathrm{X}$ ( $24 \mathrm{~g}$ ) was dried in the vacuum oven at $120^{\circ} \mathrm{C}$ under vacuum for $12 \mathrm{~h}$ prior to its impregnation with $80 \mathrm{ml}$ of furfuryl alcohol (FA) at room temperature. After subjecting the FA/zeolite mixture to magnetic stirring for $24 \mathrm{~h}$, the mixture was filtered and washed with a few drops of ethanol to remove the excess furfuryl alcohol. Subsequently, the FA /zeolite mixture was placed on high purity quartz crucible and transferred into an alumina ceramic tube furnace where it was polymerised at $80^{\circ} \mathrm{C}$ for $24 \mathrm{~h}$ under argon gas flow $(100 \mathrm{~mL}$ $\mathrm{min}^{-1}$ ). Thereafter, polymerisation was continued by heating the mixture at $150^{\circ} \mathrm{C}$ for further $8 \mathrm{~h}$. The resulting hybrid was further heated up to $700^{\circ} \mathrm{C}$ under argon flow to allow stabilization of the composite. After $3 \mathrm{~h}$, still at $700{ }^{\circ} \mathrm{C}$, the gas flow was switched to a mixture of ethylene/argon (10\% ethylene in argon) and held for $3 \mathrm{~h}$. The gas flow was switched back to argon only, while the temperature was being ramped up to $900^{\circ} \mathrm{C}$ and carbonization occurred for $3 \mathrm{~h}$. Still under argon flow, the resulting product, referred to as zeolite/carbon composite was then cooled down to room temperature. The sample was washed in $10 \%$ aqueous solution of hydrofluoric acid for $24 \mathrm{~h}$, followed by diluting the aqueous solution to $2 \mathrm{~L}$ with deionised water and filtered. The sample was further refluxed in $10 \%$ aqueous solution of hydrochloric acid for $24 \mathrm{~h}$. Finally, the resulting carbonaceous materials called ZTC was collected by filtration and washed with $2 \mathrm{~L}$ of deionised water and dried in a vacuum oven at $120^{\circ} \mathrm{C}$ for $12 \mathrm{~h}$.

\section{Synthesis of UiO-66(Zr)}

The synthesis method for $\mathrm{UiO}-66(\mathrm{Zr})$ was as reported in a previous study (Ren et al., 2014) with some changes. In a typical procedure, $1.06 \mathrm{~g}$ of $\mathrm{ZrCl}_{4}$ and $0.68 \mathrm{~g}$ of BDC were dissolved in $50 \mathrm{~mL}$ of DMF and sonicated for $30 \mathrm{~min}$. The resulting mixture along with $17.13 \mathrm{~mL}$ of formic acid was transferred into a $250 \mathrm{~mL}$ round bottom flask connected to a reflux system. Subsequently, the system was placed in an oil bath pre-heated at $120^{\circ} \mathrm{C}$ and 
kept for $4 \mathrm{~h}$. Finally, the obtained white precipitate was collected by centrifugation followed by washing with ethanol at $60^{\circ} \mathrm{C}$. The final product was then dried at $90^{\circ} \mathrm{C}$ in a conventional oven.

\section{Synthesis of PIM-1}

PIM-1 was prepared through a double nucleophilic aromatic substitution reaction between two monomers (TTSBI and TFTPN) in the presence of anhydrous $\mathrm{K}_{2} \mathrm{CO}_{3}$ catalyst as per typical procedure reported by Budd et al. (2004). In this case, a mixture of equimolar ratio amounts of TTSBI and TFTPN and certain amount of anhydrous $\mathrm{K}_{2} \mathrm{CO}_{3}$ catalyst (8 equivalent with respect to monomers) was evacuated and backfilled with nitrogen gas prior to dissolving in $100 \mathrm{ml}$ of anhydrous DMF. The mixture was kept under nitrogen flow and heated to $65^{\circ} \mathrm{C}$ under vigorous magnetic stirring. After $72 \mathrm{~h}$, the resulting yellow precipitate was cooled and dispersed in $300 \mathrm{ml}$ of deionised water and stirring continued for $1 \mathrm{~h}$. The obtained solid was collected by vacuum filtration followed by dissolving in chloroform and re-precipitated in methanol. The final product was dried at $80^{\circ} \mathrm{C}$ for $12 \mathrm{~h}$ in a vacuum oven.

\section{Synthesis of PIM-1/UiO-66(Zr)/ZTC Composites}

Different composites samples of PIM-1/80 wt\% UiO-66(Zr), PIM-1/80 wt $\%$ ZTC and PIM-1/UiO-66(Zr)/ZTC (80 wt\%) were prepared by physical mixing of pre-synthesized polymer and $\mathrm{MOF} /$ carbon powders using TCE solvent. The UiO-66(Zr) and ZTC powders were degassed at $200^{\circ} \mathrm{C}$ for $4 \mathrm{~h}$ prior to experiment to remove any adsorbed solvent or water. In the case of PIM-1/80 wt\% UiO-66(Zr), a procedure similar to the recently reported method for PIM-1/80 wt $\%$ MIL-101(Cr) composite (Molefe et al., 2019) was followed but using a different type of MOF. By modifying the synthetic method for PIM-1/80 wt\% $\mathrm{UiO}-66(\mathrm{Zr})$ through substitution of $\mathrm{UiO}-66(\mathrm{Zr})$ with ZTC, a black monolith with 80 wt\% of ZTC and 20 wt\% PIM-1 was obtained. On the other hand, the PIM-1/UiO-66(Zr)/ZTC (80 wt\%) composite consisting of $20 \mathrm{wt} \%$ PIM-1, $40 \mathrm{wt} \%$ ZTC and $40 \mathrm{wt} \% \mathrm{UiO}-66(\mathrm{Zr})$ in TCE solvent was prepared through the same solvent impregnation method. The resulting mixture was then heated at $150^{\circ} \mathrm{C}$ to remove the residual solvent inside the monolith composite.

\section{Sample Characterization}

The crystallinity analyses of the samples was conducted using the powder X-ray diffractometer (PANalytical X'Pert Pro), with a Pixcel detector $\left(\mathrm{Cu}-\mathrm{K}_{\alpha}\right.$ radiation $\left.\lambda=0.154 \mathrm{~nm}\right)$. The powder $\mathrm{X}$-ray diffraction (PXRD) patterns were measured at scanning rate of $2^{\circ} \mathrm{min}^{-1}$ at room temperature. TGA/SDTA $851^{\mathrm{e}}$ instrument (Mettler, Toledo) was used for thermogravimetric analysis (TGA). The samples were heated at a heating rate of

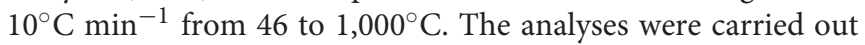
under air $\left(60 \mathrm{~mL} \mathrm{~min}^{-1}\right)$ and nitrogen flow $\left(40 \mathrm{~mL} \mathrm{~min}^{-1}\right)$ as a balance gas. All Fourier transform infra-red (FTIR) spectra were obtained using a Perkin-Elmer Spectrum 100 FTIR spectrometer, working in the range from 4,000 to $400 \mathrm{~cm}^{-1}$ with a resolution of $4 \mathrm{~cm}^{-1}$ in attenuated total reflection (ATR) mode. Prior to each FTIR measurements, 8 scans of the background were collected. The morphology of the obtained samples was observed using the focused ion beam scanning electron microscope (Carl Zeiss Auriga Cobra). The nitrogen and hydrogen sorption (up to 1 bar) isotherms were obtained from a Micrometrics ASAP 2020 $\mathrm{HD}$ analyser at $77 \mathrm{~K}$. The specific surface areas by BrunauerEmmett-Teller (BET) theory was obtained from the nitrogen physisorption isotherms. Prior to the gas sorption experiment, the samples were degassed in the degassing port under vacuum (down to $10^{-7}$ bar) at $200^{\circ} \mathrm{C}$ for at least $8 \mathrm{~h}$ for removal of moisture or other volatile residues.

\section{RESULTS AND DISCUSSION}

The PXRD pattern for the prepared UiO-66 ( $\mathrm{Zr}$ ) exhibited the main characteristic peaks which are consistent with the previous reported studies (Ren et al., 2014) and confirms the formation of pure crystalline MOF. The observed crystallinity complement the respective SEM image (Figure 4d), showing highly defined octahedral shaped crystals with sharp edges as an attribute of the presence of 100 equivalent of modulator (formic acid) used during their synthesis. The ZTC sample showed a diffraction peak at $6.2^{\circ} 2$-theta similar to that of the zeolite $13 \mathrm{X}$ template, indicating a replication of zeolite $13 \mathrm{X}$-type structural pore ordering in ZTC and also confirms successful templating process (Xia et al., 2011; Musyoka et al., 2018). After incorporating the UiO-66 (Zr) and ZTC into the PIM-1 matrix to obtain PIM-1/80 wt\%UiO-66(Zr) and PIM-1/80 wt\% ZTC composites materials, the characteristics peaks of fillers were still present and dominant. Thus, indicating that the crystal structures of fillers were retained upon the crosslinking process between the polymer matrix and filler materials. As observed in Figure 1, the diffraction patterns of composite materials are dominated by strong diffraction peaks resulting from $\mathrm{UiO}-66(\mathrm{Zr})$ and ZTC, respectively, coupled with a bit of amorphousness from PIM-1's presence which is not that much prominent because of its low weight percentages $(20 \mathrm{wt} \%)$. On the other hand, for PIM-1/UiO$66(\mathrm{Zr}) / \mathrm{ZTC}(80 \mathrm{wt} \%)$, the characteristic peaks of $\mathrm{UiO}-66(\mathrm{Zr})$ are dominant and clearly observed compared to those of ZTC and amorphous nature of PIM-1 and the crystal phase structure of $\mathrm{UiO}-66(\mathrm{Zr})$ is still maintained.

To further investigate the properties of the obtained composites, thermal behavior of all the pristine and composites materials was investigated. As depicted in the TGA curves (Figure 2), the thermal stability was found to follow the order of ZTC $>$ PIM-1/80 wt\% ZTC> UiO-66(Zr)> PIM-1/80 wt\% $\mathrm{UiO}-66(\mathrm{Zr})>\mathrm{PIM}-1>\mathrm{PIM}-1 / \mathrm{UiO}-66(\mathrm{Zr}) / \mathrm{ZTC}(80 \mathrm{wt} \%)$. Even though the incorporation of ZTC led to the improvement of thermal stability of PIM/80 wt $\%$ ZTC composite, it was interesting to note that the inclusion of $\mathrm{UiO}-66(\mathrm{Zr})$ in the composite containing the 3 filler materials (PIM-1/UiO66(Zr)/ZTC (80 wt\%)) had lesser thermal stability but still within the attractive ranges for most porous materials. In general, the thermal stability of PIM-1 (up to $415^{\circ} \mathrm{C}$ ) is known to be due to the presence of strong interactions of the nitrile groups (Du et al., 2008). On the other hand, UiO-66(Zr) weight loss at temperatures below $150{ }^{\circ} \mathrm{C}$ is often ascribed to the evaporation of adsorbed solvent and/or water molecules. The additional weight 


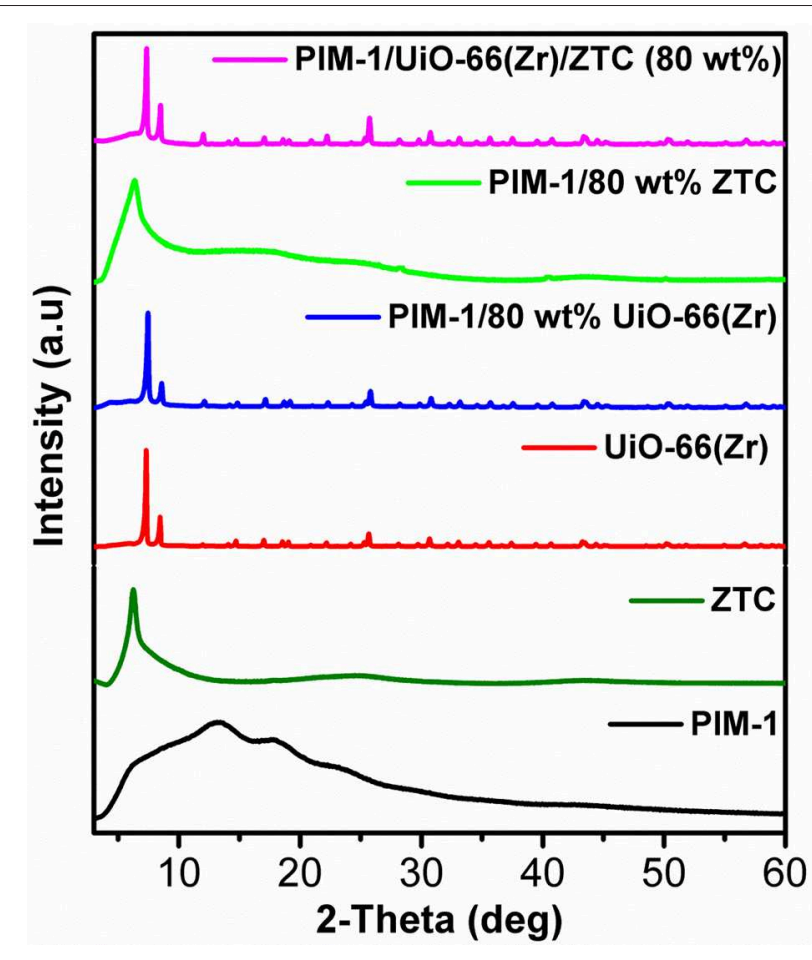

FIGURE 1 | Stacked PXRD patterns of PIM-1, ZTC, UiO-66 (Zr) and their corresponding composites samples.

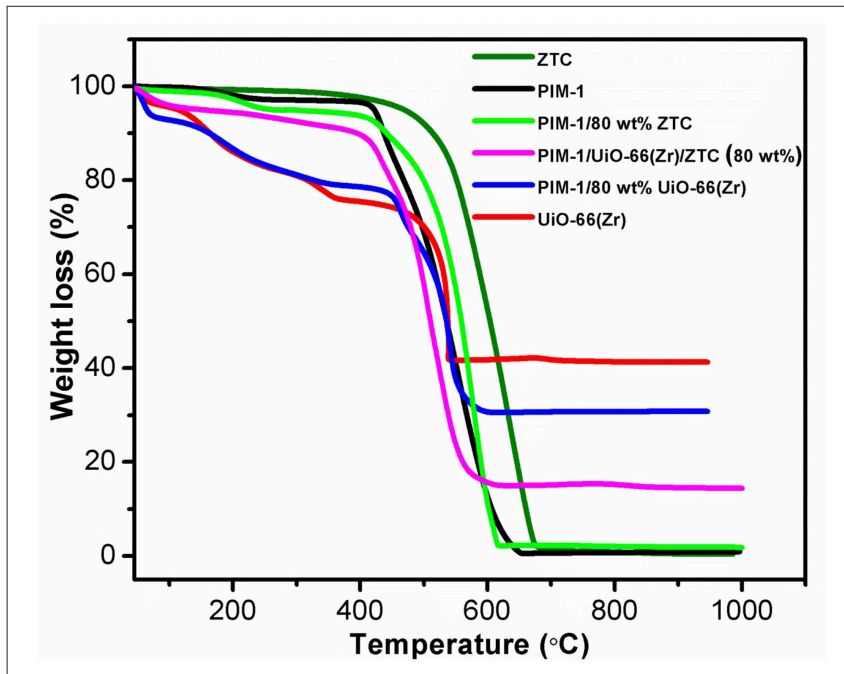

FIGURE 2 | TGA thermograms of PIM-1, UiO-66 (Zr), ZTC and their corresponding composites samples.

loss appearing in the range of 150 to $362{ }^{\circ} \mathrm{C}$ is attributed to the dehydroxylation of $\mathrm{Zr}_{6}$ clusters before the commencement of the final weight loss starting from $475^{\circ} \mathrm{C}$ until the MOFs finally degrades to $\mathrm{ZrO}_{2}$. This trend in weight loss is observed in all the MOF-containing composites synthesized in this study.

Fourier transform infra-red was used for probing and confirming the chemical composition of the resulting composites and the cross-linking between the PIM-1 matrix and the

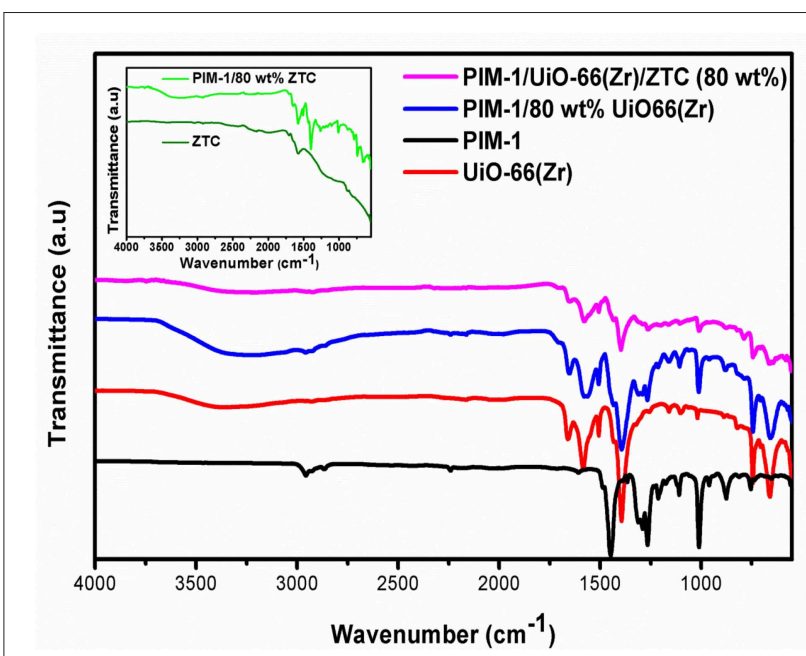

FIGURE 3 | FTIR spectra of UiO-66(Zr), PIM-1/80 wt\% UiO-66(Zr), $\mathrm{PIM}-1 / \mathrm{UiO}-66(\mathrm{Zr}) / \mathrm{ZTC}(80 \mathrm{wt} \%)$ in comparison with pristine PIM-1 and an insert showing the ZTC and PIM-1/80 wt\% ZTC spectra.

filler materials (ZTC and UiO-66(Zr)). In Figure 3, the FTIR spectrum of pristine PIM-1 displays the C-O stretch $(1,213-$ $1,250 \mathrm{~cm}^{-1}$ ) (Chaukura and Maynard-Atem, 2015), and the characteristic nitrile $(-\mathrm{C} \equiv \mathrm{N})$ stretch (around 2,229 $\mathrm{cm}^{-1}$ ) (Patel and Yavuz, 2012). The intense peak around $1,446 \mathrm{~cm}^{-1}$ is due to $\mathrm{C}=\mathrm{C}$ stretch vibrations and the other peaks observed at $1,105-1,015 \mathrm{~cm}^{-1}$ and $872 \mathrm{~cm}^{-1}$ can be assigned to C-C and C$\mathrm{O}$ stretching vibrations, respectively. On the other hand, the IR spectrum of pristine UiO-66(Zr) showed characteristic vibration peaks of benzene ring at 1,510 and $1,403 \mathrm{~cm}^{-1}$ which agrees with reported literature (Luan et al., 2015). The intense doublet peaks at 1,657 and $1,581 \mathrm{~cm}^{-1}$ could be attributed to the in- and outof-phases stretching modes of the carboxylate groups that are present in terephthalic acid linker (Zhu et al., 2014). The peaks at around 811,748 and $658 \mathrm{~cm}^{-1}$ corresponds to the $\mathrm{O}-\mathrm{H}$ and $\mathrm{C}-\mathrm{H}$ vibrations in the BDC ligand (Yang et al., 2017).

A strong broad peak observed in the range of 3,300-3,500 $\mathrm{cm}^{-1}$ is attributed to the presence of hydroxyl groups from moisture adsorbed onto the surface of UiO-66 and composite materials. According to Nishihara et al. (2009), the idealized molecular structure of ZTC has edge sites of the buckybowl units containing different types of functional groups and a significant amount of oxygen. In this case, spectra of the pristine ZTC and PIM-1/80 wt\% ZTC composite (Figure 3) showed a peak at around $1,720 \mathrm{~cm}^{-1}$ which can be ascribed to $\mathrm{C}=\mathrm{O}$ stretching and a distinct band at $1,600 \mathrm{~cm}^{-1}$ assigned to the presence of carbonyl groups. The weak broad band in the ranges of 1,000-1,400 $\mathrm{cm}^{-1}$ for the ZTC sample was also observed by Nishihara et al. (2009) and can be attributed to $\mathrm{C}-\mathrm{O}$ stretch. At the high carbonization temperature of $900^{\circ} \mathrm{C}$, during chemical vapor decomposition process, phenolic $\mathrm{OH}$ groups are completely decomposed and hence the absence of the typical broad band in the range of 3,200-3,400 $\mathrm{cm}^{-1}$ in the pristine ZTC (Fukuhara et al., 2013). On the other hand, the effect of PIM-1 on the composites (PIM$1 / 80$ wt\% UiO-66(Zr) and PIM-1/UiO-66(Zr)/ZTC (80 wt\%)) 
was found to be minimal and the expected PIM-1 peaks were masked by the prominence of UiO-66( $\mathrm{Zr})$ peaks. However, in PIM-1/80 wt $\%$ ZTC composite all of the PIM-1 peaks were clearly observed. Due to the absence of new peaks in the resulting PIM$1 / \mathrm{MOF} / \mathrm{ZTC}$ composite, it was inconclusive to confirm whether there was cross-linking that occurred between the polymeric binder and filler materials.

The SEM images of both parent zeolite and resulting ZTC neat materials (as seen in Figures $\mathbf{4 a , b}, \mathbf{c}$ ) clearly show almost similar octahedral pyramidal morphology as earlier reported by Musyoka et al. (2016) and Yang et al. (2007). Octahedral shaped crystal morphology for the UiO-66(Zr) was also observed and is consistent with the previous reports (Ren et al., 2014). On the other hand, SEM images for composites materials confirm that the ZTC and UiO-66(Zr) are well-dispersed and embedded in PIM-1 matrix phase. In Figure 4f, the dominating MOF and ZTC particles are seen closely attached together by PIM-1, indicating a good distribution of filler materials on the matrix as earlier reported (Khdhayyer et al., 2017). Furthermore, the SEM images of the three composites do not show a sieve-in-a-cage morphology which is a characteristic for poor surface adhesion of filler particles to PIM-1. Thus, dissolving PIM-1 in TCE solvent lead to fluoride chain-ends of PIM-1 to interact with the hydroxyl functional groups of the BDC linker on the surface of UiO-66(Zr) MOF and prevent the polymer from blocking the MOF pores (Tien-Binh et al., 2016).

Figure 5 presents the $\mathrm{N}_{2}$ adsorption-desorption isotherms of the pristine PIM-1, powder fillers and the resulting composites materials measured at $77 \mathrm{~K}$. The nitrogen sorption isotherms of ZTC and UiO-66 (Zr) show a steep/linear adsorption rise at low pressure ranges $(0.0-0.1)$, indicating their microporous nature. The same type I isotherm for microporous characteristic was maintained after the inclusion of PIM-1 and this is in agreement with SEM and PXRD results, wherein neither the morphology nor the crystal structure of MOF was destroyed. PIM-1 and PIM-1/80 wt\% UiO-66(Zr) exhibited a type I isotherm coupled with type IV isotherm behavior, indicating the presence of both micropores and mesopores. The surface area of PIM-1 increased significantly from 785 to $1,767 \mathrm{~m}^{2} \mathrm{~g}^{-1}$ and to $2,433 \mathrm{~m}^{2} \mathrm{~g}^{-1}$ upon addition of $40 \mathrm{wt} \% \mathrm{UiO}-66(\mathrm{Zr}) / 40 \mathrm{wt} \% \mathrm{ZTC}$ mixture and $80 \mathrm{wt} \%$ ZTC fillers respectively, which is equivalent to 3 fold increase as shown in Table 1. On the contrary, PIM-1/80 wt\% UiO-66(Zr) exhibited a slight increase which is $<2$-fold increase. In most studies, MOF-polymer composites can only achieve about $60 \%$ of the expected BET values due to pronounced pore blocking effects as was reported by other researchers such as MIL-101(Cr)@NIPAM (Wickenheisser et al., 2016),

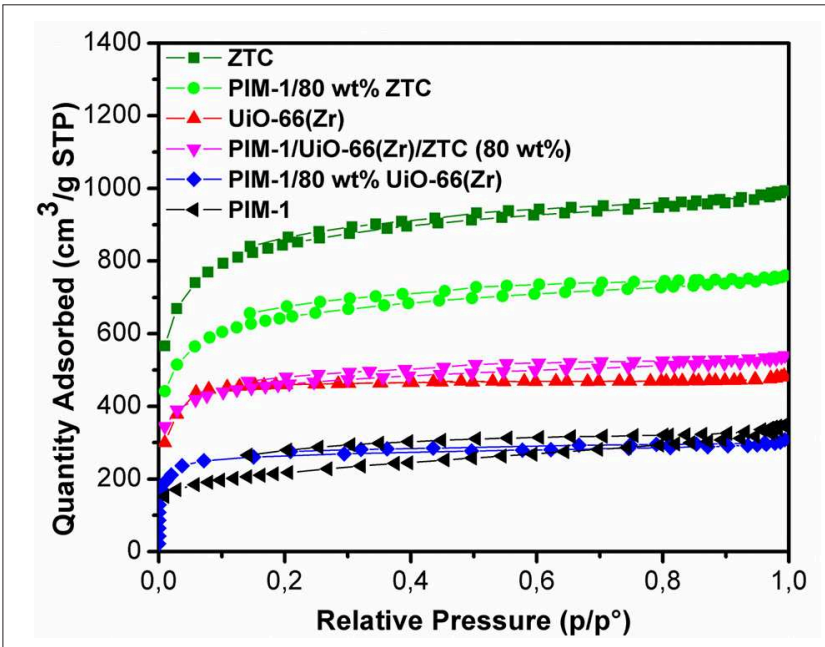

FIGURE 5 | $\mathrm{N}_{2}$ sorption isotherms of pristine and composites materials at $77 \mathrm{~K}$.
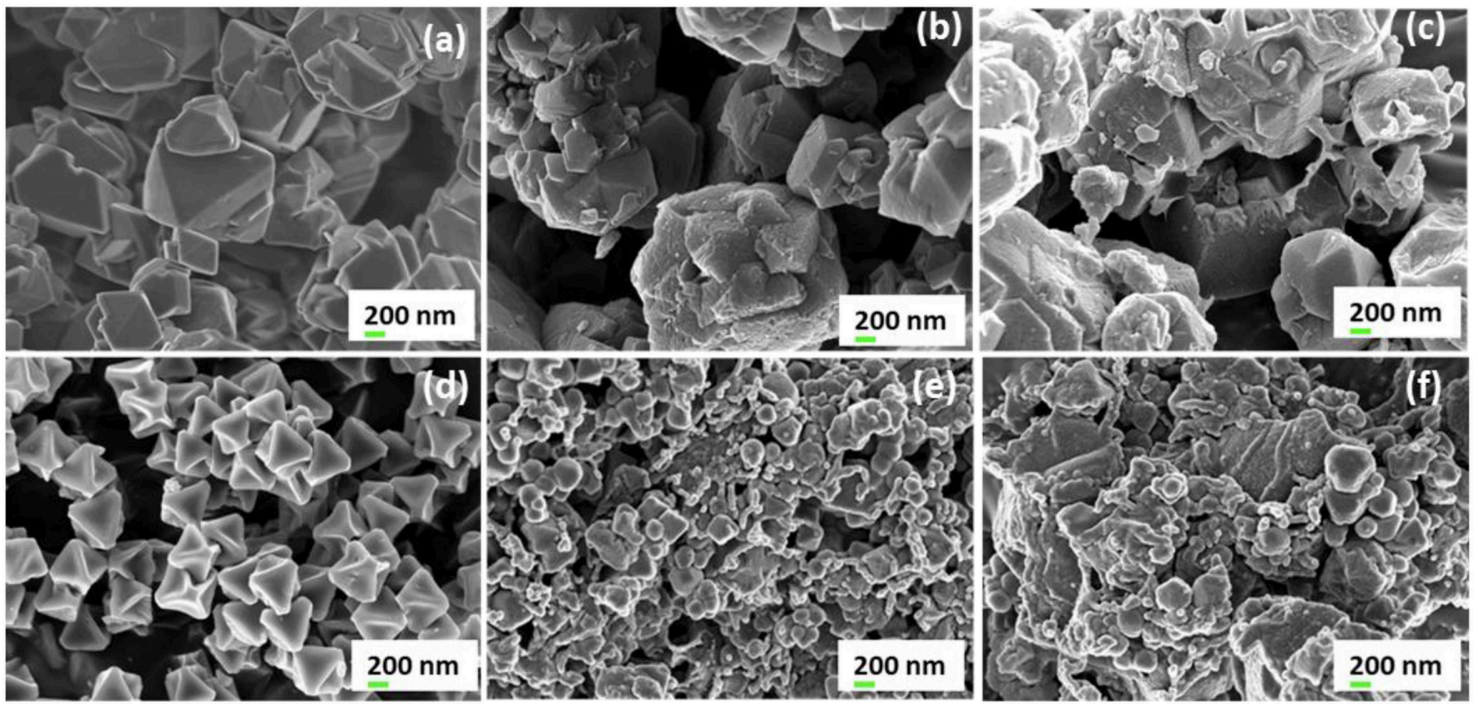

FIGURE 4 | High resolution SEM images (mag. 20000x) of (a) zeolite 13X, (b) ZTC, (c) PIM-1/80 wt\% ZTC, (d) UiO-66(Zr), (e) PIM-1/80 wt\% UiO-66(Zr), and (f) PIM-1/UiO-66(Zr)/ZTC (80wt\%). 
TABLE 1 | Summary of the physical properties of pure materials and their respective composites.

\begin{tabular}{|c|c|c|c|c|c|c|}
\hline Sample & $\begin{array}{l}\text { Measured BET } \\
\text { SSA }\left(\mathrm{m}^{2} \mathrm{~g}^{-1}\right)^{\mathrm{a}}\end{array}$ & $\begin{array}{l}\text { Estimated BET } \\
\text { SSA }\left(\mathrm{m}^{2} \mathrm{~g}^{-1}\right)^{\mathrm{b}}\end{array}$ & $\begin{array}{l}\text { Micropore area } \\
\qquad\left(\mathrm{m}^{2} \mathrm{~g}^{-1}\right)^{\mathrm{c}}\end{array}$ & $\begin{array}{l}\text { Total pore vol. } \\
\qquad\left(\mathrm{cm}^{3} \mathrm{~g}^{-1}\right)^{\mathrm{d}}\end{array}$ & $\begin{array}{c}\text { Measured } \mathrm{H}_{2} \\
\text { uptake (wt. \%) }\end{array}$ & $\begin{array}{c}\text { Estimated } \mathrm{H}_{2} \\
\text { uptake (wt. \%) }\end{array}$ \\
\hline Pristine ZTC & 3,206 & - & 3,004 & 1.54 & 2.38 & - \\
\hline PIM-1/80 wt\% ZTC & 2,433 & 2,722 & 2,262 & 1.18 & 1.87 & 2.11 \\
\hline PIM-1/UiO-66(Zr)/ZTC (80 wt\%) & 1,767 & 2,200 & 1,668 & 0.83 & 1.65 & 1.70 \\
\hline Pristine UiO-66(Zr) & 1,903 & - & 1,882 & 0.75 & 1.36 & - \\
\hline PIM-1/80 wt\% UiO-66(Zr) & 1,054 & 1,679 & 1,014 & 0.48 & 1.22 & 1.29 \\
\hline Pristine PIM-1 & 785 & - & 707 & 0.54 & 1.02 & - \\
\hline
\end{tabular}

${ }^{a} B E T$ surface area measured from $\mathrm{N}_{2}$ adsorption isotherms at $77 \mathrm{~K}$.

${ }^{b}$ BET surface area calculated as the sum of the mass-weighted surface areas of the MOF/ZTC (fillers) and PIM-1 (matrix) from this formula:

$B E T$ (estimated $)=\frac{w t \% \text { of filler }}{100} \times B E T_{\text {filler }} m^{2} g^{-1}+\frac{w t \% \text { of matrix }}{100} \times B E T_{\text {matrix }} m^{2} g^{-1}$.

${ }^{c}$ From t-plot.

'Total pore volume determined from $\mathrm{H}-\mathrm{K}$ analysis by uptake at $\mathrm{p} / \mathrm{p} \sim 0.99$

${ }^{e}$ Hydrogen adsorbed at $77 \mathrm{~K}$ and 1 bar.

${ }^{f}$ The estimated $\mathrm{H}_{2}$ uptake calculated as the sum of the mass-weighted $\mathrm{H}_{2}$ adsorption capacity of the MOF/ZTC (fillers) and PIM-1 (matrix) from this formula:

$\mathrm{H}_{2}$ uptake $($ estimated $)=\frac{w t \% \text { of filler }}{100} \times \mathrm{H}_{2}$ uptake $_{\text {filler }} w t . \%+\frac{w t \% \text { of matrix }}{100} \times \mathrm{H}_{2}$ uptake $_{\text {matrix }} w t . \%$.

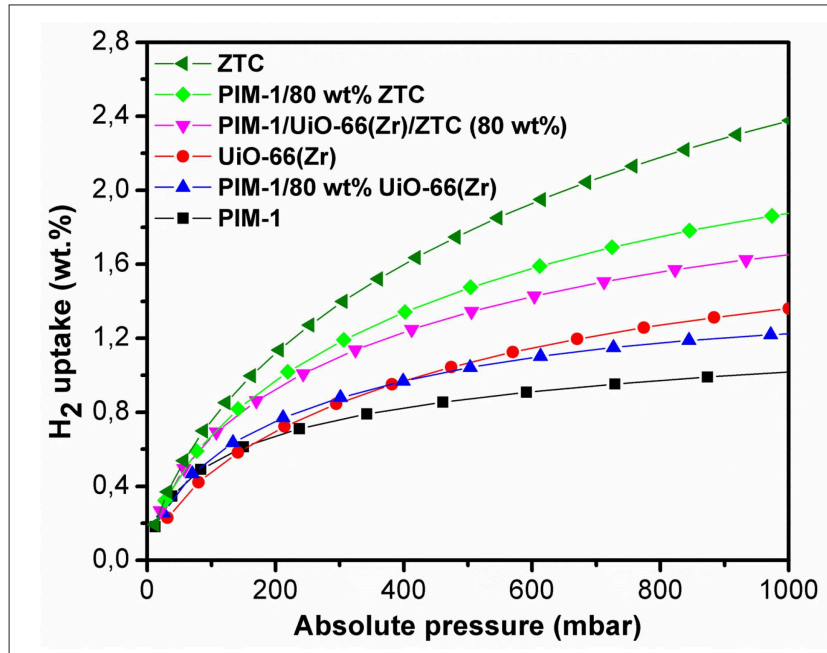

FIGURE 6 | $\mathrm{H}_{2}$ adsorption isotherms of pristine PIM-1, UiO-66 (Zr), ZTC and their corresponding composites materials at $77 \mathrm{~K}$ and 1 bar.

HKUST@HIPE (Schwab et al., 2008) and UiO-66@polyurethane (Pinto et al., 2013). Whereas, our composites have reached over $80 \%$ of the estimated surface areas with an exception of PIM$1 / 80 \mathrm{wt} \% \mathrm{UiO}-66(\mathrm{Zr})$ sample which achieved $62.8 \%$ suggesting that there are reduced pore blocking effects in ZTC containing samples. This can be attributed to ZTC's high level of stability toward PIM-1 disturbance, whereby it was seen that the ZTCbased composites retained most of its physical properties as compared to PIM-1/80 wt\% UiO-66(Zr). Similar observations were reported in a recent study for PIM-1/MIL-101 MOF and PIM-1/AX21 activated carbon (Tian et al., 2019), wherein the activated carbon based composites materials showed enhanced physical properties and best $\mathrm{H}_{2}$ storage properties at both 0.1 and $10 \mathrm{MPa}$ adsorption measurements.

The hydrogen adsorption curves of PIM-1/80 wt \% ZTC, PIM1/UiO-66(Zr)/ZTC (80 wt\%) and PIM-1/80 wt\% UiO-66(Zr) presented in Figure 6 showed a slight decrease ( $\leq 11 \%$ loss) in $\mathrm{H}_{2}$
TABLE 2 | Comparison of $\mathrm{N}_{2}$ and $\mathrm{H}_{2}$ sorption data of PIM-1 based composites materials from literature.

\begin{tabular}{|c|c|c|c|}
\hline Composites & $\begin{array}{c}\text { Measure } \\
\text { BET surface } \\
\text { area }\left(\mathrm{m}^{2} \mathrm{~g}^{-1}\right)\end{array}$ & $\begin{array}{c}\text { Experimental } \mathrm{H}_{2} \\
\text { uptake (wt. \%) at } \\
77 \mathrm{~K} \text { and } 1 \text { bar. }\end{array}$ & References \\
\hline $\begin{array}{l}\text { PIM-1/MIL-101(Cr) (80 } \\
\text { wt\%)-Monoliths }\end{array}$ & 2,333 & 1.73 & $\begin{array}{l}\text { (Molefe et al., } \\
\text { 2019) }\end{array}$ \\
\hline PIM-1/AX21 (60 wt\%) & 2,075 & 1.90 & $\begin{array}{l}\text { (Tian et al., } \\
\text { 2019) }\end{array}$ \\
\hline $\begin{array}{l}\text { PIM-1/MIL-101 (40 } \\
\text { wt\%)-Films }\end{array}$ & 1,580 & 1.11 & $\begin{array}{l}\text { (Tian et al., } \\
\text { 2019) }\end{array}$ \\
\hline PIM-1/PAF-1 (37.5 wt\%) & 1,639 & 1.15 & $\begin{array}{l}\text { (Rochat et al., } \\
\text { 2017) }\end{array}$ \\
\hline $\begin{array}{l}\text { PIM-1/80 wt\% } \\
\text { UiO-66(Zr) }\end{array}$ & 1,054 & 1.22 & This work \\
\hline PIM-1/80 wt\% ZTC & 2,433 & 1.87 & This work \\
\hline $\begin{array}{l}\text { PIM-1/UiO-66(Zr)/ZTC } \\
\text { (80 wt\%) }\end{array}$ & 1,767 & 1.65 & This work \\
\hline
\end{tabular}

uptake which is still at acceptable high capacity values $(1.87,1.65$, and $1.22 \mathrm{wt}$. \%, respectively) and comparable to the estimated values $(2.11,1.70$, and 1.29 wt. \%, respectively). The relatively high $\mathrm{H}_{2}$ uptake can be attributed to the resulting high surface area and microporous network resulting when micropores of PIM-1 interconnect with the inner pores of UiO-66 (Zr) and ZTC forming an inter-connected micropore network.

The studies shown in Table 2 are not the only ones where PIM-1 was considered as polymer matrix in carbon and MOFs composites. A wide range of PIM-1 based composites have been reported for other applications, mostly in MMMs for gas separation application. Some examples include a combination of PIM-1 with fillers such as GO (Alberto et al., 2017), carbon nanotubes (Koschine et al., 2015), MOF-74 (TienBinh et al., 2016), ZIF-67 (Wu et al., 2018), ZIF-8 (Benzaqui et al., 2016), and COFs (Wu et al., 2017) MMMs. It is only recently, that there seems to be a growing interest of PIM-1 composites fabrication toward $\mathrm{H}_{2}$ storage applications. 
Our MOF composites exhibited $\mathrm{H}_{2}$ uptake values which are within the same range with others reported in the literature. Table 2 demonstrates that the $\mathrm{H}_{2}$ uptake for all composites materials increase with the loading amount of fillers and it correlates well with the BET surface area of all samples. Another observation common in all composites, is that their $\mathrm{H}_{2}$ uptake capacities are equal to the pristine materials or in some cases (PIM-1/MIL-101(Cr) (80 wt\%) (Molefe et al., 2019) and PIM-1/PAF (37.5 wt\%) (Rochat et al., 2017) found to exceed the expected values which signify good retention of intrinsic properties of the fillers. Nonetheless, just like many other previously reported materials, our composites are also yet to meet all the United States Department of Energy (DOE) 2020 targets set for on-board automobile hydrogen storage systems (Lim et al., 2010).

\section{CONCLUSION}

In summary, the PIM-1 based composites consisting of $\mathrm{UiO}-66(\mathrm{Zr})$, ZTC, and $\mathrm{UiO}-66(\mathrm{Zr}) / \mathrm{ZTC}$ mixture were successfully fabricated. Our results showed that after compositing, the obtained monoliths still maintained the meso-microporosity and other favorable $\mathrm{H}_{2}$ uptake properties. All the composites materials showed better hydrogen storage performances which are in agreement with the predicted values with negligible loss of $<12 \%$. The results also suggest that the ZTC-based composites materials (BET surface areas 1,767-2,433 $\mathrm{m}^{2} \mathrm{~g}^{-1}$ ) were more stable and managed to retain most of the pristine ZTC intrinsic properties, with less pore blocking effects when compared to the MOF based materials (BET surface area $\left.1,054 \mathrm{~m}^{2} \mathrm{~g}^{-1}\right)$. It was found that the interactions between $\mathrm{UiO}-66(\mathrm{Zr})$ and PIM-1 matrix were more physically

\section{REFERENCES}

Alberto, M., Luque-Alled, J. M., Gao, L., Iliut, M., Prestat, E., Newman, L., et al. (2017). Enhanced organophilic separations with mixed matrix membranes of polymers of intrinsic microporosity and graphenelike fillers. J. Memb. Sci. 526, 437-449. doi: 10.1016/j.memsci.2016. 12.061

Benzaqui, M., Semino, R., Menguy, N., Carn, F., Kundu, T., Guigner, J. M., et al. (2016). Toward an understanding of the microstructure and interfacial properties of PIMs/ZIF-8 mixed matrix membranes. ACS Appl. Mater. Interfaces 8, 27311-27321. doi: 10.1021/acsami. $6 \mathrm{~b} 08954$

Blankenship, T. S. II, Balahmar, N., and Mokaya, R. (2017). Oxygen-rich microporous carbons with exceptional hydrogen storage capacity. Nat. Commun. 8:1545. doi: 10.1038/s41467-017-01633-x

Budd, P. M., Elabas, E. S., Ghanem, B. S., Makhseed, S., McKeown, N. B., Msayib, K. J., et al. (2004). Solution-processed, organophilic membrane derived from a polymer of intrinsic microporosity. Adv. Mater. Weinheim. 16, 456-459. doi: 10.1002/adma.200306053

Cavka, J. H., Jakobsen, S., Olsbye, U., Guillou, N., Lamberti, C., Bordiga, S., et al. (2008). A new zirconium inorganic building brick forming metal organic frameworks with exceptional stability. J. Am. Chem. Soc. 130, 13850-13851. doi: $10.1021 /$ ja8057953

Chaukura, N., and Maynard-Atem, L. (2015). Interaction of a Polymer of Intrinsic Microporosity (PIM-1) with Penetrants. Am. J. Appl. 3, 139-146. doi: 10.11648/j.ajac.20150303.17 than chemical since no bond formation was observed. This study presented an easy-to-fabricate PIM-1/80 wt\% ZTC, PIM-1/UiO-66(Zr)/ZTC (80 wt\%) composites that had not been reported before. However, these composites materials still need further modifications to improve their $\mathrm{H}_{2}$ uptake capacities as gravimetric capacities significantly $>4.5 \mathrm{wt}$. \% are required to achieve the set DOE targets, of which is possible to achieve at pressures slightly higher than 1 bar. Future work will focus on thermal conductivity measurements of the composites and compare that to other closely similar materials.

\section{DATA AVAILABILITY STATEMENT}

The datasets generated for this study are available on request to the corresponding author.

\section{AUTHOR CONTRIBUTIONS}

LM was responsible for synthesis, characterization of samples, and drafting the manuscript. NM and PN contributed to the experiment design and interpretation of data. JR, HL, and MM have also contributed to the interpretation of results and discussion.

\section{ACKNOWLEDGMENTS}

The authors acknowledge financial support from the Department of Science and Technology (DST) of South Africa toward HySA Infrastructure (Grant No. ENMH01X), National Research Foundation (NRF) for SA/France collaboration funding (Grant No. ENMH20X) and the Royal Society-DFID Africa Capacity Building Initiative Programme Grant (Grant No. AQ150029).
Della Rocca, J., Liu, D., and Lin, W. (2011). Nanoscale metal-organic frameworks for biomedical imaging and drug delivery. Acc. Chem. Res. 44, 957-968. doi: 10.1021/ar200028a

Du, N., Robertson, G. P., Song, J., Pinnau, I., Thomas, S., and Guiver, M. D. (2008). Polymers of intrinsic microporosity containing trifluoromethyl and phenylsulfone groups as materials for membrane gas separation. Macromolecules 41, 9656-9662. doi: 10.1021/ma801858d

Férey, G. (2008). Hybrid porous solids: past, present, future. Chem. Soc. Rev. 37, 191-214. doi: 10.1039/B618320B

Fukuhara, K., Nakajima, K., Kitano, M., Hayashi, S., and Hara, M. (2013). Synthesis and acid catalysis of zeolite-templated microporous carbons with SO 3 H groups. Phys. Chem. Chem. Phys. 15, 9343-9350. doi: 10.1039/c3cp $43853 \mathrm{~h}$

Hassan, M. H., Haikal, R. R., Hashem, T., Rinck, J., Koeniger, F., Thissen, P., et al. (2019). Electrically conductive, monolithic Metal-Organic FrameworkGraphene (MOF@G) composite coatings. ACS Appl. Mater. Interfaces 11, 6442-6447. doi: 10.1021/acsami.8b20951

$\mathrm{Hu}, \mathrm{Z}$., and Zhao, D. (2015). De facto methodologies toward the synthesis and scale-up production of UiO-66-type metal-organic frameworks and membrane materials. Dalton Trans. 44, 19018-19040. doi: 10.1039/C5DT0 $3359 \mathrm{D}$

Hua, T. Q., Roh, H. S., and Ahluwalia, R. K. (2017). Performance assessment of 700-bar compressed hydrogen storage for light duty fuel cell vehicles. Int. J. Hydrogen Energy 42, 25121-25129. doi: 10.1016/j.ijhydene.2017.08.123

Kaye, S. S., Dailly, A., Yaghi, O. M., and Long, J. R. (2007). Impact of preparation and handling on the hydrogen storage properties of $\mathrm{Zn} 4 \mathrm{O}$ (1, 
4-benzenedicarboxylate) 3 (MOF-5). J. Am. Chem. Soc.. 129, 14176-14177. doi: $10.1021 / \mathrm{ja} 076877 \mathrm{~g}$

Khdhayyer, M., Bushell, A. F., Budd, P. M., Attfield, M. P., Jiang, D., Burrows, A. D., et al. (2019). Mixed matrix membranes based on MIL101 metal-organic frameworks in polymer of intrinsic microporosity PIM-1. Sep. Purif. Technol. 212, 545-554. doi: 10.1016/j.seppur.2018. 11.055

Khdhayyer, M. R., Esposito, E., Fuoco, A., Monteleone, M., Giorno, L., Jansen, J. C., et al. (2017). Mixed matrix membranes based on UiO-66 MOFs in the polymer of intrinsic microporosity PIM-1. Sep. Purif. Technol. 173, 304-313. doi: 10.1016/j.seppur.2016.09.036

Koschine, T., Rätzke, K., Faupel, F., Khan, M. M., Emmler, T., Filiz, V., et al. (2015). Correlation of gas permeation and free volume in new and used high free volume thin film composite membranes. J. Polym. Sci. Part B 53, 213-217. doi: 10.1002/polb.23616

Kreno, L. E., Leong, K., Farha, O. K., Allendorf, M., Van Duyne, R. P., and Hupp, J. T. (2011). Metal-organic framework materials as chemical sensors. Chem. Rev. 112, 1105-1125. doi: $10.1021 / \mathrm{cr} 200324 \mathrm{t}$

Lim, K. L., Kazemian, H., Yaakob, Z., and Daud, W. W. (2010). Solid-state materials and methods for hydrogen storage: a critical review. Chem. Eng. Technol. 33, 213-226. doi: 10.1002/ceat.200900376

Liu, D., Purewal, J. J., Yang, J., Sudik, A., Maurer, S., Mueller, U., et al. (2012). MOF5 composites exhibiting improved thermal conductivity. Int. J. Hydrogen Energy 37, 6109-6117. doi: 10.1016/j.ijhydene.2011.12.129

Luan, Y., Qi, Y., Jin, Z., Peng, X., Gao, H., and Wang, G. (2015). Synthesis of a flower-like Zr-based metal-organic framework and study of its catalytic performance in the Mannich reaction. RSC Adv. 5, 19273-19278. doi: 10.1039/C4RA15257C

Marti, A. M., Venna, S. R., Roth, E. A., Culp, J. T., and Hopkinson, D. P. (2018). Simple Fabrication Method for Mixed Matrix Membranes with in Situ MOF Growth for Gas Separation. ACS Appl. Mater. Interfaces 10, 24784-24790. doi: 10.1021 /acsami.8b06592

Masika, E., and Mokaya, R. (2013). Preparation of ultrahigh surface area porous carbons templated using zeolite $13 \mathrm{X}$ for enhanced hydrogen storage. Prog. Nat. Sci. Mater. 23, 308-316. doi: 10.1016/j.pnsc.2013.04.007

Molefe, L. Y., Musyoka, N. M., Ren, J., Langmi, H. W., Ndungu, P. G., Dawson, R., et al. (2019). Synthesis of porous polymer-based metal-organic frameworks monolithic hybrid composite for hydrogen storage application. J. Mater. Sci. 54, 7078-7086. doi: 10.1007/s10853-019-03367-1

Murray, L. J., Dincă, M., and Long, J. R. (2009). Hydrogen storage in metal-organic frameworks. Chem. Soc. Rev. 38, 1294-1314. doi: 10.1039/ b802256a

Musyoka, N. M., Rambau, K. M., Manyala, N., Ren, J., Langmi, H. W., and Mathe, M. K. (2018). Utilization of waste tyres pyrolysis oil vapour in the synthesis of Zeolite Templated Carbons (ZTCs) for hydrogen storage application. J. Environ. Health, Part A 53, 1022-1028. doi: 10.1080/10934529.2018. 1471099

Musyoka, N. M., Ren, J., Annamalai, P., Langmi, H. W., North, B. C., Mathe, M., et al. (2016). Synthesis of a hybrid MIL-101 (Cr)/ZTC composite for hydrogen storage applications. Res. Chem. Intermed. 42, 5299-5307. doi: 10.1007/s11164-015-2361-2

Musyoka, N. M., Ren, J., Langmi, H. W., North, B. C., Mathe, M., Bessarabov, D., et al. (2017). Synthesis of rGO/Zr-MOF composite for hydrogen storage application. J. Alloys Compd. 724, 450-455. doi: 10.1016/j.jallcom.2017.07.040

Ngene, P., Nale, A., Eggenhuisen, T. M., Oschatz, M., Embs, J. P., Remhof, A., et al. (2017). Confinement effects for lithium borohydride: comparing silica and carbon scaffolds. J. Phys. Chem. C, 121, 4197-4205. doi: $10.1021 /$ acs.jpcc.6b13094

Nishihara, H., Yang, Q. H., Hou, P. X., Unno, M., Yamauchi, S., Saito, R., et al. (2009). A possible buckybowl-like structure of zeolite templated carbon. Carbon 47, 1220-1230. doi: 10.1016/j.carbon.2008. 12.040

Patel, H. A., and Yavuz, C. T. (2012). Noninvasive functionalization of polymers of intrinsic microporosity for enhanced CO 2 capture. Chem. Commun. 48, 9989-9991. doi: 10.1039/c2cc35392j

Pinto, M. L., Dias, S., and Pires, J. (2013). Composite MOF foams: the example of UiO-66/polyurethane. ACS Appl. Mater. Interfaces 5, 2360-2363. doi: $10.1021 / \mathrm{am} 303089 \mathrm{~g}$
Ren, J., Langmi, H. W., North, B. C., Mathe, M., and Bessarabov, D. (2014). Modulated synthesis of zirconium-metal organic framework (Zr-MOF) for hydrogen storage applications. Int. J. Hydr. Energy 39, 890-895. doi: 10.1016/j.ijhydene.2013.10.087

Rochat, S., Polak-Kraśna, K., Tian, M., Holyfield, L. T., and Mays, T. J., Bowen, C. R., et al. (2017). Hydrogen storage in polymer-based processable microporous composites. J. Mater. Chem. A 5, 18752-18761. doi: 10.1039/C7TA 05232D

Rowsell, J. L., and Yaghi, O. M. (2006). Effects of functionalization, catenation, and variation of the metal oxide and organic linking units on the low-pressure hydrogen adsorption properties of metal- organic frameworks. J. Am. Chem. Soc. 128, 1304-1315. doi: 10.1021/ja056639q

Schwab, M. G., Senkovska, I., Rose, M., Koch, M., Pahnke, J., Jonschker, G., et al. (2008). MOF@ PolyHIPEs. Adv. Eng. Mater. 10, 1151-1155. doi: 10.1002/adem.200800189

Stavila, V., Talin, A. A., and Allendorf, M. D. (2014). MOF-based electronic and opto-electronic devices. Chem. Soc. Rev. 43, 5994-6010. doi: 10.1039/C4CS00096J

Tian, M., Rochat, S., Polak-Kraśna, K., Holyfield, L. T., Burrows, A. D., Bowen, C. R., et al. (2019). Nanoporous polymer-based composites for enhanced hydrogen storage. Adsorption 25, 889-901. doi: 10.1007/s10450-01900065-x

Tien-Binh, N., Rodrigue, D., and Kaliaguine, S. (2018). In-situ cross interface linking of PIM-1 polymer and UiO-66-NH2 for outstanding gas separation and physical aging control. J. Membr. Sci. 548, 429-438. doi: 10.1016/j.memsci.2017.11.054

Tien-Binh, N., Vinh-Thang, H., Chen, X. Y., Rodrigue, D., and Kaliaguine, S. (2016). Crosslinked MOF-polymer to enhance gas separation of mixed matrix membranes. J. Membr. Sci. 520, 941-950. doi: 10.1016/j.memsci.2016. 08.045

US Department of Energy (2018). DOE Technical Targets for On-board Hydrogen Storage for Light-Duty Vehicles. Available online at: https://www.energy.gov/ eere/fuelcells/doe-technical-targets-onboard-hydrogen-storage-light-dutyvehicles (Accessed July 19, 2018).

Wang, Z., Sun, L., Xu, F., Zhou, H., Peng, X., and Sun, D. (2016). Nitrogen-doped porous carbons with high performance for hydrogen storage. Int. J. Hydr. Energy 41, 8489-8497. doi: 10.1016/j.ijhydene.2016. 03.023

Wickenheisser, M., Paul, T., and Janiak, C. (2016). Prospects of monolithic MIL-MOF@ poly (NIPAM) HIPE composites as water sorption materials. Microporous Mesoporous Mater. 220, 258-269. doi: 10.1016/j.micromeso.2015.09.008

Wu, X., Liu, W., Wu, H., Zong, X., Yang, L., Wu, Y., et al. (2018). Nanoporous ZIF-67 embedded polymers of intrinsic microporosity membranes with enhanced gas separation performance. J. Memb. Sci. 548, 309-318. doi: 10.1016/j.memsci.2017.11.038

Wu, X., Tian, Z., Wang, S., Peng, D., Yang, L., Wu, Y., et al. (2017). Mixed matrix membranes comprising polymers of intrinsic microporosity and covalent organic framework for gas separation. J. Memb. Sci.. 528, 273-283. doi: 10.1016/j.memsci.2017.01.042

Xia, Y., Mokaya, R., Grant, D. M., and Walker, G. S. (2011). A simplified synthesis of $\mathrm{N}$-doped zeolite-templated carbons, the control of the level of zeolite-like ordering and its effect on hydrogen storage properties. Carbon 49, 844-853. doi: 10.1016/j.carbon.2010.10.028

Yan, Y., Lin, X., Yang, S., Blke, A. J., Dailly, A., Champness, N. R., et al. (2009). Exceptionally high $\mathrm{H} 2$ storage by a metal-organic polyhedral framework. ChemComm. 9, 1025-1027. doi: 10.1039/b900013e

Yang, P., Liu, Q., Liu, J., Zhang, H., Li, Z., Li, R., et al. (2017). Interfacial growth of a metal-organic framework (UiO-66) on functionalized graphene oxide (GO) as a suitable seawater adsorbent for extraction of uranium (VI). J. Mater. Chem. A 5, 17933-17942. doi: 10.1039/C6TA10022H

Yang, S., Callear, S. K., Ramirez-Cuesta, A. J., David, W. I., Sun, J., Blake, A. J., et al. (2011). Pore with gate: modulating hydrogen storage in metalorganic framework materials via cation exchange. Faraday Discuss. 151, 19-36. doi: $10.1039 / \mathrm{clfd} 00006 \mathrm{c}$

Yang, Z., Xia, Y., and Mokaya, R. (2007). Enhanced hydrogen storage capacity of high specific surface area zeolite-like carbon materials. J. Amer. Chem. Soc. 129, 1673-1679. doi: 10.1021/ja067149g 
Yang, Z., Xiong, W., Wang, J., Zhu, Y., and Xia, Y. (2016). A systematic study on the preparation and hydrogen storage of Zeolite 13X-templated microporous carbons. Eur. J. Inorg. Chem.. 2016, 2152-2158. doi: 10.1002/ejic.2015 01180

Yu, G., Zou, X., Sun, L., Liu, B., Wang, Z., Zhang, P., et al. (2019). Constructing connected paths between UiO-66 and PIM-1 to improve membrane CO2 separation with crystal-like gas selectivity. Adv. Mater. Weinheim. 31:1806853. doi: 10.1002/adma.201806853

Zhu, X., Gu, J., Wang, Y., Li, B., Li, Y., Zhao, W., et al. (2014). Inherent anchorages in UiO-66 nanoparticles for efficient capture of alendronate and its mediated release. Chem. Commun. 50, 8779-8782. doi: 10.1039/C4CC02570A
Conflict of Interest: The authors declare that the research was conducted in the absence of any commercial or financial relationships that could be construed as a potential conflict of interest.

Copyright (c) 2019 Molefe, Musyoka, Ren, Langmi, Mathe and Ndungu. This is an open-access article distributed under the terms of the Creative Commons Attribution License (CC BY). The use, distribution or reproduction in other forums is permitted, provided the original author(s) and the copyright owner(s) are credited and that the original publication in this journal is cited, in accordance with accepted academic practice. No use, distribution or reproduction is permitted which does not comply with these terms. 


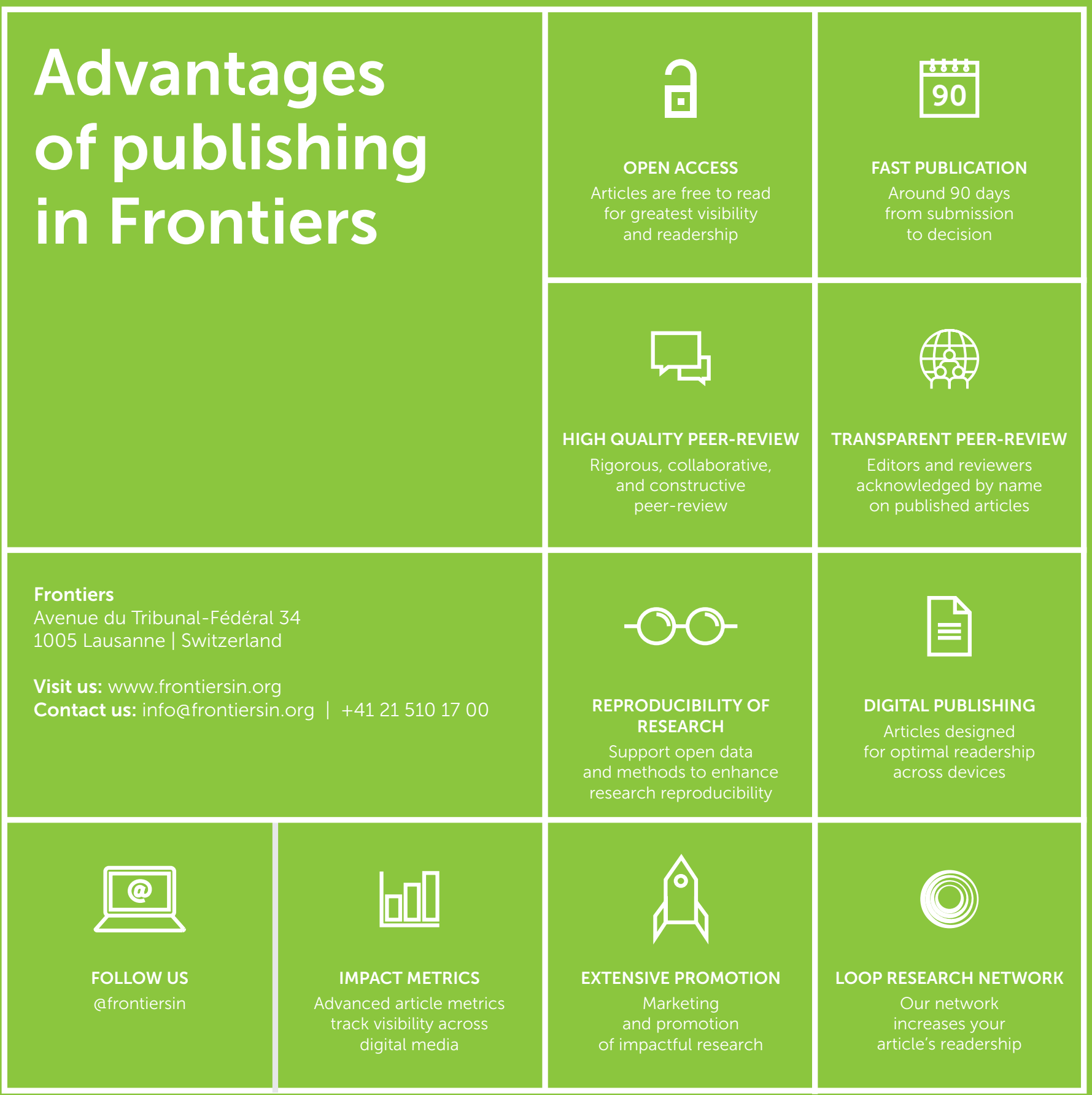

